
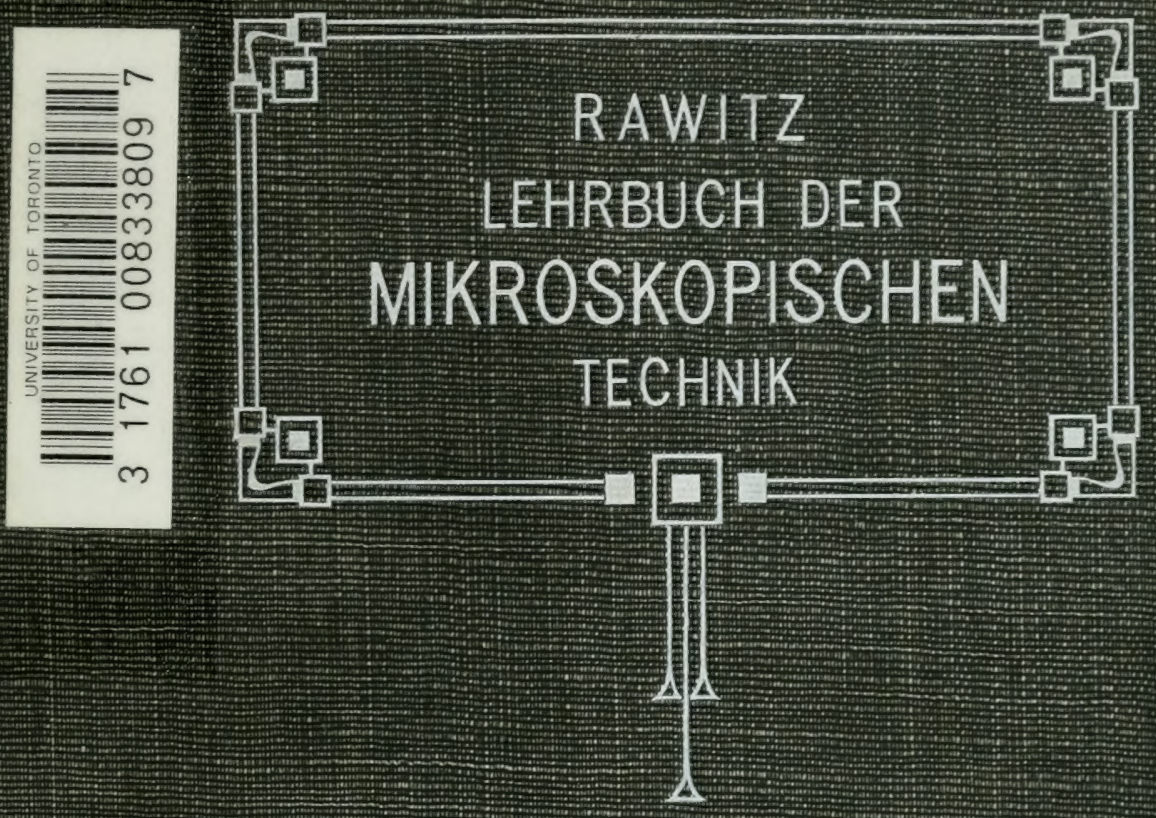

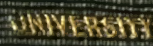
205. FORFAN

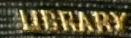




\title{
Physikalische Chemie der Zelle und der Gewebe Von
}

\section{Dr. Rudolf Höber}

Privatdozent der Physiologie an der Universität Zürich

Zweite, neubearbeitete Auflage $=$

Mit 38 Abbildungen im Text. 8. Gebunden $\mathscr{l}$ 14.-.

Das günstige Urteil, welches der ersten Auflage dieses Werkes seinerzeit auf den Weg gegeben werden konnte, hat sich durch die baldige Erschöpfung dieser Auflage als recht allgemein herausgestellt. Die vorliegende Neuausgabe ist vielfach neu geschrieben worden und gibt auch in solcher Weise ein Zeugnis für schnelle Entwicklung der physiko-physiologischen Chemie. Man darf wohl voraussagen, daß die künftigen Auflagen sich noch schneller folgen werden, da der Kreis der Mediziner, die sich eines solchen Werkes mit Erfolg bedienen können, im lebhaften Wachstum begriffen ist.

(Wilhelm Ostwald.)

\section{Über die Zelle}

\section{Nachgelassene Schrift von Alfred Schaper}

Nach dem Tode des Verfassers herausgegeben

von

\section{Wilhelm Roux}

Mit 3 Textfiguren. Gr. $8 . \quad \mathscr{M}-.60$.

Von dem verdienten, so früh aus dem Lehen geschiedenen Forscher lagen bei seinem Tode nur einige Abschnitte der Zellenlehre, die er erst als sLehrbuch herauszugeben beabsichtigt hatte, vor. Seinem Wunsche entsprechend, hat der Herausgeber, Herr Geheimrat Prof. Dr. Wilhelm Roux in Halle a. S., für die Veröffentlichung dieser, über die geschichtliche Entwicklung des Zellbegriffes, die organischen Individulalitätsstufen und über den Bau und die elementarsten Lebenserscheinungen der Zelle, speziell des Protoplasma handelnden Kapitel gesorgt.

\section{Über „Organbildende Substanzen“ \\ und ihre Bedentung für die Vererbung}

\author{
Nach seiner am 21. Juni 1906
}

in der Aula der Universität Leipzig gehaltenen Antrittsvorlesung

von

\section{Prof. Dr. Carl Rabl,}

Direktor des Anatomischen Instituts in Leipzig

Gr. 8. $\mathscr{A} 1.20$. 


\title{
Morphologische Arbeiten
}

aus dem anatomischen und zootomischen Institut der

Königl. Universität Münster i. W.

herausgegeben von

Dr. med. et phil. E. Ballowitz, o. ö. Prof.

Der bisher vorliegende erste Band umfaßt 6 Hefte

Ausführliches Inhaltsverzeichnis steht zu Diensten

Experimentelle Beiträge zur Morphologie herausgegeben von

\section{Hermann Braus (Heidelberg)}

I. Band. gr. 8

Bisher erschienen: Heft 1. $\mathscr{M}$ 4.- Heft 2. $/ l$ 3.-

\section{Das Herz}

und seine Tätigkeit im Lichte neuerer Forschung

Festrede

gehalten am Stiftungstage der Kaiser Wilhelm-Akademie

für das militärärztliche Bildungswesen 2. Dezember 1903

von

\section{Th. W. Engelmann}

gr. $8 . \quad$ A -60

Das Mikroskop und die mikroskopische Technik von

\author{
Prof. Dr. Heinrich Frey \\ Achte, vermehrte Auflage =
}

Mit 417 Holzschnitten. gr. 8. Geh. $\mathscr{U}$ 9.-, geb. $\mathscr{l} 10.50$

Der Inhalt dieses Werkes ist trotz der vorgeschrittenen Technik heute noch in hohem Maße anregend und belehrend. (Milkrokosmos. Bd. I. 1907. Heft 3/4.)

\section{Lehrbuch der Zoologie \\ von}

Dr. Alexander Goette

ord. Professor der Zoologie an der Universität Straßburg i. E.

Mit 512 Abbildungen im Text

gr. 8. Geheftet Mk. 12.-; in Leinen geb. Mk. 13.-. 


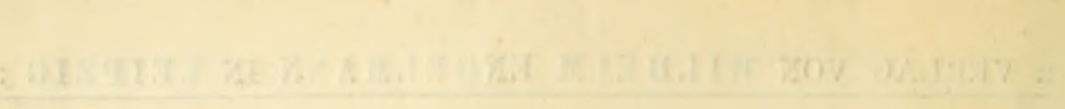

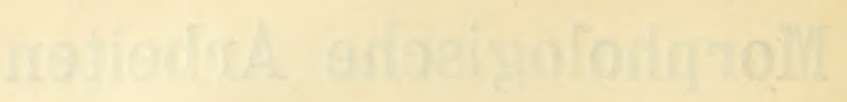

-

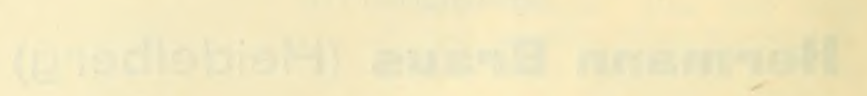

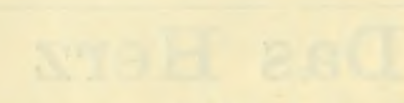

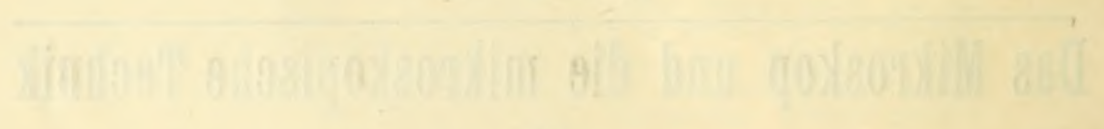

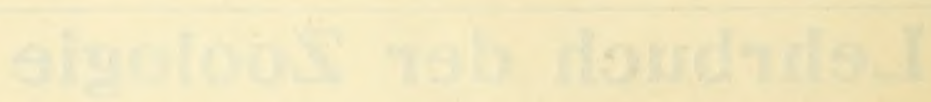




\title{
LEHRBUCH
}

\author{
DER
}

MIKROSKOPISCHEN TECHNIK 



\title{
LEHRBUCH
}

DER

\section{MIKROSKOPISCHEN TECHNIK}

\author{
VoN
}

DR. BERNHARD RAWITZ

PROFESSOR

MIT I 8 FIGUREN IM TEXT

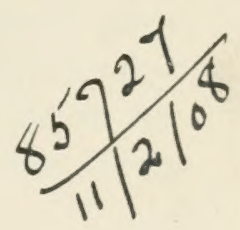

LEIPZIG

VERLAG VON WILHELM ENGELMANN 


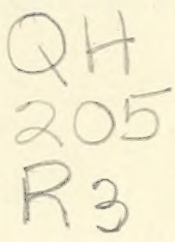

Alle Rechte, insbesondere das der Übersetzung, werden vorbehalten. 


\section{Vorwort.}

) as vorliegende Lehrbuch ist in der Absicht verfaßt, einen möglichst vollständigen Überblick über den gegenwärtigen Stand der mikroskopischen Technik in einer Form zu geben, die handlich, d. h. für den täglichen Laboratoriumsgebrauch und für den Unterricht geeignet ist. Daß die Ausführung der Absicht einigermaßen entspreche, ist mein Wunsch.

Ich habe mich nicht bloß referierend verhalten, d. h. nicht ausschließlich die Methoden aufgezählt, sondern ich habe an vielen Stellen und in wichtigen Fragen Partei ergriffen. Man wird mir dies hoffentlich nicht verargen; ich wollte ja ein Lehrbuch, aber kein Kochbuch schreiben.

Bei der Abfassung des Buches suchte und fand ich Rat in folgenden vortrefflichen Werken: Fol, Lehrbuch der vergleichenden mikroskopischen Anatomie, Leipzig I896; Lee und Mayer, Grundzüge der mikroskopischen Technik, Berlin Igor (die neue Auflage dieses Buches konnte ich nicht mehr berücksichtigen); Röthig, Handbuch der embryologischen Technik, Wiesbaden Ig04, und Enzyklopädie der mikroskopischen Technik. Anregungen mannigfachster Art gewährte mir das bekannte Buch von Fischer: Fixierung, Färbung und Bau des Protoplasmas, Jena ı 899. Daß ich die ausgezeichnete "Zeitschrift für wissenschaftliche Mikroskopie e eingehend benutzt habe, versteht sich von selber.

Meine mikroskopischen Arbeiten konnte ich im Physiologischen .Institut der hiesigen Kgl. Tierärztlichen Hochschule ausführen. Dem Chef des Institutes, meinem verehrten Lehrer Herrn Geheimrat Professor Dr. H. Munk, gebührt mein ausdrücklicher Dank, daß er mir durch Überlassung eines Arbeitsplatzes die Abfassung auch dieses Buches ermöglichte.

Habent sua fata libelli: sei dem Buche das Fatum günstig. Berlin, 25. Februar 1907.

\section{Rawitz.}





\section{Inhaltsverzeichnis.}

Seitc

Vorwort.

\section{Teil. Die Untersuchungsmethoden.}

Erstes Krapitel. Einleitung. Das Mikroskop. . . . . . . . . . . . I

Zweites Kapitel. Lebendes und überlebendes Material . . . . . . y

Drittes Kapitel. Mazeration und Isolation . . . . . . . . . . . IS

Viertes Kapitel. Fixierung und Härtung . . . . . . . . . . . 3 I

Fünftes Kapitel. Entkalken und Entfärben . . . . . . . . . . . . is

Sechstes Kapitel. Einbetten. . . . . . . . . . . . . . . $S_{4}$

Siebentes Kapitel. Schleifen. Schneiden. Aufkleben ........ . rog

Achtes Kapitel. Färben . . . . . . . . . . . . . . . . I44

Neuntes Kapitel. Die Metallimprägnation. . . . . . . . . . 209

Zehntes Kapitel. Injizieren . . . . . . . . . . . . . . . . . 216

Elftes Kapitel, Das Aufheben der Präparate . . . . . . . . . . 223

Zwölftes Kapitel. Das Abbilden. . . . . . . . . . . . . . . . 235

\section{Teil. Die Anwendung der Methoden.}

Zur Orienticrung. . . . . . . . . . . . . . . . . 243

Dreizehntes Kapitel. Die Zelle . . . . . . . . . . . . . . 245

Vierzehntes Kapitel. Die Bindesubstanzen. . . . . . . . . . . . 260

Fünfzehntes Kapitel. Das Muskelgewebe . . . . . . . . . . . 279

Sechzehntes Kapitel. Blut . . . . . . . . . . . . . 284

Siebzehntes Kapitel. Die Organe des Kreislaufs, die Blutgefäflriisen und die Drüsen ohne Ausführungsgang . . . . . . . . 306

Achtzehntes Kapitel. Die Atmungsorgane. . . . . . . . . . . 31 3

Neunzehntes Kapitel. Die Verdaunngsorgane . . . . . . . . . . . 315

Zwanzigstes Kapitel. Die Harnorgane . . . . . . . . . . . . 322

Einundzwanzigstes Kapitel. Die Geschlechtsorgane. . . . . . . . . . 325

Anhang zum einundzwanzigiten Kapitel. Eier und Embryonen. . . . 333

Zweiundzwanzigstes Kapitel. Zentrales Nervensystem . . . . . . . . 337

Dreiundzwanzigstes Kapitel. Peripheres Nervensystem . . . . . . . 389

Vierundzwanzigstes Kapitel. Die Haut ...... . . . . . . . 40 I

Fünfundzwanzigstes Kapitel. Das Geschmacksorgan . . . . . . . . . 410

Sechsundzwanzigstes Kapitel. Das Geruchsorgan. . . . . . . . . . . fII

Siebenundzwanzigstes Kapitel. Das Gesichtsorgan . . . . . . . . . 412

Achtundzwanzigstes Kapitel, Das Gehörorgan. . . . . . . . . . 419

Register. . . . . . . . . . . . . . . . . 424 



\title{
Erster Teil. \\ Die Untersuchungsmethoden.
}

\author{
Erstes Kapite1. \\ Einleitung. Das Mikroskop.
}

$\S \mathrm{I}$.

Wenn die anatomische Erforschung des ausgebildeten wie des werdenden tierischen Körpers mehr erstrebt, als die bloße Erkennung des Nebeneinander der einzelnen Organe, wenn sie versucht, den Bau dieser Organe in seinen Einzelheiten sich klar zu machen, diejenigen Bestandteile aufzufinden, welche als die morphotischen Konstituenten eines jeden Organes zu betrachten sind, dann gelangt sie sehr bald an die Grenzen der Erkenntnismöglichkeit. Denn wenn auch die Zerlegung mit Messer, Schere und Pinzette noch so weit getrieben wird: das menschliche Auge vermag ohne weiteres nicht zu erkennen, ob in den durch grobe Zerkleinerung gewonnenen Partikelchen eines tierischen Körpers wirklich die letzten Formelemente dargestellt sind, an welchen das Leben des Organismus haftet. Wir sind uns bewußt, daß unser Auge, ebensowenig wie es im All die kleinsten Weltkörper ohne weiteres zu erblicken vermag, so auch nicht imstande ist, ins Innere eines tierischen ()rganes hincinzusehen. Und wir greifen daher zu Hilfsmitteln, welche diese natiirliche, d. h. im Bau des Auges gegebene Grenze des Erkennens und damit der Erkenntnis weiter hinausrücken sollen. Zur Erforschung des Makrokosmus und des Mikrokosmus verstärken wir unsere Sehkraft durch optische Instrumente, die dort das Kleinste aus unendlicher Ferne uns näher bringen, hier das Kleinste in endlicher Nähe uns ïberhaupt erst sichtbar machen sollen. 


\section{$\S 2$.}

Das optische Hilfsinstrument, welches der Morphologe benutzt, ist das Mikroskop. Die Physik unterscheidet zwei Arten des Mikroskopes: das einfache und das zusammengesetzte Mikroskop.

Das einfache Mikroskop heißt: Lupe. Für manche Zwecke, besonders zum Präparieren feinerer Einzelheiten oder sehr kleiner Objekte genügt oft eine einfache Taschenlupe. Ich benutze hierfür mit Vorliebe die in Kork gefaßten Uhrmacherlupen, die ich ins rechte oder linke Auge klemme, je nachdem ich mir das Objekt vor das eine oder vor das andre Auge schiebe. Indessen die geringe

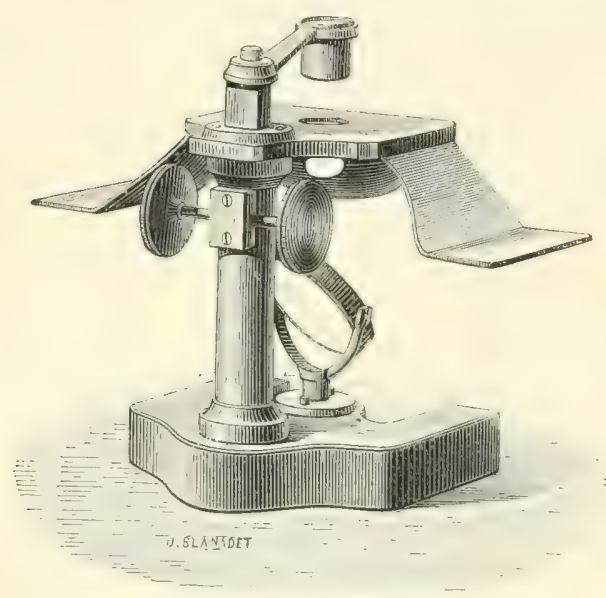

Fig. I. Fols Lupenstativ.

Fokaldistanz, die diesen kleinen Lupen eigen ist, gestattet nur eine beschränkte Anwendung.

Besser in der Leistung und bequemer in der Anwendung sind die von Steinheil zuerst konstruierten aplanatischen oder symmetrischen Lupen. Die Größe des Gesichtsfeldes, der beträchtliche Fokalabstand ermöglichen ein sehr bequemes und sorgfältiges Arbeiten. Steckt man eine solche Lupe in ein geeignetes Stativ, so hat man ein Präpariermikroskop. Die verschiedenen optischen Firmen haben derartige Instrumente in großer Zahl und mit verschiedenartiger Ausrüstung konstruiert; eines der einfachsten ist das in beistehender Figur I abgebildete Lupenstativ von Fol.

\section{$\$ 3$.}

Jedoch: viel weiter als das bloße, unbewaffnete Auge bringt uns die Lupe auch nicht; mit ihrer Hilfe feinere Organverhältnisse erhennen wollen, heißt einen Versuch mit ungenügenden Mitteln anstellen. Denn die Lupe zeigt uns meistens nur die groben Verhältnisse vergrößert, sie liefert gewissermaßen nur eine umfänglichere Makroskopie.

In seltenen Fällen allerdings kann uns die Lupe etwas von der Textur der Organe enthüllen, d. h. sie zeigt uns Andeutungen der 
gröberen Verhältnisse des Organaufbaues. IVenn wir z. B. cincn Schnitt durch den Darmkanal eines Tieres haben, dessen Blutgefaße kuinstlich angefuillt wurden, oder wenn wir ein Stïck getrockneter Lunge oder etwas $̈$ Änliches besitzen, dann können wir mit der Lupe, wie gesagt, etwas von der Textur erkennen. Wir liönnen z. B. im Lungenpräparate Bronchiolen, Infundibula und vielleicht auch Alveolen unterscheiden. Mehr aber sehen wir nicht. Die Struktur eines Organes, d. h. dessen feincrer Aufbau aus Zellen, deren Beschaffenheit usw., bleibt uns auch bei der stärksten Lupenvergrößerung völlig verborgen.

\section{$\$ 4$.}

Hier nun ist der Punkt, wo wir das zusammengesetzte Mikroskop in Anwendung ziehen müssen, mit dessen Hilfe es uns allerdings gelingt, die feinsten Einzelheiten im Bau von Zellen, Geweben und Organen zu schen. Mit diescm Instrumente, das eine ungemein bcträchtliche Amplitude in den anwendbaren Vergrößerungen gestattet, können wir Textur und Struktur der lebendigen Substanz erforschen oder wenigstens $\mathrm{zu}$ erforschen versuchen.

Bau und IVirkung des zusammengesetzten Mikroskopes sollen hier nicht näher auseinander gesetzt werden. Wer mikroskopieren will. muß sein Instrument kennen, muß die physikalischen Bedingungen gelernt und begriffen haben, unter welchen ein mikroskopisches Bild zustande kommt. Die Lehrbücher der Physik geben hieriber den nötigen und ausreichenden Aufschluß.

Zahlreiche und bedeutende Firmen beschäftigen sich mit der Anfertigung von Mikroskopen; welche von ihnen besonders Gutes leistet. ist hier nicht auseinander zu setzen. Im übrigen bin ich der Neeinung, daß, soviel auch von der Güte des Instrumentes für die Untersuchung abhängt, die Persönlichkeit des Untersuchenden doch die Hauptsache bildet. In des Stumpers Hand wird das beste Instrument versagen. während der Meister selbst mit einem weniger guten beachtenswerte wissenschaftliche Leistungen aufweisen wird. Allgemein sei die alte wirtschaftliche Regel bei Beschaffung eines Mikroskopes beachtet: das Teuerste ist immer das Billigste.

\section{$\$ 5$.}

Glaube ich einer Auscinandersetzung über den Bau des Mikroskopes entraten zu können, so will ich doch einige Bemerkungen hinsichtlich seiner Anwendung machen.

Eine alte, typische Laienfrage ist die: wie vielfach vergrößert dics oder jenes Mikroskop? Daß für die Leistungsfähigkeit des Instru- 
mentes die in Zahlen ausgedriickte lineare Vergrößerung ganz bedeutungslos ist. soll sich der Anfänger von vornherein klar machen. Die Vergrößerung ist das Produkt aus der Eigenvergrößerung des Objektivs Systems, Linsensystemsj und des Okulars. Habe ich z. B. ein Objektiv mit der Eigenvergrößerung 100 und verwende zugleich ein Okular, das 5 mal vergrößert, so ist das Restiltat 5 comalige lineare Vergrößerung. Habe ich ein Objektiv mit nur 50maliger Eigenvergrößerung, verwende aber dazu cin Okular, welches Icmal vergrößert, so erhalte ich als Resultat ebenfalls 500 linear; und dennoch sind beide Vergrößerungsziffern nicht identisch, obwohl beide 500 lauten. Denn daß das stärkere System mir sehr viel mehr zeigen muß, als das schwächere, liegt auf der Hand; jenes dringt viel tiefer in das zu untersuchende Objekt ein, definiert viel mehr, als dicses. Die ()kularrergrößerung ist reine Lupenvergrößerung des rom System entworfenen Bildes; und wenn man noch so starke Okulare nimmt, zu dem Systembilde fügen sie nichts hinzu. Es ist daher durchaus falsch, wenn die Optiker immer raten, auch stärkste Okulare zu kaufen; je stärker diese sind, desto lichtschwächer sind sie auch und zum Forschen sind sie entbehrlich. NIan beschränke sich beim Arbeiten immer auf mittlere und schwache Okulare, wende jene bei starken, diese bei schwachen Systemen an. Ich habe oft, wenn ich starke Okulare - darunter verstehe ich solche mit mehr als achtmaliger Vergrößerung - anwendete, bei intrikaten Strukturen direkt falsche Bilder erhalten, die nur auf Rechnung der ungebührlichen Lupenvergrößerung des Systembildes zu setzen waren.

Nur in einer Hinsicht geben die starken Okulare eine technische Erleichterung. Hat man sehr schwierige Strukturbilder zu analysieren, wobei man Ölimmersion benutzt, so gelingt es bei Anwendung eines mittleren Okulars zuweilen nicht, Klarheit in das Gesehene zu bringen. In solchen Fällen nehme ich dann ein sehr starkes Okular, z. B. mit I 2 facher Vergrößerung. Durch dessen geringe Lichtstärke, also durch die größere Dunkelheit des Gesichtsfeldes gewöhnt sich das Auge bald an das mikroskopische Bild und fängt an die Einzelheiten zu unterscheiden. Wechselt man nunmehr das Oliular, indem man ein schwächeres nimmt - mit ${ }_{+}$-6facher Vergrößerung - , dann erfaßt man sofort alle Details des Präparates und wundert sich nur, daß dies nicht schon anfänglich geschehen.

Wann Trocken-, wann Immersionssysteme zu verwenden sind, ergibt sich aus dem Gange der Untersuchung. Heutigen Tages benutzt man fast nur noch die Öl- (homogenen) Immersionen, während die Wasserimmersionen fast antiquiert erscheinen. Diese Vernachlässigung 
scheint mir nicht ganz gerechtfertigt, denn eine Wasscrimmersion ist einem sehr starken Trockensystem entichicden vorzuzichen. Einen großen Vorteil haben die (j)limmersionen in einem bestimmten Falle, wo sie selbst einem Trockensysteme ïberlegen sind. Wenn es sich darum handẹlt, unter dem Mikroskope festzustellen, ob gewisse Gebilde, die man sieht, kalkhaltig sind oder nicht, dann muß man seitlich zu dem untersuchten I'räparate einige Tropfen einer anorganischen Säure zusetzen. Deren Dämpfe sind gecignet, dic Frontlinse des Trockensystems zu schädigen, ja können durch den Wasisertropfen zu der Wasserimmersion hindurchdringen. Durch das zur Lntersuchung verwandte $O ̈ l$ aber dringen keine Säuredämpfe: und so kann man bei Anwendung der homogenen Immersion oft eingreifende mikrochemische Reaktionen vornehmen, ohne befürchten zu müssen, dal3 die optische Ausriistung des Instrumentes dabei leidet.

$$
\S 6 .
$$

Damit man mikroskopicren kann, muß man das Präparat beleuchten. Die Einrichtung dazu ist an den Mikroskopen derartig, daß das auf dem Objekttisch liegende Präparat durch einen Spiegel ron unten her Licht erhält. Man arbeitet also für gewöhnlich bei durchfallenden Lichte. Die mikroskopische Untersuchung undurchsichtiger Objekte kann nur in auffallendem Lichte rorgenommen werden, bei der das Licht von oben auf das mikroskopische Präparat geworfen wird. Es wird indessen selten nötig scin, für undurchsichtige Objekte die relativ starken Vergrößerungen des zusammengesetzten Mikroskopes zu verwenden. Meist reicht Lupenvergrößerung aus und ein Instrument, wie es in Figur I $S$. 2 abgebildet ist, genigt wohl allen Ansprüchen.

Wic muß die Lichtquelle beschaffen sein, die uns beim zusammengesetzten Mikroskop das Präparat durchleuchten soll? Gar viele Angaben sind gemacht worden über die Herstellung künstlicher Beleuchtungsapparate. So geistreich die Kombinationen der Erfinder sein mögen: ich halte sie alle für zweck- und wertlos. Man sollte niemals künstliches Licht verwenden, denn in unseren Breitengraden gewährt auch der nebeligste Tag hinlänglich natiirliches Licht. um dabei mikroskopisch arbeiten zu können. Die künstlichen Lichtquellen wirken ausnahmslos schädlich auf das Auge des Mikroskopikers ein. Des fernern ist der Nachteil untrennbar mit ihnen verkniipft, daß sie die Farbendifferenzen und Farbenniiancen des mikroskopischen Präparates zerstüren: künstliches Licht schluckt Farben. Es ist aber cin Hauptziel der modernen mikroskopischen Technik, die verschiedenen Bestandteile eines Präparates, die homplizierten Strukturen der Hoden- 
zelle z. B., durch eine differente Färbung hervorzuheben. Und diese Differenz hesteht oft genug nur in feinen Nüancierungen desselben Farbentones. Bei künstlichem Lichte würde man dieses Effektes der Mikroskopiertechnik verlustig gehen. (Dies Farbenschlucken ist der einzige Nachteil, der den Projektionen mit elektrischem Lichte anhaftet.) Und wenn wirklich das Tageslicht einmal zu gering ist, um für die stärksten Systeme auszureichen, nun dann arbeite man mit schwächeren Linsen. Solche Eile, daß jede Stunde ausgenutzt werden miißte, haben die mikroskopischen Arbeiten nicht, denn: die Wissenschaft hat Zeit.

\section{$\S 7$.}

Der am Mikroskop angebrachte Spiegel ist auf der einen Seite plan, auf der anderen konkav. Ich benutze niemals den Planspiegel, immer nur den Konkavspiegel und halte den ersteren, wenigstens für das Gesamtgebiet der tierischen Histologie, für iiberfluissig.

Der Planspiegel bildet mit großer Genauigkeit im Gesichtsfelde Fensterkreuze, Bäume, Häuser, kurz alles das ab, was sich von außen her in ihm spiegelt; er stört also direkt das Arbeiten. Derartige Nachteile hat der Hohlspiegel nicht. Dagegen bringt er zu viel Licht und dieses muß man abhalten. Dies geschieht, indem man unterhalb des Mikroskoptisches sogenannte Diaphragmen anbringt, welche nur einen mehr oder weniger kleinen Lichtkegel zum Präparate durchlassen. In früheren Zeiten waren diese Diaphragmen in Form sogenannter Zylinderblenden angebracht, die im allgemeinen gut funktionierten, während ihre Handhabung zicmlich umständlich war. Gegenwärtig sind sie veraltet und wohl allenthalben, wenigstens an den wissenschaftlichen Zwecken dienenden Mikroskopen, durch die von $\mathrm{Abbe}$ erfundene Irisblende ersetzt. Letztere, wenn sie exakt gearbeitet ist, gestattet ein sehr bequemes und ausgiebiges Erweitern und Einengen des Beleuchtungskegels.

Der große Gelehrte Abbe (nicht Abbé, wie so viele schreiben), der die Technik des Mikroskopbaues zu großer Höhe gebracht hat und dem dic histologische Wissenschaft dauernd Dank wissen wird fir all die zahlreichen Neuerungen und Verbesserungen, mit welchen ur das Mikroskop ausgestattet, hat cinen Beleuchtungsapparat konstruiert, der, weil er auch die schwächste Lichtquelle ausnutzt, das Mikroskopieren ungemein unterstützt. Dieser Abbesche Beleuchtungsapparat besteht, wie die Figuren 2 und 3 zeigen, aus zwei Teilen. Der eine, der Kondensor, wird von zwei, neuerdings von drei konvexen Linsen gebildet, von denen die oberste, welche in die 
(j)fnung des Mikroskoptisches paßt, an ihrer Oberfäche plan geschliffen ist (S). Der zweite Teil ist der Träger des Kondensors, welcher in geeigneter Weise am Fuße des Mikroskopes befestigt wird. Dieser Träger enthält den Blendenträger $(B)$, welcher mit der Irisblende ausgestattet ist. Letzterer kann durch Zahn und Trieb in der Horizontale verschoben werden $(g)$, um dadurch schiefe Beleuchtung hervorzubringen, und kann in der vertikalen Achse nach außen geklappt werden (Fig. 3). Im Blendenträger wird eventuell der Polarisationsapparat angebracht. Der Spiegel $(S p)$ ist ein Plan- und Hohlspiegel. Es besteht die Vorschrift, bei Anwendung des ^Abbe« und beim gleichzeitigen Gebrauch der Immersionssysteme den Planspiegel zu verwenden. Ich kann die Richtigkeit dieser Vor-

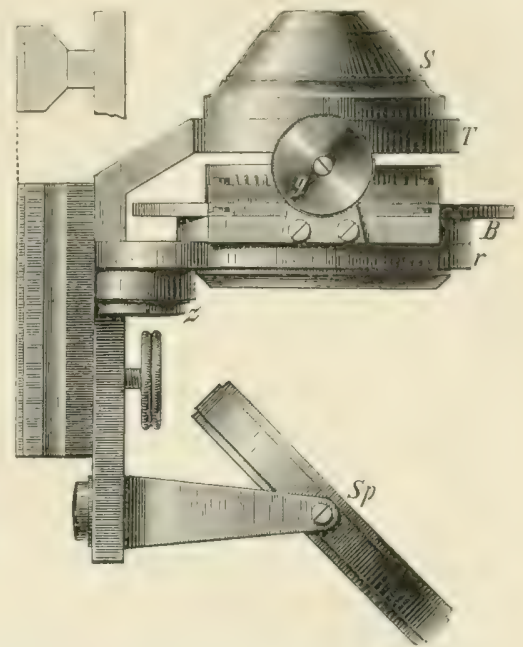

Fig. 2. Abbescher Beleuchtungsapparat. schrift nicht einsehen; die vorhin gerügten Fehler des Planspiegels treten beim Gebrauch des ^Abbe" in erhöhtem Naße auf.

Bei Gebrauch des Abbeschen Kondensors muß man zu histologischen Untersuchungen stets die Blende nehmen und muß sie enger einstellen, als dies ohne Beleuchtungsapparat nötig wäre. Denn die Lichtmassen, welche dank dem Kondensor das Präparat überfluten, sind so gewaltig, daß das Strukturbild des Objektes, das nur durch Beugung der Strahlen zustande kommt, fast ausgelöscht wird. Darauf beruht die Technik in der Bakteriologie. Hier kommt es nicht

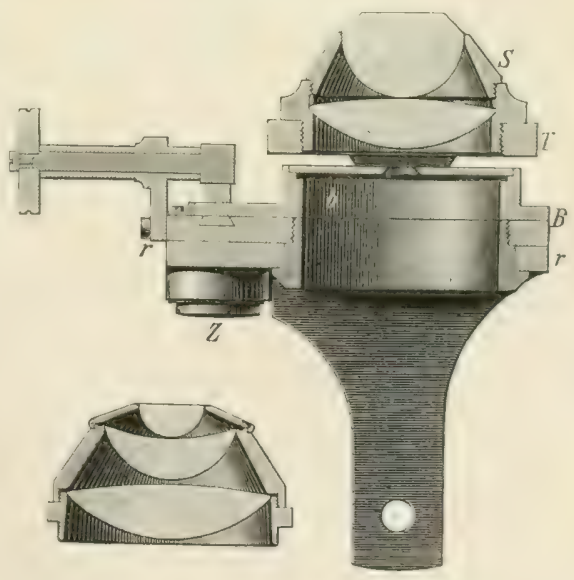

Fig. 3. Derselbe im Durchschnitt. darauf an, feinste Strukturverhältnisse aufzufinden, sondern darauf, die gefärbten Mikroorganismen im Präparate zu erkennen. Öffnet man 
daher die Blende zur vollen Weite, so ertränkt man das Strukturbild im Licht und sieht die Bakterien usw. sich scharf ron ihrer Umgebung abheben.

Nur bei Anwendung sehr schwacher Systeme ist der Abbe nicht zu gebrauchen, denn dann wird wieder die ganze Außenwelt, die sich im Beleuchtungsspiegel abbildet, in das mikroskopische Präparat projiziert.

$\S 8$.

Zahlreich sind die Bedürfnisse des Mikroskopikers an Instrumenten, die ihm zur Herrichtung und zur Ausnutzung des hergerichteten Materials dienen sollen. Mancherlei Apparate sind zur Befriedigung dieser Bedürfnisse erfunden worden, die gelegentlich in den einzelnen Kapiteln zur Besprechung kommen werden. Hier sei nur kurz eines Nebenapparates gedacht, der für manche Zwecke unentbehrlich ist: des Polarisationsapparates. Ein solcher besteht aus zwei Teilen: dem Polarisator und dem Analysator. Ersterer wird in geeigneter Weise in den Blendenträger des * Abbe " gehängt. Dann stellt man auf das zu untersuchende Objekt das System scharf ein und bringt vorsichtig, um die Einstellung nicht zu verändern, auf das Okular den Analysator. Darauf kreuzt man in geeigneter Weise die Nicols. In friheren Zeiten, namentlich in den Jugendtagen der Histologie, wurde das Polarisationsmikroskop sehr fleißig. Wenn auch meist ohne rechten Nutzen für das Gesamtgebiet der Wissenschaft, angewendet. Zurzeit wird bei histologischen Untersuchungen tierischer Gebilde der Polarisationsapparat recht wenig benutzt. Vielleicht ist diese Vernachlässigung ein Schaden für das wissenschaftliche Erkennen; möglicherweise gibt bei unserer gegen früher sehr viel ausgebildeteren mikroskopischen Technik das Polarisationsmikroskop noch über andere Gebilde, wie die quergestreiften Muskeln, wertvolle Aufschlüsse. Aufs wärmste sei daher ein Schriftchen von Ambronn empfohlen: „Anleitung zur Benutzung des Polarisationsmikroskopes bei histologischen Untersuchungen :. Auch ohne eingehende mathematisch-physikalische Kenntnisse wird man aus dem Büchlein den Gebrauch dieses Hilfsinstrumentes des Mikroskopikers leicht erlernen.

\section{$\S 9$.}

Bei durchfallendem Lichte, auf dem relativ schmalen Tische des Mikroskopes sollen wir die Untersuchungen anstellen. Da leuchtet es denn ohne weiteres ein, daß wir die Organe der Metazoën nicht einfach so, wie das Leben sie uns liefert, mikroskopieren können. Volumen, Undurchsichtigkeit des Materials usw. nötigen uns, nach 
Methoden Umschau zu halten, welche uns gestatten, die optische Kraft des Instrumentes auszunutzen, das uns Unsichtbare sichtbar, das Massige durchsichtig, das Vergängliche dauernd zu machen. Die Gesamtheit dieser Methoden ist die mikroskopische Technik oder, wie sie auch genannt wird, dic Mikrotechnik. Daß je nach dem Material, das zu untersuchen ist, je nach dem Zwecke, der erreicht werden soll, die Methode wechselt, versteht sich von selbst; in den folgenden Kapiteln soll gezeigt werden, welcher Art die Methoden und wann und wie sie anzuwenden sind.

\section{Zweites Kapite1.}

\section{Lebendes und überlebendes Material.}

$\S$ IO.

Das lebende Material, welches wir mikroskopieren wollen und können, ist von zweierlei Art. Das eine Mal handelt es sich um ganze Tiere, das andere Mal um Organe lebender Tiere. In die erste Gruppe gehören alle Protozoën. Da diese den morphologischen Wert einer einzigen Zelle haben, so besitzen sie auch hinreichende Kleinheit, un ohne eingreifende Prozeduren unter das Mikroskop gebracht zu werden. Ferner kann man auch manche Mletazoën zu dieser Gruppe rechnen. Es sind das meist durchsichtige kleine Tiere, wie Hydra, Sagitta, Creseis usw. Bei genügender Vorsicht und Abwartung, deren Tendenz hauptsächlich dahin gehen muß, die Tiere am Leben zu erhalten, also ihnen den nötigen Sauerstoff zuzufiihren, kann man oft tagelang derartige Tiere unter dem Mikroskop) beobachten. Kleinere durchsichtige Fischlarven lassen sich ebenfalls lebend untersuchen, nur besteht hier die Notwendigkeit, dem Material dauernd frischen Saucrstoff zuzuführen, weil die Ticrchen dessen in ganz anderen Mengen bedürfen als Protozoën und Exertebraten.

Dem lebenden Nateriale der vorgenannten Art gleich zu achten sind solche Organteile der Mietazoën, welche rorübergehend eine selbständige Existenz zu fuihren vermögen. Ich rechne hierher die Leukocyten und die Eier mancher Tiere. Erstere sind ohne weiteres. wie Amöben, dem Mikroskop zugänglich; letztere sind gelegentlich. wie z. B. bei Echinodermen, hinreichend durchsichtig, um bei einiger 
Vorsicht lebend mikroskopiert werden zu künnen. Das gewährt den großen Torteil, daß man die Entwickelungsvorgänge im Ei zu verfolgen imstande ist.

Die zweite Gruppe von Gebilden, die lebend untersucht werden können, wird von einigen Organen des Metazoënkörpers dargestellt. Bei geeigneter Vorbereitung der Tiere lassen sich einige später zu erwähnende Organe unter das Mikroskop bringen, so daß man in verschiedener Richtung sie studieren kann.

Die Methoden, um die erste Gruppe lebender Objekte zu untersuchen, sind die folgenden:

\section{$\S$ I I.}

I. Hängender Tropfen. Man bedarf dazu eines Objektträgers, der in seiner Vitte eine dellenförmige Vertiefung eingeschliffen besitzt, die etwa so aussieht, als wäre das noch weiche Glas mit der Daumenkuppe eingedruickt worden. Nan bringt nun einen Tropfen der Flüssigkeit, welche Protozoën oder Leukocyten oder Eier enthält, mittels einer Pipette auf ein Deckglas und legt dieses so auf den beschriebenen Objeltträger, daß der Tropfen nach unten in die Delle hineinhängt. Man wird dann sehr leicht mit dem Mikroskop die gesuchten Objekte finden. Die Beobachtung im hängenden Tropfen hat den Vorteil, daß die Objelite nicht direkt auf den Objektträger kommen und daher niemals gequetscht werden.

Indessen kann es wünschenswert sein, das Material nicht in einer Halbkugel (Tropfen), sondern in einer Ebene zu untersuchen. Dann muß man einen Tropfen mit Material auf einen gewöhnlichen Objektträger bringen und mit einem Deckglase zudecken. Ist genügend Fliissigkeit vorhanden, d. h. ist der Tropfen nicht zu klein, dann werden selbst Seeigeleier nicht zerquetscht.

2. Feuchte Kammer. Man kann rorteilhaft die Untersuchung im hängenden Tropfen mit der Aufbewahrung in einer sogenannten feuchten Kammer verbinden. Und es ist dies wichtig und notwendig, wenn das Material tagelang erhalten werden soll, wenn man ihm daher den zum Leben nötigen Sauerstoff zuführen muß.

Die einfachste Art einer solchen feuchten Kammer zeigt die beigefügte Figur 4. Auf einem gewöhnlichen Objektträger $a$ ist ein nur wenige Millimeter hoher Glasring $(b c)$ aufgekittet. In die Höhlung kann man einige kleine Algen mit etwas Wasser bringen, wobei man dafür zu sorgen hat, daß die Algen nur am Rande des Ringes sitzen. Man deckt mit einem runden Deckgläschen zu, das man vorher mit einem hängenden Tropfen beschickt hat. 
Verbessert ist dieser Apparat von I: E. Schulze. Dieser Forscher hat in einen dicken quadratischen Objektträger cine ringfürmige V'crtiefung einschleifen lassen, weiche mit Algen und Wasser ausgefullt wird. Auf den Objektträger kommt ein gliiserner Aufsatz, der natuirlich durchbohrt ist und so groß sein muß, daß er über den Algenring hinausragt. Dieser Aufsatz wird oben mit einem Deckglase eingedeckt, auf das man den hïngenden Tropfen sebracht hat.

Es gibt noch zahlreiche Abänderungen des hier erwähnten Prinzipes der feuchten Kammer, die nicht näher beschrieben werden sollen. Nur die

Zieglersche Durchströmungs-

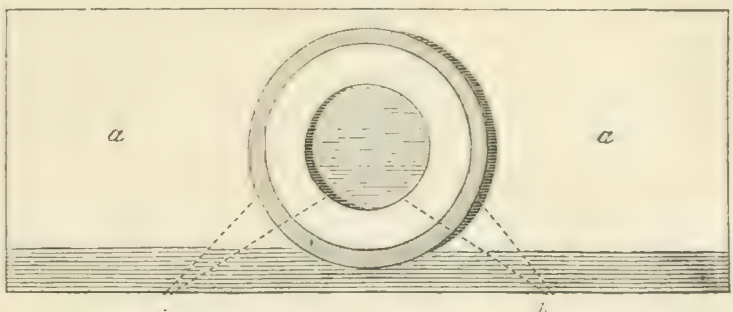

Fig. 4. Einfache feuchte Kammer.

kammer sei genannt, weil diese sich zum Aufbewahren ron Fischlarven, durchsichtigen Würmern usw, eignet.

Eine andere Verwendungsweise der feuchten Kammer sei hier kurz hervorgehoben. Hat man mikroskopische Präparate von mazeriertem Naterial gemacht oder will man frische Präparate längere Zeit $1-2$ Tage) aufheben, so verfährt man folgendermaßen: Man legt die Objektträger auf eine matte Glasplatte, legt um die Objektträger herum einige Bäusche in Wasser getauchten Filtrierpapiers und deckt mit einer Glasglocke zu, in deren Wölbung ebenfalls etwas angefeuchtetes Filtrierpapier gebracht ist. $\mathrm{L} m$ eine Verdunstung ganz unmüglich zu machen, tut man gut, den Rand der Glasglocke mit Talg oder Vaseline zu bestreichen und ihn dann fest auf die Glasplatte aufzudrücken.

3. Horizontalmikroskop von F. E. Schulze. L'm nicht hlol3 tage- sondern auch wochenlang P'rotozoün, Larven von Seetieren usw. in ihrem natiirlichen Verhalten mikroskopisch beobachten zu künnen. hat F. E. Schulze das Horizontalmikroskop lionstruiert. Es besteht aus einem horizontal gestellten Mikroskop-Tubus, der durch Zahn- und Triebvorrichtung sich in den 3 Dimensionen des Raumes verschieben läßt. Dieses Horizontalmilroskop bringt man an cin in einem Stativ entsprechend aufgestelltes Aquarium. Letzteres stellt man sich so her, daß man auf crei I $\mathrm{cm}$ dicke und $10 \mathrm{~cm}$ lange planparallele, aneinander stoßende Glasstreifen Deckerläser ron $10 \mathrm{~cm}$ Höhe und ebensolcher Länge aufkittet. So beliommt man ein 
Io qcm großes Aquarium, dessen eine offene Wand nach oben gerichtet wird. Um das nötige Licht zu haben, stellt man zwischen Aquarium und Fenster einen Hohispiegel auf, der das Aquarium durchleuchtet. Eventucll kann man auch Diaphragmen einschieben, um zu intensives Licht abzublenden. Es ist klar, daß mit einem so vollkommenen Instrumente die Welt des Kleinen gut zu beobachten sein wird.

4. Objekttischaquarium von Cori. Das eben beschriebene Horizontalmikroskop hat Cori abgeändert, um dic pekuniären Kosten zu verringern, welche mit dem Schulzeschen Instrument verknïft sind. Cori bringt auf einen ziemlich großen Objektträger durch Aufkitten drei Glasstreifen an, welche etwa $5 \mathrm{~mm}$ dick sind und ein nach einer Langseite des Objektträgers offenes Rechteck bilden. Auf diesen Rahmen wird ein entsprechendes Decliglas aufgekittet und das so entstandene Aquarium mit dem Untersuchungsmaterial beschickt. Um das Ausfließen des Wassers zu verhüten, muß natiurlich das Mikroskop horizontal umgelegt werden.

Später veränderte Cori das Instrument insofern, als er, wie beim Schulzeschen Horizontalmikroskop, das Aquarium auf beiden breiten Seiten aus Deckgläsern anfertigte und nur die Maße gegenüber dem Schulzeschen Instrument crheblich reduzierte. Zur Aufnahme des Deckglasaquarium dient ein metallener Träger, der auf dem Objekttisch angebracht wird.

5. Mikroaquarium von Schaudinn. Um einzelne Individuen niederster Organismen längere Zeit isoliert bcobachten zu können, hat Schaudinn das Mikroaquarium konstruiert. Man schleift in einen gewöhnlichen Objektträger einen viereckigen Einschnitt bis etwa zur Mitte. Dann kittet man mit kochendem Kanadabalsam, der schnell hart wird, auf beiden Seiten des Einschnittes je ein Deckgläschen auf und bringt noch seitlich auf dem Objektträger oben wie unten schmale Schutzleisten an. Das so entstandene Mikroaquarium, das bei einer Objektträgerdicke von höchstens $3 \mathrm{~mm}$ einen fast kapillären Raum bildet, beschickt man mit den zu untersuchenden Tieren und gibt cinige Algen zu. Ein Umlegen des Mikroskops ist nicht nötig; da aus dem Aquarium infolge der Kapillarattralition kein Wasser ausfließt. Will man das Wasser in diesem kleinen Behälter wechseln, so leitet man mittels eines feinen Wollfadens aus einem höherstehenden Gefäß Wasser hinein und zieht das iiberschüssige durch einen anderen Wollfaden ab. 
$\$$ I 2.

Anders gestalten sich die Methoden, wenn man dic zweite Gruppe lebender Objekte, Organe des Metazoünkörpers, untersuchen will. Die Zahl solcher Organe ist nicht groß, wenigstens hat dic Forschung. außer den zu nennenden keinc anderen in ihren Bereich gezogen. Es sind die Physiologen gewesen, die wesentlich zum Studium des Blutkreislaufes die folgenden Organe des Frosches lebend unter das Mikroskop brachten: die Schwimmhaut, die Zunge, das Mesenterium und die Lunge.

Vorbedingung fuir cine derartige Untersuchung ist die Betïubung des Ticres, die, weil es sich um den Frosch handelt, am sichersten mittels Curare erreicht wird. Man injiziert dem Tiere in den Ruickenlymphsack bis ${ }_{i 2}$ Pravazsche Spritze $I^{\circ}$ 。Curarelösung. Man muß dabei sehr genau auf die Dosis achten; zuviel Curare ruft leicht Stase in den Blutgefäßen hervor, zu wenig macht die Betäubung nicht tief genug. Auch ist es nicht gleichgültig, ob man frisch eingefangene oder alte Laboratoriumsfrösche vor sich hat; jene vertragen mehr Curare als diese.

6. Schwimmhaut des Frosches. Man befestigt das curaresierte Tier auf einem dünnen Brettchen oder auf ciner Korkplatte, die so lang und so breit sein müssen, daß das Tier bequem darauf Platz hat. Der eine Hinterfuß kommt auf ein großes kreisförmiges Loch, welches über die zentrale Öfnung des Mikroskoptisches so gelegt wird, daß das zur Untersuchung nötige Licht bequem in das Objelitiv von unten her eintreten kann. Nun spreizt man die Zehen auseinander, bringt die Schwimmhaut über die Öffnung des Untersuchungsbrettes oder der Korkplatte und hält die Spreizung durch Stecknadeln oder Igelstacheln aufrecht, welche man neben die Zehenknochen steckt. Ein Deckglas ist nicht nötig. Von Zeit zu Zeit muß man die Schwimmhaut, damit sie nicht eintrocknet. mit etwas gewöhnlichem Wasser befeuchten; auch der ganze Frosch ist zur Verhütung des Vertrocknens in angefeuchtetes Filtrierpapier zu wickeln. Blutkreislauf und die Chromatophoren in der Haut sind sehr gut zu sehen.

7. Zunge des Frosches. Man benutzt ein ähnliches Brett wie bei der Schwimmhaut, nur daß man selbstverständlich die Schnauzenspitze des auf dem Bauche liegenden Tieres an den Rand der Öffnung im Untersuchungsbrettchen bringt. Nan zicht die Zunge rorsichtig heraus, klappt sie um und befestigt ihre Spitzen mit Igelstacheln auf der Unterlage. Kreislauf, Nuskeln und Nerven sind hier gut zu erkennen; ja man kann, wenn man ein Deckglas auflegt, sogar etwas stärkere Vergrößerungen anwenden. 
8. Mesenterium des Frosches. Bei einiger Übung gelingt es leicht, das Mesenterium ohne Blutverlust aus der Bauchhöhle herauszuziehen. Nan macht dazu seitlich in der Axillarlinie einen Längsschnitt. Indem man den Frosch so auf dem Untersuchungsbrettchen befestigt, daß er seitlich von der kreisrunden Öffnung liegt, zieht man iiber letztere das Mesenterium dadurch, daß man die betreffende Dünndarmschlinge sanft anspannt. Diese heftet man dann mittels Igelstacheln in der Peripherie der Öfnung fest und declit mit einem Deckglase ein. Bei längerer Beobachtungsdauer kann man mit Leichtigkeit das Auswandern der Leukocyten aus den Kapillaren, die sogenannte Diapedese, erkennen.

9. Lunge des Frosches. Zur Untersuchung dieses Organes sind besondere Apparate von Arndt und von Holmgren angegeben. Der Holmgrensche Apparat, der in keinem bistologischen Laboratorium fehlen sollte, scheint mir am geeignetsten zu sein, weil seine Handhabung einfach und bequem ist und jederzeit gestattet, den Lungensack mit Luft aufzublasen oder ihn durch Luftabsaugung zu entspannen. Eine metallene Kanüle, die mit einem Hahne verschließbar ist, wird an ihrem unteren Ende mit Froschblase überzogen, natuirlich so, daß ihre Mündung frei bleibt. Bläst man in die Kaniile, so tritt durch feine Seitenöffnungen Luft zwischen Kanülenwand und Blase und bläht letztere tamponartig auf. Unaufgeblasen fuihrt man die Kanïle in den Kehlkopf des Frosches, befestigt sie in geeigneter Weise am Kieferrand und bläst auf, wenn die Lunge herausgezogen ist. Dies geschieht so, daß man in der Axillarlinie z. B. der linken Seite einen I $\mathrm{cm}$ langen Schnitt durch die Haut macht. Die ober- und unterhalb des Schnittes sichtbaren beiden Venen werden unterbunden. Nun schneidet man mit einer Schere vorsichtig die Muskulatur durch, wobei man sich hüten muß, die vordrängende Lunge $z u$ verletzen. Das Organ bringt man dann mit dem Tiere auf den Holmgrenschen Apparat und bläst es, wenn dies nötig sein sollte, etwas auf. Blutkreislauf und Nerven sind gut zu sehen.

\section{§ 13.}

Überlebendes Material nennt man solche Teile von Geweben und Organen, welche dem eben getöteten Tiere, womöglich noch lebenswarm, cntnommen wurden. Der Gesamttod nämlich kann eingetreten sein, also z. B. Kreislauf und Atmung eines Säugetieres haben aufgehört, dennoch ist der Zelltod noch nicht eingetreten. Ja bei manchen Bestandteilen von Warmblütern ist der Zelltod noch 24 Stunden 
nach dem Gesamttode nicht erfolgt; die Wimpern der Wimperzellen z. B. schlagen manchmal noch nach dieser Zeit. Kaltbliiter [richtiger Poikilothermen, weil sie ihre Temperatur der jeweiligen Temperatur der Umgebung ampassen] halten sich länger frisch, der Zelltod tritt sehr viel später ein, als bei Warmbliitern [richtiger Homoiothermen, die in jeder Umgebung ihre eigene Temperatur festhalten]. Organe von Kaltbliitern brauchen daher nicht notwendig sofort nach dem Tode des Tieres untersucht zu werden und hei Warmblütern kann man dann davon Abstand nehmen, wenn der Kadaver kiihl aufbewahrt wurde. Doch wird es zweckmäßig sein, überlebendes Material bei der letzteren Tiergruppe möglichst bald nach dem Gesamttode zu mikroshopieren; keinesfalls kann man darauf rechnen, nach länger als $2+$ Stunden noch wirklich überlebendes Naterial zu erhalten. Die Cetaccen zeigen sogar schon früheren Zelltod; nach Io Stunden beginnt z. B. bei diesen Tieren das Zentralnervensystem bereits zu faulen.

Die Untersuchung überlebenden Materials sollte man, wenn nur irgend möglich, nie unterlassen, besonders wenn es sich darum handelt, die an konserviertem Materiale gefundenen Strukturbilder auf ihren Wert zu priffen. Kann auch die nicht konservierte Zclle uns nicht alle feinen Einzelheiten ihres Baues enthüllen, weil wegen der geringen Lichtbrechungsdifferenzen die einzelnen Teile frisch nicht klar zu erkennen sind, so lehrt uns doch die Beobachtung des frischen Objektes und seine Vergleichung mit dem auf verschiedene Weise konservierten, inwieweit die Veränderungen durch die Konservierunguntereinander und von dem frischen Zustande abweichen. IVäre dieser Erwägung mehr Raum gegeben bei vielen histologischen Arbeiten, so wäre mancher Fehlgriff vermieden worden und würde das kritiklose Glauben an die Wahrheit des konservierten Objektes einer fördernden Kritik gewichen sein. Namentlich die neuerdings so eifrig und so eingehend untersuchte feinste Struktur der Zelle verlangt geradezu eine Kontrolle mit dem lebenden oder überlebenden Gebilde, verlangt, daß die oft sehr verschiedenen Resultate der verschiedenen Konservierungsmethoden untereinander und mit den Befunden an frischem Material verglichen werden. Wer die Struktur und Textur des Nervensystems, um ein anderes Beispiel anzuführen, bei Wirbellosen untersuchen will, wird sicherlich von der Herbeiziehung frischen, d. h. überlebenden Materiales sehr gefördert werden. Wer dagegen den Zusammenhang der Nervenelemente feststellen will, der kann leichtlich das Zuriickgreifen auf iiberlebendes Material entbehren.

Die Herstellung von Präparaten uibcrlebenden Materiales zur 
mikroskopischen Untersuchung ist nicht sehr schwierig. Man kann von dem frischen Organ ein Stückchen mit einer auf die Fläche gebogenen sogenannten Cooperschen Schere abschneiden, das so erhaltene Objekt mit Stahl- oder Glasnadeln auf dem Objektträger zerzupfen und das Zerzupfte mit oder ohne Zusatzflüssigkeit mit einem Deciglase zudechen. Oder man schneidet das Organ mit einem scharfen Messer entzwei und streift die auf der Klinge oder an der Schneide haftenden Organpartikelchen auf einen Objektträger ab und behandelt sie dort genau so wie bei der vorigen Methode. In beiden Fällen erreicht man bei einiger Übung; daß man die isolierten Zellen des frischen Organes untersuchen kann. Von den Pathologen wird die folgende Methode eifrig angewendet. Mit einem sogenannten Valentinschen Doppelmesser, dessen Klingen man je nach der Konsistenz des zu untersuchenden Organes weiter oder enger stellen muß - enger bei derben, weiter bei weichen Organen - macht man einen Schnitt durch das Objekt und bringt das zwischen den beiden Messern liegende Stück auf einen Objektträger. Selten ist das Präparat diinn genug; um ohne weiteres mikroskopiert zu werden; meist muß man es so wie vorher angegeben behandeln.

Leichter ist mit Geweben zu verfahren. Eine Bindegewebshaut, eine Harnblase usw. werden flach auf einem Objektträger ausgebreitet, mit einem Deckglase eingedeckt und untersucht. Das aus der Ader entleerte Blut kann ebenfalls in frischem, d. h. iiberlebendem $\mathrm{Zu}$ stande untersucht werden, doch sollen die näheren Angaben hierüber erst später erfolgen.

Hat man nun ein Präparat von überlebendem Naterial angefertigt, so kann man es ohne weiteren Zusatz untersuchen. Die Flüssigkeit, die in sehr geringer Mienge um die einzelnen Partikelchen des Organes zu sehen ist, stammt aus diesem letzteren selber, ist die sogenannte Parenchymflüssigkeit. Diese ist offenbar für die Erhaltung der Zellstrukturen die geeignetste, doch ist ihr Quantum so gering, daß sie bald vertrocknet, daß also die Präparate sehr schnell verderben. Man muß daher andere möglichst indifferente Fliissigkeiten wählen, die man zum Präparate zusetzen oder in denen man das auf die vorher beschriebene IVeise gewonnene Präparat von vornherein auffangen hann. Diese Zusatzfluissigkeiten sind die folgenden:

\section{$\S \mathrm{I} 4$.}

Io. Humor aqueus. Das Wasser der vorderen Augenkammer, der sogenannte Humor aqueus, hat eine für die meisten Gebilde indifferente Zusammensetzung. D. h. Form und Struktur der Ele- 
mente eines Organes werden auch bei längerem Verweilen in dieser Flüssigkeit nicht alteriert. Nan gewinnt sie, indem man z. I3. bei einem Frosche die vordere Augenkammer ansticht und die herausquellende Flissigkeit auf dem Objektträger auffingt. Indessen das Quantum des jedesmal erhältlichen Humor aqueus ist zu gering, als daß es für mehr als ein Praiparat reichte; außserdem ist dic Gowinnung mit einer für das Mikroskopieren ganz unnötigen Grausamkeit verbunden, sodal3 man von diesen Reagens gänzlich Abstand nehmen sollte.

I1. Physiologische Kochsalzlösung, $0,5^{\prime \prime},-0,75^{\circ}$. Zum Ersatz der vorgenannten Flüssigleit dient eine Kochsalzlösung von 0,5 bis $0,75^{\circ}$. Man nennt sic pysiologische, weil man glaubt, daß sie ungefihr dem Salzgehalt der Organe und Gewebe in ihrer Konzentration entspricht. In der Tat ist sie eine rorzuigliche Zusatzflüssigkeit, wenn sie auch nicht völlig indifferent ist; denn bleiben die frischen Objekte längere Zeit in ihr, so bilden sich in vielen Fällen Schrumpfungserscheinungen aus.

I 2. Künstliches Serum, ron Kronccker. Nan löst Natriumchlorïr $6 \mathrm{~g}$, Soda $0,06 \mathrm{~g}$ in $\mathrm{I} 00 \mathrm{ccm}$ destillierten Wassers. E. van Beneden hat zuerst darauf hingerviesen, daß diese Mischung ein vorziigliches Reagens sei, um lebende Fier ron niederen Tieren (z. B. Ascaris) darin zu beobachten.

I3. Heizbarer Objekttisch. Oft ist es wïnschenswert, das untersuchte frische Naterial, wenn es von Warmblütern stammt, auf derjenigen Temperatur zu erhalten, welche im Körper normalerweise herrscht. Namentlich für das Studium der Lebenserscheinungen an Leukocyten ist dies von Wert, da deren amöboide Beweglichkeit bei Körperwärme cine viel intensivere ist als im abgekühlten Zustande. L'm diesen Zwech zu erreichen, sind eine Masse heizbarer Objekttische * konstruiert worden, die alle mehr oder weniger den genannten Intentionen entsprechen. Um mich nicht zu weit auszudehnen, will ich daher nur den ältesten und, wie mir scheinen will, noch immer besten Tisch beschreiben und abbilden (S. I 8), der von IIax Schultze herrührt. Eine auf dem Mikroshoptische zu befestigende Messingplatte $(A)$ ist hinten, bei $c$, eingeschnitten, um sich dem Mikroskop anzulegen. Sic hat bei a eine kreisförmige Durchbohrung, durch die hindurch das Licht in die Präparate tritt. Nach vorn ragt in der Nitte das schräg aufwärts gebogene Thermometer hervor ( $i$. an welchem man die Temperatur des Tisches ablesen kann. Dic beiden vorstehenden Seitenarme $(b)$ werden durch darunter gestellte Spirituslampen erwärmt. Wie die Unteransicht (b) lehrt, ist die 
Kugel des Thermometers in ein Messingkästchen ( $c$ ) eingeschlossen, das von zwei vorragenden Holzleistchen begrenzt wird. Diese sollen die direkte Berihrung des heizbaren mit dem Mikroskoptische verhiiten. Das Thermometer reicht nach vorn und biegt sich an der Kante des Tisches nach oben um $(b)$.

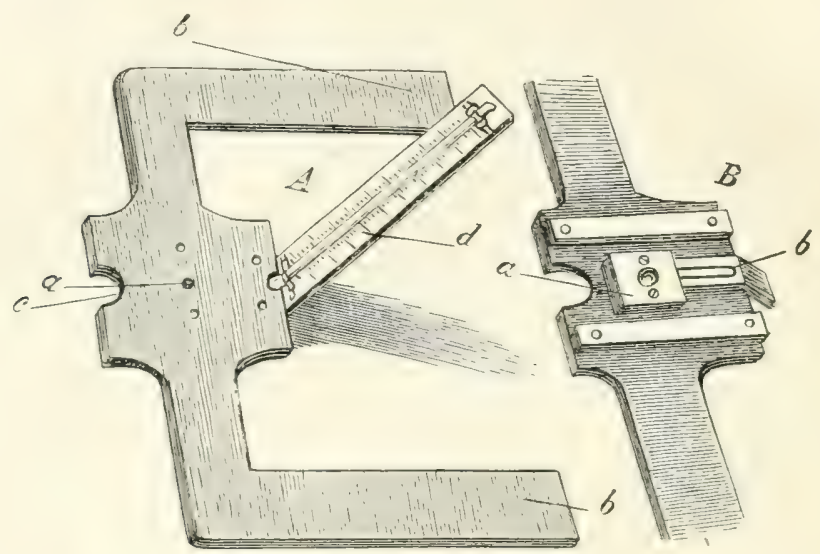

Fig. 5. Heizbarer Objekttisch nach Max Schultze.

A. Von oben gesehen. B. Von unten gesehen.

I 4. Wasser. Gewarnt sei ror dem Gebrauche des destillierten wie des gewöhnlichen IVassers. Von Indifferenz ist bei ihnen keine Spur. Sie sind im Gegenteil sehr deletäre Reagentien, da sie frische Gebilde zum Quellen bringen oder verflüssigen oder ganz zerstören. Nervenfasern z. B. werden durch Wasser zu einem zähen Brei verfluissigt; das destillierte Wasser wirkt hierbei noch kräftiger ein als das gewöhnliche.

\section{Drittes Kapite1. \\ Mazeration und Isolation.}

\section{$\S 15$.}

Wertvoll ist die Methode der Lntersuchung lebenden und überlebenden Naterials, interessant und beachtenswert auf alle Fälle sind die damit zu erhaltenden Resultate. Aber den Ansprïchen, die der Mikroskopiker stellt, wemn er sich an sein Instrument setzt, und die zu stellen er berechtigt ist, genügt die Methode nicht. Was sie uns 
zeigt, reizt mehr den Appetit, als dalk es ihn stillt. Die Strultur der Zellen, auch der Protozoën, wird uns nur angedeutet durch die Lntersuchung lebendigen Materials, wir ahnen eine Komplikation im Bau, aber wir können sie nicht sehen. Die Gewebe der Metazoün enthüllen uns, ob wir sie nun als lebende oder nur noch überlebende Gebilde studieren, auch nicht ihre letzten Gcheimnisse, ron den Organen ganz zu schweigen, die infolge ihrer voluminüsen Beschaffenheit uns knapp ihre Textur, geschweige denn ihre feinere Struktur erkennen lassen. So mïsen wir uns denn an den toten ()rganismus wenden, miissen ihn zerstören, um ihn im Geiste neu und lebendig wieder aufbauen zu können. Diesen Absichten suchen die in diesem und im folgenden Kapitel zu schildernden Methoden entgegen zu kommen.

Die in den folgenden Zeilen zu beschreibenden Methoden der Mazeration und Isolation haben selbstverständlich nur Geltung für die Gewebe und Organe des Metazoënkörpers, denn ein Protozoon ist an und für sich eine isolierte Zelle. Sie gewähren uns die Müglichkeit, die ein Organ zusammensctzenden Zellen losgelöst ron ihrer Umgebung betrachten zu können, die Konstituenten eines Gewebes und Organes frei von nachbarlichen Beziehungen in allen Dimensionen des Raumes zu untersuchen. Form und Verbindung der Zellen, Beschaffenheit und eventuell chemische Eigentümlichkeit der Gewebe aus beiden Gebilden besteht bekanntlich ein Organ - können wir durch die Mazeration und Isolation sicher feststellen. Ja in manchen Fragen haben nur diese Arten der Untersuchung allein die Aufklärung iiber das natürliche Verhalten der tierischen Gebilde erbracht. Ich will nur ein Beispiel anführen. Ob eine Ganglienzelle mit einer Nerrenfaser in dirckter Verbindung ist, hat uns nur die Isolation gelehrt: die alten Histologen, welche zuerst Schnittbilder studierten, hatten dicse Verbindung nicht crkinnt und daher die Ganglienzellen als "Belegkörper bezeichnet. ()b die Ganglienzellen des Riichenmarkes Nervenfortsätze haben oder nicht, wie ihre Form eigentlich ist, welcher Art ihre Beziehungen zu Nachbarzellen sind, all das hat der treffliche, leider so früh verstorbene Deiters an Isolationsbildern gezeigt. Schnitthilder hatten dariber keine Auskunft gegehen und geben sie auch heute nur teilweise. Denn das muß meines Erachtens ein jeder objektive Beurteiler unserer heutigen Methodik zugeben: hätten wir nicht längst gewußt, was eine Ganglienzelle ist und wic sic aussicht. weder durch Schnitte nach der Methylenblau- noch nach der Chromsilbermethode hätten wir es gelernt. Die Isolationsergebnisse alluin machten eine richtige Deutung der durch die eben erwihnten, an 
einer späteren Stelle zu schildernden Methoden erhaltenen Resultate möglich. Und wie für zentrales und peripheres Nervensystem die Isolation der Elemente eine wichtige Vorarbeit ist, so ist sie es auch für die meisten, wenn nicht für alle Organe. Namentlich der Histo$\log c$, welcher Evertebraten studiert, kann und darf auf diese Methode keinen Verzicht leisten, wenn nicht seine Untersuchungsreihe eine beträchtliche und bedenkliche Lücke aufzeigen soll.

\section{$\S$ I 6.}

Als Vorbedingung zur Erhaltung guter Isolationen ist die frische Beschaffenheit des Materials anzusehen. Lebensfrisch oder nur wenige Zeit nach dem Tode müssen die Teile in die Mazerationsfluissigkeit kommen; noch darf kein Zelltod eingetreten sein. Denn mit diesem gehen einher kadaveröse Veränderungen, welche das mikroskopische Bild zu fälschen geeignet sind. Ich bin der Meinung, daß die künstliche Mazeration der natürlichen unter allen Umständen vorzuziehen ist.

Nur bei einem Objekte müssen wir unsere Anspriche an den Erhaltungszustand des Materials zurïckschrauben: beim Menschen. Menschliche Organe und Gewebe kommen sehr selten in wirklich frischem Zustande zur Untersuchung. Nur dann ist dies der Fall, wann es sich um chirurgisch entfernte Organe oder um Organe eines hingerichteten Verbrechers handelt. Darum müssen wir bei fast allen Lntersuchungen menschlicher Teile eine gewisse Reservatio mentalis machen, müssen uns einen Irrtum vorbehalten. Und wir müssen, um letzteren auszuschließen, ausgedehnte vergleichende Untersuchungen an höheren Säugetieren anstellen.

\section{$\S \mathrm{I} 7$.}

Der Isolation muß die künstliche Mazeration vorausgehen, damit der Zusammenhang der Teile gelockert wird und ihre Trennung, Isolierung, mit sanfter Gewalt erfolgen kann. Diese Mazeration geschieht durch ganz bestimmte Reagentien. Sehen wir uns diese an, so finden wir die interessante Tatsache, auf die, glaube ich, Gage zuerst aufmerksam gemacht hat und die durchaus richtig ist, daß diejenigen Reagentien, welche die besten Konservierungs- und Härtemittel sind, zugleich auch die besten Nazerationsmittel darstellen. Natürlich unter entsprechender Verdünnung. Alkohol, Formol, Chromsäure z. B. sind als Konservierungs- und Härtemittel ganz vorzüglich, sie sind ebenso vorzügliche Mazerationsmittel.

$\mathrm{Zu}$ beachten ist bei jedem Mazerationsversuche, daß Reagens und Organ resp. Gewebe in einem bestimmten aber eigentümlichen quan- 
titativen Verhältnisse zucinander stehen müssen. Es läßt sich diese Regel negativ kurz so ausdricken: Organvolumen und Reagensquantum dürfen einander nicht direkt proportional sein. Je voluminöser das zu mazerierende Organ, um so mehr Jazerationsflissigkeit anzuwenden, ist verfehlt. Nur soviel Fliissigkeit ist zulässig: daß3 das zu mazerierende Objekt von ihr völlig bedeckt ist, aber in dem Reagens gewissermaßen schwimmen darf es nicht. Es soll eben die Quantität der Fluissigkeit nicht über ein bestimmtes Maß hinausgehen. Hier die richtigen Verhältnisse zu wahren, kann nur die Übung lehren. Die Flüssigkeitsmenge darf ein bestimmtes Maß nicht überschreiten! Denn selbst dünner Alkohol wirkt in zu großen Mengen leicht erhärtend cin und das gewünschte Ziel wird daher bei einem Überschuß an Reagens nicht erreicht.

Auch darf man meiner Ansicht nach die Mazerationsfliissigkeit, wenn sich der Mazcrationsprozeß längere Zeit hinzieht, nicht wcchseln. es sei denn, daß sich Trübung oder Fäulnis bemerkbar machen. Aus folgenden Gründen halte ich den unnötigen Flüssigkeitswechsel fiir direkt falsch:

IVir nehmen Reagentien von einer bestimmten Konzentration und bringen in sie die zu mazerierenden Objekte. Der Konzentrationsgrad erhält sich aber nur sehr kurze Zeit. Denn bald nach dem Einlegen beginnt durch Diffusion ein Austausch von Gewebs- (ParenchymFliissigkeit und Reagens, welcher dauernd die Konzentration des letzteren ändert. Ranviers ${ }_{3}$ Alkohol z. B. hat nach ganz kurzer Zeit einen viel geringeren Prozentgehait, als im Beginn der Mazeration. Außerdem treten in das Reagens aus dem Parenchym des zu untersuchenden Organes gelöste Salze ein, wodurch die Mazerationsfliissigkeit in einer bisher noch ganz unbekannten Weise geändert wird. In dieser durch das zu mazerierende Gewebe oder Organ hervorgerufenen kontinuierlich vor sich gehenden Veränderung des Reagens erbliche ich die Causa morens der Mazeration. Wir wïrden unser Bemühen illusorisch machen, wollten wir die Mazerationsreagentien erneuern. Und nur dann ist letzteres, wie bereits oben bemerht, zulässig, wenn Fäulnis oder Trübung: die meist zur Fäulnis führt, aufgetreten sind.

$$
\S I 8 \text {. }
$$

Ist die Mazeration beendet - und der Zeitpunkt hierfür ist ein sehr variabler selbst für ein und dasselbe Organ, er wird nicht an letzter Stelle durch die Temperatur der Lmgebung bedingt - , dann muß, bevor die mikroskopische Untersuchung beginnen kann. die 
Isolation der Gewebs- oder Organelemente vorgenommen werden. Diese Isolationsmethoden sind die folgenden:

I. Zerzupfen mit Nadeln. Man nimmt das Objekt oder einen Teil von ihm mittels einer Pinzette oder mit einem Hornspatel aus dem mit der Mazerationsflüssigkeit beschickten Schälchen und bringt es auf den (Objektträger. Hängt an dem zu Zerzupfenden genügend Fluissigkeit, so braucht keine mehr zugegeben zu werden, es sei denn, daß man das anzufertigende Präparat aufheben will. Dann, bei dieser Absicht, muß das Material, bevor es auf den Objektträger gebracht wird, in destilliertem Wasser ausgewaschen werden und darauf in einen kleinen Tropfen Glyzerin oder Kali aceticum kommen. Man darf nicht in zu viel Fliissigkeit zerzupfen, weil sonst nachher das aufgelegte Deckglas schwimmt und die dadurch in der Flüssigkeit entstehenden Strömungen die isolierten Teile fortschwemmen.

Das Zerzupfen nimmt man mit feinen Nähnadeln vor, die in besonderen Haltern feststecken, oder man benutzt Glasstäbe, die man über der Gasflamme in kurze aber feine Spitzen ausgezogen hat. Das zu zerzupfende Objekt wird mit der einen Nadel festgehalten, während mit der anderen mit kurzen aber schnellen Zügen der Rand des Präparates zerfasert wird. Faserige Gebilde, z. B. Nerven oder Muskeln, werden mit den Nadeln in der Längsrichtung auseinandergezogen; dabei dürfen sie nicht zu groß sein, weil sonst die Zerzupfung nicht gelingt. Nach meinen Erfahrungen sind 2-3 mm Länge ausreichend.

Wenn die Zupfpräparate nicht gefärbt sind, dann ist es sehr schwer, das System auf die kleinen Partikelchen einzustellen. Hier hilft man sich so, daß man unter das Deckglas nach dem Zerzupfen ein Haar oder eine Wollfaser bringt. Diese sucht man auf und kann dann mit Leichtigkeit die isolierten Gebilde finden.

Pokrowski hat empfohlen, statt der Nadel einen Pinsel zu benutzen. Ich halte diese Methode fuir sehr gut. Man hält dabei das Objekt mit ciner Nadel fest und fährt mit einem kurzborstigen, nicht $z u$ derben, aber vor allen Dingen nicht zu weichen Pinsel über das Präparat hinweg. Namentlich faserige Elemente müssen sich auf diese Weise sehr gut isolieren lassen.

2. Hissche Pinselmethode. His hat empfohlen, um das Stroma der Organe gesondert von den Zellen zur Erscheinung zu bringen, in folgender Weise zu verfahren: Man macht von gehärtetem Material einen feinen Schnitt, bringt diesen in Wasser und pinselt aus ihm, indem man ihn auf einer Stelle mit einer Nadel festhält, mittels eines weichen Kamelhaarpinsels die Zellen vorsichtig aus der Grundsubstanz; 
heraus. Es ist dies eine muihsame, zcitraubende und nur selten von Erfolg gekrönte Methode.

3. Zentrifugieren. Pokrowski und M. Heidenhain haben zur Fürbung isolierten Materials empfohlen, die gefürbten und in der Farbflotte schwimmenden isolierten Organteile in einer Handzentrifuge zu zentrifugicren. Dadurch gelingt es, das sonst sehr schwer zu färbende mazerierte Material in großen Mengen zu crhalten und zahlreiche Präparate - auch Daucrpräparate - anzufertigen. Nan bringt, um die Einzelheiten des Verfahrens anzugeben, z. B. mazerierte Darmteile in ein Reagensglas mit destillicrtem Wasser und schiittelt kräftig durch. Ist dic Nazeration gelungen, dann muß das Objekt bei dem Schütteln in kleinste Teile zerfallen, die höchstens ein nur geringes Nachzerzupfen mit der Nadel nötig machen. (Diese Entbehrlichkeit des Zerzupfens findet sich fast ausschließlich am Darmkanal.) Nun bringt man das Reagensglas mit dem zerschüttelten Material in eine kleine Handzentrifuge und zentrifugiert. Vom Bodensatz saugt man mit einer Pipette die Flüssigkeit ab, gibt Farblösung zu, wartet die Färbung $a b$ und zentrifugiert von neuem. Das kann man wiederholen, bis das Präparat zum Montieren reif ist, woriber bei einer späteren Gelegenheit mehr zu sagen sein wird.

Hat man Material, das sich gut mazeriert, dann kann unter Umständen ein derbes Schütteln des Objektes mit destilliertem Wrasser in einem Reagensglase ausreichen, um vollkommenste Isolation herbeizuführen. Solches Material ist, wie gesagt, der Darmkanal der Vertebraten in seiner ganzen Ausdehnung, ferner der L'terus der Säugetiere; auch quergestreifte Muskeln können so zerfallen. IVill man sich die oft nicht geringe Mühe ersparen, die isolierten Teile einzeln aus der Flüssigkeit herauszufischen, so kann man zentrifugieren und erhält, wenn man den Bodensatz mit nur wenig IVasser versetzt, große Mengen von Isolationspräparaten.

\section{§ I9.}

Ich werde jetzt die einzelnen Mazerationsmittel schildern. Wie bereits bemerkt wurde, sind Härtungsmittel auch Nazerationsmittel, wenn man sie nur genügend verduinnt. Nan wird daher hier dieselben Reagentien finden, die im nüchsten Kapitel als Fixierungsund Härtungsmittel wiederkehren. Nur eine Differenz ist zu konstatieren. Bei Fixierung und Härtung werden in ausgiebigster IVeise Mischungen verschiedener Reagentien benutzt und gerade dic allgemein als die besten ancrkannten Fixierungsmittel sind zusammengesetzter Natur. Bei den Mazerationsmitteln dagegen kommen fast 
ausschließlich einfache Reagentien in Anwendung, kaum zwei oder drei Vorschriften für Mischungen existieren. WVenn mehr als ein Reagens verwendet werden soll, dann werden meistens die zwei oder drei Lösungen gesondert gebraucht. Ob diese Differenz darin liegt, daß genischte Reagentien sich nicht zur Mazeration eignen, auch wenn sie noch so sehr verdünnt werden, ist zurzeit nicht zu sagen. Tielleicht ist sie nur eine scheinbare, ist nur dadurch hervorgerufen, daß man bisher noch nicht gepriift hat, ob nicht z. B. Flemming sche oder Hermannsche Flüssigkeit auch ebenso gute Mazerationsmittel sind, wie Chromsäure, Essigsäure oder Osmiumsäure allein. Jedenfalls wiirde es sich lohnen, Versuche nach dieser Richtung hin anzustellen.

Es mögen nun die einzelnen Vorschriften folgen:

4. Jodserum, nach Max Schultze. Man setzt zu der Amniosflïssigkeit von Wiederkäuerembryonen - Schafembryonen sind in jedem Schlachthaus mit Leichtigkeit zu erhalten - sehr viel Jodtinktur oder Jodum purum und tut zu der filtrierten Lösung etwas Kampher als Antisepticum. Es ist dies ein vorzügliches Mazerationsmittel namentlich für zarte Objekte, rersagt aber auch bei derberen nicht. Die Dauer der Einwirkung ist in jedem Einzelfalle zu erproben, indem man alle 24 Stunden Zerzupfungsversuche macht.

5. Künstliches Jodserum, nach H. Frey. Man mischt $30 \mathrm{~g}$ Hühnereiweiß mit $270 \mathrm{ccm}$ destillierten Wassers und fügt $2,5 \mathrm{~g}$ Kochsalz hinzu. Die Lösung soll einen vollwichtigen Ersatz für die vorige Flüssigkeit bilden.

6. ${ }^{\mathrm{A}}$ Alkohol Alcool au tiers), nach Ranvier. Man mischt I Teil Alkohol von $90^{\circ}$, mit 2 Teilen destillierten Wassers. Sehr kleine Objekte kommen auf 24 Stunden und länger in die Flüssigkeit. Man folge hier der in $\$$ I 7 ausfuihrlich begründeten Regel, nicht zu viel Mazerationsflüssigkeit zu nehmen, denn der $30 \%$ Alkohol, um den es sich hier handelt, kann in größeren Quantitäten erhärtend wirken. Vorzüglich für Epithelien, Drüsenzellen, quergestreifte Muskeln.

7. I/4 Alkohol, nach Rawitz. I Teil Alkohol absolutus mit 3 Teilen Aqua destillata verduinnt. Dieser $25 \%$ Alkohol hat sich mir bei Untersuchungen über das zentrale Nervensystem von Mollusken ausgezeichnet bewährt. Mazeriert man länger als 4 Tage, dann muß die Flüssigkeit eventuell erneuert werden, damit sie nicht fault. Geeignet fuir Nervensystem von Evertebraten und für Epithelien.

8. ${ }^{1} / 6$ Alkohol, nach Solbrig. I Teil käuflichen Weingeistes mit 5 Teilen Aqua destillata verdiinnt. Gut für Nervensystem von Evertebraten. 
9. Formol, nach Gage. Das von Blum zur Konservierung zuerst empfohlene Formol (Formalin), cine $40^{\circ}$ 。 käufliche Lüsung von Formaldehyd, verwendet Gage als Mazerationsmittel nach folgender Vorschrift: $2 \mathrm{ccm}$ käufliches Formol werden mit $1000 \mathrm{ccm}$ physiologischer Kochsalzlösung $10,6 \%$ ' vermischt. Die Wirkung ist eine sehr rapide, denn schon nach 3 Stunden lassen sich Flimmerepithelien isolieren. Die Organe können aber auch, ohne daß Fäulnis eintritt, bis zu ro Tagen in der Mazerationsflüsigkeit verbleiben. If ür alles geeignet.

Io. Chromsäure $0, \mathrm{I}_{0}-0,005 \%$. Dic Chromsäure ist, wie der Alkohol, in starken Verduinnungen ein vorzügliches Mazerationsmittcl. IVie sehr die Konzentration schwanken kann, zeigen die obigen Zahlen. Zarte Objekte vertragen cine stärkere, kompakte verlangen eine dünne Säure. Für alles geeignet; glatte Muskelfasern sind in 0,0 I bis $0,05 \%$ Lösung sehr gut nach 24-48 Stunden $\mathrm{zu}$ isolieren.

II. Buchholzsche Methode. Bei pulmonaten Gastropoden isolieren sich die zentralen Ganglienzellen nach der Angabe von Buchholz sehr leicht, wenn man die Ganglien zunächst in eine $\mathrm{O}, \mathrm{O} \mathrm{I} \%$ Chromsäure für $24-48$ Stunden einbringt, dann für ${ }_{2}^{\mathrm{I}}-1$ Stunde in $0,05 \%$ Chromsäure überführt und darauf in indifferenter Flussigkeit, z. B. physiologischer Kochsalzlösung, erweicht. Für Land-Evertebraten empfehlenswert.

12. Arnoldsche Methode. Dies ist eine der besten Nazerationsmethoden, die es überhaupt gibt. Für periphere Ganglien der Vertebraten empfohlen eignet sich die Methode für alle Organe der Vertebraten. MIan kann mit $0,1 \%$ Goldchloridlösung $\left({ }_{2}\right.$ - I Stunde im Dunkeln, Reduktion im Tageslichte in essigsäurchaltigem Wasser) nachbehandeln, in Glyzerin zerzupfen und aufheben. Derartige Präparate halten sich bei mir seit mehr als 20 Jahren. Der Nodus procedendi ist folgender: Objekt für 5- Io Minuten in O, I ${ }^{\circ}$. Essigsäure, dann direktes Übertragen für $24-48$ Stunden in $0,0{ }^{\circ}$. Chromsäure. Sehr leichte Isolation.

13. Ammonium bichromicum $0,025^{\circ} \circ-0, I^{\circ}$. Besondere Torteile bietet dies unzuverlässige Nittel nicht; für Epithelien bei Evertebraten geeignet.

I4. Landois-Gierkesche Flüssigkeit. Jc $5 \mathrm{ccm}$ konzentrierter wässriger Lösungen von chromsaurem (einfach saurem) Ammonium, Kaliumphosphat und Natriumphosphat werden miteinander gemischt und mit $100 \mathrm{ccm}$ Aqua destillata verdiunnt. Lavdowsky rühmt dieses Reagens sehr für das zentrale Nervensystem der Amphibien; Einwirkungsdauer 24 Stunden und länger. 
15. Deiterssche Vorschriften zur Isolation der zentralen Ganglienzelle der Säugetiere:

I5a. Kali bichromicum $0, I_{\%}^{\circ}$. Vorderhornzellen des Rückenmarkes und Hirschgeweihzellen des kleinen Gehirns sind nach zweitägiger Einwirkung gut $\mathrm{zu}$ isolieren. Auch für Evertebraten ist nach meinen Erfahrungen dieses Reagens geeignet; stärkere Verdünnungen, $0,05 \%-0,025 \%$, führen bei letzteren nach $8-2.4$ stündiger Wirkung ebenfalls zum Ziel. Nachfärben möglich; nach kurzem Auswaschen in Aqua destillata wird in verduinntem Glyzerin zerzupft.

I 5 b. Kali bichromicum o, or $-0,005 \%$. Deiters isolierte mit diesen Verdünnungen die allerfeinsten Achsenzylinder, die von ihm sogenannten feinen Achsenzylinder der multipolaren Ganglienzellen. Diese Gebilde, die von den Protoplasmafortsätzen, den heutigen Dendriten, entspringen, scheinen heutzutage in Vergessenheit geraten zu sein, denn ich glaube mich nicht zu täuschen, wenn ich meine, daß weder die Chromsilber- noch die Methylenblaumethode sie bisher gezeigt haben.

16. Kali bichromicum $4 \%-5 \%$. Flemming hat Teile des Mantelrandes von $S$ ü $\beta$ Wassermuscheln für mindestens I Woche in diese Lösung getan und erhielt dann vorzügliche Isolation von indifferenten Epithelzellen und Sinneszellen. Ein Zerzupfen war nicht mehr nötig. Es genügte, wenn man mit der Nadel auf das Objekt klopfte, dann fielen die indifferenten Epithelien ab und die Sinneszellen pendelten an dem Mantelrand- (oder Mundlappen- usw.) Stückchen hin und her. Nach eigenen Versuchen glaube ich dies Reagens

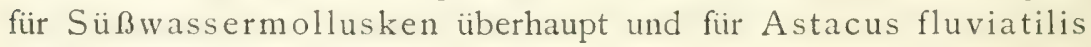
sehr empfehlen zu können.

I7. Osmiumsäure $\mathrm{I}^{\circ}{ }^{\circ}$. Die Osmiumsäure ist allein für sich und in verschiedenen Mischungen ein Fixierungsmittel, aber auch hier bestätigt sich, daß ein Fixierungsmittel zugleich für Mazeration geeignet ist, mit der Maßgabe, daß sogar die fixierende Konzentration, $I^{\circ}$, mazerierend wirkt. Denn wenn man nach Neumann periphere Nerven von Vertebraten 24 Stunden in $1 \%$ Osmiumsäure liegen läßt und die osmierten Stuicke für $2+-48$ Stunden in destilliertes Wasser bringt, dann lassen sich die Nervenfasern leicht und auf weite Strecken isolieren.

I 8. Osmiumsäure $\mathrm{o}, \mathrm{I}^{\circ}$. Sehr kleine Stücke Material kommen 24 Stunden lang in diese Lösung, werden dann sorgfältig in destilliertem Wasser ausgewaschen und in verdünntem Glyzerin oder $50^{\circ}$ : Kali aceticum zerzupft. Zur Isolation von Epithelzellen und zur Erkennung von Tastkolben sehr geeignet. 
19. Osmium-Essigsäure. R. Hertwig mischt gleiche Quantitäten von $0,05 \%$ Osmiumsäure und $2 \%$ Essigsäure. Für Actinien, bei nur minutenlanger Einwirkung, empfohlen: dürfte auch bei anderen Evertebraten gute Resultate geben.

20. Drostsches Gemisch. Man löst $0,25 \mathrm{~g}$ Chromsäure, $0, \mathrm{I} \mathrm{g}$ Osmiumsäure, $\mathrm{O}, \mathrm{I} \mathrm{g}$ Eisessig in $100 \mathrm{ccm}$ Seewasser. Epithelzellen niederer mariner Tiere isolieren sich leicht, wenn sie in dem Gemisch mehrere Tage verweilt haben. Wenn man statt des Seewassers destilliertes Vasser nimmt, so eignet sich das Gemisch auch für Organe von Vertebraten und Evertebraten des Landes.

21. Dünne Pikrinsäurelösung. Auf $15 \mathrm{ccm}$ Aqua destillata gibt man 5-10 Tropfen kalt gesättigter wässriger Pikrinsäurelösung. Nervensystem von Wirbellosen ist nach i $2-2+$ Stunden vorzüglich mazeriert. Epithel- und Drüsenzellen von Vertebraten isolieren sich bequem nach einer Einwirkung des Reagens ron + - 8 Stunden. Zerzupfen in destilliertem Wasser oder dünnem Glyzerin.

22. Pikrinsäurealkohol, nach Hopkins. Epithelzellen, besonders diejenigen des Verdauungskanals, werden nach Hopkins gut in folgender Mischung isolationsfähig: Prilirinsäure $0, \mathrm{I} \mathrm{g}, 95^{\circ}$ 。 Alkohol $25 \mathrm{ccm}$, destilliertes Wasser $75 \mathrm{ccm}$. Bereits nach einigen Stunden ist eine Isolation möglich.

23. Oxalsäurelösung. Max Schultze hat zuerst zu Mazerationen die kalt gesättigte, wässrige Oxalsäurelösung empfohlen, Boll hat sie dann in ausgedehntem Maße angewendet. Vorzüglich für Epithelund Drüsenzellen bei Vertebraten und Evertebraten. Nach I 2 bis 24 stuindiger Einwirkung ist oft ein bloßes Schuitteln des Materials in destilliertem IVasser nötig, um ausgiebige Isolation herbeizufihren, andernfalls zerzupft man nach gutem Auswaschen in M'asser.

24. Hallersches Gemisch. Für Sinnesorgane ron Mollusken empfichlt Béla Haller folgendes Reagens: 1,2 Teile Aqua destillata, 0,4 Teile Glyzerin, 0,4 Teile konzentrierter Essigsäure. Schon nach halbstündigem Verweilen in der Nischung geben die Organe gute Isolation. Für Vertebraten wird länger dauernde Nazeration nötig sein.

25. Apáthysches Gemisch. Ein von A pathy empfohlenes Gemisch kann als Mazerationsflüsigkeit betrachtet werden. 15 Teile Eisessig. 15 Teile Salpetersäure, 100 Teile absoluter Alkohol, ebensoviel Glyzerin und Wasser werden sorgfältig gemischt. Hirudineen, die in $30^{\circ}$ 。 Alkohol betäubt wurden, kommen für $2+$ Stunden hinein; dann werden sie direkt in eine geringe Menge $70^{\circ}$, Alkohol übergefuihrt, wobei sie stark quellen. Nach 2.4 Stunden werden sie in Glyzerin und Aqua destillata, zu gleichen Teilen gemischt, eingelegt; die Flüssigkeit muls 
so lange gerrchselt werden, bis sie nicht mehr sauer reagiert. Die feinsten Verästelungen des peripheren Nervensystems sind vom Ganglion bis zur Epidermis zu verfolgen.

26. Salpetersäure $20 \%$. Reichert hat diese Konzentration der Salpctersäure zuerst zur Isolation von glatten Muskelfasern cmpfohlen. Nach 24 Stunden ist Zerzupfung möglich, nach ctwa 3 Tagen geniigt leichtes Schütteln, um völligen Zerfall in die einzelnen Muskelzellen herbeizuführen.

27. Salpetersäure-Alaun. Hopkins empfiehlt folgende Modifikation der vorigen Methode. Magen oder Darmkanal wird für cinige Zeit in $20^{\circ}$ 。 Salpetersäure eingelegt. Wenn man durch Probieren festgestellt hat, daß sich Drüsen- und Muskelschicht leicht voncinander trennen lassen, dann wäscht man in Wasser aus und führt in eine konzentricrte wässerige Alaunlösung über. Darin verweilen die Objekte belicbig lange Zeit. Kleine Stiickchen lassen sich leicht zerzupfen. Dic Reichertsche Methode erscheint mir rationeller, da sie zu eincm fast freiwilligen Zerfall des Organs führt, ohne die Form der einzelnen Teile zu alterieren.

28. Kali chloricum mit Salpetersäure. Kühne empfahl die folgende Methode zur Isolation quergestreifter Muskeln. In ein Becherglas kommt soviel chlorsaures Kali in Kristallen, daß der Boden gut bedeckt ist. Dann befeuchtet man mit etwas destillicrtem Wasser und gießt das vierfache Volumen reiner, konzentrierter Salpetersäure zu. Man rührt jetzt um und legt einen Muskel, z. B. vom Frosch, auf den Boden des Glases unter die Kristalle. Schon nach i. Stunde zerfallt zuweilen der Muskel, wenn man ihn in einem Reagensglase mit VVasser schiittelt, leicht in seine Fibrillen. Geht der Zerfall nach ${ }^{\prime}$ : Stunde noch nicht ror sich, so bringt man den Muskel in die Kristalle zurïck und probiert alle 5 Minuten von neuem bis der gewünschte Effekt erreicht ist.

29. Schweflige Säure. Sandmann hat dies Reagens zur Isolation der Fibrillen quergestreifter Muskeln empfohlen und ausgezeichnete Erfolge damit erziclt. Man bringt Muskeln in ein gut verkorktes Reagensglas mit schwefliger Säure und läßt sie, je nach ihrem Volumen und nach ihrem Bindegewebsreichtum, I-8 Tage darin. Allzu voluminöse Muskeln zerteilt man in passende Streifen, die parallel der Faserung gelegt werden müssen. Dann wird sorgfältig in destilliertem Wasser, in welchem das Bindegewebe etwas quillt, ausgewaschen und darauf $3-4$ mal in jedesmal erneuertem Wasser aufgekocht. Nach der Abkiihlung schuittelt man im Reagensglase ordentlich durch und nun muß der Muskel in seine Fibrillen zerfallen. 
Tritt dieser Zerfall nicht ein, dann ist er auch am selben Muskel nicht mehr zu erzielen und man muß daher einen neuen Mazerationsversuch anstellen. Indessen gehört solches Mißglücken zu den größten Seltenheiten.

30. Rohrzucker und schweflige Säure, von Klebs. Um schonend Epithelzellen von ihrer Unterlage abzumazcrieren, ist das folgende Klebssche Verfahren sehr geeignet. Auf I ccm 5\% Rohrzuckerlösung kommt ein Tropfen schwefliger Säure. Nach I - 2 Stunden versucht man, ob sich nicht beim Schiitteln des Naterials in W'asser die Epithelzellen loslösen. Die Wirkung ist nicht immer präzis, man muß daher auch länger mazerieren und dabei von Zeit zu Zeit den Grad der Mazeration feststellen.

Ich habe gelegentlich statt der schwefligen Säure I $\mathrm{ccm}$ einer I : Lösung von Natriumbisulfit zu I ccm Rohrzuckerlösung gesetzt und an den Epithelzellen der Harnblase des Frosches gute Erfolge damit erzielt.

3I. Salizylsäure 2,5\%. Nach den Angaben von M. Heidenhain hat Froriep die Salizylsäure mit Erfolg zur Mazeration glatter Muskeln verwendet. Man kocht z. B. Katzendarm in $2,5 \%$ Salizylsäure. Nach Wochen, sogar noch nach Jahr und Tag lassen sich die glatten Muskeln durch starkes Schütteln isolieren. Heidenhain hält diese Methode für die beste bei glatten Muskeln.

32. Reine Salzsäure. Zur Isolation von Drüsenkanälen werden kleine Teile des zu untersuchenden Organes in $10 \mathrm{ccm}$ reiner (d. h. offizineller) Salzsäure 10-20 Stunden mazeriert. Dann wäscht man 24 Stunden lang in häufig gewechseltem destilliertem Wasser aus. Jetzt bereitet die Isolation keine Schwierigkeiten; oft geniigt ein starkes Schütteln des Drüsenstiickes, um das Auseinanderfallen der einzclnen Kanälchen herbeizuführen.

33. Eau de Javelle, Liquor natri hypochlorosi (nach der deutschen Pharmakopoe). Fol gibt 8 Tropfen Eau de Javelle auf $100 \mathrm{ccm}$ Wasser und mazeriert darin Nerven und Muskeln ${ }_{2} 4$ Stunden lang. Darnach zerfallen bei einfachem Schütteln die Objekte in die einzelnen Fibrillen. Das Reagens greift nach meinen Erfahrungen das Material stark an, wenn man eine nicht angemessene Konzentration gewählt hat. Was aber »angemessen : ist, muß jedesmal erst durch sorgfältiges Probieren festgestellt werden, wobei man namentlich die Temperatur der Umgebung nicht außer Acht lassen darf; kïhle Jahreszeit verlangt eine etwas stärkere, warme eine schwächere Konzentration. Diese Umständlichkeit, jedesmal erst probieren zu müssen, und die damit verbundene Unsicherheit der Ergebnisse haben es 
wohl bewirkt, daß dieses souveräne Mazerationsmittel nicht beliebt ist.

34. Lysol, von Reinke. Der Vollständigkeit wegen sei erwähnt, daß Reinke 10 。 Wässrige Lösung und andere, mit Alkohol versetzte Mischungen von Lysol zur Mazeration empfohlen hat. Nach eingichender Prüfung halte ich dies Reagens in Übereinstimmung mit A. Fischer für gänzlich wertlos.

\section{$\S 20$.}

Von der auf physiologisch-chemischem W'ege festgestellten Tatsache ausgehend, daß manche Gewebe des Tierkörpers den Verdauungssäften ganz widerstehen, andere nur langsam verdaut werden, so daß Organe, wenn man sie verdauenden Substanzen ausgesetzt hat, nach einiger Zeit nur noch ganz bestimmte Teile der sie zusammensetzenden Gewebe besitzen: von dieser Tatsache ausgehend haben einige Forscher zu Mazerationszwecken verschiedene Verdauungsmethoden empfohlen. Diese sollen in den folgenden Zeilen näher beschrieben werden, doch möchte ich vorher mein Gesamturteil über sie abgeben. Ich halte sie sämtlich für zweck- und wertlos, zum mindesten für sehr überflüssig. Denn so rationell sie aussehen, so scheinbar exakt sie erdacht sind, ebenso unsicher und unzuverlässig und zugleich so widerspruchsvoll in ihren Ergcbnissen sind sie durchweg.

35. Trypsinverdauung, nach $\mathrm{K} u ̈ h n e$. Nach den Vorschriften von Kühne und Ewald stellt man sich Trypsin auf folgende Weise her. Das Pankreas eines frisch geschlachteten Rindes wird im Extraktions-

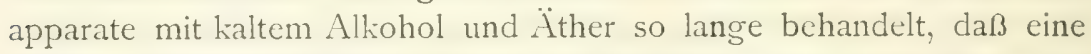
weiße, leichte zerreibliche NIasse zuruickbleibt. Ein Gewichtsteil der letzteren wird mit 3-10 Gewichtsteilen $0,1^{\circ}$. Salizylsäure 3-4 Stunden bei $40^{\circ} \mathrm{C}$. behandelt, dann durch Leinwand und nach dem Erkalten durch Papier filtriert. Nit einem aliquoten Teile dieses so erhaltenen Reagens beschickt man ein Reagensglas, bringt die Organteile hinein und stellt fur mehrere Tage in einen Briitschrank bei $37,5^{\circ} \mathrm{C}$. Dann nimmt man das Material heraus, schüttelt es in cinem Reagensglase mit cestilliertem Wasser tiichtig durch und untersucht in $0,75 \%$ Kochsalzlösung.

Wiinscht man statt der eben geschilderten sauren cine alkalische Lösung, so neutralisiert man zunächst die saure Lösung durch Soda und macht sie durch einen Überschuß alkalisch. Um das Verschimmeln der alkalischen Trypsinlösung zu verhüten, setzt man soviel von einer alkoholischen $20 \%$ Thymollösung zu, da $\beta$ in der Trypsinlösung $0,5 \%$ Thymol enthalten sind. 
36. Pankreatin, nach Schiefferdecker. Von kïuflichem, trocknem Pankreatin stellt Schiefferdecker eine gesättigte wässrige Lösung her, die filtriert wird. Organteile werden darin bei $37^{\prime \prime} \mathrm{C} .3-+$ Stunden lang verdaut. Für verschiedene Teile von Vertebraten und Evertebraten versucht.

37. Pepsin. Man kann sich Pepsin aus Schweincmagen entweder selbst herstellen oder, besser noch, man kauft das Praiparat in einer chemischen Fabrik. Die Anwendung geschieht entweder in einfacher wässriger Lösung oder mit Zusatz von Salzsäure oder von Oxalsïure. Hierbei handelt es sich nicht mehr um histologische Untersuchungen, sondern um chemische Versuche, auf die in einem Lehrbuche der mikroskopischen Technik nicht eingegangen zu werden braucht.

\section{Viertes Kapite1. \\ Fixierung und Härtung.}

\section{$\S 2 I$.}

Venn wir von der Voraussetzung ausgehen, daß die bisherige Schilderung der mikroskopischen Technik dem Gange folgte, den eine Untersuchung zu nehmen hat, so können wir uns nun einmal fragen: Was haben wir mit denjenigen Methoden, welche wir kennen gelernt, erreicht, welchen Einblick in den gröberen und feineren $13 a u$ der tierischen Organe haben sie uns verschafft? War das Organ durchsichtig genug, um im lebenden Körper untersucht zu werden. so haben wir seine Blutgefäße in Aktion gesehen, haben dic Bewcgungen verfolgen können, welche das Blut in den Kapillaren machen muß. Ferner konnten wir günstigen Falles die Nervenverteilung in dem Organe erkennen (Siegmund Mayer hat hierfuir den botanischen Ausdruck »die Nervatur adoptiert, ohne allerdings der letzten Endigungen ansichtig zu werden. Und ebenso sahen wir in guinstigem Falle, ob die Oberfläche mit wimpernden oder nicht wimpernden Zellen bedeckt war, ob und was fuir Muskulatur das Organ durchzog. ob in ihm vielleicht besondere drüsige Bestandteile vorhanden waren. Schloß dagegen die Beschaffenhcit des Tieres oder die des Organes oder beider die Untersuchung des lebendigen Gebildes aus, mußten wir also überlebendes. Material studieren oder betrachteten wir das 
vorher lcbend angeschene nun in überlebendem Zustande, so konnten wir in unserer Erkenntnis schon etwas weiter gelangen. Die Form der ein ()rgan zusammensetzenden Zellen, ihre eventuelle natüliche Färhung, die Natur und Färbung etwaiger Einschliusse, die namentlich bei verschiedenen Organen der Evertebraten von Interesse und Wichtiglieit sind (z. B. bei der Mitteldarmdrüse von Mollusken, der grünen Driise vom Flußkrebs): das sind Ergebnisse, die uns das iiberlcbende Naterial mit Sicherheit liefert. Ja eigentlich nur das iiberlebende, ohne Reagentien behandelte Material; denn jedes Reagens, wie immer seine Beschaffenheit sei, wird auf die erwähnten Einzelheiten alterierend, oft auch zerstörend einwirken. Und sind wir dann weiter zur Mazeration ibergegangen, so haben wir noch die Tatsache erfahren, daß das Organ aus verschiedenen Konstituenten hesteht und haben deren Aussehen und event. ihre gegenseitigen Beziehungen kennen gelernt.

Aber mehr haben wir auch nicht erfahren, und das genügt uns nicht. Denn alle feineren Verhältnisse, ja auch viele gröberen sind uns nach wie vor unbekannt geblieben. Der intimere Aufbau der das untersuchte Organ charakterisierenden Zellen, die Verteilung der einzelnen Organbestandteile, die Textur oder, wenn man lieber will, die Topographie der Organe sind und bleiben trotz der bisherigen Untersuchung problematisch. Denn trotz der Durchsichtigkeit des lebenden Organes ist doch die Anwendung starker Linsensysteme verwehrt; weil das iiberlebende Material nicht genügend Lichtdifferenzen besitzt, können wir nicht wissen, ob alle Strukturelemente im Mikroskope erkennbar sind. Und so wertvoll das Studium mazerierten Materials ist: eben weil die Teile aus ihrer naturlichen Lagerung entfernt sind, erfahren wir nichts über ihre gegenseitige Gruppierung. Kurz: Probleme werden durch die bisherige Methodik angeregt, aber nicht gelöst; Fragen werden gestellt, doch nicht beantwortet.

Wir müssen daher das Material, das unseren Forschungen dienen soll, in einen Zustand versetzen, in welchem die Lösung aller Probleme, die Beantwortung aller Fragen, die wir als das eigentliche Ergebnis unserer Methodik zu verzeichnen wünschen, möglich ist. Das Material muß so durchsichtig werden, daß die stärksten Linsen uns ein klares Bild zu geben vermögen von der Struktur der Zellen, von ihren Beziehungen zu einander usw. Und weiter: Wir müssen erstreben, da $\beta$ das so hergerichtete Material ein getreues Konterfei des Lebens ist, daß also alle Konstituenten eines Organes ihren inneren Aufbau, ihre gegenseitigen Beziehungen so zeigen, 
wic sie im lebendigen, funktionierenden Organe vorhanden sind. Das mikroskopische Bild mu uns ein Nebeneinander ron Zuständen enthüllen, aus denen wir einen möglichst sicheren SchluB auf das Nacheinander der lebendigen Vorgänge ziehen können.

Die Summe der Methodik, welche diesen Absichten und Münschen genigen soll, heißt Fixierung und Härtung. Nanchc Forscher rechnen auch das Konservieren hierher.

\section{$\$ 22$.}

Das Konservieren, wenn es nicht bloß in einem Aufheben des Fixierten und Erhärteten besteht, hat für den Mikroskopiker meines Erachtens nur ein sekundäres Interesse, und dies selbst dann, wenn es sich um Evertebratenmaterial handelt. Konservieren heißt, ein Tier oder ein Organ in seiner äußeren Form und womöglich in seinen natiirlichen Farben fuir lange Zeit in derselben Flussigkeit aufbewahrungsfähig machen. Damit ist aber durchaus nicht vereint eine Erhaltung der cinzelnen Elementarteile in einem solchen $\mathrm{Zu}$ stande, daß sie den Ansprïchen des Mikroskopikers entsprechen. Die besten Konservierungsmittel sind häufig genug sehr schlechte Fixierungsmittel, die schönsten Schaustücke einer anatomischen oder zoologischen Sammlung geben fast regelmäßig ganz miserable mikroskopische Präparate. Andererseits: die Reagentien, welche gut fixieren, konservieren oft recht schlecht. Ja unsere besten, zum mindesten unsere beliebtesten Fixierungsmittel konservieren gar nicht, weil sie das in ihnen dauernd verweilende Organ brüchig machen. Manche Fixierungsmittel wirken erhärtend, wie z. B. die später zu erwähnende Niullersche Flüssigkeit; aber zur dauernden Konservierung sind auch sie nicht geeignet. Nur der Alkohol und das Formol fixieren und konservieren; namentlich das letztere ist ein sehr gutes Konservierungsmittel. Alle Methoden, welche in erster Linie die Konservierung erstreben, besonders die für pathologisches Material und die für niedere Seetiere empfohlenen, weil sie in ihrer großen Mehrzahl für histologische Zwecke ungeeignet sind, werden daher hier unberücksichtigt bleiben. Nur solche sollen Aufnahme finden, die fuir den Mikroskopiker von IVert sind. Das Konservieren als solches braucht daher hier nicht näher beschrieben zu werden.

$$
\S 23 \text {. }
$$

Auf Fixieren und Härten wollen wir uns in den folgenden Auseinandersetzungen beschränken. Da fragen wir zunächst: Was heißt Fixieren?

Rawitz, Mikroskopische Technik. 
Sehr richtig definiert Fischer (in dem im Vorworte erwähnten Buche) das I'rinzip des Fixierens als die Tendenz, die Bestandteilc der lebendigen Substanz in feste, unlösliche Verbindungen und feste Strukturen ïbcrzufuhren. Denn das Lebendige hat einen, wie ich es nennen miichte, gewissemaßen hybriden Aggregatzustand, den man als sfestweich " bezeichnet. Also mit anderen Worten: Wenn wir fixieren, so wollen wir in dem Organ, und zwar in allen seincn Bestandteilen, den Zustand festhalten, in Erstarrung la la () vids Metamorphosen die Strukturen dem Mikroskop überliefern welche im Augenblicke des Einbringens in das Fixierungsmittel in seinen Zellen und Geweben vorhanden waren. Wichtig ist daher, das Material in noch lebensfrischem Zustande in die Fixierungsflussigkeit einzulegen. Und nur wenn dies nicht möglich ist, wie fast immer bei menschlichen Organen. oder wenn es sich um überaus seltenes, schwer zu erlangendes Material handelt, darf man von dieser Forderung Abstand nchmen. Das natiulich gestorbene Organ aber gewährt niemals dic relative Sicherhcit für die zu erzielenden Resultate wie das durch absichtliche Tötung des Tieres gewonnene.

Die später zu nennenden Fixierungsmittel besitzen eine sehr verschiedene ITirkung und daher einen sehr verschiedenen Wert. Die einen z. B. werden als rorzïglich gerihmt, um die feineren Strukturen des Protoplasma (besser: der Zellsubstanz zur Anschauung zu bringen, während sie auf den Zellkern ungünstig cinwirken. Bei anderen Mitteln wird das gerade entgegengesetzte Terhalten erkannt und anerkannt. Uft genug widersprechen sich auch die Angaben der Forscher: der rümt ein Reagens als liernfixierend, während jener sagt: :Bewahre nein, nur für Zellsubstanzen taugt $c s$. Wiederum gibt es Mittel, welche Zelleinschlüsse fixieren, wie Fett, Granula usw., während andere Nittel \%ellprodukte, z. B. Nucin, iorzüglich erhalten sollen. Die IIrkungen widersprechen dabei einander nicht gar so selten. In derselben Zellart läßt das eine Fixicrungsmittel uns eine fädige, das anderc eine schaumige, das dritte cine granulicrte Struktur erkennen. In Kern finden wir Stäbe oder Granula oder Krïmel, je nach dem angewandten Reagens. Die Wirkung verschicdener Reagentien auf dasselbe Objekt ist also sehr variabel: aber hinzuzufigen ist noch, dal.3 auch dasselbe Nittel ganz verschieden wirkt, je nachdem das Objekt beschaffen ist. Und all das, was soehen hervorgehohen wurde, gilt nicht bloß fü die einfachen chemischen Substanzen, dic ais Fixicrungsmittel gebraucht werden, sondern auch fuir deren Gemische.

Wie es nicht gleichgiltig ist. welches Reagens wir angewandt. 
nimlich ob wir Zcellstrukturen une Kimbiles nach Fixicrung in Sublimat oder Kali bichromicum, Astummsure orler I'ikrinsiure usw. be-

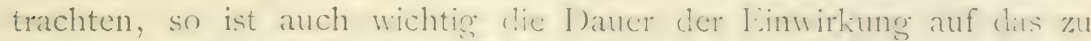

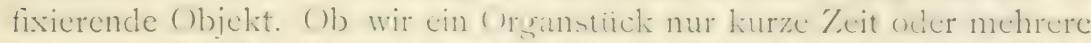
Tage, ja Mochen in cincm Föricrungsmittel lassen, das becinflust in

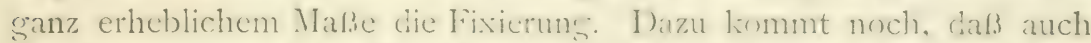
die Temperatur der Limgelums von belentencem Finfusse ist; Sommer und Winter machen erinebliche Unterschiche in ier Jixicrung. ()b dic natioliche Wirme oler cinc kimstliche cinwirlit, ist wichtig festzustcllen, weil Temperaturditerenzen der keatgenticn reft genug Fixicrungsdifferenzen hervorrufen.

Dal3 chaselbe keagens eine rerschiedene II irkung entfilti.i. die sich nath lier drt und der Beschaffenheit des Oromes richtet, ist schon sesigt worden. Leber. Milz, schleimsewehe. (hitin werden in ganz differenter 11 cise von der Chromsäure z. B. fixiert. Lne? hier ist noch cinc besondere Komplitition zu erwahnen: auch auf die Tierklasse, ja oft auch auf die Tierspezies kommt es an, die das Organ geliefert hat. Fin Reagens numlich, las rorziglich die Leber ron Säugeticren fixicrt. Kann dic ron Reptilien vielleicht zerstijren. Der Lnterschicd in der Fixierungsfihigkeit der ()rone ron Landtieren sowic ron Sïßwasser- und Seewassertieren ist ein sehr becutender; ein hier gut wirkendes Reagens kann lort schlechteste Resultate liefern.

Fü die Mirkung und I ceistung der fixicrenden Reagentien ist ferner ron 17 ichtigkeit die sogenannte Permeahilitit (ier ()rone. T)ie einen durchdringen sich leicht mit eincm Reagens, das bei einem anderen (Jgane weniger schnell ins Innere tritt. Massige, durbe Gebilde, wie Leber; Milz, Gehim, sind vich schwerer zu fixic:en als weniger kompalite, eben weil sic sich schwerer mit iem Renjens surchtränken. Daßs cine solch ungleichartige I'ermeabilitat auch zu ungleichartigen Resultaten hinsichtlich des Mertes der Fixierungsmittel fuhren muB, ist klar. Sher auch die fixierten ()ranteile einer Leber 7. B. werden an der Peripheric des ()rganes nicht die sleiche Fixicrung zeigen kïnnen wie im Zentrum. Neben diesem nuthr mechanischen .Motive, welches auf die Leistunstahiekeit unserer Fixicrungsmittel cinwirkt, kommt noch ein, ich möchte es nemnen, ritales Motiv in Betracht. Die verschiedencen ()rgane kes Körpers sind Burch die Verschicdenartiokeit lier sic zusammensetzunden /cilen charakterisicrt, und diese Differenz ist nicht hloß in Aer iubseren Form sondern mehr noch in der chemischen Konstitution ausgeprijut. Eine l'ankreaszelle z. B. ist ron einer Parotiszelle mikrosleopisch kam zu untersinei- 
den, und doch liefert jene das Trypsin, diese den serösen Speichel. Nun sollen dic ()rgane womöglich lebenswarm, also ïherlebend in dic Fixierungsfliissigkeit kommen. Daß die Zellen gegen die sie abtötenden Reagention gemäß ihrer verschiedenen chemischen Konstitution auch virschieden sich verhalten werden, erscheint selbstverständlich. Denn wenn auch Ganglienzelle, Driisenzelle, Muskelzelle aus : Protojuasma * bestehen: daß damit gar nichts gesagt ist, lehrt ihre so sehr rerschiedene Funktion. Und daß daher dasselbe Mittel die verschiedenen Protoplasmarten zu einer verschiedenen Gegenreaktion veranlassen wird, erscheint mir wahrscheinlich. Aber selbst wenn die hiermit angedeutete Hypothese, daß selbst die überlebende Zelle nicht kampflos dem fixierenden Reagens erliegt, völlig in der Luft stünde: die Unsicherheit und Ungleichmäßigkeit der fixierenden Wirkungen der einzelnen Chemikalien ist zweifelsohne vorhanden.

So türmen sich unserem Wunsche, im mikroskopischen Präparate ein naturgetreues Konterfei der lebendigen Zelle, des lebendigen Gewebes und Organes zu crhalten, zahllose Schwierigkeiten entgegen. Denn angesichts der unbestreitbaren Tatsache, daß die Reagentien so verschieden, wie vorhin dargestellt, cinwirken können, müssen wir uns fragen: wo ist die Wahrheit im mikroskopischen Bilde? wie kann man Wahres und Falsches unzweideutig unterscheiden?

\section{$\S 24$.}

Von verschiedenen Seiten ist der Versuch gemacht worden, diese so einfachen aber auch zugleich so eindringenden Fragen zu beantworten. Tellyesniczky und v. Masielewski haben eingehende, sehr verdienstvolle Untersuchungen darüber angestellt, wie die gebräuchlichen Fixierungsmittel auf die Körperzelle einwirken - Tellyesniczky z. B. benutzte die Hodenzelle von Salamandra - und haben aus den crhaltenen Bildern Schlüsse auf die Bonität der Reagentien gezogen. A. Fischer und Walther Berg dagegen haben an Eiweißstoffen, die sie aus Körperorganen erhielten und die in der Zelle intra vitam vorhanden sind, Versuche gemacht, um so die koagulierende, d. h. fixiercnde IVirkung der histologisch verwendeten Reagentien genauer zu studieren. Die Ergebnisse der beiden erst genannten Gelehrten sollen bei Schilderung der einzelnen Fixierungsmittel die gebührende Beriicksichtigung finden, hier sei kurz der bedeutsamsten Resultate von $\mathrm{Fischer}$ und Berg gedacht.

Fischer fand an seinen Stoffen zwei Arten der Gerinnung, Granula und Gerinnsel, und unterscheidet daher dic fixierenden Reagentien als 
Granulabildner und als Gerinnsclbikner. Berg fand noch zwei weitere Arten: granulierte Häute und Hohlkürper. Aus den sehr eingehenden und exakten Versuchen erheilt also, daß derselhe chemische Körper durch verschiedene Nittel verschieden gefallt wird und daß dasselbe Mittel auf verschiedene Körper vorschieden einwirkt.

Das ist ein bedeutsamer Fingerzeig für uns, wenn wir uns, was allerdings nicht jedermanns Geschmack ist, dariiher klar zu werden bemuihen, was wir eigentlich beim Fixieren machen. Nur glaube ich, daß der Eindruck der Fischer-Bergschen Resultate kein nachhaltiger sein wird, cinmal weil die lieben Gewohnheiten doch gar zu sehr aus dem Geleise geworfen wïrden und dann weil, nach Bergs eigenem Geständnisse. die Tersuche und Resultate an totem Material nicht so ohne weiteres auf das lebendige Material zu bezichen sind, mit dem es der Mikroskopiker zu tun hat. Denn ein tierischer Körper besteht im Leben nicht aus starren, unveränderlichen Gebilden, nicht aus Albumosen, Globulinen usw, sondern aus lebendiger, d. h. dauernd veränderlicher Substanz. Lnd darum ist auch die Struktur der einzelnen Bestandteile keine starre und unveränderliche, sondern sie ist an und in den Zellen selbst des überlebenden Gewebes oder Organes eine ungleichmäßige. Aber wie diese Ungleichmäßigkeit eigentlich beschaffen ist, das enthuillt uns weder das Experiment an Albumosen noch die Untersuchung an fixierten Zellen. Wenigstens, so will ich einschränkend hinzufigen, haben wir heutzutage noch keinen Anhaltspunkt, um zu entscheiden, ob die Fällungsprodukte, die wir in der fixierten Zelle mikroskopieren, der Aus- und Abdruck einer lebendigen Struktur oder das Kunstprodukt des chemischen Reagens sind. Diese Entscheidung; die für die ganze Cytologie ron grundlegender Wichtigkeit ist, wird uns um so schwerer gemacht, als wir von der Struktur des Molekiils der organisierten Substanz und seiner fuir die F'unlition maßgebenden Lagerung in der Zelle gar nichts wissen. Fällungen, wie sie die Fixierung hervorbringt, sind offenbar Ungruppierungen der Moleküle; wir kennen diese noch nicht einmal und wollen und sollen schon wissen, wie jene vor sich gehen, ob sie naturgemäße oder naturwidrige sind. Wenn die Strukturen des Protoplasmas, so meint Fischer mit Fug und Recht, so grobschlächtige wären, wie sie uns das fixierte Präparat im mikroskopischen Bilde zeigt, dann diurften sie auch im Leben nicht so leicht vergänglich sein. Das Leben müßte sich dann, so will ich hinzufügen, auch bei den höchststehenden tierischen Organismen in viel langsamerem Tempo abspielen, als es tatsächlich der Fall ist, die Lebensdauer, welche an die Integrität der Zellularstrultur, d. h. an 
die sich fichbluibende Molekulargruppierung gebunden ist, muißte für alle Tiure cine vicl größere sein, wären wirklich die Konstituenten der Zelle so grobe Gebilde, wie sie uns die heutige Cytologie vor Augen fuhrt. Andererseits: wenn uns manche sehr gewissenhafte Forschur mit Zellbestandteilen bekannt gemacht haben, zu deren Darstellung ein viele Tage, ja Wochen lang dauerndes Verweilen in der Fixierungsflissigkeit Conditio sine quat non ist, so handelt es sich hier allerdings nicht um grobschlächtige Strukturen. Die Einwirkungsdauer der Reagenticn ist aber eine so iibermäßige, daß Fällungen und Gerinnungen sckundärer Art in ganz unkontrollicrbarer Weise sich einstellen können, die ein in Wahrheit gar nicht vorhandene: Strukturbild vorzutäuschen vermögen.

\section{$\$ 25$.}

Nelches ist nun las Kriterium, das wir haben miissen, wenn unser ganz's mikroskopitches Arbeiten an seiner eigenen inneren Lnsicherheit nicht zugrunde gehen soll? Ich antworte darauf: dies Kriterium ist die Vorgleichung. und befinde mich auch hier in erfreujicher Übereinstimmung nicht nur mit Fischer, sondern wohl mit allen Mikroskopikern, welche kritisch ihren Resultaten gegeniberstehen. Als Axiom müchte ich einen. wenn ich nicht irre, auch ron Fischer ähnlich gefaßten Satz aufstellen: Wenn ganz bestimmte feinste Strukturen nur mittels einer einzigen Fixierungsflissigkeit zu erhalten sind, dann wird es sich wohl stets um Artefakte handeln. Wirkliche, d. h. der Natur entsprechende Bestandteile der Zelle missen sich durch alle dieselben fixicrenden Eigenschaften besitzenden Reagentien darstellen lassen. Lnd derjenige Forscher, welcher uns ein neucs, also bis dato unbekanntes Strukturelement der Zelle aufzeigen will, hat die meines Erachtens unerläßliche Pflicht, seine Befunde auf zahlreiche Fixierungsmittel zu begründen.

Verschieden ist also in jedem Betracht die Wirkung der Fixierungsmittel auf die cinzelnen Organ-, Gewebs- und Zellbestandteile. Zu all den erörterten Schwierigkeiten, welche mit der Deutung des fixierten Objektes verbunden sind, kommen noch zwei andere hinzu.

Die erste Schwierigkcit liegt in den fixierenden Reagentien, d. h. in ihren fallenden Mirkungen. Die Puripherie cines zu fixierenden Organteiles hommt zuerst mit dem Fixierungsmittel in Berihrung; hier also wird des letzteren sturmischste Wirkung statthaben, die Fallung unmittelbar nach dem linbringen beendet sein. Aber damit hindert das Reagens sein weiteres Vordringen selber; es setzt sich Grenzen, welche es um so schwerer iberschreiten wird, je kompakter, d. h. je weniger 
permeabel dats Orsan ist. Sumit kïnnen in '/entrum des I'räparates bereits haldweröse Verinderungen eingetreten scin, die cin ganz anderes Strukturbild liefurn als die peripheren Teile. Und besteht dats Fixierungsmittel aus mehreren Bcitanitcilen, welchen eine verechicane Pencetrationskraft eignet, dann haben wir in der I'eripherie dic Gesantwirkung. im Zentrum die linzelwirlung der Kontituenten des Mittels. Diesen Ubblstand, der gerade unseren meist geschitytun Mitteln anhaftet, sucht man daclurch zu paralysieren, dab man moglichst kleine Stiicke cinlegt. Aber abgesehen daron, daß dic Zerkleincrung des frischen Materials nicht zu weit gehen darf, wenn man dic cisch immerhin zarten ()bjekte nicht zerstüren will, so wird auch cier geriggte Nachteil nicht beseitigt. Wohl niemals ist. wenigstens nicht an solchem Mattrial, das cytologischen Studien dienen soll, Zentrum und I'eripherie im fixierten Präparate von gleichem Aussehen.

Dic zweite Schwicrigkeit, dic noch zu erwähnen ist, besteht nach muinem Dafurhalten in Folgendem. Wie bei der Mazeration, so tritt auch bei der Fixation inforge von Diffussionsvorgängen Parenchymflissigkeit in das fixierende Reagens. Dadurch wird letzteres in einer uns gänzlich unbekannten Weise geändert und ändert daher seinerscits in einer uns ebenfalls unbekannten Weise scine Wirkung aut die Organclemente. Daß wirklich ein derartiger Flissigkeitsulustausch zwischen Organ und Reagens satthat, zeigt in gribberem Malse judes blutreiche ()rgan. Dalı ein Austausch auch in einer uns weniger auffälligen Form bei jeder Fixierung statthaben wird, scheint mir nicht zweifuthaft. Denn dic Fixicrungsmittel sind durchaus nicht absolute Fallungsmittel: manches Reagens fällt hier und löst da, worauf Fischer hesonders hingewiesen hat. Ind so wird auch die Parenchymflii-iglieit nicht unhedingt zur Gurinnung gebracht, sondern wirl in der genannten Weise aus dem Organ austreten, bald mehr bald weniger, je nach Lmständen, dic wir nicht kennen und die wir daher auch nicht zu beseitigen vermigen. Hicrin liegt unstreitig eine bisher allerdings wenig beachtete Fichlerquelle, dic wir nur durch häufiges Erneucrn des Fixierungsmittels teilweise verschïtten können.

$$
\S 26 .
$$

Dic Lrwägungen, welche in len $\leqslant \leq s+$ und 25 angestellt wurden, sind ron Bedeutung für jede cytologische Untersuchung. Die Struktur der Zelle und des Kernes, die Vorgänge bei der Zellvermehrung. die Lmwandlung der Zcilsubstinz in ihre Produkte, z. 13. Mucin, Fictt usw: Forschungen, die auf derartige P'robleme gerichtet sind. rerlangen ein denkbarst sorgfaltig vorbercitetes Matturial. Denn all has, was in 
cytologischer Hinsicht gesucht wird, ist überaus intrikater Natur, liegt oft nahe der Grenze des überhaupt Sichtbaren und verlangt eine optische Ausriistung des Mikroskopes, die ihrerseits die Grenze des technisch Möglichen erreicht. Darum ist Kritik dem Gesehenen gegenuiber notwendig und Mißtrauen in die Leistungsfähigkeit der Ferwendeten Fixierungsmethoden am Platze. Ich glaube, daß seit einiger Zeit in der Wissenschaft eine gewisse Leichtgläubigkeit den Reagentien gegenuber, eine gewisse Vertrauensseligkeit bei Zellstrukturen Platz gegriffen hat, die durchaus nicht angebracht ist. Man traut den Methoden ohne weiteres alles Gute zu, und doch gilt der Satz: Quisquis praesumitur bonus, nur auf moralischem Gebiete. IVir können bei cytologischen Studien nur dann sagen: das und jenes scheint naturgetreu, wann wir es wiederholt und nach verschiedenen Methoden erhalten haben.

In sehr geistreicher Weise haben Dekhuyzen und Stoeltzner die ungüinstigen, zum mindesten unkontrollierbaren Linfluisse der Fixationsmittel zu paralysieren versucht. Hypertonische Lösungen wirken auf die tierischen Gebilde schrumpfend ein, hypotonische rufen Quellungen hervor. Indem beide Forscher von diesen Tatsachen ausgingen, suchten sie isotonische Lösungen herzustellen, in welchen weder Schrumpfung noch Quellung eintreten sollen. Der Gedanke ist entschieden wert, daß er durch weitere Proben - die von den genannten Forschern empfohlenen Reagentien werden später beschrieben werden - aus- und durchgearbeitet wird; Berg allerdings hält diese Methoden für unwichtig.

Handelt es sich dagegen nicht um rein cytologische Zwecke, werden beim Mikroskopieren mehr morphologische Probleme studiert, wie z. B. bei der Embryologie, dann genügen wohl die meisten unserer Fixierungsmittel allen irgend zu stellenden Anforderungen. Wirken sie nicht zu stark schrumpfend ein - etwas Schrumpfung ruft fast jedes Reagens hervor - oder bedingen sie keine Quellung quellend wirkende Reagentien sollten ganz verworfen werden -, dann sind sie fur embryologische Untersuchungen ausreichend und sind auch ausreichend, wenn es nur darauf ankommt, die mikroskopisch wahrnehmbare Topographie eines Organes zu erkunden.

\section{$\S 27$.}

Unsere bisherigen Betrachtungen gewähren die Möglichkeit, einige Regeln für die Fixierung aufzustellen, deren Befolgung dem Anfänger auf das dringendste zu empfehlen ist, wenn anders er sich vor Fehlschlägen, vergeudetem Material uud verlorener Zeit schiitzen will. 
Das Objekt, wenn es sich nicht un einen in toto zu helassenden Lmbryo handelt, muß, wie schon cinmal bemerlit, möglichst klein sein und es, muß möglichst vicl lilissigkeit angewendet werden. Objektgröße nicht über I ccm, Flüssigheit das 50--roofache des Objektvolumens. Dic Dauer der Einwirkung läßt sich natïrlich nicht generell bestimmen; sic wird je nach dem Objekte innerhalb weiter Grenzen schwanken. Bei den cinzelnen Mitteln und im zweiten Tcile wird die Einwirkungsdauer spezialisiert anzugeben sein.

Nïchst dem Quantum der anzuwendenden Fluissigkeit ist von größter Bedeutung deren wiederholte Ernenerung. Bei der geringsten Tribung, die auftritt, ist das bisher gebrauchte Fixierungsmittel sofort wegzugießen und neues an seine Stelle zu setzen. Dauert dic Fixicrung mehrere Tage, so muß aus den in $\$ 25$ angeführten Gründen anfänglich täglich, später in etwas längeren Intervallen dic Fixierungsfliissigheit erneuert werden. Bei wochenlang dauernder Fixierung; wie z. B. beim Gehirn in Müllerscher Flüssigkeit, ist diese nach den ersten I 4 Tagen mindestens wöchentlich zu erneuern. Nur das Formol macht eine Ausnahme; wenn dieses Reagens nach den ersten $2+$ Stunden gewechselt wurde, bedarf es keiner Erneuerung mehr, wie lange man auch die Objekte in ihm lassen will.

Nicht vergessen darf man, daß die Fixierung; weil sie auf Fällung beruht, wie ein mechanischer Reiz auf die Objekte cinwirkt. Muskelreiche Organe, z. B. Darmkanal, oder ganze Tiere kontrahieren sich daher in den Reagentien sehr stark, oft bis zur Lnkenntlichkeit der äußeren Form und einer damit einhergehenden Zerstörung, zum mindesten Verlagerung der einzelnen Teile. Tiere müssen daher ror Einbringung in die fixierenden Reagentien betäubt oder langsam getötet werden. Letzteres ist aber fast immer mit einem histologischen Nachteil verbunden, da bei manchen Arten sich in dem abtötenden Reagens das Oberflächenepithel, welches den Körper bedeckt, in großen Fetzen ablösen kann. Die Methoden der Abtötung anzufuihren gehört nicht hierher. Muskelreiche Organe befestigt man auf einem Holz- oder Korkrahmen mittels Igelstacheln oder Holznägeln und wirft sie, das angeheftete Objekt nach unten, in die Fixierungsflüssigkeit.

Von Erfolg kann bei der Fixierung von Metazö̈norganen, wenn diese umfänglicher und kompakter Natur sind, folgendes Verfahren scin. Man injiziert in die Arterie des Organes zunächst physiologische Kochsalzlösung, und zwar so lange, bis sic aus der Tene klar ausfließt. Es sollen dadurch Blutkoagula durch die nachfolgende Fixierung vermieden werden. Dann injiziert man in die Arterie die Fixic- 
rungsflissiglicit, auch hicr bis sie in der Vene wieder erscheint, und legt numnchr erst das zerkleinerte Organ in dic Fixierungsflissigheit. Es ist riics cine zwar umständliche, aber, wenn sauber ausgefiihrt. schr rortcilhafte Operation, da durch sie einc sehr gleichmäßigc birchdringung mit der Fixierungsflissigheit herbeigefuhrt wird.

\section{8}

Der Fixicrung hat die Härtung zu folgen. Die meisten fixierenden Reagention setzen trotz der durch sie bewirkten Fällung das Objekt durchaus noch nicht in cincn Zustand, daß die Anfertigung dinner Schnitte gelingt. Man muß daher nach heendeter Fixierung das Objekt schnittfahig machen. Das souveräne Reagens hierfür ist noch immer der Alkohol; das in neuerer Zeit empfohlene Aceton hat sich bisher nicht einbürgern können.

Der Härtung soll häufig ein Auswaschen vorhergehen. Ein solches ist dann nötig. Wenn die Fixierungsmittel in dirckter Berührung mit Alkohol Fallungen gehen, welche das Material verunreinigen. oft sogar verderben können. Aber ist das nicht der Fall, sind die Fixierungsmittel nicht alkoholempfindlich, dann ist das Auswaschen in destilliertem oder gewöhnlichem Wasser meist recht überfüssig. Bei den einzelnen Reagentien wird anzugeben sein, ob ausgewaschen werden soll oder nicht.

Den Alkohol verwendet man meistens - die Ausnahmen sind später zu nennen - in steigender Konzentration. Man fängt mit $50^{\circ}$. Alkohol an und steigt, mit ciner Verstïrkung ron immer $10^{\circ}$, bis zum, $6^{\circ}$ 。 Alliohol an. Soll das Material nicht sofort verwendet werden, so kann es in $90^{\circ}$. Alkohol aufgehoben werden. Es ist diesc Torschrift erlassen worden, weil manche Forscher glaubten, daß zu lanres - jahrelanges - Verweilen des Materials in $96^{\circ}$ 。 Alkohol dieses brüchig mache und scine Fürbbarkeit schädige. Ich habe mich von der Jotwendigheit dieser Vorschrift nicht überzeugen können. Ich bewahre nur in $\mathrm{g}^{\mathrm{r}}$ " "Alkohol auf und finde das Material noch nach Jahren tacillos. $70^{\circ}$. Alkohol, der ebenfalls vielfach als Aufbewahrungsfiisiglicit empfohlen wurde, ist direkt schädlich, da er allmählich mazerierenden Einfluß ausuibt.

Wie bei den fixierenden Mitteln so darf auch beim erhärtenden Alkohol mit der Filissigheitsmenge nicht gespart werden. Es beclari, glaube ich, keiner busonderen Auscinandersetzung, daß der Prozentgehalt des Alkohols anfänglich durch das aus dem Objekt austretence Vasser sehr schnell herunter gesctzt wird, daß also statt z. 13. jo' Alkohol bald nur $30^{\circ}$, rorhanden ist, und dieser wirkt in erster Linie 
mazericrend cin. Also: vicl Alkohol und häufiges Emenern, wenigstens in den ersten Tagen, bis dic Härtung beendet ist.

\section{§ 29 .}

Die nunmehr mitzuteilenden Fixicrungsmittel teilt $r$. Wasielewski ein in I. neutrale Eliissigkeiten außer Salzlösungen, 2. Salze und Salzgemische, 3. Sïuren und Sïuregemische, 4. Gemische ron Salzun und Säuren, 5. anderweite Genische. Lnstrutiog ist diesc Einteilung schr vorteilhatt, wenn es sich um eine Lntersuchung iibor die Mirksanleit und Bonität der einzelnen . Iittel handelt. Aber fur die dichatischen Zwecke cinci Lehrbuches scheint sie mir nicht geeignet, ha sic 'Zusimmenhängendes, wie z. B. die Chromsïure und ihre Salze, auseinanderreißt und so das Auffinden der einzelnen Reagentien erschwert. Ich werde daher im folgenden eine etwas andere Einteilung wihlen. Zuerst sollen die einfachen Fibllungsmittel beschriehen werden, cumn folgen die organischen und anorganischen Säuren nit ihren Salzen und ihren verschiedenartigen Kombinationen unc daran schlielsen sich die Salze der Schwermetalle.

Es werden nicht alle Fixierungsmittel aufgefiihrt worden, nur die nämlich, welche, wenn auch manche nur fü eincn speziellen Zweck empfohlen wurden, doch einer allgemeinen Anwendung fähig sind, Die rein spezialistischen Vorschriften sollen vielnehr erst im zweiten Teile Erwähnung finden.

\section{$\$ 30$.}

1. Alkohol. Als Fixierungsmittel ist meines Dafühaltens nur Lier Alkohol absolutuszu verwenden. I'aul IIayer hält auch schwachen Alkohol, unter 50 o, sceignet zum Fixieren, ich dagegen habe mit dimnen Alkoholen nur. Mazerationen erhalten. Der absolute Alkohol fixiert, weil er alle protoplasmatischen Substanzen so encrgisch fallt, daß seinc wasserentzichende ligenschaft dagegen fast ganz zuriektritt. Jede geringere Konzentration dagegen ruft heträchtliche Schrunipfung hervor, weil bei ihr dic koargulierende Wirkung der Masict-

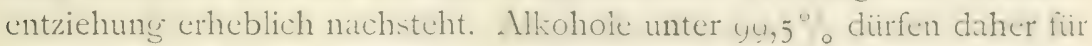
sich allein als Fixierungsnittel nicht betrachtet werden, sic kionnen nur zur Erhärtung nach cer IFixicrung dienen. Freilich darf der ahoolute Alkohol nicht für judes Material rerwendet werden: daßs z. B. Tellyesniczky ihn ganz unge gignet fand, ruihte daher, daß or ihn hei Salamanderhoden anwenclete. Dafuir sowic iıberhaupt fuir zarte Organc ist er ganz zu verwerfen. Ich halte ihn nur fuir gecignet. lompakte Gebilde, wie die großen Vurdaumngdriisen. Wie Milz und die 
Nieren der Vertebraten, ferner quergestreifte Muskeln und pathologisches Material zu fixieren. Eine Kaninchenniere z. B. gibt vorziglich konserviertes Material, wenn man sie von der Arterie aus mit absolutem Alkohol injiziert.

Man stellt sich absoluten Alkohol am besten selber dar. Man gliiht dazu Kupfersulfat und bringt das weiße Pulver auf den Boden einer Glasflasche, dann gibt man 96\%. Alkohol zu und schüttelt stark um. Durch den Rest Wasser im Alkohol wird das gegliihte Kupfer leicht grïlich; es muß erneuert werden, sowie es einen bläulichen Ton anzunehmen beginnt. Zum Gebrauche gießt man einen aliquoten Teil des Alkohols durch ein doppeltes Faltenfilter, damit keine Partikel des Kupfersulfats mit dem Material in Berihrung kommen. Aufbewahrt wird der absolute Alkohol in einer mittels eines Korkes zu verschließenden Glasflasche; Glasstöpsel sind zu vermeiden, denn sie schließen niemals dicht genug; um einen Luftzutritt zu verhüiten.

Die fixierten Objekte, die natürlich kleine Stücke sein müssen, bleiben etwa 3 Tage in dem Alkohol, der während dieser Zeit wiederholt erneuert werden muß. Zur Aufhewahrung geniigt $90^{\circ}{ }_{0}-96^{\circ}$ 。 Alkohol; doch halte ich es für ratsam, Alkoholmaterial sofort weiter zu verarbeiten.

2. Alkohol-Eisessig, nach van Beneden. \& Teile Alkohol absolutus und I Teil Lisessig werden miteinander vermischt; auf je Io $\mathrm{ccm}$ der Lösung kommen 2-3 Tropfen einer Osmiumsäurelösung von $1^{\circ}$. (nach der Zachariasschen Vorschrift,. Dauer der Einwirkung 10-25 Minuten, Überführen der Objekte für $2-3$ Stunden in absoluten Alkohol, Aufbewahren in $70^{\circ}$. Alkohol (?). Die Mischung wurde für die Fixierung der Eier von Ascaris megalocephala angegeben, eignet sich jedoch für leicht permeable Gebilde jeder Art.

3. Alkohol-Eisessig-Chloroform; Carnoysche Flüssigkeit. Man mischt Alkohol absolutus $60 \mathrm{ccm}$, Eisessig $10 \mathrm{ccm}$, Chloroform $30 \mathrm{ccm}$. Dauer der Einwirkung wenige Minuten bis I Stunde und länger. Über dieses Reagens habe ich keine Erfahrung; aber alle, die mit ihm gearbeitet, sind von scincr fixierenden Kraft geradezu entzuickt. Für Eier niederer Tiere und für alle zarten Organe soll sich die Carnoysche Fliissigkeit vorzüglich cignen. Man kann auch das Chloroform, welches dic Fixierung beschleunigt, weglassen; für diese Kombination hat Carnoy folgende Vorschrift gegeben: Alkohol absolutus $30 \mathrm{ccm}$, Lisessig io ccm. Die Objekte werden in Alkohol von $96 \%$ übergeführt, bis sie verwendet werden sollen. 
4. Alkohol-Eisessig-Chloroform-Sublimat; Ohlmachersche Lösung. Die Mischung ist konstruiert, um die durch Eisessig bedingte leichte Quellung, die iibrigens von manchen Forschern geleugnet wird, durch Sublimat zu paralysicren. Dic Vorschrift ist folgende: Alkohol absolutus $80 \mathrm{ccm}$, Chloroform i5 ccm, Eisessig $5 \mathrm{ccm}$, Sublimat bis zur Süttigung (etwa $20 \mathrm{~g}$ erforderlichı. Gewöhnliche Objekte aller Art bleiben darin ${ }^{\mathrm{r}}$ Stunde, größere Gehirnstücke is-24 Stunden. Das Material wird in so" Alkohol direkt übertragen. Nach Ohlmachers Angabe soll das Sublimat, das sich im Präparat ausgeschieden hat, erst in den mikroskopischen Schnitten entfernt werden. Ich halte dies für einen groben Kunstfehler, auf den ich im \$3t bei Besprechung des Sublimats näher einzugehen haben werde.

5. Formol. Eine $40^{\circ}$ 。 wässrige Lösung von Formaldehyd hat Blum zuerst als Fixierungs- bez. Konservierungsmittel empfohlen und diese Lösung hat den Handelsnamen Formol oder Formalin oder Formalose erhalten. Daß so vicle Namen für dasselbe Objekt recht unnötig sind, kann nicht geleugnet werden. Indessen deshalb sich darauf, wie manche Autoren wollen, zu versteifen und nur von Formaldehyd zu sprechen, scheint mir nicht minder unnötig. Daß mit einem der drei Namen immer dieselbe bestimmte chemische Konzentration des Formaldehyd gemeint ist, weil jeder, der mikroskopiert. Verwirrung kommt und kam nur dadurch zustande, daß einige Forscher ihr chemisches Gewissen beschwert glaubten, wenn sie den Namen der Handelsmarke lasen, und daher tiefe Spekulationen darüber anstellten, ob bei der Angabe $\approx 10^{\circ}$ 。Formollösung " eine Verdünnungdes Handels-Formols oder des Chemie-Aldehyds gemeint sei. Ich habe die Bezeichnung Formol , die, durch Blum in die Histologie eingeführt, das Recht der Priorität vor den beiden anderen Namen hat, als eine schr glückliche gefunden, etwa wie die Bezcichnung »Pikrinsäure statt "Trinitrophenols, und bin nie im Zweifel gewesen, da $\beta$ fast alle Autoren bei ihren Angaben die Verdumnung der Handelsmarke meinten, ohne sich um gelehrte chemische Differenzen viel zu kümmern. Die in diesem Buche empfohlenen Formolverdinnungen beziehen sich stets auf die Handelsmarke, $10^{\circ}$. Formollösung heißt daher: Io $\mathrm{ccm}$ Formol mit go $\mathrm{ccm}$ Aqua destillata (oder communis) gemischt.

Die $10^{\circ}$.Formollösung (1o Formol, go Wasser; ist ein vorzügliches Mittel, voluminöse und kompakte Organe schr gleichmäßig $z u$ fixieren und zu konservieren. Wenn man die Leber oder das Gehirn eines Säugetieres in recht viel $10^{\circ}$. Formollösung bringt - 
ein mittelgroßes Hundegehirn z. B. in etwa I Liter Flüssigkeit -, dann braucht man nur nach 24 Stunden einmal das Reagens zu erneucrn un lann dann jahrelang die ()hjekte darin aufbewahren. Besond lichim und Rückenmark crhalten in $\mathrm{IO}^{\circ}$ "Formollösung kiirzw lainn man auch sagen: $10^{\circ}$ "Formol - cine vortreffliche Konsi-tunz, werden nicht im geringsten briichig und lassen sich in ganz inlicbiger Wisc nachbehandeln (z. B. mit Müllerscher Lösung). Gehirn und zwar ein ganzes unzcrtciltes Hundegehim ron mittlerer Größe muß mindestens + Wochen in $10^{\circ}$, Formol verweilen, ehe (: gut durchtränkt ist; auch größere Gehirne bedürfen nicht schr viel mehr Zcit. So war ein von mir frisch eingelegtes Gehirn von Balaenoptera rostrata (in etwa 20 Liter Flüssigkeit) schon nach 8 Wochen völlig vom Formol durchzogen.

So hat also das Formol in $10 \%$ Lösung sehr große Vorteile, die es als ganz besonders gecignet erscheinen lassen, das Hauptrcagens des Forschers auf wissenschaftlichen Reisen zu bilden. $4 \%$ Formollisung (t Formol, yó Wasser) ist mehr ein Konservierungsmittel für Nuscumszwecke als ein Fixicrungsmittel für histologische Absichten. Andure Virdunnungen wie die genannten erscheinen mir unnötig.

Freilich darf man von der $10 \%$ Formollösung nicht zu viel verlangen. Kern- und Plasmasubstanzen werden etwa wie in Alkohol absolutus fixicrt und es bedarf im allgemeinen keiner Nachfixierung. Soll in Alkohol nachgehärtet werden, so muß man, um brauchbare Färbungsicsultate zu erhalten, gut in destillicrtem Wasser auswaschen und dann gsleich in $96^{\circ}$. Alkohol einbringen. Schnitte, die ron reinem, d. h. nicht mit Alliohol nachbehandeltem Naterial stammen, müssen cbenfalls gut gewässert werden, sonst färben sie sich ungleichmäßig. Feinste Strukturen der Zellsubstanz und des Kernes werden in $10^{\circ}$ 。 Formol nicht crhalten, aber daß das Formol das Plasma der tierischen Zelle vacuolisierc, wie v. Wasielewski solches für die Pflanzenzelle angibt, davon habe ich nichts gesehen.

Alles in allem: die $10 \%$ Formollösung ist ein vorzügliches Fixierungsmittel dann, wann es sich nicht um feinste Zell- und Fernstrukturen handelt. Ubersichtsbilder über die Textur der Organe sind gerade von Formolpriparaten gut zu erhalten: die I0". Formollösung ist daher fur schnelle Orientierung sehr zu empfehlen, zumal gerade sie dic beste Vorbehandlung gewährt, wenn man mit dem Gefricmikrotom schneiden will. Die $4^{\circ}$ 。Formollösung halte ich dagegen, in Ubercinstimmung mit Fischer, für wertlos zu histologischen Zwecken. Einc Unannchmlichlecit besitzt das Formol. Seine Dänpfe 
reizen in sche betrichtlichem Grade die Schlcimhate der Augen und der Nase und man hat kein . Wittel, un sich diesem Reize zu entzichen. Glieklicherweise hailt der keizzustann nur kume Zeit an; Ammonials, wie empfohlen wurle, in der Nähe ron IFrmolnaterial, an dem man arbeitet, rerdampfen zu lassen, hat noch meinen Frahlungen beinen Wert, heilst vielmchr den Teufel mit Buclacbuh anstriben. Auch die Iände Werden durch Formel stark scuctut; unit hat man vicl mit Formolmaterial zu arbeiten, dann muß man es mit in den Kauf nchmen, für cinge Tage fast unempfindiche Fingerspitzen zu crhalten.

Es war naturlich, dals cin Reagens wic das Formel Anrezung zu den verschierlensten Kombinationen mit anderen Fixicrungsnite eln sab, und cinc ganze Anzahl solcher Rezcpte sind daher auch empfohlen worden. Ich habe fast simtliche gepruft und bin mit l'aul Mayer der Ansicht, daß sie sämtlich irrationell sind. Die Gemische sind nicht haltbar, die Fixicrung ist cine sehr ungleichmäßrge und die Jairbung häufig noch mehr erichwert, als nach reiner wo" Formollisiung. Eingrge dieser Rezepte werden an verschiedenen Stelien dieses Buches später erwähnt werden.

Dagegen scheint es mir sehr rationell, der formolbchandlung eine Nachbehandlung mit cinem anderen Ruagens folgen zu lasien. I)ic folgende Vorschrift kann ich aufs wärmste empfehlen.

6. Formollösung $10^{\circ}$ o und Nachbehandlung in heiß gesättigter Lösung von Kali bichromicum. Möller. Kopsch und Orth haben dic Kombination ron Formol und Kali bichomicum bereits versucht, aber alle drei, inden sie beide Reagention mischten. Richtiger ist es, beide getrennt zu verwenden. Ich schlage vor: Matcrial, besonders Zentralnervensystem, das in $10^{\circ}$ 。 Formollösung rorbehandelt ist, lommt in einen aliquoten Teil ciner heil guciattigten Lösung von Kaliumbichromat. Letztere mul sellstverstänłlich ahgekiihlt sein und so lange gestanden haben, da $B$ alles iiherschüisige Chromsal\% auskristallisiert ist. Das Material kann jahrelang in formol gelegen haben. 'Zur Xachbehandlung ist eine Zurkleinerung nicht notwendig; wenn man nur entsprechend der (Größe des ()bjeltes vicl Kaliumbichromatlisung nimmt: ich habe auf dicse Wreise die ganze Medulla oblongata und las Kleinhirn rom Menschen ohne Zerstückelung tadellos durchtränken können.

Aus der 10". Formolliisung bringt man das Material direlit, ohne Auswaschen, in die Kaliumbichromatlosung. Hier schwimmt es z.1nächst an der Oberfläche und sinkt erst allmählich unter. Nach z+ Stunden wird die Chromsalzlösung erneuert. Küchenmatsistieke. Medullac oblongatae usw. ron $2 \mathrm{~cm}$ Länge und mehr sinc? nach 
+-5 Wochen vorziiglich durchtränkt, immer vorausgesetzt, daß man mit der Flüssigkcit nicht geizt und sie mindestens alle 8 Tage erneucrt. Kleincre Stuicke, bis ${ }^{\mathrm{I}} \mathrm{ccm}$, sind schon nach 8 Tagen gut chromiert. Die Nachbchandlung ist gleichgiltig; man kann Gefrierschnitte machen oder in Culloidin eimbetten und die IVeigertsche Färbung gelingt elenso wie jede andere Färbung. Natülich darf man nicht darauf rechnen, Matcrial zum Studium von Plasma- und Kernstrukturen auf diese Weise erhalten zu haben.

\section{$\S 3 \mathrm{I}$.}

7. Essigsäure. Seit einiger Zeit hat sich der Histologen wunderlicherweise eine gewisse Begeisterung fuir die Essigsäure als Fixierungsmittel für Kernstrukturen bemächtigt. Nur aus diesem Grunde wird sie hier als besondere Nummer angeführt; denn ein selbständig fixierendes Reagens ist sie nicht. Sic erhält Kernstrukturen, erhält sie aber nur in Gemeinschaft mit anderen Reagentien. Ohne solche angewendet zerstört sie in stärkeren Konzentrationen $\left(\mathbf{I}_{0}^{\circ}\right)$ - in schwächeren wirkt sie mazericrend - die Zellsubstanz und die Kerne, in Gemischen verwendet muß sie mit solchen Mitteln vereinigt werden, welche fixierend auf die Zellsubstanz einwirken. Sic muß, da sie starke Quellungen hervorruft, mit Reagentien vergesellschaftet werden, welche Schrumpfungen verursachen, so daß beide Wirkungen sich paralysieren. Der Haupteinfluß der Essigsäure besteht, wie $\mathrm{F}$ ischer mit Recht hervorhebt, darin, daß sie alkalische Zellinhalte ansäuert und dadurch den Substanzen, mit welchen sie kombiniert ist, die Möglichkeit gewährt, Fällungen, d. h. Fixierungen hervorzurufen. Mit anderen Worten: die Essigsäure bereitet in den Gemischen, in denen sie angewendet wird, die Fixierung durch die anderen Bestandteile des Gemisches vor.

8. Trichloressigsäure, nach M. Heidenhain. In $5_{0}^{\circ}-10^{\circ}$ Lösung empfiehlt Heidenhain die Anwendung der Trichloressigsäure. Die Präparate muissen nach beendeter Fixierung sofort in absoluten Alkohol, also ohne Auswaschen, übergeführt werden, weil in dem Reagens das fibrilläre Bindegewebe stark quillt. Anfänglich muß der absolute Alkohol häufig crneuert werden, später, nach einer Woche, ist dies nicht mehr nötig und das Material kann dauernd in diesem Alkohol bleiben. Die Trichloressigsäure dringt sehr rasch ein, erhärtet nicht den Rand des Materials stärker als die inneren Partien, macht also keine Kruste und fixiert auch Mucin sehr gut, während sie die serösen Drüsengranula nur an der Oberfläche der Stücke gut erhält. Die feinsten Strukturverhältnisse in Zellsubstanz und Kern 
werden nicht erhalten, wohl aber werden Centrosomen, (hromosomen, Spindeln gut. Dic Fürbbarkeit des so fixierten Matcrials ist in jeder Woise cine gute. Ileidenhain empfichlt das Reagens hauptsächlich für Unterrichtspräparate.

9. Salpetersäure. Die Ansichten iiber dic Verwendbarkeit der Salpetersïure gehen zicmlich weit auseinander. Während Tellyesn iczky starke Konzentrationen (5") für nicht gut hält, dayegen schwächeren $\left(3 \mathrm{x}_{2}{ }^{\circ}\right.$, und namentlich $2{ }^{\circ}$ ) $)$ entschieden das Wort redet, Fischer sie uiberhaupt für unzuverlässig in ihren Wirkungen hält, da ihre Fällungen sich gelegentlich wieder lösen sollen, verwendet Benda in einer später unter Nir. 32 dieses Kapitels) genauer zu beschrcibenden sehr guten Kombination sogar $10^{\circ}$ 。 Salpetersäure. Diese als Fixicrungsmittcl allcin, d. h. ohne Kombination mit anderen Reagentien, angewendet gibt keine zurerlïssigen Resultate, sie ist, wie Fischer nit Recht meint, in höchsten Maße launisch. Zudem haftet ihr cin Fehler an, der auch in Gemischen sich bemerkbar macht, welche Salpetersäure enthalten, die einzige Pikrinsalpetersäure ausgenommen. Unter der Einwirkung der Säure lösen sich nämlich geschichtete Epithelien blasenförmig von ihrer Unterlage los; Organe mit epidermoidalem Überzuge dürfen daher weder in Salpetersäure allein noch in deren Kombinationen, mit der oben erwähnten Ausnahme, fixiert werden. Organe aus Salpetersäure sind direkt in $90^{\circ}$, Alkohol überzuführen, dünnere Konzentrationen des letzteren wirken direkt zerstörend.

9a. Salpetersäure $\left.3\right|_{2}{ }^{\circ}$ 。 Von Engelmann zur Fixierung der Retina der Vertebraten empfohlen; bei Evertebraten ist sie nicht anwendbar, weil sie bei diesen das retinale Pigment zerstört. Man legt den geöffneten Bulbus eines Wirbeltieres auf $\mathrm{I}-2$ Stunden in die Säure und iiberträgt sofort in absoluten Alkohol. Selbst $96^{\circ}$. Alkohol wirkt auf die Retinaelemente nach dieser Fixierung zerstörend. Färbung mit allen Farbstoffen ausführbar.

ı. Chromsäure. Das älteste Fixierungsreagens nächst dem absoluten Alkohol ist die Chromsäure, welche $18_{+} 0$ von Hannover eingeführt wurde und anfünglich beim Fixieren und Härten eine so große Rolle spielte, dal3 Max Schultze seine Zeit als cine chromsäuresiichtige* charakterisierte. Gegenwärtig hat die unberechtignte Überschätzung ron damals ciner unberechtigten Lnterschätzung Platz gemacht; denn die Behauptung; daß unsere Säure plasmazerstörend wirke, kann ich nicht als richtig anerkennen. Sach wie vor halte ich die Chromsäure auch für sich allein, ohne Kombinationen, für cin Fixierungsmittel für Zellsubstanz und Kern. Freilich ist man hei 
ihrer Anwendung mehr als bei jedem anderen Reagens von Imponderabilien abhängig, dic teils im zu fixierenden Material licgen, teils durch die Provenienz der Säure, also von der sie liefernden Fabrik, viclleicht auch von Temperatur und Feuchtigkeitsgehalt der Umgebung bedingt werden. Aus diesen Gründen cmpfichlt es sich nicht, die Chromsäure allein, ohne Kombinationen, anzuwenden.

Sie dringt schwer ein, gibt aber den Objekten eine gute Schnittfähigkeit. Deswegen hat sie Deiters in der Weise verwendet, daß er das in Kali bichromicum vorgehirtete Material (Zentralnervensystem) in Chromsäure nachhärtete und schnittfähig machte. Will man Chromsäure allein verwenden, so nchme man sehr viel Flüssigkeit, sehr kleine Objekte und beginne mit ${ }^{\mathrm{T}} / 3 \%$, die man in den ersten 2.t Stunden mehrere Nale erneuern muß, weil sie sich trubt. Dann (nach $2+$ Stunden) steigere man für 48 Stunden die Konzentration auf $0,5 \%$, erneucre wenn nötig und führe schließlich in $1 \%$ Chromsäure über, in welcher die Objekte etwa $1-3$ Tage bleiben. Die Dauer der Fixierung hängt von der gewünschten Konsistenz des Naterials ab. Nun kann man sorgfilltig $2+$ Stunden lang und länger in destilliertem Wasser auswaschen, bis dieses sich kaum noch gelb färbt, und härtet in steigendem Alkohol $\left(50^{\circ}{ }_{0}-g 6^{\circ}\right.$ o) nach. Hierzu ist es sehr gut, die Präparate ins Dunkel zu stellen, damit nicht unter dem Einflusse des diffusen Tageslichtes das in den Ubjckten haftende Chrom zerstört werde. Besser noch ist es, sofort ins Dunkle zu stellen, wobei man das Auswaschen in Vasser erspart und sofort das Material in $96 \%$ Alkohol überfuhren kann. Dieser sehr rationclle Vorschlag riihrt von Hans Virchow her; dadurch daß die I Järtung im Dunkeln vorgenommen wird, vermeidet man, daß sich im Präparat und in Alkohol amorphe Niederschläge bilden. Ich empfehle folgenden Modus procedendi: das Gefäß mit y6\% Alkohol wird ins Dunkle gestellt; dann nimmt man das Material aus der Chromsäure heraus, wälzt es auf Filtrierpapier, um es allseitig abzutrocknen, und bringt es in das bereits im Dunkeln stehende Alkoholgefäß. Dadurch verhindert man fast völlig, daß sich Niederschläge bilden.

Ein Nachteil der in der Chromsäure und ihren Salzen vorgenommenen Fixierungen besteht darin, da! das Material im Laufe der Zeit grün wird und sich schlecht färben läßt. Nan tut dann gut, die Schnitte mit salzsaurem Alkohol $(3 \%)$ auszuwaschen, worauf sie ganz hell werden. Will man das Stiick entfärben, so bringt man es nach Edinger und Mayer in eine Salpetersäurelösung (I: IO oder I:20 Wasser) und lälst sie darin, bis sie graugruin geworden sind. Dann wäscht man die Säure gut aus und härtet in Alkohol von $96^{\circ} 0^{\circ}$. Mir 


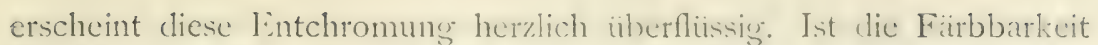
des Materials schr heruntergesetzt - alle Chromfixierungen becinträchtigen das Färben mit Karmin und Hämatnxylin -, dann beizt man die Schnitte in gecigneter IV cisc und erhalt clann stets gute Färbung (darïber siehe Kapitel 8).

Von verschiedener scite sind Lisungen wn Chromsäure in Alkohol empfohlen worden. I)a beide chemischen Kürper sich in der Mischung schr schnell zersetzen, so handelt es sich, wie P'. Mayer mit Recht herrorhebt, um irrationelle Kompositionen. Es sind dies meines Erachtens unsinnige, unwissenschaftliche Spielereien.

I I. Chromsalpetersäure, Perényische Flüssigkeit. Eine srolche irrationelle Mischung sei hier angeführt, weil sie sich einer gewisscn Beliebtheit erfreut hat und wohl auch noch erfreut. Man mischt 10", Salpetersäure $+\mathrm{ccm}, 0,5^{\circ}$, Chromsäure $3 \mathrm{ccm}, 96^{\circ}$. Alkohol $3 \mathrm{ccm}$. Die Lüsung nimmt sehr hald einen bläulichen oder einen violetten Farbenton an. Die Objekte bleiben darin $+-2+$ Stunden und werden in steigendem Alkohol erhärtet. Epidermoidale Gebilde sind zu vermeiden, weil die Epitheldecke zerstört wird; sonst für alles geeignet. Das Irrationclle dieser. Methode liegt nach P. Mayer darin, daß die Chromsäure durch die Salpetursäure zersetzt wird und man es schließlich nur mit einem schwach salpetersauren Alkohol zu tun hat, der Quellungen hervorruft.

I 2. Chromameisensäure, nach Rabl. ${ }^{1} \%$ wässrige Chromsäurelösung $200 \mathrm{ccm}$, konzentrierte Ameisensäure t-6 Tropfen. Die Mischung muß jedesmal zum Gebrauche frisch bereitet werden. Kleine Stiicke des Naterials werden für I 2-24 Stunden cingelegt, dann in destilliertem Wrasser gut ausgewaschen und in Alkohul ron langsam steigender Konzentration erhärtet. Für das Studium von Zellteilungen geeignet.

I3. Chromessigsäure, nach Ehlers. I', 'hromsäure $100 \mathrm{ccm}$, Eisessig I-5 Tropfen. Die Objekte blciben darin bis zu 24 Stunden, werden dann in destilliertem Wasser ausgewaschen und langsam erhärtct. Für zarte ()bjekte ron Evertebraten geeignet, auch für Eier niederer Wirbeltiere.

I 4. Chromessigsäure, nach Flemming. I" Chromsäure $70 \mathrm{ccm}$, Eisessig $5 \mathrm{ccm}$, Aqua destillata $90 \mathrm{ccm}$. Dauer der Fixierung 2 bis 2f Stunden, sorgfältiges Auswaschen, langsames Erhärten. Fiür Zellteilungen besonders, aber auch fuir alle Gewebe und Organe geeignet.

I5. Chromessigsäure, nach Lo Bianco, I ${ }^{\circ}$, Chromsüure roo ccm, konzentricrte gemeint ist: offizinclle) Essigsäure ro ccm. Fixicrung 
und Weiterbchandlung wie bei Nr. It. Eine schwächere, in gleicher Weise anzuwendende Lösung enthält nur $5 \mathrm{ccm}$ Essigsäure.

16. Chromessigsåure, nach Fol. I $\%$ Chromsäure $25 \mathrm{ccm}, 2 \%$ Essigsiure $50 \mathrm{ccm}$. Aqua destillata $25 \mathrm{ccm}$. Fixierung und Veiterbehandlung wie Nr. I t. Fol empfiehlt dies Gemisch aufs wärmste fur die meisten Gewebe von Wirbeltieren und Wirbellosen, nachdem schon Braun und Hertwig eine ähnliche Zusammensetzung speziell für embryologische Zwecke gerühmt hatten.

Alle Chromessigsäuregemische leiden meines Erachtens an dem Fehler, daß sie eine Konzentration der Chromsäure enthalten, die bald zu stark, bald zu schwach ist. Eine allmähliche Steigerung oder Verringerung des Chromsäuregehaltes bei sich gleichbleibender Konzentration an Essigsäure wiurde die unsicheren Virkungen der genannten Gemische ( $\mathrm{I}_{3}-\mathrm{I} 6$ ) beseitigen und die sehr rationelle Kombination beider Säuren gebrauchsfähiger, weil zuverlässiger, machen.

17. Kalium bichromicum $4 \%-5 \%$ Zur Konservierung ist seit langer Zeit das saure chromsaure Kali verwendet worden und leistet hierfür ausgezeichnete Dienste. Anders muß das Lrteil lauten, wenn es sich um Fixicrung handelt. Daß Kernstrukturen dem Kaliumbichromat keinen Widerstand leisten, sondern ron ihm zerstört werden, wird, glaube ich, von allen Autoren zugegeben. Auch die Fixierung der Plasmastrukturen ist, wie ich finde, keine gute, das Mittel homogenisiert die Zellsubstanz in einer ITeise; die sicher ebensowenig der Natur entspricht wie die ïbermäBige Spezialisicrung, dic andere Methoden herbeifuhren. Für Mollusken wirkt die $t^{n} 0-5^{\circ}$ 。 Lösung direkt mazerierend. Trenn es sich dagegen um V'ertchratenorgane handelt, deren Textur zu untersuchen ist, Organe, die namentlich für Kurszwecke in größeren Mengen vorrätig gehalten werden sollen, dann ist das Kaliumbichromat sehr geeignet, weil es das Naterial schnittfähig macht und auch so erhält. Die Nachbehandlung ist wie bci der Chromsäure: Auswaschen in Vasser, steigende Konzentration des Alkohols oder sofortige Dunkelbehandlung in $96^{\circ}$. Alkohol. Noch besser ist es, las Material unter etwas Wasser ohne Nachhärtung direkt aus dem Kalium bichromicum zu schneiden, weil dann die Färbungen mit Karmin gelingen. Dies ist namentlich ron Viert für pathologisches Material vom Zentralnervensystem.

Ist somit nach meiner. Ansicht, die mit der v. Wasielewk is übercinstimmt, der Wert des isolierten Kalium bichromicum nur ein sehr mäßiger, so wird cr dagegen sehr bedeutend in Mischungen oder Kombinationen, welche die unguinstigen Wirkungen dieses Salzes unterdriicken. Eine solche vortreffliche Kombination hahe ich beim For- 
mol unter Nr. 6 (\$ 30 mitgeteilt, andere sollen hier beschriehen werden. Die oben genannten Konzentrationen von $t$ ", -5 " haben iibrigens nur Gültigkeit für das isoliert angewendete Salz, in den Kombinationen kann die Konzentration bis zur heißen Süttigung gehen.

I8. Kalium bichromicum-Essigsäure, nach Tellyesniczky. Kalium bichromicum $3 \mathrm{~g}$, Essigsiure (konzentriert) $5 \mathrm{ccm}$, Aqua destillata Ioo ccm. Kleine Stuicke des Materials Hoden usw. kommen für $\mathrm{I}-2$ Tage, große Stiicke für längere Zeit in dic Mischung, in Wasser wird sehr sorgfältig ausgewaschen und in Alliohol nachbebehandelt, dessen Konzentration mit 15 。 beginnt. Die Lüsung soll nur dic guten Eigenschaften ihrer beiden Komponenten und nicht deren schlechte zeigen, sie licfert also gute Zellsubstanz- und Kernstrukturen und ist daher warm zu empfehlen.

I 9. Kalium bichromicum und Natrium sulfuricum, Müllersche Flüssigkeit. 2-2,5 g Kaliumbichromat. I g Natriumsulfat, Aqua destillata oder communis, Ioo ccm. Die Müllersche Fliissigkeit, die eine der altehrwürdigsten Kombinationen in der Histologie ist, besitzt fixierende und härtende Eigenschaften. Die letzteren gleichen dem des Kalium bichromicum, doch ist altes Müller-Haterial häufig brüchig. Die ersteren, die fixierenden, gleichen ebenfalls denen des isolierten Kaliumbichromat und das dort Gesagte kann hier wörtlich wiederholt werden. Die Nachbehandlung von Mïller-Naterial unterliegt den für die Chromsäure aufgestellten Regeln.

Ein geradezu unentbehrliches Hilfsmittel ist die Müllersche Flüssigkeit für die Fixicrung und Erhärtung des Zentralnervensystems von Vertebraten und Evertebraten. Je nach ihrer Größe bleiben die Gehirne ron Säugetieren z. B. + Wochen bis 3 Nonate und länger in der Fliissigkeit; man muß diese nur häufig erneuern und in reichlichen Quantitäten anwenden, um voll befriedigende Resultate zu crzielen. Die Nachbehandlung der in Niillerscher Lösung fixicrten und gehärteten Gehirne ist die gleiche, wic sic vorhin beim Kaliumbichromat erwähnt wurde.

20. Kaliumbichromat und Kupfersulfat, Erlickische Flüssigkeit. $0,5 \mathrm{~g}$ Kupfersulfat, 2,5 g Kaliumbichromat, $100 \mathrm{ccm}$ Aqua destillata. Zentralnervensystem erhärtet in dieser Mischung bei $37^{\circ} \mathrm{C}$. im Briitofen innerhalb von $8-10$ Tagen. Die Härtung ist gut; Nachhärtung in Alkohol bedingt vorhcriges gutes Auswaschen in Wasser. Voluminöse Objekte, selbst mehrmonatliche menschliche Föten sollen sich darin in toto fixieren und härten lassen. Abgesehen daron, daß im Objekt Kupferflecke entstehen, ist die Erhaltung der Zellen nach meinen Erfahrungen eine ganz minderwertige. 
21. Kalium bichromicum-Sublimat, Coxsche Lösung. $5^{\circ}$ Kalium bichromicum $20 \mathrm{ccm}, 5^{\circ}$, Sublimatlösung $20 \mathrm{ccm}, 5^{\circ}$. Kali chromicum einfach chromsaures Kali $16 \mathrm{ccm}$, Aqua destillata $30-40 \mathrm{ccm}$. Nervensystem soll darin im Sommer in einem Monate, im Winter in 2-3 Monaten gut fixiert und erhärtet werden.

22. Müllersche Lösung und Sublimat, Foàsche Lösung. In I $00 \mathrm{ccm}$ kochender Müllerscher Flüssigkeit worden 2 g Sublimat gelöst. Kleine Stücke des Naterials sind in eine reichliche Nenge Fliissigkeit für $2-3$ Stunden, zuwcilen auch für $2+$ Stunden im Brïtofen bei $35^{\circ}-40^{\circ} \mathrm{C}$. einzubringen. Dann wird in Alkohol von steigender Konzentration nachgehartet, wobei darauf $\mathrm{zu}$ achten ist, daß die niederen Konzentrationsgrade so oft erneuert werden müssen, wie sich die Flüssigkeit noch färbt. Für viele Organe geeignet, ganz besonders gut zur Erhaltung der Erythrocyten.

23. Kaliumbichromat-Sublimat-Eisessig, Zenkersche Lösung. $5 \mathrm{~g}$ Sublimat, $2,5 \mathrm{~g}$ Kaliumbichromat, $1,0 \mathrm{~g}$ Natriumsulfat in $100 \mathrm{ccm}$ Aqua destillata gelöst, dann werden $5 \mathrm{ccm}$ Eisessig zugesetzt. Am besten ist es, den Zusatz ron Eisessig erst unmittelbar vor dem Gebrauche der Flüssigkeit zu bewirken. Die Organe schwimmen anfangs auf dem Gemisch, sinken aber bald unter. Dauer der Einwirkung $1-78$ Stunden, bei Nervensystem bis It Tage. Dann gründliches Auswaschen in Wasser und Härtung in Alkohol von steigender Konzentration. Den niederen Konzentrationsgraden ist soviel Jodtinktur zuzusctzen, daß die Farbe des Portweins entsteht. Dadurch soll das Sublimat aus dem Gewebe entfurnt wercien, was sich durch eine Entfärbung des Alkohols zu erkennen gibt. Der Jodzusatz hat so lange stattzufinden, bis keine Entfärbung mchr eintritt, bis also das Sublimat entfernt ist. Färbbarkcit für alle Farbstofic erhalten. Diese Lösung wird als eine der besten Kombinationen gerühmt, die für alle Organe zeeignet sein und namentlich auch Kernstrukturen gut erhalten soll.

27. Salpetersäure-Müllersche Lösung. Man fixiert zunächst, mach Angelucci, in $3 "$. Salpetersäure ${ }^{1}$. Stunde bis 2 Stunden und bringt dann für Io Tage in Nüllersche Lösung. Nachhärten in Alkohol. Wine sehr rationclle Kombination, die namentlich für die Retina von Vertebraten geeignet sein soll.

25. Salpetersäure-Kaliumbichromat, Bendasche Methode. Die frischen ()bjekte kommen in eine $10^{\circ}$. Salpetersäure Lösung $10 \mathrm{ccm}$ offizineller Salpetersäure; $90 \mathrm{ccm}$ Aqua destillataj. Aus dieser werden sie nach 2.t-48 Stunden dirctit, olne Auswaschen, in cine Lösung von Kalium bichromicum übertragen. Anfänglich mischt man I Tolumen der kalt gesïttigten Lüsung des Chromsalzes ich nehme heiß 
sesättigte Lüsung und 3 Tolumina Aqual destillata. Xach cinigenen Stunden wird sic crneucrt und sleichzeitig steigert man allmaihlich dic Konzentration bis zur Mlischung gicicher Volumina lVasecer und Kalium bichromicum. Teist ist natch 2-3 Tagen dic Fixation beendet. Wihrend Zentralnervensystem bis zu i + Tagen nijtig hat. Aus-

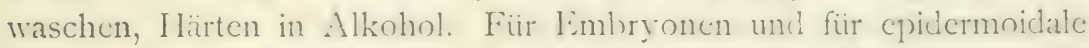
Biklungen ungecignet, sonst für alles gecignct. l)ic Firhbarkeit ist etwas herabgesetzt.

\section{$\S 32$.}

26. Osmiumsäure $0,5 \%, I_{0}-2 \%$. Seit Max Schultze die Osmiumsiure oder (berosmiumsäure, Usmiumtetroxyd) in die histologische Technik eingefuhrt, hat sich dies Reagens der gröBten Wirtschiitzung seitens aller Mikroskopiker erfreut. Denn tatsichlich werden \%ellsubstanzen und Kerne gut darin fixiert. Wenn man die nötigen Kitutelen anwendet und die unvermeidlichen lehlerquellen beriicksichtigt. Und zwar gilt dies nicht nur fü die Osmiumgemische, sondern auch fuir die isoliert angewendete Saure. Namentlich die schwächeren Konzentrationen, 0.5 " und I" ., verdienen diese's Lob, während die stärkste bisher rerwendete Lösung, $2^{\circ}$, in isolierter Anwendung zu stuirmisch einwirkt und daher nicht immer gleichmaißige Resultate liefert. Es ist daher nicht ohne Interesse, dall lorschicr, die an kïnstlichem Naterial, nicht an der Zelle, Stucien iiber die Fixierungswirkungen angestellt, nicht zu dem gleichen Rusultate gelangt sind, wie die Histologen. Fischer z. B. nennt die isoliert angewendete ()smiumsäure in der Konzentration von $\mathrm{I}^{\circ}$, ein sehr schwaches und unvollständiges Fällungsmittel. Sie lasse alles ungefällt, urst der nachtrigglich angewendete Alkohol rufe die Granulierung im Kernimem hervor; fallend wirle sie nur auf sauer reatgiercnde Gehilde. Ls ist diesc Differenz dir Erfahrungen und Anschanungen ein Beweis mohr datür; dills es nicht angeht, die an totem. d. h. kiinstlichem, Material geronnenen kesultate ohne weiteres auf lebendes. d. h. natiirliches, Material anzuwenden.

Andererseits scheint es mir, als ob vielfach cine zu große Schwärmerei fuir die Osmiumsäure I'latz gegrifen hat, die kritiklos alles das für richtig hält, was man an solchem Material erkennen kann. das in ()smiumsiture oder in ()smiumgemischen viele Tage lang fixiert wurde. Sekundäre Fällungen, Zertrimmerungen vorhandener Strukturbilder treten zweifellos hei zu stiimischer oder bei zu intensiver d. h. zu langer Osmiumwirkung auf, sodal3 man sehr vorsichtig in der Devitung des Gesehenen sein mul, namentlich dann, wann licin andicres 
Fixierungsmittel wie nur ein Osmiumgemisch die betreffenden Bildungen zeigt. Lnter die sehr verdächtigen, in neuerer Zeit beschriebenen Zellbe tanditeile rechne ich z. B. die sogenannten Mikrosomen usw., die zu ihrer Fixation ein Verweilen des ()bjektes von 8 Tagen und länger in dem fixierenden Gemisch bedüfen und dic zugleich nur mit einem Osmiumgemisch, der noch zu erwähnenden Flemmingschen Lösung, darstellbar sind.

Die Vorteile, welche der Osmiumsäure eignen - im allgemeinen gute Fixierung ron Protoplasma und Kcrn -- sind bereits erwähnt. Hier seien die Kautelen angeführt und die Bedenken hervorgehoben, zu welchen sowohl dic isolicrte ()smiumsäure wic die Osmiumgemische Veranlassung geben.

Die Osmiumsäure dringt nur langsam in die Tiefe der ()rgane ein; das sicht man sowohl bei der isoliert angewendeten Säure als auch bei dem besten aller () smiumgemische, bei der Flemmingschen Lösung. Der Rand dur Objekte wird in stiirmischer Weise fixiert, wahrend die zentralen Teile oft gar nicht berihrt werden. Kompaktere Organe, wie z. B. Leber, Milz oder Hoden von Säugetieren, sind beicle Male. d. h. nach Osmiumsäure wie nach Flem ming scher Lösung; nach $2+$ Stunden in einer mehr oder minder umfänglichen Randschicht geschwärzt, während das Zentrum weiß, d. 1. unfixiert geblieben ist. Man kann diesem Übelstande zu entgehen versuchen, wenn man recht kleine Stiicke des Materials in die Fixierungsfliissigkeit bringt. Aber eimmal kann, wie schon bei einer anderen Gelegenheit gesagt wurde, die Zerkleinerung des Materials nicht unter eine gewisse Grenze herunter gehen, weil man sonst durch das Zerschneiden, wobei man das Objekt quetscht und zcrrt, artifizielle V'ränderungen hervorrufen kann und wird. Und dann ist die Beseitigung des gerïgten Übelstandes doch immer nur cine relative, keine absolute. Um ein Beispiel zu bringen! Ein Objekt, das klein genug ist, um beim Einbringen in Flemmingsche Lösung ganz bleiben zu können, und das auch nicht zerhleinert werden darf, will man nicht das Material in seincm natiirlichen Habitus zerstören, ist der Salamanderhoden. An cinem Durchschnitte durch einen solchen Hoden, der mit Flemmingscher Lösung fixiert und nachher mit meiner adjektiven Fuchsinmethode gefärbt war, sicht man Differenzen zwischen Peripherie und Zentrum des Organes, wie sie größer kaum gedacht werden können. Die Figur 6 zeigt 2 Zellen aus der Peripherie des Hodens von Salamandra maculata. Die Attraktionssphäre der ruhenden Zelle (a) ist hell, das einfache Centrosoma ist deutlich erkennbar. Die Zellsubstanz ist nahezu homogen, kaum daß man in ihr einige 
Jäden angedeutet crkennt, und sic ist schr dunkel tingiert. Der Korn (k) ist ebenfalls dunkel, wenn auch holler als dic Zcllsubstanz, gefürbt, seine Nembran ist sehr deutlich. Er enthailt in einer homogenen Grundmassc eine ungeheure Menge kleinster Körnchen, dic ihn dicht erfillen. Außserdem treten in jedem der beiden Kerne zwei große, mit hellem Hofe ungebene, dunkel tingierte Körper hervor ' $n$, welche beinahe an die Keimflecke von Fiern erinnern. Ganz anders ist der Anblick, welchen die Zellen der Figur ; gewähren. Diese stammen aus demselben Schnitt, wie die Zellen der Figur (1, nur liegen sie fast im Zentrum des Schnittes. Die Attraktionssphären der ruhenden Zellen $(\alpha$ erscheinen geschrumpft, das Centrosoma ist nur undeutlich erlienmbar. Die Zellsubstanz $(\theta)$ ist heller gefärbt als in Figur 6 und zeigt deutlich einen Aufbau aus Fäden, deren netzförmige Anordnung allerdings nicht zu sehen ist. Die Hauptdifferenz zeigt

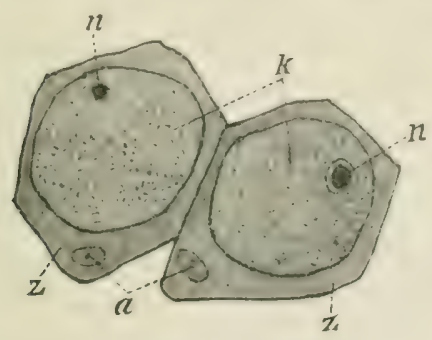

Fig. 6. Zellen von der Peripherie eines Salamanderhodens.

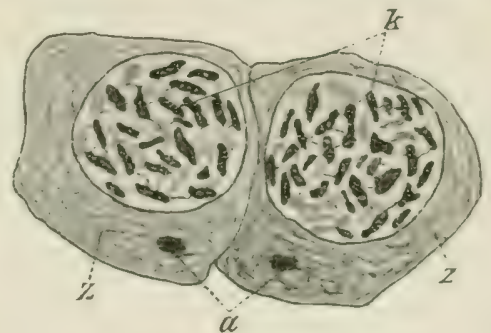

Fig. 7. Zellen aus dem Zentrum eines Salamanderhodens.

der Zellkern \%. Kein dunkler kreisrunder Körper, keine feinsten Granula, leine homogene Grundsubstanz wie in Figur 6, sondern auf hellem, farblosem Untergrunde sieht man unregelmäßis geformte Stäbchen, von denen die heller gefürbten einer anderen Ebene wic dic dunkleren angehören. Alle Stähchen - Chromosomen - sind durch zarte Fäden (Linin zu einem Gerüst untereinander verbunden. Welches von beiden Bildern ist num dasjenige, welches der Natur entspricht? Wohl die meisten Forscher, ich unter ihnen, werden ohne Bedenken erklären: die Figur 7 zeigt naturgetreue Verhältnisse, die Figur 6 dagegen nicht. Und dennoch gibt es hochachtbare Gelehrte, welche nur die Schnitte aus den peripheren Teilen des in Flemmingscher Lösung fixierten Hodenmaterials als verwendbar für Plasmastudien erklären, obwohl auch die Zellsubstanz, wie Figur u lehrt, erheblich gelitten hat, da sie fast völig homogenisiert ist. Fischer erklärt derartige Bilder als Chromwirkungen, ich deute sic als Osmiunwirkungen. Denn die Osmiumsäure ist es, welche in ihrur 
stürmischen Einwirkung Zell- und Kernstrukturen zertrümmert; darum sind die peripheren Partien der in Osmiumsäure oder Osmiumgemischen fixierten Organe nach meinem Dafürhalten für Protoplasma- wie für Kernstudien nicht zu gebrauchen. Nur clie mehr zentralen Partien zeigen eine moderierte Osmiumwirkung, zu der in dem Naterial, nach dem Figur 7 gezeichnet ist, noch die Fixierung durch die Chromsäure und Essigsäure hinzukommt.

Daher beachte man folgende Regel: Sehr zarte Objelite dürfen nur in diinner Osmiumsäure $(0,5 \%)$ oder in schwachen Osmiumgemischen fixiert werden. Kompakte Organe bedürfen stärkerer Lösungen ( $\left.\mathrm{I}_{10}^{\circ}\right)$ bzw. stärlierer Gemische und an ihnen sind die Randschichten, weil sie artifiziell verändert sind, vom Studium auszuschließen.

Die Osmiumsäure wie ihre Gemische - letztere allerdings nur in ungleichmäßiger Wreise - schwärzen Fette und verschiedene andere Substanzen. L'm osmicrtes Fett im Präparat zu behalten, darf man nach Fiemmings Vorschrift, der ich durchaus beistimmen muß, zur Paraffineinbettung - Celloidin ist ganz zu vermeiden - keine Vorbehandlung in Terpentinöl oder Xylol vornehmen, weil diese die geschwärzten Fette lösen. Nur Chloroform ist verwendbar, das auch nach meinen Lntersuchungen osmierte Fette fast völlig intakt läßt. Altes Usmiummaterial, das in diffusem Tageslichte aufbewahrt wurde, ist ganz und gar schwarz geworden, denn nummehr sind nicht bloß die Fette geschwärzt. Nan hat daher viclfache Vorschriften angegcben. um solches Material zu bleichen. Ich kann, offen gestanden, die Notwendigkeit davon nicht einsehen. Allerdings, das ist richtig: altes Osmiummaterial färbt sich schlecht oder gar nicht. Nun dann färbt man eben nicht; denn an dünen Schnitten durch derartiges Naterial hat man so feine Niiancierungen vom tiefsten Schwarz bis zum mattesten Grau, dal. ein solches Bild fast wie ein feines Lithogramm aussieht. Indessen mögen für die, welche absolut färben wollcn, die Bleichvorschriften hier folgen. Man löst nach Overton I $\mathrm{ccm}$ von käuflichem Wasserstoffsuperoxyd in $10-25 \mathrm{ccm}$ Alkohol von $70^{\circ}$. - $80^{\circ}$, , bringt darein ganze Stiicke oder die Schnitte und wartet die Bleichung ab. Besser soll eine Vorschrift von Paul Mayer sein, bei der Chlordämpfe zur Anwendung kommen. Diese histologisch wohl nicht so harmlose Hcthode soll im fünften Kapitel genauer beschrieben werden, weil sie nicht bloß zu dem unwichtigen Bleichen von altem Osmiummaterial, sondern auch zu dem gelegentlich sehr wichtigen Entfernen zu dunklen Pigments geeignet ist und daher den Wert einer besonderen Methode besitzt. 
Mit der zu starken Schwarzung alten ()smiummaterials hat iibrigens nichts zu tun die von manchen Autoren so genannte Überfixicrung. Es handelt sich hierbei um nichts anderes wic um dic vorhin genauer geschilderten Difierenzen zwischen ()ranperipherie und -zentrum; weder ron Fixieren noch von Uberfixicru kann hierbei gesprochen werden, sondern Artefakte liegen vor, wie dies vorhin gezeigt wurde.

Die Anfertigung der Osmiumlösung ist mit cinisen Unbeepuemlichkeiten verbunden. Die Säure kommt in gelben Fristallen in den I Fandel, welche in dimne Glasröhen luftdicht eingeschlossen sind. Letztere zu zersprengen ist nicht ganz leicht. Ich icrfahre so, dal ich die Röhre mit einer Dreikantfeile in der Nähe ihres spitzen lindes anschneide, sie dann schnell in die Flasche mit destilliertem Wasser werfe und durch heftiges Schiitteln völlig zerbreche. Dabei atmet man allerdings nicht unbeträchtliche Jengen von Osmiumdämpfen ein, die sehr unangenchm auf Augenbindehaut und Nasenschleimhaut wirken. Den ()smiumgeruch wird man stundenlans nicht los. Auch die Lösungen der Säure allein wie ihrer Mischungen haben die gleiche unangenehme Nebenwirkung:

Man macht sich am besten eine 2" Stammlosung ir g Osmiumsäure in $50 \mathrm{ccm}$ Aqua destillata), die man in einer braunen Flasche mit gut eingeschliffenem Glasstöpsel verwahrt. Korkstopfen sind unbedingt zu vermeiden, weil sie von der Osmiunsäure geschwïrt werden und ihrerseits die Osmiumsïure angreifen. Aus der Stammlösung kann man sich jede belicbige Verdünnung herstellen. Leichn verderben roine ()smiumlösungen, wenn sie nicht bald aufgebraucht werden, nach einiger Zeit, inden sic schwarz werden, wihrend die ()smiumgemische sich sehr lange unverändert crhalten. Lm ()smiumlösungen lingere Zeit klar zu behalten, sind verschiculene Vorschriften gegeben worden. So empfiehlt Lee (nach P. Mayer) zur $2 \%$ Osmiumsäure der Stammlösung I" (hromsiure wicriel? wird nicht gesagt zuzusetzen und die Osmiumsïure nur so zu rerwenden. Wie die chromhaltigen ()smiumgenische lehren, bleibt die (Osmiumsiure in dieser Verbindung unzersetzt. Nur hat man dann nicht mehr dic reinen Osmiumwirkungen, was z. B. bei manchen Wazerationen direlit wimschenswert ist. I'intner nach P'. Maryer setzt zu Ioo $\mathrm{ccm}$ ciner $I^{\circ}$. Osmiumsiurelöstng io Tropfen ciner 5 "Sublimatlösung und erhält dadurch die Säure lange \%cit unverindert. Cori setzt zu Osmiumsäurelüsungen soviel übermangansaures Kali, dal3 sic eine hellrosa Färbung annchmen. Der Zusatz hat so oft zu erfolgen, wic die Lösung sich wicder entfürbt. Nach IJusch setzt man jod*umes 
Natrium in ier dreifachen Menge der Osmiumsäure zu und konserviert dadurch cbonfalls die Lösungen. Von diesen Methoden scheint mir die Pintnersche die beste zu sein.

Vorhin wurde erwähnt, daß von mancher Seite die zu starke Schwärang alten Osmiummaterials als ein großer Nachteil empfunan wurde. In geradem Gegensitz zu dieser Auffassung stchen diejenigen Methoden, welche eine intensive Schwärzung des eben erst in reincr Osmiumsäurelösung oder in einem Osmiumgemisch fixierten Materials vorzeitig herbeifuhren wollen, weil dadurch eine Färbung unnötig wird. Diese Methoden sind die folgenden:

Holzessignachbehandlung von Osmiumfixierungen. Nach v. Mährenthal werden die fixierten und in destillicrtem Wasser ausgewaschenen Objekte in rohen Holzessig gebracht und darin 2 bis $2+$ Stunden je nach Größe und Permeabilität) gelassen. Dann wird sorgfältig in destilliertem Wasser ausgewaschen und in Alkohol von steigender Konzentration nachgehärtet. Der Alkohol muß so oft erneucrt werden, bis cr sich nicht mehr schwärzt. Die erhaltenen Bilder sind äußerst zart und fein und gleichen einem schr guten Lithogramm.

Hermann wendet den Holzessig an bercits in Alkohol gehärteten Präparaten an. Die Reduzierung der Osmiumsäure ist eine vollkommene, vorausgesetzt daß das Material nicht zu lange in Alkohol gelegen hat.

Pyrogallussäure zur Nachbehandlung von Osmiumfixierungen, nach Kollossow: Die Objekte kommen in folgende Redultionsflussigkcit: Pyrogallussäure $30 \mathrm{~g}$, Tannin $30 \mathrm{~g}$, Glyzerin $50 \mathrm{ccm}$, $85 \%$ Alkohol Ioo ccm, Aqua destillata $450 \mathrm{ccm}$. Darin bleiben die Objekte 5-ro Minuten und werden zur weiteren Osmierung in '1' 4 ? wässrige Osmiumlösung zurückgebracht.

Tanninbehandlung nach Osmiumfixierungen, nach Rawitz. Die gut ausgewaschenen osmierten Objekte kommen für $2+$ Stunden in cine $20^{\circ}$ 。 wässrige Tanninlösung; sie können eventuell auch länger darin verweilen. Dann wird mehrere Stunden in destillicrtem Wasser gewaschen und in Alkohol von steigender Konzentration nachgehärtet. Die Schwirzung ist eine vollkommene. Eine von Azoulay angegebene Nethode, Celloidinschnitte von Nervenmaterial zu osmieren und in $5^{\circ}$ 。- IO 。Gerbsäurclösung zu tannisieren, halte ich nicht für rationell, da die Alkoholbehandlung des Naterials Veränderungen hervorgebracht haben kann, die beim Osmieren und Tannisieren zu falschen Rcsultaten führen.

27. Osmiumdämpfe, nach Ranvier. Die Dämpfe der Osmium- 
süure, und zwar sowohl dic der Kristalle wie die der Lösungen, dringen selbst in voluminöse Organe nach den Angraben von Ranvier besser ein, als die Lösungen. Man hïngt zu dem Zwecke das Objekt in einer Flasche oder Schale auf, deren Boden mit einem Osmiumkristall oder mit etwas 2", Osmiumsäure-Lüsung bedeckt ist. Selbstverständlich diurfen Objekt und Reagens nicht in eine direkte Berihrung mitcinander kommen. Kontraktile Organc spannt man durch angehängte Gewichte aus, um ihre Krimmungen zu verhüten. Nach 2-2+ Stunden wird, da cin Abwaschen in Wasser nicht nötig ist, in Allohol von steigender Konzentration erhärtet. Isolierte Zellen setzt man auf dem Objektträger der Osmiumwirkung aus.

2\&. Osmiumessigsäure, nach Eimer und Hertwig. $0,2^{n}$.. Essigsäure $50 \mathrm{ccm}$ und $0,05^{\circ}$. Osmiumsäure ebenfalls $50 \mathrm{ccm}$ werden mitcinander rermischt. I landelt es sich um Fixicrung mariner Tiere, dann muß dic Osmiumsäure in Seewasser gelöst werden. Nach 5 bis Io Minuten werden die Objekte in $\mathrm{I}^{\circ}$. Essigsäure ausgewaschen und dann in Glyzerin aufgehoben. Für Coelenteraten, Würmer sowie fuir andere Evertebraten sehr geeignet.

29. Osmiumessigsäure, nach Fol. I ${ }^{\circ}$ Osmiumsïurc $10 \mathrm{ccm}$, $2 \%$ Essigsäure $50 \mathrm{ccm}$, Aqua destillata $40 \mathrm{ccm}$. Die Dauer der Einwirkung richtet sich nach dem Objekte, soll aber nicht lïnger als einige Stunden währen. Man kann in Salzwasser auswaschen oder direkt in Alkohol nachhärten.

30. Chromosmiumsäure, nach Flesch. I Osmiumsäure Io ccm, I․ Chromsäurc $25 \mathrm{ccm}$, Aqua destillata $65 \mathrm{ccm}$. Dauer der Einwirkung 24-31) Stunden, dann langsames Erhärten in Alkohol, ohne vorhcriges Auswaschen. Dürfte wohl für die meisten Organe der Vertebraten gecignet scin, ist besonders für deren inneres Ohr empfohlen.

31. Chromosmiumsäure, nach Lo Bianco. I ${ }^{\circ}$ Osmiumsäure $2 \mathrm{ccm}, 1 \%$ Chromsäure $100 \mathrm{ccm}$. In der Mischung bleiben dic Objekte 2-24 Stunden, dann Auswaschen in Wasser und langsames Erhärten in Alkohol.

32. Chromosmiumsäureeisessig, Flemmingsche Lösung. Diese Kombination ist die beste unter den Osmiumgemischen und vielleicht die beste Fixierungsflissigkeit iberhaupt, die wir zum Studium von Zell- und Kernstrukturen besitzen. Freilich muß man gerade dieser Lösung gegenüber sehr kritisch sein, denn alles das, was rorhin unter Nr. 26 über die Osmiumsäure gesagt wurde, gilt auch oder vielleicht erst recht für die Flemmingsche Lösung. Dic Figuren o und 7 , welche die differente Fixierungswirkung der Osmiumsiure 
illustrieren sollen, stammen von einem in Flemmingscher Lösung fixierten Material.

Flemming hat zwci Mischungsverhältnisse angegehen, die untereinander nicht unerheblich abweichen; sie werden als schwaches und starkes Gemisch unterschieden.

Schwaches Gemisch: $2^{\mathrm{I}} / 2 \mathrm{~g}$ Chromsäure, Osmiumsäure I g, Eisessig I ccm, Aqua destillata $1000 \mathrm{ccm}$.

Starkes Gemisch: $1 \%$ Chromsäure $15 \mathrm{ccm}, 2 \%$ Osmiumsäure $4 \mathrm{ccm}$, Eisessig I $\mathrm{ccm}$.

Im starken Gemisch werden schwer permeable, kompakte Objekte fixiert, in dem schwachen zartes Material. Dauer der Einwirkung bei beiden Gemischen einige Stunden bis zwei Tage: neuerdings lassen einige Forscher die starke Lösung 8 Tage und länger einwirken. Dann sorgfältiges Auswaschen in destilliertem Wrasser und Einbringen in $96 \%$ Alkohol. Die Flemmingsche Lösung hält sich sehr lange, ohne zu verderben; sie kann in Flaschen mit Korkstopfen aufbewahrt verden, da deren Schwärzung bei dieser Mischung belanglos ist. Nach Flemmingscher Lösung wird in Anilin-, Alizarinfarben oder mit den Beizmethoden gefärbt.

33. Chromosmiumessigsäure, nach Fol. Eine Modifikation des schwachen Flemmingschen Gemisches ist die folgende, von Fol sehr warm empfohlene: I $\%$ Chromsäure $25 \mathrm{ccm}, \mathrm{I} \%$ Osmiumsäure $2 \mathrm{ccm}, 2 \%$ Essigsäure $5 \mathrm{ccm}$, Wasser (Aqua destillata) $68 \mathrm{ccm}$. Sie ist nach Fol zum »allgemeinen Gebrauch s sehr geeignet.

3ł. Chromosmiumessigsäure, nach Westinghausen. Ebenfalls eine Modifikation des schwachen Flemmingschen Genisches ist folgendes Rezept: I\% Osmiumsäure I-I,5 ccm, I\% Chromsäure $25 \mathrm{ccm}, 2 \%$ Essigsäure $5 \mathrm{ccm}$, destilliertes Wasser $70 \mathrm{ccm}$.

35. Chromosmiumsalpetersäure, nach Burckhardt. Zur Fixierung des Nervensystems der Amphibien, aber auch für andere () rgane geeignct ist folgendes von Burckhardt herruhrende Gemisch: I\% Chromsäure $200 \mathrm{ccm}$, konzentrierte Salpetersäure (g*emeint ist wohl die offizinelle) Io $\mathrm{ccm}, 2 \%$ Osmiumsäure $10 \mathrm{ccm}$. Dauer der Einwirkung 2-2+ Stunden und länger, dann Abwaschen in destilliertem Viaser und langsames Erhärten in Alkohol. Durch ihren Salpetersiuregehalt remag die Lösung auf knochenhaltige Organe entkalkend zu wirken (?).

36. Osmiumsäure-Kalium bichromicum-Mischung; Altmannsche Lösung. Gleiche Volumina $2^{\circ}$ O Osmiumsäure und $5^{\circ}$ 。 Lösung von Kalium bichromicum werden gemischt. Die hineingebrachten Objekte miissen sehr klein sein; Dauer der Einwirkung $2+$ Stunden, 
Auswaschen fiur mehrere Stunden in destilliertem Masser und langsames Härten in Alkohol. ()h dicses Gemisch wirklich die beachtung verdient, die ihm Iischer schenlete, bleibe dahingestellt. IS ist mir aber sehr fraglich, ob hamit intakte fixierungen zu erhalten sind, da die eine Komponente des Gemisches licine suten Kernfixierungen liefert.

37. Osmiumsäure-Kalium bichromicum, nach I, B Biance. 5", Fillium bichromicum ros cem, I ${ }^{\circ}$ Osmiunsibure 2 cem. Dauer der Einwirkung mindestens 24 Stunden, Auswaschen in VTasser, langsames Erhärten in Alkohol. Die gegen die Altmannsche Lüsung soeben geaußurten Bedentien greifen dem Lo Biancoschen (remich gegeniiber auch Platz.

38. Osmiumsäure-Kalium bichromicum-Platinchlorid-Gemisch, nach Johnson. Paul Mayer erwähnt folgende Mischung, die bcsonders für dic Retina, aber auch für andere ()rgane sehr geeignet sein soll: $2 \%$ Osmiumsäure $10 \mathrm{ccm}, 2 \%$ Kaliumbichromat 7o ccm, I", Platinchloricl $15 \mathrm{ccm}$, Essigsäure oder Ameisensäure $5 \mathrm{ccm}$. (NB. I \% Platinchlorid z. B. heißt natürlich $\mathrm{I} \%$ wässrige Lösung von Platinchlorid; ich lasse das: "wässrige Lüsung * weg. weil ich es für selbstverständlich halte und weil die genannten Worte beim Lesen wie beim Schreiben wegen der unausgesetzten Wiederholungen ermüdend wirken.)

39. Isotonische Lösungen, ron Dekhuyzen. Un die Nachteile die fast allen Fixierungsmitteln anhaften _.. daß sie nänlich Schrumpfungen oder Quellungen hervorrufen - exakt zu rermeiden, hat Deckhuyzen die beiden folgenden Gemische konstruiert, die zunächst nur für Seetiere mit Ausnahme der Teleostier gelten.

Die salpetersäurehaltige isotonische Lösung hat folgende Zusammensetzung: 2,5 o doppeltchromsaures Kali in filtriertem secwasser gelöst $250 \mathrm{ccm}, 6,3$ i., Salpetersäure / sogenannte Normallüsung $25 \mathrm{ccm}, 2 "$, Osmiumsäure $5+\mathrm{ccm}$; die drei Flissigheiten werden gemischt.

Isotonische Lösung zur Erhaltung der Kalkgebilde: 20. Osmiumsäure in filtriertem Secwasser gelüst $20,9 \mathrm{ccm},-2,5$. Kalium bichromicum in filtriertum Scewasser gelöst I7j, I ccm; beide gemischt.

\section{\$3.}

40. Pikrinsäure. Daß dic Pikrinsüurc für sich allein kein gutes Fixicrungsmittel ist, darüber scheint allseitige lbereinstimmung orzielt zu sein. Es ist wichtig dics hervorzuheben, weil so manche 
Arbeit, die in den tour Jahren des rorigen Jahrhunderts crschienen ist. sich auf IIaterial grïndet, das in reiner Pikrinsäure fixicrt war und das zudien noch lange in Wasser ausgewaschen wurde; z. B. die Untersuchungen ron Paneth über Pteropoden. Nan wird daher gut : $11 n$, derartigen Arbeiten großes Mißtrauen entgegenzubringen. Mit Recht hebt r. Wasiclewski hervor. dals die Pikrinsäure leicht eindringt, und es ist diese Bemerkung dahin zu erweitern, daß sie selbst kompalste ()rgane ziemlich schnell und gleichmäßig durchdringt. Indessen wirkt sic nicht gleichmäßig fixierend, wic auch Stocltzner hervorhebt, und Fischers an totem kiunstlichem Material gewonnene Anschauung, dal die Fällungen unbeständig sind und im Wasser wieder gelüst werden, wird durch die Erfahrung des Histologen bestätigt. Denn die frühere Angabe - wenn ich nicht irre, hat sie auch Pancth gemacht - daß Pikrimmaterial lange und womöglich in fließendem Wasser ausgewaschen werden müsse, war ein grober Fehler. Wenn in I'ikrinsäure fixiertes Material mit Wiasser behandelt wird, dann werden die Zellen zerstört, die Terbindung ron Druisenzellen mit ihrer Tunica propria löst sich, kurz: es treten Bilder auf, die den Eindruck erwecken, als habe man kadarerüs verändertes Naterial verarbeitet.

Dagegen ist die Pikrinsäure in Verbindung mit anderen Säuren, welche ihre schlechten Eigenschaften unterdrïcken, ein ganz vorzügliches Fixierungsmittel. Ja ich stehe nicht an, die meisten Pikringemische allen anderen in der histologischen Technik üblichen Mitteln, die Flemmingsche Lösung allein ausgenommen, vorzuziehen. Nur wenige Pikringemische sind unbrauchbar.

Zur Verwendung hilt man sich eine größere Menge kalt in destilliertem Masser gesättiģter Pikrinsäurelösung vorrätig, mit der man alle Kombinationen ausfihren kann. Fixierte Objekte kommen direkt in $70 \%$ Alkohol; $50 \%$ ist nach meinen Erfahrungen zu wässrig, daher als gefährlich zu vermeiden. Aufgehoben wird das Material in $4 u^{*}$. Akohol, in dem es sehr lange viele Jahre) seine Konsistenz und seine Färbbarkeit behält.

Die Pilsrinsäure, einc Anilinfarbe, und zwar die einzige, welche in der Wikrotechnik nicht zum Färben, sordern zum Fixiercn verwendet wird, färbt dic nit ihr bchandelten ()bjekte intensiv gelb und die Farbe erhält sich auch in dem zur Aufbewahrung verwendeten $96^{\circ}$ 。 Alkohol lange Jahre unverändert. Nanche Forscher empfinden diese Tatsache als eincn Übelstand, was ich als unbegründet bezeichnen muß. Nach meinen langen Erfahrungen erleidet die Färbbarkeit des Iaterials keinerlei Einbuße, wenn auch die Schnitte noch so gelb 
sind und selbst nach tagelangem Verweiten in at', Alkohol nicht abblassen. Und ferner wird die Wirkung der Iarben durch die in den Schnitten vorhandene I'ikrinsiure in keiner Neise beeintrichtigt, es entstehen nicht die seringsten unerwinschten oder gar erwinschten Farbenkombinationen nit Gelb. Denn derjenige wiirce z. B. von einer ganz unsinnigen loraussetzung ausgehen, der stiubte, Schnitte von l'ikrinmatcrial brauchten nur mit Karmin nachgefiarbt zu werden, un eine Pihrokarminfürbung zu erhalten. Auch die I laltbarkeit der beliebig gefirtbten gelben Pikrinschnitte ist curch clas restierende Pikrin nicht im geringsten alteriert. Ich habe I'riparate, in dencn dic I Hämatoxylinfärbung an Pikrinmaterial seit mehr als I5 Jahren intakt erhalten ist: mehr kann man wirklich nicht verlangen.

Indussen gibt es num cinmal ängstliche Gemüter, welche das Pikringelb nicht mögen oder gar fürchten, und diesen sei die folgende von Jellinck konstruierte Methode empfohlen, durch welche Pikrinpraparate entgelbt werden Isit venia verbo. Zu dem Aufbewahrungsalkohol $1.6^{\circ}$, in welchem die Pikrinpräparate sich befinden. setzt man einige Tropfen kalt gesättigter wässriger Lösung von Lithion carbonicum. Es bildet sich sofort ein zarter Niederschlag, der das Pikrin an sich reißt, daher gelb wird und der sich allmahlich löst. So lange wird das Lithion hinzugesetzt, bis der Niuderschlag sich nicht mehr löst und der Alkohol sich nicht mehr gelb färbt. Häufiges Erneuern des Alkohols erwuinscht.

4I. Pikrinessigsäure, nach Hertwig. Kalt gesättigte wässrige l'ikrinsïurelösung $100 \mathrm{~cm}, 3-5 \mathrm{ccm}$ Essigsäure. Dather der Einwirkung je nach der Beschaffenheit des Objektes ${ }^{1}$ : Stunde bis i Tay. Uberfihhen direkt in $70^{\circ}$ 。 Allohol. Ist für alle zarteren ()bjekte Eier von Evertebraten, Embryonen von jedem Typus sehr empfehlenswert.

42. Pikrineisessig, nach Boveri. Man mischt konzentrierte wässrige P'ikrinsäure $100 \mathrm{ccm}$, Eisessig $3 \mathrm{ccm}$, Iqua destillata 200 ccm. Behandlung des Materials wie bei der vorigen Lösung: besonders für Ascariscier empfohlen. Nach $v$ Wasiclewski werden die Kerne schr gut erhalten, während das Plasma sehr diun erscheint. Diese Angabe düfte richtig sein, weil in dem Gemisch die Pikrinsäure in zu großer Verdinnung angewendet ist.

43. Pikrineisessig, nach Davidoff. Gesättigte wässrige Pikrinsäure $3 \mathrm{ccm}$, Eisessig I ccm. Für Ascidieneier ursprünglich empfohlun: doch dürfte das Reagens für eine allgemeine Verwendung wohl geeignet sein. Dauer der Einwirkung $3-+$ Stunden, die sicher bis 
zu 24 Stunden gesteigert werden kann, direktes Übertragen in $70^{\circ}{ }_{10}$ Alkohol, langsam steigende Konzentration. Dotterreiche Eier dürfen vor dem Einbetten nur kurze Zeit in absolutem Alkohol verweilen, sonst werden sie zu brüchig.

44. Pikrinessigsäure-Formol, nach Bouin. Konzentrierte wässrige Pikrinsäure $75 \mathrm{ccm}$, Eisessig $5 \mathrm{ccm}$, Formol $20 \mathrm{ccm}$. Eine meines Erachtens recht irrationelle Zusammensetzung, denn das Reagens muß jedesmal zum Gebrauch frisch bereitet werden, weil es sich sonst zersetzt.

45. Chrompikrinsäure, nach Lo Bianco. $1 \%$ Chromsäure und dic unter Nr. 47 zu erwähnende Pikrinschwefclsäure werden zu gleichen Teilen gemischt. Da die letztere Pikrinkombination recht wenig brauchbar ist, so erscheint auch diese Kombination irrationell.

46. Chrompikrinsäure, nach Fol. Konzentrierte wässrige Pikrinsäure ro ccm, I\% Chromsäure $25 \mathrm{ccm}$, Aqua destillata $65 \mathrm{ccm}$. Diese im Gegensatz zur vorigen rationelle Mischung hat nach Fol nur geringe Penetrationskraft, es dürfen daher nur kleine Objekte eingelegt werden. Man kann auch vor dem Gebrauche o,005 Osmiumsäure nach Fol zusetzen, um die Energie der Wirkung zu erhöhen (o,005 Osmiumsäure sind in ${ }^{\prime}$ ' $\mathrm{ccm}$ einer $\mathrm{I}^{\prime \prime}$ wässrigen Osmiumlösung enthalten). Da dieses Gemisch reichlich Chromsäure enthält, so kann nach beendeter Fixierung (ctwa 24 Stunden) in $50 \%$ Alkohol eingebracht werden, dessen starker Wassergehalt durch die härtenden Eigenschaften der Chromsäure paralysiert wird.

47.Pikrinschwefelsäure, Kleinenbergsche Flüssigkeit. Man mischt in folgendem Verhältnisse: kalt gesättigte wässrige Pikrinsäurelösung I $00 \mathrm{ccm}$, konzentricrte Schwefelsäure $2 \mathrm{ccm}$, Aqua communis $300 \mathrm{ccm}$. Die bei Zusatz der Schwefelsäure sich ausscheidenden Pikrinkristalle werden durch das IVasser wieder aufgelöst. Dauer der Einwirkung höchstens 3 Stunden, dann Überführen in $70^{\circ}$. Alkohol, der so oft zu erneuern ist, bis er nicht mehr gelb wird, dann Steigern der Konzentration bis $96 \%$. Die Kleinenbergsche Fluissigkeit läßt Bindegewebe stark quellen; man sucht dies zu vermeiden, inden man soviel Krreosot zusetzt, wie sich in der Flïssigkeit lösen will. Für

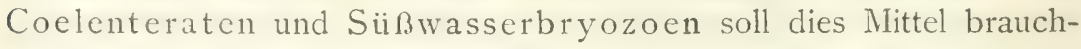
bar sein, fuir alles uibrige aber ist es unbrauchbar, da es fast gar kein Penetrationstcrmögen besitzt. Indessen hat die jetzt antiquierte Mischung das große Verdienst, die Kombinationen der Pikrinsäure begonnen und dadurch deren wertvolle Eigenschaften ausnutzbar gemacht zu haben.

Es sind eine ganze Anzahl Kombinationen (ron Mayer, Fol u. a.) 
angegeben worden, welche die Fehler der Kleinenbergschen Flüssigkeit - geringe Penetrationskraft, quellonde IVirkung - bescitigen sollen. Alle verfehlen ihren Zweck, sie sollen daher nicht erwähnt werden. Es gibt genug likrinkombinationen, welche für zarteste Objekte verwendbar sind, ohne die Fehler der Kleinenbergschen Flüssigkeit auch nur im geringsten zu besitzen. Man kann letztere daher ruhig der historischen Vergessenheit übergeben. Ein solches Reagens, welches keinen Fehler der eben genannten Fliissigkeit besitzt, ist das folgende, die:

48. Pikrinsalpetersäure, nach Paul Nayer. Nach der Vorschrift von P. Mayer stellt man dies Reagens in der IVeise her, daß man zu I $00 \mathrm{ccm}$ kalt gesättigter Pikrinsäurelösung $5 \mathrm{ccm}$ offizineller Salpetersüure $\left(25^{\circ} \%\right.$ hinzufügt. Es fällt viel Pikrin aus; man wartet $2+$ Stundenund filtriert dann. Die Pikrinsalpetersäure ist mir seit Jahren das liebste Fixierungsmittel, da sie für alle Organe mit gleich gutem Erfolge anwendbar ist. Freilich, ob sie die Mitochondria erhält oder die Centrosomen besonders schön darstellt, das rermag ich nicht zu sagen. Aber ob man Epidermis, Leber oder Pankreas, Thyreoidea, Lymphdrüsen oder Ailiz, knochenhaltige Organe, Darmkanal oder Lunge usw: fixiert, immer oder wenigstens fast immer wird man gute Resultate erzielen. Die Form der Organe im ganzen, die Form der Zellen, ihr Inhalt (Mucin), die Struktur der Kerne usw. habe ich stets in sauberster Weise fixiert gefunden und außerdem bleibt trotz der intensiven Gelbfärbung der Gewebe deren Färbbarkeit in allen Farben intakt. Für Vertebraten in jeder Beziehung verwendbar; für Mollusken und Nematoden bildet sie das einzige Reagens, das überhaupt eine passable Fixierung ermöglicht. Dagegen versagt sic bei Crustaceen des süßen Wassers vollkommen.

Die Objekte verweilen in der Lösung von ${ }^{\mathrm{I}}{ }_{2}$ Stunde bis 48 Stunden, kommen dann in $70^{\circ}$. Alkohol und werden allmählich in $06^{\circ}$ 。 übergeführt, in welchem sie jahrelang rerweilen können, ohne auch nur im geringsten Schaden zu nchmen. Die Organe bleiben gelb, auch der Alkohol wird, wenn man ihn auch noch so oft erneuert, immer etwas gelb: das ist ganz unerheblich und ohne jeden Einfluß auf dic Verwendbarkeit des Materials.

49. Chrompikrinsalpetersäure, nach Rawitz. Ich mische für Zellteilungsstudien, aber auch für andere nicht so spezialistische Arbeiten gern Chromsäure und Pikrinsalpetersäure in folgenden Verhältnisse: $I^{\circ}$ 。Chromsäure + Tolumina, Pikrinsalpetersäure I Volumen. Einwirkungsdauer 24 Stunden, "berfuhren in "O". Alkohol und langsames Ansteigen bis $96^{\circ}$. Tellyesniczky hat dieser Mischung, die 
er im Gegensatz zu mir für das Protoplasma als ungeeignet crklärt, den merkwirdigen Vorwurf gemacht, daß darin sehr schwer der Prozentgchalt ciner jcclen einzelnen Säure festzustellen sei. Er hat schließlich den Chromsäuregehalt auf $4^{\circ}$ 。 berechnet. Ich muß offen zestchen, daß ich diesun Vorwurf nicht recht verstehe, denn ich halte es für cin unnitzes Spintisieren und Zcitvergeuden, für jede einzelne Jischung festzustellen, in welchem Prozentgehalt die Bestandteile darin vorhanden sind. Ist die Kombination nur überhaupt gut, dann kommt es, wie mir Flemming einmal geschricben hat, auf einen Schuß Säurelüsung mehr oder weniger von der einen oder anderen Art nicht an. Hält man die ton mir empfohlene Kombination für schlecht, nun, dann verwerfe man sie; aber die $4 / 5 \%$ Chromsäure dïrfen mir nicht aufgemutzt werden.

Pikrinsalpetersäure und Chrompikrinsalpetersäure sind vorzüglich, das sei besonders hervorgehoben, für Organe mit geschichteten Epithelien, da die Salpetersäure in ihnen ihre die Epidermis zerstürenden Ligenschaften nicht cntfalten kann.

50. Pikrinosmiumsalpetersäure, nach Rawitz. Ich mische zur Fixierung sehr zarter Objekte: Pikrinsalpetersäure 6 Volumina, $2^{\circ}$. Osmiumsäure I Volumen; die Flüssigkeit hält sich selbst in heller Flasche sehr lange. Einwirkungsdauer ${ }^{\mathrm{T}}=3$ Stunden, $70^{\circ}$. Alkohol, der in den ersten Tagen häufig zu erneuern ist, clann allmähliches Ansteigen bis $96^{\circ}, 0^{\circ}$. Mit der Zeit werden dic fixierten Organe sehr schwarz.

51. Prikrinessigosmiumsäure, nach rom $\mathrm{R}$ ath. Man mischt konzentrierte wässrige Pikrinsäurelösung I Liter mit $4 \mathrm{ccm}$ Eisessig und löst darin I $g$ Osmiumsäure. Die Flüssigkeit wird für die Grarien ron Ascaris empfohlen, dürfte aber auch für viele Organe von Evertcbraten ron Vorteil scin. Es muß dirckt in $70^{\circ}$. Alkohol übertragen werden.

52. Pikrinosmiumsäure, nach vom Rath. $100 \mathrm{ccm}$ konzentrierter wïssriger Pikrinsäure werden mit $6 \mathrm{ccm}$ einer $2^{\circ}$ 。 Osmiumsäurelösung rermischt. Tellyesniczky hält diese Vorschrift für verfehlt, und in der Tat bedarf sie eines Corrigens, das nur die weggelassene Essigsäure sein hann. Dies Gemisch hat gegenüber dem vorigen keinen Vorteil.

\section{$\S 34$.}

53. Sublimat. Nan löst nach Rudolf Heidenhain das Sublimat in kochender $0,5^{\circ}$. Kochsalzlüsung, und zwar tut man in diese soviel hinein, wie im Kochen sich lüsen will. Dann läßt man langsam er- 
kalten. Aus der heißen trüben Fliissigheit scheiden sich allmählich die Sublimatkristalle in langen spitzen Nadeln aus. withrend die Mutterlauge klar wird. Die Verwendung eincr Kochsalzliosung ist darum inn Wert, weil sich clann mehr Suhlimat lüst als in reinem destilliertem Vasser. Für Sectiere kann man die Iösung auch in Secwasser machen, doch ist das nicht absolut notwendig. Nan hebt am besten die von den Kristallen abgegossene Nutterlauge, wclche das fixierende Reagens darstellt, in dunkler Flasche auf, da im Lichte sich Ausscheidungen auf dem Boden der Flasche bilken.

In dieser konzentrierten Lösung - konzentriert im histologischen Sinne, ob auch im chemischen kann uns gleichgiltig sein - bleiben die ()bjekte je nach ihrer Permeabilität von nur wenigen Winuten bis $2+$ Stunden. Die Fixierung ist beendet, so sagen die Autoren, wenn das ()hjekt opak, d. h. undurchsichtig geworden ist, eine Tatsache, die selbstverstïndlich nur an vorher durchsichtigen Objekten zu konstatieren ist, an vorher undurchsichtigen aber nicht. Im allgemeinen wird man die Fixicrungsdauer adäquat sein lassen der Permeabilität des Materials; je zarter dieses um so kürzer jene, je kompakter dieses um so länger jene. Nach dem Fixieren bringt man das Material direkt in $70 \%$ Alkohol und härtet in langsam steigender Konzentration. Man muß sich dabci hïten, Metallinstrumente zu verwenden, da diese von dem Quecksilberchlorid geschwärzt werden.

Dem 70\% Alkohol fügt man nach dem Vorschlage ron I'aul Nayer etwas offinelle Jodtinktur hinzu, um das iiberschüssige Sublimat aus den Geweben zu entfernen. Daß Quecksilber an das Jod herantritt - und dies geschicht auch bei fast allen quecksilherhaltigen Gemischen -, erkennt man daran, daß der Alkohol, der braun gefärbt war, sich vom Boden des Gefäßes aus zu entfärben beginnt. Man fügt so lange, unter stetigem Erneuern des $70^{\circ}$. Alkohols. Jodtinktur hinzu, bis keine Entfärbung mehr eintritt und die Ohjekte gebräunt werden. Dann überführt man in $80^{\circ}$. Alkohol, der so oft erneuert werden muß, bis die Briunung des Matcrials geschwunden ist. Dann $90^{\circ}$, und $90^{\circ}$. Alkohol; in letzterem wird aufgehoben. Zuweilen kommt es ror, daß das Jod sich in Form ron kleinen Kristallen als rotes Oueckilberjodid auf dem Material niedurschlayt; dann fügt man nach P. Mayer cinige Kristalle von Jodkalium zu und löst dadurch die neu entstandene Verbindung wieder auf. An Stelle der Jodtinktur kann man auch Lugolsche Lösung verwenden; letztere besteht entweder aus $\mathrm{I} \mathrm{g}$ Jodum purum, $2 \mathrm{~g}$ Jodkalium und $300 \mathrm{ccm}$ Aqua destillata oder man macht sich nach P. MIayer folgende Stanmlösung: Man löst $5 \mathrm{~g}$ Jodhalium in $5 \mathrm{ccm}$ Aqua destillata und firner 
$0,5 \mathrm{~g}$ Jod in $45 \mathrm{ccm}$ Alkohol von $90 \%$ und mischt beide Flüssigkeiten. Von dieser Stammlösung setzt man einen aliquoten Teil zum Alkohol des Präparates zu.

Zuweilen empfiehlt es sich, namentlich bei niederen Vertebraten und Evcrtebraten, dic Sublimatlösung warm, und zwar von $35^{\circ} \mathrm{C}$. bis zum Kochen, zuzusetzen.

Dic Sublimatfixierung soll nicht geeignet sein für Zellstrukturen mit Ausnahme der Centrosomen, dic ron ihr gut fixiert werden, und ist nicht zu gebrauchen für Mollusken aller Arten und fuir Süßwasser-Crustaceen; für alles andere, auch für Vertebraten-Embryonen, wohl geeignet.

In früheren Jahren, namentlich unter dem Einflusse der Arbeiten von Rudolf Heidenhain, herrschte eine große Begeisterung fü das Sublimat und ich selber hielt es fur eines unserer besten Fixicrungsmittel. Heutzutage ist man im Gegensatze dazu schr geneigt, das Sublimat ganz zu verwerfen. Zwar Fischer und Berg sprechen sich insofern nicht unguinstig aus, als Fischer findet, daß alle Sublimatfällungen in Wasser unlöslich sind, was Berg bestätigt. Anders lauten die Urteile ron Tellyesniczky und v. Wasielewski. Iener hält es für ein unbedingt schlechtes Fixierungsmittel, dessen Einführung ein wnicht geringer Mißgriff war. Dieser, der das Reagens bei Pflanzenzellen gepriift hat, rihnt ihm auch fast nur schlechte Eigenschaften nach. Indessen will mir scheinen, daß beide Autoren in ihrem verwerfenden Urteile zu weit gehen. Resultate der Fixicrung: gewonnen an Pflanzenzellen, sind nicht ohne weiteres auf die tierische Zelle zu ïbertragen, und Resultate, dic nur an Hodenzellen gewonnen sind, wie hei Tellyesniczky, sind zu einseitig, um eine Verallgemeinerung ohne weiteres zuzulassen. Schlicßlich gibt es noch andere Probleme wie Zellstrulituren zu lösen und anderes Material wie Salamanderhoden zu fixicren. Ich stimme daher Paul Mayer im großen und ganzen zu, wenn er das Sublimat für cin brauchbares Fixicrungsmittel hält. Ich habe es freilich in den letzten Jahren gar nicht mehr angewendet, weil meines Erachtens wir noch bessere Mittel besitzen, z. B. dic I'ikrinsalpetersäure, und dann weil Unzuträglichkeiten mit der Anwendung verkniipft sind, die sich sofort oder auch erst nach Jahren zeigen können.

Nach Jahren! Ich habe vor längerer Zeit mir sehr wertvolle Schnittsericn durch Iimbryonen von Sepia officinalis angefertigt, die sich nach wenigen Jahren als völlig verdorben darstellten. Das Material war in Sublimat fixiert, sehr stark bis zu intensiver Bräunung jodiert und dann wieder in Alkohol entfärbt worden; es war also an- 
zunchmen, daß alles Jod aus den Geweben entfernt worden war. Als ich dann nach 2 Jahren die Serien studieren wollte, fand ich fast alle Schnitte durclisctzt mit stecknadelartigen Sublimatliristallen, wie sic die beistchende Figur \& zeigt und die auch l'. Mayer liurz erwähnt. Und es konnte keinem Zweifel unterliegen, daß die Nadeln das Gewebe zerstört hatten. Dicser Übelstand stellt sich auch sofort, d. h. unmittelbar bei der Fixation ein. Denn die frischen Gewebe sind erfuilt entweder mit scharfackigen, unregelmälig geformten kristallinischen Niederschlägen von Sublimat oder, was seltener ist, mit Nadeln, wie sie Figur 8 naturgetreu wiedergibt.

Daß derartige Kristalle oder kristallinische Niederschlige inicht vorteilhaft für die Strulitur der Zellen und der Gewebe sein kinnen,

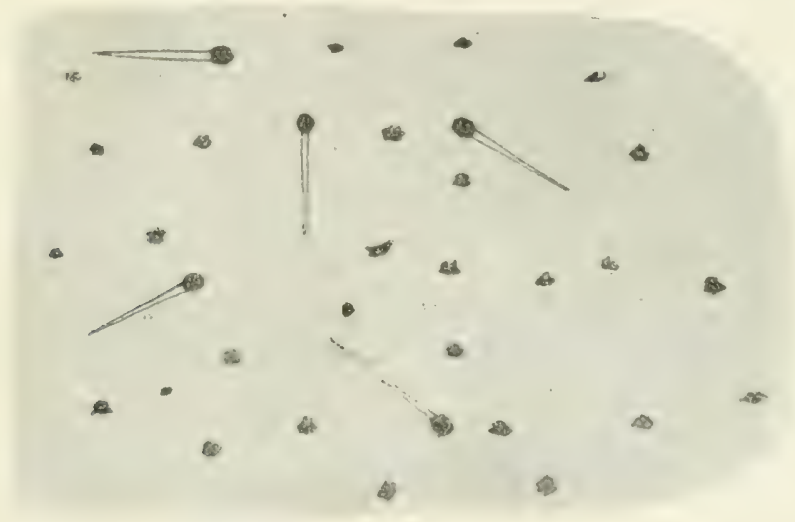

Fig. 8. Sublimatkristalle in einem alten Schnitte.

erscheint mir fast selbstrerständlich. Denn wenn man sic auch noch so schonend entfernt: da, wo sie gelegen haben, müssen in dem ()bjekt Löcher zurïckbleiben, welche sich nicht mehr schließen können, da ja das ganze Präparat durch Sublimat starr, unclastisch geworden ist. L'nd daß solche Lö̈her, wenn sie auch minutiösester Art sind, weil sie in der Zellsubstanz sich finden, einen schlechten Fixicrungszustand von dieser bedingen, ist ebenfalls selbstrerständlich. Dic schonendste Entfernung der Niederschläge ist die mittels Jod, wcil dadurch die langsamste Auflösung erfolgt. Für ganz verfehlt muß ich daher die Vorschrift halten, Sublimatpräparate in IVasser auszuwaschen. Die Löslichkeit des Sublimats in kaltem Masser ist gering; so daß nur wenig ron len Nicderschlägen fortgeschafte wird. Wenn man dagegen in fließendem WVasser auswäscht, so spiilt man gewaltsam die Niederschläge heraus und diese beschädigen womöglich noch die 
Umgebung, dic sic mit ihren scharfen Zacken und Spitzen zerreißen können. Für cinen groben Kunstfehler muß ich es laher auch erklären, wenn Ohlmacher (\$ $\$$ o, Nr. + dieses Kapitels) empfiehlt, erst die Schnitte zu jodieren, und wenn Mann die gleiche Vorschrift damit zu begründen sucht, daß er meint, das Jodieren des Stückes erweiche dieses und lasse es in Paraffin schrumpfen. Die letztere Angabe von Mann ist irrig, da genaue Messungen mir niemals eine Schrumpfung ergeben hatten. Der Kunstfehler besteht darin, daß das schneidende Messer die Sublimatniederschläge durch das Präparat zerrt und dadurch ganz unkontrollicrbare Verletzungen hervorruft. Mit Schaper und Fischer kann ich nur dringend raten, das in Sublimat fixierte Material sofort beim Einbringen in den $70^{\circ}$. Alkohol zu jodieren.

Ein mehr nebensächlicher Nachteil des Sublimats besteht darin, daß es kalkhaltige Bildungen, wie z. B. dic Kalkgebilde in der Haut der Holothurien, nicht unerheblich arrodiert.

Nit schr viel Nachteilen ist also die Fixierung in Sublimat verbunden, doch wird man dieses Reagens und seiner Mischungen nicht ganz entraten können und wollen, namentlich wenn man Verglcichungen anstellen will.

5+. Sublimat-Rohrzucker, isotonische Lösung, von Stoeltzner. Eine $t^{\mathrm{x}}=$ "' Lösung von Rohrzucker wird mit Sublimat gesättigt. Für alle Organe von Warmbliitern geeignet.

55. Sublimat-Natriumsulfat, Hayemsche Flüssigkeit. Sublimat I $\mathrm{g}$, Natriumsulfat $\mathrm{o} \mathrm{g}$, Kochsalz $2 \mathrm{~g}$ werden in $400 \mathrm{ccm}$ destillierten Wassers gelöst. Der Zweck dieser Kombination ist nicht recht ersichtlich, ihre Wirkung ist nicht anders, wie die des gewöhnlichen in Kochsalz gelösten Sublimats.

56. Sublimat-Formol, nach Bouin. Man mischt I Teil Formol und 3 Teile gesättigter Sublimatlösung; zur Fixierung von Froschlarven empfohlen. Eine irrationelle Zusammensetzung, weil das Formol verändernd auf das Sublimat einwirkt.

57. Sublimat-Pikrinsäure - Formol, nach M ann. Sublimat $2,5 \mathrm{~g}$, Pikrinsäure $\mathrm{I} \mathrm{g}$, Formol $5 \mathrm{ccm}$ werden in $100 \mathrm{ccm}$ Aqua destillata gelöst. Zur Fixicrung von Ganglienzellen empfohlen. Die Kombination dieses Gemisches ist ebenso irrationell wie die des vorigen.

58. Sublimat-Eisessig, nach Mingazzini. Konzentrierte wässrige Sublimatlösung $2 \mathrm{ccm}$, Alkohol absolutus r ccm, Acidum aceticum glaciale I ccm. Dic Nischung ist für Fischeicr als sehr wertvoll empfohlen, da das Blastoderm darin weich bleibt und die Eischale 
sich in Masser leicht ablïst. Sic dürfte auch fur andures Material geeignet sein.

59. Sublimat-Eisessig, Langsche Flüssigkeit. 3- 12 Sublimat, $\therefore$ g Alaun und 6-io $\mathrm{g}$ Kochsalz werden in $100 \mathrm{ccm}$ iqua destillati gelöst und $6-8 \mathrm{ccm}$ Eisessig hinzugefuigt. Wine seht zu empfehlende Modifikation, die für alles gecignet ist.

6o. Sublimat-Eisessig, nach David off. $\mathrm{Zu} 3$ Teilen konzentrierter wässriger Sublimatlösung wird I Teil Ëisessig gesctzt. Soll sich für dotterreiche Vier ron Evertebraten cignen, dic darin ${ }^{r}=$ bis I Stunde bleiben. Das von Davidoff vorgeschriebene Auswaschen in Wasser kann als überflüssig unterbleiben, das Jodieren muß schon im Stück vorgenommen werden.

6r. Sublimat-Eisessig-Alkohol, nach Apáthy. Man löst $+\mathrm{g}$ Sublimat, $0,5 \mathrm{~g}$ Kochsalz in $100 \mathrm{ccm}$ Wasser; davon nimmt man $75 \mathrm{ccm}$, setzt $5 \mathrm{ccm}$ Eisessig und $25 \mathrm{ccm}$ Alliohol absolutus zu und crhält so das Gemisch. Dauer der Einwirkung 6 Stunden, dann go o, $96 \%$ Alkohol je 24 Stunden. Füir alles geeignet.

62. Sublimat-Eisessig, nach $\mathrm{K}$ aiser. Io $\mathrm{g}$ Sublimat und $3 \mathrm{ccm}$ Eisessig werden in $300 \mathrm{ccm}$ Aqua destillata gelöst. Einwirkungsdauer verschieden. v. Wasielewski sagt ron dieser Kombination, daß sie keine besonderen Vorziige habe, fuihrt aber die folgenden, recht beachtenswerten Eigenschaften an: Zellsubstanz gut erhalten, Kerne gut erhalten, Mitosen im allgemeinen gut. Daraus kann man schließen, daß das Reagens recht brauchbar ist.

63. Sublimat-Essigsäure, nach Lo Bianco. Ioo $\mathrm{ccm}$ konzentricrter wässriger Sublimatlösung werden mit $50 \mathrm{ccm}$ konzentricrter, d. h. offizineller Essigsäure gemischt.

Der Zweck der Kombinationen von Sublimat und Essigsäure besteht darin, die schrumpfende Wirkung des Sublimats durch die quellende der Essigsäure zu paralysieren. Dies wird in allen Gemischen im wesentlichen erreicht, in dem letztgenannten vielleicht am wenigsten.

64. Sublimat-Aceton, nach Held. Nan löst $I \mathrm{~g}$ Sublimat in I $00 \mathrm{ccm}$ einer $70 \%$ Lösung von Aceton und härtet langsam in Lösungen von steigendem Acetongehalt, bis reines Aceton erreicht wird. Für Nervenzellen soll dicses Gemisch besonders geeignet sein.

6j. Sublimat-Salpetersäure, nach Frenzel. Zu gesättigter wässriger Sublimatlösung wird das gleiche Quantum absoluten Alkohols gesetzt und auf je I ccm dieser Nischung I Tropfen offizineller Salpetersäure zugefügt. Dauer der Einwirkung je nach dem Objekt; direktes Übertragen in $70^{\circ}$. Alkohol und langsames Härten. Infolge des 
Salpetersäurezusat»es bilden sich keine Sublimatniederschläge, so daß der Jodalkohol unnötig wird. Für alle Organe gecignet; besonders gut bei Insekten.

66. Sublimat-Salpetersäure-Eisessig, nach Gilson. $20 \mathrm{~g}$ Sublimat, $+\mathrm{ccm}$ Eisessig, I $5 \mathrm{ccm}$ Salpetersäure (1,456 spez. Gewicht, etwa $80 \%$ ), 60\% Alkohol $\mathrm{I} 00 \mathrm{ccm}$ und $880 \mathrm{ccm}$ Aqua destillata werden gemischt. Für alles geeignet.

67. Sublimat-Chromsäure, nach Lo Bianco. Ioo ccm gesättigter wässriger Sublimatlösung werden mit $50 \mathrm{ccm} \mathrm{I}^{\circ}$ 。Chromsäurclösung gemischt. Einwirkungsdauer 24 Stunden und länger, Auswaschen in destilliertem Vasser, dann $70^{\circ}$. Alkohol mit Jodzusatz. Die Fixierung ist nicht besonders schön.

68. Sublimat-Chromsäure-Eisessig-Osmiumsäure, nach Podwyssozki. Man löst - ich folge hier den Angaben von Röthig zunächst $\mathrm{I} g$ Chromsäure in $100 \mathrm{ccm}{ }_{2}^{\circ} \circ$ Sublimatlösung. Davon nimmt man i $5 \mathrm{ccm}$, fügt + Tropfen $2 "$ Osmiumsäure und 6-8 Tropfen Eisessig hinzu.

6y. Sublimat-Pikrinsäure, nach Rabl. Konzentrierte wässrigc Sublimatlösung und konzentrierte wässrige Pilrinsäurelösung je I Volumen, Aqua destillata 2 Volumina. Für ältere Embryonen, Hühnerembryonen vom 3. oder 4. Tage ab usw.; Dauer der Einwirkung I 2 Stunden bis zu 2 Tagen. NIan muß große ()uantitäten der Fixierungsflissigkeit nehmen und sie mehrere Nale erneuern. Nach beendeter Fixierung wird ein pair Stunden in Wasser gewaschen, dann in sehr schwachen Alkohol iibergeführt (er muß nach Rabls Angaben so schwach scin, daß er gerade nur einen Geschmack auf der Zunge zuriickläßt;, dann muß man rasch von Stunde zu Stunde in der Konzentration ansteigen, so daß in 24 Stunden dic Konzentration des $90^{\circ}$, Alkohols erreicht wird. Hierfür würde sich die Anwendung des Dialysators eignen. Dann absoluter Alkohol mit etwas Jodtinktur. Die IIschung diuffe auch für andere leicht permeable Objekte geeignct sein.

7o. Sublimat-Pikrinsäure-Osmiumsäure, nach Rabl. $\mathrm{Zu}$ I oo ccm des vorigen Gemisches kommen Io $\mathrm{ccm}$ einer $2 \%$ Osmiumsäure. Verwendung die gleiche wie vorhin.

;I. Sublimat-Pikrinsäure-Osmiumsäure, nach vom Rath. Kalt gesättigte Pilrinsüurclösung, heiß gesättigte Sublimatlösung je $50 \mathrm{ccm}$, dazu ${ }^{1}{ }_{2}$ - I ccm Eisessig und ro $\mathrm{ccm}$ einer $2 \%$ Osmiumsäure, weich letztere auch wegbleihen kann. Es handelt sich also um die beiden Rablschen Gemische unter 69 und 70 , die einen Zusatz von Osmiumsäure erhalten haben. 
72. Pikrinsäure-Sublimat-Eisessig, nach Hertwig. Nan mischt kalt konzentrierte wässrige Pikrinsiurclisung, heiß gesiittigte Sublimatlösung und destilliertes Wasser zu gleichen Teilen und fügt cinirge Tropfen Eisessig auf je 100 cem des Gemisches zu. Kopsch und Szymonowicz nehmen je $25^{\prime \prime} \mathrm{ccm}$ ron der l'ikrinsäure und dem Sublimat, $500 \mathrm{ccm}$ destillierten Massers und I $2 \mathrm{ccm}$ Eisessig. Ich sehe den Zweck de's Zusatzes von destilliertem Wasser nicht ein, dat dadurch die tixierende Kraft ron Sublimat und Pikrinsäure selbst zartesten (Objekten gegeniiber abgeschwächt wird. Diucr der Einwirkung 24 Stunden, allmählich steigende Alkoholkonzentration.

73. Sublimat-Eisessig-Osmiumsäure, nach I)runer. Konzentrierte Sublimatiösung; Eisessig und I" o( )smiumsäure je I ccm, Aqua destillata $20 \mathrm{ccm}$. Zur Fixierung des Hodens von Salamandra.

74. Sublimat-Pikrinsäure-Tannin, nach .Iann. Gesättigte wässrige Sublimatlösung (in $0,5^{\circ}$ " Kochsalzlösung gesïttigt) I $00 \mathrm{ccm}$, darin I g l'ikrinsäurc und 2 g Tamnin gelöst. Dauer der Einwirkung 24 Stunden, dirckt in 70 ". Alkohol, dem Jodtinktur zugesetzt ist, dann allmähliches Erhärten. Die Rancpartien der in diesem Gemisch fixierten Objekte sind gebräunt, also ron dem Tannin stark gegerbt, das nicht in das Innere der Organe eindringt. Dadurch erscheint der Zusatz ron Tannin wertlos und damit dic ganze Kombination verfehlt. Ich halte die Mannsche Mischung ferner auch deswegen für ganz schlecht, weil es absolut nicht gelingt, die Ouecksilbernicderschläge aus den Stiicken zu entfernen, wahrscheinlich deswegen, weil das Tannin dem Jod den Eintritt in das Innere der Objekte verwehrt. Die Fixicrung ist schlecht, wie ich in Uhereinstimmung mit Tellyesniczky konstatieren kann.

75. Sublimat-Kupfersulfat, nach Lo Bianco. $100 \mathrm{ccm}$ ciner Io '. Kupfersulfatlösung werden mit io ccm wässrigger Sublimatlösung gemischt. Diese urspringlich zur Fixierung ron Siphonophoren angegebene Nischung dürfte sich für vicle ancire schr zarte Gebilde eignen.

\section{$\S 35$.}

76. Palladiumchlorür o, I" ", nach F. E. Schulze. Um dis Salz in destilliertem Wasser zu lüsen ist cin Minimum ron Salzsüure crforderlich. Kleine Objekte werden 2-3 Tage und lïnger in der Lösung gelassen, in der sie schnittfahig werden und zugleich sich färben. Gut für Zellstrukturen und zum Nachweis glatter und quergestreifter Muskeln. Dieses Reagens ist merkwürdigerwcise sehr rernachlässigt worden, nur ron Frenkel liegt eine Vorschrift 
vor, zu I5 Teilen $I^{\circ}$. Palladiumchlorïrlösung 5 Teile $2 \%$ Osmiumsäure und einige Tropfen Essigsäure zu setzen.

7,. Platinchlorid. Diesem Salze wird eine schr gute Fixierung: der Kerne, dagegen eine schlechte der Zellsubstanzen nachgesagt (v. Wasielewski), während andere Autoren (Fischer) seine Wirkung der des Sublimats gleichstellen. Es setzt die Färbbarkeit der ()bjekte etwas herab, ist aber in allgemeinen ein sehr brauchbares Reagens.

Isoliert wird es angewandt in den Konzentrationen ${ }^{\mathrm{I}} /{ }_{\mathrm{O}} \% \mathrm{~T} / \mathrm{\%} \%$ I $0-1 \%$. Für Zellteilungen empfiehlt Rabl die 24stündige Einwirkung von ${ }^{\mathrm{I}} / \mathrm{I}_{0} \%{ }^{\mathrm{I}} / 8 \%$ mit langsamer Nachhärtung nach grïndlichem Auswaschen. ${ }^{3}$ ! Lösung soll nach demselben Autor für Embryonen sich eignen. Nach Löwit studiert man die Blutbildung gut am Material, das in $0,1 \%$ Lösung fixiert war.

Besser, weil gleichmäßiger in der Wirkung sind die Platinchloridgemische.

78. Platinchlorid-Chromsäure, Merkelsche Flüssigkeit. Man mischt $1^{\circ}$ 。Platinchloridlösung $100 \mathrm{ccm}, \mathrm{I}^{\circ}$ 。Chromsäure $100 \mathrm{ccm}$ und $600 \mathrm{~cm}$ Aqua destillata. Einwirkungsdauer einige Stunden bis 3 oder + Tage; direktes Übertragen in $70^{\circ}$. Alkohol und langsames Erhärten. Zell- und Kernstrukturen gut erhalten.

79. Platinchlorid-Osmiumsäure-Eisessig, Hermannsche Flüssigkeit. Die beiden folgenden Gemische werden in fixierender Kraft der Flemmingschen Lösung gleich geachtet. Für Amphibien ist folgendes Gemisch empfohlen: $1^{\circ}$. Platinchloridlösung 15 Teile, $2{ }^{\circ}$ Osmiumsäurc 2 Teile, Eiscssig I Teil. Das zweite Gemisch enthält mehr (Osmiumsäure und ist für Säugetiere gceignet: I ${ }^{\circ}$ 。 Platinchloridlösung 15 Teile, $2^{\circ}$ 。 Osmiumsäure 4 Teile, Eisessig I Teil. Nan sicht, es handelt sich um die Flemmingschen Gemische, in welchen die Chromsäure durch das Platinchlorid ersetzt ist. Einwirkungsdauer auf die schr kleinen Objekte $\mathrm{I}-2$ Tage, sorgfältiges Auswaschen, langsames Erhärten. Trorziiglich für cytologische Studien.

So. Platinchlorid-Osmiumsäure-Eisessig, nach Niessing. $10^{\circ}$ 。 Platinchlorid $25 \mathrm{ccm}, 2 \%$ Osmiumsäure $20 \mathrm{ccm}$, Eisessig $5 \mathrm{ccm}$, Aqua destillata 50. Anwendung wie Hermannsche Lösung.

8I. Platinchlorid-Osmiumsäure-Eisessig-Sublimat, nach Niessing. In dem vorigen Gemisch wird das destillierte Wasser durch $50 \mathrm{ccm}$ konzentrierte Sublimatlösung ersetzt. Beide Niessingschen Gemische sind noch teurer als das schon sehr teure Hermannsche Gemisch, ihre Zusammensetzung erinnert an die Rezente der Pharma- 
copoea elegans. I) a sic nicht mehr leisten als Flemmingsche und Hermannsche Iö̈ung, so kimn man sie füglich enthehren.

82. Platinchlorid-Sublimat, mach Rabl. I" Plitinchlorid I V nlumen, konzentrierte wissrige Sublimatliosung I Volumen, Arnua destillata 2 Volumina. Für junge Embryonen und junge Keimscheiben aller Vertebraten schr gut. Sollte sich schrumpfunde Wirkung zeigen, was aber fast nie der Fall ist, dann nimmt man $2 \%$ Platinchloridlisung und ctwas mehr Masser. Dic Fixierung ist in 2 Stunclen etwa heendet: dann sorgfältiges Auswatichen und Anhärten mit ganz diunnem Alkohol, der von Stunde zu Stunde konzentrierter genommen wird, bis nach $2+$ Stunden $90^{\circ}$. Alkohol erreicht ist. Diesem wird etwas Jodtinktur beigefügt.

83. Platinchlorid-Pikrinsäure, nach Rabl. I ${ }^{\circ}$ 。Platinchlorid I Volumen, konzentricrte wässrige Pikrinsäurelösung 2 Tolumina, Aqua destillata $;$ Volumina. Füir junge Keimscheiben wie die vorige Nischung, doch darf nicht zu lange fixiert und nicht zu lange gewäissert werden; die Nachhärtung wie bei der Platinchloridsublimatmischung.

8. Platinchlorid-Pikrinsäure-Eisessig, nach rom Rath. $200 \mathrm{ccm}$ konzentrierte wässrige Pikrinsäurelösung. I g Platinchlorid, $2 \mathrm{ccm}$ Eisessig. Einwirkung bis $2+$ Stunden, Uhertragen direkt in $70^{\circ}$, Alkohol.

85. Platinchlorid-Pikrinsäure-Osmiumsäure-Eisessig, nach vom Rath. 3-5 g Platinchlorid, $\mathrm{I}-2 \mathrm{~g}$ Osmiumsäure, Eisessig $3 \mathrm{ccm}$, konzentrierte wässrige Pikrinsäurelösung $500 \mathrm{ccm}$. Einwirkungsdauer etwa Io Minuten auf Eier niederer Tiere. Röthig fuhrt in seinem Handbuche noch zwei Modifikationen dieses Gemisches an, dic wiv das hier beschricbene sich durch den enorm teuren Preis anszcichnen, im wesentlichen aber der Flemmingschen Lösung in ihren Wirkungen gleichen. Zur Nachbehandlung kann man in Methylalkohol kurz abspülen, dann für 12-24 Stunden in rohen Holzessig oder in $20^{\circ}$ Tanninlösung einlegen, wieder in Methylalkohol abspiilen und in Äthylalkohol (gewöhnlichem Alkohol, langsim crhärten.

86. Platinchlorid-Pikrinsäure-Formol-Ameisensäure, nach Bouin. I ${ }^{\circ}$ 。 Platinchlorid $20 \mathrm{ccm}$, konzentrierte wässrige Pikrinlüsung $20 \mathrm{ccm}$, Formol io $\mathrm{ccm}$, Ameisensäure $5 \mathrm{ccm}$. Durch den zersetzenden Einfluß des Formols erscheint diese Kombination ganz irrationell.

8;. Essigsaures Kupfer und Kupferchlorid, nach Ripart und Petit. Man löst essigsaures Kupforoxyd und Kupferchlorid je o, 3 in nicht gesittigtem Kampferwasser und destilliertem ITasser zu je 
$75 \mathrm{ccm}$ und fügt I ccm Eisessig hinzu. Für zarte niedere Pflanzen geeignet, liefert keine Dauerpräparate.

\&\&. Eisenperchlorid, nach Fol ron Tulpian zuerst angewendeti. Fol empfichlt zur Fixicrung ron Wimpern und Pseudopodien auf das wärmste die alkoholische Eiscnperchloridtinktur der englischen Pharmakopoe, die er mit dem 5-rofachen Volumen $70^{n}$ 。 Alhohols verdiinnt. Falls sich ein Niederschlag im Laufe der Zeit bilden sollte, so muß man einige Tropfen Salzsiure zusetzen und kräftig schiitteln. Nan darf nur kleine Stuicke nehmen. pelagische Seetiere werden rortrefflich konserviert, IVimperepithelien werden mit der Lösung ïbergossen und nach einigen Ninuten mit dem Messer von ihrer Unterlage abgeschabt. Man wäscht in 50\% Alkohol aus, dem man $x=1^{\circ}$, Oxalsäure zugesetzt hat: nach Verschwinden der gelbrötlichen Farbe wird in Alkohol aufbewahrt.

89. Iridiumchlorid-Platinchlorid-Essigsäure, nach Eisen. Man mischt ${ }^{x_{2}^{\circ}}{ }^{\circ}$, Iridiumchlorid $50 \mathrm{ccm},{ }_{2}=$ Platinchlorid $50 \mathrm{ccm}$ und Eisessig I ccm. Für Hoden von urodelen Amphibien zu Zellstudien. Man kann auch das Platinchlorid fortlassen und dann entweder ron einer ${ }^{\mathrm{I}}=\circ$ oder ${ }^{\mathrm{T}}=$ " Iridiumchloridlösung r $00 \mathrm{ccm}$ nchmen. der man I ccm Eiscsig zufüt. Nach Fixation Waschen und langsames Erhärten.

go. Molybdänsaures Ammon und Chromsäure, nach Altmann. $\mathrm{Zu} 2^{x}:$ "molybdänsauren Ammoniak fuigt man soriel Chromsäure zu. daßß die Mischung I ${ }^{\circ}$, daron enthält. Fixicrung $2+$ Stunden, direktes Uherfuhren in . Mkohol. Zum Studium der Kerngranula.

Fünftes Kapitel.

\section{Entkalken und Entfärben.}

\section{A. Entkalken.}

$\S 36$.

Eine große Zahl ron tierischen Gebilden, die Skcletteile, enthalten Kalk in Form verschiedener Salze, welche in den Geweben rorkommen und diesen dadurch einen hohen Grad von Festigkeit verleihen. Es liegt auf der Hand, daß diese Salze entfernt werden müssen, wenn 
man feine, mikroskopisch verwendbare Schnitte erhalten will. I)enn Knochen z. B. oder der Chitinpanzer der Custaceen kïnnen ohne Entfernung der Salze, welche ihnen die eirentimliche Konsistenz verleihen, nicht untersucht werden, es sei denn, man fortige Schliffe durch die Iartgebilde an. Auch diese Methode ist erfolgreich, sie wird im siebenten Kapitel beschrieben werden. Aber die Grundsubstanz, in welcher die Salze aufgespeichert sind, lernen wir an Schliffen nicht kennen.

Entfernt man durch die Entkalkung einen matiirlichen Bestanciteil aus dem ()rginismus, so darf man doch darin keinen Mazerationsprozeß erblicken. Bei der Mazeration ist unsere Absicht, dic äußere Form cines ()rganes zu zerstören, um dessen einzelne Teile zu crkennen (einc besondere Art der » Encheiresis naturaes), wogegen es Aufgabe des Entlailkens ist, trotz eingreifender chemischer Tornahmen Form, Textur und Strulitur des betreffenden ()rganes in jeder Beziehung umverindert zu crhalten. Fine Entkalkungsmethode, die auch nur einer dieser drei Forderungen nicht genigt, ist wertlos. Daher muß man, wie ich in Übercinstimmung mit Fol und Paul Nayer betonen will, nur gut fixiertes und erhärtetes Material der Entkalkungsflïssigkeit unterwerfen, denn nicht fixiertes wird ohne Zweifel zerstört. Auch ist es nicht zu empfehlen, wie ich ebenfalls mit beiclen Forschern hervorzuheben hahe, nach Reagentien zu suchen, die zugleich fixieren und entlialken. Die Pikrinsäure und namentlich dic Pikrinsalpetersäure sind solche Nittel, in denen beide Eigenschaften vereint scin sollen. Indessen ist der Salpetersïuregchalt der letzteren nicht groß genug, un nur halbwegs voluminöse knochenhaltige ()rgane in dersclben Zeit zu entkalken, in welcher deren Weichteile fixiert sind; sie wirkt daher in der L̈berzahl der Fäle nur fixierend. Die erstere, die isolicrte Pikrinsïure, aber entlallit so langsam, clak meine Geduld wenigstens nicht ausreicht, das Ende des l'rozesses abzuwarten. Reagentien, dic zugleich fixieren und enthallen, sind meines Erachtens ein Unding. Entweder sie entkalken gut, dimn fixieren sie immer schlecht; oder sie fixieren gut, dann ist die Enthilliung nichts wert; oder endlich sic leisten nach beiden Richtungen hin nichts.

Daß die Entkalkung ein cingreifonder P'rozeß ist. kann fuiglich nicht bezweifelt werden. Da erhebt sich denn die Frage: sollen wir langsam oder sollen wir schnell entkalken? Für beides lassen sich gute (iriuncle anfüren. Iei langsamem Entkallien wird die Kohlensäure - - denn als kohlensauren Kalk finden wir die meisten derartigen Abligerungen schonend aus den Geweben ausgetrieben, keine stiurmischen Strönun- 
gen finden statt. Dageren ist der unleugbare Nachteil der, daß die weichen Gewebe cincr allzulange dauernden Einwirkung der meist in relativ konzentrierter Form angewandten Mincralsäuren ausgesetzt sincl. Dadurch ist die Möglichkeit der Arrosion der Wicichteile schr nahe gerïckt. Btim schnclien Entkalken wird dieser Nachteil vermieden, dafür aber kann das stümische Entweichen der Kohlensäuregase deletären Einfluß ausüben. Ich bin der Meinung; daß der letztere fast immer geringer sein wird als die Arrosion und empfehle daher schnclles Entkalken. Wiederholt mag werden, daß als unerläßliche Torbedingung fur die relative oder absolute Lnbedenklichkeit des Lintkalkungsprozesses gute Fixierung und Erhärtung der Weichteile des betreffenden Organes z. B. cincs Felsenbeines) unter allen Umständen anzusehen sind.

Lm festzustellen, of dic Entkalkung beendet ist oder nicht, nehme man von Zeit zu Zeit das Objekt aus dem Reagens heraus und prüfe an einer gleichguiltigen Stelle mit einer Nadelspitze, ob das Organ genügende Weichheit erlangt hat. Der Anfänger huite sich aber dabei auf das sorgfältigste, clas Ohjukt zwischen den Fingern oder zwischen den Branchen cincr Pinzette zu drücken, sonst könnten tiefgreifende Zerstörungen im Innern erfolgen.

Als eine Form der Beseitigung von Hartgebilden ist das Entkiescln zu betrachten, das glüchlicherweise nur sehr selten vorzunehmen ist. Das dabei einzuschlagende Verfahren wird nachher beschrieben werden.

Das beste Enthalkungsmittel ist die Salpetersäure. Dic Schwefelsäure ist ganz unbrauchbar. Wcil sic mit dem Kalli zu unlüslichem Gips sich rerbindet: dic Salzsäure ruft Quellungen der Weichteile hervor und bedarf eines Corrigens; das durch Schrumpfung jene Wirkung paralysiert.

\section{$\S 37$.}

I. Salpetersäure $3 \%-9 \%$. Je nach der Härte des zu entkalliendenden ()bjektes richtet sich die Konzentration der Säure, die in wässriger Lösung angewendet und von der viel Flüssigkeit genommen werden muß. Einen Zusatz von Kochsalz, den ich früher empfahl, halte ich jetzt für überflïsig. Es bildet sich nur Salpeter, ein Teil der Säure wird also anderweitig okkupiert und weder die Dauer der Entkalkung noch dic Erhaltung der Teile wird im Vergleich zur kochsalzlosen Säure geändert. Alle 3 Tage muß die Säure gewechselt werden. richtiger ist, sie alle 48 Stunden $z u$ crneuern. Ein Auswaschen in Wasser; das ich friher für nötig hielt, kann ich nach 
meinen seitdem gewonnenen Erfahrungen nicht mehr amraten. Ich iibertrage nach beendeter lintkilkung sofort in $7 \sigma^{\circ}$. Alkohol, der in den ersten 3 Stunden hëufiger $2-3$ mal zu erneuern ist; dann langsames Weiterhärten und Aufheben in $96 \%$ Alkohol.

2. Salpetersäure-Alaun, nach Gagc. Zu einer gusïttigten Alaunlösung wirl das gleiche Quantum Wasser gesetzt. Zu $25 \mathrm{ccm}$ daron ist I ecm starke Salpetersäure hinzuzufugen. Bchandlung wic bei Salpetersäure allein. Der Alaun soll dic Ouellung verhüten.

3. Schweflige Säure, nach Ziegler. Material, das wrher in Formol fixiert war, kommt in eine gesättigte wässrige Lösung der schwefligen Säure. Soll sehr gut dic einzelnen Elemente erhalten.

4. Salzsäure-Kochsalz, v. Ebners Flüssigkeit. Zu roo ccm cincr IO" "- $5^{\circ}$." Kochsalzlösung gibt man I-3 ccm reine Salzsäure. Der Prozentgchalt richtet sich nach der Massigkeit der Kalkguhilde. Es wird sorgfältig in Wasser ausgewaschen und langsam crhärtet.

5. Chlorpalladiumsalzsäure, nach Waldeyer. Nan mischt $I^{\circ}$ Salzsüure mit $1^{\circ}$ 。Chlorpalladiumlösung in dem Grade, daß in IOO $\mathrm{ccm}$ des Gemisches o,OOI ${ }^{\circ}$ Chlorpalladium enthalten sind. Man macht dies folgendermaßen: I ccm einer $1 \%$ Lösung enthält $0,01 \mathrm{~g}$ der gelösten Substanz, dazu setzt man $9 \mathrm{ccm}$ Wasser. I ccm dieser Verdünnung enthält I Milligramm der gelösten Substanz, in unseren Falle des Palladiumchlorïr, und gibt man diesen einen $\mathrm{ccm}$ in $99 \mathrm{ccm}$ einer I : Salzsäurelösung, dann hat man die vorgeschriebene Fombination. Nach dem Entkalken sorgfältiges Waschen und langsames Erhärten.

6. Chromsalpetersäure, nach Fol. I ${ }^{\circ}$ Chromsäure $70 \mathrm{ccm}$, Salpetersäure $3 \mathrm{ccm}$, Aqua destillata $200 \mathrm{ccm}$. Sorgfältiges IVaschen und langsames Erhärten.

7. Chromsalpetersäure, nach L. Katz. Diese für Gehörschnecken der Säuger empfohlene Methode düfte fuir alle knochenhaltigen Bildungen und für Knochen allein sehr brauchbar sein. Bei dünner Knochensubstanz Schnecken kleiner Säugetiere entkalkt man in folgendem Gemisch: Chromsäure $0,+\mathrm{g}$, Salpetersäure $5 \mathrm{ccm}$, Aqua destillata $100 \mathrm{ccm}$. Beim Felsenbein des Menschen, also bei sehr harten bzw. sehr roluminösen Knochen mul3 eine $10^{\circ}$ Chromsäure genommen werden. Nach dem Entkalken wird sorgfältig gewässert und langsam erhärtet.

8. Chromsalzsäure-Palladiumchlorür, nach L. Katz. Man stellt sich folgendes Gemisch her: Chromsäure $0.4 \mathrm{~g}$, Salzcüure $10 \mathrm{ccm}$, Aqua destillata roo $\mathrm{cm}$, dazu etwa ein EBlöffel einer ${ }^{\mathrm{z}}=0$ Chlor- 
palladiumlösung. Zur Lintkalkung ganz besonders harter Knochen geeignet.

q. Salpetersäure-Chrom-Pikrin-Sublimat-Gemisch, nach Hennings. Konzentrierte Salpetersäure i $6 \mathrm{ccm}, 0,5^{\circ}$ 。Chronsäure I $6 \mathrm{ccm}$, in $60^{\circ}$. Alkohol gesättigte Sublimatlösung $24 \mathrm{ccm}$, gesättigte wässrige l'ikrinsäurclösung I I ccm, Alkohol absolutus $+2 \mathrm{ccm}$. Dieses Gemisch ist zur Entkalkung des Chitinpanzers angegeben, dürfte aber wohl allgemeiner Anwendung fähig sein. Die Chitinorgane kommen fuir $\mathrm{I}_{2-2}+$ Stunden in das Gemisch und werden in $70^{\circ}$. Jodalkohol ausgewaschen. Die Schnitte durch das entkalkte Material müssen mit Mastixkollodium (vgl. später) behandelt werden.

I0. Phloroglucin-Salpetersäure, nach Andeer. Eine in warmem Vasser gesättigte Lösung ron Phloroglucin wird entsprechend dem Härtegrade der Knochen mit $5^{\circ} \circ-50^{\circ}$, (!) Salpetersäure versetzt. Nach dem Entkalken sorgfältiges Auswaschen.

r I. Phloroglucin-Salzsäure, nach Ferreri. Phloroglucin, das sei hier bemerkt, eignet sich nur zum Entkalken ron Knochen, ist dagegen für Conchyolin, Chitin, Elfenbein usw. röllig unbrauchbar. Ferreri nun gibt folgende Vorschrift: Phloroglucin I g, Salzsäure IO $\mathrm{ccm}$, Wasser $100 \mathrm{ccm}$. Man löst in der Wärme und fügt nach dem Erkalten $200 \mathrm{ccm}$ Alkohol ron $70^{\circ}$ 。 hinzu. Entkalliung bei Zimmertemperatur, Fliissigkeitswechsel jede IToche. Die Lösung entlialkt offenbar sehr langsam, denn Ohrlabyrinth vom Menschen bedarf 30- to Tage. Auswaschen in $70^{\circ}$. Alkohol, bis dieser nicht mehr sauer reagiert; langsames Härten.

I2. Phloroglucin-Salpetersäure, nach Haug. Nan erwärmt sehr vorsichtig und langsam unter leichtem Schütteln i $g$ Phloroglucin in I o ccm Salpetersäure vom spez. Gew. I, +. Die dunkelrubinrote Flüssigkeit wird mit $50 \mathrm{ccm}$ Aqua dest. verdiunnt. Man kann noch bis auf $300 \mathrm{ccm} 20^{\circ}$. Salpetersäure zusetzen. Die Entkalkung erfolgt rapide. Schaffer hat dic Vorschrift folgendermaßen modifiziert: Phloroglucin $x$ g, Salpetersäure $5 \mathrm{ccm}$, Alkohol $70 \mathrm{ccm}$, Aqua dest. $30 \mathrm{ccm}$. Man muß nach der Haugschen Methode 2 Tage lang in fließendem Wasser auswaschen.

I3. Entkieseln. Um z. B. die Kiesclnadeln ron Spongien zu entfernen, bringt man das gut fixierte Material in diinnen Alkohol und setzt tropfenweise Fluorwasserstoffsäure zu. IVegen der giftigen Dämpfe muß man eminent vorsichtig scin, auch ist es besser, nicht im geschlossenen Raume zu entkicseln und man muß Bleioder Guttaperchagefäße dazu benuitzen, denn die Säure zerstört die Gläser. Neuerdings nimmt P. Nayer Gläser, die innen mit Paraffin 
iilerzogen sind und dachurch cinen Schutz gegen dic Filußsiure haben.

14. Eau de Javelle, mach Fol. Sollte dic vorige Methode die Kieselgebilde aus den Geweben entfernen, so ist die Bestimmung der jetzt zu gebenden originellen Torschrift dic; die Kicselgehilde zu erhalten und das Gewebe, in welchem sie liegen, zin entfernen. Die Methode gehört streng genommen zu den Mazerationsmethoden, soll aher um ihrer Gegensïtzlichkeit willen zur verigen Nuthode hier angefuihrt werden. Man legt nach dem Torschlage von I:ol einfach Kieselschwämme oder Radiolarien in die offizinclle Jarellesche Lauge und erhailt das Kiesclskelett im Zusammenhange. Kialkgebilde dagegen werden mehr oder weniger angegriffen.

\section{B. Entfärben.}

$\S 38$.

Bei den Fixierungsmethoden habe ich bereits ausgefuhrt, daß mir das Entfärben d. h. Bleichen zu dunkel gewordener ()smiumpräparate ein höchst überfliisciges Unternchmen zu sein schcint. Das Gleiche ist der Fall mit zu dunklen Goldpräparaten. Ich ühergehe daher alle Methoden, die bloß Bleichmethoden für diese Zwecke sind. Die anzufuhrende Methode ron Paul Mayer kann auch zar Entfernung sehr resistenten Pigmentes dienen, daher findet sie hier ihren Platz. Viele Gebilde nämlich, z. B. die Augen der Tiere, sind bei manchen Individuen so dicht pigmentiert, dals dadurch jedes histologische Detail vollständig verdeckt wird. Nan muß daher cntfärben, un ïherhaupt etwas sehen zu können. Daß hicr wie heim Enthallien die Fixicrung und Härtung rorausgegangen sein müssen, ist selbtrerstindlich, denn manche Methode ist nur an Schnitten ausfuihrbar.

\section{\$ 39 .}

15. Salzsaurer Alkohol, nith Grenacher. Diese rorziglichste aller Entfirhungsmethoden wird nach Grenachers Vorschrift folgendermaßen ausgefuhrt: Man mischt 2 Teile Alkohol ron so' und I Tcil Glyzerin und setzt I" - - ". Salzsäure zu. Sowohl zur Entfärbung ganzer Stiicke als auch zur Entfirbung der Schnitte gecignet. Ist die Entfärbung beendet. Welchen Vorgang man gonau herbachten muß, dann wird in $\varepsilon_{0}{ }^{\circ}$, . llkohol so lange ausgewaschen, his keine saure Reaktion mehr vorhanden ist.

16. Salpetersaurer Alkohol, nach Hennings. I Teil Glyzerin, 2 Teile Alkohol von 80"... kazu 2 Volumina konzentrierte Salpetersïure. Die Schnitte, nicht dic Stiicke, kommen aus wo Alkoho! 
in das Gemisch uncl werden nach der Entfärbung in $60^{\circ}$ Alkohol ausgewaschen.

17. Alkoholische Natronlauge, nach Rawitz. Es gibt sehr säurebeständige Pigmente namentlich bei den Nollusken, die nur durch die Anwendung eines Alkali zu entfernen sind. Mir hat folgendes Verfahren sehr gute Dienste geleistet. Ganze Organteile (Stiicke) oler Schnitte werden in I 5-20 ccn Alkohol ron $96^{\circ} \%$ gebracht, dem 3-9 Tropfen offizineller Natronlauge zugefuigt werden. Die Entfärbung ist in kürzester Frist beendet. Es muß dann in neutralen $96 \%$ Alkohol übergefuihrt werden.

18. Folsche Chromsalpetersäure, nach Jander. Die gut fixierten und gehärteten Objekte kommen zunächst in Wasser, dann gewöhnlich für 12- ti Stunden, gelegentlich auch für + Tage, in die von Fol zur Lntkalkung empfohlene Chromsalpetersäure-Mischung (vgl. dieses Kapitel Nr.6).

I 9. Entiärbung mittels Chlordämpfen, nach Paul Mayer. Man bringt auf den Boden eines Glases, das mit Alkohol gefüllt ist und in dem das Objekt sich befindet, Kristalle ron chlorsaurem Kali und gibt soviel Salzsäure zu, daß der Alkohol ctwa $I^{\circ}$ 。 daron enthält. Das Glas muß gut verschlossen werden, denn durch den Salzsäurezusatz entwickeln sich Chlordämpfe. Der Prozeß muß sehr genau überwacht werden, damit die Chlordämpfe das Objekt nicht angreifen. Ist die Entfärbung beendet, so wird direkt in Alkohol übergeführt. $\mathrm{Zu}$ bleichendes Chitin muB in ein Gemisch kommen, das keinen Alkohol sondern Wasser enthält.

\section{Sechstes Kapitel.}

\section{Einbetten.}

$\S 40$.

Wenn die Fixierung und Erhärtung beendet ist, wenn crentuell die Entkalkung stattgefunden hat, dann ist das Material soweit vorbehandelt, daß wir daran denken können, es in Schnitte zu zerlegen. Natülich müssen diese fein, d. h. duimn sein, damit das System des Mikroskopes uns ein Bild ron ihrem Bau entwerfen kann. Zwei Methoden stehen uns zur Terfïgung, um diese Zerlegung vorzu- 
nchmen. Entweder wir benutzen ein gewöhnliches Rasiermesser, das wir mit der freien Hand führen: eine kium noch geübte Art der Schnittanfertigung, die aber der Anfïnger, wenn er ïherhaupt dazu kommt, selbständig einen miliroskopischen Schnitt zu machen, untur leinen Umständen vernachlässigen sollte. Oder wir ersetzen die Hand durch eine Naschine, um so die individuelle Geschicklichkeit oder Ungeschicklichkeit auszuschalten. Freilich wïrde man sehr irren, wollte man glauben, daß bei Benutzung des Mikrotoms - so heißt die Maschine - die Anfertigung mikroskopischer Schnitte eine rein mechanische Tätigkeit sei. Es gehört zur Herstellung eines guten, diinnen Mikrotomschnittes wohl ebensoviel Geschicklichkeit wie zum Freihandschneiden, wenn sich diese Geschicklichkeit auch der Maschine gegenüber in etwas anderer Weise äußert, wie gegenuber dem gewöhnlichen Rasiermesser.

Zum Freihandschneiden ist es nötig, das Objekt in irgendeiner Weise zu umhüllen, und zwar darum, weil dem Schneiden die Erhärtung in Alkohol vorausgegangen ist. Läßt man das Objekt, das in der linken Hand gehalten wird, ohne Hülle, so kann es durch Verdunstung des Alkohols in mehr oder minder beträchtlichem Grade eintrocknen. Aber auch wenn es nicht aus Alkohol genommen ist, wenn es sich z. B. um Material handelt, das in Miillerscher Flïssigkeit erhärtet war, auch dann ist eine Umhüllung nötig. Und zwar diesmal weniger des Materials als des Arbeitenden wegen, dessen Hände durch Müller-Material unnötig beschmutzt werden.

Sind die Objekte zu klein, um in der Hand gehalten zu werden, sind sic auch zu zart, um den beim Halten unvermeidlichen Druck zu vertragen, so muß man sie mit dem Nikrotom schneiden. Dies können wir auf zweierlei Art machen. Entweder wir kleben das erhärtete Objekt auf irgend eine angemessene Unterlage auf, die in das Nikrotom paßt, und umgeben es mit einer schiitzenden Hülle. Oder wir durchtränken es mit irgend einer erhärtenden Masse, die uns die Möglichkeit der Anfertigung feiner Schnitte auf mechanischem WVege gewährt. Dieses Durchtränken ist das eigentliche Einbetten. Drci Hauptarten gibt es also, das schnittfahig gemachte Material zum Schnciden herzurichten und diese sollen hier beschricben werden; iiber das Schneiden selber wird das folgende Kapitel handeln. Die drei Arten sind a) Einklemmen, b) Aufkleben, c) Einbetten. 


\section{a) Einklemmen.}

$\$+\mathrm{I}$.

I. Einklemmen in Leber. Rindsleber und die sogenannte Speckleber des Menschen, die bei vielen Krankheiten vorkommt, werden in starkem Alkohol so gleichmäßig erhärtet, daß die Anfertigung hinreichend feiner Schnitte mit dem freihändig geführten Rasiermesser sehr leicht ist. Ein solches Stück Leber nimmt man nun, spaltet es durch einen Schnitt und steckt das gehärtete Objekt hinein. $\mathrm{Ob}$ die Klemmleber hierbei etwas eintrocknet oder nicht, ist unerheblich, da deren Studium uns nicht beschäftigt. Nun schneidet man zunächst sehr oberfä̈chlich die Leber an und führt dann in langem, ziemlich schnellem Zuge die Klinge durch Leber und Objekt. Damit dieses nicht auf der Rasiermesscrklinge festklebt, hat man letztere mit Alkohol befeuchtet, ehe der Schnitt begonnen wurde. Den erhaltenen Schnitt iiberträgt man mit einem feinen, in Alkohol getauchten Haarpinsel in ein bereit gestelltes Gläschen oder Schälchen und behandelt weiter (Färben usw.). Bei einiger Übung und mäßiger Geschicklichkeit kann man von einem Objekt zahlreiche hinreichend dünne Schnitte anfertigen, die namentlich für den pathologischen Anatomen ron IVichtigkeit sind, um schnell eine Diagnose stellen zu können. Der Anfanger sei wiederholt ermahnt, diese Methode zu iiben, da sie eine gute Torschule für die Handhabung des Mikrotoms ist.

2. Einklemmen in Hollundermark. In ein Stiickchen völlig trocknen Hollundermarkes macht man ein Loch, das groß genug sein muß, um das Objekt aufzunehmen. Dieses, aus Alkohol oder einer wässrigen Fliissigkeit stammend, wird in das Loch gesteckt und mit dem Hollundermark in Wasser geworfen. Hierin quillt das Mark stark auf und hält dadurch das Objekt fest, das nunmehr bequem geschnitten werden kann. Freilich kann die durch das quellende Hollundermark bewirkte Pressung des Materials diesem nicht selten schädlich werden.

b) Aufkleben.

\section{$\S 42$.}

Ist die Ausfiihrung freihändiger Schnitte nicht erwünscht, sei es daß das Material zu wertwoll ist, um es dem ungewissen Resultate der persönlichen Geschicklichleit auszusetzen, sei es dal seine Zartheit usw. das Einklemmen direlit verbieten oder, und dies wird das Hauptmotiv sein, daß Schnitte ron größerer Feinheit erforderlich 
sind, als sie mit der freien I land angefertigt werden künnen: in allen diesen Fällen wird man zum Milkrotom greifen. Die beim Freihandschneiden das ()bjekt haltende I Iand wird beim Mikrotom durch die sogenannte I'räparatenklammer ersetzt. In diese komnt das Präparat, natiulich nicht ohne irgendwelche Schutzmaßregel, weil sonst die Klammer das P'räparat zu Mus zerquetschen wïrde. Ticlmehr wird in die Klammer selber ein Stïchelen hartes Paraffin oder ein Kork oder ein Stabilit- oder Holzblock gcklemmt und auf dieser feststehenden Unterlage das I'räparat aufgeklebt. ()der aber man steckt das l'räparat in das Dikrotom, wenn dieses, wie beim Zylindermikrotom der liall, das Objekt in sich aufnehmen kann, nachdem man es zuror mit einer Masse umhüllt hat, welche es im Mikrotomzylinder festhält. Diese Methode ist für ganz bestimmte Zwecke angegeben worden, hat aber heute wohl nur noch historischen Wert.

3. Aufkleben mit Gummi. Man taucht die Präparate flichtig in eine schr dicke Lösung ron Gummi arabicum, bringt auf den Kork oder den Stabilitblock einen Tropfen derselben Gummilösung und stellt das Präparat hinein. Natiirlich muß man es so auf seiner Unterlage zu befestigen suchen, dal3 es beim Schnciden vom Messer in der gewünschten Ebene getroffen wird. Den Klotz mit dem flüchtig gummierten Präparate bringt man in absoluten Alkohol oder in solchen ron $96^{\circ}$. Darin wird der Gummi sehr bald hart und man kann nun schneiden, wobei man die Messerklinge mit dem Härtungsalkohol befeuchten muß, weil diinnere Alkohole den Gumni lösen. Die Schnitte bringt man in Wasser, un den Gummi aufzulüsen. Nicht immer hält der Gummi fest, namentlich wenn seine Alkoholhärtung nicht gelungen. Man kann daher die Methode folgendermaßen modifizieren, und diese Modifikation ist eine entschiedene Verbesserung. Nan nimmt das Präparat aus der Härtungsflüsigkeit, bringt auf den Block; auf dem es befestigt werden soll, geschmolzene Glyzeringelatine in sehr heißem Zustande und stellt schnell das Präparat hinein, dessen Fuß tief in der Gelatine stehen muß3. Nach dem Eirkalten legt man Block und Präparat in 10\% Formollösung, worin die Gelatine nicht nur erhärtet, sondern auch völlig unlöslich wird, so daß man nachher das Messer mit einer beliebigen Flüssigkeit befeuchten kann. Wihlt man diese. Modifikation, clann darf man das Präparat nicht, wic bei der Gummilösung, in die Gelatine cintauchen. MIuß man nämlich die Schnitte färben, so färbt sich die Gelatine in sehr störender ITeise mit. In Allohol, der, wic wir noch sehen werden, das Montieren der Präparate vorbereitet, wirft sich dic Formolgelatine und ruft dadurch Terkrimmen der Schnitte hervor. 
7. Umranden mit Walrat oder Paraffin. Diese Methode. nicht durchtränktes Material zum Mikrotomschneiden herzurichten, ist besonders für die Färbungen nach Nissl (vgl, später geeignet.

Man bringt auf einen erwärmten Metallspatel oder eine erwärmte Messerklinge etwas IValrat oder Paraffin und wälzt in der alsbald geschmolzenen Masse das Präparat so, daß seine Seiten sowie die obere und untere Fläche gleichmäßig mit einer dünnen Walrat- bzw. Paraffinkruste überzogen sind. Das Präparat muß gewissermaßen kandiert sein. Dann gibt man einen Tropfen geschmolzenen Paraffins usw. auf die zu benutzende Unterlage Holzklotz, Stabilitblock, stellt das Präparat hinein und umgibt nach dem Erkalten seinen Fuß mit soviel geschmolzenem Paraffin, daß das Präparat später, wenn das Paraffin hart geworden, von dem drückenden Finger nicht ohne weiteres abgebrochen werden kann. Die Beschreibung dieser kleinen Prozedur liest sich umständlich, die Ausführung ist aber sehr einfach. Man nuß sich nur hüten, die Umrandung des Präparates zu dicls zu machen, weil dadurch die Schnitte ungleichmäßig werden, indem sich das Messer beim Übertritt aus dem harten Paraffin in das weichere Objekt wirft. Das geschmolzene Paraffin oder Walrat, in welchem das Objekt gewälzt wird, darf nicht zu heiß sein, weil sonst nach dem Erkalten die Rinde abspringt.

5. Guddensche Masse. Die Hirnpathologen befolgten frïher, und wohl teilweise auch noch jetzt, die Regel, Naterial vom Zentralnervensystem, das in Miillerscher Lösung fixiert war, nicht in Alkohol nachzuhärten. Denn diese Nachhärtung verdarb die iibliche Karminfärbung und damit die Erkennung der erkrankten Hirn- und Riickenmarkspartien. An dieser Regel muß man auch heute noch festhalten, wenn man nicht eine der neueren Methoden der Färbung anwenden, sondern beim Karmin bleiben will, das gleichzeitig Nervenfaser- und Ganglienzellfärbung ermöglicht. Die Objekte kommen direkt aus der Miillerschen Lösung in die zu beschreibende Masse, die von Gudden für sein Zylindermikrotom angegeben wurde.

Man schmilzt I 2 Teile Stearin, I 2 Teile Schweinefett und I Teil Wachs zusammen. Die Nasse wird heiß über das im Guddenschen Mikrotom sich befindende Präparat gegossen. Damit Müller- bzw. Kalium bichromicum-Präparate die Masse besser annehmen, soll man nach derVorschrift von $\mathrm{F}$ orel die Objekte vorher einige Zeit in warmes Wasser legen. Der Ėrärmungsgrad der Masse wie des Wassers richtet sich nach dem Präparate; doch lassen sich bestimmte Regeln nicht aufstellen; die Erfahrung, welche der einzelne sammelt, muß ihn hierin den richtigen histologischen Takt lehren. Von der Innen- 
fläche des Metallzylinders des Gudienschen Mikrotoms zicht sich allmählich die Unhiillungsmasse zuriick, so dals das ()bjekt beim Schneiden wackelt. Dies zu heseitigen empfichlt Forel, zwischen Metallzylinder und Präparat kleine Ifolzsplitter cinzukeilen, die allerdings auch nur palliative Hilfe bringen. Forel rät dither an, das Präparat mit der es ungebenden Einbettungsmalsse aus dem Nikrotomzylinder herauszunehmen, in diesen neue heiße Masse zu gießen oder seine Wand mit einer heiß bereiteten Mischung von Terpentin und Wachs zu bestreichen. Das Präparat wird dann in seiner I'eripherie rasch erwärmt und schnell und sorgfältig in den Zylinder cingeschoben.

\section{c) Einbetten.}

\section{$\S 43$.}

Indessen: so wertvoll die bisher geschilderten Methoden sind, sie reichen doch nicht aus, um unseren Anspriichen an cin mikroskopisches Präparat zu geniigen. Feinste, d. h. diinnste Schnitte, welche die Anwendung unserer stärksten Linsensysteme ermöglichen, können wir auf diese Weise nicht anfertigen. Die Schnitte werden nicht röllig gleichmäßig, mancher geht verloren und so sind wir der Möglichkeit beraubt, wertvolles Material in eine liichenlose Schnittserie zu zerlegen, wie das bei embryologischen Studien nötig ist. Und wenn wir den Grund für die ungenügenden Erfolge suchen, so können wir ihn nur darin finden, daß unser Naterial nicht hart genug ist, um so feine und so gleichmäßige Schnitte zu ermöglichen, wie wir wünschen. Um dieser Forderung einigermaßen gerecht zu worden, muissen wir clas Material einbetten, d. h. wir müssen es mit einer. Masse zu durchtränken versuchen, welche es so hart, bzw. so zähe zu machen vermag; daß alle Wünsche, dic wir hinsichtlich der Dünnheit der Schnitte, ihrer Gleichmäßigkeit, der grïndlichen Ausnuitzung des Naterials und seiner schonendsten Behandlung nur stellen mögen, in jeder Bezichung erfuillt werden.

Die Objekte muissen zweclis der Einbettung gut gehärtet werden und beduirfen dann noch einer weiteren Behandlung, über die später im einzelnen das Nötige zu sagen sein wird. Auf zweierlei Arten kann man die Einbettung - richtiger die Durchtränkung - vornehmen. Entweder man iiberträgt die Objekte direkt in die Durchtränkungsmassen. Dann müssen diese so beschaffen sein, daß sie sich mit Alkohol oder Wasser mischen, je nachdem man alkoholisiertes oder nicht alkoholisiertes Material untersuchen muß. () Aer aber die Durchtränkungsmassen gehen nicht in die auf gewöhnliche 
Weise (in Alkohol usw, aufbewahrten Objekte hincin. Dann müssen diese einer Prozedur unterworfen werden, durch welche eine Durchtränlung mit derartigen Substanzen herbeigefuihrt wird. Zwischen den sewöhnlichen Aufbewahrungsalkohol und die Durchtränkungsmasse treten daher die neuerdings ganz treffend so genannten Intermedien. Die Methoden, durch welche auf diese Weise dic Einbettung des Materials erzielt wird - die Paraffin- und die Celloidinmethode - geben die weitaus besten Resultate. Die Durchtränkung ohne Intermedien halte ich persönlich nach meinen früheren Erfahrungen für gänzlich überfüssig. Indessen sie wird noch immer angewandt, hier und da sogar besonders empfohlen, sodaß sie der Tollständigkeit halber in möglichster Ausfuihrlichkeit hier angefuihrt werden soll. Verbietet die technische Vorschrift, das Material mit Paraffin oder Celloidin zu durchtranken, und ist die Gefriermethode nicht angebracht, dann ziehe ich das Schneiden nach bloßem Umranden ' $(\mathbf{s}+2,4)$ dem Schneiden solchen Materials vor, das ohne Intermedien durchtränkt worden ist.

a) Ohne Intermedien.

$\S 44$.

6. Einbetten in Gummilösung, nach Klebs. Man bringt das gut fixierte Material aus Wasser - Alkohol ist zu vermeiden - in sirupdicke Lösung ron Gummi arabicum und lässt es, je nach Größe und Permeabilität, wenige Stunden bis 3 Tage und länger darin. Ist die Durchtränkung vollendet - den Zeitpunkt kann man nur durch lange Übung erschließen - , dann nimmt man das Objekt aus dem Gummi heraus und härtet es in $c 6^{\circ}$ "oder absoluten Alkohol. Das Messer wird beim Schneiden mit Alkohol von gleicher Konsistenz befeuchtet. Hat man ein Material, das z. B. eine Höhlung enthält, die mit irgendeinem Inhalte erfuillt ist, dann darf man die Schnitte aus dem Alkohol, um sie zu färben, nicht in Wasser tun, weil sonst der erwähnte Inhalt ausfallen kann. Es ist daher empfehlenswert, die Stiiclie vor der Durchtränkung mit Gummi im ganzen zu färben.

Dic von manchen I:orschern empfohlene Hinzufügung ron Glyzerin zum Gummi ist nicht ratsam, weil die Erhärtung im Alkohol dadurch verzögert wird.

7. Glyzerinleim, nach Klebs. Man bringt die crhärteten Objekte in eine dicke Leimlösung, der man je nach Bedarf und Gutdiinken Glyzerin zugesetzt hat. Die weitere Behandlung ist wie bei der Einbettung in Gummilösung. Hat man im Stuick gefärbtes Naterial mit Glyzerinleim durchtränkt, dann kann man statt in Alkohol in $10^{\circ}$ 
Formol nachhärten. Der Leim wird darin wenigstens in denjenigen Mitteln unlöslich, die der Mikroskopiler anwenden kann, ohne dås das Vaterial zerstört wird. Fomolisierte Schnitte hebt man am besten in Glyzerin auf.

8. Glyzerinleim, nach M. Heidenhain. Mim lüst $+5 \mathrm{~g}$ fuinstur Gelatine unter gelindem Erwärmen in 2 ro ccm Açulat destillitia und setzt $35 \mathrm{ccm}$ Glyzerin hinzu. Das Gemisch wird bei $=0^{\prime \prime} \mathrm{C}$. in IVirmeschrank filtriert. In das klare Filtrat kommen unter starkem Umrïhren und tropfenweisem Zusatz $70 \mathrm{ccm}$ absoluten Alliohols.

9. Glyzerinleim, nach Nicolas. Müller-Maturial, das sorgältig: in flicßenden Masser gewaschen ist, wird bei $25^{\circ} \mathrm{C}$. in eine ; , bis $5^{\circ}$. Gelatinclösung gebracht. Nach $2+$ Stunden wird in $10^{\prime \prime}$, Gelatine bei $35^{\circ}$ C. übergefuhrt, nach weiteren 24 Stunden in $20^{\circ}-25^{\circ}$. Gelatine bei der gleichen Temperatur und nun dieser Gelatine is". his $10^{\circ}$.Glyzerin zugesetzt. Nach 2-3 Tagen werden die Präparate mit der Gelatine in Papicrkapseln ausgegossen. Ist Erstarrung cingetreten, dann wird in eine Formollösung ( 1 : 7 Teilen ITasser) eingebracht. Die Härtung hierin erfolgt sehr gleichmäßig, die Schnittfähigkeit ist gut und die Aufhebung infolge dor Unlüslichkeit der Gelatine gleichgiiltig. Da die Gelatine sich beim Schnittfärben mitfärbt, so ist dies, namentlich wegen ihrer Ĺnlüslichlicit, ein großer Nachteil. Die Schnitte werfen sich im Alkohol, daher am besten Einschluß in Glyzérin.

10. Eiweiß und Talg, nach Bunge. $2+\mathrm{ccm}$ frisches Hühncreiweiß, aus welchem die Chalazen entfernt sind, werden mit $2^{\mathrm{T}}=\mathrm{ccm}$ einer IO" Sodalösung in weitem Reagensglase stark geschüttelt. Dahinein bringt man $9 \mathrm{ccm}$ geschmolzenen Talg. Das ()bjekt kommt in ein Papierkästchen, wird mit dem Gemenge übergossen und in absoluten Alkohol iibergefuihrt. Vatülich dürfen nur wässrige, nicht alkoholisierte Objekte verwendet werden, weil der Alkohol das Eiweiß gerinnen macht.

I . Eiweißeinbettung, nach Calberla. Die Eiwcißlösung wirl wie bei der vorigen Nethode mit Soda zubereitet: das Verhältnis zur Sodalösung ist folgendes: I 5 Teile Eiweiß werden mit I Teil Io". Sodalösung geschiittelt. Dann fuigt man den zugehürigen Dotter hinzu, schiittelt intensiv und gießt das Gemisch in ein Becherglas. Nach dem Absetzen, das nur ganz kurze Zeit dauert, entfernt man am besten mit etwas Papicr den auf der Oberfläche stehenden Schaum. Man kann auch, nach Thoma, den Eiinhalt im Mïrser stampfen und dann durch ein Tuch filtrieren. Das Filtrat wird mit Soda geschiittelt. In diese Eiweislösung kommen die vollkommen wasserhaltigen Prï- 
parate: cs muß aus ihnen jede Spur von Alkohol und auch jede Spur Süure entfernt sein, weil sonst das Eiweiß vorzeitig gerinnt. Man gießt das Eiweiß in ein Papierkästchen - die Herstellung cines solchen wird beim Paraffin beschrieben werden -, giht das Präparat $z u$, orientiert es, so daß es beim Schneiden die richtige Lage zum Messer hat, und wartet seine Durchtränkung ab. Hicrzu sind oft mehrere Tage erforderlich. Ist die Durchtränkung anscheinend beendet, dann bringt man das Eiweiß durch die Dämpfe erhitzten Alkohols zur vorläufigen Gerinnung, was keine sehr angenehme Prozedur ist, und erhärtet in absolutem Alkohol. Die Schnitte, welche mit dem durch Alkohol befeuchteten IIesser ausgeführt werden, kommen in Glyzerin. Eine Methode von einer Umständlichkeit Anfertigen der Eiwcißlösung, vorläufige Ėrhärtung -, die sie sicher wenig praktikabel erscheinen läßt. Man muß die Objekte vorher durchgefärbt haben, denn Schnittärbung ist darum vollständig ausgeschlossen, weil das eingedrungene Eiweiß im Präparat sich mitfärben und dadurch zu größten Irrtimern Veranlassung geben muißte.

12. Transparentseife, nach Flemming. Man muß die im Handel befindliche Transparent- oder Glyzerinseife in schwachem Alkohol warm lösen, und zwar in einem Verhältnisse, daß beim Eintrocknen die Durchsichtigkeit erhalten bleibt. Eine Angabe, die durch die Bemerkung von Frey, daß man die Seife in ${ }^{2} /{ }_{3}-{ }^{x} / 2$ ihres Volumens Weingeist löst, weder genauer noch klarer wird.) Das fixierte Material wird wasserfrei gemacht, nit Glyzerin durchtränlt und dann in die Seifenmasse gegeben, welche auf dem Wasserbade erwärmt wird. Darin bleibt das Material einige Minuten bis I Stunde, dann läßt man alles erkalten. Das hartgewordene Stiick Seife, welches das Objelit enthält, wird dann zum Schneiden hergerichtet - man kann es direkt in der Nikrotomklammer festmachen - und mit trocknem Messer geschnitten. Die Schnitte fängt man in destilliertem Wasser auf, wodurch die Seife aufgelöst wird.

\section{ß) Mit Intermedien.}

\section{$\$ 45$.}

Die Wiederaufnahme der Einbettung ohne Intermedien halte ich für einen entschiedenen Rüickschritt. Die Schnitte werden nur wenig gut, die Durchtriinliung ist niemals gleichmäßig und die Ausnutzung des Materials claher keine ausgiebige. Die beiden Methoden dagegen, welche Intermedien verlangen, leisten in jeder Beziehung allen Ansprïchen Geniige und die Manipulation mit den Intermedien ist so einfach und so leicht ausfiihrbar, daß nur wenig Geschicklichkeit dazu 
gehört, mit beiden '. Icthoden das Material gut cinzubetten. Ist letzteres nur gut fixiert und erhärtet, wird es weiterhin beim Schneiden und Färben richtig behandelt, dam liefurn P'araffin- und Celloidineinbettung stets gute Resultate: Ich Irenigstens bin der Mcinung, daß schr große Ungeschiclilichkeit oder zum mindesten sehr großc Unachtsimkeit notwendige ist, um gut vorbehandeltes Naterial bei der Einbettung in Paraffn oder Celloidin zu verderben. Diese fast absolute Sicherheit, welche dic beiden Methoden hinsichtlich der gewiinschten Resultate gewähren, hat ihnen ihre weite Verbrcitung und ihren Sieg ïber alle anderen Linbettungsmethoden verschafit. Dic l'araffinmethode gewïhrt die Möglichkeit, mit trocknem Messer zu schneiden, die Celloidinmethode verlangt ein feuchtes Messer.

13. Paraffinmethode. Die harte Masse des Paraffins muß scschmolzen werden, wenn das Material mit dieser Substanz durchtränkt werden soll; sie mischt sich aber nicht mit gewöhnlichen Alkoholpräparaten oder gar mit wässrigen Präparaten. Man muß also den Alkohol durch eine Substanz aus dem Präparat zu vertreiben suchen, welche mit Paraffin sich mischt und muß dieses Intermedium dann durch das Paraffin selber verdrängen. Dazu verfährt man in folgender Weise:

In wässriger Flüssigkeit aufhewahrtes Naterial muß sorgfältig in Alkohol nachgehärtet werden und kommt dann, wie auch das in $90^{\circ}$ 。 oder $96^{\circ}$. Alkohol aufbewahrte Präparat, in absoluten Alkohol. Hicrin muß auch das zarteste Objekt einige Stunden bleiben, weniger zarte, voluminöse Organe sind mindestens $\mathrm{I}-3$ Tage im absoluten Alkohol zu entwässern, der event. täglich gewechselt werden muß. Vielfach wird davor gewarnt, den Aufenthalt in Alkohol zu lange auszudehnen. In einem später zu erwähnenden Falle mag eine solche Warnung vielleicht am Platze sein; für gewöhnlich aber kann ich von einer grüdlichen Entwässerung keinen Nachteil verspüren. Dagegen halte ich die jetzt von verschiedenen Seiten empfohlenen Methoden zur Schnelleinschmelzung für verfehit; denn alle Manipulationen werden nur fluichtig gemacht und dadurch, um eines ganz geringen Zeitgewinnes wegen, oft kostbares Material aufs Spiel gesetzt. Solche Eile - ich wiederhole, was ich schon friher einmal gesagt habe - hat das wissenschaftliche Arbeiten nicht, ein industrielles Uberhasten ist durchaus verkehrt. Wer keine Zeit hat, um gewissenhaft alle einzelnen Handgriffe mit der gebiihrenden Genauigkeit auszufuhiren, der soll die Histologie in Ruhe lassen. Die angegebenen Schnelleinbettungsmethoden erwähne ich nicht. Ich habe bisher manche Nethode anführen müssen, obgleich ich sie für nicht gut, ja oft für schlecht halte. 
weil vielleicht doch der oder jener Forscher mit ihr was anfangen kann oder durch sic zu neuen und guten Methoden zu gelangen vermag, und weil der Anfünger auch manche Fehlgriffe im Arbeiten kennen lernen soll. Die Schnelleinbettungsmethoden halte ich für direkt filsch, und Falsches braucht in ein Lehrbuch nicht aufgenommen zu werden.

Die Präparate müssen also in absolutem Alkohol entwässert werden. Man stellt sich diesen am besten selber dar. $\mathrm{Zu}$ dem Zwecke erhitzt man in einem Metalltiegel über der offenen Flamme Kupfersulfat so lange, bis es cin röllig weißes Pulver bildet. Dieses bringt man auf den Boden der für den absoluten Alkohol differenzierten Flasche und gießt gewöhnlichen $90^{\circ}$. Alkohol darauf. Bei dem Einfüllen des gegliihten Kupfersulfats ist Torsicht anzuraten, damit man den feinen Staub nicht in die Nase bekommt; sonst hat man mindestens einen Tag einen elelhaften Kupferschnupfen. Das geglühte Kupfersulfat nun saugt gierig Wasser an, wird dadurch leicht grünlich, macht aber den $6^{\circ}$.Alkohol wasserfrei. Man braucht nach meinen Erfahrungen das Kupfersulfat erst dann zu erneuern, oder das alte, wenn es trocken geworden ist, erst dann von frischem zu glïhen, wenn die grünliche Fürbung einer bläulichen Platz macht. Zum Gebrauche gieß3t man cinen aliquoten Teil Alkohol durch ein doppeltes Faltenfilter, damit auch nicht die geringste Spur von Kupfersulfat mit dem Präparat in Beriihrung kommt. Denn dadurch kann dieses leicht gebläut werden, was auf die Färbung usw. unter L'mständen nachteilig wirkt. Viele Histologen wickeln das gegliihte Kupfersulfat in Filtrierpapier ein, um es hübsch sorgsam in der Flasche zusammen zu halten. Ich verfahre gerade entgegengesetzt; ich schuittle, namentlich wenn ich verbrauchten Alkohol durch Nachfiillen ersetze, stets stark um, damit der Alkohol in ausgedehntesten Kontalit mit dem Kupfersulfat kommen kann.

Für manche zarten Objekte ist der Transport aus dem einen Gefïß in ein anderes, um den Alkohol zu wechseln, oder das Weggießen der einen Konzentration und Aufgießen der neuen und stïrkeren nicht gerade ron Vorteil. Hier kann mit rroßem Erfolg ein kleiner Apparat angewendet werden, den F. E. Schulze konstruicrt und Dialysator genannt hat. Dicser Entwässerungsapparat besteht aus eincr weithalsigen Flasche und zwei an beiden Enden weit offenen, ineinander und in die Flasche $z u$ steckenden trichterförmigen Einsätzen. Bcicle Einsätze, von denen der weitere in den Flaschenhals gesteckt wird, werden an ihrer Unterfläche mit einem Stuickchen Seidenpapier rerschlossen. Letzteres geschieht so, daß man den Rand des Trichters mit Eiweißlösung bestreicht, das Stückchen Papier 
fest auflriekt und nun im Wirmeschrank bei $60^{\circ}-62^{\circ} \mathrm{C}$. das Fiweils zur Gerinnung bringt. In die grolse Flasche kommt geoliihtes Kupfersulfat und 96" Alkohol, in den weiten Einsitz 90". Alkohol und in den engen Einsatz, weleher in den weiten gesteclit wird, das Präparat mit scinem Aufbewahrungsalkohol. Der zweite Einsatz wird oben zugedeckt, damit leein Alkohol verdunstet. Nunmelur beginnen durch das Seidenpapicr dic I)iffusionsströmungen, als deren Resultat nach -4 Stunden dic Tatsache erscheint, daß in ken beiden Einsiitzen chenso wie in der Flasche absoluter Alkohol ist. I)enn die Terwässerung, welche ron dem dïnneren Aufbewahrungsalkohol ausgeht, wird durch das gegliihte Kupfersulfat sofort wieder wett gemacht. Eine von Kolster vorgenommene Teränderung des eben heschricbenen Instrumentes halte ich für keine Verbesserung.

Das Präparat ist nunmehr im absoluten Alkohol völlig wasserfrei gemacht worden. Da aber Alkohol und Paraffin sich nicht mischen, dieses wenigstens jenen im Präparate nicht ersetzen oder verdrängen kann, so müssen andere Reagentien herbei geholt werden, welche den Alkohol austreiben. Als die Paraffinmethode aufkam, wurde fur diesen Zweck das

a) Terpentinöl benutzt. Ist das Präparat wirklich völlig wasserfrei, so dringt das Terpentinöl ziemlich schnell cin. Die röllige Durchdringung crkennt man daran, daß das Präparat ganz durchsichtig ist. Jetzt bringt man Paraffin in das Terpentinöl, so daß allmühlich eine sehr diclie Lösung entsteht, stellt das Gefäl3 mit dem Präparat auf die Decke eines Wärmeschrankes, damit alles schmilat, und führt nach 27 Stunden in reines geschmolzenes Paraffin über. Hierin bleiht das Präparat je nach seiner Konsistenz rerschieden lange; die allgemein giltigen Regeln sollen etwas später gegeben werden. Die Terpentinuilmethode ist antiquiert, und das mit Recht. Das Paraffin wird durch das Öl schmicrig und schneidet sich daher nicht gut, das Material wird - und das ist ein noch größerer Nachteil - brüchig.

b) Xylol. Trotz der großen Beliebtheit, welcher sich dieses Reagens als Intermedium crfreut, kann ich ron sciner Verwendung nur abraten. Es hat dieselben Nachteile wie Terpentinöl, wenn auch nicht in so hohem Grade, und steht den meisten der noch zu nennenden Intermedien entschieden nach. Nur die Bequemlichleit seiner Anwendung kann seinc mir sonst unverständliche Belicbtheit erklären. Die Objekte müssen sehr gut entwässert sein, sonst treten in Xỵlol Trübungen auf. Aus dem absoluten Alkohol werden sie zunächst in eine Mischung ron Alkohol und Xylol (etwa zu gleichen Teilen! gcbracht, ron da, je nach ihrer Permeabilitiit, nach $2+$ Stunden oder 
nach kürzerer oder längerer Zeit in reines Xylol. Dann, wenn die Präparate gut durchsichtig geworden sind, bringt man sie in ein Näpfchen mit Xylol, dem man viel geschabtes Paraffin beigemengt hat und zwar von solchem Paraffin, das denselben Schmelzpunkt hat wic das nachher zu nehmende reine Paraffin. Dieses Xylolparaffin mit Präparat kommt in offener Schale auf die Decke des Wärmeschrankes, hleibt dort iiber Nacht stehen, dann wird das Präparat in geschmolzenes reines Paraffin getan, aus dem es nach etwa 2 Stunden zur definitiven Einschmelzung gelangt. Hicriber das Nähere beim Chloroform. Statt des absoluten Alkohols ist zur Entwässerung neuerdings Aceton empfohlen worden.

c) Zedernöl. Das zum Eintauchen der homogenen Immersionen benutzte Zedernöl (Oleum ligni cedri) ist von Lee als Intermedium aufs wärmste empfohlen worden. Dieser Forscher rühmt dem Reagens nach, daß es rasch eindringe, selbst die zartesten Gewebe schone, nicmals die Objekte briichig mache und das Paraffin nicht verschmierc. Auch macht das Zedernöl die Objekte durchsichtig. Letzteres Moment hat Apáthy benutzt, um cine gleich zu erwähnende Modifikation oder besser eine Kombination mit der Chloroformmethode zu crzielen. Ich sclber habe das Zedemöl nie als Intermedium benutzt, offen gestanden deshall, nicht, weil ich gegen das Arbeiten mit diesen schmierigen Ölen eine geradezu physische Abncigung hahe. A páthy macht folgende Kombination: Er durchtränkt die Objekte dirckt aus dem absoluten Alkohol mit Zedernöl. W' Wenn sie völlig durchsichtig geworden sind, mißt und zeichnet or sie und bringt sie dann in ein Gemisch von Chloroform und Paraffin, das er sich durch kalte Sättigung des Chloroforms mit einem Paraffin von $55^{\circ} \mathrm{C}$. Schmelzpunkt hergestellt hat. Dies Gemisch wird auf $60^{\circ}$ C. I bis 3 Stunden lang erwärmt und dann das Objekt in reines Paraffin von gleichem Schmelzpunlite für mehrere Stunden übertragen.

d) Bergamottöl. Dieses zum Aufhellen der Schnitte sehr gecigncte $O 1$ wird als Intermedium von verschiedenen Autoren in folgender Veise benutzt: Entweder man bringt dic Objekte direkt aus $96^{\circ}$. Alkohol in das (O), das auch wasserhaltiges Material durchtränlt, oder man mischt es zunächst mit Alkohol, indem man successive den Alkohclgehalt vermindert und den Ölgehalt vermehrt. Also zuerst 9 Alkohol: I Öl his schließlich I Alkohol: 9 Öl. Dann wird in reines Öl iibergefuhrt und etwa wie nach Zedernöl- oder Xylolbehandlung weiter verfahren.

e) Benzol. Von Bra $B$ als Intermedium empfohlen wird es nach P. Nayer in folgender Wreisc angewandt. Die Ohjekte kommen 
aus dem absoluten Alkohol in das Benzol, am besten wohl durch das später beim Chloroform genauer zu beschreibende Senkverfahren. Das reine Benzol wird ein- bis zwcimal gewcehselt, dann gibt man etwas l'araffin ron hohem Schmelzpunlite $158^{\prime \prime}-60^{\circ} \mathrm{C}$. hinzu, das man bei Zimmertemperatur sich lüsen läß3t. Nach etwat I5 Stunden wird die Benzol-Paraffinschale nit dem (objckt offen in den zunächst kalten IVärmeschrank gestellt. Diesen heizt man allmählich an, so daß er in etwa 2 Stunden eine Innentempcratur von $60^{\prime \prime}$ C. annimmt. Das Benzol verdampft dahei und dementsprechend fügt man geschmolzenes Paraffin zu. Ist das Benzol ausgetrieben, dann wird in ganz reines Paraffin übertragen und in spoiter heim Chloroform näher zu heschreibender IVeise eingeschmolzen.

f Schwefelkohlenstoff, von M. Heidenhain. Die Torschrift zur Verwendung dieses eminent feuergefährlichen Reagens lautet folgendermaßen: Man hält sich 3 Pillengläser mit sehr gut schließenden Glasstopfen vorrätig. In das erste bringt man Schwefelkohlenstoff und Alkohol zu gleichen Teilen, in das zweite und dritte reinen Schwefelkohlenstoff, der also einmal zu wechseln ist. Zur Einbettung bedarf man zweier Wärmeschränke (Thermostaten), von denen der eine auf $36^{\circ}-38^{\circ} \mathrm{C}$, der andere auf $56^{\circ}-57^{\circ} \mathrm{C}$. erwärmt wird. In zwei Pillengläser mit sehr gut schließenden Glasstopfen bringt man ${ }_{15}{ }^{1}{ }_{4}+$ ihres Rauminhaltes Schwefelkohlenstoff und tut soviel Paraffin vom Schmelzpunkt $55^{\circ} \mathrm{C}$. $\mathrm{zu}$, wie sich nur lösen will. Jedes Glas kommt auf einen Thermostaten. Aus dem reinen Schwefelkohlenstoff, in welchen die Objekte aus dem Glase, das das Reagens in Nischung mit Alkohol enthält, gebracht werden, liommen diese zunächst in das Glas, welches auf dem Thermostaten mit der niedrigen Temperatur steht, und dann in das stärker erwärmte. Aus letzterem werden sie in reines Paraffin gebracht, das nach $\mathrm{I}^{\mathrm{I}}$ a Stunden gewechselt werden muß. In diesem zweiten reinen Paraffin bleiben die Objekte ebenfalls $\mathrm{I}^{\mathrm{x}}{ }_{2}$ Stunden. Un den widerlichen Geruch zu vermeiden, den der Schwefelkohlenstoff rerbreitet, darf man die betreffenden Gefäße nicht schiitteln; ebenso müssen die l'räparate sehr vorsichtig eingelegt werden.

g) Chloroform. Unbedingt zuverlässig in seiner Wirkung als Intermedium, indem es bei richtiger Anwendung sowohl die voluminösesten als auch die zartesten Objekte sehr gleichmäligig und schonend durchtränkt, ist das (hloroform, das Giesbrecht zucrst empfohlen hat. Die nachherige Durchtränkung mittels Paraffin. also die Verdrängung des Chloroforms, ist ebenfalls eine sehr schonende, das Paraffin wird nicht schmierig, das Objekt nicht brüchig. Allgemein 
wird wohl ron denjenigen Forschern, welche Chloroform als Intermedium benutzen, die folgende Methode bevorzugt. Das in reichlicher Menge absoluten Alkohols sehr gut entwässerte Objekt siouren ron IVasser in letzterem geben Trübungen im Chloroform - kommt in ein hohes, gut verschließbares Gefäß, welches soviel absoluten Alkohol enthält, daß das Objekt ron ihm gerade noch bedeckt wird. Nun bringt man mit einer Pipette Chloroform auf den Boden des Gefäßes: das Chloroform bleibt infolge seiner Schwcre unten und hebt Präparat und Alkohol in die Höhe. Nan gibt soviel Chloroform zu, daß von ihm ein Vielfaches des Volumens des Präparates vorhanden ist. Nun beginnen an der Grenze ron Alkohol und Chloroform, da wo das Praparat letzterem aufliegt, Diffusionsströmungen, infolge deren allmählich das Präparat in das Chloroform einsinkt. Dieses nämlich vertreilut einen großen Teil des Alkohols aus den Geweben. Wieriel Zeit zu diesem Vorgange erforderlich, läßt sich natülich nicht präzis angeben; das hängt von der Konsistenz des Objektes und wohl auch ron der Temperatur der Umgebung ab. In der Wärme sollen nach verschiedenen Angaben alle Intermedien schneller eindringen.

Dies ist das von F. E. Schulze für andere Zwecke konstruierte Senkverfahren. Wenn das Präparat untergesunken ist - bei nur einigermaßen voluminösen Objekten tut man gut, bis zum nächsten Tage zu warten -, dann gießt man rasch das Alkohol-ChloroformGemisch ab und gibt reines Chloroform in großer Quantität zu. In diescm letzteren findet erst die völlige Verdrängung des Alkohols statt, darum muß man es ein- bis zweimal und öfter erneuern, je nach der Zeit. welche die ()bjekte im Chloroform bleiben sollen. Für zarteste Ohjekte genügen einige Stunden; aber auch längeres Verweilen bis zul $2+$ Stunden schadet nicht das geringste. Voluminöse Objekte lasse ich bis zu acht, ja bis zu I+ Tagen in reinem Chloroform und habe davon niemals einen Nachteil bemerkt, vorausgesetzt natülich, daß sie gut fixiert und gut erhärtet waren.

Die allermeisten Objekte schwimmen im Chloroform, d. h. sie halten sich dicht unter der ()berfläche ohne diese zu überragen. Usmiumgemische, welche zur Fixierung verwendet waren, bewirken nach meinen Erfahrungen stets ein Zubodensinken des Materials. Um dies Schwimmen zu verhiiten, sind einige Torschriften angegeben worden, welche ich aher nicht anführen will, denn sic sind unnötig und verleiten gelegentlich zu falschen Anschauungen. Sic sind unnötig, denn das Schwimmen schadet dem Naterial nicht im geringsten, weil dieses, wenn man es lange genug in Alkohol-Chloroform gelassen 
hat, nicmals iiber dis Nircau des Chloroforms hinausreicht. Von einer Vertrockmung der Oberfliche des I'riparates, dic manche Autoren befürchtet haben, kann nach meinen Erfahrungen nic dic Rede sein. Untersinkendes Material liann aluer auch gelegentlich zu falschen Anschaumgen führen. Hat man namlich knochunhaltige ()hjekte, so sinlien diese im Chloroform unter, sobald sic nicht vollstindig entkalkt sind, wihrend sie sich schwimmend crhalten, wenn dic Entkalkung einc vollkommene ist. Dadurch wird man vor Schaden bewahrt. I)enn nicht viollig entkalkte Organe schmelzen sich schlecht ein und bei ihrem Schneiden wird das Messer ruinicrt. Bewint man nun auf kinnstlichem Wege das völlige Zubodensinken des Materials. dann beraubt man sich des eben genannten Kriteriums, hommt zu falschen Anschauungen über die Beschaffenheit des Materials und kann dieses durch das Einschmelzen verderben.

Nachdem das Chloroform in dis ganze Objelt eingedrungen ist, wird in Paraffin eingeschmolzen. Zunachst schaht man sich Paraffin zurecht, das denselben Schmelzpunkt hat wie das definitive Einschlußparaffin, und tut es in grolser Menge in ein Schälchen mit Chloroform, in das man das Objekt gebracht hat. Letzteres muß stets darauf ist mit Sorgfalt zu achten - vom Paraffin uiberdeckt sein, darf nicht auf diesem liegen, weil es sonst tatsächlich eintrocknen kann. Dieses Chloroformparaffin läßt man zunächst einige Stunden bei Zimmertemperatur unzugedeckt stehen, um es clann cbenfalls unzugedeckt in den Thermostaten oder auf das Neapler Wasserbad zu bringen, die auf $62^{\circ}-65^{\circ} \mathrm{C}$, erwärmt sind. Gleichzeitig stellt man eine zugedeckte andere Schale nit reinem Paraffin ron $56^{\prime \prime}-58^{\circ} \mathrm{C}$. Schmelzpunkt mit in den Thermostaten. Vicl Wert wird von mancher Seite auf dic Zeitdauer gelegt, welche das Prajarat mit lem (hloroformparaffin im ()fen bleiben soll. Sehr zarte Objekte sollen durch zu langes und zu starkes Erwärmen schrumpfen. In solchen Fällen wird empfohlen, das Chloroformparaffin auf den ()fen und nicht in ihn zu stellen, cimit so zwar sehr langsam aber doch nicht minder sicher als in der hiheren Temperatur dus Chloroform veriunstet. Für embryologische ()bjekte mas cine derartige Vorsicht am Platze sein, für rein histologische halte ich sie für ganz uiberflissig selbst bei Zcllstudien. Ich wenigstens bringe scit vielen Jahren alles Material in Chloroformparaffin für etwa $2+$ Stunden in den Thermostaten. der auf $62^{\prime \prime}-65^{\circ} \mathrm{C}$. angewarmt ist. Nach dicser \%eit ist sicherlich alles Chloroform verdunstet. Dann gehe ich das Material noch auf ": bis 2 Stunden in die Schale mit reinem Paraffin. Niemals habe ich bei guter Vorbehandlung un? namentlich bei genugent grandicher 
Chloroformierung der Objekte damit Mißerfolge nach der Richtung hin gehabt, daß Schrumpfungen im Material oder irgendwelche anderen unerwïnschten Artefakte aufgetreten sind. Immer habe ich ein durchaus gleichmäßig durchtränktes Präparat zum Schneiden erhalten. Da jeder nur nach seiner eigenen Erfahrung in diesen Dingen urteilen kann, so kann ich nur sagen: ich finde für die Bedenken anderer, die namentlich das lange Erwärmen des Chloroformparaffins für ungünstig halten, in meinen Erfahrungen keinen Grund. Wohl aher hat meine Art und Weise der Paraffindurchtränkung den Vorteil. daß alles Chloroform aus dem Naterial entfernt wird; und dies ist fur die Anfertigung guter Schnitte von großer Wichtigkeit.

Für bestimmte Zwecke sind von beachtenswerter Seite Änderungen des vorhin geschilderten Verfahrens empfohlen worden, die hier eine Erwähnung finden müssen. Für embryologisches Material empfiehlt Rabl folgende Art der Paraffindurchtränkung: Die Objekte kommen aus absolutem Alkohol ganz langsam und allmählich in Chloroform oder Bergamottöl. Chloroformparaffin dürfen sie nicht passieren, sondern sie werden aus dem Intermedium in ein Paraffin von $45^{\circ} \mathrm{C}$. Schmelzpunkt gebracht, in dem sie sich durchtränken müssen. Ist das geschehen, dann legt man sie für höchstens ${ }^{\prime}$ = Stunde in ein Parafin von $56^{\circ \prime} \mathrm{C}$. Schmelzpunkt. Dieses hat man vorher auf dem auf $80^{\circ}-90^{\circ} \mathrm{C}$. erhitzten Wasserbade geschmolzen.

Retterer warnt davor, Gebilde, welche dichtes Bindegewebe enthaiten, zu lange in Alkohol zu lassen und für sie zu heißes Paraffin zu nehmen. Er schlägt für derartige Objekte folgendes Verfahren ror: I Stunde in 90". Alkohol. " Stunde in absoluten Alkohol, 20 Minuten Xylol, 30 Minuten Paraffin von 36" C. Schmelzpunkt. Damn bringt man sie in ein Probierröhrchen, das mit dem gleichen geschmolzenen Paraffin erfïllt ist und in welchem man mit der Wassersaugpumpe einen luftverdiinnten Raum herstellt. Darin bleiben die Objekte 15-20 Minuten und kommen zum Schluß in ein Parafin ron $5 t^{\circ}$ C. Schmelzpunkt für Io Minuten. Über den Wert dieser Methode habe ich keine eigenen Erfahrungen.

Wiederholt schon ist Paraffin von $56^{\circ}-58^{\circ} \mathrm{C}$. Schmelzpunkt erwähnt worden. Tatsächlich ist für das Gelingen der mikroskopischen Arbeiten ron großer Wichtigkeit, was für eine Sorte Paraffin man zum Einschmelzen wähit. Paraftine, deren Schmelzpunkt bei $50^{\circ}$ C. und darunter liegt, sind sehr fett und schmierig. Die Schnitte von Naterial, das mit solchem Paraffin durchtränkt wurde, kleben am Messer und reißen daher leicht ein. Man muß3 auch da, wo man nach der Vorschrift mit niedrig schmelzendem Paraffin beginnt, immer 
bis zu Paraffin mit hohem Schmelzpunkte fortschreiten. Die communis Opinio geht wohl dahin, Paraffin mit $56^{\prime \prime}$ bis $58^{\circ} \mathrm{C}$. Schmelzpunkt zu wählen, weil sehr dünne und hinreichend dicke Schnitte sich damit herstellen lassen und weil das Material trocken und reinlich ist. Um dieses Paraffin geschmolzen zu erhalten, muß man den Wärmeschrank auf $62^{\circ}-65^{\circ} \mathrm{C}$. angeheizt haben. Denn hätte dieser nur die Temperatur des Paraffinschmelzpunktes, dann wirde bei der geringsten Abkiihlung; z. B. bei der zum L'mlegen des Objektes aus Chloroformparaffin in das reine Paraffin nötigen (j)ffnung der Schranktiire, das reine Paraffin sofort gerinnen. Dadurch aber müßste das Material geschiidigt werden. Dic relativ hohe Temperatur von $62^{\prime \prime} \mathrm{C}$. ist fuir gut fixicrtes und gehärtetes und für gut chloroformicrtes Material bedeutungslos. Tritt im Thermostaten Schrumpfung ein, so war die Vorbehandlung des Materials eine unzureichende gewesen.

Ist die Durchtränkung vollendet, dann muß noch eingeschmolzen werden. Man gießt dazu das heiße Paraffin in einen Behälter, fügt das Präparat zu und kühlt ab.

Bei zartem Material, bei sehr kleinen Objekten Seeigeleier usw. nimmt man am besten eine Uhrschale. Diese bestreicht man auf ihrer Innenfläche ganz leicht mit etwas Glyzerin, so daß das Glas eben nur einen Anflug ron Feuchtigkeit erhalten hat. Darauf bringt man die Schale auf ein geheiztes Wasserbad, gießt geschmolzenes Parafin in sie und muß dafür sorgen, daß letzteres flüssig bleibt. Dann hebt man mit heißem Metallspatel das Präparat aus der Schale reinen Paraffins und bringt es in die L'hrschale. Diese nimmt man rom Wrasserbade herunter und stellt sie in ein flaches Glasgefäß oder in eine Waschschüssel, in welche man soviel kaltes Wasser gießt, daß dieses nicht ganz bis an den Rand der Uhrschale reicht. Jetzt kiihlt sich das Paraffin schnell ab, was man daran erkennt, daß es undurchsichtig wird. Hat sich auf seiner Oberfläche eine Haut gebildet, dann gießt man von neuem vorsichtig kaltes Wasser in die IVaschschüssel und gibt acht darauf, daß das Uhrglas allmählich rom Wasser röllig überdeckt ist. Stürmisches Eingießen ist zu vermeiden, damit die duinne Paraffinhaut nicht reißt und das einströmende Wasser das Paraffin nicht aus der Schale treibt. Im kalten IVasser bleibt die Uhrschale, bis das Paraffin hart ist, wovon man sich durch Eindrickien mit einem Finger überzeugen kann. Hartes Paraffin widersteht dem Druck. Solche eingeschmolzene Objekte kann man jahrelang aufheben, wenn man sie von der Schale loslöst. Letzteres ist auch nötig, um das Material schneiden zu können. $\mathrm{Zu}$ dem Zwecke kann man entweder die Uhrschale zerbrechen oder man erwärmt sie vorsichtig 
und leicht iiber der Spiritusflamme; nach liurzer 'Zeit kann man den Paraffinblock von seiner Unterlage entfernen.

Für geröhnlich reicht aber diese Methode nicht aus, weil die Uhrschalen nicht tief genug sind, um andere wie kleinste und zarteste Objekte aufzunchmen. Man stelit sich dazu andere Behälter her, indem man Metallwinkel oder, nach F. E. Schulze, Glaswinkel anwendet. Nan setzt sie auf eine Spiegelglas- oder eine dünne Zinnplatte, die mit ctwas Glyzerin befeuchtet sind. Die IVinkel wgl. Fig. 9) verschiebt man so gegeneinander, daß in dem von ihnen eingeschlossenen Raum die Objekte genügend

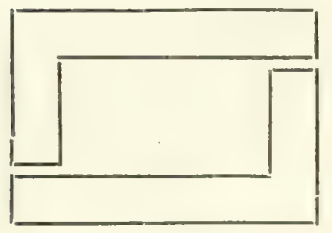

Fig. 9. Platz haben. Winkel und Platten müssen natürlich die Wärme des Paraffinofens haben, damit das ausgegossene Paraffin geschmolzen bleibt. Zur Abkühlung wird genau so verfahren, wie bei dem gleich zu schildernden Papierkästchen. Die Winkel schließen nicht immer völlig dicht, sodaß häufig genug das Paraffin ausfließt.

Sicherer und darum praktischer, außerdem auch billiger sind die Papierkästchen. Man kann sie sich aus Karton oder aus gewöhnlichem Schreibpapier zum jedesmaligen Gebrauch in folgender IVeise herstellen: Man nimmt ein Stïck Schreibpapier, das die Gestalt eines Rechtecks hat und genuigend groß sein muß, um das einzubettende Material nachher aufnehmen zu können. An diesem Rechteck linifft man die beiden Langseiten je etwa I $\mathrm{cm}$ um, klappt sie zurück und knifft nun die beiden Kurzseiten je etwa $2 \mathrm{~cm}$ um. So entsteht ein zentrales rechteckiges Feld, das den Boden des Kästchens bilden wird. Nunmehr legt man die eine Langseite um und biegt die beiden Ecken nach hinten zurück, so daß sie den Kniff der Kurzseiten decken; ebenso verfährt man mit der anderen Langseite. Richtet man die Kurzseiten nunmehr nacheinander in ihren Kniffen hoch, so kann man die infolge der sich ebenfalls aufrichtenden Langseiten entstehenden Papierohren nach hinten umlegen und sie durch Umbiegen des überstehenden Teiles der Kurzseiten festhalten. So ist das Kästchen fertig. Nach der Schilderung, die sehr umständlich sein muß, wenn sie deutlich sein soll, urscheint die kleine Verrichtung schwierig. Indessen wird sich jeder nach zwei, drei Versuchen vom Gegenteil überzeugen und wird bald Papierkästchen von heliebiger Größe herstellen können. Die oben angegebenen Maße sind naturlich nur des Beispiels wegen genommen; man kann die Kästchen so groß machen. wie man will. 
Um num einzuschmelzen, legt man eine Zimnplatte auf einen in jelem Laboratorium vorhandenen eisernen Dreifur und heizt irn unten mit einer Spirituslimpe an. Auf die Platte bringt man etwas Paraffin und stellt, wenn dieses geschmolzen ist und sich glcichmälig ausgebreitet hat, das l'apierkïstchen darauf. I)essen Boden durchtrankt sich mit dem Paraffin und das Kastchen haftet nach iem Erkalten fest an seiner Unterlige. In den Raum de's Kastchens wird das geschmolzene reine I'araffin gegossen, wobci man dafür zu sorgen hat, daß die Platte heiß ist, damit das Paraffin nicht gerinnt. I)ann hebt man mit einem heißen Metallspatel das ()bjekt hinein und oricntiert es mit erwärnter Nadel. D. h. man legt es so, daß es die fuir die auszufihrenden Schnitte geeignete Lage hat. Das ist uberaus wichtig bei embryologischen Untersuchungen, sollte aber auch an anderem Materia! nie vernachliissigt werden und ist unbedingt auszuftihren, wenn man ron cinem Organ Quer- oder Längsschnitte anfertigen will. Nach beendeter ()rientierung hebt man die heiße Zinnplatte mit dem Kästchen mittels ciner oder zweier Tiegelzangen von dem Dreifuß herunter und bringt sie in eine Schale mit ebenem Boden. Sollte das Naterial dabci aus seiner Lage gekommen sein, so orientiert man mit heißer Nadel noch einmal schnell nach und gießt dann in die Schale soriel kaltes Wasser, daß das Kästchen etwa bis zur halben Höhe im Wasser steht. Hat sich, wie vorhin beim Uhrschälchen schon gesagt wurde, eine zarte Haut auf dem Paraffin gebildet, dann hält man die Metallplatte mit einer Hand fest, gießt mit der anderen soviel kaltes Wasser zu. daß dieses allmählich in das Papierkästchen fließt, und hört mit dem Zugießen erst auf, wenn das Kästchen ganz unter Wasser ist. Die I'latte muß festgehalten werden, weil sie sonst durch das Wasser in die Höhe gehoben wird, infolge wovon naturlich nichts in las Küstchen fließen kann. Die auf die beschriebene IVeise bewirkte schnelle Abkihhlung des Paraffins ist nötig, damit nicht in ihm Luftblasen entstehen, wie das bei langsamem Abkühlen der Fall ist, und damit es zu einer ganz homogenen Masse wird. Langsam erstarrtes Paraffin ist gewissurmaßen kristallinisch und krimelt heim Schneiden.

Nach ctwa Io Minuten kann man das Papierkïstchen leicht ron der Platte abheben. Nan reiBt dann das Kiistchen ab. Wirft den Block, damit er ganz hart wird, noch einmal in das kalte Masser und legt die Netallplatte auf ihn, damit er nicht schwimmt. Die Glas- und die Metallwinkel lassen sich leicht abnehmen. sohald das Paraffin völlig erstarrt ist. Sind alle Verrichtungen beim Einschmelzen richtig gemacht worden, dann miissen die so erzielten l'araffinblücke durchsichtig sein. 
L'm die verschiedenen Blöcke und damit das Material gut von einander unterscheiden zu können, muß man sie bezeichnen. Ich mache dies stets so, daß ich auf ein dreieckiges Papierschnitzel Namen des Objekts und Art der Fixierung mit Bleistift aufschreibe, dieses Schnitzel mit einer Spitze in das geschmolzene, in das Kästchen aussugossene Paraffin an einer Ecke eintauche und mit dem Objekt einschmelze.

Hat man sehr kleine Objekte oder will man Protozoën schneiden, so kann die Einbettung in dem im zweiten Kapitel unter Nr. 5 'S. I 2) beschriebenen Mikroaquarium von Schaudinn vorgenommen werden. Die Herstellung dieses Hilfsinstrumentes ist etwas anders wie bei der Lntersuchung lebenden Naterials. Der Einschnitt in den Objektträger wird dreieckig gemacht und die Deckgläser werden mit Fischleim aufgeklebt. Die Protozoën oder die kleinsten Objekte, bei denen es nicht auf Orientierung ankommt, werden in einer Lhrschale gehärtet und mit Xylol durchtränkt. Dann bringt man sie mit einer Pipette in das senkrecht gestellte Mikroaquarium, wo sie in der Spitze des Dreiecks sich ansammeln. Xylol wird - so lautet wörtlich die Angabe - durch Paraffin ersetzt. Man muß also offenbar nit einer Pipette das Xylol aus dem Mikroaquarium entfernen und heißes Paraffin an seine Stelle bringen. Dann legt man den Objektträger in kaltes Wasser. in welchem sich das Paraffin infolge seiner schnellen Erstarrung ron den Glaswänden trennt und die Deckgläser infolge Lösung des Fischleims rom Objektträger sich lösen. Der auf diese Weise frei werdende Paraffinblock lamn geschnitten werden.

Nanche Objekte durchtränken sich so schwer, namentlich wenn sie sehr roluminös sind, dals oft nach tagelangem Verweilen in geschmolzenem Paraffin sich Stellen im Zentrum finden, in die kein T'araffin gedrungen ist. Organe, welche Höhlungen einschließen, fillen oft zusammen, so daß natürlich unbrauchbare milkroskopische Präparate entstehen. L'm derartige L̈belstände zu vermeiden, soll man die Einschmelzung im luftverdünten Raum vornehmen. F. IV. Hoffmann hat ein Verfahren angegeben, das von Fol in folgender, allgemeine Anwendung gestattender Form modifiziert worden ist. Jan nimmt einen Glastubus, der unten verschlossen und in den oben ein Kautschulstopfen fest eingepaßt ist. Letzterer ist durchbohrt. In den Tubus kommt das Objekt mit dem geschmolzenen Paraffin, der Tubus selber wird in ein nicht über $60^{\prime \prime}$ C. erhitztes Wrasserbad gebracht. Über den Kautschukstopfen wird ein dickwandiger Gummischlauch gezogen und dieser mit einer Wassersaugpumpe in Verbindung gebracht. Ein gut schließender Quetsch- 
hahn wird an dem Verbindungsschlauch angebracht. Nun setzt man die Wassersaugpumpe in Tätigkeit und pumpt etwa 2 mal dic Luft aus dem Tubus. Nach jedem Pumpen schließt man den Quetschhahn und lïßt das ()bjelit 5-30 Ninuten im luftverdünnten Raume. Nicht eher darf man den Tubus von der Pumpe abnehmen, als bis keine Luftblasen mehr um das Objelit entstehen. Man gießt nach beendeter Evakuicrung das Paraffin, das schwer schmelzbar geworden ist, ab und die Ënschmelzung wird in gewöhnlicher V'cise in gewöhnlichem Paraffin vorgenommen. Aus der Tatsache, daß kcine Luftblasen mehr beim Evakuieren in der Nähe des Präparates entstehen. kann man den sicheren Schluß ziehen, daß die Durchtrïnkung mit Paraffin eine vollkommene und gleichmäßige ist.

14. Celloidin. Im Gegensatz zum Paraffin, das die Anwendung trockner Messer verlangt, ist bei Celloidin-Material die Befeuchtung des Mikrotommessers mit Alkohol notwendig. Dies ist ein Nachteil, da das trockne Arbeiten natülich viel sauberer ist. Andererseits kann man mit Celloidin viel größere Organe mit Leichtigkeit durchtränken, als dies beim Paraffin möglich, und kann auch vicl dickere Schnitte anfertigen, als von Paraffinmaterial. Bei letzterem nämlich kann man wohl dicke Schnitte von 20-30 und mehr $\mu$ herstellen, doch ist dies sehr unvorteilhaft. Denn die Schnitte brechen sehr leicht entzwei und das Paraffin ist auch schwer aus ihnen zu entfernen. Die Methode der Dickenschnitte ist aber z. B. für Studien iiber den Faserverlauf im Zentralnervensystem die allein richtige, weil in diinnen Schnitten die Nervenbahnen ganz unnötigerweise zerschnitten sind.

Erwähnt wurde soeben die Bezeichnung der Schnittdicke mit $\mu$; es sei daher die Bedeutung dieses Buchstabens hier kurz erklärt. Die Mal3einheit, mit welcher der Mikroskopiker zu rechnen hat, ist das Nikromillimeter $=0,00 \mathrm{I} \mathrm{mm}$, auch das Mikron genannt. Man schreibt statt o,0o I $\mathrm{mm}=\mathrm{I} \mu$; $30 \mu$ heißt also o,o3o $\mathrm{mm}$, usw:

An Stelle des von Duval und Schiefferdecker eingefiihrten Celloidins hat Krysinski das Photoxylin empfohlen. Leichte Löslichkeit und Durchsichtigbleiben beim Härten sollen die Vorteile der letzteren Substanz gegenüber dem Celloidin sein. Leider hat sich kurz nach der Krysinskischen Empfehlung dic Handelsware des Photoxylins so sehr verschlechtert — unglcichmäßige Löslichkeit, schlechtes Eindringen in die Objekte - , daß man jetzt vor sciner Anwendung geradezu warnen muß.

Für manche Zwecke scheint das gewöhnliche Celloidin trotz bester Härtung zu elastisch zu sein und daher nicht die Anfertigung genügend dünner Schnitte zu ermöglichen. Unna hat deswegen die Elastizitiat 
der Substanz herunter gesetzt, indem er $2^{\circ}$ 。 Terpentinöl oder $2^{\circ}$ 。 stearinsaures Natron oder $2^{\circ}$. Rizinusöl zusetzt. Diese Modifikation ist kituflich durch die Scheringsche Fabrik (Berlin zu beziehen.

Beror ich dazu übergehe, die Einzelheiten der Anwendung des Culloidins zu schildern, möchte ich wenigstens noch eine Icthode erwähnen, die eine Kombination von Celloidin- und Paraffineinbettung empfiehlt. Ich will die Methode allerdings nur erwähnen, beschreiben will ich sie nicht. Denn eine sinnlosere Kombination als die, celloidiniertes Naterial zu paraffinieren, gibt es nach meiner Erfahrung wohl kaum. Beider Methoden Vorteile werden vernichtet und es summieren sich nur die Fehler.

Um Material in Celloidin einzubetten, verfährt man folgendermaßen. Das käufliche Celloidin, eine Substanz von geringer Elastizität und milchigem Aussehen, zerschneidet man in möglichst kleine und dünne Stuickchen, die man auf einer flachen Schale oder auf einem Porzellanteller ausbreitet und an möglichst staubfreiem Ort lufttrocken werden läßt. Dies ist erreicht, wenn die einzelnen Stiickchen ganz durchsichtig und zugleich gelblich sind; lufttrockenes Celloidin ist außerordentlich hart. Ich will nicht unterlassen zu bemerken, daß das Prinzip, das eben gekaufte Celloidin nur in lufttrocknem Zustande zu verwenden, von Anatomen und Neurologen vom ersten Augenblicke der Einführung dieses Präparates in die Mikrotechnik befolgt wurde; einer besonderen Empfehlung von zoologischer Scite bedurfte es daher nicht.

Die Vorschläge der Autoren lauten für die weitere Verwendung des Celloidins dahin, daß man die gut entwässerten Objekte erst in eine ganz dünne, dann in eine Lösung bringt, welche Glyzerinkonsistenz, und endlich in eine solche, welche etwa Honigkonsistenz hat. Ich verfahre seit mehreren Jahren auf die folgend zu schildernde Art, die es mir gestattet, voluminöseste Gehirnteile auf das gleichmäligste zu celloidinieren. Und ich will hinzufügen, daß ich noch niemals eine schlechte Einbettung mit ihren bösen Folgen zu beklagen hatte. Allerdings kostet das Verfahren Zeit; aber wer sich zum wissenschaftlichen Arbeiten - und die gute V'orbereitung des Materials ist dazu zu rechnen - nicht Zeit lassen kann und will, der soll das Arbeiten iiburhaupt lassen. Ich verfahre also folgendermaßen:

Die Objelite werden je nach Art und Umfang 3-14. Tage in absolutem Alkohol entwïssert, cler jeden Tag erneuert worden muß. Dann kommen sic für $2+$ Stunden in ein Gemisch ron Alkohol absolutus und $\ddot{A}$ ther sulfuricus zu gleichen Teilen. In dieses Gemisch, das sich 
in einer Glasschale, welche einen aufgeschliffenen, gut schlielsenden Glasdechel hesitzt, oder in cinem Standgefälse mit gut schlielsendem Korken befindet, bringe ich nach 2 \& Stunden von dem getrockneten Celloidin einige wenige Partikel, die sich in etwa einem Tage gelüst haben. Dann füge ich allmählich mehr und mehr Celloidin zu, dessen Lösung in der Glasschale ich dadurch befördere, dat.3 ich alle 2-3 Titge die Fliissigkeit mit einem skalpellstiel rorsichtig aber doch gründlich umrihre, damit dâs noch ungulöste Celloidin ins Schwimmen kommt. Die Schale muls immer wieder sorgfïltig geschlossen werden. Habe ich ein Standgefäß (Pillenglas usw.) genommen, dann schüttle ich zur Erleichterung der Lösung das Gefïß mehrere Nale tüchtig durch. Nan mul.3 also zarte Objekte in einer Glasschale celloidinicren, wahrend für gröhere z. B. Leber) ein Pillenglas ausreicht. Das Zusetzen ron Celloidin geschicht so lange, bis die Lösung die Konsistenz von dickem Glyzerin hat. Jetzt rührt man in der Glasschale die Flüssigkeit noch einmal um, damit man sich überzeugt, dals alles Celloidin gelöst ist, bzw. schiittelt das Standgefäß gründlich, orienticrt das Objekt, d. h. bringt es mit einer Nadel in eine für die zu wählende Schnittrichtung geeignete Lage, wartet bis alle Luftblasen geschwunden sind und stellt Schale oder Standgefäß, jetzt nur halb zugedeckt. an einen nicht zu kühlen dunklen Ort. Ich wähle letzteren deshall, weil es mir scheint, als ob in der Dunkelheit die Verdunstung ron Alkohol- Ither langsamer erfolgt als im Licht. Und die langsame Verlunstung ist Vorbedingung für cine gute Konsistenz des Materials. Dadurch daß die Lösungsmittel des Celloidins, nämlich Alkohol und Äther, verdunsten, wird das Celloidin allmählich hart. l'avlow verwendet übrigens statt Ithylalkohol Methylalkohol.) Nan erkennt dies daran, daß die Celloidinmasse keine Bewegungen mehr zeigt. Wenn man die betreffenden Gefïße rorsichtig neigt. Vorsichtig muß man dies tun, un die orientierten I'riparate nicht aus ihrer Lage zu bringen. Man üherzeugt sich auch noch von dem Zustande des Celloidins, indem man mit einem Finger die Oberfläche der Celloidinmasse einzudruicken versucht. Ist diese resistent, dann hïrtet man nunmehr das eingebettete Präparat.

Zu dem Zwecke gielse ich in die Glasschale oder in das Standgefäls soviel $50^{\circ}$, Alkohol, dals er mindestens a $\mathrm{cm}$ hoch über dem Celloidin steht. Schale und Gefills werden von jetzt ab wieder gut geschlossen. Alle $2+$ Stunden muls dir 50" "Alkohol mindestens einmal erncuert werden. Man kinn sehr gut beohachten, wie die Härtung allmählich in die Ticfe schreitet, indem die geharteten Partien ein leicht weißliches Ausschen erhalten. Man befördert die Hiir- 
tung, wenn man an der Glaswand vorsichtig mit einem Messer bis in den noch nicht gehärteten Teil an verschiedenen Stellen einsticht und so dem $50^{\circ}$. Alkohol einen Zugang in die Tiefe eröffnct. Ist cic (elloidinmasse gleichmäßig weißlich geworden, was man an den Glasgefäßen ja sehr lcicht feststellen kann, dann ist die Härtung beendet.

Dieses Verfahren kostet viel Zeit. Selbst für zarteste Objekte hat man mindestens I 4 Tage nötig, größ3ere Objekte verlangen 3-6 Wochen und mehr. Aber der Lohn für die bei dieser Arbeitsmethode geübte Geduld ist auch ein großer: tadellose Durchtränkung, schonendste Behandlung und leichteste Weiterverarbeitung des Naterials. Ich habe auf diese Weise ein Phocaena-Rückenmark in eine luickenlose Querschnittsserie von circa 7000 Schnitten zerlegen können.

Ist die Härtung beendet, dann schneidet man das Präparat aus der Celloidinmasse heraus, wobei es selbstverständlich - des späteren Mikrotomschneidens wegen - von einem genügend breiten Celloidinand allseitig umgeben sein muß. Das abfallende Celloidin kann man weiter benutzen, indem man es in der vorhin angegebenen VTeise lufttrocken macht. (Altes Celloidin wird mit der Zeit schmutziggrau und ist dann zum Einbetten nicht mehr zu gebrauchen.) Die Celloidinblöcke hebt man bis zu ihrer Verarbeitung am besten in $50 \%$ Alkohol auf; der vielfach empfohlene $70^{\circ}$. Alkohol ist meiner Erfahrung nach zu stark und verhindert eine wirlilich gleichmäßige Härtung.

Von Lee ist zur Härtung kleiner celloidinierter Objelte das Chloroform empfohlen worden. Manchmal soll in 3 Stunden, in den meisten Fällen nach spätestens 3 Tagen, die Härtung der Celloidinblöcke, also der das eingebettete Objekt enthaltenden festen Massen, beendet sein. Von anderer Seite ist zur definitiven Härtung $10^{\circ}$ : Formollösung angepriesen worden.

Will oder kann man das celloidinierte Material nicht sofort verarbeiten oder will man Reste von verarbeiteten Blöcken für später auflceben, so bringt man alles am besten in Glastuben, welche $50 \%$ Alkohol enthalten, mit einem Kork gut verschlossen werden können und an denen man außen eine Etikette mit der nötigen Bezeichnung aufklebt. Das ist die einfachste und sicherste Methode. Wichtig ist, daß der Alkohol nicht den Kork beruhrt, damit aus diesen kein Tannin ausgelaugt werden kann; denn dieses könnte unter Umständen das Präparat verderben. In welcher Weise die Celloidinblöcke für das Mikrotomschneiden befestigt werden muissen, soll im folgenden Kapitel auseinandergesetzt werden. 
Einen schr großen Nachteil hat das Celloidin gegenüher dem Paraffin. Dieses kann man aus den Schnitten entfernen oder vielmehr man muß dies tun, um ein gutes, durchsichtiges Prïparat zu erhalten. Das Celloidin kann man zwar auch entfernen, für gewöhnlich aber wird man es erhalten wollen und müssen, namentlich wenn man lose in einer Höhle des Körpers steckende Tcile hat, die nicht aus ihrer Lage kommen dürfen. Ist das Material nicht vorher im Stiick gefärbt worden (vgl. achtes Kapitel), sondern sollen erst die Schnitte gefärbt werden, dann zeigt sich der Nachteil. Und er besteht darin, daß das Celloidin in allen Farblösungen sich sehr intensiv mitfïrbt und dadurch das mikroskopische Bild verdirbt. Leider entfärbt es sich nur bei einer Methode, bei der später zu erwähnenden Weigertschen Hämatoxylinfärbung, während es alle übrigen Farbstoffe oft züher festhält, als dies die tierischen Gewebe tun. Mit Berïcksichtigung dieses Umstandes wird man sich zu entscheiden haben, ob man Stiick- oder Schnittfärbung wählen soll und ob man für letztere das Celloidin aus dem Schnitt entfernen muß oder nicht.

\title{
Siebentes Kapite1.
}

\section{Schleifen. Schneiden. Aufkleben.}

\author{
a) Schleifen.
}

$\S 46$.

Die fixierten, erhärteten und eingebetteten I'räparate, soll anders ihre mikroskopische Durchforschung möglich sein. müssen in diinne Schnitte zerlegt werden. Wie dies zu geschehen hat, werden wir bald erfahren. Es gibt aber Objekte, welche Hartteile enthalten, Wodurch natuirlich ihre Schnittfähigkeit unmöglich gemacht wird. Da solche Hartteile in den weitaus meisten Fällen aus kohlensaurem Kalk bestehen, so kann dic Schnittfähigkeit dadurch herbeigefuihrt werden, daß man mit einer der im fünften Kapitel angefühten Entkalkungsmethoden den Kalk aus den Geweben austreibt.

Nicht immer aber wird eine solche Entkalkung wünschenswert sein. Es gibt Fälle, in denen die Beziehung der Weichteile zu den Hartgebilden nur dann gut erkennbar ist, wenn der Kalk an seiner Stelle geblieben ist. Bei den Steinkorallen z. B. ist die Entkalkung ein Fehler, 
wenn man den Aufbau nicht bloß des Weichkörpers sondern des ganzen Tieres studieren will. Bei Arbeiten über die Struktur der Knochen oder der Zähne, um ein anderes Beispiel zu bringen, könnten durch die Entlialkung feinere Verhältnisse zerstört werden. die bei Erhaltung des Kalkes der Beobachtung relativ leicht zugänglich wären. Lnd so ließen sich noch zahlreiche Beispiele dafuir anführen, daß gelegentlich eine Notwendigkeit vorliegen kann, Hart- und Weichgebilde in ihrer naturgemäßen Beschaffenheit zu erhalten. IIcthoden, welche diesem Zwecke genügen, sind die in folgenden Zeilen zu schildernden Schleifmethoden. Das ihnen zugrunde liegende Prinzip ist das, ron gut fixiertem und erhärtetem Material, an welchem voraussichtlich alle feineren Strukturverhältnisse erhaiten sind, trotz der Anwesenheit unveränderter kalkhaltiger Bestandteile feinste mikroshopische Präparate zwar nicht mit dem . Nikrotommesser wohl aber mit dem Schleifstein herzustellen.

Das Schleifen harter (Objekte ist eine alte Methode. Aber sie wurde ausschließlich für totes, d. h. für mazeriertes MIaterial verwendet, aus dem alle Weichgebilde auf das sorgfältigste entfernt waren. Zur Erkennung der groben Textur des Knochens, der Zähne usw: reicht diese Art Schleifen, die in einem späteren Kapitel beschrieben werden soll, vollkommen aus. Für feinere Strukturverhältnisse. zu deren Erfassen die Anwesenheit der Wcichteile Conditio sine qua non ist, muß sie dagegen als gänzlich unbrauchbar verworfen werden. Die hier folgenden Schleifmethoden stellen daher einen erheblichen technischen und damit wissenschaftlichen Fortschritt dar.

\section{$\$ 47$.}

I. Kolophoniummethode, nach $v$ Koch. Man fixiert gut, härtet. färbt und entwïssert das Material ganz in der Weise, wie sie für Paraffin- oder Celloidineinbettung vorgeschrieben ist. Nach der Entwässerung; die sehr sorgfältig ausgeführt werden muß, kommt das Objekt in cine dickfliissige Lösung ron Kolophonium in Alkohol absolutus. Im Brütofen dringt allmählich die Masse in das Objekt ein und wird dabei schr fest. Besser ist es, das ()bjekt bei Zimmertemperatur in der Kolophoniumlösung zu lassen, das Gefäß, welches beide enthält. gut verschlossen zu halten und erst, wenn die Durchtränkungrollendet ist. Wozu stets längere Zeit erforderlich ist, das offene Gefäß in den Brütofen zu bringen, um durch Verdunstung des Alkohols die Erstarrung des Irolophoniums schnell herbeizufihren. Ferner ist es auch ratsam. das gut durchtränlte ()bjekt aus dem Gefäße heraus zu nehmen und es auf einer Glasplatte in den Britschrank zu stellen. 
Man erspart so die Miihe, las ()bjekt aus der erstarrten KolophoniumMasse auszustolen. Das sehr hart gevordene ()bjelit wird mit ciner Laubsïge in mehrure Teile zersigt. Jeden Teil schlcift man zunichst auf einem Schleifstein cben und kittet ihn mittels ier Kolophoniumlösung auf eine handliche, d. h. nicht zu grolse und nicht zu dicl:e Glasplatte, also am besten auf einen ()bjekttriiger auf. Die eben erst abgeschliffene Seite kommt auf die Glasplatte. Ist dats abrgesiegre Stiick fest aufgckittet, dann schleift man es zuerst auf einem etwas grobkörnigen Schleifstein und poliert es, wenn es diinn genugg geworden ist, auf einem sogenannten Abzichsteine, wie or fur Rasiermesser gebräuchlich ist. Dann wäscht man die rom Schleifen herrühenden Splitter sorgfältig mit Wasser ab und hat nach dem Trockncn ias fertige Prïparat. Denn jetzt hat das Stiick die genügende Dünne, um ohne weiteres untersucht werden zu können. Aus diesem Grunde empfiehlt es sich, die Sägestiicke auf (Objektträger aufzukitten. Man kann, und für die längere Aufbewahrung derartiger Präparate ist dies vorteilhaft, auf den Schnitt einen Tropfen der Kolophoniumlösung bringen und mit einem Deckglase eindecken. Auch der Einschluls in Kanadabalsam ist empfohlen worden.

Diese ganz ausgezeichnete Methode ist nicht bloß fir Steinkorallen verwendbar, wofür v. Koch sie zuerst konstruiert hat, sondern eignet sich für alle Skelettgebilde aller Tierklassen.

2. Kolophonium mit Wachs, nach Ehrenbaum. Io Teile Kolophonium werden mit I Teil Wachs zusammengeschmolzen: in dem Gemisch durchtränkt man die Objekte. Schleifon wie rorhin angegeben. Man entfernt dann die Masse erst mit Terpentinöl und dann mit Chloroform. Zwar nur für Hartgebilde ohne Rücksicht auf die Weichteile empfohlen, doch auch für Weichteile mit Hartteilen verwendbar.

3. Schellack, nach Giesbrecht. Wic die vorige Methode nur für Hartgebilde allein, ohne Rücksicht auf die Weichteile, angegeben. dennoch für beide zugleich verwendhar. Die ()bjekte kommen in cinen heißen geschmolzenen Schellack. Mit einem dicken Schellackmantel werden nach der Erstarrung die Objekte in der bei Nr. I angegebenen Weise zersägt und geschliffen.

+. Kanadabalsam, nach IVeil. Nach dieser Methode, die für Zähnc von Menschen angegeben wurde, aber ebensogut für alle iibrigen Hartgebilde brauchbar ist, die mit ihren Veichteilen in Verbindung bleiben sollen, muß man dem fixierenden liengens den Zugang zu den Weichteilen frei machen. Das geschicht \%. I3. hui den Zähnen durch Zersïgen. I lat man dem fixierenden Keagens cien 
Zugang zu den Weichteilen ermöglicht, so fixiert man in konzentrierter Sublimatlösung oder in einem anderen nicht entkalkenden Mittel. Bei Sublimatanwendung wäscht man nach Weils Vorschrift aus, während ich davon aus den bereits im vierten Kapitel erörterten Gründen abrate. Dann erhärtet man in steigendem Alkohol, jodiert und verfährt so, wie wenn man durch Chloroform hindurch in Paraffin einbetten wollte. Im reinen, in großer Menge zu verwendenden Chloroform bleibt das Material $2+$ Stunden; nun kommt es in ChloroformKanadabalsam. Diesen stellt man sich folgendermaßen her: Man kocht auf dem Wasserbade gewöhnlichen Kanadabalsam, wobei man sich hüten muß, ihn zu heiß zu machen, weil er sonst dunkel wird. Nach dem Erkalten muß der Balsam auf Stoß wie Glas zerspring $€$ n. Von diesem Balsam setzt man zu dem reinen Chloroform, in welchem das Objekt schwimmt, soviel zu, daß eine dïnne Lösung entsteht. Nach 24 Stunden setzt man frischen Balsam zu und fährt damit fort, bis sich kein Balsam mehr löst. Nunmehr kommen die Objekte mit dem Balsam in eine Schale, werden gut zugedeckt und auf dem Wasserbade - offenes Feuer ist zu vermeiden - langsam gekocht. Aus der nach dem Erkalten glasharten Masse sticht man die Objekte heraus, zersägt sie mit der Laubsäge in Platten, die man in der bei Nr. I angegebenen Weise zu mikroskopischen Präparaten abschleift. Die fertigen Schnitte werden in Balsam eingeschlossen.

b) Schneiden.

$\S 48$.

So interessant die eben geschilderten Methoden sind, so finden sie doch nur ausnahmsweise Anwendung. Die beste Methode, von Weichteilen mikroskopische Präparate zu erhalten, welche jedem Anspruche nach Möglichkeit genügen, ist die Schnittmethode. Wir können 3 Arten des Schneidens unterscheiden: I) des in Paraffin eingeschmolzenen oder in Celloidin eingebetteten Materials mit dem Mikrotom, 2) des gefrorenen Materials ebenfalls mit dem Mikrotom, und 3) des uneingebetteten, ich möchte es nennen, des nackten Materials mit der freien Hand. Diese drei Arten werden der Reihe nach beschrieben werden. Welche von ihnen man auch anwenden will, unerläßliche Vorbedingung fuir das Gelingen des Schneidens ist ein scharfes Messer. Wie der Mikroskopiker sich selber seine Messer scharf macht und scharf erhailt, soll daher zunächst erörtert werden.

Messer, mit denen man aus freier Hand schneidet, sind die gewöhnlichen Rasiermesser. Sie sind dadurch charakterisiert, daß sie eine dünne, federnde Schneide haben. Eine solche ist notwendig, 
damit beim Rasieren die Krlinge sich der Haut anlegt und nicht über die Barthaare hinwegspringt. Dies aber würde der Fall scin, wenn das Rasiermesser eine unnachgiebige Schneide besilise. Ich kann für die Zwecke des Freihandschneidens nur auf das dringendste cmpfehlen. die fuir das Rasieren des Bartes malßgebenden Erwigungen auf das Schneiden der nackten (Objekte zu übertragen. Man gebrauche daher niemals plankonkave harte Rasiermesser, sondern nehme nur die bikonkav geschliffenen mit federnder Schneide. Jene sind nur geeignet, das Naterial in grobe Abteilungen zu zerlegen, und dafür sind sie besser als ein Skalpell; zur Herstellung mikroskopischer Schnitte eignen sich allein dic letztgenannten Messer. Diese braucht man sich nicht selbst zu schleifen; das verstehen sogar die chirurgischen Instrumentenmacher, wclche Nikrotommesser immer ruiniert abliefern.

Anders müssen dic Mikrotommesser beschaffen sein, mit denen paraffiniertes oder celloidiniertes Naterial geschnitten werden soll. Hier darf unter keinen Umständen die Schneide federn. Davon kann man sich sehr leicht überzeugen, wenn man den Versuch macht, mit einem gewöhnlichen Rasiermesser von einem Paraffinblock einen duinnen Schnitt ( 15 - Io $\mu$ ) anzufertigen. Die Schneide springt einfach über den Block hinweg, ohne in ihn einzudringen, während ihn die Mikrotommesser bei geniigender Schärfe leicht schneiden. Diese Messer soll man sich selber schleifen, wenn nicht die Schneide beträchtliche Verletzungen (Liicken, Beulen usw.) erlitten hat. Um diese zu beseitigen, bedarf es eines rotierenden Schleifsteines, den man in angemessener Qualität wohl selten in einem Laboratorium hat. Es ist daher anzuraten, verletzte Messer dem Instrumentenmacher zur Reparatur zu schicken, welcher sie verfertigt hat.

Handelt es sich dagegen nur um stumpfe Messer, so verfahre man folgendermaßen. Man verschaffe sich einen Schleifstein, entweder einen Öl- oder elsäßischen Stein oder einen Mississippistein. Von technischer Seitc wird als Regel aufgestellt, daß man für harten Stahl einen weichen und für weichen Stahl einen harten Stein wählen solle. Der Öl-oder elsäßische 'fälschlich französische Stein ist weich, der Mississippistein ist hart. Am Messer bringe man die sogenannte Abziehvorrichtung an. Da nämlich die Nikrotommesser plankonkav oder fast plankonkav geschliffen sind, so würde beim Schleifen auf dem Stein die plane Fläche glatt aufliegen. Dies hätte cinmal zur Folge, daß die Klinge sich schwer vom Stein abheben ließe, dann, daß sie mit abgeschliffen würde, und endlich, daß die Herstellung einer keilförmigen Schneide, das Ziel des Schleifens, eine Lnmöglichkeit wäre. Die jedem Mikrotommesser beigegebene Abziehvorrichtung 
verdickt auf beiden Messerflächen den Rücken derart, daß nur die Schneide dem Stein aufliegt und zwar in gleicher Weise auf der planen wie auf der konkaven Fläche.

Der Stein wird reichlich mit (̈I befeuchtet. Ich benutze seit Jahren nur noch das sogenannte Paraffinöl, Paraffinum liquidum, dessen Vorzug darin besteht, nie sauer, d. h. nie ranzig zu werden, also das Messer nicht anzugreifen. Man legt das Messer mit einem Ende so auf den Stein, daß man es mit der Schneide voran schräg über die Fläche des Steines hinwegzieht. Hierbei hat man darauf zu achten, daß die Schneide stets von Öl bedeckt ist und daß man während des Hinwegziehens auch nicht im geringsten drückt. Ferner muß das Messer ganz gleichmäßig gezogen werden und darf sich niemals, weder mit dem Rücken noch mit der Schneide, vom Stein entfernen. Ist man mit dem Vorschieben zu Ende, so dreht man auf dem Rücken, d. h. der Abziehvorrichtung, um und schiebt, wiederum die Schneide voran, das Messer in entgegengesetzter Richtung zuriick. Bei einiger Übung lernt man bald, diese Umkehrung des Messers im Handgelenk auszuführen; das ist von Wichtigkeit, da man hierdurch vermeidet, das Messer auf den Stein aufzuschlagen. Dieses Vor- und Rückziehen des Messers führt man so lange aus, bis man sich mit der Lupe davon iberzeugt hat, daß kein sogenannter "Grat " mehr an der Schneide ist, d. h. daß die Stumpfheit der Messerschneide beseitigt ist. Dann entfernt man die Abziehvorrichtung, um sie und die Messerklinge vom Paraffinöl zu reinigen, was mit einem Leinwandlappen geschieht. Es ist das darum empfehlenswert, weil sonst der nach dem Schleifen auf dem Stein zu benutzende Streichriemen unnötigerweise eingeölt wird. Auf alle Fälle hüte man sich, die Schneide selber mit dem Lappen zu reinigen; sie wird dadurch ruiniert. Zuweilen finden sich an der Schneide ganz minimale Liicken, die kaum mit der Lupe wahrnehmbar sind. Diese werden mit der eben geschilderten Art des Schleifens beseitigt. Daß dies geschehen, stellt man dadurch fest, daß man sehr vorsichtig unter Vermeidung jeden Druckes mit dem Rücken des Daumennagels uiber die Schneide hinfährt; die minutiöseste Lücke wird dabei als ein holpriges I Indernis wahrgenommen. Der Stein wird abgetrocknet und mit Benzin oder Xylol gereinigt.

Nun muß das geschliffene Nesser auf dem Streichriemen abgezogen werden. Ich benutze seit Jahren ausschließlich den großen Walbschen Streichriomen, der nur eine rote Abziehfläche hat. Die bei anderen Streichriemen vorhandenen anders gefärbten Flächen halte ich für überflissig. Das Mcsser wird, um abgezogen zu werden, mit 
der Abziehvorrichtung versehen und nun verfiht man wic beim Schleifen auf dem Stein. Man legt las Messer unter Vermeidung jeden Druckes gleichmaßig mit Rücken und Schneide auf den Streichriemen und zicht es üher dessen Fläche - dies im Gegensatzc zum Schleifen auf dem Stein - mit dem Rücken voran. Würde man auch hier die Schneide vorangehen lassen, dann wïrde man den Streichriemen zerschneiden. Ist man am Ende des Messers angelangt, so dreht man auf dem Rücken um und schiebt in entgegengesetzter Richtung zurïch. Wie oft man dieses Abzichen vornchmen soll, darüber lassen sich keine zahlenmäßigen Angaben machen; Ühung lehrt sehr bald, das richtige Maß zu treffen. Darauf nur sei der Anfänger aufmerksam gemacht, daß zu langes Abzichen die Schneide wieder abstumpft. Den Druck muß3 man auf Stein wie auf Riemen deshalb vermeiden, weil auch durch ihn ein Abstumpfen der Schneide herbeigeführt wird. Darin verhalten sich die Nikrotommesser mit starrer Schneide anders wie die Rasiermesser mit federnder Schneide; diese müssen mit leichtem, elastischem Druck abgezogen werden.

Die genügende Schärfe des Messers prüft man dadurch, daß man ein Kopfhaar zwischen Daumen und Zeigefinger der linken Hand festhält, so daß es ein Weniges heraussteht, und daß das Messer, wenn man es dicht über den Fingern durch das Haar zieht, dieses glatt durchschneidet. Geschieht dies nicht, so muß man entweder noch einmal abziehen oder sogar noch einmal schleifen.

Das Messer wird mit einem weichen Lederlappen gereinigt, wobei man sich wiederum hüten muß, die Schneide zwischen den Fingern zu pressen. Dann ist es fertig zum Gebrauch. Vor dem jedesmaligen Schneiden muß auf dem Streichriemen abgezogen werden; das Schleifen soll man nur selten vornehmen, nur wenn nach sorgfältigem Abziehen keine guten Schnitte zu erzielen sind.

Die rote Fläche des Streichriemens muß sauber gehalten werden und darf nicht glänzend aussehen. Ist letzteres der Fall, dann hat das Leder zu wenig Paste und muß neu patiniert werden. Zu dem Zwecke nimmt man etwas von der jedem Streichriemen beigegebenen Mineralpaste, bringt es mit einigen Tropfen Paraffinöl auf die Streichfäche und verreibt es sorgfältig und gleichmäßig in deren ganzer Ausdehnung.

\section{$\S 49$.}

Das Schneiden in Paraffin eingebetteten Materials. Jedes der Mikrotome, die für diese erste und wichtigste Art des Schneidens in Betracht kommen und deren Modelle später beschricben werien sollen, 
hat eine sogenannte Präparatenklammer. In dieser die Präparate direkt einzuklemmen, ist nicht angängig, denn selbst paraffiniertes Maturial wïrde durch das Pressen leiden, welches die Klammer ausïben muß, soll sie den Paraffinblock festhalten. Celloidiniertes Material ist selbst bei größter Härtung für den Druck der Klammer nicht widerstandsfähig genug; ließe man aber die Spannung der Klammer nach, um das Material zu schonen, so müßte dieses beim Schneiden hin- und herwackeln. Dann aber wïrde die Anfertigung gleichmäßiger Schnitte zur Unmöglichkeit. Es ist daher notwendig, eingebettetes Material auf einen harten Klotz aufzukleben und letzteren in die Klammer einzuspannen. Solche Klötze für Paraffin sind aus Holz oder Stabilit, auf die man einige Tropfen geschmolzenen Paraffins bringt, um darauf den Block anzuschmelzen, oder es sind Metallzylinder, die mit Paraffin ausgegussen sind. Das Aufkleben der Celloidinblöcke wird in nächsten Paragraphen beschrieben werden. Zunächst, ehe man aufschmilzt, muß man sich den Paraffinblock herrichten und dies hat so zu geschehen, daß danach das Schneiden mit größter Leichtigkeit möglich ist. Je nach der gewählten Stellung des Mikrotommessers richtet sich die Form des Paraffinblockes; schneidet man mit quergestelltem Messer, so muß der Paraffinblock rechteckig, schneidet man mit schräggestelltem, so mul3 er dreieckig zugeschnitten werden. Den dreieckigen Paraffinblock stellt man sich folgendermaßen her: Zunächst schneidet man ron dem ïber die zukïnftige Schnittflache des Objektes herausstehenden Paraffin so viel weg, daß nach wenigen Schnitten das Messer in das Objekt gelangt. Denn man muß vermeiden, zuviel leeres Paraffin ohne Naterial zu schneiden, weil dies das Messer unnötig abstumpft. An den Rändern läßt man aus dem gleichen Grunde einen nur wenige Millimeter dicken Paraffinmantel; diesen ganz zu entfernen, ist nicht ratsam, weil beim eventuellen Einrollen des Schnittes dann das Material sich selber cinrollen würde. Dic Seite des Blockes, welche auf den Klotz aufgeschmolzen wird, muß mehr Paraffin als die entgegengesetzte enthalten. danit, wenn alles Material aufgebraucht wird, die Messerschneide nicht auf den Klotz stoßen kamm. Der dreieckige Block wird so auf die Unterlage aufgeschmolzen, daß beim Schneiden das Messer einen spitzen Winkel zuletzt trifft. Würde das Messer zuletzt an eine Seite des Dreiecks kommen, dann ließe sich der Schnitt nicht ron der Messerklinge, "lenigstens nicht unverletzt, abheben. Die Erfahrung hat nämlich gelehrt, claß eine breite Schnittseite fast untrennbar der Schneide anhaftet. Man orientiert also den Block so, daß das Messer eine Dreiecksseite voll trifft, wenn es in das Präparat eindringt, und 
dal es aus ihm an einer Spitze heraustritt. Einige Ühung lehrt hierin bald das Richtige zu treffen.

Bei querer Messerstellung soll der l'araffinblock die Gestalt eines Rechteclis besitzen. Will man genau ancinander passende Schnitte crzielen, so miissen immer zwei gegenüberliegende flächen vollkommen parallel sein unci mul3 die Oberfliche vier rechte IVinkel haben. Man kann jeden einzelnen Schnitt rom Messer abzuheben versuchen. doch wird das namentlich bei sehr duinnen Schnitten grol.se Schwierigkeit haben, wenn es nicht iberhaupt mil3lingt. Besser ist es, man macht erst den zweiten Schnitt; dieser nämlich stößt den crsten fort und erleichtert dadurch dessen Wegnehmen vom Messer. Die quere Messerstellung crmöglicht einc Art des Schneidens, welche bei der schrigen unmöglich ist. Bei letzterer muß jeder Schnitt einzeln, sobald er gemacht ist, von der Klinge abgehoben werden; bei ersterer dagegen kimn man Schnitt auf Schnitt folgen lassen und braucht sie einzeln nicht abzunehmen. Dies erreicht man dadurch, daß man auf dic beiden Flächen des Blockes, welche dem Messer parallel gerichtet sind, cine diunne Schicht sogenannten fadenziehenden Paraffins $\left(35^{\circ}-40^{\prime \prime} \mathrm{C}\right.$. Schmelzpunkt mit erwärmtem Metallspatel auftrïgt. Nan hüte sich dabei, zuviel von diesem weichen Paraffin zu nchmen, denn es ist sehr fett und bewirkt dadurch leicht, dal3 die Schnitte an Miesser kleben. Hat man nun den ersten Schnitt durch den Block gemacht und macht dann den zweiten, so klebt dessen vordere Fläche dank dem weichen Paraffin an der hinteren des ersten Schnittes. Und so klebt jeder folgende am vorhergehenden Schnitte fest. Diese von Graf v. Spee zuerst angegebene. Methode ist die sogenannte Bandwurmmethode, weil in der Tat das auf diese Art hergestellte Schnittband einer Proglottidenkette gleicht.

Fragen wir uns nun, welche Art der Messerstellung die vorteilhaftere ist, so lautet meine Antwort und die der. Winorität der Forscher: die schräge; die Majorität dagegen erklärt sich fuir die (luere Messerstellung. Heidenhain und Tellyesniczky gehen sogar so weit, die querc Messerstcllung fuir dic allein zulässige zu bezeichnen, und ersterer Forscher nennt das Schneiden mit schrägem Nesser -Sägen", was dem Begriffe sägen durchaus widerspricht. Unstreitig bietet die quere Messerstellung schr vicl Vorteile dar, whhrend das Schnciden mit schrägem Messer mihhsin und zeitraubend ist. Denn hundert Schnitte und mehr bei einer fortlaufenden Serie einceln rom Messer abheben zu muissen, ist in höchsten Grade ermüdend. Bei quergestelltem Messer digegen macht die Anfurtigung zahlreicher Schnitte sehr wenig Mühe und die weitere Verarheitung des Schnittbandes -.. 
Aufkleben usw. - ist leicht und bequem. Und dennoch halte ich im allgemeinen die quere Messerstellung wegen der mit ihr verbundenen Nachtcile für irrationell, weil diese Nachteile die genannten Vorteile mehr als aufwiegen. Von Schneiden kann dabei, wie ich in Gegensutz zu den vorhin genannten Gelehrten betonen muß, gar keine Rede sein. Das quergestellte Messer, und dies ist das entscheidende Moment, wird durch die Objekte hindurchgequetscht, das schräggestellle Nesser dagegen hindurch gezogen; und im Begriffe »Schneiden " liegt das Hindurchziehen der Klinge durch das Objekt.

Beim Schneiden des fuir histologische Zwecke allein verwendbaren harten Paraffins tritt unvermeidlich eine innere Zusammenschiebung des Schnittes ein, d. h. die abgeschnittene Lamelle Paraffin hat eine geringere Ausdehnung als der Paraffinblock, von dem sie stammt. Ich habe nachgewiesen, daß bei einem leeren Paraffinblock von I I $^{\mathrm{I}}{ }_{2} \mathrm{~mm}$ Schnittläche bei schräger Messerstellung die innere Zusammenschiebung der Schnitte 0,5 mm betrug; gleichgiltig ob man eine Schnittdicke von I $5 \mu$, io $\mu$ oder $5 \mu$ wählte. Bei querer Messerstellung dagegen und rechteckigem Block mit gleichgroßer Schnittfläche betrug die innere Zusammenschiebung bei ${ }_{5} \mu$ Schnittdicke $2 \mathrm{~mm}$, bei io $\mu 2_{2}{ }_{2} \mathrm{~mm}$ und bei $5 \mu 3^{\mathrm{T}}=\mathrm{mm}$. Und das geschah am leeren Block; wie stark muß die innere Zusammenschiebung erst sein, wenn das Paraffin ein Präparat enthält, und viclleicht gar ein solches, das aus sehr ungleichartigen Geweben besteht, die dem Messer einen sehr ungleichmäßigen Widerstand entgegensetzen. Das kann für die innere Konfiguration des Präparates nicht gleichguiltig sein, mögen auch die Verteidiger der queren Messerstellung noch so sehr das Gegenteil behaupten. Bei wenig umfänglichen Naterial, das mit einem Ruck und Druck gleich röllig durchschnitten ist, mag die quere Stellung passieren, bei jedem anderen Objekte halte ich sie für eine beträchtliche Fehlerquelle. Deswegen verzichte ich für meine Person gern auf die Vorteile der Bandwurmmethode und scheue nicht die Mühe, sclhst die umfänglichsten Serien mit schrägem Messer anzufertigen und Schnitt für Schnitt sorgsam von der Klinge abzuheben. Und ich rate jedem Anfänger, sich nicht durch die größere Bequemlichkeit des Schncidens auf die (quere Messerstellung allein einzuïben, sondern dic Arbeit mit der schrägen aluch an Paraffinmaterial gründlich $z$ erlernen.

Die Stellung des Messers zur Mikrotomachse muß bei Paraffinmaterial einen Winkel ron $+5^{-1}$ ausmachen. Aus den genannten Grinden - das sei schon hier bemerkt - verwerfe ich auch alle sogenannten Schaukelmikrotome, deren Prinzip später zu beschreiben ist. 
Wie soll man schneiden? Soll man das .Iesser schnell oder lingsam durch das Präparat zichen? Einc bestimmte schematische Regel läßt sich hierfür nicht aufstellen, das Tempo des Schneidens hängt vom Objekt ab; manchmal ist bei schrïgem Messer ein schnelles Durchziehen der Klinge durch das Objekt angebracht, mainchmal cin langsames. Je dünner der Schnitt werden soll, um so vorsichtiger soll man schnciden; denn unnötiges Hasten ist türicht, verdirbt das Material. Bei querer Messerstellung wird schnell geschnitten, ja mit den Schaticlmikrotomen kimn man gar nicht langsam schnciden.

In neuerer Zeit hat man angefangen, der Neigung, welche das Messer zur Ebene des Praparates hat, etwas mohr Aufmorksimkit zu widmen, als in fruheren Zeiten. Es genügt nicht, einfach das Messer in den Nesserhalter zu klemmen und dabei nur darauf zu achten, daß es beim Schneiden nicht wackelt usw. Paraffinmesser sind plankonkav geschliffen; wenn nun die plane Fläche, die zugleich die untere ist, horizontal oder nur wenig abwärts geneigt ist, dann lassen sich häufig dic Paraffinblöcke nicht schneiden. Dies ist besonders der Fall, wenn man harte und sehr verschieden zusammengesetzte Objekte zu bearbeiten hat, denn an diesen wirft sich das Messer hoch und geht über den Paraffinblock hinweg, wobei natürlich der Messerschlitten leicht gehoben wird. Ob diese große Unannchmlichkeit daher ruhrt, daß die Vikrotommesser, un eine federnde Schneide zu verhüten, plankonkav geschliffen sind, wodurch die nötige keilförmige Beschaffenheit der Schneide nicht genügend ausgeprägt ist, vermag ich nicht zu sagen. Zur Beseitigung des gerigten Übelstandes sind rerstellbare Messerhalter von Hesse, Mayer-Schöbel, Apathy konstruiert worden, deren Prinzip dahin geht, die Neigung der Schneide zur Schnittfläche zu vermehren, was durch Höherstellen des Messerrüickens erreicht wird.

Bei querer Messerstellung legen sich die Schnitte der Oberfläche des Messers im allgemeinen glatt an, bei der schrägen dagegen haben sie dic Jeigung, sich cinzurollen und sind dann vollig unbrauchbar, weil sie nicht wieder aufzurollen sind. Man kann dies dadurch zu verhüten suchen, daß man, sowie das Messer den l'araffinmantel erfaßt hat, den sich bildenden Sichnitt mit einem Stuichchen Papier odur einer l'inzette oder einer Nadel glatt zu crhalten sucht. Es gelingt dies auch bei nur einigermaßen vorhandenem körperlichem Geschick sehr leicht. Bequemer aber und sicherer sind die nach den rerschiedensten P'rinzipien lionstruierten Schnittstrecker, leren einfachster wohl der ron dem verdienstrollen Zoologen P'aul Mayer angegebene ist. Mán mul3 die Nadel dieses kinen Instrumentes so 
auf der Schncide lagern, daß sie halb über sie hinausragt. Trifft die Schneide den Block, so rollt sich der Paraffinmantel leicht ein, wird aber am weiteren Einrollen durch den Schnittstrecker gehindert, der, um diesen seinen Zweck erfüllen zu können, stets glatt der Klinge aufliegen muß. Nanchmal rollen sich die Schnitte um die Nadel des Schnittstreckers; doch ist dies bedeutungslos, da sie leicht abzunehmen und glatt zu legen sind.

Ein mit der Paraffineinschmelzung rerbundener Nachteil, der sich bei jeder Messerstellung zeigt, ist das Zerbrechen der Schnitte, was sich namentlich bei sehr sprödem und brïchigem Material einstellt. Bei dotterreichen Eiern (Teleostier, Insekten). beim Schneiden ron Nematoden usw. findet dies z. B. sehr leicht statt. Um eine hierdurch bedingte Zerstörung des oft wertvollen Materials zu verhindern, eignen sich die folgend angeführten Methoden.

Man bestreicht, bevor man einen Schnitt macht, nach v. Davidoff die Oberfläche des Paraffinblockes jedesmal mit etwas Kollodium. Wenn dieses zu einer diunnen Haut erstarrt ist, dann macht man den Schnitt, der nun keine Spur ron Zerbröcklung zeigt. Die Kollodiumschicht läßt sich nach dem Aufkleben der Schnitte durch Äther auf das leichteste entfernen. Etwas anders ist die Methode von Heider, der Mastixkollodium empfiehlt. Käufliches Kollodium und sirupdicke Mastixlösung werden zu gleichen Teilen gemischt und mit Äther-Alkohol zu gleichen Teilen so verdünnt, daß die Lösung wasserduinn wird. Man bestreicht vor dem Schneiden die Schnittfäche und läßt erstarren. Auch zur Anfertigung sehr dünner Schnitte, unter $5 \mathrm{u}$, ist diese Hethode sehr geeignet, nur muß man sich dann hüten, daß man nicht die Hautseite der Schnitte beim Aufkleben auf Deckglas oder Objektträger bringt. Siding empfiehlt zur Verhütung des Bröckelns Anwendung sehr weichen Paraffins, sogenannten Zugparaffins. Es ist dies das vorhin bei Besprechung der Bandwurmmethode als "fadenziehendes « bezeichnete Paraffin. Siding preßt mit den Fingern ein Stiickchen daron zu einer ganz dünnen Platte von der Größe der Schnittfläche und druickt sie auf die Oberfläche des Blockes fest an. Sehr umständlich und daher sehr unpraktisch ist die Methode, vor jedem Schnitte die Oberfläche des Blockes mit geschmolzenem Paraffin $z u$ bestreichen. Das ist auch darum nicht $z u$ empfehlen, weil durch das warme Paraffin der Block allmählich zu weich wird; die von v. Lendenfeld angegebene Nethode, zur Erhïrtung einen kühlen Luftstrahl über den Block zu leiten, ist zu umständlich. Ganz falsch oder vielmehr ganz irrationell ist die Methode von MIann, welcher geknitterte Schnitte auf warmes Wasser bringt. Wohl breiten 
sic sich auf der ()berfläche glatt aus; sic aber wieder herunter zu nehmen ist keine Kleinigkeit, dic meisten Schnitte, namentlich dinne; zerreißen dabei.

Beim Schneiden mul3 das Mikrotommesser ganz gleichmäßig durch den Paraftinblock gezogen werlen. Das ist nicht leicht bei solchen Instrumenten, deren Messerschlitten durch dic Hand bewegt wird, und ist nicht viel leichter da, wo die fuhrende Hand durch eine Kurhel abgelöst ist. Ühung und ror allem Selbstbeobathtung, d. h. Aufpassen auf die eigenen Fehler, sind notwendig, um hierin die nötige Geschicklichkeit zu erlangen.

Es seien noch einige Worte ïber dic Schnittdicke gesagt. Im allgemeinen wird man l'araffinschnitte nicht dicker als $20 \mu$ machen. Was i $u$ bedeutet, wurde schon im vorigen Kapitel S. I05 auseinandergesetzt). Dickere Schnitte werden nur ausnahmsweise nötig sein, z. B. bei manchen Spongien; immer wird dabei beachtet werden müssen, dal3 mit der zunehmenden Schnittdicke auch die Brïchigkeit zunimmt. $7,5 \mu$ und 5,4 sind die Maße, die für die Erkennung feinster Strukturverhältnisse geeignet sind, ro $\mu$ und I $_{5} \mu$ sind für Texturverhältnisse die richtigen Dicken. Wie man nicht ohne zwingenden Grund iiber 20 , Dicke hinausgehen soll - will und mul3 man dicker schneiden, damn soll man in Celloidin einbetten - so soll man auch nicht ohne Not unter 5,4 heruntergehen. Die von vielen Autoren geübte und empfohlene Verdünnung bis zu $2 u$ oder gar I $\mu$ halte ich für eine ganz unnützc Spielerei. Man zerschneiciet dabei alle Strukturbestandteile von Zellsubstanz, und Kern, erschwert sich dadurch das Terständnis des Gesehenen, ohne sich den Einblick in das Präparat zu erleichtern.

Nicht immer kann man das aufgeklebte Naterial an einem einzigen Tage fertig schneiden; man mul also dic Arbeit unterbrechen. Da ist es denn von der allergrößten Wichtigkeit, daß3 das Messer unverändert in seiner Klammer stehen bleibt. Denn hat man es erst einmal daraus entfernt, so gelingt es nie wieder, absolut genau dieselbe Messerstelle zum Schneiden zu verwenden, mit der man angefangen hat. Das aber hat den Nachteil, daß dic Neigung des Messers zur Oberfläche des Blockes verändert ist und das Material daher in einer anderen, von der ursprünglichen abweichenden Ebene geschnitten wird.

Lïßt man über Nacht den Paraffinblock in der Präparatenklammer. dann geschicht es oft, daß das Messer am anderen Tage nicht faßt, sondern über das Präparat hinweggleitet Vorsichtig muß man daher mittels der Nilirometerschraube crst eine neue Schnittfläche herstellen. 
Wahrscheinlich handelt es sich hier um eine Austrocknung, die sich auf keine Weise vermeiden läßt.

\section{$\S 50$.}

Das Schneiden celloidinierten Materials. Den das eingebettete Material enthaltenden Celloidinblock richtet man sich in der Weise zu. daß man zunächst die über der gewünschten Schnittfläche stehende Celloidinmasse bis auf ein Minimum wegschneidet. Auf der entgegengesetzten Fläche läßt man soviel Celloidin stehen, daß das Messer, wenn das Präparat zu Ende geht, nicht auf den zum Aufkleben benutzten Klotz aufstoßen kann. Den um das Objekt stehenden Celloidinmantel trägt man nach Möglichkeit bis auf wenige Millimeter ab, weil zuviel Celloidin um den Schnitt herum dessen weitere Behandlung unnötig erschwert.

Der aus dem $50^{\circ}$. Alkohol entnommene Block ist nun aufzukleben. Als Klötze sind nur Holzklötze aus Buchsbaum und solche aus Stabilit zu empfehlen, es sei denn, man habe Metallplatten von genügender Breite, die das Präparat aufnehmen können und die einen in die Präparatenklammer passenden Fuß besitzen. Das von Jellinek empfohlene Stabilit, das von den Elektrizitätsgesellschaften als Isolationsmaterial benutzt wird, kommt in Platten von 8- $10 \mathrm{~mm}$ Dicke in den Handel und ist von roter oder grauer Farbe. Da es sehr hart ist, so kann man sich von ihm Klötze von der gewünschten Fläche zurecht sägen. Anderes Holz wie Buchsbaum sollte man nicht benutzen; denn Holz enthält viel Tannin, dieses wird im Alkohol ausgelaugt und kann das Präparat schädigen. Buchsbaum wird gar nicht ausgelaugt und hat noch vor den anderen Holzarten den großen Vorteil, daß es sich, wenn es nach geschehener Benutzung zum Trocknen hingestelit wird, gar nicht oder so gut wie gar nicht wirft. Korke sind ganz zu vermeiden, denn deren außerordentlich großer Tanningehalt muß allmählich jedes Präparat verderben.

Man bringt nun auf die möglichst rauhe Oberfläche des Holz-: Stabilit- oder Mctallh-lotzes etwas dickflüssiges Celloidin, das man sorgfältig über die ganze Fläche ausbreitet. Ratsam ist es, auch die Kanten des Klotzes mit Celloidin zu überziehen, damit, wenn dieses eintrocknet, was gelegentlich beim Schneiden vorkommt, die Celloidinhaut nicht rom Klotz abspringen kann. Dies auf die Oberfläche gebrachte Celloidin läßt man durch Verdunsten an der Luft trocken werden. Jctzt stellt man den gut abgetrockneten Celloidinblock mit der Fläche, welche der späteren Schnittfäche entgegengesetzt ist; in ein Glasschälchen mit ither. Dadurch wird die Unterfläche des 
Blockes aufgeweicht und nimmt das auf den Klotz zu bringende Celloidin an. Wird dies außer acht gelassen, dann kann man nicht aufkleben, weil das gehärtete Celloidin sich mit dem weichen nicht mischt. Man nuß nämlich jetzt auf den Klotz, welcher die Celloidinhaut erhalten hat, etwas dickflüssiges Celloidin bringen, stellt darein den Block, wobei man ihn leicht andruickt und bringt mit einem Metallspatel soviel dickfliissiges Celloidin um ihn herum, daß seine unterste Partie ganz in Celloidin steht. Man wartet, bis das neu aufgetragene Celloidin eine trockene Haut bekommen hat, und stellt den Klotz mit dem Präparat in 50\% Alkohol. Stabilit und Metall stehen auf dem Boden des den Alkohol enthaltenden Glases fest, Buchsbaum dagegen schwimmt. Um dies zu vermeiden, weil dadurch die Erhärtung des Aufklebecelloidins eine ungleiche wird, kann man in beliebiger ITeise den Buchsbaumklotz beschweren, so daß er untersinken muß. Oder aber man verfährt folgendermaßen: Ein zylindrisches Glasgefäß füllt man mit dem 50\% Alkohol bis zum Rande. Dann taucht man den mit dem Präparat versehenen Buchsbaumklotz verkehrt, so daß also das Präparat nach unten hängt, in den Alkohol und schiebt eine Glasplatte iiber den Rand des Glasgefaßßes so, daß der Klotz mit seiner freien Fläche gegen die Platte stößt. So kinn sich der Klotz nicht mehr halb aufrichten und das Präparat ist allseitig vom Alkohol umgeben. Nach $2+$ Stunden ist das Aufklebecelloidin hart und man versucht vorsichtig mit dem Finger, ob das Präparat auf seiner Lnterlage fest haftet. Ist dies der Fall, so kann geschnitten werden; ist das Präparat dagegen nicht fest, so muß die ganze Prozedur wiederholt werden, und zwar muß man das Aufklebecelloidin vollständig mit der Haut abreißen.

Man schneidet mit schräggestelltem Messer und es ist am vorteilhaftesten, wenn dieses mit der Achse des Mikrotoms einen Winkel von etwa $30^{\circ}$ bildet. Stärkere Winkelstellung drückt das Präparat, so daß es leicht abreißt, geringere erschwert das Schneiden. Das Messer darf nie zu schnell durch das Präparat gezogen werden, weil sonst der Schnitt leicht einreißt.

Es ist empfohlen worden, Celloidin trocken zu schneiden. Nach meinen Erfahrungen geht dies nur dann, wenn das Celloidin zum ersten Male verwendet wird, also bei einem neucn Präparat. Hat man dagegen schon gebrauchtes Celloidin wieder verwandt - und das ist durchaus zulässig; oft auch aus Ersparnisrücksichten nötig - . dann versagt das Trockenschneiden. Ich halte dies für eine um so überfiüssigere Spielerei, als selbst neues Celloidin, wenn das Schneiden stundenlang daucrt, stark eintrocknet. Min schncidet der Vor- 
schrift gemäß feucht, und zwar ist es am vorteilhaftesten, das Messer und das Priparat mit $96^{\circ}$. Alkohol zu befeuchten. Im 50 。 Alkohol ist das Celloidin sehr hart geworden, aber seine Schnittfähigkeit ist gering. Es ist in gewissem Sinne spröde und die Schnitte gelingen nicht. Der 96\% Alkohol weicht dagegen das Celloidin ein wenig auf: gerade genug; um Schnitte bis zu ro $\mu$ und weniger anfertigen zu können, und nicht so stark, daß es zu weich wird, zu nachgiebig gegenuiber dem Messer sich wcrhailt. Man kann an geeignetem Material Schnitte ron $5 \mu$ Dicke anfertigen und kam bis zu to $\mu$ und 5o $u$ ansteigen, ohne dal. die Gleichmäßigkeit der Schnitte leidet. Beim Zentralnervensystem muß man gelegentlich solch dicke Schnitte machen. Das schneidende Messer muß stets sehr feucht gehalten werden.

Für Celloidin gilt die gleiche Regel, wie für Paraffin: kann das Naterial nicht an cinem Tage aufgearbeitet werden, so muß das Messer unbedingt in seiner Klammer stehen bleiben. Und zwar aus den gleichen Gründen wie beim Paraffin. Das Präparat mit seinem Klotz dagegen muß in den $50^{\circ}$.. Alkohol zurüickgebracht werden, damit es nicht eintrocknet, bez. damit es wieder hart wird. G. Alexander hat zwar eine Methode angegeben, das Praparat in der Klammer zu belassen und es trotzdem feucht zu erhalten. Doch erscheint mir diese Methode herzlich überflissig; denn wenn man nur bei Wiederaufnahme des Schneidens die nötige Sorgfalt auf das Einklemmen des Klotzes verwendet - die ganze Präparatenklammer mit Klotz einzulegen, ist nicht bei jedem . Jikrotom möglich - , dann verliert man keinen Schnitt. Der Vollständigkeit halber sei jedoch die Alexandersche Methode angeführt. Man trocknet zunächst den Klotz sorgfältig ab, bestreicht seine obere Fläche dick mit Vaselin, stellt einen Glaszylinder darauf, den man mit dem Härtungsalkohol füllt und deckt mit einer Glasplatte zu. Es mul.3 so viel Vaselin genommen werden, daß der Alkohol nicht abfließen kann. Bei Wiederbenutzung saugt man mit einer Pipette den Alkohol ab und nimmt dann den Zylinder fort.

\section{$\S 5 \mathrm{I}$.}

Die Mikrotome. Dic Erfindung des Mikrotoms rerdanken wir dem bekannten Anatomen His. Der Physiologe Hensen hatte zwar schon cinen ron ihm sugenannten Ouerschnitter konstruiert: ein Instrument, das die Anfertigung düner Schnitte unter dem Mikroskope ermöglichen sollte: doch konnte es sich nicht einfuihren. Die Anwendung war schwierig und die Resultate unzureichend. Das His- 
sche Instrument hat dagegen sehr bald die IVelt erobert. Denn die ausgedehnte Anwendungsmöglichkeit, die es gewährte, die Gleichmäßigkeit der mit ihm anzufertigenden Schnitte, die Möglichkeit, ein Objekt in eine lïckenlose Serie von vielen hundert Schnitten zu zerlegen: all das waren so vielversprechende Vorteile; daß die Forscherwelt berechtigterweise den Hisschen Gedanken mit Eifer ergriff und das ron ihm angewandte Prinzip, dic Ersetzung der I Iand durch ein I'rïzisionsinstrument, aus- und durchzubilden suchte. Die Tatsache: daß His das erste Mikrotom konstruiert hat - es war, wenn ich nicht irre, ein hölzernes Instrument -, scheint fast allenthalben in Vergessenheit geraten zu sein; die alte Erfahrung: über Phidias und Praxiteles ist der Name des Erfinders des Meißels verschollen. Seit der Hisschen ersten Publikation über die mit seinem Instrument erzielten Ergebnisse sind zahlreiche Mikrotome verschiedener Bauart konstruiert worden. Es gibt sehr einfache und sehr komplizierte Instrumente, welche den extrawigantesten . Insprüchen der Mikroskopiker Genüge leisten sollen und auch meistens Genüge leisten. Wie immer aber das . Nikrotom auch beschaffen sein möge, unerlialiche Vorbedingung für ein erfolgreiches Arbeiten mit ihm ist peinlichste Genaugkeit in der Handhabung les mechanischen Apparate's und größte Sauberkeit. Terstaubte, eingeschmutzte, gar verrostcte Instrumente beweisen nach meinem Uafuirhalten unzweideutig, daß der Besitzer nicht zu mikrotomicren versteht, daß er mit dem l'rïzisionsinstrumente nicht präzis umzugehen gelernt hat.

Nicht gar so selten mißlingen die Mikrotomschnitte; dem Anfänger wird das zunächst sehr häufir passieren. dem Geuibteren dann, wann or den Mechanismus des Instrumentes nicht genïgend verstanden hat. Dats werlen freilich weder dur Anfänger noch der Geubtere zugeben wollen, daß die Schuld fuir das Miß3lingen an ihnen liegt; sie werden fälschlich das Instrument anklagen. Ich bin aber der Meinung, die ich allezeit als zutreffend crkannt habe: das Instrument hat immer recht. Mißlingt ein Milirotomschneiden, dann sche man erst genau nach, ob man die Vorbereitungen zum Schneiden auch so getroffen hat, wie es der Mechanismus des Instrumentes verlangt. In fast allen Fallen wird sich crgeben. dals eine oder die andere Kleinigkeit uibersehen wurde, ron deren Beachtung das Gelingen der Schnitte abhängig ist.

Ich gebe nun die Schilderung der Mikrotome, unter denen man die folgenden vier Grundprinzipien unterscheiden kann: I. SchraubenZylindermikrotom, 2. Schienenmikrotom, 3. Schrauben-Schienenmikrotom, 4. automatisches oder Schaukelmikrotom. 
5. Schrauben-Zylindermikrotom. In unvollkommener IVeise zuerst ron Ranvier konstruiert, wurde dies Instrument dann von Schiefferdecker verbessert. Der Körper des Mikrotoms ist ein Netalizylinder, in welchem das Objekt durch eine Klemmschraube festgchalten wird. An seinem oberen Rande befindet sich eine drehbare Platte, auf welche das gewöhnliche Rasiermesser aufgelegt wird. Durch das Drehen der Platte rückt deren Ebene am Präparat herab und man kann so den überstehenden Teil des letzteren mit dem Rasiermesser in Gestalt eines feinen Schnittes abschneiden. Dieses sehr primitive Schiefferdeckersche Mikrotom, das seinerzeit mit Recht als ein brauchbares Instrument galt, ist heutigen Tages antiquiert. Denn die Anfertigung der Schnitte ist eine unsichere, wenn auch das Material sehr fest steht.

Das Guddensche Mikrotom, das zum gleichen Typus gehört, sich aber mehr dem Ranvierschen Modell nähert, besteht aus einem in eine große Wanne fest eingelassenen Metallzylinder; auf dessen Boden ein Stempel sich befindet, der durch eine Mikrometerschraube höher und tiefer gestellt werden kann. In den Zylinder kommt das Gehirn eines Säugetieres - und nur für Gehirne ist das Instrument verwertbar - , das mit der im sechsten Kapitel unter Nr. 5 angegebenen Gud denschen Masse (S. 88) umschmolzen wird. Ist diese Masse erstarrt, dann füllt man die Wanne mit Wasser. Die Schnitte werden mit einem eigens konstruierten Rasiermesser angefertigt, das man mit beiden Händen führen muß. Sie schwimmen im Wasser umher und müssen auf breiten Glasplatten aufgefangen werden. Für alkoholisches Material ist das Instrument nicht verwendbar; für Gehirne, namentlich auch für Menschengehirne dagegen, die aus Müllerscher Lösung direht geschnitten werden sollen, ist es sehr brauchbar. Der bekannte Psychiater Forel hat einige Regeln gegeben, welche derjenige beachten muß, der mit diesem Instrumente erfolgreich schneiden will. Die Einbettungsmasse, weil sie nur das Präparat im Mikrotomzylinder stiitzen soll, muß so weit bei Beginn des Schneidens abgetragen werclen, wie man zu schneiden gedenkt und wie es möglich ist, ohne die ruhige Stellung des Präparates zu gefährden. Das Messer darf nicht in die Masse treffen, da es verschmiert werden würde. Soll das Schneiden unterbrochen werden, so entleert man die Wanne und überzieht die Oberfläche des Objektes mit neuer Guddenscher Masse. Bei der Messcrfiihrung - das sei noch hinzugefuigt - muß man ganz gleichmäßig zichen, sonst bekommon die Schnitte sogenannte Treppen.

Eine ganz ausgezeichnete Modifikation des Schrauben-Zylinder- 
mikrotoms ist das Jungsche Gefriermikrotom, mit dem auch paraffiniertes Material geschnitten werden kann. Das Prinzip besteht darin, daß ein das Präparat tragender Metallzylinder in den Zylinder des Mikrotomkörpers fest eingesetzt und durch eine an der Unterfläche vorhandene Mikrometerschraube gehoben wird. Das Instrument, das an den Arbeitstisch angeklemmt wird, trägt in einer beweglichen Achse den Messerhalter, der zugleich mit dem Messer durch die Hand in einem Halbkreise bewegt wird. An derselben Achse ist in der Höhe der Mikrometerschraube eine Klaue federnd angebracht, welche die Schraube automatisch einstellt. Bewegt man nun den Messerhalter an seinem Griffe so, daß er von dem Arbeitenden entfernt wird, dann zieht die Klaue die Schraube an - die dadurch herbeigeführte Schnittdicke ist regulierbar - und das Präparat wird in die Höhe gehoben. Man muß die Bewegung soweit führen, daß der Griff des Messerhalters an den Träger der drehbaren Achse anschlägt, sonst wird die Schraube nicht genügend gehoben. Dann macht man mit dem Griffe eine schnelle Bewegung nach der entgegengesetzten Richtung und stößt dadurch das Messer durch das Präparat. Dies kann man so lange fortsetzen, bis entweder das Naterial erschöpft oder die Schraube zu Ende ist. Bei nur einigermaßen genügender Sorgfalt im Arbeiten läßt sich die Handhabung dieses Instrumentes sofort erlernen und beherrschen. Für Celloidinmaterial ist es ungeeignet.

6. Schienenmikrotom. Eine viel ausgedehntere Anwendung gestattet das Schienenmikrotom, da es für jede Einbettungsart und auch für nacktes oder umrandetes Material sich eignet. Zuerst von RivetLeiser angegeben, dann von Fritsch verbessert, hat es durch Thoma seine höchste Vervollkommnung erfahren. Es wird von verschiedenen Instrumentenmachern in den Handel gebracht, die seine Mechanik so durchgearheitet haben, daß die Anfertigung tadelloser Schnitte sogar durch ein unzerlegtes Menschenhirn möglich ist.

Der Körper des Mikrotoms besteht aus einer metallenen, langen Fußplatte und aus einer senkrecht auf dieser stehenden ebenfalls metallenen langen und ziemlich hohen Platte. $\mathrm{Zu}$ beiden Seiten der letzteren sind zwei Schienen so angebracht, daß sie mit der senkrechten Platte einen mehr oder weniger spitzen Winkel bilden. Bei manchen Mikrotomen sind diese Schienen mit dicken, rollkommen ebenen Spiegelglasplatten belegt, was die Reinhaltung des Instrumentes sehr erleichert. Die rechte Schiene trägt den Messerschlitten; ihre Achse ist parallel der Grundplatte. Der Messerschlitten hat einen dreieckigen Durchschnitt, ist schwer und trägt auf seiner oberen 
Fläche, der Basis des Dreiecks, den Messerhalter, in den das Messer eingespannt wird. Die linke Schiene trägt die Praparatenklammer. Damit diese, wenn sie vorgeschoben wird, ansteigt und so das Präparat dem Messer entgegen bringt, ist sie nach oben geneigt, d. h. bildet mit der Grundplatte einen spitzen Winkel, dessen Schenkel nach vorn divergieren. Die Präparatenklammer wird durch eine verschiedenartig konstruierte Nikrometerschraube bewegt, welche Schnitte ron I $\mu$ Dicke ermöglichen soll. Die Bahn des Messerschlittens muß sehr sauber gehalten sein und wird vor dem jedesmaligen Gebrauche bei denjenigen Instrumenten, bei welchen sie keine Glasverkleidung trägt, gut mit Paraffinum liquidum (sogenanntem Paraffinöl) eingeölt. Der Schlitten muß, wenn er angestoßen wird, die ganze Bahn mit Leichtigkeit durchlaufen. Auch ist anzuraten, beim Schneiden stets die ganze Bahn den Schlitten entlang zu ziehen, damit ihre Abnutzung eine iiberall gleichmäßige sei. Eine Ölung der Bahn der Präparatenklammer ist nur selten nütig und hat dann nur in einer geringen Anfeuchtung zu bestehen, die ausreicht, um das Netall vor dem Verrosten zu schützen. Wichtig ist es, von Zeit zu Zeit alle Teile des Mikrotoms mit etwas Xylol oder Benzin zu reinigen.

7. Schraubenschienenmikrotom. Der Körper dieses Instrumentes ist wie der des Schienenmikrotoms beschaffen; an seiner rechten Seite trägt es ebenfalls eine Schiene fiir den Messerschlitten. Der Unterschied gegen das vorige Mikrotom besteht darin, daß an der linken Seite die Präparatenklammer nicht auf einer Schiene läuft, sondern daß sie durch eine Mikrometerschraube senkrecht in die Höhe gehoben wird. Zu dem Zwecke ist die Präparatenklammer in geeigneter II eise am vorderen Ende des Instrumentes angebracht und die Mikrometerschraube durchbohrt die Fußplatte des Nikrotoms, um genügenden Spielraum nach unten zu haben.

An beiden Instrumenten ist eine Vorrichtung angebracht, um das Präparat nach vorn oder hinten sowie nach rechts oder links zu senken. Da ferner dessen Drehung um die eigene senkrechte Achse ohne weiteres möglich ist, so sind wir imstande, die Präparate nach den drei Dimensionen des Raumes zu orientieren. Beide Instrumente ferner verlangen entweder eine Fiihrung des Messerschlittens mit der Hand oder besitzen Einrichtungen, den Schlitten mittels einer Kurbel mechanisch zu hewegen. Beides will gelernt sein, sollen der Schlitten und das Messer ihre Bahn gleichmäßig durchlaufen.

Jedes der beiden Nodelle hat seine Vorzuige und seine Nachteile. Ein Nachteil des Schrauben-Schienenmikrotoms besteht darin, daß die Mikrometerschraube leicht schlottert oder leicht sogenannte tote 
Gänge bekommt. In letzterem Falle dreht sich wohl die Schraube, aber das Präparat wird nicht gehoben. Diesen Fehler habe ich beim Schienenmikrotom nie gefunden. Des letzteren Nachteil, der beim Schrauben-Schienenmikrotom nicht vorkommt, ist darin zu sehen, daß, wenn die Bahn, welche die Präparatenklammer durchläuft, zu Ende ist, das Präparat gehoben werden muß und dann nur allzuleicht sich um seine Längsachse (senkrechte Achse; drehen kann. Dann aber, und wenn diese Drehung auch nur einen Bruchteil eines Millimeters ausmacht, ist der Winkel des Präparates zum Messer verändert und dadurch ist auch die Schnittebene eine veränderte geworden. Hat man ferner ein Präparat zu verarbeiten, welches so hoch ist, daß die obere Fläche des Messerschlittens und damit das Messer zu tief stehen, dann muß letzteres durch untergelegte Metallklötze gehoben werden. Bei der geringen Hubhöhe nun, welche für das Präparat beim Schienenmikrotom ermöglicht ist, kommt man sehr bald an einen Punkt, wo das durch die Klötze gehobene Messer zu hoch über dem Präparate steht, dieses aber, wenn anders es fest in seiner Klammer sitzen soll, nicht mehr gehoben werden kann. Dann muß man das Messer durch Entfernung der stützenden Klötze senken und dabei verändert sich ganz unvermeidlich sein Winkel zum Präparat. Hierdurch wird wiederum die Schnittebene geändert - durch einen Versuch kann sich jedermann auf das leichteste hiervon iiberzeugen - und damit geht Naterial verloren.

8. Automatisches oder Schaukelmikrotom. Während bei den bisher beschriebenen Instrumenten das Messer stets in einer eigenen Bahn mittels einer Kurbel oder mit der Hand bewegt wird, besteht das Prinzip der automatischen Mikrotome, von denen verschiedene Modelle existieren, darin, daß das Messer fest stcht und das Präparat gegen seine Schneide vorgeschoben wird. Dieses geschieht auf mechanischem Wege bei gleichzeitiger Drehung der Nikrometerschraube. Hierbei ist nur ein Schneiden mit quergestelltem Messer möglich; die Anfertigung sehr schnittreicher Serien geschieht außerordentlich schnell. Fast alle Modelle automatischer Mikrotome haben den großen Nachteil, daß von dem Präparat nicht eine gerade Ebene, sondern ein Kreissegment oder ein Teil eines Zylindermantels abgeschnitten wird. Das ist belanglos bei ganz kleinem Naterial, dagegen eine beträchtliche Fehlerquelle bei nur einigermaßen voluminösen Objekten. Soll der eben gerügte Fehler vermieden werden, wie das bei einem Modelle der Fall ist, dann schlottert die Präparatenklammer und es leidet dadurch die Sicherheit der Schnittfiihrung. Wie die quere Messerstellung so lehne ich auch die Schaukelmikro- 
tome ab: ich sehe keine Notwendigheit ein, in einer Viertelstunde ein paar hundert Schnitte anfertigen zu können. Zum exakten Arbeiten muß man sich Zeit lassen oder man soll iiberhaupt nicht histologisch arbeiten.

\section{$\S 52$.}

Das Schneiden gefrorenen Materials. An dem in Nr. 5 dieses Kapitels (\$ 5 I, S. I 26) beschriebenen vortrefflichen Schrauben-Zylindermikrotom ron Jung läßt sich in geeigneter Weise eine Einrichtung treffen, durch die man das Material zum Gefrieren bringen kanm. Der die Präparate tragende Klotz, welcher, selber zylindrisch gestaltet, in den Milirotomzylinder eingeschoben wird, ist nämlich hohl und so ist es möglich, seine obere Fläche von unten her durch verstäubten Äther Athyläther so abzukühlen, daß das Präparat gefriert. Vielfach wird auch Äthylchlorid als Abkühlungs- hzw. Gefriermittel empfohlen. Für den Gebrauch des Gefriermikrotoms sei die Beachtung der folgenden Regeln empfohlen, die die Zusammenfassung von Erfahrungen sind, welche ich bei ausgedehnter Benutzung dieses Instrumentes gesammelt habe.

Vor allem muß endlich mit der Auffassung gebrochen werden, als könnte man von ganz frischem, d. h. nicht fixiertem bzw. gchärtetem Material irgendwie brauchbare Präparate durch Gefrierenlassen erlangen. Daß Strukturbilder nicht an unfixiert gefrorenen und dann wieder aufgetauten Zellen und Geweben zu erhalten sind, wird wohl selbst von den begeistertsten Verehrern der Gefriermethode zugegeben. Frisches Naterial - erst gefroren, dann aufgetaut - zeigt keine normalen Bilder mehr. Die Eiskristalle, welche sich beim Gefrieren gebildet haben und bilden mußten, sollte das Objekt die genügende IIärte zum Schneiden erlangen, haben alle Zellstrukturen zerstört. Die Zellen und die Gewebe erscheinen oft fein durchlöchert, wie mit feinsten Nadeln durchbohrt, und dies ist die Wirkung der Eiskristalle. Ich hin daher der Meinung, dal3 die Methode, frisches Material gefriercn zu lassen und die von ihm angefertigten Schnitte zu mikroskopieren, jedes wissenschaftlichen Wertes entbehrt, weil sie niemals eine gute Erhaltung der Organelemente gewährt.

Das zu untersuchende Material muß aus diesem Grunde vorher fixiert sein. Aber auch dann wird man nicht mehr von der Gefriermethode crwarten dürfen, als sie zu leisten vermag. Vorzügliche Texturbilder sind damit zu erhalten: der Aufbau des Zentralnervensystems, die Verteilung der Pulpa in der Milz usw., lassen sich sehr gut an Gefrierschnitten studieren. Aber trotz der rorhergegangonen 
Fixierung muß man auf die Gewinnung feinster Strukturbilder Verzicht leisten. Woran dies liegt, kann ich nicht genau sagen. Eine Durchlöcherung der Organbestandteile durch Eiskristalle findet am fixierten Material nicht statt, wahrscheinlich weil die das Material erfüllende Flüssigkeit im Gegensatz zur Parenchymflüssigkeit gleichmäßig, d. h. amorph, gefriert. Dennoch aber gibt die Untersuchung der Zellsubstanzen mit stärksten Immersionslinsen keine befriedigenden Resultate. Die Zellleiber erscheinen trübe, fast homogenisiert, die Kerne entbehren feinerer Strukturbilder. Ob hier die Wirkung des Gefrieren- und wieder Auftauenlassens vorliegt, wage ich nicht $\mathrm{zu}$ entscheiden. Aber von diesem einzigen Nachteil abgesehen, liefert die Nethode sehr brauchbare Präparate; man muß ja nicht immer und nicht allenthalben Zellstudien machen.

Fixiertes Material muß vor dem Gefrieren gehärtet werden, es sei denn, man habe zur Fixierung Kali bichromicum oder Nïllersche Lösung gebraucht: Reagentien, die bekanntlich gleichzeitig fixieren und erhärten. Versäumt man nämlich die Vorhärtung, dann schrumpfen die Schnitte, wenn sie nach der Färbung in Alhohol entwässert werden sollen, so beträchtlich, daß sie in ihrer Form oft ganz unkenntlich werden. Damit ist zugleich eine mikroskopische Untersuchung gänzlich ausgeschlossen.

Hat man Kali bichromicum- oder Müller-Material, welches die geniigende Härte besitzt, dann wässert man flïchtig in Aqua destillata aus, lediglich um den Metallzylinder des Gefriermikrotoms nicht $\mathrm{zu}$ beschmutzen. Formolmaterial muß wie jedes auf andere Weise fixierte Objekt auf mindestens $2+$ Stunden in $96^{\circ}$. Alkohol kommen oder man kann auch in reines Aceton einbringen. Dann, wenn man annehmen kann, daß Alkohol oder Aceton völlig in das Präparat eingedrungen sind, muß letzteres gewässert werden. Man wirft es also in destilliertes Wasser und wartet, bis es darin untergesunken ist; dann erneuert man das Wasser. Fällt das Objekt jetzt sofort auf den Boden der das Wasser enthaitenden Schale, dann kann geschnitten werden, schwimmt es dagegen noch, dann mul das WTasser erncuert werden. Hicrmit ist so lange fortzufahren, bis die Objekte nicht mehr schwimmen.

$\mathrm{Zu}$ beachten ist ferner, dal das Material keine bindegewebige Hülle haben darf. Hat man z. B. von einem Stück Riickenmark die Pia nicht abgezogen, dann gefriert das Stück nicht, und wenn man noch so lange mit dem đ̈therspray arbeitet. Pia mater, bindegewebige Kapseln der Organe usw. sind daher, am besten vor dem Einbringen in die Härtungsfliissigkeiten - bei Chromsalzpräparaten 
nach dem kurzen IVässern -, sorgfältig mit einer Pinzette abzuziehen.

Es ist ron mancher Seite empfohlen worden, auf die Platte des Mikrotomzylinders, bevor man gefrieren läßt, ein Stückchen Seidenpapier zu legen. Dies ist unzulässig, denn das Papier hält das Gefrieren ungebihrlich auf, ja macht es zuweilen ganz unmöglich.

Das aus dem Wasser oder der chromsalzhaltigen Lösung entnommene Objekt wird auf die obere Platte des Mikrotoms gestellt. Man sieht dabei, daß das vom Objekt abfließende IVasser auf dem Metall zu einem Tropfen zusammenfließt. Würde man jetzt zum Gefrieren bringen und dann schneiden, so würde das Objekt sehr bald von seiner Unterfläche abreißen, die Arbeit wäre also vergebens gewesen. Um dies zu vermeiden, verfahre ich stets so, daß ich einen mit einem Hornspatel auf die Platte des Mikrotoms gebrachten Wassertropfen mit dem Zeigefinger der linken Hand zu verreiben suche. Die leichte Erwärmung der Metallfäche, welche dadurch eintritt, bewirkt eine gleichmäßige Verteilung des Wassers auf der Platte. Dann gebe ich noch mehrere Tropfen Wasser zu, stelle das Präparat in die Mitte der Platte und tropfe noch etwas Wasser darüber. Dies ist nach meiner Erfahrung ein sehr wertvoller Kunstgriff. Ist nämlich das Präparat von einem Mantel von Eis umhüllt, dann haften die Schnitte leichter am Messer, legen sich, da die diinne Eislamelle bald schmilzt, eng aneinander, rollen sich nicht ein und lassen sich leicht vom Messer in das Gefäß mit Wasser iibertragen, in das sie vor der Weiterbehandlung kommen müssen.

Ist das Präparat auf die Platte des Mikrotoms gestellt, dann setzt man das Spraygebläse in Tätigkeit. Bald friert die unterste Wasserschicht fest, was sehr leicht zu erkennen ist. Man fährt nun so lange mit dem Zerstiuben des Äthers oder des Äthylchlorids fort, bis die obere Fläche des Präparates ganz trocken geworden ist. Dies ist das Zeichen dafuir, daß das Präparat durch und durch gefroren ist. Am schnellsten gefriert Material, das in Chromsalzen fixiert und gehärtet war, etwas weniger schnell Acetonmaterial, am langsamsten alkoholisiertes und dann gewässertes Material. Die Zeit, in der das vollstündige Gefrieren eintritt, hängt ab von der Höhe des Präparates, während dessen Breite gleichguiltig ist. Das läßt sich verstehen. Die Kälte dringt von unten nach oben in das Präparat ein und in diesem weiter. Bei breiter Grundfläche, sofern diese nur nicht die Breite der oberen Metallplatte ïberschreitet, wirkt die Kälte zwar auf eine linear ausgedchntere Masse cin, als hei schmaler; aber da die Metallplatte in ihrer ganzen Ausdehnung gleichmäßig abgekiihlt wird, so verschlägt 
es nichts oder nur wenig, ob das, was mit ihr zusammen abgekiihlt werden soll, das Präparat, eine Grundfläche von einem Millimeter oder einem Centimeter hat. Von Wichtigkeit ist dagegen die Höhe des Präparates. Je höher dieses, um so längere Zeit braucht die Kälte, um nach oben zu gelangen. Ich halte eine Höhe von $5 \mathrm{~mm}$ fuir das Optimum, bei welchem eine gleichmäßige und schnelle Gefrierung zu erzielen ist. Man sollte nicht unnötig höhere, nicht unnötig niedrigere Objekte wählen; jene gefrieren zu langsam und werden nicht gleichmäßig hart, diese gefrieren zu schnell und werden dabei leicht spröde.

Ist das Präparat durch und durch gefroren, dann kann man mit der Ätherzerstäubung aufhören; selten wird es nötig sein, wïhrend des Schneidens, das jetzt folgt, den Spray noch ab und zu in Bewegung zu setzen. Denn das Gefrieren geht noch immer weiter fort, auch wenn man den Spray ruhen läßt. Man sicht dies daran, dal3 die ()berflïche der Platte nach und nach trocken wird, weil der Ïther, welcher sich in dem Metallzylinder auf dem Boden gesammelt hatte, allmählich verdunstet. Und man sicht dies ferner daran, dall die Außenwand des Mikrotoms mit Schnec beschligt. Die Oberfläche der Platte war feucht gewesen, vielleicht weil Ithertropfen, die von unten her gegen die l'latte treffen sollten, seitlich aus dem Zylinder ausgetreten sind und sich auf der Platte niedergeschlagen haben. Ihre Verdunstung bewirlt ebenfalls dic Trocknung der Oberfläche.

Fängt man nun an zu schneiden, so muß man zuerst vorsichtig das Messer durch das Präparat stolken. Man bewirkt dadurch, daß der Schnitt sich der Klinge anlegt und ein wenig taut. Der nun folgende Schnitt legt sich dann dem ersten leicht an und auf und man behält dann die ganze Schnittmasse während des Schncidens auf dem Messer, von dem man sie iibrigens je nach Belieben, indem man mit der Messerfuhrung einige Sekunden pausiert, auch vor Erschöpfung des Naterials in Wasser bringen kann. Zuweilen aber legt der Schnitt der Messerklinge sich nicht an, sondern springt ab und kann dann verloren gehen. Das ist besonders bei chromiertem Material der Fall und ist darauf zuriickzuführen, daß das Messer infolge der von dem Präparat ausstrahlenden Kälte seinerseits zu stark sich abkiihlt. Ich begegne diesem Nachteile in der Weise, daß ich mit dem Finger ein Minimum von Wasser auf die Stelle der Messerschneide bringe, welche in das Präparat eindringt. Infolge der dadurch bewirkten Erwärmung der Schneide tauen die ersten Schnitte und die nächstfolgenden legen sich leicht an. Doch muß man hier aufpassen; die übermäßige Abkuihlung stellt sich bald wieder ein und das alte 
Spiel beginnt ron neuem. Man nimmt daher die gemachten Schnitte herunter und befeuchtet die Schneide von neuem.

Die Schnitte müssen in einer Schale mit destilliertem Wasser aufgefangen werden. Man bringt sie am besten in diese so hinein, dars man mit cinem feinen Hornspatel die Schnittmasse an die Messerschneide schiebt und sie in das untergehaltene Gefäß mit Wasser fallen läßt. Im Wasser breiten sich die Schnitte aus und schwimmen manchmal an der Oberfläche. Man muß sie nun einzeln mittels einer Platinnadel in eine Schale mit frischem destilliertem Wasser bringen, damit das Schmelzwasser ganz entfernt wird. Zuweilen schwimmen die Schnitte, weil eine minutiöse Luftblase, die ihnen anhaftet, sie hoch hält. Die Luftblase kann man mit großer Vorsicht und Übung durch eine Platinnadel entfernen; oft ist es hierfür auch empfehlenswert, die Schale mit den Präparaten über Nacht in den Brütofen (Temperatur bis $37^{\circ}$ C.) zu bringen. Wenn alles nichts hilft, dann muß man bis zur Entwässerung warten; im Alkohol zerplatzen die Luftbläschen. Die fertigen, gut gewässerten Schnitte bchandelt man beiebig weiter.

Es sind von verschiedenen Autoren eine ganze Anzahl von Gefriermassen empfohlen worden, mit denen man das Material durchtränken soll, bevor man es zum Gefrieren bringt. Ich halte dies für zwecklos. Solche Massen sind allenfalls dann anwendbar, wenn es sich um Gebilde handelt, die in Hohlrïumen stecken. Diese würden beim Auftauen der Schnitte herausfallen. Dann benutze man eben bei solchen Objekten das Gefriermilirotom nicht! Ich bin überhaupt der Meinung; daß die Gefriermethode nur auf homogenes und zugleich kompaktes Material anzuwenden ist, bei zarten Objekten oder ungleichmäßig zusammengesetzten aber vermieden werden soll.

\section{$\S 53$.}

Freihandschneiden. Nacktes, d. h. nicht eingeschmolzenes oder nicht eingebettetes Material, das man in Klemmleber oder Hollundermarl: gebracht hat oder das man ohne diese beiden I Iilfsmittel schneiden will, falst man zwischen Zeigefinger und Daumen der linken Hand. Mit der Rechten führt man das gut mit starkem Alkohol befeuchtete Rasiermesser. Wan bringt dieses an den Rand des Präparates so. daß die Schneide dem Untersucher zugekehrt ist. Dann zieht man gleichmäßig in nicht zu schnellem und nicht zu langsamem Tempo das Messcr durch das Präparat. Um den Schnitt möglichst dünn zu erhalten, soll man das Präparat erst mit schräg gestellem Messer einschneiden und dieses dann parallel zur Obcrfläche des Prïparates 
richten. Gewöhnlich sind nur die Stellen des Schnittes hinreichend duinn, an die das Messer zuletzt gekommen ist. Der Schnitt wird mit Alkohol von der Oberfläche der Klinge abgespült. Diese Methode, einstmals die einzige, über welche die Forscher geboten, ist heutigen Tages antiquiert und sie hat daher auch nur aus einer gewissen Pietät und aus didaktischen Gründen hier Erwähnung gefunden. Selbst der pathologische Anatom, bei dessen Arbeiten es häufig nur darauf ankommt, an einem wenn auch unvollkommenen Schnitte rasch eine Diagnose zu stellen, hat das Freihandschneiden nicht mehr nötig; ihm leistet das Gefriermikrotom viel bessere Dienste.

\section{c) Aufkleben.}

\section{$\S 54$.}

Haben wir Celloidinmaterial geschnitten und kommt es uns nicht darauf an, sämtliche Schnitte in ihrer Reihenfolge, wie sie gemacht wurden, aufzuheben, dann beduirfen wir keiner weiteren Zwischenmethode zur Erleichterung der jetzt noch nötigen Behandlung der Schnitte. Denn Celloidinschnitte sind so zäh und widerstandskräftig; daß sie fast jede Mißhandlung ertragen. Anders liegt die Sache, wenn wir die Schnitte insgesamt als eine liickenlose Serie aufheben wollen. Dann müssen wir sie, namentlich wenn sie noch zu färben sind, aufkleben, un die Manipulationen zu erleichtern und um die Schnitte zu schonen.

Paraffinschnitte, wenn sie nicht iibermäßig dick sind, müssen stets aufgeklebt werden. Denn das Paraffin ist unter allen Umständen auszutreiben. Oft müssen die Schnitte gefärbt und weiter behandelt werden, ehe man sie als fertig betrachten und aufheben kann. Dazu sind aber Maßnahmen erforderlich, welche die dünnen und briichigen Schnitte nicht vertragen; sie würden unbedingt zerreißen. Indem man sie auf eine feste Unterlage klebt, erhält man sie unverletzt. Die Aufklebemethoden sind von den Gelehrten der zoologischen Station zu Neapel erfunden worden; die Größe des Verdienstes, das sich hierdurch die Herren Giesbrecht und Paul Mayer erworben haben, vermag nur der zu beurteilen, der, wie der Schreiber dieser Zeilen, Serienschnitte aufheben wollte zu einer Zeit, in der Aufklebemethoden noch nicht existierten. Die Schonung und Ausnuitzung des Materials ist dank der im folgenden zu schildernden Methoden eine volllommene; gelingt die Methode nicht, schwimmen die Präparate fort, dann - dies möge sich der Anfänger einschärfen - liegt dic Schuld nicht an der Methode. 
Ich beschreibe nur die wirklich brauchbaren Methoden. Zufolge der in der mikroskopischen Technik herrschenden Polypragmasie sind auch für das Aufkleben eine Masse Vorschriften entstanden, deren Notwendigkeit nicht einzusehen ist, zumal die wenigsten von ihnen Verbesserungen oder Neuerungen darstellen. Die brauchbaren Nethoden sind die folgenden:

9. Schellackmethode, nach Giesbrecht und P. Nayer. Da der Schellack in Alkohol gelöst werden muß, so ist diese Methode, die älteste aller Aufklebemethoden, nur für durchgefärbtes Material verwendbar. Man bringt in absoluten Alkohol soviel weißen Schellack, wie sich löst. Das Glasgefäß, in dem man die Schellacklösung anfertigt, soll ein hohes Standgefäß sein, weil dies für die Anwendung der Lösung am bequemsten ist. Es wird mit einem Kork verschlossen, der in der Nitte durchbohrt ist; in die Öffnung wird ein Glasstab geschoben, der ganz fest stecken muß. Die Aufklebung geschieht auf dem Objektträger. Den letzteren reinigt man sorgfältig, erwärnt ihn über der Spiritusflamme, damit alle Feuchtigkeit entfernt wird - sonst trübt sich der Schellack - und streicht nun mit dem Glasstabe, dẹr in das Schellackgefäß taucht, schnell über den warmen Objektträger. Dadurch wird dieser mit einer feinen Schellackschicht überzogen. Nan muß hierbei beachten, daß der Glasstab dem Ohjektträger ganz gleichmäßig anliegt; versäumt man dies, so wird der Schellackiiberzug ungleich und muß daher wieder entfernt werden. Das Trocknen der Schellackschicht braucht nicht viel Zeit. Man verreibt nun auf dem Schellacküberzuge nach Giesbrechts Angabe ctwas Nelkenöl oder Kreosot, ungefähr in der Breite des später aufzulegenden Deckglases. Man legt auf diese Nelkenölstelle die Paraffinschnitte - und nur für Paraffinschnitte gilt die Methode drückt sie mit einem Hornspatel leicht an und bringt, wenn eine genügende Anzahl Schnitte aufgelegt ist, den Objektträger in den Wïrmeschrank. Nach etwa Io Minuten sind Öl oder Kreosot verdunstet, das Paraffin gelöst und das mikroskopische Präparat kann nunmehr in der später zu schildernden Weise montiert werden.

l'aul Mlayer nimmt weder Nelkenöl noch Kreosot, sondern er legt die Schnitte direkt auf die Schellackschicht, glättet sie leicht mit einem Hornspatel und bringt die Objektträger, wenn sie mit der ausreichenden Zahl ron Schnitten beschickt sind, in einen Glaszylinder, auf dessen Boden etwas Äther sich befindet. IIan verschließt den Zylinder mit einem Korlien, senkt ihn, sodaß dic Itherdämpfe auf die Schnitte kommen, nimmt nach einigen Sekunden den Objektträger heraus und bringt ihn in den Wärmeschrank. 
Der Vorteil dieser beiden Methoden, die absolut sichere Befestigung der Schnitte auf dem Objektträger, ist ganz evident. Ein großer Nachteil haftet ihnen aber an, sodaß sie in den letzten Jahren nur noch wenig verwendet werden, und nur bei solchem Material, das nicht auf Jahre hinaus zu Vergleichszwecken aufgehoben werden soll. Dieser Nachteil besteht darin, daß im Laufe der Jahre der Schellack aus der Umgebung Feuchtigheit aufnimmt und sich dadurch trübt. Dann aber sind die Präparate verloren, da auch sic trübe geworden sind und nicht wieder geklärt werden können.

Io. Kollodiumnelkenöl-Methode, nach Schällibaum. Auch diese Nethode ist nur für durchgefärbtes Paraffin-Material geeignet, weil das Kollodium bei eventueller Nachfärbung durch den Entwäisserungsalkohol aufgelöst werden würde und dadurch die aufgeklebten Schnitte sich ablösen müßten.

Man mischt 3 Teile Nelkenöl mit I Teil Kollodium, streicht von dem Gemisch ein wenig auf einen Objektträger, ordnet die Schnitte auf ihm und legt ihn auf das erhitzte Wasserbad. Das Nelkenöl verdampft und die Schnitte kleben fest. Nan darf nicht zuviel von dem Gemisch nehmen, sonst schwimmen die Schnitte beim Abdampfen fort.

Rabl hat diese Mcthode in der Weise modifiziert, daß er 3 Teile Nelkenöl und 2 Teile Kollodium nimmt. Dieses muß vollkommen klar sein und lange gestanden haben, jenes muß recht hell sein; die Mischung wird immer alle 4-5 Tage erneuert. Auch dampft Rabl das Nelkenöl nicht auf dem Wasserbade ab, sondern erwärmt die beschickten Objektträger über der Flamme des Bunsenbrenners, bis das Paraffin geschmolzen ist, und montiert dann sofort.

II. Aufkleben mit Aqua destillata. Von Gaule wurde zum Aufkleben $50^{\circ}$. Alkohol empfohlen; doch hat sich diese Methode nicht bewährt, da die Schnitte nicht immer fest an ihrer Unterlage haften. Mehr Freunde hat die Anwendung des destillierten Wassers gefunden, das, wenn ich nicht irre, Gaule und NuBbaum empfohlen haben. Bei dieser Methode, die wie die vorigen nur für paraffiniertes Material gilt, handelt es sich mangels eines Klebestoffes natürlich nicht um ein Aufkleben. Das Haften der Objekte an ihrer Unterlage ist nichts weiter als eine Wirkung der Kapillarattraktion.

Handelt es sich darum, zwei oder drei Schnitte auf einmal auf dem Objektträger unter einem Deckglase zu haben, so leistet die Methode sehr Gutes; ja sie ist bei Nachfärbung der Objekte darum von besonderem Wert, weil keine Klebemasse da ist, die sich mitfärben könnte. Andererseits aber versagt die Methode doch auch 
recht oft, und umfangreiche Serien mit ihr aufzukleben ist dirckt zu widerraten. Je größer die Zahl der Schnitte ist, die gleichzeitig auf einen ()bjekttrïger geklebt werden sollen, um so unsicherer ist die Wirkung dieser Methode und um so größer dementsprechend die Gefahr, wertvolles Material zu verlieren.

Man reibt die Objektträger oder Deckgläser, auf die man aufkleben will, mit einem feuchten Tuche ab, damit sich das Wasser auf ihnen gleichmäßig verteilen kann. Dann bringt man mit einem Haarpinsel destilliertes Wasser in solcher Menge auf, daß die Präparate auf ihm schwimmen; es darf aber nicht überfließen. Auf dem Wasser breiten sich die Schnitte glatt aus. Man stellt dann in den Briitschrank bei $3 i^{\circ} \mathrm{C}$. Temperatur und läßt das Wasser langsam verdampfen. Meist ist dies nach einer Nacht erfolgt. Dann, wenn die Gläser rollkommen trocken geworden sind, kleben die Schnitte ihnen fest an. Hicr braucht nicht hloß durchgefärbtes Material verwendet zu werden, hier kann man nachfärben, sodaß die Gebrauchsfähigkeit der Methode umfänglicher ist, als die der beiden vorhin beschriebenen Methoden.

I 2. Eiweißmethode, nach Paul Mayer. Diese Methode, namentlich in ihrer Kombination mit Wasser nach Henneguy, macht meines Erachtens alle übrigen Aufklebemethoden, soweit es sich um Paraffinmaterial handelt, überfliissig. Zuverlässigkeit in der Wirkung, Leichtigkeit der Anwendung, Brauchbarkeit für die meisten Nachfärbungen des Materials: das sind Vorteile, wie sie keine der anderen Methoden in sich vereinigt. Allerdings darf man nicht mit alkalischen Fliissigkeiten an Objekte kommen, die mit Eiweiß aufgeklebt sind: denn Eiwciß löst sich in Alkalien. Auch darf man nicht zu riel Eiweiß nehmen, sonst färbt sich dieses in höchst störender Weise mit. Gegen ersteren Nachteil, weil er dem Reagens als solchem anhaftet, kann man sich nur dadurch schiitzen, daß man mit Eiweiß aufgeklebte Schnitte nicht in alkalischen Fliissigkeiten nachbehandelt. Letzteres ist kein Nachteil der Nethode, sondern nur eine Ungeschicklichkeit des Arbeitenden, die durch Übung beseitigt werden muß.

Man nimmt das Weiße eines frischen Hïhnereies, gießt es in einen Maßzylinder, um seine Quantität festzustellen, und schlägt es in einer Porzellanschale oberfächlich zu Schnee, nachdem man es vorher mit einer Schere zerschnitten hat. Dann setzt man die gleiche Quantität reinun Glyzurins hinzu, mischt beides durch Schiitteln und hebt in einem weithalsigen, mit Kork zu verschließenden Glas ofefi.. auf. Zur Verhiitung der Fäulnis bringt man einige Stiicke Kampfer in das Gefäß. Dieses Glyzerineiweiß hält sich Jahre lang unverändert. 
Nur wenn die gelbliche Flissigkeit eine bräunliche Farbe angenommen hat, dann ist sie nicht mehr verwendbar, denn dann hat sie keine klebenden Eigenschaften mehr. Wanche Autoren, wie Mann, verdünnen das Eiweiß mit Wasser. Ich halte das für ganz irrationell, weil durch die Wasserverdinnung die Lösung trübe wird und zwar gleichgültig, ob man Wasser zu reinem oder zu Glyzerineiweiß zusetzt. Das Glyzerin setzt man zum Eiweiß, damit sich dieses gleichmäßig auf Objektträger oder Deckglas verteilen läßt.

Ian klebt am besten mit der Kombination Eiweiß-destilliertes Wasser auf: eine Methode, die allen Anforderungen genugt. Folgendermaßen ist dabei zu verfahren:

Objekttrïger oder Deckgliser, die gut gereinigt sein müssen, werden mit einem ganz feinen Tröpfchen Eiweißglyzerin nach Paul Maycr befeuchtet. Dann zerreibt man das Tröpfchen auf der Glasplatte ()bjektträger usw., so dals diese nicht mehr feucht, sondern nur noch glänzend ist. Es soll dadurch vermieden werden, dals zuviel lïreiß auf dem ()bjektträgur oder Deckgläschen vorhanden ist. weil es sich beim Färben sehr stark mitfärbt. Dann bringt man nach Henneguy einen Tropfen destillierten Wassers auf die Eiweil3schicht, der sich glatt aushreiten muls. Auf das Wasser legt man die Paraffinschnitte, haucht sic nach der Empfehlung von Albrecht und Stoerk an, damit sie sich auf dem Wasser glatt ausstrecken, und stellt in den Briitschrank $37^{\prime \prime}$ C.) Am anderen Morgen ist das Wasser verdunstet und die Schnitte liegen der Eiweilsschicht dicht an. Jetzt schieht man die beschickten Deckgliser oder ()bjektträger in den Wärmeschrank für $10-20$ Minuten, damit bei $65^{\circ} \mathrm{C}$. das Jiweil3 gerinnt. Man kann auch die Präparate schnell durch die Spiritusflamme ziehen; schmilzt das Paraffin, dann ist meist auch das Eiweil\} geronnen. Man läß dann noch die ()bjekitträger bzw: Deckglïser, Wenn sie aus dem Wärmeschrank genommen sind, abkühlen und kann beliebig weiter behandeln.

I 3. Serumalbuminmethode, nach M. Heidenhain. Dieser Gelehrte empfiehlt folgendes Terfahren, das sich natürlich auch nur für Paraffinschnittc cignet. Man zerreibt Albuminum purissimum Merck (aus Bluti zu einem schr feinen Mehle. Davon giht man $+\mathrm{g}$ auf $100 \mathrm{ccm}$ Aqua destillata, schüttelt stark um, lälst $2+$ Stunden absetzen, dekantiert und filtriert. Dann setzt man dazu das gleiche Volumen $50^{\circ}$. Alkohol. Mit dieser Mischung bestreicht man Deckgläser oder Objektträger und bringt die Schnitte darauf.

14. Eiweiß für Celloidinschnitte, nach Argutinski. Die bisher geschilderten Methoden dienten nur für Paraffinmaterial. die jetzt zu 
schildernde bildet den Übergang zu den nur für Celloidinmaterial geeigneten, indem sie einen Teil der Eiweißmethode für Celloidinschnitte verwendet.

Nach Argutinski soll man die Schnitte von Celloidinmaterial in $70^{\circ}$. Alkohol auffangen. Vorher hat man sich Objektträger hergerichtet, die mit Mayers Glyzerineiweiß bestrichen und bei $100^{\circ} \mathrm{C}$. im Trockenschrank erhitzt wurden. Auf solche Objektträger bringt man die Celloidinschnitte. Sind deren genügend auf einem Objektträger angeordnet, so saugt man vom Rande aus den Alkohol ab, legt einen 8- I 2mal gefalteten Streifen Filtrierpapier auf die Schnitte und streicht mehrere Male sehr fest uiber den Streifen, um durch den auf diese Art ausgeübten Druck die Schnitte fest anzukleben. Man nimmt dann das Filtrierpapier $a b$ und hebt den Objektträger bis zur Weiterbehandlung in destilliertem Wasser oder, wenn man mehrere Tage warten muß, in diinnem Alkohol auf. Die Schnitte kleben fest.

I5. Kollodiumlappenmethode, nảch Weigert. Celloidiniertes Material, wenn es in eine fortlaufende Schnittserie zerlegt werden soll, muß aufgeklebt werden. Den ersten IVeg hierzu bot die in den folgenden Zeilen zu schildernde Methode von Weigert. Sie ist indessen sehr umständlich und daher mit Recht von der unter Nr. 16 zu beschreibenden Methode verdrängt worden. Immerhin behalte sie hier ihren Platz, schon um der historischen Reminiscenz willen. Die Methode besteht nach Weigerts Angaben aus vier Abschnitten. Im ersten Abschnitte werden die Glasplatten hergerichtet. Man gießt auf die Witte eines sehr großen Objektträgers Kollodium und sorgt durch Heben und Senken dafür, daß die ganze Glasplatte gleichmäßig mit einer möglichst dünnen Kollodiumschicht überzogen ist. Nan läßt die Platten an der Luft trocknen, indem man sie auf die hohe Kante stellt, und hebt sie damn auf. Der zweite Abschnitt ist die Anfertigung der Schnittserien. Da diese dieselbe ist wie für die unter Nr. I6 zu schildernde Methode, so soll sie erst dort beschrieben werden und cbenso der dritte Abschnitt, der in der Ablegung der Schnitte besteht. In vierten Abschnitte werden die auf einer Kollodiumplatte abgelegten Schnitte mit einer neuen Kollodiumschicht iberzogen, die ganz in der Weise des ersten Abschnittes ausgebreitet wird. Ist diese zweite Schicht trocken geworden, dann stellt man den Objektträger entweder in $80^{\circ}$. Alkohol, falls man noch nicht färben will, oder man legt ihn in die Färbeflüssigkeit. In dieser hebt sich die doppelte Kollodiumschicht mit den eingeschlossenen Präparaten leicht $a b$, der Lappen, der so enstanden ist, wird weiter behandelt und vor dem 
Montieren der Präparate mit der Schere so zurecht geschnitten, daß er vom Deckglase bequem eingedeckt wird.

16. Celloidinlappenmethode, nach Obregia. Diese ingeniöse Modifikation der vorigen Methode ist einfacher und hat vor der vorigen so viele Vorteile voraus, daß sie diese verdrängt hat. Namentlich wird bei ihr vermieden, die Schnitte zwischen zwei Kollodium- oder Celloidinschichten einzuschließen. Nur eine solche Schicht ist vorhanden und diese kann man durch geeignete Anordnung der Schnitte zur unteren machen, so daß sie für das Mikroskopieren keinen Nachteil bietet.

Man hält sich zwei Lösungen vorrätig. Die eine ist die Zuckerlösung, die man sich in folgender Weise herstellt: Gepulverter Kandiszucker wird in hochendem destilliertem VVasser gelöst, so daß Sirupkonsistenz entsteht. I ch nehme statt dessen den Sirupus simplex der deutschen Pharmakopoe. Je $30 \mathrm{ccm}$ dieses Sirups mischt man mit $20 \mathrm{ccm}$ Alkohol von $96^{\circ}$, und $10 \mathrm{ccm}$ einer sirupösen Lösung von Dextrin. (Es berihrt sonderbar, daß ein Forscher diese Obregiasche Vorschrift dadurch zu verbessern geglaubt hat, daß er Dextrinzusatz empfohlen. Er hatte übersehen, daß schon Obregia dies getan.j Der Alkohol ist nötig, damit die Flïssigkeit sich gleichmäßig auf den Objektträgern ausbreitet. Die zweite Lösung ist eine dünne Celloidinlösung (Obregia hatte I'hotoxylin empfohlen). Man löst etwa $6 \mathrm{~g}$ Celloidin in $100 \mathrm{ccm}$ Alkohol absolutus und $100 \mathrm{ccm}$ Äther sulfuricus.

Große Objektträger, die man über einer Spiritusflamme erwärmt hat, damit ihnen keine Feuchtigkeit mehr anhaftet, werden mit der Zuckerlösung übergossen, so da $\beta$ eine gleichmäßige Schicht entsteht. Nan legt sie flach hin und bringt eine größere Zahl von ihnen in den Briitofen bei $37^{\circ} \mathrm{C}$. fuir $2+4$ Stunden, damit der Alkohol verdunsten kann und die Zuckerschicht trocken wird.

Die Schnittserien ordnet man in folgender Weise an. Man nimmt dazu sogenanntes satiniertes Seidenpapier, das als Tennesmannsches Klosetpapier in jeder guten Drogenhandlung zu haben ist. Dies Papier hat ror dem gewöhnlichen Klosetpapier den Vorzug, daß es bei den zur Anordnung der Schnitte nötigen Manipulationen unzerreißbar ist und daß man ein Blatt wiederholt gebrauchen kann, wenn man es über Nacht in, $6^{\circ}$. Alkohol aufbewahrt. Von diesem Papier schneidet man sich ein Blatt von der Größe des Objehtträgers zurecht und zeichnet auf ihm mit Bleistift den Umfang des Deckglases genau ab. Das Blatt legt man in eine flache Glasschale und befeuchtet es mit $96^{\circ}$. Alkohol, auch die Glasschale mußs etwas $\mathrm{A}$ - 
kohol enthalten. Während des Schneidens hat man dafür zu sorgen, daß das Blatt nicht eintrocknet. Die Schnitte nimmt man vom Mikrotommesser mit einem Schnitzelchen des Papiers herunter, legt sie auf das Blatt und ordnet sie hier mit einem weichen, in Alkohol von $96^{\circ}$ 。 getauchten Pinsel so an, daß man sie in wagerechten Reihen von links nach rechts - also genau'so wie man liest - nebeneinander legt. Ist der umzeichnete Raum mit Schnitten bedeckt, dann hebt man das Papier vorsichtig an einer Ecke hoch und läßt es flüchtig abtropfen. Wenn nicht zu viel Alkohol auf dem Papier vorhanden war, dann bleiben die Schnitte in ihrer Lage. Nun legt man das Blatt verkehrt, die Schnitte nach unten, auf den Objektträger mit der Zuckerschicht, deckt ein vierfach gefaltetes Filtrierpapier dariber und trocknet vorsichtig durch festes Andrücken ab. Das Papier zieht man ab, bringt es in die Glasschale zuriick und befeuchtet es mit Alkohol. Unterdessen sind die Schnitte etwas getrocknet; man übergießt sic jetzt mit der Celloidinlösung, läßt diese in ein Glasgefäß abtropfen, um das gebrauchte Celloidin wieder lufttrocken zu machen, und legt die Glasplatte mit den Schnitten flach hin. Um die Schnitte herum entsteht eine mehr oder minder starke Truibung im Celloidin, die nach und nach verschwindet. Das wartet man in Ruhe ab und wartet auch ab, bis das aufgegossene Celloidin fest geworden ist. Würde man das Celloidin mit der Glasplatte noch feucht zur Lösung des Zuckers in Wasser werfen, dann würde es zur Unkenntlichkeit schrumpfen. Man kann, ehe man weiter behandelt, ruhig eine neue Serie auf dem Papicrblatte anordnen, ja wenn nur wenige Schnitte auf das Blatt gehen, kann man auch zwei bis vier und mehr Serien - wie beschrieben machen, ehe man die erste weiter behandelt.

Ist die Celloidinschicht fest geworden, dann bezeichnet man die rechte Ecke - bei Umkehrung des Celloidinblattes wird sie wieder die linke, ron wo man die Anordnung der Schnitte begonnen - in beliebiger Weise, z. B. mit einer Zahl, in Spiegelschrift. Man nimmt dazu etwas gelbe Ülfarbe, wie sie die Maler verwenden. Dann wirft man die Glasplatte in eine Schale mit gewöhnlichem IVasser. Hierin löst sich der Zucker auf und das Celloidinblatt oder der Celloidinlappen mit den ihm fest anhaftenden Schnitten löst sich ron seiner Unterlage allmählich los und schwimmt dann im Wasser umher. Dreht man ihn um, so liest sich die Spiegelschrift jetzt richtig und die Präparate sind genau in der Reihenfolge fest geklebt, in der man sie haben will. Nan hringt dic Celloidinlappen für mindestens $2+$ Stunden in reines gewönnliches Wisser, damit jeder etwa an den Schnitten haftende Zucker gelöst wird. Ich habe die Lappen oft \& Tage und 
länger im Wasser gelassen, um dann die ganze Serie auf einmal färben zu können. Die Färbung der Schnitte richtet sich nach dem Material.

Obregia glaubte, daß seine Methode auch für Paraffinschnitte anwendbar sei. Ich sehe in ihr gegenüber der Eiwcißwassermethode nur den Vorteil, daß man alkalische Reagentien anwenden kann, sonst aber hat sie große Nachteile, weil sich das Celloidin stark mitfärbt und weil es in Terpentin oder Xylol, die zum Austreiben des Paraffins dienen, leicht schrumpft.

17. Formolgelatine, nach Olt. Neuerdings hat Olt zum Aufkleben von Gefrierschnitten folgendes Verfahren empfohlen: Man stellt sich zunächst eine Phenolgelatine her, indem man $10 \mathrm{~g}$ Gelatine in $\mathrm{I} 0 \mathrm{ccm}$ Aqua destillata auf dem Wasserbade löst und dazu das Eiweiß eines Hühnereies setzt. Letzteres dient dazu, um bei weiterem Kochen und Umrühren alle Verunreinigungen an sich zu reißen. Die Nischung muß klar filtrieren und wird mit Io $\mathrm{cm}$ einer $5^{\circ}$. Karbolsäurelösung versetzt. Die erstarrte Gelatine hält sich außerordentlich lange. Nan bringt nun die Gefrierschnitte entweder aus Wasser oder von der Klinge des Gefriermikrotoms in Phenolgelatinelösung, und zwar I Teil der vorhin erwähnten Phenolgelatine auf Io Teile Wasser. Dann ordnet man die Schnitte auf dem Objektträger, saugt alle ïberschüssige Flüssigkeit ab und sorgt, daß sie glatt liegen. Darauf bringt man den Objektträger in ein Gefäß, dessen Boden mit 40\% Formol bedeckt ist, und zwar kann man es so einrichten - O1t gibt leider nicht an, wie! -, daß die Schnitte horizontal oder vertikal unmittelbar über der Formolschicht liegen. Nach einer Stunde wird das Präparat in 10\%。 Formol getaucht, um nach wenigen Minuten für jede beliebige Weiterbehandlung reif $z u$ sein. Die Schnitte lösen sich nun nicht mehr los, da die Gelatine im Formol völlig unlöslich geworden ist. Diese höchst ingeniöse Methode hat noch den ferneren Yrorteil, daß die Formolgelatine sich in den Farbstoffen nicht mitfärbt.

Olt glaubt die Formolgelatine auch für das Aufkleben von Paraffinschnitten empfehlen zu sollen. Obwohl es mir zweifelhaft scheint, daß sie die Eiweißaufklebung je wird völlig ersetzen können, gewährt sie doch infolge der Lnlöslichkeit der Gelatine die Möglichkeit, alkalische Farbflotten anzuwenden. Das ist aber bei dem in Alkalien löslichen Eiweiß unmöglich.

Olt beschickt, wie bei der Celloidinlappenmethode, zunächst einen Objektträger mit ciner ganz dümnen Gelatineschicht. Ist diese trocken geworden, dann werden die Paraffinschnitte auf die Gelatine gelegt 
und glatt angedrückt. (Hier liegt der Fehler, denn ein faltenloses Andriicken von Schnitten, die $5 \mu$ dick sind, ist nicht immer möglich.) Nachdem die nötige Zahl Schnitte auf dem Objektträger angebracht ist, legt man einen mit $4{ }_{10}^{\circ}-10^{\circ}$ 。 Formol getränkten Papierstreifen auf die Schnitte und deckt eine Glasplatte auf. Nach I Minute oder länger bringt man in $10 \%$ Formollösung auf einige Minuten, dann in absoluten Alkohol und schließlich, zur Lösung des Paraffins, in Benzol. Wertvolle Schnitte - also wohl sehr diinne Schnitte - bringt Olt in eine Lösung von I Teil Phenolgelatine auf Io Teile Wasser. Die Flüssigkeit wird erwärmt, worauf sich die Schnitte glatt ausbreiten. Nach dem Erkalten soll man die Schnitte auf einen Objektträger bringen. Ich halte es aber für fast unmöglich, dünne Schnitte $15 \mu$ unverletzt vom Wasser abzuheben. Man kann nach Olts eigenem Vorschlage die Erwärmung auch auf dem Objektträger selber vornehmen, läßt die Flüssigkeit verdunsten und behandelt, wie vorhin angegeben. Bei diesem Verfahren aber wird man kaum eine größere Anzahl von Schnitten auf einem Objektträger anbringen können. Wie immer: die Methode von Olt ist jedenfalls sehr beachtenswert.

\section{Achtes Kapite1.}

\section{Färben.}

\section{a) Zweck des Färbens.}

\section{$\$ 55$.}

Die von tierischen Organen angefertigten Schnitte, gleichgültig ob das Material fixiert war oder frisch verarbeitet wurde, müssen a ufgehellt werden, weil die einzelnenen Elemente nicht durchsichtig genug sind, um das zum Mikroskopieren nötige Licht durchzulassen. Dic Anwendung starker Systeme verbietet sich daher ganz, denn diese Systeme sind immer etwas lichtschwach. Schon die alten Histologen haben kiärende Reagentien angewendet, um dem genannten Übelstande zu begegnen. Essigsäure, Glyzerin, Natron- oder Kalilauge usw. wurden hierfuir benutzt. Natürlich ließen sich, wenn wir vom Glyzerin absehen, damit keine Dauerpräparate erzielen; und trotz aller wertvollen Aufschliusse, welche die Klärung gab, behielt man doch kein Vergleichsmaterial in Händen. Das aber ist bei mikroskopischen Unter- 
suchungen im höchsten Maße nicht bloß wünschenswert, sondern auch notwendig: Schnitte, die von Paraffin- oder Celloidinmaterial stammen, verlangen eine etwas eingreifendere Klärung, um benutzbar zu werden. Z. B. im Paraffinschnitte muß das Paraffin entfernt werden, weil es all und jede Textur und Struktur verdeckt. Man nimmt dazu Terpentinöl oder Xylol und löst dadurch das Paraffin auf. Die Textur wird in ihren groben Ziigen enthiillt; des ferneren sieht man, ob das Material gut fixiert ist, ob z. B. Druisenzellen noch auf ihrer Tunica propria aufsitzen, ob Schrumpfungen von Zellen vorhanden sind oder nicht, usw. Ich versäume nie - das möchte ich parenthetisch bemerken -, den ersten Schnitt, den ich von irgendeinem Objekte angefertigt, auf diese Weise in Terpentinöl zu untersuchen. Wenn man nicht ïbermäßig viel Reagens nimmt, nicht über eine mittlere Vergrößerung hinausgeht, dann entsteht für das System des Mikroskopes licine Gefahr. Ich halte diese Beobachtung in Terpentinöl für sehr wichtig, weil ich mich davon überzeugen kann, ob die Fixierung usw. gelungen ist. Zeigt sich, daß dies nicht der Fall, dann werfe ich das Material weg und erspare dadurch unnötige Arbeit. Feinere Untersuchungen kann man mit diesem klärenden Reagens natiirlich ebenfalls nicht anstellen. Stärkere Linsen vertragen nicht die Terpentinoder Xyloldämpfe und ferner hellen diese beiden. Mittel binnen ziemlich kurzer Zeit so intensiv auf, machen alles so übermä13ig durchsichtig, daß $\beta$ wie beim nicht geklärten Schnitte nichts mehr zu sehen ist. In der das I'räparat durchflutenden Lichtmasse ertrinkt jedes Strukturhild und jede Textureigentümlichkeit.

Nur wenige Reagentien kennen wir, welche neben ihren fixierenden Eigenschaften noch die Fähigkeit besitzen, dic ()bjekte zu färben. Denn durch eine künstliche Färbung die einzelnen Bestandtcile eines Schnittes scharf hervorzuheben, das war der einzige Ausweg, welcher aus dem oben genannten Dilemma herausbrachte. Aber, da nun cinmal der Appetit beim Essen kommt, bald genügte es den Forschern nicht mehr, die einzelnen Teile eines Präparates schärfer hervorzuheben und dadurch leichter sichtbar zu machen, sie wollten und wollen das der Natur nach Differente auch in differenter Färbung oder mindestens in verschiedener Niiancierung zur Erscheinung bringen. Und dies ist der Zweck der Färbung.

Ich sagte soeben, daß nur wenige Reagentien zugleich färben und fixieren; dies sind die Chromsäure, die Pikrinsäure und die Osmiumsäure. Die im nächsten Kapitel zu erwähnenden Netallsalze haben zuweilen die gleiche Eigenschaft, doch ist deren Wirkung zu unzuverlässig, als daß sie allgemein für das Färben mikroskopischer Prä- 
parate in Betracht lämen. Und auch die hier genannten Reagentien, dic Chromsäure und Pikrinsäure, färben ungenügend, denn sie färben so leichmäßig, daß das Differente durchaus nicht different erscheint. Einzig die Usmiumsäure liefert hinreichend charakteristische Bilder, :mi eine andere Färbung entbehrlich zu machen. Namentlich zarte hautige Gebilde, Nervenfasern und ihre Endigungen geben in der unvermischt angewendeten Osmiumsäure schr instruktive und dauernder Aufbewahrung fähige Praparate. Bei Osmiumgemischen kanı man die Nachfarbung nur dann entbehren, wenn man die Reduktion der Säure in Tannin, Holzessig usw. vorgenommen hat. Doch hat die Verwendung der Osmiumsäure ihre Grenzen; denn erstens kann man sic nicht übcrail anwenden, da sie nicht für alles geeignet ist und weil sie auch nicht in alle Objekte gleich gut eindringt. Und zweitens liefert sie zwar Nüancen eines Farbengrundtones, ermöglicht aber dennoch nicht, feinere Lnterschiede, z. B. der Drüsensekrete, zu erkennen, weil die Grundfarbe schwarz ist, daher nicht viele Nüancen besitzt. So muß man zur künstlichen Fürbung des Materials und zu geeigneten Farbstoffen greifen und man wird ganz verschiedene Arten der Färbung und ganz verschiedene Färbemittel wählen müssen, die sich nach dem Ziele der Untersuchung zu richten haben.

Verfolgt man rein morphologische Zwecke, will man z. B. den Bau irgend eines kleinen Evertebraten erforschen, der zu klein ist, um Lege artis präpariert zu werden, dann wird es nur nötig sein, durch die Farbung zu zeigen, daß Zellen vorhanden sind und wie diese lagern. Die gleiche Tendenz hat meist der Embryologe. Ihm wird es ebenfalls gewöhnlich nur darauf ankommen $\mathrm{zu}$ erkennen, ob irgendein sich ihm zeigcndes Gebilde aus Zellen besteht, weil er schon aus dieser Tatsache allein einen wissenschaftlichen Gewinn erzielt. Um aber zu erkennen, ob man es mit Zellen zu tun hat oder nicht, braucht man nur die Zellkerne zu sehen. Für dic cben genannten Zwecke reichen daher die Kernfärbemittel völlig aus, zumal die allermeisten von ihnen das Protoplasma immer in leichtem Grade mitfärben. Man kann aber auch, wenn man die Kontraste zwiichen Zellsubstanz und Kern schärfer markicren und wenn man lie segenceitigen Grenzen der Zellen zur Erscheinung bringen will, zubleich mit dem Kernfarbstoffe einen Plasmafarbstoff verwenden un\} erzielt durch diese Doppelfärbung die schönsten Resultate. Der Aufbau cines Organs, seine Beziehungen zu Nachbarorgancn lasion sich auf diese Weise cinwandfrei feststellen. Auf die Erkennung feincrer Yerhältnisse: Zell- und Kernstrulituren. Zelleinschliisse. Zcllumwandlungen usw., wird man dabei allerdings verzichten 
miissen. Denn zum Studium dieser Fragen sind meist andere Fixierungen und andere Färbungen nötig; wie diejenigen, welche bei morphologischen und morphogenetischen Lntersuchungen ausreichen. Für letztere hat man nur darauf zu achten, daß der angewandte Farbstoff gut und sicher färbt und daß seine Anwendung so einfach wie möglich ist.

Andere Ansprüche an die Leistung der Färbemittel müssen wir stellen, wenn wir Zellvorgänge (Teilung', Zellstrulturen, am Ei z. B., Spermatogenese, Sekretion, dic feinsten Bezichungen der Zellen zueinander usw. zu bearbeiten haben. Dann ist die richtige Auswahl der Färbung oft entscheidend für das Gelingen der Untersuchungen. Denn wir wollen dann nicht hloß die Zellen roneinander, nicht bloß Zelle und Kern, sondern in Zelle und Kern die verschiedenen Teile in klarer und unzweideutiger Weise zur Anschauung bringen. Einzelfürbungen sowie Kombinationen ron zwei und drei Farbstoffen kommen diesen unseren Wünschen entgegen, vorausgesetzt, dal3 der richtige Farbstoff oder die richtige Kombination gewahlt wurden. Mehr als drei Farbstoffe sollte man nicht kombinieren; die allzubunten, harlekinartigen Bilder wirken unruhig, ror lauter färberischen Unterschieden kann man dann nichts mehr unterscheiden.

Alle diese Erwägungen muß man anstellen, bevor man fürbt.

b) Die Arten des Färbens.

\section{$\S 56$.}

Es gibt drei Arten, wie wir die (Objekte mit den Farbflüssigkeiten, den sogenannten Farbflotten, in Beziehung bringen können: diese Arten sind die Stückfärbung, die Schnittfärbung und die vitale Färbung. Letztere, die, wie der Name besagt, die Absicht verfolgt, die lebende Zelle im lebenden Organismus zu färben, soll später, am Ende dieses Kapitels, genauer besprochen werden. Sie ist eine nur selten und nur für bestimmte Organe verwendbare Methode. Die beiden anderen Arten oder Methoden dagegen sind allenthalben anwendbar und werden auch täglich angewendet.

Bei der Stückfärbung oder Durchfärbung bringen wir das ganze zu untersuchende ()bjekt vor seiner Einbettung in l'araffin oder Celloidin in die Farbflotte. Ist die letztere eine alkoholische, so hat die Einbringung weiter licine Schwierigkeiten; man wirft eben das betreffende Material in ein Gefiiß, das eine genigend große Quantität Farbflüssigkeit enthailt. Nehmen wir aber wässrige Farblösungen, so sind mancherlei Vorsichtsmaßregeln zu beobachten. Zwar 
der Unstand ist bedeutungslos, daß alkoholisiertes Material in eine wässrige Flïssigkeit kommt. Waren Fixierung und Härtung nur tadellos ausgefiihrt, dann hält das Präparat die infolge der Verdrängung des Alkohols durch die wässrige Farblösung sich einstellenden Diffusionsströme vollkommen gut aus. Ja man kann direkt sagen, daß, wenn das Präparat bei dieser Stiickfärbung leidet, es schlecht fixiert gewesen sein muß. Wohl aber ist sehr zu beachten, ob die Farbflissigkeit mit Alkohol sich verträgt, ob keine Niederschläge in ihr und damit auch im Objekte entstehen, durch welche die Schnittc verunreinigt und wertlos werden können. Alaunhaltige Lösungen z. B. lassen sich nicht mit Alkohol ohne weiteres mischen, weil der Alaun in amorpher Form im Präparate niedergeschlagen wird und aus diesem nur schwer oder gar nicht mehr entfernt werden kann. Ehe man in Alkohol erhärtetes Naterial in derartige Farbflotten überträgt, muß man es laher gut wässern. Es wird also aus dem Aufbewahrungsalkohol in destilliertes Wasser gebracht und so lange darin belassen, bis es auf den Boden des Gefäl.ses gesunken ist. Dann wird das destillierte Wasser erneuert und man hat darauf zu achten, ob das Präparat jetzt anfänglich auch noch schwimmt. Ist dies der Fall, so muß wiederum nach dem Untersinken das Wasser erneuert werden; und dies hat so lange zu geschehen, bis das Präparat sofort beim Einbringen in das destillierte Wasser untersinkt. Erst dann ist man sicher, daß jeder Alkohol aus dem Präparate ausgetrieben ist, und erst dann kann man es gefahrlos in die wässrige Farbflotte einbringen.

W'ie lange die Stuckfärbung zu dauern hat, läßt sich ziffermäßig nicht bestimmen: man kann nur sagen: so lange, bis der Farbstoff auch die innersten Teile des Objektes durchdrungen hat. Das hängt natiirlich $\mathrm{ab}$ von der Penetrationskraft der Farbflotte, der Durchdringbarkeit des Materials und oft auch von der Temperatur der Umgebung. Aus alkoholischen Farblüsungen kommen die durchgefärbten Stiicke zunïchst in Alkohol meist von der gleichen Konzentration, wie der dè Farblösung. In diesem werden sie mit oder ohne Zusatz von anderen Reagentien so lange gerraschen, bis er farblos bleibt, d. h. es wird alle überschüssige Farblösung entfernt oder es wird in dem Waschalliohol differenziert. Letzteres verlangen einige Reagentien. Stiiclie aus einer wässrigen Farbflotte werden in destilliertem W'asscr gewaschen. bis dieses reinen Farbstoff mehr auszieht. Dann wird in der bekannten IT'ise in Alkohol von steigender Konzentration gehärtet. Die für beide Arten der Stïckfärbung nötige Weiterbehandlung des Materials bis zum Einbetten unterscheidet sich in nichts ron der Art des Einbettens ungefärbter Objekte. 
Die Stückfärbung ist eine für viele Zwecke sehr wertvolle Methode. Kleinste Objekte oder solche, die sehr durchsichtig sind, werden nach der Färbung viel bequemer eingebettet, als dies ohne Färbung möglich wäre. Kleine Eier, z. B. von Seeigeln, sind auf diese Weise am leichtesten zu behandeln, namentlich wenn man damit noch die früher beschriebene Zentrifugierung verbindet. Ferner wird das Objekt, die richtige Ausfühmung aller nötigen Nanipulationen vorausgesetzt, sehr gleichmäßig von dem Farbstoff durchtränkt und man erhält daher auch sehr gleichmäßige Schnittbilder. Indessen, und das ist ein nicht unbeträchtlicher Nachteil, kann man auf diese Weise feinere Färbungen, d. h. solche, welche dic verschicdenen Teile eines Objektes in distinktester Weise hervorheben, und solche, welche die intimsten Strukturbilder enthüllen, nicht erhalten. Stück- oder Durchfärbung erweist sich daher am geeignetsten für morphologische und morphogenetische Untersuchungen.

Bei der Schnittfärbung ist der eben gerügte Nachteil nicht vorhanden; sie ist die klassische Methode, um alle feinsten Details der Zelle in die Lrscheinung treten zu lassen. Die Natur der Drüsensekrete kann man nie so gut an durchgefärbtem wie an schnittgefärbtem Material erkennen. Die einzelnen Phasen der Färbung lassen sich bei dieser Art überwachen; man kann die Färbung beliebig unterbrechen, um die Fortschritte des Farbstoffes zu beaufsichtigen, um zu erkennen, welche Teile und wie er sie zuerst färbt. Diesem großen Vorzuge gegenuiber kommt es gar nicht in Betracht, daß Paraffinschnitte aufgeklebt sind und daher nur an einer Fläche mit dem Farbstoff in dirckte Beriihrung kommen. Selbst die dicksten Paraffinschnitte sind so dünn, daß nur ein Minimum von Zeit erforderlich ist, his der Farbstoff alle Schichten des Schnittes durchdrungen hat.

Wie lange soll man die Schnitte färben? Man kann, wie vorhin bemerkt wurde, bei der Schnittfärbung den Prozeß des Färbens nach Belieben unterbrechen und kann sich unter dem Mikroskope davon überzeugen, wie weit die Fürbung vorgeschritten ist und ob und wann sie ihren Zweck erfiillt hat. Ein solches Unterbrechen ist nötig bei jenen Methoden, die zur Ausführung der verschiedenen Manipulationen mit Sekunden rechnen. Ich will nicht verhehlen, daß ich derartigen Vorschriften, bei denen es auf die Sekunde ankommt, ob der gewünschte Effekt erzielt wird oder nicht, ein großes Mißtrauen entgegenbringe. Denn die mit ihnen erzielten Resultate sind Zufallsergebnisse, lassen meines Erachtens keinen Schluß, wenigstens keinen buindigen Schluß dariber zu, ob die so dargestellten Strukturbilder in natura wirklich vorhanden sind oder nicht. Ich rate jedem 
Anfänger al), sich auf die Schnellfärberei zu versteifen; ich ziehe die langsame Fürbung entschieden vor und lasse fast immer dic Schnitte mindestens einige Stunden, meist 24 Stunden, zuweilen auch 2 Tage in der Farbflotte. Ich finde, daß bei langsamem Färben mit duinnen I.isungen das Resultat ein viel distinkteres ist; alle Feinheiten des Präparates treten besser hervor als nach der Schnellfärberci. Mein Ideal des mikroskopischen Färbens wäre dies, den Schnitt in die Farblösung zu bringen und ihn darin beliebig lange Zeit bis mehrcre Wochen lassen zu können, ohne daß eine sogenannte Überfärbung eintreten kann, bei der die Farbe alle Strukturbilder zudeckt. In gewissem Grade kann man diesem Ziel nahe kommen, wenn man sehr verdünnte Farbflotten wählt. Die Besorgnis ron Paul Nayer, daß in wässrigen Fliissigkeiten die Schnitte leiden, kann ich nach meinen ausgedehnten Erfahrungen mit dem langsamen Färben nicht teilen. Freilich wende ich keine Farblösungen an, die, wie das Pikrokarmin. tatsächlich die Zellen und die Gewebe oft schon nach relativ kurzer Zeit angreifen.

\section{$\S 57$}

Die färberische Absicht, so wurde friiher gesagt, besteht darin. das der Natur nach Differente auch different zur Erscheinung zu bringen. Man drickt dies auch so aus: die Färbung soll eine elektive Färbung sein. D. h. der Farbstoff soll nur ganz bestimmte Teile hervorheben und an andere nicht herangehen. Bei der Färbung z. B. der Leukocytengranula sind die ron Ehrlich und anderen Forschern angegebenen Färbungsverfahren so konstruiert, daß die Granula in einer bestimmten Farbe hurvortreten, während alle anderen Bestandteile des Präparates eine hiergegen scharf kontrastierende Färbung crhalten. Der Gegensatz zur elektiven ist die diffuse Färbung, bei der zwar ein buntes Bild zu sehen ist, an dem aber die Einzelheiten in dem allgemeinen Farbenton völlig verschwinden. Ehe man diffus färbt, untersuche man lieber ungefärbte Schnitte, weil man an diesen immer noch Einzelheiten zu erkennen vermag. Elektiv muß untur allen L'mständen gefärbt werden, ob man Schnitte oder ganze Stiicke in die Farbflotte einbringt. In ganz origineller Weise hat Bethe dieses Prinzip so ausgedriickt, daß3 cr crklärte, sein Ideal bezüglich der Fürbung des Zentralnervensystems sei, alles, wie Neuroglia, Bindegewche: Gefille, wegzuschaffen und nur Ganglienzellen und Nerven zu bchalten. Da man sclbstrerständlich die Stütsubstanzen eines Organs nicht beseitigen liann, wenn man nicht das ganze Organ vernichten will. so deutet die Meinung Bethes an, daß $\beta$ es wiinschens- 
wert wäre, einen Farbstoff zu besitzen, der nur Ganglienzellen und Nerven bis in ihre feinsten Verzweigungen färbt, alle anderen Organbestandteile dagegen ungefärbt läßt. Es kommt also färberisch nur darauf an, einen ganz bestimmten Teil eines Präparates zu färben, oder aber die Unterschcidung der Teile durch Kontrastfärbungen zu erleichtern. Eine besondere Terminologie haben für diese färberischen Intentionen Ehrlich und Lazarus eingefuhrt. Sie nennen solche Färbungen, durch die nur eine bestimmte Zellart hervorgehoben wird, singuläre, diejenigen, welche viele oder alle Bestandteile eines Organs in verschiedenen Farben zur Erscheinung bringen, panoptische Färbungen. Beide stehen in Gegensatz zu solchen Methoden, dic nur Übersichtsbilder liefern.

$\mathrm{Paul}$ Mayer u. a. unterscheiden zwischen progressiver oder dirckter und regressiver oder indirekter Färbung: Nayer nennt dic erstere Art diejenige, bei welcher zu einer empirisch festgestellten Zeit der Färbungsprozeß unterbrochen wird, wenn nämlich der zu färhende Bestandteil des Objektes gefärht, alles übrige dagegen ungefärht ist. Èr meint dann, daß durch Auswaschen der Farblösungdie Farbe an dem bestimmten Teil fixiert werde, wohei es nur merkwürdig erscheint, daß ein Waschprozeß zugleich ein Fixierungsprozeß sein soll. Die regressive oder indirekte Methode ist dicjenige, hei welcher zuerst stark ïherfärht und clann wieder entfärbt wird. Ehrlich hat diese Art das Prinzip der maximalen Uherfärbung mit nachfolgender maximaler Entfärbung genannt.

Diese Terminologie ron Mayer, Ehrlich u. a. scheint mir nicht ganz zutreffend. Man kann auf zweicrlei Art iiberfärhen : d. h. den Schnitt oder das Stiick mit Farbstoff so ïherfüllen, daß nichts mehr zu sehen ist: einmal hei Anwendung der Beizfarhen und dann durch zu langes Anwenden zu konzentrierter Farblösungen. Ủber die Beizfärbung wird der nächste Paragraph handeln. Die Üherfullung des Materials mit Farhstoff, die z. I3. heim Hämatein oder bei manchen Anilinen usw: sehr leicht durch falsche Anwendung der Methoden zu

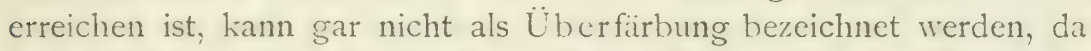
man nicht feststellen kann, ob wirklich gefürbt worden ist. Denn der Farbstoif kann am Gewehe festhaften, oft so fest, daß er auch durch eingreifundste Reagention nicht wieder entfernt werden kann, ohne daß er auch nur im geringsten gefärbt hat. An Schnitten, welche mit Hämatoxylin absichtlich überfärht wurden, konnte ich hei der nachher unter dem Mikroskope vorgenommenen Entfürbung erkennen, daß nicht aus dem Gewebe heraus, sondern von dem Gewebe herunter der Farbstoff entfernt wird. Ich will damit sagen, daß er nicht in 
das Gewebe eingedrungen ist, sondern es nur bedeckt. Und dies trifft auch für Stückfärbung zu. Wenn also keine Überfärbung, im wörtlichen Sinne des Wortes, vorhanden ist, so kann auch keine Entfärbung eintreten oder vorgenommen werden. Ich sehe daher nicht ein, wo hier die regressive Veränderung vor sich gehen soll und kann. Denn ein einfaches Auswaschen mit und ohne Säure oder Alkali, wodurch angeschwemmte Nassen allmählich wieder cntfernt werden, verdient nicht die Bezeichnung eines regressiven Vorganges. Auch was M. Heidenhain zu gunsten der eben kritisierten Terminologie vorbringt, ist nicht stichhaltig; da der Nachweis, daß die Bezeichnungen "progressiv: und "regressiv" theoretisch richtig und praktisch wichtig seien, nicht erbracht ist.

\section{$\S 58$.}

Dic von mir vor längerer Zcit vorgeschlagene Unterscheidung der Färberei zu milkroskopischen Zwecken in substantive und adjektive Färbung halte ich noch immer trotz des Viderspruches, den ich erfahren, fuir die zurzeit beste. Die Ausdruicke "substantive" und "adjelitive Färbung sind nicht von mir erfunden, sie sind der industriellen Fürbetechnik entnommen und dort von Bancroft eingeführt worden. Zwar hat Paul Mayer gemeint, daß die Ausdriicke willkürlich gewählt seien: doch ist das ein Vorwurf, der so ziemlich jeder Terminologie anhaftet. Denn eine willkürlich unterbrochene Färbung progressiv, eine unnötig vorgenommene Überfärbung regressiv zu nennen, dazu liegt eine zwingende Notwendigkeit eigentlich auch nicht vor. Die L'nterscheidung in substantive und adjektive Färbung ist darauf begruindet, daß die einen Substanzen sich ohne weiteres mit der Farbflotte durchtränken, dic anderen nicht, dal3 vielmehr bei diesen erst noch etwas zur Substanz oder zur Farbflotte hinzugefügt werden muß, damit eine Färbung erfolgen kann. Alle industriellen Garne tierischer Herkunft - Seide, Wolle - nehmen leicht und dauernd den Farbstoff an, wenn man sie nach ausgiebiger Reinigung, namentlich nach grïndlicher Entfettung, direkt in die Farblösung bringt. Da die Suhstanz ohne weiteres sich färbt: substantive Fürbung. Andurs rerhalten sich die Garne und Gewebe pflanzlichen Lrsprungs - Leincn, Baumwolle, Papier - . Diese nehmen den Farbstoff nicht an oder aber, falls dies scheinbar doch geschehen, geben sie ihn beim Spuilen in Wasser vollständig wieder ab: eine etwas komplette regressive Färbung. Hier muissen die Garnfaser oder der Papierbrei mit einem chemischen Priparate hehandelt werden, das man Beize nennt, weil angenommen wird, daß dadurch das innere Gefüge der Faser 
gelockert, diese gewissermaßen angenagt wird. Erst die gebeizte Faser nimmt die Farbe an; da also zwischen Substanz und Farbflotte etwas hinzugefügt werden muß: adjektive Färbung. Die zwischen Beize und Farbstoff entstandene Verbindung nennt man einen Farblack und dis auf diese WVeise erzielte Färbung ist eine echte Färbung. Auch die substantiv erzielten Färbungen sind echt oder sollen echt sein, d. h. bei keiner der noch vorzunehmenden Prozeduren - Waschen, Trocknen - abblassen oder gar verschwinden.

Die Art nun, wie der Mikroskopiker hauptsächlich färbt, ist die substantive Art, ganz egal, ob er Schnitt- oder Stiickfärbung vornimmt. Und nur darin unterscheidet er sich rom Färber, daß er eine ungleichmäßige, elektivc Färbung will, während letzterer eine gleichmäßige Färbung der Gespinnstfaser erzielen will und muß. Diese verschiedenen Färbungsziele sind im verschiedenen Material begrïndet. Der industrielle Färber hat eine in sich gleichmäßige Gespinnstfaser tierischen oder pflanzlichen Ursprungs, der Mikroskopiker hat in sich ungleichartige Gebilde zu färben; und diese Ungleichartigkeit tinktorielk hervorzuheben ist, wie wiederholt ausgefiihrt, seine Aufgabe. Daher wird er die industriellen Fürbevorschriften nur cum grano salis bei scinen Objekten verwenden dürfen, aber dic industriellen Färbebezeichnungen kann er unbedenklich anwenden. Ja, der Mikrosliopiker muß noch vielmehr als bisher beim Fürber in die Schule gehen, wenn anders die mikroskopische Färberei endlich aus der wüsten Empirie heraus soll, in die sie jetzt versunken ist, wenn sie endlich auf einen rationellen Boden gelangen soll. Darum ist die Differenz in der Terminologie nicht gleichguiltig, bedeutet keinen Streit um Quisquilien, sondern bedingt den rationellen Fortschritt der Methodik.

Auf zweierlei Arten verwenden wir also, ganz wie in der Technik, die Farbstoffe, in dem wir entweder substantiv oder adjektiv fürben. Die substantiv verwendeten Körper sind entweder einfache Lösungen in Wasser oder Alkohol, oder es sind Verbindungen des Farbstoffes mit einer Substanz, durch welche er in einen Lack verwandelt wird. Und erst mit diesem Lack wird gefärbt. Dabei, wie z. B. bei den Alaunverbindungen, wirkt nicht etwa der Alaun als Beize auf das histologische Präparat, sondern der Alaunkarmin wirkt als einheitlicher Körper ein. Damit ist aber die Differenz zur adjektiven Färbung klargestellt; denn bei dieser müssen Beize und Farbkörper gesondert angewendet werden, weil die Herstellung des Lackes auf der Gespinnstfaser oder im tierischen Organ erfolgen soll. Es deutet daher auf eine merkwürdige Verkennung des IVesens der Beizfärbung 
hin, wenn Paul Mayer meint, daß man Beizen und Färben im Wortgehrauche umkehren könne. Wendet man erst Alaun und dann die Karminsäure an, so heiße das: mit Alaun gebeizt, mit Karminsiiure gefürbt. Das ist richtig. Aher wenn der genannte treffliche Gelehrte dann weiter sagt: wendet man erst Karminsäure und dann den Alaun an, so heiße das: mit Karminsiure gebeizt und mit Alaun gefärbt, so ist das unrichtig. Färben kommt von Farbe, denn erst muß diese dagewesen sein, ehe jenes ausgeführt werden konnte. Die Farbe aber ist in dem Mayerschen Beispiel die Karminsäure und nicht der Alaun, gleichgïltig in welcher Reihenfolge beide Substanzen angewendet werden. Nicht von ciner Alaunfärbung sondern von einer Karminsäurefärbung wird gesprochen: und das mit Recht nach dem alten Grundsatze: a potiori fit denominatio. Das Potius ist die Karminsäure. Auch bei den sogenannten Entwickelungsfarben, den in-graincolours, gilt dieser Grundsatz. Denn nicht die Färbesalze, welche stets zuletzt angewendet werden müssen, färben, sondern sie entwickeln nur die Farbe; der Farbkörper ist die zuerst angevendete Substanz (Thiochromogen, Primulin usw.).

Schen wir uns die adjektiven Fürbungen näher an. Bisher hat in dieser Weise nur Hämatoxylin bez. Hämatein eine ausgedehntere Verwendung gefunden, während die adjektive Färbung mit Anilinen und Alizarinen nicht beliebt ist. Die Alizarine -- Anthracenderivate - färben übrigens, das sei hier parenthetisch bemerkt, sclbst Wolle und Seide nur im adjektiven Verfahren.

Der große Vorteil der adjcktiven oder Bcizfärbungen besteht darin, daß wir altes Alkoholmaterial, welches auf substantivem IVege keinerlei Jarbstoff mehr annimmt, gut und distinkt durch sie färben können. Der Unterschied zwischen den drei Farbstoffarten, mit denen wir adjektiv fürben können, ist cer folgende. Die Alizarinfarben sind nach meinen Erfahrungen absolut cht; in ITasser und Alkohol veränclert sich die Färbung nicht mehr, namentlich wird kein Farbstoff ausgezogen. IJas Gleiche kann ich von den Anilinlacken sagen, auch Siesc entfärben sich nicht mehr in reinem, d. h. nicht gesäuertem usw., Alkwhol. Anders die I Iämatoxylin- bez. Hämateïnlacke. Durch sie wird laine echte Färbung erzielt, vielmehr wird das Präparat derartig mit dem Farbstoff überschwemmt, daß es undurchsichtig wird und daß der Lack teilweise wieder gelöst werden muß. Diese Lösung. das Differenzicren, lann entweder durch organische oder anorganische Säuren oder durch dic Beize selbst bewirkt werden. I.ctzteres entspricht durchaus der fïrberischen Eirfahrung: daß Lacke sich in einem ¿berschul3 der Beize lissen. Man entfärbt, man differenziert den 
Hämatoxylinlack so lange, bis der gerrïnschte Färbeeffekt erreicht, bis das, was man im Präparate sucht oder zu sehen erwartet, färberisch dargestellt ist. Und hierin besteht die Gefahr der Hämatoxylinlacke, hier liegt ihre große Fehlerquelle: nur die Rudolf-Heidenhainsche Färbung hat sie gar nicht, die Neigertsche Methode in nur geringem Maße.

Denn die Differenzierung schicbt in den Proze $\$$ des Färbens ein subjeltives Moment ein: die willkürliche Unterbrechung nänlich, durch die der Tunsch des Forschers, bestimmte Strukturelemente zur Anschauung zu bringen, in einer Weise erfuillt wird, die nicht vom Farbstoffe sonciern rom Iärbenden abhängt. Denn man entfärlat nur so lange, bis die Prüfung unter dem Mikroskop zeigt, daß der geriinschte firberische Effelt erziclt ist. Aber ob das Bild objektiv richtig ist. nb das, was entfirbt ist, nicht ein Strukturelement darstelite, das willkiulich zum Verschwinden gebracht wurde: daruber zu urteilen besitzen wir kein Kriterium. Denn wir wissen ja gar nicht, wie die Zelle usw, strul:turiert ist, darum künnen wir mit positiver Bestimmtheit auch niemals behaupten oder diurften es wenigstens nicht, daß der feinere Bau der Zellsubstanz nur ron den nach : Differenzierung: des Hämatoxylinlaclies gefirbt zuriickbleibenden Elementen gehildet wird. Jede Beschreibung eines Hämatoxylinlackbildes enthält daher cine Art Petitio principii: es wird vorausgesetzt, dal.3 das Entfirbte nicht zur struktur gehört, dalß diese nur von dem Gefärbten clargestellt wirl, wihrend solches zu beweisen dic erste nicht nur sondern. wie ich meine, die alleinige Aufgabe hilden müßte. Es mehren sich daher die Stimmen derjenigen, welche vor einer Überschitzung der Hämatoxylinlacke, namentlich in der Centrosomenfrage, warnen (Boveri z. B.). Fischer zeigte, daß an den Granulis der von ihm benutzten organischen nichtorganisierten Substanzen bei dur Anwendung der Eisenlacke des Hämatoxylins cine sogenannte Spierrelfürhung auftritt. Man erhält nämlich cin lisild wie eine Schützenscheibe mit schwarzem Zentrum und weißem, d. h. hellem Hofe. Das Zentrum ist dem Centrosoma vergleichbar und es kann sich durch weitergehende Differenzierung verkleinern. Es scheint, namentlich nach den Boverischen Untersuchungen, keinen Zweifel zu unterliegen, dalls so manches in tierischen Zellen mit den Hämatoxylinlacken dargestellte Centrosoma nur dits Resultat ciner Spiegelfärbung ist.

\section{$\S 59$.}

Eine eigentünliche Tominologie haben L'nna und M. Heidenhain eingefuhrt. Letzteru Forscher farbte die Schnitte zunächst; 
bevor er scinen Eisenhämatoxylinlack ausführte, mit Bordeauxrot vor. Er wollte dadurch verhindern, daß der Lack an Plasma und Chromatin ginge. Weil so ein Teil des Gewebes der Hauptfärbung, den Hämatoxylinlack, entzogen wird, nannte er dies Verfahren: subtraktive Färbung. Unna hat der Tatsache den Namen tinktorielle Praeoccupation gegeben. Ich bekenne offen, daß ich einen wissenschaftlichen Gewinn in diesen Bezeichnungen nicht erblicken kann und auch mit ihnen nichts anzufangen weiß.

\section{c) Theorie des Färbens.}

\section{$\S 60$.}

Demjenigen, der nur morphologische Zwecke bei seinen mikroskopischen Studien verfolgt, wie demjenigen, der ausschließlich die Textur eines Organes studieren und beschreiben will: diesen beiden Forscherhategorien kann ganz gleichgiiltig sein und ist auch ganz gleichgiiltig, was beim Färben zu mikroskopischen Zwecken geschieht. Wenn nur der Farbstoff den an ihn zu stellenden Anspriichen genügt: gut zu färben und Dauerpräparate zu liefern, dann sind die meisten Mikroskopiker befriedigt. Daß dieser Standpunkt ein berechtigter ist, wer wollte das leugnen! Aber nicht minder berechtigt ist das Verlangen derjenigen, welche intrikate Strukturen untersuchen, welche Farbenreaktionen auf die verschiedenen Zellbestandteile, auf dic Sekrete usw. studieren wollen, darïber Klarheit zu erhalten, was beim Färben geschieht. Denn dic richtige Einsicht in den Färbeprozeß würde zu weitgehenden Rückschlïssen auf die Beschaffenheit der lebendigen Substanz berechtigen. Daß eine Verbindung des Farblörpers mit den Elementen der tierischen Organe bewirkt wird, ist selbstverständlich: aber ob diese Verbindung glcichzeitig eine chemische Bindung ist oder nicht, das ist nicht ohne weiteres auszumachen.

In Küirze sollen die über das Wesen des Färbeprozeßes aufgestellten Theoricn erörtert werden. Sie in aller Breite vorzuführen. die cigene Stellungnahme womöglich durch neue Tersuche zu begründen, wiirde dem Zwecke eines Lehrbuches nicht entsprechen. Andererseits dic theoretische Betrachtung ganz zu übergehen, würde ebenfalls ein Fehler sein, denn namentlich der Anfänger hat eir Recht darauf, in die Theorie eingefuhrt zu werden, und der Verfasser eines Lehrbuches hat die Pflicht. dieses Recht zu achten. Es sei denn, man betrachte das Mesen eines Lehrbuches der mikroskopischen Technik in einer kochbuchartigen Zusammenstellung einer Anzahl technischer Rezepte. 
Es gibt 3 Theorien über das Wesen der mikroskopischen Färbung: die chemische Theorie, die von Ehrlich, Paul Mayer, Weigert, Unna, M. Heidenhain, Benda und wohl von den meisten Mikroskopikern als die allein richtige bezeichnet wird, dann die physikalische Theorie, von Gierke, Fischer, Rawitz und von den meisten Industriefärbern angenommen, und endlich die Theorie der festen Lösung, welche von WVitt und L. Michaelis vertreten wird. Die Theorien wollen feststellen, welcher Art bei substantiver Färbung die Verbindung des Farbkörpers mit dem Organelement, bei adjektiver die Verbindung der Beize mit diesem ist.

Die Theorie der festen Lösung wurde ron Witt aufgestellt und von L. Miachelis namentlich gegen Heidenhain verteidigt. Die Theorie nimmt an, daß das zu färbende Gewebe wie ein Lösungsmittel wirke. Der Farbstoff, der in flüssiger Form mit dem Gerebe zusammengebracht wird, soll sich entscheiden, welchem Lösungsmittel er sich zuwenden will, dem Wasser bzw. Alkohol der Farbflotte oder dem zu färbenden Gewebe. Je nach dem Ausfall dieser Entscheidung tritt Färbung ein oder bleibt aus. Die physikalische Theorie verwirft IVitt vollständig, er hält sie für gar keine Theorie, sondern nur fuir die Umschreibung der Tatsache, daß gefärbt wird: die chemische Theorie ist nach ihm unzurcichend. Bis jetzt ist die Theorie der festen Lösung nicht über das Stadium des geistreichen Aperçu hinausgekommen und hat ihre tiefere Begründung nur in einem summarischen Verwerfen der entgegenstehenden Theorien erhalten.

Die chemische Theorie nimmt an, dals die Färbungen die Folgen chemischer Vorgänge seien, die allem Anscheine nach dadurch zustande kïmen, daß die Farben durch mehrwertige, in den Teilen des Präparates vorhandene Elemente gebunden wïrden. Aus den vielen "Beweisen", die für die chemische Theorie ins Feld geführt werden, scien nur die beiden folgenden erwähnt. Wenn zu Salmonucleïnsäure nach P. Mayer Alaunlösung zugesetzt wird, so entsteht ein weißer Niederschlag. Das ist selbstverständlich ein chemischer Vorgang, d. h. die Nucleinsäure fällt den Alaun aus seiner Lösung. Wenn man Karmalaun nimmt, so entsteht ein roter Niederschlag, denn Karminsäure und Alaun sind ein einheitlicher Körper geworden. Auch dies ist ein chemischer Vorgang; nur begreife ich nicht, wie man ihn für die mikroskopische Färberei verwerten kann. Denn, soweit ich die Mayersche Beweisfihrung rerstanden habe, wird nicht die Nucleïnäure rot gefärbt; und darauf käme es allenfalls an, wenn solche Versuche mit toten Produkten iiberhaupt zwingende Beweiskraft für organisierte Substanzen hätten. 
Einen anderen Berreis glaubt Unna in folgendem Versuche geliefert zu haben. Während Metaphenylendiamin und salpetrige Säure außerhitb der Gespinnstfaser sofort zu Vesuvin sich vereinigen, tun sie dics nicht, wenn sie einzeln an die Faser gebracht werden. Darin cinen Beweis, und zwar cinen unantastbaren Beweis für die chemische Theorie der Färbung zu erblicken, erscheint mir unzulässig. Im Gegenteil, ich sehe darin einen Beweis für die physikalische Theorie. Die ()berflächenattraktion der Gespinnstfaser gegen die Komponenten des Farbstoffes ist cine derartige oder, um die I ischersche Terminologie zu gebrauchen, die Adsorptionskocffizienten beider Reagentien zur Faser sind so verschieden, daß sie sich in dieser nicht in äquivalenten Verhältnissen mischen können. Wäre die Färbung der Gewebe wirklich ein chemischer Vorgang, so hätte die Bildung von Vesuvin erfolgen müssen.

Bei der physikalischen Theorie des Färbens wird angenommen, daß der Farbstoff wie auf der Gespinnstfaser so auch auf den Bestandteilen cines tierischen ()rganes nicht chemisch gebunden, sondern durch ()berflächenattraktion festgehalten wird. D. h. die Molekiile des Farbstoffes und die Moleküle der eine Zelle oder ein Gewebe zusammensetzenden Tcile haften aneinander fest, die beiderseitigen Molekiile oder Molekiilgruppen lagern sich fest aneinander. Gicrke nannte dies Oberflïchenattraktion, welchen Ausdruck ich als sehr passend gefunden habe, da er gerade das, worauf es ankommt, nämlich daß die Molekïlgruppen je nachden fest oder lose aneinander haften, geradezu plastisch veranschaulicht. Fischer der neueste geistrciche Verfechter der physikalischen Theorie, nannte dies Aneinanderhaften: Adsorption, ein ebenfalls durchaus brauchbarer Ausdruck. Es ist nicht zu leugnen, daß wir hinsichtlich dessen, was beim Färben zu mikroskopischen Zwecken geschieht, noch völlig im Dunkeln tappen. Wir können und dïrfen daher auch nicht sagen: nur die chemische oder nur die physikalische Theorie ist richtig die Wittsche Theoric der festen Lüsung glaube ich hier nicht besonders beriicksichtigen zu müssen, denn sie ist nur eine etwas eigenartige Fassung der physikalischen -, sondern wir kömnen und dürfen nur sagen, diese oder jene Theoric hat mehr Wahrscheinlichkeit für sich. Darum müssen wir uns so ausdruicken, weil die Grundlagen der beiden in Retracht kommenden Theorien noch sehr schwankende sind. Wäre die chemische Theorie richtig, dann müßte die Vereinigung ron Gewcbscloment und Farbstoff nach chemischen Iqquivalenten erfolgen. Dicse Iquivalente hat aber noch kein Mensch bisher aufgezeigt, ja nicht cinmal sie andeutungsircise dargelegt. Denn 
die von den Anhängern der chemischen Theorie gebrauchten Ausdrücke "Valenzen", mehrwertige Elemente" sind Worte, aber keine Begriffe. Andererseits sind, wie Gierke bereits crklärt hat und worin ich ihm rückhaltlos zustimmen muß, die Gesetze der Oberflächenattraktion uns noch völlig unbekannt. Auch stehe ich nicht auf dem exklusiven Standpunkte, nun all und jeden Chemismus beim mikroskopischen Färben zu leugnen. So halte ich zum Beispiel die Tatsache, daß die Mucine eine ungemein große Affinität zu Alaunhämatoxylinen und zu basischen Anilinen zeigen, für eine höchstwahrscheinlich chemische Erscheinung ebenso wie die Tatsache, daß mit der Weigertschen Hämatoxylinfärbung nur die Markscheiden der Nerven gefärbt werden können. Aber die Summe aller Fürbungsresultate auf Chemismen zurückzufuihren, kann ich mich nicht entschließen, weil das Wenige, das wir vom Färben wissen, auf dic ()berflïchenattraktion hinweist. Ich führe in den folgenden Zeilen nur einige wenige Beweise, oder vielleicht besser Gründe, für dic ()berfächenattraktion an, ohne nur im geringsten die Frage erschöpfend behandeln $\mathrm{zu}$ wollen.

Bei einem sehr ingeniösen Versuch, den Röthig zur Erkenntnis der "Wechselbezichung zwischen metachromatischer Kern- und Protoplasmafärbung der Ganglienzelle und dem Wassergehalt alkoholischer Hämatoxylinlösungen angestellt hat, ergab sich folgendes Resultat. Die alkoholische Hämatoxylinlösung farbt den Kern gar nicht oder nur schattenhaft. Verdinnt man sie mit Wasser, so erreicht man allmihlich, d. h. bei steigendem Wasserzusatze, wobei die verwendete Quantität der Farbflotte stets dieselbe hleibt, eincn Verdünnungsgrad, bei welchem eine schöne Blaufürbung des Kernes eintritt. Jenseits dieses Verdinnungsgrades, also bei schwächerem IVassergehalt der Farbflotte, ist die Färbung gar nicht oder nur angedeutet vorhanden, diesseits, d. h. bei stärkerem Wassergehalt, schwindet sie wieder. Die chemische Theoric kann diese Tatsache nicht erklären, wohl aber die physikalische. Denn wäre die Kernfärbung das Resultat einer chemischen Verbindung der Kernsubstanzen mit dem Hämatoxylin, so mïßte sie sich immer einstellen, gleichguiltig ob die Farbflotte stärker oder schwächer allsoholisch ist. Daß dies nicht geschieht, spricht gegen den Chemismus. Physikalisch erklärt sich das Järbungsresultat dadurch, daß bei der Wasserverduinnung der Farbflotte ein Grad der Auscinanderdrängung der Farbstoffmolekülgruppen erreicht wird, der als Optinum fuir das Färben wirkt. (Jede Lösung scheint ja nach den neuesten Erfahrungen nur auf einer durch das Lösungsmittel bewirkten Auseinanderdrängung der Molckiilgruppen, nicht auf ihrer 
wirklichen Auflösung zu beruhen. Je konzentrierter die Lösungen, desto dichter die im Lösungsmittel aufgeschwemmten Molekiilgruppen, je verdinnter, desto weiter auseinander befinden sich die Molekülgruppen. Das Siedentopfsche Mikroskop hat das unstreitig bewiesen.) Und bei diesem Optimum findet allein eine ausgiebige Oberflächenattraktion statt.

Eine andere färberische Tatsache ist ebenfalls nur durch die physikalische, durchaus nicht durch die chemische Theorie zu erklären. Färbt man nach Sahli Ruickenmark mit Methylenblau-Säurefuchsin vgl. zweiundzwanzigstes Kapitel) und differenziert man nach der Vorschrift dieses Autors in Ätzkalialkohol, dann crhält man ganz merkwürdige Bilder. Einige Nervenfasern haben eine rote, andere eine blaue Markscheide. Und es zeigt sich, wenn man die von Sahli veröffentlichte Farbenfigur genau hetrachtet, daß nicht die Größe der Faser die Färbung bestimmt, daß nicht die feinen Fasern z. B. rot (erythrophil) die groben blau (kyanophil) sind, sondern daß unmittelbar nebeneinander liegende Nervenfasern von gleicher Größe die einen kyanophil die anderen erythrophil sind. Hier versagt die chemische Theorie vollkommen; die physikalische weist darauf hin, daß durch ungleiche Fixation der Fasern deren Adsorptionsvermögen sich ungleich gestalten muß.

Auch eine Erfahrung, die Rhumbler gemacht hat, läßt sich zur Stüze der physikalischen Theorie verwerten. Dieser Gelehrte fand nämlich, daß man an Schnitten durch Protozoën feststellen kann, welche Teile bei der Konservierung noch lebendig und welche bereits abgestorben waren. Die Färbung wurde in Methylgrün-Eosin vorgenommen (vgl. dreizehntes Kapitel) und es zeigte sich, daß die lebend fixicrten Abschnittc rot, die tot fixierten grün gefärbt waren. Selbst der abgestorbene Teil einer Zelle, sofern nur nicht bereits die Zersetzung begonnen hat, ist Protoplasma; und es ist im höchsten Grade unwahrscheinlich, daß das tote Protoplasma eine andere chemische Konstitution besitzen wird wie das lebende. Darum müssen die durch die Fixierung hewirkten Fällungsprodukte chemisch übereinstimmen und müssen chemisch die gleichen Farbenreaktionen geben, ob die Produkte nun an totem oder an lebendem Material erzielt worden sind. Es ist dies ja auch tatsächlich der Fall, wie wir aus histologischen Präparaten, die von tot fixiertem Menschenmaterial stammen, bei Vergleichung mit lebensfrisch eingelegtem Säugetiermaterial lernen können. Chemisch ist also das Rhumblersche Ergebnis nicht zu erklären. Daß das Adsorptionsvermögen der beiden in ungleichem Zustande fixierten Teile eines Protozoon ein ungleiches war, das 
scheint mir ohne weiteres klar. Dadurch erklärt sich dies merkwürdige Färbungsresultat Rhumblers.

Von den zahlreichen Beispielen, welche Fischer für die physikalische Theorie anfuhrt, soll nur das folgende hier Platz finden. Menschlichen Hoden fixierte $\mathrm{F}$ ischer in Flemmingscher Lösung. Die aufgeklebten Schnitte wurden in eine Lichtgrünlösung gebracht, die mit Schwefelsäure angesäuert wurde. Der ganz grüne Schnitt wurde dann mit Laugenalkohol kurz behandelt, dann nach Abwaschen in Safranin gefärbt. Als Resultat zeigte sich eine völlige Umkehrung der färberischen Eigenschaften der angewendeten Aniline. Lichtgrün, ein Plasmafarbstoff, färbte in dem Versuche die Kerne, Safranin, ein Kernfarbstoff, färbte dagegen die Zellsubstanz. Man konnte sogar in einem und demselben Kernknäuel die in die Tiefe des Schnittes verlaufenden Teile rein grün, die zur Oberfläche aufsteigenden rein rot gefärbt und daneben auch Mischtöne finden. Daß hier die chemische Theorie direkt versagen muß, kann keinem Zweifel unterliegen.

Fischer hat auch den Nachweis erbracht, daß aus Deuteroalbumose gefällte und mit Süurefuchsin-Pikrinalkohol gefärbte Granula rein gelb sich färbten, wenn sie großen oder mittleren Umfanges waren, dagegen intensiv rot erschienen, wenn sie nur sehr geringen Umfang hatten. Der Physiker Strehl hat vollkommen recht, wenn er darauf dringt, bei der milrroskopischen Färbung zu berücksichtigen, daß verschiedene Färbbarkeit bzw. sogar verschiedene Färbung nicht immer Anzeichen stofflicher Verschiedenheit, manchmal nur von verschiedener Dichtigkeit sein wird

Vielfach wird die sogenannte Metachromasie als Beweis für die chemische Natur des Färbeprozesses angeführt. Man versteht darunter die Eigentümlichkeit eines Farbstoffes, die Teile eines Objekts, z. B. Kern und Kernkörperchen, in zwei verschiedenen Farben zu färben. Farben, nicht Farbentönen; denn wenn ein grüner Farbstoff zugleich blau oder violett färbt, dann muß, so ist die Meinung, die blaue oder violette Färbung ein Beweis für den Chemismus sein. Leider sind die metachromatischen Farbstoffe, wie Methylgrün, unrein es enthält viel Methylviolett - oder sie sind wie das Methylenazur nur scheinbar einheitlich. Letzteres entsteht aus Eosin und Methylenblau.

\section{d) Vorbereitung zum Färben.}

$$
\S 6 \mathrm{I} \text {. }
$$

Celloidinschnitte können ohne weiteres in die Farbflotte kommen, es sei denn, daß man beabsichtige, sie zu entcelloidinisieren. Will 
man aus einzelnen Schnitten das Celloidin fort bringen, damit durch sein Nitfärben in der Farbflotte kein schmieriges oder gar falsches Bild entstehe, dann muß man den Schnitt in eine Mischung von Alkohol absolutus und ither zu gleichen Teilen einlegen. Hierin löst sich das Celloidin. Sollen Celloidinschnitte mit Lösungen gefärbt werden, die keinen Alkohol vertragen, so bringt man sie zunächst in destilliertes Wasser, um den Alkohol auszutreiben. Einige Autoren verfahren dabei sehr vorsichtig, indem sie die Schnitte in immer dünneren Alkohol allmählich übertragen. Ich halte diese Vorsicht für unnötig; man kann ohne die geringste Besorgnis die Schnitte auch aus starkem Alkohol direkt in destilliertes Wasser überfiihren.

Anders muß Paraffinmaterial zur Färbung vorbereitet werden. Zur Entfernung des Paraffins kommen die aufgeklebten Schnitte auf Io Ninuten bis ${ }^{\mathrm{I}}$. Stunde in Nylol oder Terpentinöl. Ersteres löst das Paraffin schneller als letzteres, ist aber auch bedeutend teurer. Dann werden die Schnitte in $96^{\circ}$ 。Alkohol gebracht, den man zur volligen Austreibung des Xylols bzw. Terpentinöls wiederholt wechseln muß. Die im Xylol durchsichtig gewordenen Schnitte müssen wieder undurchsichtig geworden sein, wenn alles Xylol ausgetrieben ist. Dann vermindert man in schneller Folge die Konzentration des Alkohols $\left(80^{\circ},-30^{\circ}\right.$, führt die Schnitte in destilliertes Wasser über, das man mehrere Nale erneuern muß. Endlich wird in die Farbflotte eingebracht. Man kann auch, wenn man die immerhin etwas umständliche Überfuihrung in die Alkohole der rerschiedenen Grade vermeiden will, die Schnitte nach Austreibung des Xylols anhauchen. Die Feuchtigkeit des Atems reicht völlig zur Verwässerung aus. Schnitte, welche nur mit destilliertem Wasser aufgeklebt sind, dürfen allerdings nicht angehaucht werden; sie heben sich dabei von ihrer Unterlage buckelformig ab und schwimmen in der Farblösung fort. Ist die Farblösung alkoholisch, dann können die Schnitte in sie direkt aus dem $96 \%$ Alkohol übergeführt werden.

Eine originelle Methode hat Lardowsky angegeben, die dazu geeignet sein soll, alte Schnitte, deren Färbung abgeblaßt ist, wieder aufzufrischen. Zur Belebung alten, wertvollen Materials bereitet man sich folgende Lösung: Kaliumbichromat chemisch rein, $20-25 \mathrm{~g}$. konzentrierte, filtrierte, wässrige Sublimatlösung $5-10 \mathrm{ccm}$. Aqua destillata und $I^{\prime \prime}$ Eisessig manchmal auch $4^{\circ},-5{ }^{\prime \prime}$, Eisessig) $500 \mathrm{ccm}$. Man entfernt Deckgläser und Balsam ron dem alten Material in Xylol, treiht dieses durch Alkohol aus, diesen durch Wasser und legt in die ehen genannte Restaurierungsfluissigkeit ein. Hierin bleiben die Schnitte 6-I 2-24 Stunden, sie werden dann entweder mit Wei- 
gerts Hämatoxylinlack oder in Fuchsin gefärbt und sind vollkommen restauriert.

e) Die Farbstoffe.

$\$ 62$.

Die zur mikroskopischen Färberei benutzten Farbstoffe entstammen entweder dem Tierreiche, wie Cochenille und Karmin, oder dem Pflanzenreiche, wie Hämatoxylin, Orcëin und Brasilin, oder sind endlich als Aniline und Anthracene Alizarine) aus dem Steinkohlenteer gewonnen. Die rersuchte Einfuhrung neuer Farbstoffe pflanzlichen Ursprungs, wie z. B. das Ribesin durch Fol, hat keinen Erfolg gehabt. Mit Recht, denn die neuen Farbkörper waren keine Bereicherung unseres Farbstoffschatzes.

Es sollen hier nur diejenigen Methoden genauer beschrieben werden, die eine allgemeine Anwendung gestatten. Die für spezielle Zwecke angegebenen und auch zu einer gencrellen Verwendung nicht geeigneten Torschriften werden in den Kapiteln des II. Teiles Unterkunft finden.

Ich gebe zunächst die Methoden der substantiven Färbung und darin die einfachen Farben. d. h. Methoden, bei denen nur ein Farbstoff rerwendet wird, Doppelfärbungen und Dreifachfärbungen. Dann folgen die adjektiven Färbungen und endlich die vitale Färbung.

\section{Die substantive Färbung.}

a) Einfache Farben.

$$
\text { ș } 63 \text {. }
$$

Cochenille. Die getrockneten Leiber der Weibchen der Cochenillelaus Coccus cacti; zur Familie der Pflanzenläuse, Phytophthires, gehörig enthalten den Farbstoff, welcher die Karminsäure ist. Die getrockneten Leiber selber werden in den folgenden Vorschriften zur Färbung verwendet.

I. Alauncochenille, nach Partsch und nach Czokor. Die Vorschrift des letztgenannten Autors hat sich am meisten eingebuirgert; sie lautet: $7 \mathrm{~g}$ Cochenille und $7 \mathrm{~g}$ gebrannten Alauns werden $\mathrm{zu}-$ sammen zu einem Pulver zerrieben. Man kocht sie dann in $700 \mathrm{ccm}$ Aqua destillata und dicht die Lösung auf $400 \mathrm{ccm}$ ein. Nach dem Erkalten muß sehr haufig filtriert werden. Als Antisepticum bringt man einige Thymolkristalle in die Lösung.

Rabl stellt die Alauncochenille folgendermaßen dar: $25 \mathrm{~g}$ pulverisierte Cochenille, nahezu ebensoviel pulverisierter Alaun werden ge- 
mischt und in $800 \mathrm{ccm}$ Aqua destillata im Abdampfapparate unter beständigem Umrihren gekocht. Nach etwa ${ }_{1 / 2}$ Stunde ist die Lösung auf $600 \mathrm{ccm}$ eingeengt. Nach dem Erkalten wird mehrere Male filtriert und I Stück Thymol zur Verhütung von Fäulnis hinzugefügt. Jüngere Lösungen färben besser als alte.

Für Stück- und Schnittfärbung geeignet; gute Kern-, leichte Plasmatinktion. Die Stücke, die gut gewässert sein müssen, bleiben je nach Notwendigkeit I Stunde bis mehrere Tage in der Farbflotte; nach dem Färben gut Auswaschen in destilliertem Wasser. Platinfixierungen müssen spätestens 8 Tage nach der Härtung gefärbt werden, sonst geht der Farbstoff schlecht an die Teile heran.

2. Cochenilletinktur, nach Paul Mayer. Zur Stückfärbung bringt Mayer pulverisierte Cochenille in die 8-rofache Menge $70^{\circ} \mathrm{Al}-$ kohols und läßt die Mischung mehrere Tage in der Kälte stehen. Dann wird filtriert. Die gefärbten Stücke werden in $70 \%$ Alkohol gewaschen.

Neuerdings empfiehlt Paul Mayer folgende Cochenilletinktur. $5 \mathrm{~g}$ Cochenille, $5 \mathrm{~g}$ Chlorcalcium, $0,5 \mathrm{~g}$ Chloraluminium werden zusammen gut verrieben. Dann werden $100 \mathrm{ccm}$ Alkohol von $50 \%$ und 8 Tropfen Salpetersäure von 1,20 spez. Gewicht zugesetzt. Die Lösung wircl bis zum Kochen erhitzt, dann läßt man sie einige .Tage unter häufigem Schüitteln stchen und filtriert. Die gefärbten Stücke werden in $50 \%$ Alkohol gewaschen.

3. Eisencochenille, nach Spuler. Fein gepulverte Cochenille wird in destilliertem Wasser gekocht, nicht ganz bis zur Trockne eingedampft und dann wiederum mit destilliertem Wasser versetzt. Die Lösung wird filtriert. Die Stücke kommen hier hinein für $2+$ Stunden oder länger und werden auf den Paraffinofen gestellt. Nach dem Färben wird gewaschen und in eine $3 / \%$ Eisenalaunlösung gebracht. In dieser Beize werden die Stiicke schwarz. Dann Waschen und Härten wie gewöhnlich.

Eine andere Vorschrift desselben Autors lautet: to $\mathrm{g}$ Cochenille werden in destilliertem Wasser (wieviel?) gekocht; nach dem Erkalten wird filtriert. Der Filterrückstand wird nochmals gekocht und filtriert. Beide Filtrate mischt man und engt sie auf dem IVasserbade auf $200 \mathrm{ccm}$ ein. Dann setzt man $96^{\circ}$, Alkohol zu, bis eine Fällung entsteht. Man läßt absetzen, filtriert und kocht das Filtrat auf $400 \mathrm{ccm}$ ein. Stuickfärbung; wobei die Farbflotte mit dem gleichen Volumen destillierten Wassers verdiinnt wird, im Brütschrank 48 Stunden lang. Man wäscht und legt für 24 Stunden in das $3{ }_{4} \%$ Eisenalaunbad, dann 
verstärkt man letzteres auf $I^{\circ}$ ound beläßt darin einige Tage. Waschen, Härten wie gewöhnlich.

4. Ferricochenille, nach Hansen. $8 \mathrm{~g}$ Eisenalaun werden in $200 \mathrm{ccm}$ Aqua destillata gelöst, 5- $\mathrm{log}$ pulverisierte Cochenille sorgfältig darin verteilt, $15 \mathrm{ccm} 10^{\circ}$. Schwefelsäure vorsichtig zugesetzt und das Gemisch unter Umrühren bis zum Kochen erhitzt. Nan läßt 15-20 Minuten kochen, wobei man das abgedampfte Wasser von Zeit zu Zeit ersetzt. Nach dem Kochen ı $\mathrm{ccm}$ Schwefelsäure von I ${ }^{\circ}$ 。 zugesetzt; nach dem Erkalten wird filtricrt. Schnittfärbung; jeder beliebige Grad von Kernfärbung in verdünnten Säuren erreichbar. Die Lösung ist dunkelbraun bis schwarzbraun.

5. Chromalauncochenille, nach Hansen. $5 \mathrm{~g}$ Chromalaun und Io $\mathrm{g}$ Cochenille (gepulvert) werden in $200 \mathrm{ccm}$ Aqua destillata I 5-20 Minuten lang gekocht. Eventuell kann man $5 \mathrm{ccm}$ einer $10 \%$ Schwefelsäure zufügen. Filtrieren. Dunkelgraublaue Lösung für Schnittfärbung.

\section{$\S 64$.}

Karmin und Karminsäure. Die Karminsäure ist das färberische Prinzip der Cochenille, das Karmin ein aus letzterer hergestellter Farbstoff, der eine eiweißhaltige Tonerdekalkverbindung ist. Da erst in neuerer Zeit die Karminsäure auf Empfehlung von Paul Nayer für histologische Zweche verwendet wurde, so sollen die alteren Karminvorschriften in der Schilderung vorausgehen. Ich halte die Anwendung der Karminsäure für rationeller als die des Karmins. Denn jene, ein chemisch präzis zu fabrizierender larbkörper, ist immer in gleicher Giite zu haben, wenigstens nach meinen Erfahrungen. während die Larmine des Handels, selbst wenn man sie stets vom selben Lieferanten bezieht, fast immer in ihrer Wirkung variicren. Die Herstellung der in den folgenden Nummern empfohlenen Karminlösungen kann daher noch so exakt ausgefüht sein, gelegentliche Mißerfolge, d. h. Unzulänglichkeit der Lösungen, werden nicht ausbleiben. Das Karmin wurde zuerst von Corti und Gerlach für tierische Gewebe verwandt; von letzterem Autor in Form der roten Tinte.

6. Ammoniakalisches Karmin. I g gepulvertes Karmin in $100 \mathrm{ccm}$ Aqua destillata durch Zusatz von einigen Tropfen Ammoniak gelöst. Nan läßt die Lösung in offener Schale so lange stehen, bis der Ammoniakgeruch verschwunden ist. Dann wird, wenn nötig, filtriert. Man färbt entweder in dieser Lösung oder verdünnt einen aliquoten Teil von ihr mit destilliertem WVasser, bis die gewuinschte Konzentration erreicht ist. Die verdiinnten Lösungen färben besser, als die 
konzentrierten; freilich muß man die Schnitte lange in ihnen lassen. Auswaschen der Schnitte in Essigsäure-haltigem Wasser. Besonders zur Darstellung der Achsenzylinder im Rückenmark geeignet. Mit Eiweiß aufgeklebte Schnitte können nicht mit diesem Farbstoff gefärbt werden, da das Ammoniak das Eiweiß auflöst.

7. Lithionkarmin, nach Orth. $2,5 \mathrm{~g}$ Karmin in $100 \mathrm{ccm}$ kaltgesättigter Lösung von Lithium carbonicum gelöst. Die Schnitte werden in $1^{\circ} \%$ Salzsäure enthaltenden Alkohol $\left(70^{\circ}\right.$ ) direkt aus der Farbflotte übertragen. Eine sehr alkalische Flüssigkeit.

8. Salzsaures Karmin, nach Paul Mayer. $4 \mathrm{~g}$ Karmin, $15 \mathrm{ccm}$ Aqua destillata, 30 Tropfen reiner Salzsäure gemischt und durch Kochen gelöst. Nach dem Erkalten Zusatz von $95 \mathrm{ccm}$ Alkohol von $96^{\circ}$. Man filtriert und setzt dem Filtrat vorsichtig Liquor ammonii caustici $z u$, bis die Säure neutralisiert ist. Nur Stückfärbung; das Naterial kommt auf $2+$ Stunden und länger in die Lösung. Zur Erzielung reiner Kernfärbung wird in salzsäurehaltigem Alkohol i I I 000 Alkohol; ausgewaschen, bis kein Farbstoff mehr ausgezogen wird. Darauf Überfuihren in neutralen Alkohol. Bringt man die Objekte aus der Farbflotte direkt in neutralen Alkohol - Wasser ist zum Auswaschen unbedingt zu vermeiden - , dann erhält man auch leichte Plasmafärbung. Die Färbung ist beendet, wenn der Waschalkohol keinen Farbstoff mehr auszieht.

9. Wässriges Boraxkarmin, nach Grenacher. $2 \mathrm{~g}$ Borax mit ${ }^{3}$ - I $\mathrm{g}$ Karmin verrichen und in $100 \mathrm{ccm}$ Aqua destillata gekocht. Nach dem Erkalten wird unter stetem U'mriihren Essigsäure tropfenweise zugesetzt, his die Lösung kirschrot ist wie das ammoniakalische Karmin. Dann läßt man $2+$ Stunden stehen und filtriert. Nur Schnittfärbung. Die Schnitte werden 5 Minuten bis 24 Stunden gefärbt. Dann kommen sie nach flüchtigem Abspülen in salzsauren Alkohol ( 1 : 1000 ron $96^{\circ}$, bis keine Farbstoffwolken mehr entweichen. Unterbricht man die Prozedur des Differenzierens zu früh. dann erhält man amorphe Niederschläge des Farbstoffes in Präparat; denn die Färbung mittels des Boraxkarmins findet erst im salzsauren Alkohol statt, bis dahin war der Schnitt nur mit Farbstofflösung bedeckt, aber noch nicht gefärbt.

Io. Alkoholisches Boraxkarmin, nach Grenacher. $2-3 \mathrm{~g}$ Karmin mit $+g$ Borax verrieben und in $100 \mathrm{ccm}$ Aqua destillata gekocht; nach dem Erkalten Zusatz des gleichen Volumens Alkohol von $96^{\circ}$. IIan läßt stehen und filtriert nach einiger Zeit. Nur Stückfärbung. Die Färbungsdauer variiert nach der Beschaffenheit der Stiicke. Aus der Farbflotte wird direkt in salzsauren Alkohol 
I : I000; eingebracht und so lange differenziert, bis kein Farbstoff mehr entweicht. Die Grüde sind die gleichen wie bei der vorigen Farblösung.

I I. Wässriges Alaunkarmin, nach Grenacher. $3 \mathrm{~g}$ gepulverten Alauns werden mit $\mathrm{I} g$ Karmin verrieben und in $100 \mathrm{ccm}$ Aqua destillata I $0-20$ Ninuten gekocht. Nach dem Erkalten wird filtriert. Zur Verhuitung des Faulens wird etwas Karbolsäure oder Thymol zugesetzt. Ich nehme stets Ammonalaun, da dieser leichter löslich ist als die übrigen Alaune. Nur Schnittfärbung. Ein vorzügliches Kernfärbemittel; Kerne rotviolett, Muskelfasern, Knochengrundsubstanz und Nucin rötlich gefärbt. Färbungsdauer wenige Minuten bis 24 Stunden; es tritt keine Überfärbung ein.

I 2. Alkoholisches Alaunkarmin, nach v. Mährenthal. Um dic Schimmelbildung in der vorigen Lösung zu verhüten, setzt v. Mïhrenthal zu + Volumina von ihr I Volumen Alkohol von $96 \%$. Wenn kein Karmin und kein Alaun mehr ausfallen, wird filtriert. Nur Schnittfärbung; es wird wie bei Nr. II in Wasser abgewaschen.

I 3. Essigsäurekarmin, nach Schneider. $45 \%$ Essigsäure wird zum Kochen gebracht und darin Karmin bis zur Sättigung gelöst. Nach dem Erkalten wird filtriert. Man verwendet entweder die unverdünnte Lüsung oder die so stark verdünnte, daß sie nur noch $I^{\circ}$ 。 Essigsäure enthält. Die Präparate halten sich nicht; die Vorschrift ist recht überflüssig.

I . Urankarmin, nach Schmaus. I g Natriumkarmin mit $0,5 \mathrm{~g}$ Uranum nitricum verrieben und in $100 \mathrm{ccm}$ Aqua destillata ${ }_{\text {s }}$ Stunde gekocht. Nach dem Erkalten wird filtriert. Rückenmarkschnitte aus II üllerscher Lösung 15-20 Minuten bis 24 Stunden gefärbt; besonders für Achsenzylinder geeignet. Knochenpräparate werden $2+$ Stunden lang in der Farbflotte gelassen und dann in $1 \%$ Salzäurealkohol ausgewaschen.

15. Magnesiakarmin, nach Paul Mayer. I g Karmin und o, I g Magnesia usta in $50 \mathrm{ccm}$ Aqua destillata 5 Minuten lang kochen; nach dem Absetzen wird filtriert. 3 Tropfen Formol werden als Antisepticum zugesetzt. Bei der Anwendung sehr stark verdünnen. Für Schnitt- und Stückfärbung. Die Lösung ist mäßig alkalisch. Ein schwaches Magnesiakarmin wird bereitet, indem man o, I g Kar$\mathrm{min}$ in $50 \mathrm{ccm}$ Magnesiawasser kocht. Magnesiawasser stellt man sich so her, daß3 man roo ccm geröhnliches Wasser auf o, I g Magnesia usta cine Woche stehen läßt; mehrmaliges Umschiitteln. Dann wird das Magnesia-haltige Wasser klar abgegossen. 
16. Mucikarmin, nach Paul Mayer. I $g$ Karmin mit ${ }_{2} g$ Chloraluminium, das nicht gelb sein darf, verrieben und $2 \mathrm{ccm}$ Aqua destillata dariiber gegossen. Dann erhitzt man auf schr kleiner Spiritus- oder Gasflamme 2 Minuten, bis die Lösung dunkelrot geworden ist. Darauf wird in die zähflüssige heiße Masse etwas Alkohol von $50^{\circ}$ 。 gegeben und nach der Lösung alles durch $50^{\circ}$. Alkohol in eine Flasche gespült; man fügt dann soviel $50^{\circ}$. Alkohol zu, daß $100 \mathrm{ccm}$ Flüssigkeit entstehen und überläßt die Mischung mindestens $2+$ Stunden sich selber. Dann wird filtriert. Zum Gebrauche wird ein aliquoter Teil mit der Iofachen Menge von kalkhaltigem Brunnenwasser verdünnt. Die Lösung färbt nur den Schleim. Sie filtriert aber niemals gut, das anfänglich klare Filtrat wird immer sehr schnell trübe und bei der Verdünnung mit Brunnenwasser scheidet sich oft Karmin in Flocken aus. Ich ziehe daher die unter Nr. 27 dieses Kapitels zu erwähnende Mucikarminsäure vor.

17. Pikrokarmin, nach Ranvier. Ich habe alle Pikrokarmine geprüft, die Vorschriften sowohl selbst ausgeführt als auch die Pikrokarmine fertig gekauft: eine wirkliche Doppelfärbung - gelb und rot - habe ich nie erhalten. Denn das anfänglich vorhandene Gelb schwand im Entwässrungsalkohol spurlos und es blieb eine reine Karminfärbung uibrig. (Darum stelle ich die Pikrokarmine zu den einfachen Farben.) Die Vorschrift Ranviers lautet folgendermaßen: In ammoniakalisches Karmin wird kalt gesättigte wässrige Pikrinsäurelösung bis zur Sättigung eingegeben. Darauf wird die Mischung auf ${ }_{15}^{1}$ ihres Volumens eingedampft. Nach dem Erkalten wird filtriert und von neuem abgedampft, dieses Mal bis zur Trockne. Das rot-ockergelbe Pulver, das erhalten wird, benutzt man in $1^{\circ}$. wässriger Lösung.

I8. Pikrokarmin, nach Weigert. $2 \mathrm{~g}$ Karmin werden mit $4 \mathrm{ccm}$ Ammoniak übergossen; nach $2+$ Stunden werden $200 \mathrm{ccm}$ kalt gesättigter Pikrinsäurelösung zugefügt. Nach weiteren $2+$ Stunden wird Essigsäure so lange zugesetzt, bis ein stärkerer Niederschlag entsteht, der durch tropfenweisen Zusatz von Ammoniak gelöst wird.

I g. Pikrokarmin, nach Hoyer. I $g$ Karmin wird in $\mathrm{I}-2 \mathrm{ccm}$ Ammoniaklösung und $6-8 \mathrm{ccm}$ Wasser gelöst. In einem Glaskolben wird auf dem Sandbade die Lösung so lange erhitzt, bis das Ammoniak verflichtigt ist; dies ist daran zu erkennen, daß in der heißen Fliissigkeit keine Bliischen aufsteigen und daß die Farbe hellrot ist. Nach dem Erkalten wird filtriert. Zu der Lösung kommt das + bis 6 fache Volumen Alkohol von 90'。. Infolge des jetzt entstehenden Niederschlags wird filtriert, der Filterrückstand wird gewaschen, zu 
einem Pulver getrocknet oder durch Übergießen mit Alkohol, der Glyzerin und Chloral enthält, in eine Paste verwandelt. Pulver oder Paste werden in einer konzentrierten Lösung von pikrinsaurem Ammoniak gelöst. Das Hoyersche Pikrokarmin ist wegen seines Gehaltes an pikrinsaurem Ammoniak zur Fixierung der vitalen Methylenblaufärbung empfohlen worden.

20. Pikrokarmin, nach Malassez und Baber. (Ich zitiere diese Vorschrift nach Frey: Das Mikroskop und die mikroskopische Technik.) I g Karmin, $200 \mathrm{ccm}$ Aqua destillata, $4 \mathrm{ccm}$ Ammoniakflüssigkeit. Nachdem die Lösung des Karmins erfolgt ist, setzt man $5 \mathrm{~g}$ Pikrinsäure $z u$, schüttelt und läßt dekantieren. Man läßt die Flüssigkeit mehrere Tage unter wiederholtem Unschiitteln stehen und trocknet sie dann in einer Schale an der Luft während mehrerer Wochen. Von dem so erhaltenen roten Pulver löst man $2 \mathrm{~g}$ in $100 \mathrm{ccm}$ Wasser und filtriert. Zur Verhütung der Fäulnis setzt man etwas Karbolsäure zu.

20a. Pikrolithionkarmin, nach Orth. $\mathrm{Zu}$ I Volumen des Orthschen Lithionkarmins, (dieses Kapitel, Nr. 7) werden 2-3 Volumina kalt gesättigter wässriger Pikrinsäurelösung zugefügt. Eine sehr stark alkalische Lösung:

Da die Herstellung der Pikrokarmine sehr umständlich ist, so tut man gut, die Substanzen oder Lösungen von Dr. Grübler und Co. oder einer ähnlichen Firma fertig zu beziehen.

21. Pikromagnesiakarmin, nach Paul Mayer. Auf 3 Volumina Magnesiaharmin (dieses Kapitel, Nr. I 5) wird I Volumen $0,5^{\circ}$. Pikrinsäurelösung zugesetzt, oder noch besser: mit $0,6 \%$ pihrinsaurer Magnesialösung wird die starke Magnesiakarminlösung auf das ı ofache verduinnt. Die pikrinsaure NIagnesia stellt man so dar, daß man zu $200 \mathrm{ccm}$ einer $0,5^{\circ}$. Pikrinsäure $0,25 \mathrm{~g}$ kohlensaure Magnesia setzt und kocht; dann wird filtriert. Auch dies Pikrokarmin ist, wie Nayer selber zugibt, kein sehr empfehlenswerter Farbstoff; die Pikrokarmine sollten endlich der Vergessenheit überlassen werden.

22. Natronpikrokarmin, nach Loewenthal. Zunächst bringt man $0,4 \mathrm{~g}$ gepulverten Karmins in $100 \mathrm{ccm}$ Aqua destillata, fügt $0,8 \mathrm{ccm} 10 \%$ Natronlauge zu und erwärmt bis zur völligen Lösung des Karmins. Unter stetem Umrühren, damit kein Niederschlag entsteht, werden $25 \mathrm{ccm} 0,5^{\circ}$ 。 wässriger Pikrinlösung allmählich tropfenweise zugesetzt. Dieses Natronpikrokarmin wird mit dem halben Volumen Salzsäure von I, I 25 spez. Gewicht $\left(=24,8^{\circ}, \mathrm{o}\right)$ nach dem Erkalten versetzt. Es entsteht ein roter Niederschlag; man filtriert und wäscht 
den Filterriickstand so lange, bis weder im Filtrat noch auf dem Filter eine Gelbfärbung mehr zu sehen ist, sondern das Filtrat anfängt, rötlich abzulaufen. Der Filterriickstand wird nunmehr unter Salzsäurezusatz mit $7 \mathrm{O}^{\circ}$. Alkohol gelöst. Dieser Farbstoff soll das gleich zu erwähnende Parakarmin ersetzen.

23. Parakarmin, nach Paul Mayer. Mit diesem Farbstoffe beginnen die Torschriften zur Verwendung der Karminsäure. I g Karminsäure, $0,5 \mathrm{~g}$ Chloraluminium und $4 \mathrm{~g}$ Chlorcalcium werden entweder warm oder kalt in $100 \mathrm{ccm}$ Alkohol von $70 \%$ gelöst. Nach dem Absetzen wird filtriert. Stückfärbung: man wäscht in $80^{\circ} \%$ oder $90 \%$ Alkohol so lange aus, bis kein Farbstoff mehr ausgeht. Ein ganz vorzüglicher Farbstoff, der sehr zu empfehlen ist: erstens braucht man nicht mit Säure zu differenzieren, zweitens überfärbt er nicht und drittens ist seine Herstellung überaus einfach. Das Material soll nicht alkalisch reagieren.

24. Karmalaun, nach Paul Mayer. I g Karminsäure und $10 \mathrm{~g}$ Alaun werden in $200 \mathrm{ccm}$ Aqua destillata durch Erhitzen gelöst. Man läßt kalt werden, gießt von dem Bodensatz ab und filtriert. Zur Verhütung der Fäulnis Zusatz von Thymolkristallen. Schnittfärbung. Ich habe keine guten Erfahrungen mit dieser Vorschrift gemacht. Zwar die Kern- und leichte Plasmafärbung waren vortrefflich, aber erstens erhielt ich fast immer Farbstoffniederschläge in den Schnitten trotz wiederholten Filtrierens der Lösung und zweitens faulte diese trotz der Antiseptica in ziemlich kurzer Zeit. Ich habe daher die folgende Lösung konstruiert und empfehle sie aufs wärmste, da sie bei gleicher Färbekraft wie Karmalaun die eben gerügten Fehler nicht besitzt.

25. Glyzerinkarmalaun, nach Rawitz. $20 \mathrm{~g}$ Ammonalaun werden in $150 \mathrm{ccm}$ Aqua destillata gelöst und zwar unter leichter Erwärmung auf dem Sandbade, dann $2 \mathrm{~g}$ Karminsäure zugefügt und mehrere Male aufgekocht. Nach dem Erkalten werden $150 \mathrm{ccm}$ Glyzerin hinzugefügt. Eine Filtration ist nicht notwendig; man läßt die Lösung cinige Zeit im Glaskolben stehen, weil sich rot gefärbte Alaunkristalle niederschlagen; dann gießt man in die Vorratsflasche ab. Die Lösung ist jahrelang haltbar, es tritt niemals Fäulnis ein. Nicmals habe ich, richtige Anwendung vorausgesetzt, amorphe Farbstoffniederschläge im Präparat erhalten. Dies riihrt meines Erachtens vom Ammonalaun her; und darin besteht dessen Vorteil gegenüber dem gewöhnlich verwendeten Kalialaun, der fast immer in Lösungen, die einige Monate gestanden haben, ausfällt und im Präparat sich niederschlägt. Nur Schnittfärbung; man kann in 5 bis 
Io Minuten bei Anwendung der konzentrierten Lösung vorzügliche Färbung der Kerne und leichte Anfärbung der Zellsubstanzen erhalten, bei sehr starker Verdünnung kann man $2+$ Stunden in der Farbflotte lassen. Quergestreifte Muskelsubstanz und Hornsubstanz intensiv rot. Wenn gelegentlich die Färbung zu gleichmäßig erscheint, kann man in ganz dünnem Ammonalaunwasser abspülen. Die gefärbten Schnitte müssen vor Einbringen in Alkohol sorgfältig gewässert werden.

26. Eisenkarmalaun, nach de Groot. $0, \mathrm{I} g$ Eisenoxydulammonsulfat (Mohrsches Salz) werden unter Erwärmen in $20 \mathrm{ccm}$ Aqua destillata gelöst, dann fügt man I $g$ Karminsäure $z u$, löst und vermehrt die Fliissigkeit durch Zusatz von destilliertem Wasser auf $200 \mathrm{ccm}$. Man erwärmt weiter bis zu mäßiger Dampfentwickelung und fügt $5 \mathrm{~g}$ Alaun bei. Wenn die Lösung klar, läßt man erkalten und filtriert; dann werden noch 2 Tropfen Salzsäure und I Kristall Thymol zugegeben. Die Verwendung des Oxydulsalzes halte ich für irrationell, da es sich heim Kochen und an der Luft in das Oxydsalz verwandelt.

27. Mucikarminsäure, nach Rawitz. Den Nachteilen des von Paul Mayer konstruicrten Mucikarmins zu begegnen, habe ich die Mucikarminsäure empfohlen. Der Vorteil ist unstreitig gegenüber der Mayerschen Vorschrift vorhanden, daß die Lösung sich niemals trübt. Die von mir im Jahre rsigg hergestellte Flüssigkeit ist jetzt I 906 - noch genau so klar wie an Tage ihrer Anfertigung. Die Vorschrift ist folgende: $0,5 \mathrm{~g}$ Karminsäure und $\mathrm{I} g$ Aluminiumchlorid werden in $100 \mathrm{ccm}$ Alkohol von $50^{\circ}$ im Kolben auf dem Sandbade leicht erwärmt. Nachdem alles gelöst ist, wird in eine offene Porzellanschale gegossen und diese auf dem Sandbade so lange erhitzt, bis der Alkohol völlig verdunstet ist. Der Trockenrückstand wird in $100 \mathrm{ccm}$ Alkohol von $50^{\circ}$ 。 gelöst; er löst sich quantitativ. Die so erhaltene purpurfarbene Mucikarminsäure färbt das Mucin vortrefflich purpurn, alles andere graurot. Eine Filtration ist nie notwendig. Nan verdiunnt einen aliquoten Teil der Flüssigkeit mit dem ro-2ofachen an destilliertem Wasser.

Das Abdampfen zur Trockne ist nötig, weil die ursprüngliche Flüssigkeit nur ganz minimale Färbung hervorbringt. Paul Mayer meint, daß durch das Abdampfen das Aluminiumchlorid weniger sauer würde und glaubt denselben Effekt durch folgende Abänderung meiner Formel zu erreichen: I g Karminsäure, I g Natriumkarbonat, 2 g Chloraluminium, Alkohol 200. 


\section{$\$ 65$.}

Hämateïn und Hämatoxylin. Das Hämatoxylin wird in Form von Kristallen aus dem Blauholz (Kampescheholz) gewonnen. Eine wirkliche, für die Zwecke des Mikroskopikers ausreichende Färbung geben die alkoholischen und wässrigen Lösungen nur in Verbindung mit Alaun, Eisen, Kupfer usw. Die Hämatoxyline des Handels sind von sehr verschiedener Reinheit oder richtiger von sehr verschiedener Unreinheit, so daß ihre sogenannte :Reifung " in den Tonerdelösungen sehr verschiedene Zeit beansprucht. Die Verbindung nämlich von Hämatoxylin und Alaun ist nicht sofort verwendbar, die frischen Mischungen sind sehr hellviolett und haben fast gar keine Färbekraft. Läßt man die Lösungen dagegen stehen, am besten bei ungehindertem Luftzutritt, so »reifen "sic, werden rötlich und färben schr gut. Dieser Reifungsproze $\beta$ beruht auf eincr Oxydation, die man auch, wie einige Vorschriften zeigen werden, künstlich schnell herbeiführen kann. Es entsteht dadurch im Hämatoxylin das Hämatein, das Paul Mayer als den färberisch wirksamen Bestandteil des Hämatoxylins nachgewiesen hat. Hämateïnlösungen brauchen nicht zu reifen, sie sind sofort verwendbar und ihre Wirkungen unterscheiden sich in nichts von denen der verschiedenen Hämatoxylinlösungen. Nur bei dem später unter Nr. I 26 dieses Kapitels zu erwähnenden IV cigertschen Hämatoxylinlack habe ich vom Hämateïn keincn Vorteil, wohl aber einen großen Nachteil gehabt. Und dieser bestand darin, daß in der Weigertschen Entfärbungsfliussigkeit, trotzdem diese außerordentlich verdünnt angewendet wurde, die Entfärbung so schnell erfolgte, daß keine Differenzierung: vorhanden war. Ich glaube, dies dadurch erklären $\mathrm{zu}$ sollen, daß der mit dem Hämatoxylin im Gewebe erzeugte Farblack nur dann haltbar ist, wenn zugleich mit der Differenzierung auch die Oxydation erfolgt; daß dagegen keine Differenzierung sondern nur Entfärbung eintritt, wenn die Entfärbungsflüssiglieit schon auf einen oxydierten Farbstoff trifft.

Die Herstellung des Hämateins ist sehr schwierig; man kauft daher seinen Bedarf davon, man fabriziert ihn aber nicht selber.

Dic Alaunhämatoxyline und -hämateine färben die Zellsubstanzen blaßblau, die Kerne tiefblau und haben eine große Affinität zu dem Mucin, das sich in ihnen veilchenblau färbt. Man kann, namentlich wenn man konzentrierte Farblösungen verwendet, schr leicht überfärben und die Entfärbung; welche dann nötig ist, soll anders das Präparat brauchbar sein, gelingt nicht immer. Nan muß überfärbte Schnitte in Salzsäure- oder Essigsäure-haltigem Wasser oder nach Nayer in $\mathrm{I}-2{ }^{\circ}$ Alaunlösung Alaunwasser) entfärben und muß sehr 
genau diese Entfärbung überwachen. Die Säuren müssen dann sehr sorgfältig ausgewaschen werden, sonst blassen die Präparate mit der Zeit ab. Alle mit Hämateïn- oder Hämatoxylinalaunen gefärbten Schnitte müssen sorgfältig ausgewaschen werden, damit nachher im Entwässrungsalkohol kein Niederschlag entsteht. Das Waschen nimmt man am besten zuerst in gewöhnlichem Wasser vor, dessen leichte Alkalescenz die Farben satter macht; erst dann geht man zu destilliertem Wasser über.

Es wurde vorhin erwähnt, daß bei Anwendung der konzentrierten Farbflotten sehr leicht Überfärbung eintritt. Nan kann diesen Nachteil mit fast absoluter Sicherheit vermeiden, wenn man, wie dies von den verschicdensten Seiten empfohlen wurde, sehr verdünnte Lösungen nimmt. Ich selber verfahre seit vielen Jahren so, daß ich bis 3 Tropfen der Farblösung auf $20-25 \mathrm{ccm}$ Aqua destillata gebe und die Schnitte darin $2+-48$ Stunden lasse. Die Zartheit der Färbung ist viel schöner als bei Anwendung der konzentrierten Lösungen und eine Uberfärbung habe ich nie zu beklagen gehabt. Ich lasse nun die einzelnen Färbevorschriften folgen und führe zuerst die Hämateine und dann die Hämatoxyline an.

28. Hämalaun, nach Paul Maycr. I $\mathrm{g}$ Hämatein wird in $50 \mathrm{ccm}$ Alkohol von $90^{\circ}$ 。 unter leichter Erwärmung gelöst; diese Lösung wird in eine Alaunlösung getan, dic in I Liter destilliertem Wasser $50 \mathrm{~g}$ Alaun, und zwar Kalialaun, enthält.

29. Saures Hämalaun, nach Paul Mayer. Zum vorigen Hämalaun wird $2{ }^{\circ}$. Eisessig gesetzt. Zum Auswaschen ist die Verwendung von Leitungswasser unbedingt erforderlich, damit die Schnitte sich bläuen. Hält sich besser als die vorige Lösung.

30. Glychämalaun, nach Paul Mayer. $0,+\mathrm{g}$ Hämatein werden mit einigen Tropfen Glyzerin zerrieben und in eine Lösung gegeben, welche $5 \mathrm{~g}$ Alaun, $30 \mathrm{ccm}$ Glyzerin und $70 \mathrm{ccm}$ Aqua destillata enthält. Gibt keine scharfe Kernfärbung; um diese zu erhalten, muß man in Alaunwasser (siehe oben) oder in schwacher Säure differenzieren.

31. Glyzerinalaunhämateïn, nach Rawitz. Um eine unbegrenzt haltbare Lösung zu haben, deren Färbevermögen der des Hämalauns völlig gleich ist, habe ich folgende Flüssigkeit hergestellt: $0,5 \mathrm{~g} \mathrm{Hä-}$ matein wird unter Erwärmen in $100 \mathrm{ccm}$ Aqua destillata gelöst. In die noch warme Flüssigkeit werden $3 \mathrm{~g}$ Aluminiumammoniumsulfat (Ammonalaun) gebracht und gelöst. Nach dem Erkalten werden I $00 \mathrm{ccm}$ Glyzerin hinzugefügt. Ein Filtrieren ist nicht nötig. Nur Schnittfärbung; denn keine Glyzerinlösung eignet sich zur Stück- 
färbung. Dic schönsten Bilder erhält man in den ganz dünnen Lösungen, deren Anfertigung ich oben (Seite 173) beschrieben habe.

32. Hämateïnlösung IA, nach Apáthy. Zunächst macht man sich eine Hämateintinktur, indem man I g Hämatoxylin in $100 \mathrm{ccm} \mathrm{Al-}$ kohol von $70^{\circ}$. löst. Man läßt die Tinktur 6-8 IVochen ausreifen, damit Hämatein in ihr entsteht. Eine zweite Lösung enthält in $100 \mathrm{ccm}$ Aqua destillata $9 \mathrm{~g}$. Alaun, $3 \mathrm{ccm}$ Eisessig, o, $\mathrm{g}$ g Salizylsäure. Man mischt beide Lösungen miteinander und fügt $100 \mathrm{ccm}$ Glyzerin hinzu. Soll sich auch zur Färbung der Nervenprimitivfibrillen eignen.

33. Hämacalcium, nach Paul Mayer. I $g$ Hämatein und I $g$ : Chloraluminium werden fein zerrieben und in einem Gemisch aus Io $\mathrm{ccm}$ Eisessig und $600 \mathrm{ccm}$ Alkohol von $70^{\circ}$ 。 gelöst. Nach der Lösung gibt man $50 \mathrm{~g}$ Chlorcalcium hinzu. Nur zur Stückfärbung; hierfür ist es aber das beste Reagens, das ich kenne, denn es wird von keinem anderen Farbstoff an Zartheit der Färbung, an Sicherheit des Effektes und an Einfachheit der Anwendung übertroffen. Die gefärbten Stücke werden in $80^{\circ} \circ-90^{\circ}$. Alkohol so lange gewaschen, bis keine Farbe mehr in den Alkohol geht. Dann wird in der üblichen Treise eingebettet. Ist der Farbenton zu rot, so kann in $2^{\circ}$ 。 alkoholischer Chloraluminiumlösung bis zur Erlangung der gewünschten Nüance eingelegt werden.

3ł. Muchämateïn, nach Paul Mayer. $0,2 \mathrm{~g}$ Hämatein werden mit einigen Tropfen Glyzerin verrieben, dann werden $60 \mathrm{ccm}$ Aqua destillata und to ccm Glyzerin zugefügt und in die Lösung $0,1 \mathrm{~g}$ Chloraluminium eingebracht. Färbt, aber nur in der konzentrierten Lösung, Mucin mit himmelblater Farbe; in verdünnter Lösung dagegen tritt eine gleichmäßige schwarzblaue Färbung ein, die an den später zu erwähnenden Rudolf-Heidenhainschen Hämatoxylinlack erinnert.

35. Hämateïn-Eisen, nach Hansen. Statt des Hämateïns verwendet Hansen Hämatoxylin, bringt aber des letzteren Oxydation bei Bereitung der Farblösung; also sofort, hervor; es bedarf daher nicht der langen Zeit zum Ausreifen. Die hier angeführte Lösung wird nach folgender Vorschrift angefertigt:

Io $\mathrm{g}$ reiner Eisenalaun werden warm in $150 \mathrm{ccm}$ Aqua destillata gelöst; r, $6 \mathrm{~g}$ Hämatoxylin warm in $75 \mathrm{ccm}$ Aqua destillata gelöst. Beide Lösungen werden nach dem Erkalten in der Weise gemischt, daß man das Eisen unter stetem Lmrühren in das Hämatoxylin einträgt. Zur Beschleunigung der Oxydation wird bis zum Kochen erhitzt und dann eine Minute lang gekocht. Die "gut haltbare "Lösung (sie g-ibt Niederschläge und muß jedesmal vor dem Gebrauche filtriert 
werden!, soll von dunkelbrauner Farbe sein. Besonders gut ist die Kernfärbung, manche Plasmastrukturen treten auch hervor. IVenn Überfärbung der Schnitte sich eingestellt hat, muß man in Essigsäure oder Schwefelsäure differenzieren. Will man nur Kernfärbung haben, so füge man auf $+\mathrm{ccm}$ Farblüsung I ccm verdünnter Schwefelsüure $\left(\mathrm{I}^{\circ},{ }_{0}\right.$ oder $2^{\circ}$ ) $\mathrm{zu}$.

36. Chromalaunhämateïn, nach $\mathrm{H}$ ansen. Chemisch reiner Chromalaun $\mathrm{IO} \mathrm{g}$ in Aqua destillata $250 \mathrm{ccm}$ in der Hitze gelüst, bis die Lösung gruin ist. I g kristallisiertes Hämatoxylin in $10-15 \mathrm{ccm}$ heißen Aqua destillata gelöst. Beide Lösungen werden gemischt; man kann aber auch die Hämatoxylinkristalle in dic heiße Chromalaunlüsung bringen. Nach dem Erkalten werden 0.5 reine Schwefelsäure, d.h. etwa $5 \mathrm{ccm}$ einer $10^{\circ}$, Schwefelsäure, zugefügt und tropfenweise unter stetem Umruhren $20 \mathrm{ccm}$ einer Lösung beigefügt, die $0,55 \mathrm{~g}$ Kalium bichromicum enthält. Man lüst die genannte Menge des Chromsalzes heiß in $20 \mathrm{ccm}$. Aqua destillata und läßt erlialten.) Die Mischung wird erhitzt und soll I-2 Minuten kochen. Vor dem Gebrauch wird filitricrt. Schnitte färben sich in ${ }^{{ }^{2}}-5$ Minuten, Überfärbung tritt nicht ein; Farbenton tief blauschwarz.

37. Manganhämateïn, nach Hansen. $5 \mathrm{~g}$ Manganosulfat und I g Hämatoxylin werden in $200 \mathrm{ccm}$ Aqua destillata gelöst. Nan oxydiert mit Kaliumpermanganat, indem man 0,18-0, Ig g des Permanganats in $10 \mathrm{ccm}$ Aqua destillata löst und dies zur ersten Lösung zugibt. Auf $200 \mathrm{ccm}$ der Hämateinlösung fügt man $\mathrm{I}-1,2 \mathrm{ccm}$ einer Schwefelsäure von $10 \%$ zu. Die Farbflüssigkeit ist braun.

38. Böhmersches Hämatoxylin. Diese älteste Vorschrift wird immer noch benutzt, obgleich sie die wenigst rationclle ist. Man löst I,5 g Hämatoxylin in $30 \mathrm{ccm}$ Alkohol absolutus. Zu einer Lösung von $0, \mathrm{I}$ - Alaun in $30 \mathrm{ccm}$ Aqua destillata wird von der Hämatoxylinlösung soviel tropfenweise zugesetzt, daß eine violette Färbung entsteht. Dic Reifung kann durch Offenlassen der Flasche beschleunigt werden, auch nimmt man am besten alte Hämatoxylinlösungen. Nur Schnittfärbung:

39. Delafieldsches Hämatoxylin (fälschlich Grenachersches Hämatoxylin genannt. $+\mathrm{g}$. Hämatoxylin werden in $25 \mathrm{ccm}$ absoluten Alkohols gelöst und dann in $400 \mathrm{ccm}$ einer konzentrierten wässrigen Ammonalaunlösung gegeben. Nan läßt $3-4$ Tage offen am Lichte stehen, filtriert und fügt je $100 \mathrm{ccm}$ Glyzerin und Methylalkohol zu. Nach einigen Tagen wird von neuem filtriert. Zum Gebrauch verdünnt man einen aliquoten Teil mit Wasser.

+o. Glyzerinalaunhämatoxylin, nach Rawitz. I g Hämatoxylin 
und $\mathrm{I} g$ Ammonalaun werden in $65 \mathrm{ccm}$ Aqua destillata und $35 \mathrm{ccm}$ Glyzerin gelöst. Zur Reifung sind 6-8 Wochen nötig; die Lösung hält sich jahrelang unverändert. Nur Schnittfärbung.

+ I. Ehrlichsches Hämatoxylin. $2 \mathrm{~g}$ Hämatoxylin in $10 \mathrm{ccm}$ Eisessig, je $100 \mathrm{ccm}$ Alkohol absolutus, Glyzerin und Wasser gelöst und Alaun im Überschuß hinzugefügt. Überfärbt sehr selten.

42. Molybdänhämatoxylin, nach Mallory. I, $75 \mathrm{~g}$ Hämatoxylin werden in $10 \mathrm{ccm}$ Phosphormolybdänsäure von $10 \%$ und $200 \mathrm{ccm}$ Aqua destillata gelöst; 5 Teile kristallisierter Karbolsäure werden zugefügt. Eine andere Vorschrift lautet: I Teil Hämatoxylin, 6-1o Teile Chloralhydrat, I Teil $10_{\text {: }}^{\circ}$ Phosphormolybdänsäure und Ioo Teile Wasser. Es sind Wochen für das Reifen erforderlich. Soll sich besonders zur Achsenzylinderfärbung eignen.

43. Hämatoxylinschwefel, nach Unna. I g Hämatoxylin, Io g Alaun in $100 \mathrm{ccm}$ Alkohol und $200 \mathrm{ccm}$ Aqua destillata gelöst; nach 2-3 Tagen fuigt man $2 \mathrm{~g}$ sublimierten Schwefel hinzu. Durch den Schwefelzusatz soll die Lösung unverändert bleiben.

44. Chloralhämatoxylin, nach Gage. 7,5 g Kali- oder Ammonalaun durch Kochen in $200 \mathrm{ccm}$ Aqua destillata gelöst; man fuigt $+\mathrm{g}$ Chloralhydrat zu. Wenn alles gelöst ist, gibt man $10 \mathrm{ccm}$. $\mathrm{l}$ kohol von $95^{\circ}$, zu, in welchem $0, \mathrm{I} g$ Hämatoxylin gelöst ist. Braucht zur Reifung $\mathrm{I}-2$ IVochen. Oft setzen sich im Schnitt amorphe Farbstoffkörner $a b$, dann muß filtriert werden.

45. Kleinenbergsches Hämatoxylin. Man macht erstens eine gesättigte Lösung von Chlorcalcium in $70^{\circ}$. Alkohol, der man soviel Alaun zusetzt, wie sich lösen will. Zweitens wird eine gesättigte Lösung von Alaun in $70^{\circ}$. Alkohol hergestellt. \& Teile von Lösung 2 werden in I Teil von Lösung I getan. Drittens endlich macht man eine konzentrierte Lösung von Hämatoxylin entweder in Alkohol oder in der ersten Lösung und gibt davon einige Tropfen in die Mischung der beiden ersten Lösungen. Nur Stückfärbung; diese Lösung ist durch Mayers Hämacalcium antiquiert.

40. Alaunhämatoxylin, (alkoholisch), nach Harris. 0,5 g Hämatoxylin, $0,5 \mathrm{~g}$ Aluminiumchlorid werden in $150 \mathrm{ccm}$ Alkohol von $70^{\circ}$ 。gelöst; man kocht und setzt allmählich I g Quecksilberoxyd zu. Die Lösung wird sehr bald dunkelpurpurrot, dann von der Flamme abgenommen und schnell gekühlt. Nan fügt $2,5 \mathrm{ccm}$ Eisessig hinzu. Durch das Quecksilberchlorid wird die Oxydation des Hämatoxylins sehr beschleunigt. Eine zweite Lösung besteht aus Calciumchlorid $25 \mathrm{~g}$, Eisessig $2,5 \mathrm{ccm}, 70^{\circ}$ 。 Alkohol $150 \mathrm{ccm}$. Unmittelbar vor dem Gebrauch werden beide Lösungen zu gleichen Teilen gemischt. Nur 
Stückfärbung; soll trotz seiner umständlichen Herstellung ein Ersatz für Hämacalcium sein.

47. Alaunhämatoxylin (wässrig), nach Harris. Als Ersatz für Delafieldsches Hämatoxylin dient folgende Vorschrift: I $g$ Hämatoxylin in $6 \mathrm{ccm}$ Alkohol gelöst, dazu $100 \mathrm{ccm}$ gesättigte wässrige Alaunlösung. Jetzt wird aufgekocht und $0,5 \mathrm{~g}$ Quecksilberoxyd zugesetzt. Sobald die Lösung dunkelpurpurrot ist - Oxydation des Hämatoxylins -, wird sie von der Flamme abgenommen und nach dem Ablïhlen mit $25 \mathrm{ccm}$ Methylalkohol und ebensoviel Glyzerin versetzt. Die Lösung ist sofort gebrauchsfähig; nur Schnittfärbung.

48. Aluminiumchlorid-Hämatoxylin, nach Harris. Zum Ersatz von Muchämateîn: $0, \mathrm{I} g$ Aluminiumchlorid, $0,2 \mathrm{~g}$ Hämatoxylin, $100 \mathrm{ccm}$ Alkohol von $70^{\circ}$ 。 mischen und unter vorsichtigem Kochen $0,6 \mathrm{~g}$ Quecksilberchlorid zusetzen. Vor und nach dem Aufkochen wird I Tropfen Salzsäure zugesetzt.

\section{$\S 66$.}

Orcein. Aus der Orseilleflechte erhält man Orcin und dieses wird mit Ammoniak und Luft zum Orcein. Der Farbstoff hat hauptsächlich Anwendung zur Färbung der elastischen Fasern gefunden; es sollen daher die zu diesem Zwecke aufgestellten Vorschriften erst im zweiten Teile genauer beschrieben werden. Zur Färbung von Zelle und Kern wird der Farbstoff wenig gebraucht, obgleich er nach der folgenden Vorschrift Zellsubstanzen rot, Kerne blau färbt. Eine technische Durcharbeitung der mit dem Orcein möglichen Methoden wäre sicher aussichtsreich.

49. Orceïn-Eisessig, nach O. Israel. I $\mathrm{g}$ Orcein wird in I ccm Eisessig und $50 \mathrm{ccm}$ Wasser gelöst. Schnittfärbung; die Schnitte werden gewaschen, kommen in absoluten Alkohol für kurze Zeit und müssen in dickem Zedernöl aufgehoben werden.

50. Brasilin. Das farberisch wirksame Prinzip des Fernambukholzes (Rotholzes) wird, wie der vorige Farbstoff, nur wenig verwendet und scheint auch nach den vorliegenden Mitteilungen herzlich uiberflüssig zu sein. Die Art der Bereitung ist genau wie bei dem Böhmerschen Hämatoxylin (vgl. Nr. 38 dieses Kapitels!

$$
\S 67 \text {. }
$$

Anhang. 51. Kernschwarz wurde von Platner zur Färbung der Mitosen empfohlen. Es ist nach Mayer eine Eisentinte, deren Gebrauch niemals allgemein geworden ist. Die mit Kernschwarz gefärbten Schnitte werden in einem Alkali (z. B. dünnem Lithium 
carbonicum längere Zeit gewaschen und zeigen dann weitgehende Niiancenunterschiede in der Färbung zwischen ruhendem und sich teilendem Kern.

\section{$\S 68$.}

Die Anilinfarben. Die aus dem Steinkohlenteer gewonnenen Anilinfarbstoffe sind gleichzeitig ron Waldeyer und Frey im Jahre I 863 in die histologische Färbetechnik eingeführt worden. Seitdem ist die Zahl der Farbkörper, die zur Färbung mikroskopischer Präparate empfohlen sind, ganz außerordentlich groß geworden und bei der Polypragmasie, die gerade auf dem Gebiete der Färbung herrscht. ist zu erwarten, daß die Zahl noch größer werden wird. Dabei ist ein neuempfohlener Farbstoffname oft genug nur ein Synonym für einen bereits bekannten. Z. B. Anilinblau, Synonyma: Bleu de Lyon; Methylblau: oder Fuchsin, Synonyma: Rubin, Diamantfuchsin, Magenta usw. Nanchmal auch leistet der empfohlene Farbstoff nicht mehr als bereits bekannte und nur die Nüance ist dem Empfehlenden sympathischer. Eine Anzahl Methoden sind ausgedacht worden, bei deren Anwendung der Sekundenzeiger der Lhr unausgesetzt beobachtet werden muß. Andererseits ist nicht zu verkennen, daß wir den Teerfarben den tiefsten Einblick in die Struktur der Zelle usw. verdanken, und es ist festzuhalten, daß wir nur damn in der Erkenntnis der Zelle und ihrer Lebensäußerungen Fortschritte machen können, wenn es gelingen sollte, mehr als bisher die Teerfarbstoffe rationell zu verwenden und mit ihnen echt zu färben, so echt wie der Färber Wolle und Seide färbt. Bei allen Vorziigen nämlich, welche die Teerfarbstoffe haben: Feinheit der Niiancen, Detaillierung der Strukturelemente usw, haftet ihnen dennoch ein großer Nachteil an: die Farben sind gegenuber dem zum Waschen benutzten Wasser und Alkohol fast immer nicht widerstandsfähig. Wird der Schnitt aus der Farbflotte entnommen, so ist er fast immer überfärbt; wäscht man ihn dann aus und entwässert ihn für die weiteren Manipulationen, so mul3 man sich rorsehen, daß nicht im Alkohol und schließlich im Aufhellungsreagens die ganze Färbung schwindet. Fast alle färberischen Resultate, dic wir mit Teerfarbstoffen erzielen - ich meine hier nur die Aniline, nicht die wenig gebrauchten Anthracene beruhen auf frihzeitig unterbrochenen Auswaschungen. Leider zeigt sich fast gar keine Tendenz in der Forscherwelt, diesen Fehler bei der substantiven Färbung mit Anilinen zu verbessern. Bis zu cinem gewissen Grade kann man die Farben haltbarer machen: man muß nämlich ganz dïnne Lösungen nehmen. Schon die Bakteriologen 
z. B. Günther) haben darauf hingewiesen, daß Schnitte viel besser den Farbstoff festhalten, wenn sie in sehr verdiunten Farbflotten gefärbt werden. Ich kann diese Tatsache nur nach jeder Richtung hin bestätigen; sehr verdünnte Lösungen von Fuchsin z. B. geben viel dauerhaftere Bilder als konzentrierte. Daher empfehle ich für alle Farblösungen, für deren Anwendung nicht bestimmte spezielle Vorschriften maßgebend sind, stärkste Verdünnung: bis zu 5 Tropfen höchstens auf $30 \mathrm{ccm}$ Wasser.

Die Aniline werden gewöhnlich in Alkohol oder Wasser gelöst; manche sind nur in dem einen oder dem anderen löslich. Meistens, immer wieder von Spezialvorschriften abgesehen, genight bei wässrigen Lösungen die Konzentration ron $\mathrm{I}^{\circ}$, mit der man eigentlich wohl immer auskommt. Bei alkoholischen Lösungen digegen empfiehit es sich, den Farbstoff bis zur Sättigung einzutragen, um von dieser Stammlösung die nötige Verdiinnung mit destilliertem Wasser zu machen.

Eine besondere Methode. Anilinfarben zu lösen, hat Ehrlich mit seinem Anilinwasser angegeben. Dieses Anilinwasser bereitet man folgendermaßen: MIan schiittelt wiederholt und kriiftig $1 \mathrm{ccm}$ Anilinöl mit etwa $25 \mathrm{ccm}$ Aqua destillata - cin absolut genaues Abmessen der Nengen ist durchaus nicht nütig — in einem Reagensglase und filtriert durch ein Filtcr. das mit destilliertem Wasser befeuchtet ist. Letzteres ist unbedingt erforderlich, damit beim Filtrieren das Anilinöl auf dem Filter zuriickbleibt. Durch das Schiitteln von Anilinöl mit Wasser wird ein Teil von ersterem gelöst und das ist das Anilinwasser. Hierin werden die Farbstoffe gelöst. Die Färbung mit solchen Anilinwasserlösungen ist sehr gut. die Farbentöne sind leuchtend, aher dic Haltbarkeit der Färbung ist gering in der Bakteriologie mag dies anders sein, sodal eine allgemeine Anwendung von Anilinwasserlüsungen sich nicht empfiehlt. Dazu kommt, daß diese Lösungen sehr schnell verderben, während die gewöhnlichen wässrigen sich oft jahrelang halten können.

Eine eigenartige Methode. Anilinfarben zu fixieren, ist das nach seinem Entdecker Gram benannte Gramsche Virfahren oder die Gramsche Mcthode. Zwar ist sie nur für Bakterien angegeben und soll dazu dienen, die Kerne zu entfärben, während in den Bakterien der Farbstoff fixiert wird; doch wird sie auch hie und da in der Histologie angewendet und soll daher ihren Platz hier finden. Die in einer Anilinwasser-Farbstofflösung gefurbten Schnitte kommen direkt in sogenannte Lugolsche Lösung ( $\mathrm{g}$ Jod, $2 \mathrm{~g}$ Jodkalium, $300 \mathrm{ccm}$ Aqua destillata; dann nach mehreren Minuten in Alkohol, 
um in Nelkenül oder Bergamottöl oder Xylol aufgehellt zu werden. Ich habe diesem Verfahren bei histologischen Studien keinen Geschmack abgewinnen können.

Dic Anilinfarben können wir nach ihrer Wirkung einteilen in Plasma- und Kernfarben. Die einen, so soll das heißen, färben nur die Zellsubstanzen, die anderen nur die Kerne. Erstere sind die sauren Anilinfarben, letztere die basischen; bei diesen ist die färbende Base an eine nicht gefärbte und auch nicht färbende Säure gebunden, bei jenen färbt eine Säure. Durch Mischung saurer und basischer Farbkürper entstehen die neutralen, die zunächst als schwer oder gar nicht lösliche Körper ausfallen. um in einem L̈berschuß von Farbsäure sich wieder zu lösen. Diese von Ehrlich herrïhrende Einteilung hat mit der chemischen Einteilung übrigens gar nichts gemeinsam; aber sie ist für dic Zwecke des Mikroskopikers sehi praktisch und das ist die Hauptsache.

Ich führe in den folgenden Zeilen die Aniline nach ihren Farben (rot usw. an und erwähne diejenigen, welche allgemein angewendet werden. Diejenigen Farbstoffe dagegen bzw. diejenigen Vorschriften, welche nur für ein bestimmtes Organ und nur zu einem sehr spezialisicrten Zwecke empfohlen sind, sollen im zweiten Teile Unterkunft finden.

Rote Farben.

$$
\S 69 \text {. }
$$

52. Bordeauxrot. In $I^{\circ}$ 。 wässriger Lösung als Vorfärbung für den später zu erwähnenden Eisenhämatoxylinlack von M. Heidenhain, sowie als Grundlage für eine Doppelfärbung mit Hämatoxylin.

53. Chromotrop, nach M. Heidenhain. Die Farbstoffe $2 \mathrm{R}$ und 2 B färben gelbrot, $6 \mathrm{~B}$ und $7 \mathrm{~B}$ blaurot. Nan macht in Alkohol eine konzentrierte Lösung, hat die vorher gefürbten Schnitte Delafieldsches Hämatoxylin' in aikalischem Alkohol ! Liq. ammon. caust. : I000 alkalesciert und bringt in die Chromotroplösung ein. Bindegewebe. Basalmembranen, lymphatisches Reticulum sind prachtvoll gefürbt.

54. Congorot, nach Alt. Der Farbstoff wird in absolutem Alkohol gelöst, filtriert, bei gewöhnlicher Temperatur oder bei $35^{\circ} \mathrm{C} .{ }_{4}^{3}$ bis 2 Stunden zur Einwirkung gebracht. Soll sich für die Achsenzylinder in den Organen besonders eignen. Die Zuverlässigkeit der Methode wird von Schiefferdecker mit Recht bestritten.

55. Congo-Corinth $\mathrm{G}$ und Benzopurpurin 6 B, nach M. Heidenhain. Jenes fürbt blaurot, dieses gelbrot. Die Farbstoffe werden in 
gesättigter alkoholischer Lösung angewendet und auf Schnitte gegossen, die mit einem Hämatoxylin vorgefärbt sind und in Alkalialkohol 'vgl. Nr. 53 alkalisch gemacht wurden. Nach des Autors eigener Aussage halten sich die Färbungen nicht.

56. Eosin. Plasmafarbstoff - man nimmt am besten - Eosin gelblich - , der in I ${ }^{\circ}$ 。wässriger Lösung angewandt wird. Als Grundlage für Doppelfürbungen vorzüglich, färbt die Sekrete seröser Drüsen leuchtend rot.

57. Erythrosin. In $\mathrm{I}^{\circ}$ 。 Lösung, an Stelle des Eosins, empfohlen; ist aber nicht so gut, wie der vorige Farbstoff.

58. Franceïn, nach Léon. Dieser Farbstoff, der vor einigen Jahren empfohlen wurde, scheint verschollen zu sein. Vielleicht wird er wieder gefunden; denn die von Léon gegebenen Vorschriften fuir seine Terwendung zeigen eine Methodik, die bei den anderen Anilinen nicht gebräuchlich ist und die die Hoffnung erwecken mußte, durch diesen Farbkörper zu einer rationelleren Behandlung der Aniline im allgemeinen zu gelangen. Ich gebe die 3 Vorschriften von Léon wieder; I) Francein $1 \mathrm{~g}$; Borax 2 g, Wasser Ioo,o; nach der Lösung Zufügen von $95^{\circ}$, Alkohol $300 \mathrm{ccm}$, Filtrieren. 2j Francein $2 \mathrm{~g}$ in $25 \mathrm{ccm}$ Wasser mit geniigender Menge ron Ammoniak gelöst. Man läßt die Lösung Io Tage an der Luft stehen und fügt dann + Volumina gesättigter wässriger Pihrinsäurelösung zu. 3) Francein I $g$, starke ammoniakalische Lösung $+\mathrm{ccm}$. Wasser $50 \mathrm{ccm}$. Das Franceïn wird in der Ammoniaklösung gekocht, das Wasser wird zugegossen und nun läßt man so lange stehen, bis der Ammoniakgeruch verschwunden ist.

59. Fuchsin (Magenta). Prachtvoller Kernfarbstoff, der zugleich sehr intensiv Mucin und hyaline Knorpelgrundsubstanz mitfärbt; der Farbenton ist rotviolett. Ich ziehe Fuchsin dem anderen, häufiger gebrauchten Kernfarbstoffe, dem Safranin, vor, dessen Farbenton ein brutales Rot ist. Man hält sich cine konzentrierte alkoholische Lösung der großen Kristalle des Fuchsins vorrätig und verdünnt zum jedesmaligen Gebrauche einen aliquoten Teil mit soviel destilliertem Wasser, daß die gew ünschte Nüance entsteht. Färbungsdauer bis 24 Stunden, direktes Auswaschen in $95 \%$ Alkohol.

6o. Fuchsin, nach Nissl. Nan färbt in gesättigter wässriger Fuchsinlösung, erhitzt, bis sich Dampfbildung zeigt, und wäscht in Alkohol aus. Die Differenzierung der Schnitte erfolgt in Nelkenöl.

6r. Karbolfuchsin, nach Ziehl. I g Fuchsin wird in $100 \mathrm{ccm}$ wässriger Karbolsäure von $5 \%$ gelöst; dann fuigt man von $95 \%$ Alkohol ı $\mathrm{ccm}$ zu. Die sehr haltbare Lösung färbt sehr intensiv; für bakterio- 
logische Zwecke empfohlen, dürfte aber auch für histologische sich eignen.

62. Fuchsinalkali, nach Löffler. Zu roo ccm Anilinwasser mischt man I ccm Natronlauge von $\mathrm{I}^{\circ}$ 。 bei und löst darin $4-5 \mathrm{~g}$ Fuchsin. Sehr haltbare Lösung, senr große Färbekraft.

63. Fuchsin-Resorcin, nach Weigert. Diese Fuchsinlösung gehört streng genommen unter die Spezialmethoden, da sie ausschließlich oder doch fast ausschließlich die elastischen Fasern färbt. Indessen da das in der folgenden Nummer zu erwahnende Kresofuchsin die gleiche Eigenschaft besitzt und noch andere Gewebe färbt, so mußte auch die Weigertsche Nethode hier untergebracht werden. Die Vorschrift ist folgende: $2 \mathrm{~g}$ Fuchsin und $+\mathrm{g}$ Resorcin werden in $200 \mathrm{ccm}$ Aqua destillata gelöst und in einer Porzellanschale gekocht. Während des Kochens fügt man unter stetem Umruihren $25 \mathrm{ccm}$ Liquor ferri sesquichlorati (der deutschen Pharmakopoe) zu und kocht weiter noch 2 bis 5 Minuten. Es bildet sich ein Niederschlag. Man läßt abkühlen, aber nicht erkalten, und filtriert. Das Filtrat wird weggegossen. Der Filterrickstand wird mit dem Filter in die bereits benutzte, inzwischen trocken gewordene Schale getan, dort mit $200 \mathrm{ccm}$ Alkohol 950。) unter stetem Umrühen auf dem Sandbade gekocht, wobei man das Filtrierpapier aus der Flüssigkeit herausfischt. Man läßt jetzt erkalten, filtriert, bringt das Filtrat durch Zuguß von Alkohol auf $200 \mathrm{ccm}$ und setzt $t^{\circ}$ 。 Salzsäure zu. Die Schnitte werden 20 Minuten bis I Stunde gefärbt; die elastischen Fasern sind dunkelblau auf hellem Grunde. Ein vortreffliches Reagens auf elastische Fasern; die Präparate sind sehr lange haltbar, denn meine i 898 angefertigten Präparate sind heute nach \& Jahren genau so schön wie am ersten Tage.

64. Kresofuchsin, nach Röthig. Den durch Weigerts Methode entstandenen Farbstoff hat Spiegel isoliert und Kresofuchsin \& genannt. In wässriger Lösung ist nach Röthigs Angabe das Kresofuchsin rot, in alkoholischer blau; letztere färbt die elastischen Fasern tiefblau, Schleim, Knorpel, Kerne, Keratin intensiv rot. In wässriger Lösung werden die elastischen Fasern gar nicht gefärbt, wohl aber die anderen erwähnten Gebilde. Durch diese Eigenschaften ist die Anwendbarkeit des Kresofuchsins eine ausgedehntere als die des Weigertschen Fuchsins. Angewendet wird nach Röthig das Kresofuchsin folgendermaßen: Man löst 0,5 g Kresofuchsin in $100 \mathrm{ccm}$ Alkohol von $95 \%$ und setzt $3 \mathrm{ccm}$ Salzsäure zu. Zum Gebrauche nimmt man $40 \mathrm{ccm}$ der Stammlösung, setzt von $95 \%$ Alkohol $24 \mathrm{ccm}$ und 32 Tropfen einer wässrigen Pikrin- 
säurelösung (I Pikrin : 3 Wasser $)$ zu. Färbungsdauer 2 Stunden oder länger, bis 24 Stunden; dann Abwaschen in $95^{\circ}$. Alkohol, Entwässsern in absolutem Alkohol nicht zu lange), Xylol usw. Der Farbstoff verdient die größte Beachtung.

65. Kresofuchsin, nach Pranter. Statt der Pikrinsäure nimmt Pranter Salpetersäure in folgendem Verhältnisse: Kresofuchsin 0,2 g, offizinelle Salpetersäure $3 \mathrm{ccm}, 70 \%$ Alkohol $100 \mathrm{ccm}$. Die von Pranter empfohlene Salzsäure hat Röthig bereits angewandt.

66. Magdalarot. In wässriger Lösung zu verwenden; Kernfarbstoff, ähnlich wie Safranin und Fuchsin.

6\%. Neutralrot. Dieser Farbstoff ist ein basischer und färbt wie alle basischen in wässriger Lösung. Seine Hauptverwendung findet er zur vitalen Färbung; daher soll später näher auf ihn eingegangen werden.

68. Ponceau. Plasmafarbstoff in wässriger Lösung; hat vor dem Eosin nichts voraus.

69. Safranin. Der beliebteste Kernfarbstoff. Man macht, wie beim Fuchsin, eine konzentrierte alkoholische Stammlösung oder hält sich eine gesättigte wässrige Lösung in Vorrat. Zum Gebrauch verdünnt man - von Spezialiorschriften abgesehen - cinen aliquoten Teil nach Belieben mit Aqua destillata und färbt I Stunde bis $2+$ Stunden. Man wiischt in reinem oder salzsaurem Alkohol aus; doch muß man sich bei letzterem sehr vorsehen. Denn das Safranin ist ungemein säureempfindlich und verändert leicht seine rote larbe in ein schmutziges Tiolett. Bei gelungenen Färbungen ist die chromatische Substanz knallrot, Mucin und hyaline Knorpelgrundsubstanz violett, Zellsubstanz nach schwachen Lösungen zartrot, nach starken schmutzig violett.

7o. Safraninanilinwasser, nach Babes. $2 \mathrm{~g}$ Safranin, $3 \mathrm{ccm}$ Anilinöl, $100 \mathrm{ccm}$ Aqua destillata. Die Mischung hält sich schlecht. Man färbt 5 Minuten bis einige Stunden und zieht, eventuell nach Anwendung des Gramschen Verfahrens, in Alkohol von $95 \%$ aus.

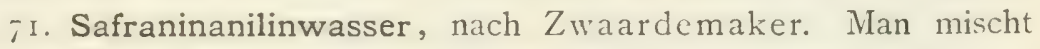
gleiche Teile konzentrierter alkoholischer Safraninlösung und Anilinwasser. Die Lösung soll sich lange halten.

72. Säurefuchsin (Fuchsin S). In konzentrierter oder $1 \%$ wässriger Lösung verwendbar. Wird meist als Grundlage für Dreifachfärbungen benutzt, soll in osmierten peripheren Nerven die Achsenzylinderfibrillen färben. Nach Altmann ist folgende Lösung gut für Zellstudien: $20 \mathrm{ccm}$ Säurefuchsinlösung; $100 \mathrm{ccm}$ Anilinwasser. 
73. Scharlach $\mathbf{R}$, nach $F$ ischer. Die Substanz wird in kochendem 70\% Alkohol gelöst und die Lösung muß über Nacht in den Brütschrank. Gefürbt wird bei Zimmertemperatur in IO-I 5 Minuten, hei Briittemperatur $\left(37^{\circ}\right.$ C. $)$ in $I-2$ Ninuten. Die Farbflotte muß stets filtriert werden, die Schalen, in welchen die Färbung vorgenommen wird, soll man stets sorgfältig zudecken, sonst treten Niederschläge im Schnitt auf. Soll nur Fett färben.

7ł. Sudan III, nach Daddi. Man macht eine gesättigte Lösung in $96 \%$ Alkohol. Schnitte 5- ro Minuten gefärbt, ebenso lange in $96 \%$ Alkohol abgespuilt und in Glyzerin aufgehoben. Soll nur Fett färben. Herxheimer, der übrigens Fettponceau (Scharlach R) vorzieht, macht in einem Gemisch von $70 \mathrm{ccm}$ absoluten Alkohol, $20 \mathrm{ccm}$ Natronlauge von $\mathrm{IO}_{10}^{\circ}$ und I $\mathrm{ccm}$ Wasser eine gesättigte Lösung des Farbstoffes. In der Kälte dauert die Färbung 2 Minuten, in der Wärme 20 Sekunden. Meine Erfahrungen mit den beiden zuletzt genannten Farbstoffen sind keine guten.

\section{Gelbe Farben.}

$\S 70$.

75. Orange G. In gesättigter wässriger Lösung als Grundlage für Doppel- und Dreifachfärbungen zu verwenden. Reiner Plasmafarbstoff, dessen Lösungen leicht schimmeln. Orangefärbungen diirfen nicht allzulange in Wasser ausgewaschen werden, weil sich sonst alles entfärbt; sie muissen ferner mit Vorsicht in Alkohol gebracht werden, wenn das Auswaschen in Wasser nicht angängig ist, weil in Alkohol das Orange $G$ sehr gern kristallinisch ausfällt.

76. Pikrinsäure. Das Trinitrophenol, die Pikrinsäure, ist eine Anilinfarbe und muß daher hier erwähnt werden. Irgend welche histologisch beachtenswerte färberische Qualitäten kommen ihr nicht zu.

\section{Grüne Farben.}

$$
\$ 7 \mathrm{I}
$$

77. Coeruleïn S, nach Rawitz. Dieser Farbstoff, die Bisulfitverbindung des Anthracengriins, ist von M. Heidenhain verwendet worden, doch habe ich die von diesem Forscher gegebene Formel nicht auffinden können. Ich empfehle das Coeruleïn $\mathrm{S}$ in folgendem Rezept: Coerulein S o, I g, weinsaures Antimonkalium I,O g, Aqua destillata $100 \mathrm{ccm}$. Man löst zunächst den Brechweinstein in lauem Wasser, gibt den Farbstoff zu und kocht auf dem Sandbade. Nach dem Erkalten wird von dem geringen Bodensatze abgegossen, 
ein Filtrieren ist nicht nötig. Die dunkelgrüne Flüssigkeit hält sich viele Monate unverändert. Zum Gebrauch nimmt man einen aliquoten Teil und verdünnt ihn mit dem Io-2ofachen Tolumen destillierten IVassers. Coerulein $\mathrm{S}$ in dieser Zusammensetzung ist ein vorzuiglicher Farbstoff zur Darstellung der Ganglienzellen im Rückenmark, während es bei Großhirn und Kleinhirn versagt. Die Glia ist blattgrün, die Ganglienzellen, deren Kerne farblos bleiben, und die Achsenzylinder sind dunkelgrün gefärbt. Die Farben sind echt, denn in Alkohol tritt keine Entfärbung ein, und sehr haltbar.

78. Lichtgrün. Wird in wässriger oder, nach Benda, in alkoholischer Lösung angerendet und dient zur Grundlage von Doppelfärbungen. Reiner Plasmafarbstoff.

79. Malachitgrün. Ein glücklicherweise immer weniger verwendeter Kernfarbstoff, dessen Färbungen sehr unecht sind.

8o. Methylgrün. Kernfarbstoff, der in wässriger Lösung angewendet wird, doch fast ausschließlich in Doppel- und Dreifachfärbungen. Die dem Methylgrün nachgerühmte Metachromasie beruht auf einer Verunreinigung mit Methylviolett, denn schüttelt man eine Lösung des Grün mit Amylalkohol, so färbt sich dieser violett (Fischer). Das oft genannte Jodgrïn, dessen Jodgehalt recht zweifelhaft war, ist im Handel nicht mehr $z u$ haben, wird wenigstens nicht mehr fabrikmäßig hergestellt. An seiner Statt ist Methylgrün zu nehmen.

Blaue Farben.

\section{$\S 72$.}

8 . Anilinblau. Es gibt ein wasserlösliches und ein spritlösliches Anilinblau, deren Anwendung nur eine ganz beschränkte ist. Unter besonderen Manipulationen kann man distinkte Nervenfaserfärbungen erzielen, worïber im zweiten Teil das Nähere mitgeteilt werden wird.

82. Azur oder Methylenazur. Durch Oxydation aus dem Methylenblau wird das Azur gewonnen, ein Farbstoff, der sich durch seine ungemeine Färbekraft auszeichnet. Nan kann ihn auch durch Mischung von Eosin- und Methylenblaulösungen erhalten; am besten ist es natïlich, wenn man ihn von Griibler oder von den Höchster Farbwerken bezieht. In wässriger Lösung färbt er wie Methylenblau, ist daher namentlich für Nervensystem zu empfehlen. Nethylenblau ist aber rorzuziehen, da Azur außerordentlich teuer ist. Die spezielle Verwendung des Farbstoffes für Blutpräparate wird im sechzehnten Kapitel beschrieben werden.

83. Methylblau (Bleu de Lyon). Ein Plasmafarbstoff, der 
nur in zwei später zu erwähnenden Doppelfärbungen Verwendung findet.

S. Methylenblau. In verdünnten wässrigen Lösungen ein vorzüglicher Farbstoff für Ganglienzellen sowohl des Gehirns als auch des Rückenmarkes. Ich verwende ihn ohne besondere Komplikationen einfach derart, daß ich von einer $1 \%$ Lösung $1-2$ Tropfen in 20-30 ccm destillierten Wassers gebe, eventuell, wenn die Farbe mir zu intensiv erscheint, noch mehr verduinne und darin die mittels des Gefriermikrotoms hergestellten Schnitte von formolisiertem Material Zentralnervensystem) $24-48$ Stunden färbe. Dann wasche ich in Wasser kurze Zeit und behandle mit y $6^{\circ}$. Alkohol solange, bis fast keine Farbstoffwolken mehr ausgehen. Dann wird montiert. Lnd ähnlich wie beim Zentralnervensystem verfahre ich auch bei jedem anderen Material. Der Nachteil der schönen Färbungen beruht darin, daß sie nach kurzer Zeit abblassen. Über die Verwendung des Methylenblau zur vitalen Färbung vgl. später.

85. Methylenblau, nach Löffler. Gleich dem alkalischen Fuchsin hat Löffler sein alkalisches Methylenblau konstruiert. 4-5 g Methylenblau, I ccm Natronlauge von $\mathrm{I}^{\circ}$,, $100 \mathrm{ccm}$ Anilinwasser. Die außerordentliche Färbekraft dieses Reagens ist offenbar dem durch die Natronlauge gebildeten Methylenazur zuzuschreiben. Ich würde raten, bei Verwendung dieses den Bakteriologen gehörigen Farbstoffes zu histologischen Zwecken nur äußerste Verdünnungen zu wählen.

80. Methylenblau, nach Noesske. Konzentrierte alkoholische Methylenblaulösung $2 \mathrm{ccm}$, konzentrierte wässrige Lithion carbonicumlösung $5 \mathrm{ccm}$, Alkohol I0,0 ccm, Aqua destillata $80 \mathrm{ccm}$.

87. Polychromes Methylenblau, nach Unna. Auch dieses Reagens verdankt seine Färbekraft wohl hauptsächlich dem in ihm enthaltenen Nethylenazur. Zur Färbung der verschiedensten Organe geeignet. Die stets überfärbten Schnitte müssen differenziert werden, und zwar entweder in dem käuflichen Glyzerinäthergemische von Unna oder nach Gothard in einem Gemenge von $5 \mathrm{ccm}$ Kreosot, $5 \mathrm{ccm}$ Xylol, 4 ccm Kajeputol und $16 \mathrm{ccm}$ absoluten Alkohol. Zur Färbung des Zentralnervensystems verfahre ich einfacher so, daß ich die Schnitte für $24-48$ Stunden in stark verduinntes polychromes Methylenblau i : 50 Wasser bringe unc sie nach kurzem Abwaschen in Wasser in Alkohol ron $96^{\circ}$, überführe. Hierin bleiben sie mindestens $2+$ Stunden, die Extraktion kann aber auch auf 72 Stunden ausgedehnt werden: die Schnitte müssen ganz blaßblau sein. Die Färbung ist vorzüglich, die Präparate halten sich einige Monate.

88. Toluidinblau. Hoyer hat diesen Farbstoff in die Technik 
eingeführt; er wirkt ähnlich wie Methylenblau und soll haltbarer sein. Ich habe von letzterer Eigenschaft nichts gemerkt, dagegen kann der Farbstoff als mikrochemisches Reagens auf Mucin gelten. Er wird in wässriger Lösung angewandt.

\section{Violette Farben.}

$$
\S 73 .
$$

Sg. Dahlia (Methylviolett R-5R). Ein Kernfarbstoff, der gewöhnlich in wässriger Lösung zu verwenden ist. Zur Färbung von Mastzellen in Alkohol-Material empfiehlt Ehrlich folgende Vorschrift: Alkohol absolutus $50 \mathrm{ccm}$, Aqua destillata $100 \mathrm{ccm}$, Acetum glaciale $12_{2}^{\mathrm{I}} \mathrm{ccm}$, Dahlia bis zur Sättigung. Fürbungsdauer für Schnitte mindestens 12 Stunden.

go. Gentianaviolett (Methylviolett 6B; Benzylviolett usw.). Wird in konzentrierter wässriger Lösung als Kernfarbstoff benutzt und leistet als solcher vorzügliche Dienste. Gentianaviolett nach Ehrlich wird nach folgendem Rezept angefertigt: I g Gentianaviolett, Alkohol $15 \mathrm{ccm}$, Anilinöl $2 \mathrm{ccm}$, Aqua destillata $15 \mathrm{ccm}$. Färbungsdauer 5-15 Minuten, nachher Anwendung des Gramschen Verfahrens.

91. Kresylechtviolett, nach Herxheimer. Eine konzentrierte wässrige Lösung; die vor dem Gebrauch filtricrt werden muß, wirkt Io Minuten auf dünne Schnitte ein. Man wäscht in Alkohol ab. Kerne blau mit Kernnetz, Protoplasma rötlich. Wenn die Schnitte 3o Sekunden mit käuflichem Aceton behandelt werden, dann erhält man reine Kernfärbung.

92. Kristallviolett. In wässriger oder alkoholischer Lösung. Über seine Terwendung bei der Bendaschen Mitochondriafärbung vgl. dreizehntes Kapitel.

93. Thionin (Lauffs Violett). NIan färbt in konzentrierter wässriger Lösung kürzere oder längere Zeit und muß in letzterem Falle länger in Alkohol ausziehen. Von Hoyer für Mucinfärbung, von Heidenhain für Kernfärbung empfohlen. $\mathrm{Da}$ das Thionin dem Methylenblau chemisch nahe steht, so ist es auch für Ganglienzellfärbung verwendbar.

Braune Farben.

$\S 74$.

94. Bismarckbraun (Vesuvin, Phenylenbraun usw.). Man hält sich eine konzentrierte wässrige Lösung vorrätig und färbt darin 
Schnitte 2+ Stunden lang, wäscht in IT'asser ab und zicht in Alkohol so lange aus, bis kein Farbstoff mehr ausgeht. Die Verwendung sehr verdiinnter Lösungen ist sehr zu empfehlen, da dann ein Ausziehen in Alkohol kaum nötig ist, der Alkohol wird also nur zum Entwässern gebraucht. Vorzügliche Kernfärbung, die nur bei chromiertem und osmiertem Material versagt, schwache Plasmafärbung. Bismarckbraun ist ein exquisites Reagens auf Mucin, denn die Zellen der Mucindrüsen und mucinhaltige Becherzellen werden in ihm dunkelbraun. Die Färbungen sind sehr lange haltbar.

\section{Schwarze Farben.}

\section{$\S 75$.}

95. Brillantschwarz 3 B und Blauschwarz B, nach M. Heidenhain. Es sind dies neutrale Farben. Beide Farbstoffe in $1 \%$ wässriger Lösung verwendet; Blauschwarz iberfärbt leicht, so daß die Färbungsdauer ro Minuten nicht übersteigen darf. Für verschiedene Organe nach Sublimatfixierungen sehr geeignet, namentlich für die Herzmuskulatur (vgl. siebzehntes Kapitel).

\section{ß) Die Doppelfärbungen.}

Die Anwendung zweier Farben, deren IVirkung sich ergänzen muß (Plasma- und Kernfarbstoff), kann einzeitig oder zweizeitig geschehen. D. h. die beiden Farbstoffe können in einer Mischung zugleich angewendet werden oder aber man färbt erst mit dem einen und dann mit dem anderen Farbstoffe. Ob man den Plasmafarbstoff zuerst und den Kernfarbstoff zu zweit anwendet oder umgekehrt verfährt, ist meist irrelevant.

\section{$\S 76$.}

96. Hämatoxylin-Karmin, nach Strelzoff. Schnitte erst in Alaunhämatoxylin gefärbt, dann gut in Wasser gewaschen und in einer möglichst ammoniakarmen Karminlösung nachgefärbt. Man wäscht wiederum und differenziert eventuell in einer dïnnen Alaunlösung. Zum Studium der Knochenentwickelung: Knorpel blau, Knochen rot.

97. Karmin-Hämatoxylin, nach G. Fritsch. Man nimmt von einer konzentrierten ammoniakalischen Karminlösung einige Tropfen (5-IO) auf etwa to ccm Aqua destillata. Die Schale, welche die Farbflotte enthält, wird auf eine weiße Unterlage gestellt und nun wird mit einem Glasstabe tropfenweise Essigsäure zugesetzt, bis die 
ursprünglich kirschrote Farbe hellrot mit einem Stich ins Gelbe geworden ist, was man beim Umrühren der Lösung gegen die helle Unterlage sehr bald erkennt. In diesem Karmin, das ganz neutral ist, werden die Schnitte bis I Stunde gefärbt. Man färbt mit Hämatoxylin kurz nach, da bei zu langer Färbung das Karmin verdrängt wird. Zellsubstanzen rot, Kerne blau.

98. Boraxkarmin-Indigkarmin, nach Merkel. Die Methode wird auch Norris und Shakespeare zugeschrieben. Nan löst durch Kochen $2 \mathrm{~g}$ Karmin und $8 \mathrm{~g}$ Borax in I $30 \mathrm{ccm}$ Aqua destillata und löst ferner $8 \mathrm{~g}$ Indigkarmin und $8 \mathrm{~g}$ Borax in $130 \mathrm{ccm}$ Aqua destillata ebenfalls durch Kochen. Nach dem Erkalten wird filtriert und beide Farben werden zu gleichen Teilen gemischt. Die Herstellung der Farbflotte ist nicht sehr rationell, der Färbeeffekt aber ist ganz vorzüglich. Man färbt die Schnitte 2.t Stunden in dem Gemisch und iiberträgt sie dann direkt, ohne Auswaschen, in kalt gesättigte wässrige Oxalsäurelösung für 15-20 Minuten. Ein rorheriges Auswaschen ist direkt schädiich, weil die Indigkarminfärbung dadurch ausgewaschen wüirde. Das Resultat ist: Kerne tiefrot, Bindegewebe hellrot, Plasma der Epithelzellen grülich und Muskulatur, glatte wie quergestreifte, leuchtend blau oder blaugrïn. Besonders für Evertebraten geeignet, um fuir die hier oft schwierige Unterscheidung von Bindegerrebs- und Muskelfibrille einen färberischen Anhalt zu haben.

99. Boraxkarmin-Bleu de Lyon (Methylblau), nach Blochmann. IIan färbt in Boraskarmin durch und färbt die aufgeklebten Schnitte in Methylblau nach. Letzterer Farbstoff wird in IVasser gelöst und ihm dann soviel Alkohol zugesetzt, daß die Lösung von diesem $10^{\circ}$ o enthält. Im Methylblau bleiben die Schnitte, bis sie blau sind; ausgewaschen wird in Alkohol. Bei gelungener Färbung Plasma blau, Kerne rot.

I oo. Orange G-Alaunkarmin, nach Rawitz. Man färbt 24 Stunden in konzentrierter wässriger Lösung von Orange $G$ und bringt dann direkt auf Io Minuten in Alaunkarmin oder Karmalaun oder Glyzerinkarmalaun, wäscht in W'asser usw: Zellsubstanz orangegelb, Kerne rot, Mucin intensiv rotviolett, daher für Mucindrüsen sehr geeignet.

I OI. Hämatoxylin-Safranin, nach Rabl. Man färbt die Schnitte zunächst in Delafieldschem Hämatoxylin so schwach, dạ sie so nicht brauchbar sind. Dann wäscht man gut aus und bringt in Safranin ein (alkoholisch gesättigte Lösung zum Gebrauch mit dem gleichen Volumen IVasser verdünt). Hierin bleiben die Schnitte 
24 Stunden und werden so lange in absolutem Alkohol ausgezogen, bis kein Farbstoff mehr ausgeht. Besonders für Zellteilungen geeignet.

I 02. Eosin-Hämateïn bzw. -Hämatoxylin. Die urspriingliche, von Rcnaut herrihrende Vorschrift, von Eosin- und Hämatoxylinlösung cin Gemisch herzustellen, ist völlig antiquiert und wert, der Vergessenheit anheimzufallen. Nan färbt zweizeitig und nach den ausgedehnten Erfahrungen, die ich mit dieser vortrefflichen Kombination besitze, kann ich das folgende Verfahren als das beste und hinsichtlich des Erfolges sicherste empfehlen: Man färbt die Schnitte $2+$ Stunden lang in sehr stark verdünnter Glyzerinalaunhämateïn- oder, weniger gut, Hämalaunlösung. Erentuell kann man auch die entsprechenden Hämatoxyline nehmen. Dann wird sehr gut in destilliertem Wasser abgewaschen, für kurze Zeit ${ }^{I}{ }_{4}$ Stunde in gewöhnliches Vasser gebracht und auf $\mathrm{I}-2$ Stunden in verdünnter Eosinlösung: nachgefärbt. Letztere stellt man dar, indem man ${ }^{\mathrm{I}}=\mathrm{ccm} \mathrm{I}^{\circ}$, Eosinlösung mit 25- $30 \mathrm{ccm}$ Aqua destillata verdünnt. Nach der Färbung wird gut in Wasser abgewaschen und in Alkohol ibergeführt. Es ist ratsam, die aufgeklebten Schnitte, d. h. die Objektträger hzw. Deckgläser, auf denen die Schnitte aufgeklebt sind, schnell in den Alkohol zu tun. Immer nämlich haftet der Oberfläche der Schnitte noch etwas Hämatein an, das beim schnellen, plötzlichen Einbringen in den Alkohol weggespiilt wird, während es sich bei vorsichtigem Einlegen in den Präparaten körnig niederschlägt. Man sieht das durch den Alhohol gewissermaßen weggeschossene Hämatein als eine bläuliche körnige Schicht auf der Oberfläche des Alkohols schwimmen. Der Torteil der verdünnten Eosinlösung besteht darin, daß die roten Töne nicht so grell sind, wie bei Anwendung einer konzentrierten Farbe, daß die Färbung also zarter, diskreter und darum besser ist. Im Alkohol wird nicht riel Eosin ausgezogen: wieder ein Beweis dafur, daß duinne Lösungen der Anilinfarben besser färben und fester haften als starke. Das Resultat der Färbung ist: Kerne dunkelblau, Nucin reilchenblau, Bindegewehe graublau, Zellsubstanzen zart rot, Muskeln und scröse Drüsen leuchtend rot. Ich rate dringend, stets „Eosin gelblich» zu nehmen.

103. Orange G-Hämateïn bzw. -Hämatoxylin, nach Rawitz. Diese von mir eingeführte Kombination muß ebenfalls zweizeitig ausgefuihrt werḑen. Nur für Schnittfärbung geeignet. Der Modus procedendi muß anders sein wie hei der vorigen Kombination, da erst in Orange zu färben ist und dann konzentrierte Hämateinlösungen angewendet werden muissen. Denn dreht man die Färbung um, nimmt man also 
Orange an zweiter Stelle, dann muß der Hämateïntonerdeverbindung wegen gründlich in Wasser ausgewaschen werden. Dadurch aber wird alle Orange ausgetrieben. Nimmt man dagegen Orange zuerst, dann wird der Farbstoff durch die an zweiter Stelle verwendete Hämateinlösung gewissermaßen fixiert, denn in Wasser geht fast gar nichts mehr aus und in Alkohol stellen sich keine Orangeniederschläge ein. Man färbt $2+$ Stunden in konzentrierter wässriger Orange G-Lösung, dann ohne Auswaschen für ${ }_{1}=-2$ Minuten in eine Hämatein- bzw. Hämatoxylinlösung, gutes Auswaschen in Wasser, Alkohol 96 $6^{\circ}$. usw. Bei zu langem Terweilen im Hämatein tritt Überfärbung ein. Das Resultat der Färbung ist: Muskulatur hellgelb, Zellsubstanzen, seröse Driisen, Knochengrundsubstanz orangefarben, fasriges Bindegervebe graublau, Mucindrüsen, mucinhaltige Becherzellen und Knorpelgrundsubstanz. veilchenblau, Kerne dunkelblau.

rof. Eosin-Methylblau, nach Mann. Diese Doppelfärbung ist eine einzeitige, bedarf aber der Differenzierung. Nan mischt $35 \mathrm{ccm}$ einer $I^{\circ} \%$ wässrigen Lösung von Nethylblau $00,45 \mathrm{ccm}$ einer $\mathrm{I}_{\text {, }}^{\circ}$ wässrigen Eosinlösung und $100 \mathrm{ccm}$ Aqua destillata. Schnitte von Sublimat- usw: Naterial werden in dieser Farbflotte 24 Stunden lang gefärbt, in TWasser gewaschen, in Alkohol ausgezogen und in folgender Lösung differenziert: $I^{\circ}$ 。alkoholische Natronlauge + Tropfen, Alkohol absolutus $50 \mathrm{ccm}$. Darin werden die Schnitte rötlich; sie werden herausgenommen, mit etwas absolutem Alkohol abgespiilt, auf 2 Minuten in VTasser eingelegt, worin blauc Farbstoffwolken ausgehen und nun zur Neutralisierung der Lauge in Wasser gebracht, dem einige Tropfen Essigsäure zugesetzt sind. Die Schnitte werden hierin blauer. Resultat der Färbung: Zellen blau mit Ausnahme der Nucleolen, Blutgefäße rot.

I05. Eosin-Methylgrün. Die Schnitte kommen zunächst für 5 Minuten in den aliquoten Teil einer Eosinlösung; die aus 0,5 g Eosin, $100 \mathrm{ccm}$ Aqua destillata und $300 \mathrm{ccm}$ Alkohol absolutus besteht. Man wäscht aus und färbt ebenfalls 5 Minuten lang in einer $0,5^{\circ}$ 。 wässrigen Methylgrünlösung. Man wäscht in Masser und zieht in Alkohol aus, bis die Eosinfarbe wieder erscheint.

106. Safranin-Gentiana, nach Flemming. Nach Fixierung in Flemmingscher Lösung oder einem anderen Chromosmiumgemisch verwendbar. Man färbt die Schnitte 48 Stunden lang in gewöhnlicher Safraninlösung, wäscht in Wasser aus, bis fast kein Farbstoff sich mehr löst, und färbt mit konzentrierter (Flemming sagte: undurchsichtiger) Gentianariolettlösung einige Stunden bis I Tag. NIan zieht nun entweder in ganz schwach saurem Alkohol aus oder be- 
nutzt das Gramsche Verfahren, wäscht damn in Wasser und zieht in Alkohol aus, bis keine Farbstoffwolken mehr ausgehen. Für Zellteilungen und Spermatogenese. Es handelt sich hier und bei der folgenden Vorschrift um die Kombination zweier basischer Anilinfarben, also um zwei Kernfärbemittel.

I0;. Safranin-Gentiana, nach Hermann. Für Schnitte, die ron einem in Hermannscher Flüssigkeit fixierten Material stammen. Nan färbt entweder in Babesschem Safranin vgl. Nr. ;o) oder nimmt folgendes Safranin nach Ehrlich: i g Safranin, $10 \mathrm{ccm}$ Alkohol absolutus, go ccm Anilinwasser. Darin werden die Schnitte $2+--48$ Stunden lang gefärbt, dann in IVasser gewaschen, in salzsaurem Alkohol ausgezogen und in neutralen d. h. nicht säurehaltigen absoluten Alkohol übertragen. Bevor sic in diesem völlig entfärbt sind, werden sie für 3 - 5 Minuten in wässrige Gentianaviolettlösung ühertragen, in Vasser abgespuilt und I-3 Stunden nach Gram behandelt Dann absoluter Alkohol usw: Gelungene Färbungen zeigen einen violetten Ton mit einem Stich ins Bräunliche. Für Zellteilungen und Spermatogenese.

I08. Safranin-Lichtgrün, nach Benda. Die Schnitte osmiertes Material werden in Babesschem Safranin $2+$ Stunden vorgefärbt und kommen für ${ }^{\mathrm{I}}{ }_{4}-{ }^{\mathrm{I}}$. Minute in $\mathrm{I}^{\circ}$ alkoholische Lichtgrülösung. Man darf in letzterer nicht zu lange belassen, weil sonst das Safranin ganz verdrängt wird.

Ioy. Eosin-Methylenblau. Diese Kombination hat zur Herstellung des Methylenazur gefuhrt: die Vermischung des sauren und des basischen Farbstoffes liefert einen sogenannten neutralen. dessen » Metachromasie aber auf scinen Ursprung hinweist und tatsächlich eine Doppelfärbung ist. Er wird in der Bakteriologie und bei Blutuntersuchungen viel verwendet (vgl. II. Teil).

Nach Laurent mischt man Eosin = eosinsaures Kalium) und chemisch reines Methylenblau ad usum internum zinkfrei), die in Lösungen von I : 1000 in Vorrat gehalten werden, im Verhältnis von $72+$ Eosin zu 638.8 Methylunblau. Nach +8 Stunden ist der neutrale Farbstuff fast völlig ausgefallen, der von Grubler hergestellt und in den Handel gebracht wird. Man löst von dem Azur I Teil auf + Teile Wasser, kocht im Reagensglase schnell auf, läßt etwas abkiihlen, bringt die Objekte für ${ }_{2}-6$ Stunden in die noch warme Fliissigkeit und wäicht. falls sich Niederschläge gebildet haben, in absolutem Alkohol aus.

Nach L. Michaclis löst man $2 \mathrm{~g}$ Methylenblau medicale in $200 \mathrm{ccm}$ Aqua destillata, fügt I o $\mathrm{ccm}^{\text {I }}$ ro ${ }^{\circ}$. Normal-Natronlauge hinzu und läßt 
${ }_{4}$ Stunde kochen. Nach dem Erkalten fügt man io $\mathrm{ccm}$ Normalschwefelsäure zu und filtriert. Man färbt in einer Mischung, welche I Teil dieser Lösung und 5 Teile Eosin I : I000) enthält, die Präparate ${ }^{1} / 4$ Stunde.

Ich will bei dieser Gelegenheit anführen, daß ich eine ganz gute Doppelfärbung mit polychromem .Iethylenblau und Eosin in der Weise erhalte, daß ich in ersterem Farbstoff 24 Stunden vorfärbe. Ich benutze natürlich die unter $\mathrm{Nr}$. 8; angegebene starke Verdünnung. Nach sorgfältigem Auswaschen bringe ich die Schnitte in eine ganz dünne Eosinlösung und färbe hierin ${ }^{2}{ }_{2} \rightarrow$ I Stunde. Im Eosin geht sehr viel polychromes Methylenblau aus. Nach kurzem Wässern wird in Alkohol ausgezogen und ror völliger Entfärbung montiert. Bei gelungener Doppelfärbung erscheint der Untergrund des mikroskopischen Bildes rötlich und die Färbung mit polychromem Nethylenblau dunkel purpurn. Namentlich bei Schnitten durch Zentralnervensystem habe ich sehr schöne Bilder erhalten. Freilich gelingt die Färbung nicht immer, da die Eosinwirkung, welche in der Verdrängung des Methylenblau besteht, sehr oft zu intensiv ist.

I Io. Thionin-Rutheniumrot, nach Eisen. Für dic mit Iridiumchlorid-Eisessig vgl. viertes Kapitel Mr. 88 fixierten Objekte wird folgende Doppelfärbung empfohlen. Dic Schnitte fürbt man zunächst in einer Thioninlösung, welche $\mathrm{I} g$ Thionin in $10 \mathrm{ccm}$ Alkohol und $90 \mathrm{ccm}$ Wasser gelöst enthält. Nach 5 Minuten wird in Wasser eingebracht, dem man einige Tropfen Rutheniumrotlösung beigemengt hat. Man löst diesen Farbstoff, indem man eine geringe Menge von ihm in eine Mischung von Io $\mathrm{ccm}$ Alkohol absolutus, I o ccm Glyzerin und $80 \mathrm{ccm}$ Wasser bringt. Die Rutheniumrotlösung ist leicht verderblich, sie erscheint dann braun statt rot. Wenn man das Thionin stark verdinnt, kann man auch 24 Stunden lang darin färben.

\section{r) Die Dreifachfärbungen.}

Die meines Erachtens höchste Zahl von verschiedenen Farbstoffen, die kombiniert werden können, ist drei. Denn auch bei diesen werden die Bilder oft in einer IVeise bunt, daß dadurch mehr Verwirrung als Klärung bewirkt wird. Für Blutuntersuchungen, für Drüsenstudien und eventucll noch für das Studium des Verhornungsprozeßes sind die Dreifachfärbungen von entschiedenem Werte, bei Zellteilungen liefert das zu schildurnde Orangeverfahren ron Flemming schöne Bilder, die aber kaum mehr erkennen lassen, als Doppelfärbungen. Bei allen anderen Objekten halte ich die Dreifachfärbungen für iiberflüssig. 


\section{$\$ 77$.}

I I. Pikrokarmin-Hämatoxylin, nach Flcmming: Nan färbt die Schnitte $2+$ Stunden in einer mittelstarken Pikrokarminlösung und bringt dann für einige Zcit in Delafieldsches Hämatoxylin, wäscht in Wasser gut aus usw. Soll für Hautschnitte geeignet sein: Bindegewebe rosa, Zellsubstanzen und Muskeln gelbrötlich, Zellkerne dunkelpurpurn bis violett, hornige Substanz des Haares pikringelb, innere Wurzelscheide lichtblau, Stratum lucidum grün. Die Färbung gelingt nicht immer, weil das Pikrokarmin oft versagt.

I 2. Karmin-Pikroindigkarmin, nach Calleja. 2 g Karmin werden in $100 \mathrm{ccm}$ gesättigter wässriger Lösung ron Lithiumkarbonat gelöst. Hierin bleiben die Schnitte, die natuirlich nicht mit Eiweiß aufgeklebt sein düren, 5- Io Minuten, werden in Salzsäurealkohol (i : 100 Alkohol ron $70^{\circ}$ ' $20-30$ Sekunden differenziert, dann zur Entfernung der Säure griindlich gewaschen und 5-ro Minuten in Pikroindigkarmin ron Cajal gefärbt. Letzteren Farbstoff stellt man sich folgendermaßen dar: Indigkarmin $0,25 \mathrm{~g}$, gesättigte wässrige Pikrinsäure 100 ccm. Nach kurzem Maschen in dünner Essigsäure 15-6 Tropfen auf Io ccm Aqua destillata) wird in reinem Wasser gewaschen, in Alkohol entwässert usw: Resultat der Färbung: Kerne der Epithelzellen und des Bindegewebes intensiv rot. Protoplasma der Epithelzellen gelb, Bindegewebsfibrillen hei erwachsenen Tieren dunkelblau, alte verhornte Elemente orangerot. Statt Lithionkarmin kann man auch Alaunkarmin nehmen; darin färbt man 2-4 Stunden. Oder man nimmt Karmalaun und färbt I 5 Minuten bis I Stunde.

\section{I 3. Orange G-Säurefuchsin-Methylgrün, Ehrlich-Biondisches}

Gemisch. Die urspringliche Vorschrift lautet: Ioo $\mathrm{ccm}$ wässriger Lösung von Orange G, $20 \mathrm{ccm}$ gesättigter wässriger Lösung von Säurefuchsin und $50 \mathrm{ccm}$ gesättigter wässriger Methylgrünlösung werden gemischt. (Man tut gut, sich die fertige Lösung zu kaufen, da das Jischen nicht gerade leicht ist.) Zum Gebrauche verdiinnt man einen aliquoten Teil der Lösung mit dem 60-roofachen an destillicrtem Vasser; Färbungsdauer $2+$ Stunden. Für die verschiedensten Zwecke geeignet, besonders für Blut- und Drüsenuntersuchungen. Die urspriingliche Vorschrift hat mannichfache V'eränderungen erfahren, die, Weil sie lieine besonderen Methoden sind, auch keine besondere Bezifferung erhalten. Folgende Modifikationen sind beachtenswert: Iodifikation von Rosin. Dieser Forscher macht zwei Lösungen: Lösung I enthïlt ron dem von Grïbler trocken hergestellten Gemisch $0,+9$ in Aqua destillata $100 \mathrm{ccm}$ und $0,5^{\circ}$. Säurefuchsinlösung $7 \mathrm{ccm}$. Lösung II enthält: + Teile der Lösung I und I Teil 
$0,5^{\circ}$. Säurefuchsinlösung. Dic Lösung II ist für Celloidinschnitte bestimmt, die Schnitte dürfen nur I Minute in ihr bleiben und werden so nachbehandelt, wie dic Schnitte nach Lösung I. In Lösung I wird I5 Ninuten lang gefärbt, dann in destilliertem Nasser abgewaschen, nicht ausgewaschen, da dic Farbe im Wrasser nicht ausgehen darf. Zum Abwaschen geniigen $\mathrm{I}-2$ Minuten. Darauf kommen die Schnitte in eine Essigsäurelösung ron I : Iooo / = I Tropfen Eisessig auf Ioo ccm Wasser und bleiben darin 5-io Sekunden zur Fixierung des roten Farbstoffes. Darauf für I Ninute Überfïhren in Aqua destillata, um die Essigsiure auszuwaschen, dann absoluter Alkohol, der so lange cinwirken muß, wie violette Farbe ausgeht (etwa 2-3 Minuten), Xylol usw. Es entsteht ein recht buntes Bild: purpurn, orange, violett und blaugriin gefärbte Teile. Modifikation von R. Krause: + ccm gesättigte wässrige Säurefuchsinlösung und $7 \mathrm{ccm}$ gesättigte wässrige Orange G-Lösung werden gemischt; dann fügt man $8 \mathrm{ccm}$ gesättigte wïssrige Nethylgrünlösung zu. Von dieser Stammlösung, die wie auch dic ursprüngliche Ehrlichsche Vorschrift in konzentrierter Form überfärbt, nimmt man I ccm auf $50-100 \mathrm{ccm}$ Aqua destillata. Nanchmal ist es gut, die Schnitte vorher I-2 Stunden in $2^{\circ}$, Essigsäure anzusäuern. Gefärbt wird 24 Stunden lang, dann in Alkohol von $90^{\circ}$ 。 für I Minute übertragen, in Alkohol absolutus, dem I-2 Tropfen Essigsäure auf 50 ccm zugesetzt sind, entwässert und dann montiert. Modifikation von Trambusti. Die Schnitte werden zunächst in Essigsäure I : 500 Wasser angesäucrt. Die sauren Aniline färben saure Gewebe kräftiger als neutrale.) Dann in EhrlichBiondisches Gemisch I Teil, Aqua destillata $150 \mathrm{ccm}$ und I Essigsäure $25 \mathrm{ccm}$. Darin wird $2+$ Stunden gefärbt. Modifikation von Bergonzini. $0,2^{\circ}$ 。 Säurefuchsinlösung I Teil, $0,2^{\circ}$ 。 Methylgrünlösung 2 Teile und $0,2^{\circ}$, Orange $\mathrm{G}$ - oder Goldorangelösung 2 Teile. Gefärbt wird $3-+$ Minuten, $1-2$ Minuten in Wasser gewaschen, 2 Minuten absoluter Alkohol, dann Xylol usw.

I I . Triacidgemisch von Ehrlich. In einer Literflasche mischt man $100 \mathrm{ccm}$ Aqua destillata, $135 \mathrm{ccm}$ gesättigter wässriger Orange G-Lösung und $65 \mathrm{ccm}$ gesättigter wässriger Lösung von Säurefuchsin. Der Maßzylinder, in dem man die Quantitäten gemessen hat, wird mit $100 \mathrm{ccm}$ Aqua destillata ausgespiilt, die dem vorigen Gemisch beigefuigt werden. Dann bringt man unter häufigem Schiitteln allmählich I $25 \mathrm{ccm}$ gesättigter wässriger Nethylgrünlösung zu, fügt I $00 \mathrm{ccm}$ Aqua destillata nach und setzt zu dem Gemisch Ioo ccm $96 \%$ Alkohol und $125 \mathrm{ccm}$ Glyzerin. Das Gemisch muß verdünnt angewendet werden. Bei der Umständlichkeit seiner Anfertigung und 
namentlich bei der Schwicrigkeit, gesättigte Lösungen von Fuchsin S herzustellen, empfiehlt es sich, das Triacidgemisch fertig zu kaufen. Vorzüglich für Blut- und Drüsenstudien.

II5. Dreifarbengemisch, nach Oppel. I ${ }^{\circ}$ wässrige Mcthylgriulösung I $20 \mathrm{ccm}, \mathrm{I} \%$ wässrige Eosinlösung $2 \mathrm{ccm}, I_{i}^{\circ}$ wässrige Säurefuchsinlösung to ccm und $40 \mathrm{ccm}$ Alkohol absolutus. In dem

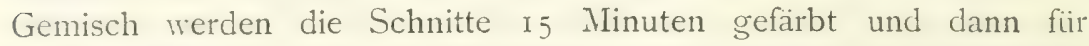
3o Sekunden in folgende Pikrinsäurelösung uibergeführt: gesïttigte wässrige Pikrinsäure $80 \mathrm{ccm}$ und $20 \mathrm{ccm}$ Alkohol absolutus. Dann absoluter Alkohol und Montieren.

I 16. Bordeaux R-Thionin-Methylgrün, nach Grâberg. I\% wässrige Bordeauxlösung + Teile, 12 ! Thioninlösung 2 Teile, I wässrige Methylgrünlösung, der auf Ioo ccm $25 \mathrm{ccm}$ absoluter Alkohol zugefuigt sind, 3 Teile. Von dieser Stammlösung werden $5 \mathrm{ccm}$ mit $95 \mathrm{ccm}$ Aqua destillata zum Gebrauch verdünnt; Filtration notwendig, da ein Niederschlag entsteht. Die Schnitte kommen für $2+$ Stunden in die Farbflotte, dann in $93 \%$ Alkohol, dem auf $100 \mathrm{ccm} 4$ bis 6 Tropfen konzentrierter Essigsäure zugesetzt sind. Wenn keine Farbstoffwolken mehr ausgehen, werden die Schnitte Ammoniakdämpfen für einige Minuten ausgesetzt, dann absoluter Alkohol und Montieren. Fixierung in Sublimat; für Milz, Leber und Hoden geeignet.

I 7. Orangeverfahren, nach Flemming. Zu Zellteilungsstudien kommen Schnitte von osmiertem oder mit Platin fixiertem Naterial für 2-3 Tage in wenige ccm gewöhnlicher Safraninlösung, werden in destilliertem Wasser abgewaschen und in salzsaurem absolutem Alkohol (I : Iooo ausgezogen, bis nur noch wenig Farbe ausgeht. Dann kurzes Waschen in destilliertem Wasser und für I bis 3 Stunden Einbringen in ein kleines Quantum wässriger Gentianaviolettlösung. Nach kurzem Waschen werden die Schnitte in konzentrierte wässrige Lösung von Orange G eingelegt. Hier gehen starke Farhstoffwolken aus; nach wenigen Ninuten direkt in absoluten Alkohol, der einmal gewechselt wird. Dann Montieren.

I I. Säurefuchsin-Orange G-Anilinblau, nach Mallory. Die Schnitte von Material, das in Sublimat oder Zenkerscher Flüsigkeit fixiert ist, werden in $0,5^{\circ}$ - $1^{\circ}$. Säurefuchsinlösung bis 3 Minuten gefärht, dann geraschen und in $\mathrm{I}^{\circ}$. Lösung von Phosphormolybdänsäure fuir I Minute eingebracht. Man wäscht in 2 mal gewcchseltem Wasser, färbt 2-20 Minuten und länger in folgendem Gemisch: wasserlösliches Anilinbliu Grübler $0,5 \mathrm{~g}$, Orange $\mathrm{G}=\mathrm{g}$, ()xalsäure $2 \mathrm{~g}$, Aqua destillata $100 \mathrm{ccm}$, und behandelt wic gewöhnlich weiter. 
Bindegewebsfibrillen, Reticulum, Schleim, Amyloid, hyaline Substanzen blau; Kerne, Plasma, elastische Fasern, Achsenzylinder, Neuroglia, Fibrin rot; Erythrocyten und Markscheiden gelb. Daß dieses bunte, aber nichts wahrhaft charakterisierende Resultat die Muihe lohnen dürfte, scheint mir zweifelhaft. Wie wenig die Methode distinkte Färbungen liefert, zeigt sich darin, daß Kerne und Plasma dieselbe Farbe annehmen.

I I 9. Hämatoxylin-Pikrin-Säurefuchsin, van Giesonsche Färbung. Nan färbt die Schnitte ${ }^{1}$ : Stunde in Delaficldschem Hämatoxylin, wäscht $12-24$ Stunden in destilliertem IVasser aus und bringt für $\mathrm{I} / 2$ - I Minute in folgende (van Giesonsche) Mischung: $150 \mathrm{ccm}$ warm gesättigte wässrige Pikrinsäurelösung und $3 \mathrm{ccm}$ gesättigte wässrige Lösung von Säurefuchsin. Man spült in einer geringen Wassermenge $a b$, der einige Tropfen van Giesonscher Mischung beigefügt sind, und bringt nach ${ }^{\mathrm{T}} / 4-{ }_{1}^{\mathrm{T}_{2}}$ Ninute für $2-5$ Ninuten in c, $6 \%$ Alkohol, der mit dem van Giesonschen Gemisch hellrot gefärbt ist, entwässert und montiert.

I 20. Eisenhämatoxylin-Pikrin-Säurefuchsin, nach Weigert. Von einer $I \%$ Hämatoxylinlösung in Alkohol von $96 \%$ und von folgender Eisenchloridlösung: $4 \mathrm{ccm}$ Liquor ferri sesquichlorati, I $\mathrm{ccm}$ offizinelle Salzsäure und $95 \mathrm{ccm}$ Aqua destillata, werden gleiche Mengen gemischt. Dic Mischung, die sofort schwarz wird, muß crst vor dem Gebrauche hergestellt werden. Nach wenigen Minuten sind die Schnitte gefärbt, eine Überfärbung tritt angehlich nicht ein. Nach kurzem Abwaschen wird in eine modifizierte van Giesonsche Nischung ( $100 \mathrm{ccm}$ kalt gesättigte wässrige Pikrinsäurelösung und Io $\mathrm{ccm}$ Säurefuchsin $\mathrm{I}^{\circ}{ }^{\circ}$ ) gebracht. Darin bleiben die Schnitte nur kurze Zeit, werden gewaschen, entwässert und montiert.

\section{Die adjektive Färbung.}

ठ) Die Hämatoxylinlacke.

$$
\S 78 .
$$

I 21. Hämatoxylinchromlack, nach R. Heidenhain. Mit dieser Methode wurden die adjektiven Färbungen eingefüht. Sie unterscheidet sich von den anderen Hämatoxylinlacken dadurch, daß bei ihr zuerst der Farbstoff auf dic Gewebe einwirkt und dann erst durch Anwendung der Beize der Lack erzeugt wird. Sie ist der einzige echte Hämatoxylinlack, denn cine Differenzierung ist nicht nötig. Leider wird die Methode heutigen Tages nur noch wenig gebraucht: 
sie ist curch dic eleganteren, aber färberisch unsolidercn Eiscnlacke verdrängt worden.

Man macht sich eine ${ }^{1}{ }_{2}^{\circ}$ 。 wässrige Lösung ron Hämatoxylin, dic: weil ein Ausreifen nicht nötig ist, sofort gebraucht werden kann. Vom Hämateìn macht man eine entsprechend schwächere Lösung. Dic gut fixierten und gehärteten Objekte werden im Stïck $2+$ bis t\& Stunden, eventuell auch länger, darin gefärbt. Dann kommen sie in ein ebenso großes Quantum ciner ${ }^{1}, 0$ ? wässrigen Lösung des chromsauren Kali, also des neutralen gelben Salzes. Sofort beginnen blauschwarze Farbwolken aus dem Präparat zu entweichen - der Chromlack bildet sich -, die schließlich so dunkel werden, daß nichts mehr zu sehen ist. Das chromsaure Kali muß daher wiederholt gewechselt werden. In der Beize bleiben die Objekte $2+$ bis 48 Stunden, mindestens aber so lange, his keine Farbwolken mehr entweichen. Dann wird sehr sorgfältig gewaschen, in Alkohol von steigender Konzentration gehärtet und in Paraffin oder Celloidin eingebettet. Da die Objekte dunkelschwarz sind, so müssen sie in sehr dünne Schnitte zerlegt werden. Die mikroskopischen Bilder gleichen nach R. Heidenhains treffender Bezeichnung einem : gut ausgeführten Holzschnitter. Für alle Objekte geeignet. Eine Nachfarbung in Alaunkarmin, wie sie Flemming empfohlen hat. halte ich für überflüssig.

122. Hämatoxylineisenoxydullack, nach Benda. Die Schnitte werden zur Beizung auf Minuten oder Stunden in eine konzentrierte Lösung ron Mohrschem Salz schwefelsaures Eisenoxydul-Ammonium) gebracht. Nach sorgfältigem Auswaschen wird in eine $I^{\circ}$ 。 wässrige Hämatoxylinlüsung ibergeführt. Hierin bleiben die Schnitte, bis sie schwarz sind, also etwa ro Minuten. Dann wird in einer Chromsäurelösung I : 2000 differenziert.

I23. Hämatoxylineisenalaunlack, nach M. Heidenhain. Die Schnitte kommen in eine $1,5^{\circ}-4^{\circ}$. Eisenalaunlösung (schwefelsaures Eisenoxyd-Ammonium) für ${ }^{\mathrm{I}}{ }_{2}-3$ Stunden, werden in Wasser abgespült und auf ${ }_{2}{ }_{2}-\mathrm{I} 2$ Stunden in eine $1 \%$ wässrige Hämatoxylinlösung gebracht. Vachdem sie hierin dunkelschwarz geworden sind, werden sie in der Beizfliissigkeit differenziert, wobei der Grad der fortschreitenden Entfärbung unter dem Mikroskop zu beaufsichtigen ist. Die Differenzierung durch die Beize beruht auf der in der industriellen Färberei bekannten Tatsache, daß Farblacke in einem Überschuß der I3eize sich wieder lösen vgl. S. I 54). Heidenhain hat der Beizung eine Vorfärbung in wässriger Bordeauxlösung vorausgeschickt, um den Hämatoxylinlack in seiner Wirkung einzuschränken. Für Zellteilungen 
und besonders für Centrosomenfärbung geeignet. Die rorstehend mitgeteilte Torschrift hat dann Heidenhain folgendermaßen modifiziert. Die Schnitte kommen in eine $2^{x}=$. Eisenalaunlösung mindestens 3 Stunden bis zu i 2 Stunden. Der Ohjektträger mit den Schnitten soll senkrecht in der Lösung stehen. Nach dem Beizen muß sehr sorgfältig in ITasser abgespuilt werden, che man zur Färbung in Hämatoxylin schreitet. Man hat eine Lösung vorrätig von I $g$ Hämatoxylin in $10 \mathrm{ccm}$ Alkohol ron $96^{\circ}$. und $90 \mathrm{ccm}$ Aqua destillata, die mindestens + Wochen alt sein muß. Zum Gebrauch wird mit dem gleichen Volumen destillierten Viassers verdünnt. Die Färbung soll 24-36 Stunden dauern. die Objektträger müssen dabei senkrecht auf der schmalen Kante stehen, damit etwa sich bildende Niederschläge ablaufen können. Man kann NB. die einmal gebrauchte Farbflotte so oft wieder gebrauchen, bis sie verdorben ist.! In einem großen Gefäße mit Leitungswasser werden nach leendeter Färbung die Objektträger abgeschwenkt. Die Differenzierung wird in $2^{x}{ }_{2}^{0}$ 。 Eisenalaunlösung vorgenommen und behufs Kontrollierung durch das Mikroskop von Zeit zu Zeit unterbrochen. Dann wird gewaschen usw. Die Aufhellung darf nur in Xylol erfolgen. Tährend R. Krause bei dem Lack, statt wie Heidenhain mit Bordeaux, mit Säurefuchsin rorfärbt, färbt Squire mit einem Gemisch ron ()range-Säurefuchsin nach: die benutzte Lösung hat dic Formel: Süurefuchsin $\mathrm{I} g$, Orange $6 \mathrm{~g}$, Alkohol $60 \mathrm{ccm}$, Aqua destillata $240 \mathrm{ccm}$. Während die V'orfärbungen wenigstens den Sinn hahen sollen, durch die sogenannte stinktorielle Praeoccupation Unnas zu verhindern, daß die Eisenverbindung an Plasma und Chromatin geht, hat die Nachfärbung von Squire gar keinen Sinn.

Der Heiden hainsche Hämatoxylincisenalaunlack hat sich, so kann man sagen, die W'elt erobert, nicht, wie ich hinzufuigen mul3, zum Torteil der Histologie. Ohne im geringsten das Verdienst schmälern zu wollen, das sich Heidenhain mit seiner Methode erworben hat und das namentlich darin besteht, daß man mit diesem Lack ältestes Material färben kann: die Anwendung der Methode (und auch der Bendaschen Hämatoxylinlacke) hat viel mehr ideelle Nachteile als praktische V'orteile gezeitigt. Nicht bloß, daß der Lack bei allen möglichen und unmöglichen Gelegenheiten angewendet wird, nicht bloß daß er, wie vom Rath treffend bemerkt, alles gleichmäßig schwarz färbt und so eigentlich jede Unterscheidung aufhebt; sondern daß er die Kritiklosigkeit gegenüber den färberischen Resultaten geradezu züchtet: das ist der schwere Schaden, den der Eisenlack uns gebracht hat. Die meisten Mikroskopiker glauben sich berechtigt, 
aus den Ergebnissen der Differenzierung direkte Schlüsse auf lebendige Strukturen zichen zu dürfen. Die Größe der Centrosomen wird nach dem mikroskopischen Bilde beurteilt und doch wird sie bedingt durch die Dauer der Differenzierung oder, wie vom Rath meint. durch die Dauer der Beizung. IVas entfärbt ist, existiert angeblich iiberhaupt nicht; und doch handelt es sich bei den Bildern, welche man nach Anwendung der Eisenlacke des Hämatoxylins erhält, um nichts weiter als um willkïrlich unterbrochene Entfärbung. Diese kurz skizzierten Bedenken, welche vor ciner falschen Vertrauensseligkeit warnen sollen, richten sich übrigens nur gegen die Verwertung der Lacke für das Studium von Zell- und Kernstrukturen; wo dagegen nur Texturbilder in Frage kommen, können sie Ausgezeichnetes leisten.

I24. Hämatoxylineisenlack, nach Benda. Zur Beizung der Schnitte wird der Licpuor ferri sulfurici oxydati der deutschen Pharmacopoe verwendet, der entweder mit dem gleichen oder mit dem doppelten Volumen Aqua destillata verdünnt wird. Die Beizung dauert 24 Stunden. Dann wird sehr sorgfältig in destilliertem Wasser gewaschen, in gewöhnliches IVasser übertragen, damit die Schnitte alkalisch werden und sich besser in dem Hämatoxylin färben, und in $1 \%$ wässriger Hämatoxylinlösung gefärbt, bis die Schnitte schwarz sind. Nach kurzem Waschen wird in $30 \%$ Essigsäure differenziert. Wählt man eine schwächere Säure, so braucht die Differenzierung nicht uiberwacht zu werden.

125. Hämatoxylinkupferlack, nach Benda. Schnitte von Flemming-Naterial werden in gesättigter wässriger Lösung von Cuprum aceticum 24 Stunden bei Brüttemperatur oder 48 Stunden bei Zimmertemperatur gebeizt. Nach gutem Auswaschen wird in $I^{\circ}$ 。 wässriger Hämatoxylinlösung gefärbt, bis die Schnitte schwarz sind. Dann wird in Salzsäure I : 300-500 Wasser differenziert. Man muß warten, bis die Schnitte gelb geworden sind, und bringt sie dann zur Neutralisienung der Säure in dic Kupferlösung zuriick. Dann wird gewaschen, entwässert, montiert.

I 26. Weigertsche Hämatoxylinfärbung. Es ist dicse Methode eine der wertvollsten Errungenschaften zur Untersuchung des Zentralnervensystems der Vertebraten. Nach Weigerts urspringlicher Angahe sollen die celloidinierten und aufgeklcbten Objekte in toto aus dem Alkohol in cine gesättigte wässrige Lüsung von Kupferacetat kommen und darin 2ł- 2 Stunden bei Briitofentemperatur bleiben. Die gekupferten Stiicke werden gewaschen und allmählich bis zu Alkohol von $80^{\circ}$ o gebracht. Ich habe währond der letzten Jahre zahl- 
reiche nervöse Zentralorgane mit dieser Methode gefärbt und empfehle daher auf das angelegentlichste statt der Kupferung der Stücke die Kupferung der Schnitte. Man macht also die Celloidinschnittserie fertig und bringt die nach der Obregiaschen Lappenmethode aufgeklebten Schnitte in eine Lösung, die aus konzentrierter wässriger Kupferacetatlösung I Teil zu $3-4$ Teilen gewöhnlichen Wassers besteht. Darin bleiben die Schnitte 24- 48 Stunden bei Zimmertemperatur. Dann wird in gewöhnlichem Wasser gewaschen - einmal erneuern und in die Hämatoxylinlösung übergeführt. Diese wird nach Weigert folgendermaßen hergestellt: I $\mathrm{g}$ Hämatoxylin wird in $90 \mathrm{ccm}$ Aqua destillata unter Erwärmen gelöst und nach dem Erkalten mit Io ccm Alkohol von $96^{\circ}$ io versetzt. Unmittelbar vor dem Gebrauch wird auf je $100 \mathrm{ccm}$ dieses Hämatoxylins I $\mathrm{ccm}$ kalt gesättigte wässrige Lithion carbonicum-Lösung zugegeben, wodurch eine violette Farbe entsteht. Hämatein ist entschieden für diese Zwecke unbrauchbar, da der Lack in der Differenzierungsflüssigkeit zu schnell und darum unkontrollierbar sich löst. In das Hämatoxylin kommen die Schnitte für mindestens 2+ Stunden; ich habe bessere Resultate erzielt, wenn ich länger färbte, etwa bis zu 5 Tagen. Dann wird mehrere Male in gewöhnlichem Wasser ausgewaschen und in einer besonderen Entfärbungsfliissigkeit differenziert. Letztere hat folgende Zusammensetzung: Rotes Blutlaugensalz (Ferridcyankalium) $2 \mathrm{~g}$, Borax 2,5 g, Aqua destillata $100 \mathrm{ccm}$. Man muß langsam entfärben, wenn man eine gute Färbung haben will. Ich verdünne die beschricbene Blutlaugensalz-Boraxlösung im Verhältnis von I : Io mit gewöhnlichem Wasser und wechsle nach $2+$ Stunden. Nach 48 Stunden inach Beginn der Differenzierung) kann, wenn noch keine Entfärbung der grauen Substanz bemerkbar ist, dic Lösung im Verhältnis 2: 1o verdiinnt angewendet werden. Meistens kommt man mit dieser Konzentration aus, wenn man nur lange genug wartet; ich habe die Schnitte zuweilen bis 3 Wochen in dieser allerdings öfter erneuerten duinnen Entfärbungsflïssigkeit gelassen. Höher als wie 4: Io sollte man ohne Not die Konzentration nicht treiben. Doch liegt gelegentlich eine solche Not vor. Ja ich habe Naterial gehabt, das selbst bei Anwendung der vollen Konzentration sich nicht entfärbte, bei dem ich die doppelte Konzentration anwenden mußte, ehe die Differenzierung eintrat. Die Differenzierung ist beendet, wenn dic graue Substanz entfärbt, bräunlich oder gelblich geworden ist und nur die weiße Substanz blau gefärbt erscheint. Dann ist das Nervenmark der zentralen Fasern allein gefärbt und man ist dadurch in den Stand gesetzt, die Bahnen im Zentralnervensystem zu studieren. 
Die Methode ist für pathologisches Material besonders wertvoll, weil an den degenerierten Nerven das Nervenmark völlig geschwunden ist und so eventuell ein Vergleich mit der gesunden Seite angestellt werden kann. Nach beendeter Differenzicrung wird mehrere Tage lang in gewöhnlichem, häufig erneucrtem Vasser abgewaschen, damn in $96 \%$ Alkohol eingebracht und montiert.

127. Palsche Hämatoxylinfärbung. Diese Methode ist lediglich eine Nodifikation der ehen beschriebenen Weigertschen. Sie hat sich merkwüdigerweise viel Freunde crworhen, obwohl sie meines Erachtens nicht cinen einzigen Vorteil vor W Weigerts Methode voraus hat, sondern im Gegenteil, da sie mit Sekunden rechnet, dieser gegenüber entschieden die minderwertige Methode ist. Infolge der komplizierten Ausfuhrung eignet sie sich nicht zur Färbung von Schnittsericn. Dic Schnitte vom Zentralnervensystem kommen in eine Hämatoxylinlösung, die ganz wie die von Weigert empfohlene angefertigt ist, nur daß sie statt $1 \%$ bloß ${ }^{3}+$ Hämatoxylin enthält. Eine Vorkupferung findet nicht statt, daher bildet sich hier offenbar ein Chromlack. Nach beendeter Färbung, d. h. nach 5-6 Stunden doch wird man gut tun, etwa $2+$ Stunden lang zu färben -, wird in lithionhaltigem Wasser abgewaschen. Dann werden die Schnitte in r. \% Lösung von Kali hypermanganicum für 15-20 Sekunden eingebracht, damit sich hier die Oxydation des Lackes vollzicht, und kommen von da direkt in folgende Differenzierungsflissigkeit: I $g$ Oxalsäure, I g Kali sulfurosum, $200 \mathrm{ccm}$ Aqua destillata. Die Differenzierung ist beendet, wenn das Zwischengewehe entfärbt ist und die markhaltigen Nervenfasern blau hervortreten. Man kann mit Alaunkarmin nachfärben und hebt dadurch die Kerne hervor. Ich halte diese Nachfärbung für völlig überflüssig.

I28. Pals Hämatoxylin mit Safranin, nach Hermann. In platinhaltiger Lösung fixiertes Material wird in Hämatoxylin ( $\mathrm{g}$ Hämatoxylin, $70 \mathrm{ccm}$ Alkohol absolutus, $30 \mathrm{ccm}$ Aqua destillata) im Dunkeln durchgefärbt, dann ebenfalls im Dunkeln in allmählich steigendem Alkohol gehärtet und wie üblich eingebettet. Die Schnitte werden in hellrosafarbener Kali hypermanganicum-Lösung so lange belassen, bis sie selbst hellrosa geworden sind, darn fluchtig in WTasser abgespuilt, in die 5-Iofach verduinnte Palsche Entfärbungsflüsigkeit gehracht und 3-; Minuten, aber nicht länger, in Safranin nachgefärbt. 
E) Die Anilinlacke.

$\S 79$.

I 29. Tannin-Brechweinstein-Methode, nach Rawitz. Diese von mir zuerst empfohlene Nethode ist der in der Baumwollenfärberei iiblichen Verwendung der Anilinfarben nachgebildet. Sie ist nur anwendbar auf basische Aniline. Das Material muß in Flemmingscher Lösung oder in einem Chromgemische fixiert sein. Die Schnitte kommen für 24 Stunden in eine $20 \%$ Tanninlösung und bleiben darin 24 Stunden. (So starke Tanninlösungen halten sich sehr lange ganz unverändert, während dünnere sehr bald faulen.) Dann wird gut ahgewaschen und in eine $1_{10}^{\circ}-2_{2}^{1} \%$ Brechweinsteinlösung übergeführt. Hierin bleiben die Schnitte entweder bei Zimmertemperatur $2+$ Stunden lang oder bei etwa $40^{\circ}$ C. $2-+$ Stunden lang; zu letzterem Zwecke stellt man auf die Decke des Paraffinofens. Dann wird wiederum gut gewaschen und in die Farbflotte eingelegt. Man kann dazu jeden basischen Anilinfarbstoff nehmen. Von ciner gesättigten alkoholischen Fuchsinlösung z. B. macht man eine verdünnte Farbflotte; ich nehme jetzt nur sehr dïnne Lösungen, da der Endeffekt mit diesen auch bei adjektiver Verwendung ein viel besserer ist, als mit konzentrierteren Fliissigkeiten. Gefärbt wird 24 Stunden lang, dann wäscht man flichtig in Wasser ab und zieht in Alkohol von $96 \%$ so lange aus, bis keine Farbstoffwolken mehr ausgehen. Ist dann die Färbung zu intensiv geworden, dann bringt man in $2^{\mathrm{x}} \mathrm{I}_{2}^{\circ}$ 。 Tanninlösung, in der sich der Anilinlack wieder etwas löst. In diesem Differenziertannin bleiben die Schnitte nach Bedarf 2 bis 24 Stunden, dann wird gewaschen, entwässert, montiert. Wenn man von dem Anilinfarbstoff eine wässrige Stammlösung hat, so wird die Verdünnung genau in demselben Maße vorgenommen, wie bei einer alkoholischen.

Das Resultat der Färbung ist, wie ich es genannt habe, eine Inversion der Färbung. Die basischen Aniline, also die reinen Kernfarben, gehen nach der Vorbeizung in Tannin-Brechweinstein nicht mehr an die Zellkerne - weder an die ruhenden, noch an die sich teilenden -, sondern sind reine Plasmafarbstoffe geworden. Zellsubstanz, Centrosoma, Sphäre, Spindelfasern sind im Sinne des Farbstoffes gefärbt, während die Chromatinmassen braun gefärbt erscheinen. Vorbedingung ist für das Gelingen der Färbung der Chromgehalt der Fixierungsflïsigkeit. $\mathrm{Da}$ sich auch das Eiweiß mitfärbt, mit dem die Schnitte aufgeklebt sind, erscheint mir bedeutungslos. 
Diese von mir empfohlene neue Verwendung der Aniline hat in der Forscherwelt wenig Gegenliebe gefunden; dem einen schienen die Färbungen schmutzig, was nicht der Fall ist, dem anderen geniigte nicht der Endeffekt, worïber sich nicht rechten läßt. Fischer Slaubt die Methode mit der Bemerkung abgetan zu haben, daß es sich bei der von mir crzielten Inversion um eine Verstopfung handle. IV arum eine Verstopfung zur Inversion führen muß, läßt Fischer aber unerklärt und gerade in der Inversion sehe ich den Vorteil der Methode. Denn durch sie kann man ziemlich exakt die Bestandteile der Zellsubstanz zu gleicher Zeit nebeneinander sehen, was mit anderen Methoden nicht so gut sich erreichen läßt. Ich empfehle die Methode nochmals und zwar für Zellstudien; Kernteilungen werden mit ihr nicht untersucht werden können.

I 30. Zeitlinsche Modifikation. Statt der $20 \%$ Tanninlösung verwendet Zeitlin cine $10^{\circ}$ 。Tanninlösung; der er auf $100 \mathrm{ccm} \mathrm{I} \mathrm{ccm}$ Essigsäure zusetzt. Er sieht ferner einen Vorteil darin, auch Fuchsin und Safranin nicht aus alkoholischer, sondern aus wässriger Stammlösung zu nehmen. Warnen möchte ich davor, Anilinwasserlösungen der Farbstoffe zu wählen; diese geben nach meinen Erfahrungen schmierige Effekte.

\section{Z) Die Anthracene.}

$\S 80$.

I3I. Alizarin. Ehrlich war es, der zuerst die Derivate des Anthracens, die Alizarinfarben, für Lntersuchungen des tierischen Körpers verwendete. Das von ihm henutzte Alizarinblau $S$ ist allerdings wegen seiner leichten Zersetzlichkeit nicht geeignet. Anders dagegen verhalten sich die von mir zuerst verwendeten Alizarin I, RI, SDG und Alizarinorange, von denen ich hauptsächlich das von den Höchster Farbwerken in den Handel gebrachte Alizarin I empfchle. Die Alizarine werden zur Türkischrotfärberei benutzt und hodiurfen selbst hei Wolle und Seide der Vorbeizung (S 58). Die Nethode ist nach jeder Fixierung anwendbar, nur muß man stets festhalten, dal alle Chrom- und Osmiumfixierungen, weil sie die Färbharkeit der Gewebe herabsetzen, stärkerer Vorbeizen bedurfen, als die ührigen Fixierungen. Als Vorbeize verwende ich die von den Ḧ̈chster Farbwerken produzierten Chrombeizen G.। I und G. I III, welche Lösungen von chromsaurem Chromoxyd sind. G.A I enthält noch etwas salzsäure. $30 \mathrm{ccm}$ Chrombeize GA I werden mit I $j^{\circ} \mathrm{ccm}$ Aqua destillata rerduinnt und dies ist dic Stammlösung: 
Die Schnitte kommen in die verdünnte Stammlösung. Und zwar setzt man bei Chromosmiummaterial die gleiche Quantität Wasser zur Beize, bei reinem Chrommaterial das doppelte bis vierfache, bei allem anderen Material das 6- Iofache Volumen destillierten Wassers zu der Beize der Stammflüssigkeit. Gebeizt wird 24 Stunden bei Zimmertemperatur, dann wird grüdlich ausgewaschen, bis das Wasser sich nicht mehr färbt, und endlich in die Farbflottc eingebracht.

Die Höchster Alizarine kommen in Gestalt von dunkelgelben, honigdicken Pasten in den Handel mit einem I arbstoffgehalt von $20 \%$. Von dieser Alizarinpaste macht man eine $5 \%$ Aufschwemmung in destilliertem Wasser, da eine Lösung nicht stattfindet, und verdiinnt in genau derselben Weise, wic man die Beize verdünnt hat. Ferner setzt man jedesmal zur Farbflotte, bevor man die Schnitte einbringt, einige Tropfen $I{ }^{\circ}$ Lösung von Calciumacetat, da die Alizarine nur in kalkhaltigem Wasser färben. Man färbt nun $2+$ Stunden bei Bruittemperatur oder auf der Decke des Paraffinofens und bringt dann in destilliertes Wasser. Hier müssen die aufgeklebten Schnitte bewegt werden, damit die ihnen äußerlich anhaftenden Nlizarinmassen abgespiilt werden. Die Alizarine nämlich sind keine Farben wie die Aniline, sondern werden erst durch die Beize zu Farben. Was daher von der Beize nicht in Farbe umgewandelt ist, licgt als amorphe Masse auf den Schnitten auf. Nach fluichtigem Abspuilen bringt man in Alkohol ein und hier löst sich das unverbrauchte Alizarin vollkommen klar, während aus dem gefärbten Präparate keine Spur von Farbe mehr ausgeht. Die Alizarinfärbung ist also echt. Der Färbungseffekt ist ein sehr schöner, insofern Zellsubstanz und Kern in verschiedenen Farben sich voneinander abheben.

Benda hat die vorstehend geschilderte Methode durch Verwendung des alizarinmonosulfosauren Natrons modifiziert; darüber im dreizehnten Kapitel das Nähere. Sonst aber hat die Alizarinmethode wenig Anklang gefunden; sie ist offenbar zu umständlich und wegen der Unlöslichkeit der Paste in Wasser anscheinend nicht sehr reinlich. Dennoch sind meines Erachtens die mit ihr zu erzielenden Resultate - echte Färbungen, die keiner Differenzierung bediirfen - derartige, daß eine weitere Durcharbeitung der Alizarine und ihre Gewinnung fuir die mikroskopische Färberei von großem Vorteil bei Zell- und Kernstudien sein dürfte.

132. Alizarincyanin RRR doppelt. Diese von den Elberfelder Farbenfabriken in den Handel gebrachte Paste ist ebenfalls nur adjektiv verwendbar. Als Beize dient der von Benda zuerst empfohlene Liquor ferri sulfurici oxydati, der mit dem 5-2ofachen Volumen 
destillierten Wassers zu verduinnen ist. Der Grad der Terdiinnung richtet sich nach der Art der Fixierung: und die eben beim Alizarin Nr. I 3 I auseinandergesetzten Regeln finden hier wörtliche Anwendung. Die Beizung dauert 24 Stunden, dann wird wiederholt in destilliertem II asser abgespuilt und in Alizarincyanin gefärbt. Wie beim Alizarin so mache ich auch hier eine $5^{\circ}$. Aufschwemmung der Paste, die ich zum Gebrauche stark verdiinne. Zur Farbflotte wird ebenfalls etwas Calciumacetat in $I_{j}^{\circ}$ 。 Lösung zugefügt. Nan färbt in der Wärme wie beim Alizarin und behandelt überhaupt ganz wie bei jenem Iarbkörper. Der Lisenlack zeigt cine hlaue Farbe, die keiner Differenzierung bedarf und die an Flemmingpräparaten alle Einzelheiten in scharfen Nüancen unterscheiden läßt.

\section{Die vitale Färbung.}

$\$ 8 \mathrm{I}$.

Einer der ersten. welche lehende Organismen in basischen Anilinfarhen zu färhen versuchten, ist whhl Karl Brandt gewesen. Denn in den joer Jahren des vorigen Jahrhunderts hat er Actinosphaerium eichhornii mit Bismarckhraun in der Terdünung I 5000 gefärbt. Diese Tatsache, daß basische Aniline von lebenden Zellen gern und leicht aufgenommen werden, ist also relativ alten Datums. Und chenso ist die Tatsache seit langem hekannt, daß die lebende Zelle sehr schnell die Farbe wieder eliminiert.

133. Anders ist die von Ehrlich angegebene Methode der Injektion von Methylenblau. Dicser Farbstoff, wenn er intra ritam angewendet werden soll, wird nach Ehrlichs Vorschrift in eine Tene des Versuchstieres injiziert, während Semi Meyer ihn subkutan rerwendet. Die Annahme, daß es sich um cine vitale Färbung handle. hat sich als unzutreffend erwiesen. Nicht die lehendige, sondern die ahsterhende, aher noch nicht ahgestorbene Substanz nimmt das VIethyicnhlau an. Daraus erklärt es sich. daß auch Gewebe und Organe. welche aus dem Kürper herausgenommen sind, sich ebenso gut wie im? Kïrperinnern färhen, rorausgesctzt daß noch kein Zelltod eingetreten ist.

Man lüst zur vitalen Injektion I g . Vethylenblau - und zwar nimmt man am besten das Methylenblau medicinale purum, das zinkfrei ist in $30 x-400 \mathrm{ccm}$ ciner $0,5 \%$ Kochsalzlösung. Man kann in der Konzentration bis $0.1^{\circ}$, heruntergehen und bis $z u t^{\circ}$ 。aufsteigen. Die injizierten Partien sind tiefblau. Friher war die Vorschrift gegeben. die gefärbten Teile einige Minuten bis Stunden der Luft auszusetzen. 
weil man der Meinung war, daß eine gewisse Oxydierung durch den Sauerstoff der Luft zum Gelingen der Färbung nötig sei. Diese Meinung ist mit Recht preisgegeben worden. Die blaugefärbten Teile werden aus dem Körper herausgeschnitten und nach geeigneter Kompression untersucht oder man fixiert in ihnen auf gleich zu schildernde Weise den Farbstoff. Nimmt man überlebende Teile, so bringt man sie für 10 Minuten bis zu 2 Stunden in die genannte Methylenblaulösung, wäscht sie dann in $0,5^{\circ}$. Kochsalzlösung: fixiert sie und untersucht sie nach Zerzupfen, nach Ausbreiten auf dem Objektträger oder nach Schneiden in Hollundermark.

Eine für Seewasser-Crustaceen geeignete Methode der vitalen Methylenblaufärbung hat E. Holmgren angegeben. Da bei diesen Tieren die Injektion des in Seewasser gelösten Methylenblau gefihrlich ist, so läßt Holmgren Crustaceen ${ }_{2}$ Stunde in physiologischer Kochsalzlösung schwimmen und injiziert dann erst den in Kochsalz gelösten Farbstoff.

Zur Fixierung der Methylenblaufärbung - und zwar sowohl nach Injektion als auch nach Färbung uiberlebender, d. h. aus dem Kürper entfernter Teile - sind verschiedene Vorschriften angegeben.

Das Einlegen in Iloyersches Pikrokarmin wurde wohl zuerst empfohlen; das wirksame Prinzip ist darin das pilininsaure Ammoniak. Sigmund Mayer macht deshalb eine kalt gesättigte wässrige Lösung von pikrinsaurem Ammoniak (also ohne Karmin) und versetzt sic zum Gebrauche mit dem gleichen Quantum Glyzerin.

A. S. Dogiel widerrät entschieden die Anwendung von Glyzerin zur Fixierung. Er nimmt entweder nur eine wässrige Lösung ron pikrinsaurem Ammoniak oder bereitet folgende Mischung: gesättigte wässrige Lösung ron pikrinsaurem Ammoniak $100 \mathrm{ccm}$, I ${ }^{\circ}$ Osmiumsüurelösung $\mathrm{I}-2 \mathrm{ccm}$. Darin werden die gefürbten Teile i $\delta-24$ Stunden belassen. Zum Aufheben dient Glyzerin, dem etwas Lüsung von pikrinsaurem Ammoniak beigemengt ist. Durch die Fixierung wird die ursprünglich blauc Farhe rötlichbraun, rotbraun, blauschwarz und blaugriin.

Sehr kompliziert ist eine Fixierungsvorschrift von Bethe. Material von Vertebraten, das nach der Fürbung in Kochsalzlösung abgewaschen war, kommt in folgende Fixierungsfluissigkeit: molybdänsaures Ammonium I $\mathrm{g}$, Aqua destillata $10 \mathrm{ccm}$, Wasserstoffsuperoxyd I ccm, offizinelle Salzsäure I Tropfen. Der bei dem Zusatz der Salzsiure entstehende weiße Niederschlag wird durch Schuitteln gelöst. Material von Evertebraten fixiert man in: molybiün- 
saurem Ammonik I $\mathrm{g}$, Aqua destillata io $\mathrm{ccm}$, Wasserstoffsuperoxyd ${ }^{x}=\mathrm{ccm}$. Die Lösungen müssen jedesmal frisch bereitet werden, da sie sich nur 8 Tage lang halten.

Die Fixierungsflüsigheit muß auf $+2^{0}$ bis $-2^{\circ} \mathrm{C}$. abgekiihlt scin, wenn die Präparate in sie hinein kommen. Kleinere Stücke bedürfen $2-3$ Stunden, Stuicke bis zu I ccm $4-5$ Stunden zur Fixicrung des Farbstoffes. Dann läßt man sie in der Flüssigkeit noch einige Zeit bei Zimmertemperatur. Nachher wird in destilliertem Wasser -2 Stunden gewaschen, in Alkohol entwässert, der kiuhi angewendet werden muß und endlich kann in Celloidin oder Paraffin eingebettet werden. Die Anfertigung von Dauerpräparaten ist also das Resultat der Betheschen Fixierung des Methylenblau. Es dürfen mit den Präparaten keine Mineralsäuren, keine Alkalien, keine Seifen in Berührung gebracht werden. Man kann mit Alaunkarmin oder Alauncochenille nachfärben.

Wenn man Methylenblaupräparate mit Silher nachbehandeln will, so nimmt man zur Fixierungsflüssigkeit Salpetersäure statt der Salzsäure. Will man das gefärbte Material osmieren, so setzt man nachträglich, d. h. nachdem das Präparat schon einige Zeit in der Fixierungsflüssigkeit gelegen, der letzteren etwas Osmiumsäure zu. Will man statt zu härten Mazerationspräparate machen, dann nimmt man nach beendeter Fixierung Holzessig, dem man reichlich molybdänsaures Ammon beigefügt hat. Neuere Bethesche Methoden werden im zweiundzwanzigsten Kapitel beschrieben werden.

Das Resultat der Methylenblaufärbung ist sowohl nach der Injektion wie nach dem direkten Einlegen uberlebenden Materials das folgende: gefärbt sind die Achsenzylinder der Nerven der Hirnrinde, der sensiblen Nerven und der motorischen Nerven der glatten IIuskeln; alles übrige färbt sich nicht. Das Gefärbte reagiert nach Ehrlichs Meinung sauer, das Ungefärbte alkalisch; doch scheint der treffliche Gelehrte diese Auffassung nicht mehr festzuhalten.

134. Neutralrot. Das Neutralrot, das salzsaure Salz einer Farbbase, ist von Ehrlich zur vitalen Färbung der Granula empfohlen worden. Der Farbstoff löst sich in destilliertem IVasser fuchsinrot, in gewöhnlichem Wasser wegen dessen, wenn auch geringer, Alkalescenz gelhorange. Man kann ihn subkutan oder intravenös anwenden und benutzt ihn in Lösungen von I : I0000-I : I00000, damit die Zellkernc keinen Farbstoff annehmen. Froschlarven und Weichtiere kann man in diesen dïnnen Lösungen schwimmen lassen. Alle Teile sind dunleclrot, der Farbstoff ist in den Zellen an Körnchen gebunden (Farbstoffniederschläge?). Bei höheren Tieren erhält 
man auch gute Resultate durch Verfiitterung. Überlebende Teile läßt man in physiologischer Kochsalzlösung schwimmen, der eine Spur Neutralrot beigemengt ist. Für reichlichen Luftzutritt muß man sorgen. Nur die Granula sollen sich färben; die Mehrzahl ist bei den Vertebraten orangerot, die wenigsten sind fuchsinrot gefärbt. Ehrlich hält jene für schwach alkalisch, diese für schwach sauer.

\section{Neuntes Kapitel.}

\section{Die Metallimprägnation.}

$\S 82$.

Im vierten Kapitel wurde eine große Zahl von Metallsalzen angefüht, welche zur Fixierung der Gewebe und Organe sich eignen. Wenige von ihnen hatten gleichzeitig die Eigenschaft, die Teile zu färben; und wo dies der Fall war, da konnte die Färbung nicht gebraucht werden, denn eine diskrete Unterscheidung der Bestandteile eines Gewebes war nicht möglich. Anders verhalten sich die in diesem Kapitel behandelten beiden Metalle, das Gold und das Silber. Deren Salze Goldchlorid, Goldchloridkalium oder -natrium und der Höllensteinj fixieren und färben zugleich. D. h. sie verleihen bestimmten Geweben eine ganz charakteristische Farbe, wenn es sich dabei auch nicht immer um eine Färbung im eigentlichen ITortsinne handelt. Beim Silber wird wohl immer nur eine Imprägnation erfolgen; es schlägt sich das Metallsalz, indem es gleichzeitig reduziert wird, körnig auf bestimmten Teilen der Gewebe nieder, ohne in diese Teile einzudringen. Letzteres soll aber durch eine Färbung bewirkt werden. Beim Gold zeigen gelungene Präparate wohl meistens Färbung; doch da auch bei diesen Salze wie beim Silbersalze eine Reduktion eintritt, haben wir auch hier häufig genug nur Imprägnationen. Hicrin aber liegt das Unzurerlässige der von den Salzen der Edelmetalle gelieferten mikroskopischen Bilder. Denn man weiß nie und hat gar kein Kriterium in der Hand, um beurteilen zu können, ob das Metallsalz nicht reduziert wurde, weil keine reduzierenden Gewebsbestandteile vorhanden waren, oder ob durch irgendwelche Imponderahilien die Reduktion trotz vorhandener Teile ausgeblieben ist. Und des Ferneren hann man nicht mit positiver Bestimmtheit behaupten, da 3 
ein Reduktionsbild entstanden ist, weil ein Gewebsbestandteil vorhanden ist, denn die Möglichkeit, daß zufällige Reduktionen Täuschungen hervorrufen, kann nicht ausgeschlossen werden. In unserer Zeit, wo Silberlösungen zum Nachweise intrikatester Strukturen verwendet werden, sei die historische Erinnerung aufgefrischt, daß der Physiologe Brücke mit Höllensteinlösungen die Endothelzeichnung auf rein en Objektträgern hervorgerufen hat. IVürden wir Ganglienzelle und Nerv nicht längst durch die Färbungsmethoden kennen gelernt haben: die Versilberung, namentlich nach der Golgischen Methode, hätte uns nie gezeigt, was eine Ganglienzelle ist. Und ebenso steht es im großen und ganzen mit der Vertrauenswürdigkeit der Goldlösungen. Darum glaube ich zum Mißtrauen gegenüber den Metallimprägnationen raten zu müssen. An Material, dessen Textur und Struktur wir in seinen Grundzügen kennen, werden sie manche neue Einzelheiten zur Erscheinung bringen: aber eben nur Einzelheiten an bekannten Strukturelementen. Ob dagegen neue Strukturbilder, welche uns das Mikroskop zeigt, wirklich Strukturelemente darstellen, ist sehr fraglich, wenn wir unsere Erkenntnis nur den Metallsalzen verdanken. Die erstaunliche Kritiklosigkeit, mit der manche Autoren die Ergebnisse der Metallimprägnationen aufnehmen, ist beinahe so groß wie die Launenhaftigkeit dieser Methoden.

Die Goldlösungen haben vor den Silberlösungen den Vorzug, mehr in die Tiefe zu dringen und dabei nicht bloß zu fixieren, sondern auch etwas zu härten. Den Silberlösungen eignet dagegen eine größere Reduktionsfähigkeit und daher eine größere Umfänglichkeit der hervorgebrachten Bilder.

Als drittes Metall führe ich Eisen an. Die interessanten und ingeniösen Methoden von Theodor List, welche bei weitem nicht die ihnen gebührende Beachtung seitens jener Forscher gefunden haben, die iiber Zellstrukturen arbeiten, lehren, daß es sich dabei um wirkliche Färbungen handelt. Sonach hätten diese letzteren Methoden eigentlich im vorigen Kapitel aufgeführt werden müssen. Aber da keine Farbkörper bei ihnen zur Anwendung kommen, so müssen sie in diesem Kapitel Unterkunft finden.

Die Methoden der Vergoldung.

$\$ 8 \hat{\jmath}$.

Nan kamn Goldlösungen auf frische und auf bereits fixierte Gewebe einwirken lassen. Dic erstere Anwendungsweise nennt man nach Apathy Vorvergoldung; die letztere Nachvergoldung. Die Resultate 
sind bei beiden Methoden grundverschieden. Bei der Vorvergoldung färbt sich das Plasma der Zellen dunkelrot oder violett, der Kern gar nicht, die Nervenfasern werden dunkelrot oder violett. Bei der Nachvergoldung färbt sich das Plasma wenig, der Kern intensiv und an den Elementen des Nervensystems treten spezifische Details hervor. Des letzteren Umstandes wegen soll die Nachvergoldung erst im zweiundzwanzigsten Kapitel beschrieben werden; hier soll nur die Vorvergoldung abgehandelt werden. Auch diese eignet sich in erster Linie für die Untersuchung der peripheren Nerven und ihrer Endigungen.

Hauptsächlich wird Goldchlorid verwendet; doch unterscheiden sich Goldchloridkalium und Goldchloridnatrium von jenem in ihren Wirkungen nicht.

I. Vergoldung, nach Cohnheim. Der große Pathologe Cohnheim war der erste, welcher das Goldchlorid in die mikroskopische Technik einführte; J. Gerlach hat dann das Goldchloridkalium empfohlen. Nach Cohnheim verfährt man folgendermaßen: Ganz frische Objekte werden in $I_{\%}$ Goldchloridlösung is Minuten bis ${ }_{12}$ Stunde eingebracht und ins Dunkle gestellt. Sind sie strohgelb geworden, dann ist die Imprägnation beendet, man wäscht in destilliertem Wasser ab und bringt zur Reduktion in Wasser, das mit einigen Tropfen Essigsäure oder Ameisensäure angesäuert ist. Zur schnelleren Reduktion kann man auch die Prichardsche Mischung verwenden: $1 \mathrm{ccm}$ Amylalkohol, I ccm Ameisensäure, $98 \mathrm{ccm}$ Wasser. Die Reduktion muß im diffusen Tageslicht erfolgen; man hat dafür zu sorgen, daß das Licht von allen Seiten an das vergoldete Material herankann. Ist letzteres rot oder violett geworden, wozu stets mehrere Tage erforderlich sind, dann ist die Reduktion beendet. Man kann nun, nach gutem Auswaschen, entweder in Glyzerin zerzupfen und darin einschließen, oder man härtet nach dem Auswaschen in Alkohol von steigender Konzentration. Aus der Goldlösung darf man die Objekte nicht mit Metallinstrumenten herausnehmen, da diese schwarz werden und zugleich das Reagens verderben.

2. Vergoldung, nach Löwitt. Ist besonders zur Untersuchung quergestreifter Muskeln geeignet. Man bringt kleine Stiicke des frischen Materials in eine Mischung von I Teil Ameisensäure und 2 Teilen Aqua destillata und läßt sie darin I Minute. Darauf überträgt man in eine kleine Quantität $1 \%$ Goldchloridlösung, bis das Naterial gelb geworden ist; dazu sind 5- Io Minuten erforderlich. Nachher wird in dünner Ameisensäurelösung ausgewaschen, dann in konzentrierte übertragen und für I Tag ins Dunkle gestellt. Man untersucht in Wasser oder in verdünntem Glyzerin. 
3. Vergoldung, nach Ranvier. Zur Untersuchung der Cornea. Frisch alggetragene Cornea wird für 5 Minuten in frisch gepreßten und filtrierten Zitronensaft gebracht, dann für 20 Minuten in $\mathrm{I}^{\circ}$.。 Goldchloridlösung (mindestens $3 \mathrm{ccm}$ für jede Cornea) eingelegt und wird dann in $30 \mathrm{ccm}$ Wasser, dem 2 Tropfen Essigsäure beigenengt sind, dem Lichte ausgesetzt. Die Reduktion ist nach etwa $3-4$ Tagen heendet. Nach gutem Auswaschen wird in Alkohol von steigender Konzentration erhärtet.

4. Vergoldung, nach Marinescu. Sie ist als Modifikation der vorigen zu betrachten, ist aber nicht auf die Cornea beschränkt. Man zerlegt Teile des zu vergoldenden Materials longitudinal zum Nervenverlaufe. Die so erhaltenen Organpartikel werden Io-I5 Minuten in frisch bereiteten filtrierten Zitronensaft eingelegt, kurz gewaschen, mit Glasnadeln in Wasser etwas zerzupft und in $0,5 \%$ Goldchloridkaliumlösung übertragen. Hierin bleiben sie 20 Minuten im diffusen Tageslicht, bis sie gelblich geworden sind. Sie werden während dieser Zeit leicht in der Goldlösung bewegt, in destilliertem Wasser, ebenfalls unter Bewegung, leicht abgewaschen und in ein Gemisch von Ameisensäure I Teil mit Glyzerin 10 Teilen übertragen. Im Dunkeln und im Britofen bei $27^{\circ} \mathrm{C}$. wird die Reduktion vorgenommen; diese gilt als beendet, wenn das Glyzerin violett gefärbt ist, wozu einige Tage bis 2 Monate erforderlich sind. In Glyzerin wird zerzupft und aufgehoben.

5. Vergoldung, nach Flemming. Diese Nethode ist zur Vergoldung von Organen der Mollusken cmpfohlen, die im allgemeinen etwas schwer permeabel sind. Man legt die frischen Objekte für I Stunde in $0,1 \%$ Salzsäurelösung, bringt sie dann in ${ }^{\mathrm{r}} \%$ \% Goldchloridlösung bis zu I 2 Stunden und reduzicrt im Licht in Vasser, das mit Essigsäure ein wenig angesäuert ist. Dann wird in Alkohol von steigender Konzentration erhärtet.

6. Vergoldung, nach Golgi. Frisches Material kommt ${ }^{\mathrm{I}} / 4^{-}{ }^{\mathrm{I}}$ : Stunde lang in Arsensäurelösung von $1 / \%$, dann wird kurz in Wasser abgeraschen und in Goldchloridkaliumlösung von I \% auf solange cingebracht, bis alles gelb ist. Die Reduktion findet im Sonnenlichte in $1 \%$ Arsensäurelösung satt.

7. Vergoldung, nach Retzius. Bei dieser Methode findet cine Osmierung der Präparate statt, ehe sie dem Golde ausgesetzt werden. Man legt in 0,5 () smiumsäurelösung für ${ }^{I}$. Stunde ein, wäscht in Wasser aus und hringt wiederum für ${ }^{\text {If }}$. Stunde in ${ }^{\mathrm{I}}=$ ?. Goldchloridlösung. Dann wird $2+$ Stunden in 2\% Ameisensäure zur Rcdultion belassen. 
8. Vergoldung, nach Apáthy. Frische Objekte kommen auf mindestens 2 Stunden in Goldchloridlösung und werden ins Dunkle gestellt. Dünne Membranen, die aufgespannt werden mïssen, bleiben über Nacht in der Goldlösung. Dann wird das Material direkt für 24 Stunden in verdünnte Ameisensäure $\left(\mathrm{I}^{\circ}{ }^{\prime}\right.$ ibertragen und gut durchlichtet 'vgl. auch zweiundzwanzigstes Kapitel). Nach 6-8 Stunden, während welcher event. bereits dunkel gewordene Reduktionsfliissigkeit durch frische zu ersetzen ist, ist die Reduktion beendet. Man iiberträgt dirckt in Gummisirup oder in konzentriertes Glyzerin. Es lassen sich auch in ${ }^{5}$ Alkohol mazerierte Objekte auf diese Weise vergolden.

\section{Die Methoden der Versilberung.}

\section{$\$ 84$.}

Das ausschließlich angewandte Silbersalz ist das salpetersaure Silber, der Höllenstein. Dieses Salz eignet sich nicht bloß für nerröse Elemente, sondern ist auch ein nahezu souveränes Nittel zur Sichtbarmachung der Grenzen der Endothelzellen. Bei den Endigungen der peripheren Nerven versagt es, wann man es nicht nach der Golgischen Vorschrift anwendet.

9. Versilberung, nach Ranvicr. Man verwendet Lösungen von $0.2^{\circ}-2^{\circ}$. Frische Objekte werden für I Stunde in die Höllensteinlösung eingebracht und nach kurzem Abwaschen in destilliertem Wasser zur Reduktion 24-48 Stunden dem Tageslichte ausgesetzt. Dabei verweilen sie ebenfalls in destilliertem Wrasser. Nan muß sich hüten, gewöhnliches Wasser zu nchmen, da sich in diesem Chlorsilber ausscheidet und so die Bildung des braunen Silberalbuminates verhindert wird. In verdünntem Glyzerin wird zerzupft und aufgehoben. Die fertigen l'räparate müssen im Dunkeln gehalten werden, weil sonst die Reduktion weiter geht und diffus wird.

Io. Versilberung, nach Deckhuyzen. Frisches Aaterial wird in

Lösung von Kalisalpeter abgespuilt, dann in $0,25^{\circ}$ 。 Höllensteinlösung gebracht, die $3 "$ "Salpetersäure zugesetzt erhält. Nach cinigen Ninuten führt man in $96 \%$ Alkohol ïber und aus diesem in Nelkenöl. In letztercm tritt die Reduktion ein. Nachfärbung der Kerne in Alaunhämatoxylin, Safranin oder Methylgrün.

II. Versilberung, nach Golgi; die Golgische Chromsilbermethode. Diese Methode ist in erster Linie zum Studium des Zentralnervensystems bestimmt. Sie hat aber so vielfache anderweite Verwendung gefunden, z. B. für Nervenendigungen, zur Darstellung des bindegewebigen Stroma mancher Organe, zur 
Erkenntnis dur sogenannten Sekretkapillaren usw, daß sie als eine allgencin anwendbare Methode betrachtet werden kann und daher im ersten Teil ihren Platz finden muß. Das Gleiche gilt von den 3 Modifikationen, die hier aufgezählt werden. Die rein speziellen Vorschriften sollen im zweiten Teil beschrieben werden.

Die Vorschrift von Golgi lautet: $I-I^{I}$ a $\mathrm{ccm}$ große Stiicke ron Zentralnervensystem (event. ron den zu versilbernden Organen) werden in Müllerscher Lösung oder in Kali bichromicum-Lösung ron $2^{\circ}$, fixiert. Die Konzentration des letzteren Reagens muß schnell bis auf $5^{\circ}$ o erhöht werden. Die Objekte bleiben I4-50 Tage in der betreffenden Lösung, und zwar in der warmen Jahreszeit kiirzere, in der kalten längere Zeit. Dann wäscht man sie in ganz dünner Höllensteinlösung kurze Zeit und bringt sie in eine große Menge von 0,75\%' bis $I^{\circ}$ "Lösung von Argentum nitricum. In der ersten Zeit muß diese häufig emeucrt werden. Die Objekte können in der Silberlösung dem Lichte ausgesetzt werden, man kann sie aber auch im Dunkeln lassen; für die Bildung des Chromsilberniederschlages ist dies ganz irrelevant. Nach 2, 3 oder $\delta$ Tagen oder nach noch längerer Zeit wird direkt, nach kurzem Einbringen in $50^{\circ}$. Alkohol, unter $\mathrm{CO}^{\circ}$. Alkohol geschnitten; oder man bringt in absoluten Alkohol, taucht in Celloidin ein, härtet dieses in iblicher ITeise und schneidet. Die Schnitte müssen sehr dick, $40-60 \mu$, sein, sonst bekommt man unzusammenhängende Bilder.

Das durch die Verbindung des Chromsalzes mit dem Höllenstein entstandene Chromsilber schlägt sich hauptsächlich auf Ganglienzellen und Nerven nieder, imprägniert aber auch das parenchymatöse Gewebe von Drüsen, die Neuroglia usw. Hierin und in der Lnzurerlässigkeit der Mtcthode liegt ihr Hauptnachteil. Sie schwärzt gleichmäßig Nerven- und Bindegewebe, so daß man zur Unterscheidung beider nur subjektive Kriterien hat. So läßt sich der Neurit rom Dendrit nur dadurch unterscheiden, daß ersterer glatte Konturen, letzterer dasegen unregelmäßige rauhe Konturen besitzt. Dic Unzurerlässigkeit der Methode besteht darin, daß man nie sicher ist, wirklich brauchbare Bilder zu erhalten. Denn bald liefert sie glänzende Resultate, balc lälst sic völlig im Stich und es ist gar nicht einzusehen, warum hier Erfolg, dort Mißerfolg eintritt. Das Chromsilber liefert keine Färbung, denn immer handelt es sich bei dem Zentralnervensystem um einen kömigen Silberniederschlag in den Lymphbahnen der Zellen und Fascrn, bein Bindegewebe um einen solchen auf der Fibrille. Hat man mit Formol-Kali bichromicum vorbehandelt (rgl. viertes Kapitel, dann imprägnicren sich auch in ausgedehntem Grade die Blut- 
gefäße. Es imprägnieren sich auch nicht alle in einem Rückenmarkschnitt vorhandenen Ganglienzellen, sondern nur wenige, wodurch zwar die Übersichtlichkeit erleichtert wird, von Naturtreue aber natuirlich nicht mehr gesprochen werden kann.

Gelungene Golgipräparate zeigen in vortrefflicher IVeise die Ramifikationen der Dendriten, die Schicksale bzw. den Verlauf der Neuriten usw., und durch Kombination verschiedener Schnittbilder kann man zu einem Verständnis der Textur des betreffenden Organes gelangen. Immer aber muß man daran denken, daß die Chromsilbermethode nicht bloß Teile sichtbar macht, sondern auch, wo sie keine Niederschläge gebildet, Teile verschwinden läßt. Nan kann nicht durch Nachfärbung der Schnitte diesem Übelstande begegnen, denn wässrige Farblösungen dürfen an Golgimaterial nicht herankommen, weil das Chromsilber sich in Wasser sehr leicht löst. Eine große Zahl der Neurologen arbeitet nur mit dieser Methode, leider nicht immer mit der nötigen Kritik und dem nötigen Mißtrauen gegen die Resultate.

12. Chromsilbermethode, nach Fusari. Diese Modifikation, für das Gehirn der Knochenfische angegeben, besteht im wesentlichen darin, daß zur Müllerschen Flüssigkeit Osmiumsäure zugesetzt wird. Man verfährt folgendermaßen: Kleine Organteile werden für 2 Tage in Muillersche Flüssigkeit gebracht, die mit ${ }_{3}{ }_{3}$ ihres Volumens Wasser verdiunnt ist. Dann wird für 2 Tage in reine Müllersche Lösung (gleiches Quantum Fliissigkeit wie zuerst), für weitere 2 Tage in ${ }^{4} / 5$ Müller $+{ }^{r} / 5$ Osmiumsäure $I^{\circ}$ 。 und schließlich in $0,75^{\circ}$. Höllensteinlösung gebracht.

I3. Chromsilbermethode, nach Ramòn y Cajal. Hier wird von vornherein Osmiumsäure angewandt. Man legt für mehrere Tage in eine Mischung von 8 Teilen $2^{\circ} \%$ Kali bichromicum + I Teil $1^{\circ} \%$ Osmiumsäure. Dann Überführen für 2 Tage in ${ }^{2} / 2 \%$ - $1 \%$ Lösung von Argentum nitricum und Veiterbehandlung wic bei der ursprünglichen Golgischen Methode.

I +. Chromsilbermethode, nach Köllicker. Man härtet in einem Gemisch, welches aus gleichen Teilen einer $3 \%$ Lösung von Kali bichromicum und einer $I^{\circ}$ 。Osmiumsäure besteht. Kurz nach dem Einbringen in das Reagens soll die Mischung erneuert werden; dann bleiben die Objekte $24-36$ Stunden darin und werden jetzt in $\%$ \% Argentum nitricum ausgewaschen, und zwar ${ }_{1 / 4}-{ }_{i}$. Stunde. Sodann wird in sehr viel $0,75^{\circ}$ : Lösung von Argentum nitricum für 30 bis t\& Stunden eingelegt. Nachhärtung und Celloidinierung wie bei der ursprünglichen Methode. 
Es gilt als Regel für alle Golgischen Methoden, daß die Schnitte nicht mit einem Deckglase bedeckt werden dïrfen.

Die Verwendung des Eisens.

$$
\$ 85 \text {. }
$$

I5. Berliner Blaufärbung, nach List. Die geistreichen Methoden, welche List ersonnen hat und die besonders beim Studium der Kernbestandteile sich wirksam zeigen, sind ron den Zellforschern nicht in dem Maße beachtet worden, wie sic es verdienen. Es sind drei Methoden, nach welchen das Eisen, das wirklich färbt, angewendet werden kann.

Die Methode I besteht darin, daß man zunächst auf einen Schnitt (Sublimatmaterial) 2 Tropfen einer $1,5^{\circ}$ 。 Lösung des gelben Blutlaugensalzes (Ferrocyankalium; 5 Ninuten lang cinwirken läßt. Dann gießt man $a b$ und setzt $\mathrm{I}-2$ Tropfen einer $\mathrm{I} \%$ Salzsäure zu. Vorbedingung für das Gelingen der Reaktion ist, daß der Schnitt mit der Luft in Berührung bleibt.

Bei der Methode II wird etwas anders verfahren. Die Schnitte werden mit Whasser aufgeklebt und fuir ${ }^{{ }^{1}}, 2$ Stunde in folgendes Eisenbad gebracht: Io Tropfen einer $0,5^{\circ}$. Eisenchloridlösung $0,5 \mathrm{~g}$ an der Luft zerflossenen Eisenchlorids wird in Ioo ccm Aqua destillata gelöst), 5 Tropfen $I^{\circ}$ 。 Salzsäure und $50 \mathrm{ccm}$ destilliertes Wasser. Dann tüchtig in destilliertem Wasser abspiilen, 2 Tropfen einer I, $5 \%$ Ferrocyankaliumlösung für 5 Minuten auf jeden Schnitt bringen, abgießen und 2 Tropfen einer I ${ }^{\circ}$. Salzsäure zusetzen. Die Reaktion tritt augenblicklich ein.

Die Methode III unterscheidet sich von II dadurch, daß in dem Eisenbad 15 Tropfen $I^{\circ}$. Salzsäure enthalten sind und nicht blok 5 Tropfen. Dadurch werden die Nebennucleolen besonders intensiv gefärbt.

\section{Zehntes Kapite1.}

\section{Injizieren.}

$\S 86$.

Um die Verteilung der Blutgefäße in einem Organ, um die Anordnung der Lymphbahnen zu studieren, vor allem um festzustellen. ob wir allenthalben cincn geschlossenen Kreislauf vor uns haben, oder 
ob die kanalartigen Blutbahnen eine Unterbrechung zeigen: zur Lirledigung all dieser und ähnlicher wichtiger Probleme muissen wir Blutund Lymphbahnen kïnstlich sichtbar machen, dadurch daß wir sie in bestimmter Weise farbig anfuillen. Diese Anfuillung nennen wir die Injektion oder das Injizieren. Wohl könnte man gelegentlich sich mit der sogenannten natiirlichen Injektion begnügen. Tiere nämlich, welche durch Erstickung eingegangen sind, zeigen eine pralle Füllung der Blutgefäße bis in die feinsten hapillären Verzweigungen. Aber erstens kann man nicht immer und nicht ausschließlich erstickte Tiere verwenden, und zweitens geschieht es nur allzuoft, daß bei Fixierung, Härtung und Färbung die roten Blutkörperchen cntfärbt werden. Dann ist natürlich der Wert der natülichen Injektion illusorisch.

Das Studium der künstlich injizierten Organe ist sehr wichtig und hat in der Histologie der Vertebraten sehr bedeutende Ergebnisse gezeitigt. Unser Verständnis für den eigentümlichen Bau der Leber; unsere Einsicht in die Funktion der Niere usw. haben wir nur den künstlichen Injektionspräparaten zu verdanken. Es ist sehr zu bedauern, daß bei den Evertebraten, wo die technischen Schwierigkeiten allerdings sehr viel größer sind als bei den Vertebraten, die Verwendung von Injektionen nicht einen ähnlichen Umfang angenommen hat wie in der Wirbeltierhistologie. Nianches Problem harrt dort noch der Lösung durch die Injektion.

\section{$\S 87$.}

Die Injektion der Blutbahnen ist technisch gänzlich verschieden von der der Lymphbahnen. Bei ersterer kann man das Organ von der Arteric oder ron der Vene oder auch ron beiden Gefäßen aus zu glcicher Zeit injizieren. Wie immer man verfahren möge, zunächst müssen die Blutbahnen gereinigt werden. Damit nicht die injizierte Fluissigkeit auf ein postmortal entstandenes Blutgerinnsel trifft - dadurch würde eine gleichmäßige Injektion verhindert, ja es könnte durch den plötzlich auftretenden Widerstand die Injektionsmasse in falsche Bahnen gedrängt werden -, ist stets die gesamte Blutbahn des Organs mit $0,75^{\circ}$. Kochsalzlösung zu durchspülen. Man injiziert mit dieser Lösung ron der Arterie aus so lange, bis aus der Vene klare Flüssigkeit austritt. In das Gefäß, von welchem aus die Injelition vorgenommen werlen soll, bindet man luft- und wasserdicht eine Kanüle ein. Diese kann von Metall sein, wie dies bei den käuflichen Spritzen der Fall, nder man bedient sich einer Glasröhre, deren eines Ende am Glasblaseapparat in eine feine Spitze ausgezogen ist. Hat man die Kaniile eingebunden, so muß man noch sorgfältig L'm- 
schau halten, ob nicht ron dem zu injiziercnden Hauptgefäß Seitenäste abgehen, welche die Injektionsmasse nach falschen Stellen hinlenken hönnen, oder welche, falls sie abgeschnitten sind, einen Austritt der Masse ins Freic bewirken würden. Derartige Seitenäste sind sorgfältig zu unterbinden.

Ist die zu injizierende Masse nur in der IVärme flüssig. dann müssen die Spritze wie die Kanüle warm gehalten werden und das betreffende Organ muß in warmem Wasser liegen. Aus leicht erklärlichen Gründen; denn kalte Instrumente würden die Injektionsmasse zu früh zur Erstarrung bringen. Sind dagegen die Injektionsmassen kaltflüssig, dann sind derartige Torsichtsmaßregeln unnötig: Nur dafür ist in diesem Falle zu sorgen, daß das Organ, welches injiziert werden soll, nicht während der Injektion vertrocknet.

Ist die Kaniile eingebunden, die Spritze mit der Injektionsmasse gefüllt und in die Kanüle gesteckt, dann wird der Stempel der Spritze langsam, kontinuierlich und unter stets gleichem Drucke so lange vorgeschoben, bis die Injelition beendet ist. Dies erkennt man daran, daß das Organ sich gleichmäßig im Sinne der farbigen Injektionsmasse gefärbt hat. Sollen Arterie und T'ene gefuillt werden, so muß man natürlich zwei verschicden gefärbte Injektionsmassen nehmen. Diese kann man gleichzcitig, indem man zwei Kanülen - in jedes Hauptgefäß eine - einbindet und zwei Spritzen nimmt, mit der Injektionsmasse anfillen, oder man injiziert erst von dem einen und dann von dem anderen Gefäße aus. Sorgfailtig ist beim Einbinden der Kanule und heim Befestigen der Spritze darauf zu achten, daß nirgends eine Luftblase sich findet. Denn eine solche wiirde, wie ein Blutgerinnsel, die gleichmäßige Anfüllung der Gefäße verhindern.

Da bei Benutzung der mit der Hand zu entleerenden Spritzen die Druckintensität trotz größter Sorgfalt und langer Übung sich zuweilen andert, so daß cine ungleichmäßige Füllung der Blutgefäße erfolgen muß, so bedient man sich besser eines Apparates zur Injektion unter konstantem Druck. Namentlich bei kaltflüsigen Nassen ist cliese Methode sehr zu empfehlen. Man verfährt dabei folgendermaßen:

Nan besorgt sich zwei große Flaschen, dic mindestens I Liter Inhalt haben, und verschließt jede mit einem doppelt durchbohrten Kork. Die cine Flasche wird mit der Injektionsmasse gefült; in das eine Loch des zugehörigen Korkes steckt man eine bis auf den Boden reichende Glasröhre, welche man an ihrem freien Ende rechtwinklig gebogen hat, und befestigt an diesem einen langen Schlauch, in den die Injektionskaniile gesteckt ist. In das zweite Loch des Korkes 
hommt eine doppelt knieförmig gebogene Glasröhre, deren untere Öffnung dicht am Ende des Korkes sein muß, jedenfalls die Injektionsmasse nicht berühren darf. Das noch freie Ende der doppelt gebogenen Röhre kommt in das eine Loch des Korkes der zweiten Flasche und darf hier ebenfalls nur bis an die untere Korkfläche reichen. In die zweite Korköfnung der zweiten Flasche kommt ein mit einem Trichteransatze rerschenes, sehr hohes und nicht zu weites Glasrohr, das bis auf den Boden der Flasche reicht und das man in geeigneter W'eise in lotrechter Stellung festhalten muß. Diese zweite Flasche ist nämlich der Windkessel: denn gießt man nunmehr in den Trichteransitz des lotrechten Rohres Quecksilber, so läuft es in den IVindkessel und trcibt hier die Luft in die doppelt lnnieförmig gebogene Röhre hinein. Diese führt sie in die Flasche mit der Injektionsmasse und dadurch wird letztere, wie ohne weiteres hlar, in die Kanïle gedriicht.

Einfacher verfährt man nach Paul Mayer in folgender Weise: Die zweite Flasche, den Windkessel, nimmt man schr groß - etwa Io Liter fassend --, verbindet sie ganz wie bei der vorigen Methode mit der Injektionsflasche und bringt durch die zweite Korköfnung ein Rohr, das in den Schlauch cines Doppelgebläscs gesteckt wird. Durch fortgesetztes Zusammendriiclien des Gummiballes des letzteren wird die Luft im Windkessel komprimiert und tritt damn in dic Injektionsflasche über, aus der sie die Injektionsfluissigkeit austreibt.

Anders verfährt man bei der Lymphgefäßinjektion; hierbei bedient man sich des Einstichverfahrens. Mit einer Staarnadel oder einer feinen Scherenspitze, dic beide in die Injektionsmasse getaucht sein müssen, macht man eincn kleinen Einstich in das Organ. In die Öffnung, welche sich als gefürbter l'unkt darstellt, schicbt man die Kaniile vorsichtig ein, verbindet mit der Spritze und injizicrt. Gelegentlich genïgt auch die Einfuihrung der Kanüle einer Pravazschen Spritze und die Injektion mit dieser, wenn die zu injizierende Partie klein ist.

Hat man injiziert, dann erst darf man härten. Am besten geschieht dies in absolutem Alkohol, denn auf feinere Fixierungsmethoden wird man verzichten miissen, weil diese leicht die Injektionsmassen und Injelitionsfarben angreifen kömnen. Die Art der Finbettung des injizierten Materials ist gleichguiltig; ob diche oder duinne Schnitte anzufertigen sind, hängt von den zu untersuchenden Objekten ab; Niere z. B. wird dicke, Leber wird dünne Schnitte verlangen. Eine Nachfärbung der Schnitte, eventuell auch der Stiiclie, wird am rorteilhaftesten in solchen Farblösungen vorgenommen, welche eine Kontrastfärbung zur Injektionsmasse haben. Und man tut gut, sich auf 
einfache Kernfärbemittel zu beschränken, um nicht ein allzu buntes Bild zu erhalten und um ferner nicht durch komplizierte Methoden die Injektion zu gefährden.

Nan unterscheidet zwei Hauptarten der Injektionsflüssigkeiten: crstarrende und nicht erstarrende; und die ersteren teilt man, wie rorher schon angedeutet wurde, in warme und kalte Massen ein. Aus dieser Einteilung ergibt sich die Disposition für die nun folgende Aufzählung der Injektionsmassen ron selber. Von warmen Massen existieren zahlreiche Vorschriften; ich führe nur die folgenden drei an, die ich nach Frey »Das Mikroskop usw.« zitiere.

a) Erstarrende Massen.

a) Warme Injektionsmassen.

$\S 88$.

I. Rote Masse, nach Gerlach. $5 \mathrm{~g}$ feinsten Karmins werden in $4 \mathrm{ccm}$ Wasser und $\mathrm{x} / 2 \mathrm{ccm}$ Liquor ammonii caustici gelöst. Die Lösung bleibt mchrere Tage in nicht zu fest rerschlossenem Gefäße stehen und wird dann in eine konzentrierte Lösung feinster weißer Gelatine eingetragen. Dic Gelatinelösung bercitet man sich, indem man $6 \mathrm{~g}$ Gelatine in $80 \mathrm{ccm}$ Wasser in der Wärme löst. Hat man Karmin- und Gelatinelösungen durch L'mrïhren vereinigt, dann neutralisiert man durch Zusatz einiger Tropfen Essigsäure. Zur Injektion muß man die Masse auf $40^{\circ}-45^{\circ} \mathrm{C}$. erwärmen.

2. Blaue Masse, nach Harting. I Teil Oxalsäure wird im Mörser zerrieben und dann I Teil Berliner Blau zugesetzt. Unter stetem Umruhren werden I 2 Teile Vasser zugefügt und der Lösung I 2 Teile warmer Gelatinelösung beigemengt.

3. Gelbe Masse, nach Thicrsch. Ton einer wässrigen Lösung (I : I I, ron einfach chromsaurem Kali wird I Teil mit + Teilen einer konzentrierten Gelatinelösung vermischt. 2 Teile einer wässrigen Losung (I : I I) ron salpetersaurem Bleioxyd mischt man mit + Teilen konzentrierter Gelatinelösung. Bei $25^{\circ}-32^{\circ} \mathrm{C}$. werden beide Lösungen vorsichtig und unter beständigem Umrühen miteinander vermischt und nach geschehcner Vercinigung etwa I Stunde lang auf dem IVasserbade auf $70^{\circ}-100^{\circ} \mathrm{C}$. erhitzt. Das so entstandene transparente Gelb wird durch Flanell filtriert.

B) Kalte Injektionsmassen.

$$
\S 89 .
$$

4. Blaue Masse, nach Tandler. $5 \mathrm{~g}$ möglichst salzfreier Gelatine werden in IOO ccm Aqua destillata zum Quellen gebracht und 
dann leicht erwärmt. Der geschmolzenen Gelatine wird Berliner Blau zugesetzt und zwar nach Bedarf, d. h. je nachdem, ob man dunkle oder weniger dunkle Injektionen haben will. Dann trägt man langsam 5-6 $\mathrm{g}$ Jodkalium ein, um die Erstarrung der Masse bei gewöhnlicher Temperatur zu verhüten. Ist die Masse bei $7^{\circ} \mathrm{C}$. nicht mehr dünnflissig, so muß man noch etwas Jodkalium hinzufügen. Zur Verhütung der Fäulnis bringt man in die Injektionsmasse einige Thymolkristalle und hebt sie in einer Flasche mit Glasstöpsel auf. Sie hält sich monatelang. Nach der Injektion wird das Organ in $5^{\circ}$. Formollösung konserviert. Dadurch wird die Gelatine unlöslich gemacht; man kann sogar entkalken, ohne daß die Farbe der Gelatine sich ändert oder daß die Gelatine angegriffen wird. Tandler enthallt in schwefliger Säure.

5. Transparente Ölmasse, nach Hoyer. Zur Injektion von Milzgefäßen empfohlen eignet sich diese Vorschrift sicherlich auch für alle anderen Organe. $5 \mathrm{~g}$ Ölfarbe werden mit $5 \mathrm{~g}$ eingedicktem Leinöl in einer Reibschale zerrieben; dann setzt man allmählich etwa $30 \mathrm{~g}$ eines in Alkohol leicht löslichen ätherischen $\ddot{j}$ les zu Lavendelöl, Fenchelöl, Thymianöl, Rosmarinöl. Die so erhaltene Nasse wird in ein weithalsiges Glasgefäß mit gut schließendem Stöpsel eingefüllt und $12--2+$ Stunden in Ruhe gelassen. Man gießt vom Bodenrüchstand rorsichtig ab und hat nun eine unbegrenzt haltbare, leicht injizierbare Masse. Man injiziert und härtet darauf $2+$ Stunden in absolutem Alkohol. Durch letzteren wird das ätherische Öl gelüst und der Farbstoff an der Gefäßinnenwand niedergeschlagen. Mit dem so injizierten Organ kann man nun alle möglichen Prozeduren anstellen.

0. Rizinusölinjektion, nach Altmann. Man injiziert mit einem Gemisch aus 2 Teilen Rizinusol und I Teil Alkohol. Membranen sowie dünne, leicht permeable Objekte werden sofort für $\mathrm{I}-2$ Tage in $\mathrm{I} \%$ Osmiumsäure eingelegt. Dicke Organe läßt man zunächst gefrieren, damit das $\dddot{O} 1$ nachher beim Zerteilen nicht ausfließt, und zerlegt die gefrorenen in dünne Scheiben. Dann kommen auch sie für I-2 Tage in I ${ }^{\circ}$ 。Osmiumsäure. In dieser wird das Öl schwarz und zugleich hart, so daß es aus dünnen Schnitten nicht mehr ausfließen kann. Hauptsächlich ist bei dieser Methode das Korrosionsverfahren anzuwenden. Schnitte oder dünne Scheiben - je nachdem man Flächenbilder oder topographische Übersichtsbilder haben will - kommen in Eau de Javelle; in welcher Fliissigkeit nach längerer oder kürzerer Zeit alle geweblichen Elemente zerstört werden, so daß nur die injizierten Gefäße übrig bleiben. 
b) Nicht erstarrende Massen.

$\S 90$.

7. Berliner Blau, nach Paul Mayer. $20 \mathrm{~g}$ gelbes Blutlaugensalz (Ferrocyankalium werden in $500 \mathrm{ccm}$ Aqua destillata gelöst. Io ccm Liquor ferri sesquichlorati der deutschen Pharmakopoe werden mit $500 \mathrm{ccm}$ Aqua destillata verdünnt. Die zweite Lösung wird unter stetem Umrüren in die erste getan, so daß von dieser stets ein Überschuß vorhanden ist. Dann läßt man 12 Stunden stehen. Die gelbe Lösung gießt man so gut wie möglich ab und filtriert die blaue. Man wäscht mit destilliertem Wasser so lange aus, bis das Filtrat tiefblau abläuft, wozu I-2 Tage erforderlich sind. Der Filterrückstand wird durch Aufgießen von destilliertem Wasser allmählich aufgelöst. So erhält man I Liter Injektionsmasse. Bei alkalisch reagierenden Organen muß, um ein Ausblassen der Farbe zu verhüten, mit etwas Essigsäure angesäuert werden.

8. Injektion mit Höllenstein. Um die endotheliale Natur der Kapillaren festzustellen, injiziert man in kleine Gefäßbezirke mittels einer Pravazschen Spritze ${ }_{2}^{1 / 2}:{ }_{0} \%$ Höllensteinlösung. Nach eingetretener Reduktion wird in Alkohol gehärtet.

9. Pikrin-Osmiumsäure-Höllensteinlösung, nach Regaud. Zur Injektion von Lymphgefäßen kann man sich drei verschicdene Lösungen machen, welche aus Prikrinsäure, Osmiumsäure und Argentum nitricum bestehen. Dabei tut man gut, die Höllensteinlösung der Pikrinosmiummischung erst kurz vor dem Gebrauche zuzusetzen, die Nischung selber in gelben Flaschen aufzubewahren. Die Lösungen sind folgende: I. gesättigte wässrige Pikrinsäurelösung $80 \mathrm{ccm}, \mathrm{I}^{\circ}$, ()smiumsäurelösung $20 \mathrm{ccm}$, beides gemischt; 4 Teile davon mit I Teil einer Höllensteinlösung von $\mathrm{I}^{\circ}{ }_{0}$ versetzt. II. Pikrinosmiumgemisch wie bei I; 3 Teile davon mit I Teil I $\%$ Argentum nitricumLösung vereinigt. III. gesättigte wässrige Pikrinsäurelösung $40 \mathrm{ccm}$, I". ()smiumsäurelösung $20 \mathrm{ccm}$; von dieser Mischung 4 Teilc, dazu I Teil I $\%$ Argentum nitricum-Lösung.

Man macht einen Einstich mit der Injektionskanïle, injiziert zuerst ${ }^{1}{ }_{2}-1 \mathrm{ccm}$ Aqua destillata und gibt dann, ohne die Einstichstelle zu wechseln, mehrere ccm einer der drei Injektionsflüsigkeiten nach. Die Vorinjektion mit destilliertem Vasser ist nötig, um nicht durch den eventuellen Salzgehalt der Lymphbahnen eine Chlorsilberreduktion herbeizuführen. Das injizierte Stiick wird herausgeschnitten und in starkem Alkohol erhärtet. Man kann einbetten, nachfärben oder un- 
gefärbt untersuchen. WVen anscheinend die Reduktion des Silbers ungenügend ist, dann braucht man die Schnitte bloß dem diffusen Tageslicht auszusetzen. Die Präparate müssen im Dunkeln aufgehoben werden.

\section{Elftes Kapite1. \\ Das Aufheben der Präparate.}

$\S 9 \mathrm{I}$.

Frisch zerzupftes Material und Schnitte, die von ganz frischen Objeliten angefertigt und ohne weiteren Zusatz untersucht wurden, sind einer dauernden Aufbewahrung nicht fähig. Denn entweder gehen die Präparate in Fäulnis über oder sie werden, falls man klärende und zugleich konservierende Reagentien, wie z. B. das Glyzerin, gewählt hat, so durchsichtig, daß weder ein Struktur- noch ein Texturbild erhalten bleibt. Im allgemeinen sind iibrigens derartige frische Präparate auch nicht des Erhaltens wert, denn stammen sie wirklich cinmal von überaus seltenem und wertvollem Material, dann kann man sich auch die Mühe geben, dieses Lege artis zu fixieren und zu konservieren.

Von mazerierten Objekten dagegen, wenn man sie gut gefärbt hat, von Metallimprägnationen, von Injektionspräparaten und vor allen Dingen von gefärbten Schnitten kann man Dauerpräparate anfertigen. Und hat man nur alle bis zur endlichen Fertigstellung des Präparates nötigen Manipulationen sauber und exakt ausgeführt, dann halten sie sich oft viele Jahre.

Man unterscheidet 2 Arten des Aufhebens oder Montierens der Präparate: trocknes und feuchtes Aufheben. Jedes Material, mit Ausschluß natürlich des von ganz frischen Objekten gewonnenen, ist beiden Arten zugänglich. Im allgemeinen allerdings hebt man Präparate von mazericrtem Material meist feucht auf, Schnitte dagegen meistens trocken. Neuerdings machen sich Anzeichen bemerkbar, die fast auf eine Umkehrung der bisherigen Gebräuche hindeuten. Dank der ingeniösen Zentrifugiermethode von Prokowski und Heidenhain wächst die Möglichkeit, von Mazerationsobjekten gute Dauerpräparate zu erhalten, während andererseits die Stimmen sich mehren, welche einem feuchten Aufheben der Schnittpräparate das Wort reden. Es soll die trockne Aufhebung die letzteren zu durchsichtig machen, 
wodurch viel Detail im Strukturbilde angeblich verloren gehe. Wie ich gleich hier bemerken will, scheinen mir diese Befürchtungen ganz irrig und die Methoden, wodurch sie beseitigt werden, völlig unnötig. Ich habe nie finden können, daß ein regelrecht aufgehelltes und in Balsam aufbewahrtes Präparat weniger Detail zeigt, als ein in Zecicrnöl odur Paraffinöl eingelegtes. Wohl aber haben diese eben genannten modernsten feuchten Aufbewahrungen den großen Nachteil, daß die Präparate unsauber, um nicht zu sagen schmierig, sind und trotz L $\mathrm{Cm}$ randung sehr leicht verderben. Das aber ist der große Vortcil des trocknen Aufhebens: größte Saubcrheit, denn man kann dic Präparate putzen und abreiben, und unbegrenzte Haltbarkeit, wenn nicht dic Färbung allmählich verblaßt. Wo man daher irgend die trockne Aufhebung anwenden kann, da soll man es tun; die feuchte Aufhebung ist meines Erachtens nur ein Notbehelf, dann allerdings unentbehrlich, wann die zum trocknen Aufheben der Präparate nötige Vorbehandlung in Alkohol vermieden werden muß, wie z. B. beim Studium der Fette.

\section{a) Trocknes Aufheben.}

\section{$\S 92$.}

Das trockne Aufhcben kann in zwei verschiedenen Formen ausgefuiht werden: entweder ohne Intermedien oder mit Intermedien. Für beide Formen ist notwendig, entweder die gefürbten Schnitte oder die gefürbten Nazerationspräparate in Wasser auszuwaschen und das hat bei fast allen wässrigen Farblösungen zu geschehen, damit im nachher anzuwendenden Alkohol keine Niederschläge entstehen - und dann zu entwässern oder, wenn man alkoholische Farbflotten verwendet hat bzw. wenn die Vorschrift es verlangt, sofort in starken Alkohol zum Auswaschen und gleichzeitigen Entwässern zu bringen. Der Entwässerungsalkohol muß völlig oder doch fast villig klar bleiben, damit sich das Einschlußmedium nicht unnötig färbt. Verwendet man keine Intermedien, so kommen die Präparate sofort in die Einschlußmittel; sind Intermedien anzuwenden, so werden die Präparate aus dem Entwässerungsalkohol zunächst in diese gebracht und dann erst in die Einschlußmittel.

Hat man mazeriertes Material gefärbt, so wäscht man es aus, zentrifugiert, wecheelt das Vasser so oft und zentrifugiert ebenso oft, bis kein Farbstoff mehr ausgewaschen wird. Dann entwïssert man in Alkohol und zentrifugiert ebenfalls, kann danach entweder das Intermedium anwenden oder ohne solches einlegen. In beiden Fällen gielst man aus dem zur Zentrifugierung benutzten Reagensglase die 
oben stehende Flüssigkeit vorsichtig ab und schüttet nach der Vorschrift von Prokowski den Bodensatz in ein Glasschälchen, welches die verdünnte Einschlußflüssigkeit enthält. Aus dieser bringt man mittels einer Pipette einen Tropfen, welcher das gefärbte Material enthalten muß, auf einen Objektträger und deckt ein.

Es gibt noch eine besondere Methode des trocknen Aufhebens, die, soviel ich weiß, von den Botanikern häufig angewendet wird. Bei dieser werden die Präparate aus Wasser oder verdünntem Glyzerin auf einem Objekttrüger in einer Leimmasse eingeschlossen.

Hat man die Schnitte auf dem Objektträger aufgeklebt, so bringt man einen Tropfen des Einschlußmittels auf sie und deckt mit einem Deckglase ein. Letzteres hält man an einem Rande mit einer feinen Pinzette, legt den anderen Rand so auf den Objektträger in nächster Nähe der Schnitte, daß die Fläche des Deckglases zu der des Objektträgers einen IVinkel von $45^{\circ}$ bildet und läßt schncll auf den Tropfen des Einschlußmittels auffallen. Man vermeidet so, daß sich Luftblasen unter dem Deckglase einstellen Für alle Fälle legt man dann die Präparate in den Brïtofen (Temperatur bis $40^{\circ} \mathrm{C}$ ); das Lösungsmittel des Einschlußreagens verdunstet und die ewaigen Luftblasen verschwinden. Hat man auf dem Deckglase aufgeklebt, dann kommt der Einschlußtropfen auf den Objektträger und das mit den Präparaten beschickte Deckglas wird ganz wie vorhin beschrieben aufgelegt. Sind nicht aufgeklebte, also lose Schnitte aufzuheben, so ordnet man diese in der gewünschten Zahl so auf dem Objektträger, daß das Deckglas nachher auf allen Seiten über sie hinüberragt. Man drückt sie fest an (mit Filtrierpapier), bringt den Einschlußtropfen auf das Deckglas, verteilt ihn hier über dessen ganze Fläche und deckt ein, indem man das Deckglas, den Tropfen nach unten, glatt auflegt. Man vermeidet dadurch, daß die Schnitte wegschwimmen, wenn der Einschlußtropfen sich ausbreitet. In ganz gleicher Weise verfährt man bei mazeriertem Material. Ich will nicht verfehlen, bei dieser Gelegenheit darauf hinzuweisen, daß die Deckgläser nicht dicker als $0,15 \mathrm{~mm}$ sein sollen, es sei denn, man verzichtet wie bei manchen Gehirnuntersuchungen auf die Anwendung starker Linsensysteme; dann kann man eventuell sogar mit einem diinnen Objektträger eindecken. Auch die Objektträger sollen nicht zu dick sein, damit nicht zu viel Licht verloren geht; auf O, I5 mm Deckglasdicke sind unsere Linsensysteme korrigiert.

Die Methoden des trocknen Aufhebens werden in die ohne und die mit Anwendung von Intermedien eingeteilt. Zu den ersteren rechne ich das Aufheben in Gelatine. 
a) Ohne Intermedien.

$\S 93$.

I. Glyzeringelatine. Wenn man sich Glyzeringelatine nicht fertig kaufen will, was am richtigsten ist, sondern sie selber herzustellen beabsichtigt, so versetzt man entweder geschmolzene, d. h. in der Wärme in Wasser gelöste Gelatine mit dem gleichen Volumen reinen Glyzerins und läßt erstarren. Die erstarrte Masse, der zur Verhütung der Fäulnis etwas Karbolsäure zugesetzt war, verwendet man in der nachher zu erwähnenden Weise. Oder aber man stellt sich nach der Vorschrift von Fol in folgender Mischung das Einschlußmittel her: $30 \mathrm{~g}$ Gelatine werden in $70 \mathrm{ccm}$ Aqua destillata eingeweicht, dann auf dem Wasserbade geschmolzen, mit $100 \mathrm{ccm}$ Glyzerin versetzt und nach tropfenweisem Zusatz von $5 \mathrm{ccm}$ alkoholischer Kampferlösung zur Erstarrung gebracht. Der Kampfer dient hier als Antisepticum. Eine andere Vorschrift von Fol lautet: Gelatine $20 \mathrm{~g}$, Wasser $150 \mathrm{ccm}$, Glyzerin $100 \mathrm{ccm}$, alkoholische Kampferlösung I $_{5} \mathrm{ccm}$. Bei dieser zweiten Mischung bedingt die größere Wassermenge mehr Antisepticum, weil die Fäulnis bei der dünnen Gelatine leichter eintritt als bei der konzentrierten. Die erste Vorschrift ist Fols starke, die zweite Fols schwache Glyzeringelatine. Eine Vorschrift von Kaiser lautet: I Teil Gelatine, 6 Teile Aqua destillata, 6 Teile Glyzerin. Auf je $100 \mathrm{ccm}$ wird $0,5 \mathrm{ccm}$ Karbolsäure zugefügt.

Will man Zupfpräparate oder ähnliches Naterial in Glyzeringelatine einschließen, so ordnet man zunächst die Präparate auf dem Objektträger, wärmt diesen an, ohne ihn zu erhitzen, gießt geschmolzene Gelatine über und legt ein über der Spiritusflamme erwärmtes Deckglas auf. Dann wird der Objektträger sofort auf eine kalte Unterlage gelegt; die Gelatine erstarrt augenblicklich und das Präparat ist fertig. Man kann aber auch folgendermaßen verfahren: Von der erstarrten Gelatine bringt man ein kleines Stiickichen - die Größe richtet sich nach dem Deckglase und der Quantität des Präparates, man lernt sehr leicht durch Übung das richtige Maß treffen - auf den Objektträgur in unmittelbare Nähe des Präparates und deckt ein Deckglas darauf, das natiirlich schräg liegen muß. Dann erwärmt man vorsichtig uber der Spiritusflamme, bis die Gelatine schmilzt, nimmt von der Flamme weg, wartet bis sich das Deckglas völlig auf der geschmolzenen Gelatine ausgebreitet hat und kühlt den Objektträger. schnell ab. Ich ziehe die letztere Anfertigungsweise der ersteren vor. Einmal kann es mir dabei nicht passieren, daß die Gelatine erstarrt ist, bevor das Deckglas aufgelegt wird, und dann schwimmen bei der zweiten 
Methode die Zupfpräparate, d. h. die zerzupften Stiicke, nicht auseinander, wie bei der ersten. Die Gelatine wie die Objektträger dürfen nicht erhitzt, sondern nur erwärmt werden, weil sonst Luftblasen in der Gelatine sich bilden und weil die Präparate anfangen zu schmoren. Die Methode des Glyzeringelatine-Einschlusses ist seh $\mathrm{r}$ gut. Hämatoxylinpräparate bleichen allerdings leicht aus, wenn als Antisepticum Karbolsäure verwandt wurde. Die Folschen Massen sind deswegen vorzuziehen.

2. Kolophonium. Man löst Kolophonium in Terpentinöl in der Wärme, indem man nach Lee im Paraffinofen die Erwärmung des Terpentinöls vornimmt. Ist die Lösung dick genug, dann wird zweimal warm filtriert. Nach etwa I 4 Tagen ist die Lösung fertig. Die Objekte kommen aus absolutem Alkohol hinein. Man kann auch statt Terpentinöl Benzin als Lösungsmittel nehmen ( 1 Kolophonium zu 10 Benzin, nach der Torschrift von Rehm); man erhitzt nach Einlegen des Präparates, bis das Benzin verdampft ist, und deckt dann mit dem Deckglase ein. Viele Autoren (Fol, Lee, Nissl) rühmen dem Kolophonium nach, daß in ihm viele Strukturen erhalten, d. h. sichtbar bleiben, die in dem hauptsächlich gebrauchten Einschlußmittel, dem Kanadabalsam, verschwinden. Meine Erfahrungen mit dem Reagens sind die denkbar schlechtesten; es liefert brutale Bilder, die wenigstens an den von mir verwandten Objekten nicht mehr erkennen ließen als Kanadabalsampräparate. Das Terpentinöl greift Anilinfarben an.

3. Venetianisches Terpentin, nach Vosseler. Weit besser als das Kolophonium ist als Einschlußmittel das venetianische Terpentin. Vosseler, der es in die IVissenschaft eingefüht hat, gibt folgende Vorschrift: Das rohe Terpentin, ein zähfluissiger schmutzig orangegelber Balsam, wird in einem hohen Zylindergefia mit dem gleichen Volumen Alkohol von $96 \%$ verdiunt und in einen Paraffinofen bei $60^{\circ}-65^{\circ}$ C. gestellt. Nach 24 Stunden sind die Unreinigkeiten des venezianischen Terpentins zu Boden gesunken, die über ihnen stehende dunkelgelbe bis orangegelbe Fliissigkeit, die sehr zähe ist, wird vorsichtig in ein mit Kork zu verschließendes Gefäß abgegossen. Von dieser Stammischung wird ein aliquoter Teil zum Gebrauch mit soviel $96 \%$ Alkohol verdünt, daß die gewünschte Konsistenz erreicht wird. Die Präparate, die zum Einschluß in diesem Nittel bestimmt sind, werden aus $96^{\circ}$. Alkohol entnommen - man braucht also nicht völlig zu entwässern - und mit einem Tropfen des venezianischen Terpentins bedeckt. Dann wird das Deckglas aufgelegt. Die Aufhellung findet im Einschlußmittel selbst statt. Das ist ein sehr grol3er 
Vorteil, dem aber als Nachteil gegenuiber steht erstens das schnelle Ausblassen der Anilinfarben und zweitens das sehr langsame Erstarren des Terpentins. Namentlich letzterer Umstand ist sehr zu beklagen, weil die Terwendbarkeit der Präparate für homogene Immersion so gut wie nicht vorhanden ist, denn die Reinigung von dem Immersionsöl kann fast nie ohne Zertörung des Präparates erfolgen. Für Serienschnitte von Embryonen usw, besonders solchen die in Cochenille oder Karminsäure gefärbt sind, ist dagegen das venezianische Terpentin ein hevorragend brauchbares Einschlußmittel, da durch Ausschluß der Intermedien Zeit und Mühe erspart wird.

\section{ß) Mit Intermedien.}

\section{\$94.}

Wir besitzen nur zwei Einschlußmittel, den Kanadabalsam und den Dammarlack, welche zum dauernden Aufheben der Präparate in jeder Beziehung geeignet sind und jedem Wunsche entsprechen. Allerdings müssen die Präparate vorher in den Intermedien aufgehellt werden, weil die genannten Harze ohne Intermedien selbst in völlig entwässertes Material nicht oder nur selten eindringen. Wohl hat G. Fritsch angegeben, daß man Schnitte aus absolutem Alkohol direkt in Kanadabalsam bringen kann. Zuweilen gelingt auch der Einschluß, es crfolgt eine Aufhellung im Balsam; aber eben nur zuweilen, nicht immer und ausnahmslos. Die Methode, Kanadabalsam ohne Intermedien zu verwenden, ist daher zu unsicher und bei umfangreichen Serien durchaus nicht bequemer als die gewöhnliche Methode.

Ich will zunächst die Intermedien und dann die Einschlußmittel beschreiben.

\section{Die Intermedien.}

Zweck der Anwendung der Intermedien ist, den Alkohol aus den Präparaten, Schnitten oder Zupfpräparaten, auszutreiben, diese dabei aufzuhcllen und zur Aufnahme des Einschlußharzes zu befähigen. Letzteres mischt sich mit dem im Schnitt usw. zurückgebliebencn Intermedium oder treibt solches allmählich aus. Hat man die Schnitte auf dem Objekttriger aufgeklebt, dann bringt man diesen aus dem Entwässerungsalkohol, nachdem man seine Unterfläche rasch mit einem Handtuche abgetrocknet hat, in ein Standgefä $\beta$, welches soriel ron dem Intermedium enthält, daß die Schnitte röllig bedecht sind. Die Wirkung, d. h. die Aufhellung ist eingetreten, wenn alle Schnitte 
durchsichtig geworden sind. Dies erkennt man daran, daß man durch die Schnitte hindurch Bleistift- oder Tintenschrift sehen kann. Dann hebt man den Objektträger aus dem Standgefäß heraus, trocknet seine Unterfläche und von seiner Oberfläche die Teile seitlich von den Schnitten mit einem Tuche ordentlich ab, legt ihn flach hin, bringt auf die Schnitte das gewählte Harz (Kanadabalsam oder Dammarlack) und deckt mit einem Deckglase ein.

Sind die Schnitte auf dem Dechglase aufgeklebt, dann hebt man dieses mit einer feinen Pinzette aus dem Entwässerungsalkohol heraus und legt es auf den Boden eines Uhrglases, die Schnitte nach oben gekehrt. Das Deckglas beriihrt das Uhrglas nur mit seinen 4 Ecken. Jetzt bringt man mit einer Pipette vorsichtig einen oder mehrere Tropfen des Intermedium auf die Schnitte und sorgt dafuir, daß sie sich gleichmäßig ausbreiten. Das Deckglas muß ganz wagerecht liegen, sonst läuft das Intermedium $a b$ und verschmiert das Glas. Ist die Aufhcllung beendet, dann saugt man mit einer Pipette das Intermedium ab, das meist wieder benutzt werden kann, hebt mit einer Pinzette das Deckglas vorsichtig aus der Uhrschale heraus, tropft etwa noch vorhandenes Intermedium auf Filtrierpapier ab und legt das Deckglas, die Schnitte nach unten, auf eine doppelte Lage Filtrierpapier. Mit einem einfachen Streifen Filtrierpapier drückt man das Deckglas auf seine Unterlage an und saugt so den Rest des Intermedium aus dem Schnitt heraus. Dies ist für die Durchtränkung mit Balsam darum von Vorteil, weil auf diese Weise der Balsam nicht verunreinigt wird und weil er auch schneller fest wird. Man hebt mit einer Pinzette das abgetrocknete Deckglas hoch und legt es, die Schnitte natülich nach unten, auf den mit einem Tropfen Einschlußharz beschickten Objektträger.

Ich ziche das Aufkleben auf dem Deckglase dem auf dem Objektträger vor, und zwar aus folgenden Gründen: Erstens brauche ich weniger Lösemittel für das Paraffin, weniger Alkohol zum Austreiben des Löscmittels, weniger Farbflotte usw. Zweitens findet sich zwischen unterer Deckglasfläche und oberer Schnittfläche nur eine kapilläre Schicht Kanadabalsam bez. Dammarlack und das ist bei der Anwendung namentlich starker Trockensysteme von Vorteil. Denn bei den auf dem Objektträger aufgeklebten Schnitten muß das System erst durch Dechglas und Balsamschicht hindurchdringen, ehe es zum Präparat grelangt, so daß dadurch nicht gar so selten die Folaldistanz des Systems bis auf ein Minimum verringert wird und leicht eine Verletzung des Präparates und des Systems eintreten kann. Die Besorgnis, daß man häufig Deckgläser mit den auf- 
geklebten Schnitten zerbrechen kann, ist grundlos; freilich muß man alle Verrichtungen mit Sorgfalt und Vorsicht ausführen.

Hat man lose Schnitte mit Intermedien zu behandeln, so hebt man sie mit einer Platinnadel aus dem Entwässerungsalkohol und bringt sie in ein mit dem Intermedium, das in reichlicher Menge vorhanden sein muß, beschicktes Uhrschälchen. Hierin, d. h. in dem Intermedium, breiten sich die Schnitte, oft unter lebhaften und heftigen Virbeltänzen, aus und schwimmen zunächst auf der Oberfläche. Erst wenn der Entwässerungsalkohol völlig ausgetrieben ist, sinken sie unter. Sieht man tribe Stellen in den Schnitten, die auch bei längerem Verweilen im Intermedium nicht schwinden, dann war nicht ausreichend entwässert worden, denn die Trübung rührt vom Wassergehalt der Schnitte her. Man muß diese daher in den Entwässerungsalkohol zurückbringen und nach einiger Zeit die Prozedur wiederholen. (Dies gilt natürlich auch für aufgeklebte Schnitte.) Sind die Schnitte vollkommen durchsichtig geworden, dann bringt man sie im Intermedium mit einem feinen Haarpinsel auf einen Metallspatel, hebt diesen heraus, läßt etwas abtropfen und überträgt die Schnitte mit demselben Pinsel auf cinen Objektträger. Hier ordnet man sie in der gewiinschten Zahl an und verfährt so, wie dies bereits in $\S 92$ geschildert worden ist.

Ich zähle nun die wichtigsten Intermedien auf:

4. Terpentinöl. Nur noch von historischem Interesse, da dieses Reagens zur Aufhellung wohl nicht mehr gebraucht wird. Hämatoxylin- und Anilinfärbungen gehen nach Aufhellung in Terpentinöl schnell zugrunde. Man muß lange und sorgfältig in absolutem Alkohol entwässern, da selbst dic geringste Spur von Wasser in den Schnitten Trübungen gibt.

5. Xylol. Ein sehr gutes Intermedium, das die Präparate schonend aufhellt und das namentlich gegeniiber den sehr empfindlichen Anilinfärbungen durchaus angebracht ist. Denn das Xylol schont die Farben, d. h. zieht sie nicht mehr aus; es mischt sich ferner sehr leicht mit den Einschlußharzen. Nur müssen die Präparate, bevor sie in das Xylol kommen, in absolutem Alkohol völlig entwässert sein, weil die kleinste Spur Wasser die Aufhellung verhindert.

6. Bergamottöl. Nach meinen Erfahrungen das weitaus beste aller Intermedien. Man hat zunächst nicht nötig, dic Präparate in absolutem Alkohol zu entwässern, sondern man kann aus $96 \%$ Alkohol direkt in dies Intermedium bringen und erhält dennoch nach kurzer Zeit eine vorzügliche Aufhellung. Ein weiterer Vorteil besteht darin, daß wie beim Xylol subtile Färbungen durch das Öl nicht an- 
gegriffen werden. Auch für Celloidinschnitte ist das Bergamottöl als Aufhellungsmittel zu gebrauchen, da es das Celloidin nicht löst. Sein Vorzug gegenüber dem Xylol besteht bei derartigem Material darin, daß die Celloidinblätter ihre im $96 \%$ Alkohol erlangte Weichheit behalten, während sie im Xylol hart und zuweilen kraus werden. Das benutzte Bergamottöl kann man sehr oft wieder gebrauchen, während dies beim Xylol mir nicht angängig erscheint. Auf eines hat man genau zu achten: das Bergamottöl muß dunkelgrasgrün sein, wenn es die eben geschilderten Vorzüge entfalten soll. Sowic es auch nur einen Stich ins Gelbe hat, muß es verworfen werden, denn es ist dann sauer geworden, greift die Färbungen an und löst Celloidin auf. Man hält sich das sehr schnell verdunstende Öl in einer Flasche, in die eine Pipette als Glasstöpsel eingeschliffen ist.

7. Nelkenö1. Ist weniger gut als das vorige, da es Anilinfärbungen angreift; man kann es hierfuir geradezu als Differenzierungsfliissigkeit benutzen. Für Celloidinschnitte ist es ganz zu verwerfen, da es das Celloidin auflöst. Nur die hellen Nelkenöle sind brauchbar, die dunklen sind direkt schlecht.

8. Origanumöl. Verwendet sollte nur das Oleum origani cretici werden; das Ol. orig. gallici ist schlecht. Es ist dies ein gutes Intermedium für Celloidinschnitte; doch darf man nur das dunklere Öl benutzen, das hellgelbbraune löst Celloidin auf. Der Verwendung dieses Öles stellt sich eine große Schwierigkeit entgegen: sein nicht gerade angenehmer Geruch ruft bei empfindlichen Menschen unerträgliche Kopfschmerzen hervor.

9. Cajeputö1. Wird als Intermedium für Methylenblaufärbungen empfohlen. Es gibt ein grünes und ein fast wasserhelles Öl; letzteres verschmiert aber nach meinen Erfahrungen die Schnitte derartig, daß sie sich mit Balsam nur langsam durchtränken.

Io. Kreosot-Terpentinöl. Nach Golgi mit Chromsilber imprägnierte Schnitte lommen aus dem Alkohol, in dem sie beim Schneiden aufgefangen wurden, in weißes Kreosot, worin sie fast augenblicklich durchsichtig werden. Dann werden sie in Terpentinöl übergeführt, damit das Kreosot ausgetrieben wird. Der Einschluß geschieht in Dammarlack.

II. Karbol-Xylol, nach VVeigert. Für die Celloidinserien, die nach der Lappenmethode angefertigt wurden, eignet sich diese von Weigert empfohlene Methode ganz besonders. Die Lappen kommen aus dem Alkohol in cine Mischung von 3 Teilen Xylol und I Teil Acidum carbolicum liquefactum. Wenn die Lappen durchsichtig ge- 
worden sind, bringt man sie in neues Intermedium und eventuell noch in reines Yylol. Für große Celloidinserien die beste Aufhellungsmethode.

\section{Die Einschlußmittel.}

I2. Kanadabalsam. Der käufliche Kanadabalsam wird am besten in Xylol gelöst, denn dieser Xylolbalsam verhält sich gegen die diffzilsten Färbungen indifferent, er trocknet ziemlich schnell und wird, wenn er getrocknet ist, nicht brïchig. Als Lösungsmittel sind noch Chloroform, Benzol, Terpentin usw. empfohlen worden: nach meinem Dafiirhalten ohne ersichtlichen Grund. Zwar trocknet der Xylolbalsam nicht so schnell wie der Chloroformbalsam, letzterer aber wird dafür sehr leicht brüchig.

Man bringt den dickflüsigen Balsam in ein weithalsiges Glasgefäß, über das ein tubenförmiger aufgeschliffener Glasdeckel gedeckt werden kann. Nan gibt ein wenig Xylol zu und ruihrt mit einem Glasstäbchen ordentlich um. Viel Xylol zu nchmen wäre ein Fehler, da der Balsam zu dünnflissig werden würde. Nach dem man einige Male mit dem Glasstäbchen, das in der Flasche bleibt und zum Auftropfen des Balsams benutzt wird, gründlich umgerührt hat, iiberzeugt man sich, ob der Balsam die gewünschte Konsistenz hat oder nicht. In letzterem Falle wird es sich darum handeln, ob er zu dick oder zu diinn ist; man wird dann entweder Balsam oder Xylol zusetzen müssen.

Man soll stets nur wenig Balsam nehmen, sodaß der Raum unter dem Deckglase gerade ausgefuillt ist. Zuvicl Balsam ist von Nachteil, weil die Präparate nur sehr langsam hart werden; zu wenig Balsam kann zu einem Verderben der nicht ausreichend eingeschlossenen Schnitte führen.

Kanadabalsam ist das souveräne Einschlußmittel, an dessen Enthronung schon viel gearbeitet wurde, das aber von keincm anderen Mittel bisher verdrängt werden konnte. Denn dem angeblichen Nachteil, daß in ihm die Präparate zu durchsichtig werden, stehen zahllose Vorteile gegenuiber, von denen hier nur der hervorgehoben werden soll, daß die Präparate unbegrenzt haltbar sind, insofern der Xylolbalsan sich nie trubt und nie brüchig wird. Den Nachteil, daß in ihm alles zu durchsichtig werde, halte ich nur für einen angeblichen, da ich mich trotz eingehcnder darauf gerichteter vergleichender Studien davon nicht habe überzeugen können.

I3. Dammarlack. Nan löst das reine Dammarharz in Xylol, wie den Kanadabalsam, und benutzt es auch wie letzteren. Die Filem- 
mingsche Vorschrift, das Harz in Benzin-Terpentin zu lösen, hat sich nicht bewährt, da der Lack relativ schnell trübe wird. Dieser Lack soll vor dem Kanadabalsam den Vorteil haben, daß er zarteste Strukturbilder erhält, die im Balsam wegen zu starker Aufhellung verschwinden. Den Nachteil hat der Lack sicher, daß er noch schwerer hart wird als der Balsam. Bei Golgipräparaten soll er allein angewendet werden, während man den Kanadabalsam vermeiden muß.

b) Feuchtes Aufheben.

$\S 95$.

Nur ein Notbehelf, der dann benutzt werden mag, wenn ein trocknes Aufheben unmöglich, wenn selbst die Anwendung der Glyzeringelatine ausgeschlossen ist! In früheren Zeiten dagegen war das feuchte Aufheben für Zupf- und Mazerationspräparate die einzig mögliche Art, von derartigem Material Dauerpräparate zu erlangen. Die Notwendigkeit, feucht aufzuheben, kann vorliegen, wenn Zupfpräparate gemacht wurden und ihnen die Prozeduren (Alkohol, Intermedium) bis zum Balsam nicht mehr zugemutet werden können; z. B. bei versilberten markhaltigen Nerven, bei Präparaten, die zum Studium der Fette dienen sollen. Aber die neucrdings aufgetauchte Mode, Schnittpräparate von nicht nur fixicrtem sondern auch von paraffiniertem Material feucht aufzuheben, hat meines Erachtens gar keine Berechtigung. Denn man sieht nicht mehr Detail im feucht, als im trocken aufgehobenen Schnitte.

Die feuchten Präparate müssen umrandet werden, d. h. das Deckglas muß durch irgendein Fixativ in seiner Lage erhalten werden, damit es sich nicht verschiebt. Und die Umrandung soll dann noch den ferncren Zweck erfüllen, das Verdunsten der Einschlußfliissigkeit $z u$ verhüten. Ich gebe zunächst die Einschlußmedien, um dann die Mittel zur Umrandung aufzuzählen.

\section{a) Die Einschlubflüssigkeiten.}

$$
\S 96 .
$$

I . Glyzerin. Das reine Glyzerin hellt zu stark auf und läßt daher viele Strukturdetails verschwinden. Des ferneren nimmt es begierig Wasser auf und bewirkt daher recht beträchtliche Schrumpfungen in dem nicht entwässerten Material. Endlich greift es Anilin- und Hämateinfärbungen an. Daher ist es ratsam, Glyzerin stets mit dem gleichen Volumen destillierten Wassers zu verdünnen und dann erst in Gebrauch zu nehmen. 
Zerzupft man in einem Tropfen Glyzerin, so darf man ihn nicht zu groß und nicht zu klein nehmen. Denn im ersteren Falle tritt er nach dem Eindecken mit dem Deckglase über dieses hinaus, in letzterem bleibt unter dem Deckglase Luft, durch welche das Präparat rerdirbt. Bei zuviel Glyzerin schwimmen auch die zerzupften oder mazerierten Teile auseinander, sowie man das Deckglas autlegt; die Arbeit war daher pro nihilo. Das richtige Maß hier einzuhalten ist nicht leicht; dazu bedarf es langer Übung.

15. Liquor Kali acetici. Max Schultze hat die 50\% Lösung des Kali aceticum zum Ersatz des Glyzerins empfohlen. Tatsächlich ist dies Einschlußmittel viel besser als das Glyzerin, doch werden die Anilinfarben mit der Zeit ausgezogen.

16. Zedernöl. Wird von Lee und O. Israel an Stelle des Kanadabalsams empfohlen. Da man eingedicktes Öl nchmen muß, so sind die Präparate recht schmierig.

17. Paraffinöl. An Stelle von Kanadabalsam ist das Paraffinum liquidum, das sogenannte Paraffinöl, von zwei Autoren, Stransky und Harz, empfohlen worden. Die Präparate werden gründlich entwässert, abgetrocknet und in Paraffinöl eingeschlossen. Die Deckgläser muissen mit Glyzeringelatine umrandet werden. Die Methode soll für Spaltpilze gut sein; ich kann ihre Notwendigkeit nicht einsehen und die Schmiererei mit dem Öl kann das saubere Arbeiten mit Kanadabalsam nicht ersetzen.

ß) Die Umrandungsmittel.

$$
\S 97 .
$$

I8. Wachs. Die einfachste Umrandung ist die mit Wachs, die neben dem Vorzug der Billigkeit noch den der leichten Ausführung und der großen Haltbarkeit besitzt.

Ein dünnes Wachslicht wird angezündet und so lange brennen gelassen, bis das Wachs am Docht geschmolzen ist. Dann löscht man aus und zieht nun rasch am Rande des Deckglases und zum Teil auf dem Objektträger den Docht entlang, so daß das flüssige Wachs einen schnell erstarrenden Streifen hinterläßt. Liegt dieser halb auf dem Deckglase und halb auf dem Objektträger, dann wird ersteres fixiert.

I9. Asphaltlack. Eine Auflösung von Asphalt in Leinöl oder Terpentin, die käuflich zu haben ist. Wenig empfehlenswert, weil der Lack sehr leicht abspringt.

20. Maskenlack. Eine käufliche Lösung von mir unbekannter Zusammensetzung, die ganz vorzuiglich ist. Der schwarze Lack 
hält sehr fest am Glase, springt nicht ab, wird nicht brüchig und wird nicht durch austretende Einschlußflüssigkeit abgehoben. Zu dicker Lack wird mit einigen Tropfen 96\% Alkohols verdünnt.

21. Krönigsche Masse. 2 Teile weißes Wachs und 2 Teile Kolophonium werden warm miteinander vereinigt. Die harte Masse wird mit erwärmtem Metallspatel so auf den Rand des Deckglases aufgetragen, wie dies vorhin beim Wachs auseinander gesetzt wurde.

22. Bernsteinlack, nach Behrens. Aus der großen Fülle der übrigen empfohlenen Umrandungsmittel sei nur noch der Behrenssche Bernsteinlack erwähnt, der käuflich zu haben ist.

\title{
Zwölftes Kapitel.
}

\section{Das Abbilden.}

\author{
$\S 98$.
}

Das Arbeiten mit dem Mikroskop, die mikroskopische Untersuchung im eigentlichen Wortsinne, ist durchaus nicht leicht. Die Fuille der verschicdensten und oft sehr sonderbaren Figuren, welche zu sehen sind, die Differenz von gefärbten und ungefärbten oder nur wenig gefärbten Teilen wirken auf den Anfänger direkt verwirrend ein. Wer zum erstenmal an das Mikroskop kommt, um ein Demonstrationsobjekt zu betrachten, das den eben gehörten Vortrag des Lehrers erläutern soll, der glaubt alles sehen zu können und sieht tatsächlich nichts. Und derjenige, welcher zum erstenmal ein selbst angefertigtes Präparat betrachtet, glaubt ebenfalls zu sehen, was er nach den Lehr- und Handbüchern sehen soll, und auch er sicht nichts oder wenigstens nichts richtig. Dem crsteren Fehler ist leicht abzuhelfen, indem an Stelle des subjektiven Bildes der mikroskopischen Betrachtung das objektive Bild der mikroskopischen Projektion gesetzt wird: eine Methode, welche uns hier nicht weiter interessiert. Dem an zweiter Stelle gerügten Fchler muß der Lcrnende selber abhelfen, und er kann dies, wenn er jedes Präparat, das cr macht, nachzuzeichnen sich bemüht. Nicht mit den Abbildungen in den Lehrbüchern oder Atlanten vergleiche der Anfänger sein Präparat, sondern er zeichne es und erst diese Zeichnung vergleiche or mit denen der Buicher. Der Zeichenstift ist das beste, ja vielleicht einzige Mittel, 
um mikroskopisch sehen zu lernen. Denn von dem Augenblicke an, wo der Beobachter den Zeichenstift ansetzt, muß er sich, er mag wollen oder nicht, Rechenschaft über das geben, was er sieht. Und damit hört der unbewußte Selbstbetrug auf, der zu sehen, d. h. zu erkennen glaubte, wo kein Erkennen vorhanden war. Ob die Zeichnung vollkommen oder unvollkommen ist, darauf kommt gar nichts an, wenn sie nur einigermaßen zeigt, daß der Anfänger überhaupt etwas gesehen hat. Übung macht auch hier den Meister; sehr bald wird der Ungeschickte - sogenannte Ungeschicklichkeit ist häufig nichts weiter als Mangel an Zutrauen zum eigenen Können - geschickt genug werden, um hinreichend deutliche Skizzen sich von seinen Präparaten anzufertigen. Und damit wird er die große Befriedigung empfinden, die mikroskopische Anatomie für sich selber gewissermaßen von neuem entdeckt $z u$ haben. Das steht fest: wer nicht zeichnet, lernt nicht mikroskopisch sehen. Künstlerisch vollendet brauchen die Bilder nicht zu sein, welche der Anfänger macht; das ist gar nicht notwendig, wenn sie nur deutlich und richtig sind. Künstlerschaft ist angeboren, Geschicklichkeit wird erworben.

\section{$\S 99$.}

Auch der Forscher, welcher durch seine Arbeit die Grenzen unserer Kenntnis und Erkenntnis zu erweitern trachtet, muß das, was er im Mikroskop gesehen, abbilden. Denn oft ist eine Abbildung ausreichend, um langatmige Schilderungen zu ersparen, und stets ist sie notwendig, wenn sie Neues, bishor nicht Gekanntes uns aufzeigt. Die Zeichnung des Schülers soll richtig sein, die des Forschers muß außerdem noch Genauigkeit besitzen; jene muß Altbelanntes erkennbar wiedergeben, diese soll Neues so darstellen, daß es von anderen dann wieder erkannt wird, wann diese anderen an dasselbe Objekt herantreten. Nicht jeder hat die Fähigkeit, derartig exakt die feinsten Einzelheiten zeichnerisch wiederzugeben, wie es ron der Wissenschaft gefordert wird. Vom Auge durch die Hand in den Bleistift hinein ist oft ein weiter IVeg, auf dem das Beste der Zeichnung, die Naturtreue, verloren geht. Hier trcten helfend dic Zeichenapparate ein; sie ermöglichen, wenn man nur ein klein wenig sorgfältig im Arbeiten ist, auch dem zeichnerisch Unbegabtesten eine getreue Wiedergabe seiner mikrosliopischen I'räparate. Ein solcher Zeichenapparat heißt Camera lucida. Nach rerschiedenen Prinzipien werden diese Apparate angefertigt, ron denen dic besten ron Oberhäuser und von $\mathrm{Abbe}$ herrihren.

I. Camera lucida (Zeichenapparat), von () berhäuser. Das Prin- 
zip dieses Apparates besteht darin, das mikroskopische Bild nach außen auf den Zeichentisch zu projizieren und dadurch die Möglichkeit zu gewähren, wie auf einer Pause mit dem Bleistift alle Einzelheiten nachzuzcichnen. Man setzt einen rechtwinkelig gebogenen Apparat auf den Tubus des Mikroskopes. Das Bild, welches vom Präparat nach oben entworfen wird, gelangt in das erste große Prisma und wird von diesem rechtwinkelig in den horizontalen Arm des Apparates reflektiert. Nachden es das Okular passiert hat, trifft es auf ein zweites kleines Prisma, das Zeichenprisma. Durch dieses sieht

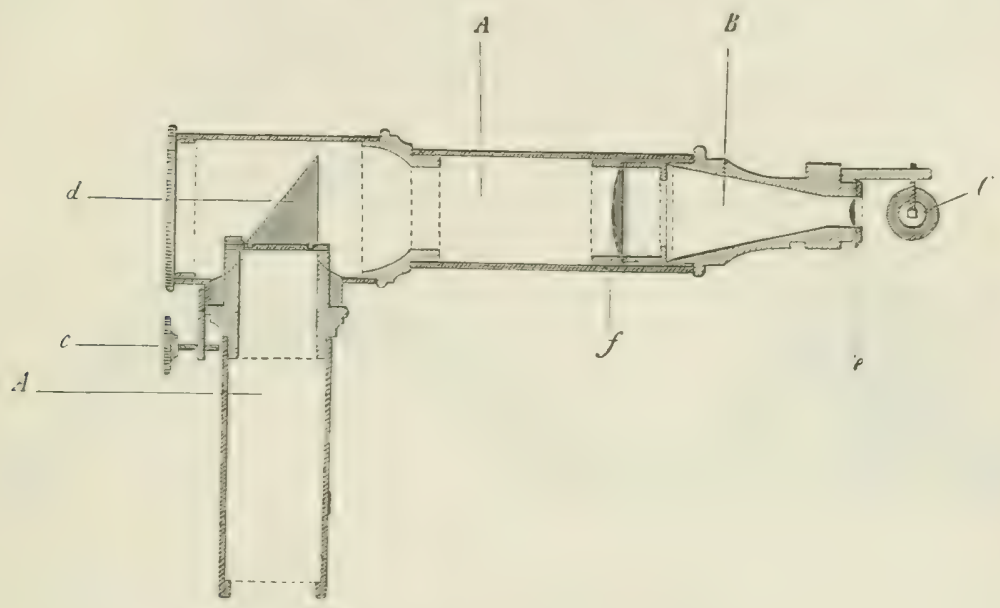

Fig. 10. Camera lucida von Oberhäuser.

$A$ Aufsatz auf den Tubus; $c=$ Schraube zum Feststellen; $d=$ Prisma;

$B=$ Okular; e und $f=$ dessen Linsen; $C=$ Prisma um $45^{\circ}$ gedreht.

der Beobachter das Bild, welches auf dem darunter stehenden Zeichenbrett entworfen ist, und kann nun nachbilden. Dadurch daß beide Prismen rechtwinklig reflektieren, entsteht keine Bildverzerrung und darum ist das Instrument namentlich für embryologische Arbeiten fast unentbehrlich. His hat zur Zeichnung mit der Oberhäuserschen Camera seinen Embryographen konstruiert, der ron Hartnack fabriziert wird. Ein großer Nachteil haftet der Camera dann an, wenn man sehr starke Linsen anwenden muß; dann wird das Bild durch dic doppelte Prismenreflexion so lichtschwach, daß fast nichts $\mathrm{zu}$ sehen ist.

2. Camera lucida (Zeichenapparat), von Abbe. Im Gegensatz zum Oberhäuserschen hat der Abbesche Zeichenapparat das Prinzip, das Zeichenpapier und den Bleistift in das mikroskopische Bild 
zu projizieren. Der auf das Okular des Mikroskopes aufgesetzte Apparat besteht aus dem sogenannten Abbeschen Würfelchen und einem durch Hebelarm damit verbundenen Planspiegel. Das Würfelchen besteht aus zwei gleichschenkligen rechtwinkligen Prismen, welche zusammengekittet sind. Es wird in der Höhe des Augenortes, d. h. da, wo das Auge des Mikroskopikers beim Arbeiten sich befindet, angebracht. Das obere Prisma hat an der Kittfläche einen Silberbelag, dessen Mitte eine kreisförmige Öffnung von I oder 2 mm Durchmesser besitzt. Der Planspiegel, welcher seitlich an einem langen Hebelarm sitzt, muß im Winkel von $45^{\circ}$ eingestellt werden. Er entwirft von dem Zeichenpapier und der Bleistiftspitze, die senkrecht unter ihm sich befinden, ein Bild, das er in das Würfelchen

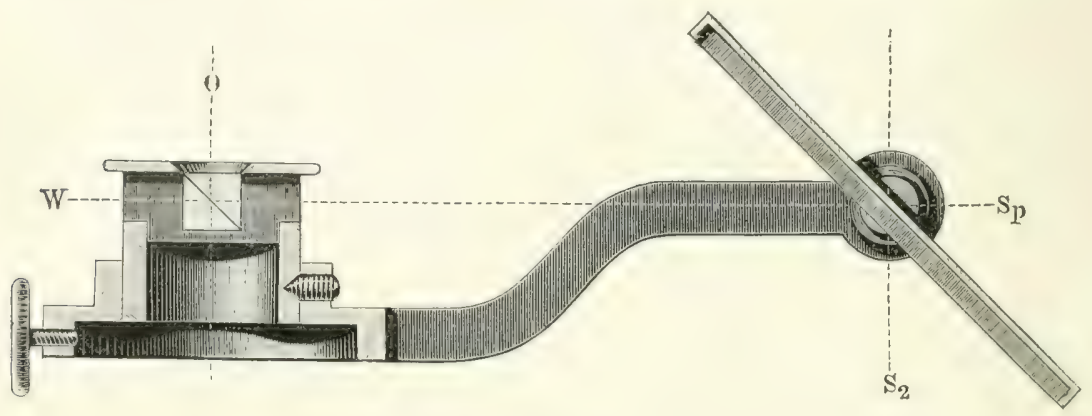

Fig. II. Camera lucida, nach Abbe.

$W=$ Abbesches Würfelchen; $O=$ Öfnung im Würfelchen; $S p=$ Spiegel。

reflektiert, und dieses wirft das l3ild nach unten ins mikroskopische Präparat. Sicht man nun von oben durch die Öffnung im Silberbelag des Würfelchens in das Präparat, so sieht man zu gleicher Zeit die Bleistiftspitze und kann so die Einzelheiten der Beobachtung auf dem Papier genau nachbilden, wenn man das Spiegelbild der Bleistiftspitze über die Einzelheiten hinwegführt. Entfernt man sich mit der Hand etwas vom Papier, so wird die Bleistiftspitze im Mikroskop undeutlich. Dieser Apparat ist bei allen Vergrößerungen gleich lichtstark.

Fïir die Verwendung dieses ausgezeichneten Instrumentes möchte ich folgende Verhaltungsmaßregeln der Beachtung empfehlen. Der Winkel des Spiegels muß genau $45^{\circ}$ betragen, sonst wird die Abbildung keine Zeichnung, sondern eine Verzeichnung. Das Zeichenpapier muß in der Höhe des Mikroskoptisches sich befinden, sonst tritt ebenfalls Verzeichnung ein. Die Öffnung im Abbeschen Würfelchen muß genau in der Achse des Tubus liegen, sonst wird das 
Bild unklar oder unvollständig. Mit Recht hat $\mathrm{Fol}$ darauf hingewiesen, daß die Helligkeit des Papieres und die des mikroskopischen Bildes iibereinstimmen müssen, sonst sieht man entweder das Papier nicht, wenn dieses zu schwach beleuchtet ist, oder man sieht das Präparat nicht, wenn das Papier zu hell ist. Die dem Abbeschen Apparate beigegebenen Rauchgliiser ermöglichen nicht immer eine ausreichende Verdunkelung des Papiers, daher muß man — es ist dies besonders der Fall, wenn man bei Immersion zeichnen will - zwischen Zeichenbrett und Fensterscheibe einen undurchsichtigen Gegenstand einschieben.

Man kann mit weichem sehr spitzem Bleistift bei beiden Zeichenapparaten den ersten Entwurf machen, dann die dunklen Striche vorsichtig wegradieren und mit einem harten Bleistift nachziehen. Oder man nimmt von vornherein einen harten Bleistift und gibt nach $\mathrm{Ab}$ nahme der Camera der Zeichnung die definitive Stärke.

Es wird vielfach empfohlen, zwei oder mehr Schnitte in der Zeichnung zu kombinieren - ausgeschlossen ist dabei die Verwendung einer Camera --, wenn die Struktureigentümlichkeit, die man abbilden will, sich auf 2 oder mehrere Schnitte verteilt. Dagegen ist nichts einzuwenden, wenn in der Figurenerklärung auf diesen Umstand aufmerksam gemacht wird. Ich rate aber davon ab, diese Manier allzu häufig anzuwenden; derartige Zeichnungen haben keine Naturtreue und kömnen leicht Mißtrauen in die Zuverlässigkeit der Angaben erwecken.

Die zahlreichen verschiedenen anderen Zeichenapparate sind alle auf eines der beiden hier beschriebenen Prinzipe zuriickzufiihren.

\section{\$ 100.}

Eine andere Art des Abbildens ist die Mikrophotographie. Ich gehe hier auf diese nicht näher ein, weil ihr Gebiet zu umfangreich ist, um in einem Kapitel eines allgemeinen Lehrbuches der Technik abgehandelt zu werden. Verschweigen will ich nicht, daß die Mikrophotogramme mir im allgemeinen recht wenig gefallen. Sie sind meist zu undeutlich, die Details zu verwischt, als daß sie eine gute Zeichnung zu ersetzen imstande wären. Und ferner erscheint mir die Exaktheit der mikrophotographischen Bilder oft recht zweifelhaft. IVenn man eine Landschaft photographiert oder ein Porträt anfertigt, dann hat man sichere Kriterien an der Hand, um entscheiden zu können, ob das Photogramm unter-, über- oder richtig exponicrt war. Denn man kann ohne weiteres das Negativ mit dem Original vergleichen und einwandfrei feststellen, daß die Expositions- 
dauer richtig war oder nicht, daß also das Photogramm gelungen ist oder nicht. Bei der Mikrophotographie ist diese Vergleichsmöglichkeit nicht vorhanden, wenigstens dann nicht, wann es sich um die photographische Wiedergabe bisher unbekannter Textur- und Strukturbilcier handelt. Dann soll ja durch das Photogramm erst festgestellt werden, wie beschaffen das Bild ist, und daher läßt sich ein sicherer Entscheid nicht fällen, ob während der Expositionsdauer Zeit genug vorhanden war, damit auf der photographischen Platte alle Einzclheiten in charakteristischer Schärfe sich abbilden konnten. Ver in die Mikrophotographie sich einarbeiten will, der ziehe eines der Lehrbücher zu Rate, welche diesen Gegenstand behandeln.

Anders liegt die Sache, wenn man in ultraviolettem Licht beobachten will. Hier kann man direkt das Objekt nicht untersuchen, man ist auf die photographische Platte angewiesen. Inwiefern die auf diesem Wege erhaltenen Bilder naturgetreu sind, vermag ich nicht zu beurteilen, da ich mit ultraviolettem Licht noch nicht gearbeitet habe.

\section{§ IOI.}

Für embryologische Zwecke und gelegentlich auch für morphologische ist ein Abbildungsverfahren ganz eigner Art ausgebildet worden, das hier in Kürze beschrieben werden soll. Es ist dies die plastische Rekonstruktion. Nan erreicht durch sie die Möglichkeit, Organisationsverhältnisse eines Embryo oder den morphotischen Aufbau eines Organes, welche ihrer Kleinheit wegen nicht mit Messer und Pinzette zu präparieren waren, in plastischer Form und in nicht unbeträchtlicher Vergrößerung zur Anschauung zu bringen. Die mit dieser Methode erzielten Resultate sind höchst beachtenswert. Der leitende Gedanke der Methode stammt von His, der stets einer Modellierung der Embryonen das Wort geredet und sie auch zur Ausführung gebracht hat. Das Naterial zur Ausführung der Rekonstruktion verdanken wir Born, welcher die Wachsplatten - mit Papier auf beiden Seiten überzogene gewalzte Wachsplatten - eingeführt hat. Strasser endlich konstruierte das Instrument, durch velches eine exakte Anbringung der sogenannten Definierebene - dieser Ausdruck wurde zuerst von Kastschenko gebraucht - ermöglicht wird. Dies Instrument ist der Ritzer. Ich beschreibe im folgenden nur die Bornsche Plattenmodelliermethode; andere Nethoden, wie die Rekonstruktion mit Karton, Celluloid usw, übergehe ich. Ihre Notwendigkeit vermag ich nicht einzusehen, sic stellen keine Bereicherung sondern eine Belastung unserer Methodik dar. 
Die Exaktheit der mit der Bornschen Methode zu erzielenden Resultate ist eine sehr große, vorausgesetzt, daß man überhaupt gewohnt ist, exakt und sauber $z u$ arbeiten, und nicht aus Bequemlichkeit usw. die Anfertigung von Schnittserien und die Ausführung der Rekonstruktion dem Laboratoriumsdiener überläßt.

Der Paraffinblock, der das zu schneidende und zu rekonstruicrende Präparat birgt, muß rechteckig zugeschnitten werden, damit die Anbringung der Definierebene erfolgen kann. Ein Schneiden mit quergestelltem Messer ist nicht absolut notwendig, man kann selbst bei rechteckiger Schnittläche die schräge Messerstellung anwenden. Bedingung fuir das Gelingen der Rekonstrultion ist, daß nach Anbringung der Schnittfläche am Paraffinblock dieser nicht mehr aus der Präparatenklammer entfernt wird und daß das Mikrotommesser während der Dauer der Anfertigung der ganzen Serie in seiner ersten Stellungeingespannt bleibt. Die Schnittfäche und diejenige Fläche, auf welcher die Definierebene angebracht wird, müssen genau einen Winkel von $90^{\circ}$ miteinander bilden. Das ist auszuführen, wenn man den Paraffinblock auf eine Klammer aufschmilzt, welche um $90^{\circ}$ gedreht werden kann; der Paraffinblock selber darf, wie gesagt, nicht geriihrt werden. Man stellt also zunächst die Schnittfäche her, dreht die Klammer um $90^{\circ}$ und macht die zur ersten senkrechte Fläche. Damn zieht man den Messerschlitten zuriick, bringt auf dem Messer den Ritzer an und führt diesen über die zu zweit hergestellte Ebene hinweg. So stellt man ein System feiner Rillen her, die wie die zwischen ihnen liegenden flachen Partien mit Ruß überzogen werden müssen. Den Ruß gewinnt man, indem man ein Stïckchen Kampfer anzündet - ich entnehme diese Angabe dem Buche von Röthig - und den sich hierbei bildenden Ruß auf dem gewölbten Teil eines Uhrschälchens auffängt. Dann taucht man einen feinen Haarpinsel in Chloroform, nimmt mit dem feuchten Pinsel den Ruß auf und bestreicht damit die geritzte Fläche. Das Chloroform ist nach 24 Stunden völlig verdunstet und nun schmilzt man auf die berußte Fläche Paraffin auf.

Die eben geschilderte Methode stellt nur das Prinzip dar, das in verschiedener Weise individuell modifiziert werden kann, wenn auch nicht jede Modifikation den Wert einer Methode beanspruchen darf. Ebenso hat der Strassersche Ritzer sehr viele Modifikationen erfahren, von denen die nach den Wünschen von Röthig durch R. Magen in Berlin ausgefiihrte sehr zweckmäßig ist.

Wenn die Serie geschnitten ist, dann wird mit Hilfe des Zeichenapparates auf der Wachsplatte gezeichnet. Die Dicke der Schnitte und die gewünschte Vergrößerung entscheiden über die Dicke der 
Wachsplatte und auch dariber, ob jeder Schnitt abgezeichnet werden mul3 oder ob einzelne Schnitte ausgelassen werden können. Nach Beendigung des Zeichnens entfernt man das Papier, schneidet aus der IVachsplatte alles heraus, was nicht zu rekonstruieren ist, läßt letzteres mit der Definierebene in Verbindung und legt die einzelnen Platten so aufeinander, da $\beta$ sich die Definiercbenen decken. Dann werden diese mit den Verbindungsstiicken entfernt, das erhaltene-Modell wird mit einem heißen Spatel geglättet und kann eventuell mit Ölfarbe überzogen werden. Die plastische Rekonstruktion ist nicht leicht ausführbar, so zahlreich auch die Einzelvorschriften der Autoren sind. Dennoch aber scheue der Anfänger nicht die Mühe, sich in die Methode hineinzudenken und hineinzuarbeiten: der Lohn entspricht der aufgewandten Arbeit. 


\title{
Zweiter Teil.
}

\section{Die Anwendung der Methoden.}

\author{
§ 102.
}

Zur Orientierung. Nachdem wir die cinzelnen Methoden, mit Hilfe deren eine mikroskopische L'ntersuchung angestellt werden kann, im I. Teil kennon gelernt hahen, soll in diesem Teil deren Anwendung auf die verschiedenen ()rgine und Gewebe beschricben werden. Es kann diese Beschreibung natiirlich nicht die Becleutung haben: so muß es gemacht werden, sondern es kommt ihr nur die Bedeutung zu: so ist es gemacht worden. Darum braucht nicmand, der an die mikroskopische Erforschung irgundeines Gebildes herantritt, die Methoden nachzumachen, die seine Vorgänger angewandt. Lir sollte dics aber tun, um Verylcichsobjekte für die erentucllen cignen Nethoden zu erlangen, um zu crkennen, wie die bisherigen Resultate der Forschung gewonnen sind und inwicweit deren Begründung eine cinwandfreie ist. Gar schr erscheint mir nämlich unsere Methodik reformbediuftig, wenigstens soweit Zellstrukturen in Frage kommen. Dennoch möchte ich nicht einer Polypragmasie das Wort reden, da wir daran schon allzusehr leiden. Wohl aber sei auch bei dieser Gelegenheit darauf hingewiesen, daß wir zurzeit noch keinen Maßstab besitzen, um zu erkennen, inwieweit unsere Fixierungsmethoden natürliche Verhältnisse erhalten und unsere Färbungen differente Funktionen in die Erscheinung treten lassen.

IVonn in den einzelnen Kapiteln dieses Teiles auf hereits beschriebene Methoden hingewiesen werden muß, so wird das betreffende Kapitel des I. Teiles, sowie eventuell die laufende Nummer in den Kapitel zitiert werden. Dic hier aufufuihrenden Spezialmethoden gelten nur für das ()rgan bez. Gewebe und nur für den Zweck, wo- 
fiir sic empfohlen sind. Erzielt man mit derartigen Methoden an anderen wie den genannten Objekten keine Resultate, so darf daraus den Autoren der Methoden kein Torwurf erwachsen. Immerhin diurfte us sich aber lohnen, Torschriften, welche für einen bestimmten Zweck Torzuigliches leisten, daraufhin zu prüfen, worin diese Leistung begruindet ist. Man wird so die Möglichkeit crhalten, von eincm festen Punkte aus neue Wege zu finden, auf denen man an anderen ()bjekten zu guten, einwandfreien und darum sicheren Resultaten wird gelangen können. Unser Fortschritt in der Histologie ist der Hauptsache nach ein methodologischer. Die Texturverhältnisse der Organe und Gewebe sind wenigstens bei den Hauptrepräsentanten der meisten Typen uns bekannt. Und wo dies noch nicht ausreichend der Fall, wo sich noch erhebliche Lücken finden (z. B. Bindesubstanzen der Wirbellosen, da handelt es sich um relativ einfache Lntersuchungen, die ohne komplizierte Methodik ausgefüht werden können. Was uns fehlt, ist der Einblick in den Aufbau der Zelle und damit in deren Physiologie. Einzelhinntnisse besitzen wir, aber wir können deren Wert nicht abschätzen und wir wissen nicht, was wir aus ihnen für Schliisse zu ziehen berechtigt sind. Die Cellularphysiologie ist noch immer ein Desiderat; sie zu begründen und auszubauen ist die Aufgabe der histologischen Forschung. Lnd gelöst werden kann diese Aufgabe nur durch den Fortschritt der Methodik, der zugleich ein Vorschritt sein muß.

Die Einteilung in dic einzelnen Kapitel ist dic naturgemäßs, wie sie in den Lehrbuichern der Histologic gebräuchlich ist. Das Bewegungssystem allerdings brauchte nicht besonders behandelt zu werden, da IIuskeln und Knochen anderweitig Lnterkunft gefunden hahen. Lnd ebenso ist dem Nervengewebe kein besonderer Platz eingeräumt worden, sondern es werden die Ganglienzellen beim zentralen und die Nervenfasern beim peripheren Nervensystem erledigt werden. Wenn keine besonderen Bemerkungen sich finden, so gelten die Vorschriften auch für die Gewebe und Organe der Evertebraten. 


\section{Dreizehntes Kapite1.}

\section{Die Zelle.}

\section{$\$ 103$.}

Die lebende Zelle. Die Protozoën sind es, an welchen die Vorgänge in den lebenden Zellen untersucht werden können. Amöboide Bewegung: Körnchenströmung, Wimperbewegung, Geißelbewegung, Kontrahtilität: alle diese Lebensäußerungen können an den stets oder fast stets mikroskopischen Protozoën unter dem Mikroskop genau studiert werden. Ebenso ist die Art der Nahrungsaufnahme zu verfolgen, die Assimilation dagegen natiirlich nicht. Daß die Fortpflanzung am lebenden Objekt studiert werden kann, ist nicht minder wertvoll. Selbstverständlich müssen die Protozoën, da sie alle Wassertiere sind, in dem ihnen zugehörigen Medium untersucht werden, also entweder im süßen oder im Seewasser.

Die Methode, mittels der man die Protozoën unter das Mikroshop bringt, ist ziemlich gleichgiiltig. Gemeinhin wird man in einem Glase, das protozoënhaltiges Wasser enthält, den Boden und die Wände mit einer Pipette absuchen und Tropfen für Tropfen unter das Mikroskop bringen, um zu sehen, ob die gew uinschten Formen vorhanden sind. Diese kann man, wenn man nicht sofort zu genauerer Untersuchung schrciten will, isolicren, indem man sie in flache Schalen gibt. wclche grüne Pflanzenteile zur Entwicklung des Sauerstoffs enthalten, oder indem man sie in Schaudinns Mikroaquarium bringt $\mathrm{rgl}$. zweites Kapitel. Zur Untersuchung gibt man einen Wassertropfen, der Protozoën enthält, auf einen Objektträger, deckt entweder mit einem Deckglase ein oder läßt unbedeckt. Sehr zweckmäßig ist oft dic Untersuchung im hängenden Tropfen, weil man hier seitlich dem Tropfen Reagention zufügen kann, wodurch die Tiere leicht gelähmt werden. Das ist namentlich beim Studium der Wimperbewegung der Infusorien nötig, da bei der Schnelligkeit, mit der diese Tierchen im Wasser hin und herschwimmen, an eine genaue Betrachtung nicht zu denken ist. Auch die Schulzesche feuchte Kammer und das Schaudinnsche Mikroaquarium sind für Protozö̈nstudien bestimmt zweites Kapitel. Eine feuchte Kammer ist auch gecignet, gewöhnliche Protozoënpräparate — Tropfen auf Objektträger mit Dechglas eingedeckt - tagelang aufzubewahren. und gestattet so, cin oder mehrere Tiere gewissermaßen in Reinkultur zu untersuchen. 
Dic Untersuchung im hängenden Tropfen und im Schaudinnschen Mikroaquarium gibt auch die Möglichkeit, vitale Färbungen mit Protozoën vorzunehmen. Die ersten Versuche rihren von K. Brandt her, der Bismarckbraun in der Lösung von I : 5000 verwendete. Certes nimmt Dahlia und Chinolinblau, ersteres I : Ioooo, letzteres I : 500000 Wasser. Man setzt den Farbstoff in Substanz zu dem protozoënhaltigen Wasser und läßt ihn sich darin lösen, so daß die erwähnten Konzentrationsgrade entstehen. Diese vielversprechenden Methoden sind leider von den Protozoënforschern gar nicht aus- und durchgebildet worden, so daß sie für unsere Kenntnis vom Bau der Zelle kein Material geliefert haben. Und dennoch wäre durch dic Protozoën auch ein Aufschluß iiber die Zelle der Metazoën zu erhalten.

Lebende Zellen der Mctazoën zu untersuchen, gelingt nur in den seltensten Fällen. Spermatozoën, durchsichtige Eier, namentlich von Echinodermen, sind dem Mikroskope ohne weiteres zugänglich. An letztgenanntem Objekt wurde der Vorgang der Befruchtung und der Eifurchung intra vitam studiert, wodurch uns tiefe Einblicke in das Vesen der Fortpflanzung und Vererbung ermöglicht wurden. Hat man Eier ron Echinodermen kïnstlich besamt - diese Bemerkung möge hier Platz finden --, dann gieße man vorsichtig das trube Nasser, das die Schale erfüllt, von den Eiern ab und crsetze es durch frisches Seewasser. Dann kann man die Beobachtung bis zur Pluteusbildung fortsetzen. Wie Echinodermeneier sind auch die von Tunicaten (Phallusia z. B.) zu verwenden.

Ganze Ticre kann man ebenfalls mikroskopisch ohne weiteres untersuchen, sie müssen nur diinn und klein genug sein. Z. B. die Chätognathen, Rotatorien, Cresëis, durchsichtige Larven usw: Doch wird es sich dabei kaum jemals ermöglichen lassen, in vivo Zellstudien zu unternehmen. Den morphologischen Aufbau zu crkennen, ist nicht mit Schwierigkeiten verknüpt; aber den feincren Bau der Organe dürten selbst bei Rotatorien die Untersuchungen der lebenden Tiere uns kaum enthiillen. Zu derartigen Zwecken muß man zum konservierten Objekt und zum dünnen Schnitt greifen.

Nur cine Zellform der Metazoën ist in allen ihren Lebensäußerungen gicich einem Protozoon zu beobachten: nämlich die Leukocyten der Virtebraten. Die Methode, wie man I.eukocyten in großer Menge zur Untersuchung erlangt, soll im sechzehnten Kapitel beschrieben werden.

\section{$\S 104$.}

Die überlebende Zelle. Die Zellen der Metazoën, sollen sic in möglichst frischem Zustande untersucht werden, können nur als 
iiberlebende unter das Nikroskop kommen. Das geschieht, indem man Teilchen der Organe entweder mit einer auf die Fläche gebogenen Schere abschneidet und in einer indifferenten Flüssigkeit untersucht, z. B. physiologischer Kochsalzlösung (vgl. zweites Kapitel), oder indem man in anderer geeigneter Weiser frische Organstückichen abträgt. Ganz besonders interessant und wichtig ist diese Methode der Untersuchung bei der Beobachtung der Wimperzellen. Der Mantelrand der Muscheln, die Pharynxschleimhaut des Frosches sind sehr geeignete Objekte hierfür; ersteren untersucht man in dem Wasser des Aufenthaltes der Tiere, letztere in physiologischer Kochsalzlösung:

Aber nicht bloß für die Feststeliung der Vimperbewegung ist diese Art der Beobachtung von Wert; sie sollte überall, wo es nur irgend angeht, gebraucht werden. Denn z. B. die Formen der Zellteilung lassen sich, wie Flemming gezeigt hat, an frischem Material sehr gut crkennen. Nan zerschneidet zu dem Zwecke Hoden von Salamandra maculosa mit der Schere in kleine Partikelchen und untersucht sie nach leichtem Zerzupfen in physiologischer Kochsalzlösung. Eine Nasse gut erhaltener Zcllen schwimmt im I'räparat herum, von denen manche sehr deutlich die Formen der Karyokinese zeigen. Ebenso sind Leber, Milz und Lymphdriisen Organe, von welchen mit Leichtigkeit Präparate der ïberlebenden Zellen angefertigt werden können. An anderen Organen dagegen lassen sich derartige Untersuchungen kaum ausführen, namentlich versagen Gehirn und Rückenmark völlig.

Als eine Behandlung ïberlebender Zellen betrachte ich dic Darstellung der Kittlinien der Endothelzellen. Man benutzt dazu - wenn man nämlich Demonstrationspräparate haben will - Mesenterium und Ligamentum suspensorium hepatis vom Frosch und Centrum tendineum des Diaphragma vom Mcerschweinchen. Die ersteren Präparate fertigt man so an, daß man ein Deckgläschen von i $8 \mathrm{qmm}$ unter das Mesenterium legt oder das Ligamentum hepatis auf einem solchen ausbreitet. Das Mesenterium schneidet man so an den Rändern des Deckglases ab, daß es etwas uibersteht. Fast von selber legen sich dann die Ränder des Mesenteriums nach unten um, so daß das Präparat scine natiirliche Spannung beibehält. Centrum tendineum legt man auf einen Objelitträger. Alle ähnlichen Membranpräparate bringt man auf solch eine gläserne Unterlage und läßt sie auf dieser leicht antrocknen. Dann bringt man sic in die Fixierungsflüssigkeit bzw. im vorliegenden Fall in die Höllensteinlösung und bedient sich dabei der Methoden von Ranvier oder Deckhuyzen Ivgl. neuntes 
Kapitel Nr. 9 u. Io S. 2I3). Heben sich in der Flüssigkeit die Membranen von ihrer Unterlage $a b$, dann bleiben sie gespreitet und es tritt keinerlei Schrumpfung mehr ein.

\section{$\$ 105$}

Die mazerierte Zelle. Die Methoden der Mazeration enthält das dritte Kapitel; dort ist auch beschrieben worden, daß man zur Anfertigung von Dauerpräparaten der Zentrifuge mit Erfolg sich bedienen kann. Zur Mazeration von Epithelien und Drüsen dienen am besten die dünnen Alkohole und Oxalsäure, zur Mazeration von Nervenzellen ${ }^{\top} / 4$ Alkohol und die dünnen Chromgemische. Zur Färbung scheint mir am geeignetsten Goldchlorid in ganz dünner Lösung und nächst ihm mein Glyzerinkarmalaun (vgl. achtes Kapitel Nr. 25 S. 170$)$.

\section{$\$ 106$.}

Die fixierte Zelle. Zunächst muß die Struktur der ruhenden Zelle crforscht werden. Hicrzu reichen die bisherigen Methoden nicht aus und darum müssen die Fixierungsmittel in IVirksamkeit treten.

Bei Protozoën ist es nötig; die Tierchen vor Anwendung der Fixierung zu lähmen. Denn da alle Fixierungsmittel starke chemische Reize ausüben, auf welche der lebende Organismus normalerweise mit einer heftigen Kontraktion antwortet, so muß diese Reaktion nach Möglichkeit ausgeschaltet werden. Man crreicht dies, indem man die Tiere zu betäuben oder zu ersticken sucht. Zu dem Zweclie setzt man zur Untersuchungsfluissigkeit ganz dünnen Alkohol, Methylalkohol, Cocainlösung, Chloralhydrat, vielleicht auch Curarelösung. Chloroform und $\ddot{A}$ ther, die sich mit IVasser, in welchem die Protozoën untersucht werden, nicht mischen, haben die Eigenschaft, durch ihre Dämpfe betäubend zu wirken, indem diese in das Wasser eindringen. Sehr rationell ist fur diese Zwecke und für die nummehr folgende Fixierung das Mikroaquarium von Schaudinn, dessen Verwendung im zweiten Kilpitel beschrieben wurde. Hat man die Tiere auf dem Objektträger betüubt - und es empfiehlt sich, hierfür mit einem Deckglase einzudecken - so saugt man das Wasser auf der einen Seite des Dechglases mittels Filtrierpapier ab, indem man gleichzeitig auf der anderen Seite das Fixicrungsreagens zusetzt. Sublimat, Pikrinsalpetersäurc, $\mathrm{I} \%$ Osmiumsäure, Flemmings- und Hermanns-Flüssigkieit werden als vorziiglich empfohlen (viertes Kapitel). Zur Fixierung von Flagellatenkolonien Uroglenakugeln) empfiehlt Zacharias ein Gemisch 
von 2 Volumina konzentrierter wässriger Borsäurelösung und $3 \mathrm{Vo}$ lumina gesättigter wässriger Sublimatlösung. Nach 3 stiundiger Einwirkung wird in $2^{\circ}$, Formollösung aufgehoben. Fol fixiert Tintinnen mit Eisenperchlorid (vgl. viertes Kapitel Nr. 88 S. 78). Noch zahlreiche andere, oft sehr sonderbar komplizierte Methoden sind angegeben, für deren Komplikation ein zureichender Grund nicht einzusehen ist. Man wird im allgemeinen mit den im vierten Kapitel beschriebenen Mitteln auskommen, nur muß man, da wir eben kein allen Anforderungen genügendes Reagens haben, jedesmal crst ausprobieren, welche Vorschrift anzuwenden ist. Dic Arbeiten der Autoren, d. h. die zu berücksichtigende Literatur, geben hierüber den nötigen Aufschluß.

Sehr originell ist die Anwendung des Methylgrüns in stark saurer Lösung. Bütschli hat, wenn ich nicht irre, als der erste die gefärbte Essigsäure für Protozoën als zugleich fixierendes und färbendes Reagens empfohlen. Beim Methylgrün verfährt man nun folgendermaßen: Man reinigt es zunächst vom Methylviolett, indem man seine konzentrierte wässrige Lösung mit Amylalkohol (nach Fischer) oder mit Chloroform 'nach Mayer! schuittelt. Diese nunmehr rein grüe Farbe wird mit Lssigsäure versetzt, so daß die Farbflotte $I^{\circ}$ 。 der Säure enthält. Resultat: reine Kernfärbung und gute Fixierung.

Interessant ist folgende Methode ron Rhumbler. Man fixiert in Pikrinschwefelsäure (viertes Kapitel) oder Alkohol und färbt in nachstehendem Gemisch: I ${ }^{\circ}$ owässriges Methylgrün 5o Teile, o, $8 \mathrm{~g}$ Eosin in $50 \%$ Alkohol gelöst 50 Tcile, Alkohol absolutus 50 Teile. Schnitte oder ganze Protozoën werden darin ${ }^{\prime \prime}$. Stunde gelassen, dann wird in Wasser ausgewaschen und in Alkohol von steigender Konzentration schnell gehärtet, so daß die ganze Prozedur nach dem Färben in ${ }^{x}$ Stunde beendet ist. Montiert wird beliebig. Nas zur Zeit der Fixicrung noch lebendig war, ist grellrot gefärbt; was abgestorben war, erscheint ebenso wie färbbare anorganische Einschliisse grellgrïn. Wo beide Substanzen, lebendige und tote, gemischt sich finden, da ist der Farbenton rotviolett, violett, blau oder blaugrün.

Protozoën müssen unter Umständen geschnitten werden. Im sechsten Kapitel (S. IO4) ist gezeigt worden, daß das Mikroaquarium von Schaudinn eine schr leichte Einschmelzung in Paraffin ermöglicht. Die Schnitte können dann je nach der vorausgegangenen Fixierung mit Eisenhämatoxylin, Safranin, Fuchsin oder dem Flemmingschen Orangeverfahren gefärht werden achtes Kapitel). Safranin und die anderen basischen Aniline werden die Kernstrukturen besonders herrorheben, dic Eisenhämatoxylinlacke sind zur Darstellung der Centro- 
somen und etwaiger fädiger Strukturen gecignet, das Orangeverfahren zeigt heiderlei Strukturbilder. Tielleicht empfichlt es sich, dic von Neigert modifizierte van Giesonsche Färbung achtes Kap. Nr. I 20 S. Iy7) auch bei Protozoën zu versuchen. Bei Metazoën gibt sie sehr schöne Bilder.

\section{s. 107.}

Die ruhende Zelle der Metazoën läßt ihre Struktur am besten an solchen Objekten crkennen, welche großzellig sind. Die Ovarialeier und die Ganglienzellen aller Gruppen bilden treffliche Objekte für Studien iiber Zellstrukturen, da sie große Zellen sind und sich relativ leicht in gutem Zustande fixieren lassen. Ferner kommen in Betracht die Organe der urodelen Amphibien, der Selachier und der Arthropoden. Diese drei Gruppen sind dadurch dem Histologen wertvoll, daß sie schr große somatische Zellen besitzen. Weniger groß, doch immerhin noch wohl verwendbar für cytologische Studien sind die Organe der anuren Amphibien. Die Organe der Sauropsiden, der Süuger und der anderen Typen sind kleinzellig. Wohl ist es unbedingt erforderlich, daß man auch an den kleinzelligen Tiertypen cytologische Studien macht, schon um die Lberzeugung zu gewinnen, ob und daß anderweitig gemachte Befunde allgemeine Guiltigkeit beanspruchen dürfen, aber beginnen mul3 man immer mit großzelligen Formen. In den kleinen Zellen sind alle Struktureinzelheiten so eng: ancinander gedrängt, diese Einzelheiten selber sind so intriliater Natur, daß es sehr schwer ist, sie auseinander zu halten, ja auch nur sie zu erkennen. An großen Zellen dagegen finden sich, wie die Erfahrung gelehrt hat, übersichtlichere Verhältnisse.

Als Regel für jede Fixierung zu cytologischen Studien ist festzuhalten, dal3 die Objekte möglichst klein, die fixierende Flüssigkeit möglichst reichlich gewählt werde. Große Organe (Leber, Milz, Nierc) müssen daher zerschnitten werden. Zellstudien an Frosch-, Salamanderund Tritonenhoden bedingen dagegen, daß die Organe nicht zerkleinert werden. Durch das Anschneiden und das nachherige Fixieren wcrden die einzelnen Hodenteile aus ihrer Lage gedrängt und damit die Zellen vielfach lädiert. Sehr wechselnde Resultate erhält man bei der Fixierung der Süßwassercrustaceen: dasselbe Reagens wirkt das eine Alal rorziglich cin, während es ein andermal völlig rersagt.

Als fixierende Reagentien kommen in erster Linie in Betracht: Carnoysche Fliissigkeit, Flemmings-, Hermanns-Gemisch. Sublimat, die Torschriften von van Beneden, Zacharias diese beiden besonders für Nematodeneier), von Zenker und von Benda. In 
zweiter Reihe stehen die chromhaltigen Gemische ohne Osmium, Pikrinsalpetersäure und ähnliche Lösungen. Die Niessingschen Flüssigkeiten sollen besonders bei Milz und Leber von Salamandra angebracht sein. (Über die Zusammensetzung der erwähnten Reagentien vgl, viertes Kapitel.)

Die Bestandteile der Zelle: Centrosoma mit Attraktionssphäre die Terminologie ändert sich hierin vielfach —, die Filarsubstanz, der Kern mit seinen Nucleolen, dem Chromatin und dem Linin werden von den rerschiedenen Mitteln nicht in gleicher Weise fixiert. Oft ist nur die Zellsubstanz, oft nur der Kern gut crhalten. Und dieselben Reagentien ändern ihre IVirkung nach dem Tiertypus. Die Crustaceen verlangen eine andere $\mathrm{Be}-$ handlungsweise wie die Amphibien; so haben mir z. B. Sublimat und Pikrinsalpetersäure bei Crustaceen ganz versagt, die Flemmingsche Lösung gab einigermaßen brauchbare Bilder an den Kernen der zentralen Organpartien. Gut fand ich als Fixierungsmittel bei Crustaceen den Alkohol absolutus und die ran Benedensche Mischung; wahrscheinlich wird auch das Carnoysche Reagens beachtenswerte Resultate liefern. Bei Mollusken versagte Sublimat mir

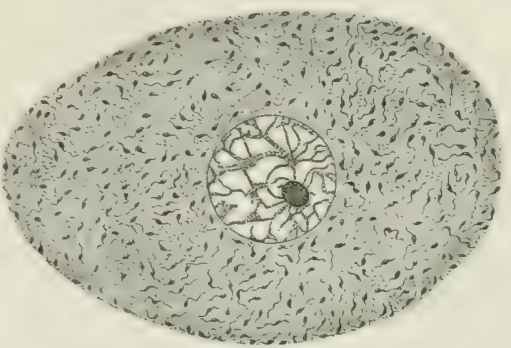

Fig. I2. Spinalganglienzelle, rom Hunde; Schnitt aus einem Chromsäurepräparat mit Hämatuxỵlin gefärbt. Im Zellleib geschlängelte Fäden mit dickeren Knötchen; beide nehmen die Blauholzfärbung an, jedoch in schwächerem Grade als der Kern mit seinem netzfömigen Geriiste und dem Nucleolus; nach Flemming. ganz, brauchbare Resultate erhiclt ich bei diesem Typus allein mit Pikrinsalpetersäure, die ebenfalls bei den Raubanneliden gute Dienste tat. Bei Medusen fand ich Sublimat vorzüglich, während ich mit Flemmingscher Lösung geradezu schlechte Resultate erhielt. Die Poriferen sind am besten in absolutem Alkohol zu fixieren.

Indessen: alle diese und noch andere von den Autoren mitgeteilten Erfahrungen haben doch nur approximativen Wert. Man muß von ihnen ausgehen, um nicht ohne weiteres nur Mißerfolge zu erzielen, dann aber muß man sich seinen Weg selber suchen. Erhält man die Bilder, welche die Autoren veröffentlicht haben, nach genauer Innehaltung ihrer Torschrift wieder, dann kann man ihre Angabe bestätigen. So z. B. wenn man bei Ganglienzelluntersuchungen das obenstehende Bild erhält, dann hat man die Flemmingschen An- 
gaben bestätigt; ob diese aber richtig sind oder, was dasselbe bedeutet, ob das mikroskopische Bild die natïrlichen Verhältnisse wiedergibt, folgt aus dieser Bestätigung keineswegs. Dic L'nsicherheit hinsichtlich der Bedeutung der Fixierungsmittel ist sehr groß, woruber das vierte Kapitel zu vergleichen ist.

Sehr wichtig für die Erkennung der Elemente der Zelle ist nächst der Fixierung die Färbung; daß hier die Sicherheit nicht größer ist als beim Fixieren, lehren die theoretischen Auseinandersetzungen im achten Kapitel.

Für die Eier der Ascariden (und anderer Nematoden) sind die Karmine und Hämateïne (bzw. Hämatoxyline) als Kernfärbemittel ausreichend; die letzteren Farbstoffe vielleicht in Kombination mit Eosin. Herla und Zoja fixieren die Eier von Ascaris megalocephala in Alkohol-Eisessig (5: I) 24 Stunden lang und färben dann 48 Stunden in einer Bismarckhraunlösung, die warm gesättigt und nach dem Erkilten filtriert wurde. Aufgehoben wird in ${ }^{T / 3}$ Glyzerin und ${ }^{2}$ Wasser.

Zur Darstellung der Centrosomen sind die zurzeit hauptsächlich angewandten Methoden der Heidenhainsche Hämatoxylineisenlack mit und ohne Vorfärbung in Bordeauxrot, sowie Bendas Hämatoxylinlacke (vgl. achtes Kapitel Nr. 122-124). Die beste Vorbehandlung ist, besonders für die Riesenzellen des Knochenmarks, die Fixierung in Sublimat. Neucrdings hat Benda zur Darstellung der Centrosomen die folgende Methode angegeben: Er härtet in $90 \%-95 \%$ Alkohol vor und kann noch infolge einer geeigneten Nachchromicrung 5 Jahre altes Alkoholmaterial verwenden. Die Färbung gelingt an Gefrier-, Paraffin- und Celloidinschnitten. Der Modus procedendi ist der folgende: Härtung in $93^{\circ}$, Alkohol mindestens 2 Tage. Dann für 24 Stunden in I ccm offizinelle Salpetersäure und $10 \mathrm{ccm}$ Aqua communis. Wahrend im Alkohol die Objekte voluminös sein konnten, müssen sie vor Einbringen in die Salpetersäure in $0,5 \mathrm{~cm}$ dicke Scheiben zerteilt werden, weil sonst die Salpetersäure den Alkohol nicht vertreiben kann. Aus der Salpetersäure für etwa 24 Stunden in $2 \%$ Kalibichromicumlösung, dann für etwa 48 Stunden in $\mathbf{I}_{\%}^{\circ}$ Chromsäurelüsung. Dann wird gründlich gewässert und entweder mit dem Gefricrmilirotom geschnitten oder nach langsamer Alkoholhärtung in Paraffin oder Celloidin eingebettet. Die Schnitte kommen auf 5 Minuten in $0,5^{\circ}$. Lösung von übermangansaurem Kali, werden dann in einer Lösung, welche Natriumnitrat und Oxalsäure nach der Formel der Palschen Fürbung enthält (vgl, achtes Kapitcl Nr. I27 S. =02, reduziert, bis sic weil sind. Man trocknet die Schnitte und uiber- 
spült sie mit folgender cbenfalls von Benda angegebenen Lösung von Kristallviolett: alkoholische Lösung von Kristallviolet I, Salzsäurealkohol I, Anilinwasser 2. Dann wird abgetrocknet und mit Lugolscher Lösung überspïlt, nach gründlichem Abtrocknen in Anilinöl-Xylol (zu gleichen Teilen', differenziert, dann wiederum abgetrocknet (zwischen Filtrierpapier), mit Xylol überspiilt, in Balsam aufgehoben.

Fast in jeder Zelle sind die Centrosomen sichtbar.

Eine andere Färbung, die ebenfalls ron Bunda herrihht, ist dic folgende. Schnitte, die von einem Alkoholmaterial stammen, das in der eben beschriebenen IVeise chromiert wurde, kommen zur Beizung in $t^{\circ}$ 。 Eisenalaunlösung oder in rerdünnten Liquor ferri sulfurici oxydati ( 1 : 2 Volumina Wasser, für 24 Stunden. Dann werden sic gründlich in fließendem Wasser oder in Schalen, deren Wasser vielfach crneuert wird, gewaschen und kommen für $2+$ Stunden in eine dünne (bernsteingelbe' wässrige Lösung von sulfalizarinsaurem Natron. Nach dem werden sie in Wasser eingetaucht, auf Filtricrpapier abgetupft und in $0, I^{\circ}, \circ$ wässrige Toluidinblaulösung übergefiihrt. In dieser Farbflotte bleiben die Schnitte entweder I-2.t Stunden bei Zimmertemperatur oder man crrärmt das Uhrschälchen mit der Farbflotte und den Schnitten und läßt is Minuten in der erkaltenden Flüssigkcit. Nunmehr werden die Schnitte in $1 \%$ Essigsäure cingetaucht, mit Fließpapier abgetrocknet, in absoluten Alkohol eingetaucht und in Buchenholzkreosot io Minuten lang differenziert Kontrolle durch das Mikroskop, dann Abtrocknen, Xylol, Balsam. Auch bei dieser Methode sind fast in allen Zellen die Centrosomen sichtbar. Statt des Alizarins empfiehlt Benda cine hellgelbe Hämatoxylinlösung (2+ Stunden, Waschen in gewöhnlichem Wasser und Entfärben mit IVeigerts Blutlaugensalz (achtes Kapitel S. 201). Ferner sind für Zellstrukturen als Färbungsmittel rerwendbar Ehrlich-Biondis Dreifarbengemisch, Triacid und, besonders nach Fixierung in Flemmingscher oder Hermannscher Lösung, das Orangeverfahren ron Flemming (achtes Kapitel Nr, I I 7).

Für Sublimatmaterial empfiehit Pianese folgende Färbung: Nalachitgrün $0,5 \mathrm{~g}$, Säurefuchsin $0, \mathrm{I} \mathrm{g}$, Nartiusgelb o, o $\mathrm{g}$, Aqua destillata $150 \mathrm{ccm}, 96^{\circ}$. Alliohol $50 \mathrm{ccm}$. In dieser Farbflotte bleiben die Schnitte ${ }_{2}+$ Stunden, werden flüchtig in Wasser abgespuilt, in salzsaurem Alkohol ( $\mathrm{r}$ : 10000) differenziert und auf gewöhnliche Weise in Xylolbalsam montiert. Das Resultat ist: Protoplasma, Plasomen, Plasomenketten leuchtend rot, $Z$ wischensubstanz ungefärbt, intensive Granula im Protoplasma und Kerne rot, Nucleolen violett. 
Die eben genannte Methode hat uns auf einen Bestandteil der Zellsubstanz gefuhrt, der neuerdings Gegenstand eifriger Forschung Geworden ist: die Mikrosomen, Plasomen, Mitochondria. Es handelt sich hier wohl nur um rerschiedene Namen für dieselben Gebilde. Am Ascaridenei kann man bei günstiger Fixierung - ich habe mit Erfolg bei Ascaris mystax alkoholische Salpetersäure angewandt - die Mikrosomen oft schon bei einer gewöhnlichen Färbung schen, bei der der Kern intensiv gefärbt ist, die Zellsubstanz dagegen nur einen leichten Farbenhauch angenommen hat (Hämalaune, Karmalaune; achtes Kapitel. Bei allen anderen Zeliarten bedarf es dagegen besonders sorgfältiger Vorbehandlung, um diese Gebilde sichtbar zu machen. Dic Methoden, welche zur Darstellung der Mitochondria gecignet sind, stammen ron Benda; es sind die folgenden:

Das Material wird in $10 \%$ Formol gehärtet, dann ohne Auswaschen in Chromsäure von steigender Konzentration nachbehandeit. Und zwar kommen die Stiicke zunächst in Chromsäure von $0,25^{\circ}$, für I Tag, dann in $0,33 \%$ für I Tag und schließlich für $2-3$ Tage in $0,5 \%$ Chromsäure. Dann wässert man 2-3 Tage, härtet in Alkohol ron steigender Konzentration, führt in Burgamottöl über, darauf in Benzin-Paraffin man muß offene Gefüße nehmen; bei Zimmertemperatur, bis das Paraffin auskristallisiert, dann stellt man für cinige Stunden in den Paraffinofen. Die Färhung ist die gleiche wie bei der nächsten Methode. Benda hat nämlich noch folgende Fixierung: zur Darstellung der Mitochondria empfohlen:

Die lehensfrischen Gewebsstiicke kommen in kleinsten Portionen in sehr viel Flemmingsche Lösung und bleiben darin 8 Tage. Bei sehr kompakten Organen, z. B. Leber, empfiehlt Benda, mit der Schere kleinste Scheibchen abzutragen; leicht permeable Organe, wie Rattenhoden, diurfen auch nur höchstens 2-3 mm dick sein. Dann wird I Stunde lang gewässert und für $2+$ Stunden in gereinigten In lzessig und I" Chromsäurelösung zu gleichen Tcilen übertragen. Darauf $2+$ Stunden in $2^{\circ}$. Killibichromicumlösung, $2+$ Stunden in wielurholt erncuertem Wasser gewaschen, in Alkohol ron steigender Konzentration nachgehärtet und in Paraffin eingeschmolzen. Die Paraffinicrung nuß der Härtung unmittelbar folgen, weil zu langes Verwcilen in Alkohol das Material ändert. Die Schnitte müssen 5 u diinn sein. werien auf dem Deckglase aufgeklebt und zunächst mit einer Eisenheize behandelt, aus der sie in sulfalizarinsaures Natron Kahlbaum; iibergufuhrt werden. Diese Methode ist eben crst bui der Darstellung der Centrosomen beschrieben worden. Es folgt nun 
nicht die Toluidinblau-Nachfärbung: sondern die Färbung nit Bendas Kristallviolettlösung. Aus dieser Farbflotte konmen die Schnitte nach Abtrocknen auf I Minute in $30^{\circ}$. Essigsäure, werden abgetrocknet, in Alkohol absolutus getaucht, bis keine größeren Farbstoffwolken mehr ausgehen; dann Xylol und Balsam.

Ein anderer Bestandteil der Zellsubstanz, dessen Existenz aber vielfach bestritten wird, den manche Autoren zum mindesten nicht als ein konstantes Organ der Zelle betrachten, ist die Attraktionssphäre (Archiplasma, Idiozoma). An Ascarideneiern ist sie leicht zu schen, die Fixierung in Carnoyscher, wan Benedenscher oder Zachariasscher Flüssigkeit reicht aus (viertes Kapitel) und Färbung in Boraxkarmin usw: genügt. Anders bei den Organen der Vertebraten, wo sie deutlich nur in Leukocyten und in Hodenzellen zu erkennen ist. Man hat sie in Spinalganglienzellen der Vertebraten und in Ganglienzellen Wirbelloser cbenfalls angetroffen. Fixierung bei Tertebraten in Flemmingscher oder Hermannscher Flüssigkeit. Fürbung mit Flemmings Orangeverfahren, worin die Sphäre blaugrau erscheint. Gut ist auch meine Alizarinmethode nach der gleichen Fixierung und besonders geeignet erscheint meine viel geschmähte Methode der Anilinlache (Tannin-13rechweinstein, Safranin oder Fuchsin: achtes Kapitel Nr. I 29 S. 203). Bei letzterer stelit die Sphäre den cinzigen intensir gefärbten Bestandteil der Zelle dar, während die Filarsubstanz blaßrot gefärbt ist und der Kern braun erscheint. Auch Bendas Färbung Safranin-Lichtgriin gibt sute Bilder, wihrend der Heidenhainsche Eisenhämatoxylinlack mir wenigstens versagte. Benda empfiehlt, nach Eisenheizung ${ }^{\mathrm{r}}$ : Stunde in folgender Nischung zu färben: 3 Tropfen $10^{\circ}$. Hämatoxylinlösung und 3 Tropfen $\mathrm{I}^{\circ}$, Säurefuchsinlösung in einem Uhrschilchen mit Wasser. Auch folgende Methode desselben Autors soll gute Resultate geben: Beizen ${ }^{\mathrm{I}}{ }_{+}$Stunde in $\mathrm{I}^{\circ}$. Chromsäure, Abspülen und in wässriger Hämatoxylinlüsung Färben, bis die Schnitte dunkelgrau sincl. Dann wird gewaschen und ${ }^{\mathrm{a}}$ Stunce in Babesschem Safranin achtes Kapitel Nr. jo S. 183) gefärbt. Dann Auszichen in . Nkohol, bis kein Safranin mehr ausgeht, Balsam. Chromatin rot. Cytoplasma dunkelgrau. Idiozoma fast schwarz.

Der Inhalt mancher Zellen, die Sekretgranula, färbt sich mit den gewöhnlichen Methoden mit; die gesonderte Darstellung gelingt nach folgender Methode von Benda: Man härtet Formolmaterial mit Chromsiure in stcigender Konzentration nach, wie dies vorhin bei der Schilderung dur Methoden für die Mitochondria nach Bendas Vorschrift buschrieben wurde. Dic Färbung der Schnitte geschieht auf folgende Weise: Man mischt cinc Lisung ${ }^{\circ}$ wässriges Losin gelb- 
lich 3 Teile + - Aceton 7 Teile mit ${ }^{\circ}$, owässrigem Methylenblau 5 Teile +5 Teile absoluten Alkohols. Die Schnitte werden auf dem Deckglase aufgeklebt, dann nach bekannter Vorbereitung in cin mit der Farblösung beschicktes Uhrschälchen so gebracht, daß das Deckgläschen mit den Schnitten nach unten auf der Farbflotte schwimmt. Dann erwärmt man, bis kein Aceton mehr zu riechen ist, und lälst dann noch ${ }^{1}$ Stunde darin. Nan spült kurz in destilliertem Wasser ab, trocknet zwischen Filtrierpapier und läßt lufttrocken werden. Darauf kurze Zeit in Anilinöl, dann auf Fließpapier abtupfen, Xylolbalsam. Im übrigen sind hierfür die für die Granula der Leukocyten von Ehrlich und seinen Schiilern konstruierten Methoden verwendbar.

Einen sehr interessanten Zellinhalt stellt das Glycogen dar. Für gewöhnlich wird es durch Jodjodkaliumlösung Lugolsche Lösung; achtes Kapitel oder durch Methylriolett nachgewiesen. In dem Farbstoffe farbt es sich rubinrot. Neuerdings hat Best folgende Karminfärbung empfohlen: Schnitte ron celloidiniertem Naterial Paraffinembettung ist unzulässig - werden in Böhmerschem Hämatoxylin oder in Hämalaun stark gefïrbt, so daß eventuell in Salzsäurealliohol differenziert werden muß. (Wieweit die Differenzicrung zu gehen hat, wird nicht angegeben!) Dann wird auf 6 Minuten in eine Mischung ron Kaliumkarminlösung $2 \mathrm{ccm}$, Liq. Ammonii caustici $3 \mathrm{ccm}$, Methylalkohol $3 \mathrm{ccm}$ eingebracht. Die Kialiumliarminlösung stellt Best nach folgender Vorschrift dar: Karmin $2 \mathrm{~g}$, Kalium carbonicum I g, Chlorkalium nicht etwa das chlorsaure Kali) 5 g, Aqua destillata $60 \mathrm{ccm}$ werden zusammen einige Minuten geliocht. Nach dem Erkalten Zufuigen von $20 \mathrm{ccm}$ Liquor Ammonii caustici. Es wird also das Kaliumkarmin in oben erwähnter Nischung angewendet. Nach der Färbung 5 Minuten) wird in ein Gemisch von absolutem Alkohol $80 \mathrm{ccm}$, Methylalkohol $70 \mathrm{ccm}$ und Aqua destillata $100 \mathrm{ccm}$ auf I-5 Minuten zur Differenzierung übertragen. Die Differenzierungsfluissigkeit wird wiederholt erneuert, bis sie klar bleibt. Dann Überfuhren in $80^{\circ}$. Alkohol, absoluten Alkohol usw. und Balsam. Das Kaliumkarmin hält sich im Sommer 3 Wochen, im Vinter 2 Monate. IVer diese Methode nachprüfen will, darf nicht iibersehen, dal3 diss Kaliumkarmin von Best die vielleicht am stärksten allialische Farblösung ist, die wir besitzen.

\section{$\S \mathrm{ro8}$}

Der ruhende Kern. Im allgemeinen sind die für die Zellstrukturen verwendbaren Nithoden cler Fixierung auch fur die Kernstruk- 
turen geeignet, wenngleich es nicht gerade leicht ist, die naturliche Struktur des ruhenden Kerns zu erkennen. Die z. B. in der Fig. I 3 abgebildeten Kerne zeigen nach Flemmings Angabe die Kernstruktur in Ruhe. Trifft man also gleiche oder ähnliche Bilder in eigenen Präparaten, so sind diese mit anerkannten Figuren in Übereinstimmung. Damit ist aber noch nicht gesagt, daß abweichende Befunde nun auf schlechtes Material usw. zuriickzufuhren sind, und ebensowenig ist die gefundene Übereinstimmung mit lem Paradigma ein Beweis dafür, daß das mikroskopische Bild ein Abbild der Natur ist. Denn die Möglichkeit kann bestehen, daß Paradigma wie Nachahmung Artefakte sind. Diese Unsicherheit liegt in der Natur unserer Fixierungsmittel, mit ihr müssen wir bis auf weiteres rechnen (vgl. viertes Kapitel). Ferner muß in Betracht gezogen werden, daß die ruhenden Kerne in ihrer Struktur viel vulnerabler sind als die sich teilenden und daß daher Fixierungsmittel, welche die letzteren tadellos erhalten, den ersteren gegenüber hüchst deletär wirken
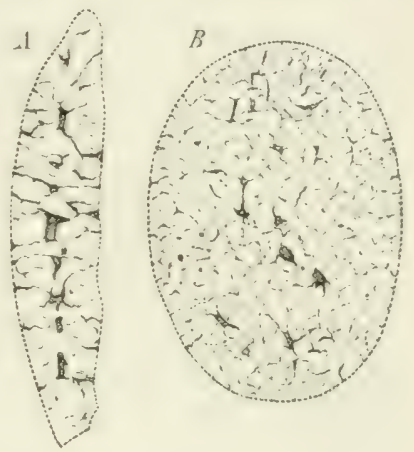

Fig. 13. Kernnetz $A$ eines Muskelkernes. B eines Epithelzellenkernes ron sialamandira, nach Flemming. können.

Als Kernfarbemittel dienen in erster Reihe die Hämateinlösungen mit Alaun und dic Karminsäure- bzw. Karmin-Alaunlösungen sowic Boraxkarmin. Namentlich Nucleolen färben sich mit ihnen gut, während die eigentliche feinere Struktur, Liningeriist und chromatische Suhstanz. entweder gar nicht oder nicht diskret gefarbt wird. Kernstrukturen kann man mit Karmin und Hämatein nicht studieren, wenigstens nicht, so lange es sich um ruhende Kerne handelt. $\mathrm{Zu}-$ dem versagen alle Karmine bei osmiertem Material, also gerade nach denjenigen Fixierungsmitteln, welche als die besten Erhalter von Zellund Kernstruktur gelten. Und die Hämateine bzw: Hämatoxyline, wenn man nicht die Kupfer- oder Eisenlacke benutzt, liefern nach meinen Erfahrungen nur undeutliche Färbungen.

Die besten Kernfärbemittel sind die sogenannten basischen Anilinfarben. Obenan stehen Safranin, von den Rosanilinfarbstoffen Fuchsin, Methylviolett Gentiana. Dahlia, Methylgrïn und von den Azofarbstoffen das Bismarckbraun. Letzterer Farbstoff ist vorzüglich anwendbar nach allen Fixierungsmitteln, welche kein Chrom und kein Osmium enthalten, gleicht aber in seiner Wirkung den Karminen und 
Hämateincn, (1. h. färbt bald zuviel bald zuwenig rom Kern, färbt also auf keinen Fall diskret. Reiner Kernfarbstoff ist nur das vom Methylviolett befreite Methylgrün in saurer Lösung, die Zusammensetzung vgl. S. 249). Alle übrigen färben, wenn auch nur schwach, die Zellsubstanz mit. Im Kern wird in erster Linie oder auch ausschließlich - es hängt dies »oder" von der Bezugsquelle, d. h. von der Fabrik ab, von der der Farbstoff stammt - das Nuclein gefärht, das deswegen auch die Bezeichnung Chromatin oder chromatische Substanz crhalten hat. Die achromatische Substanz, das Linin, dagegen wird gar nicht oder nur angedeutet gefärbt; um sie zur Anschauung zu bringen, muß man zu Doppeifärbungen greifen, z. B. Safranin-Lichtgrün, Hämatoxylin-Safranin usw., oder zu Dreifachfärbungen, z. B. Flemmings Orangeverfahren, Triacid, oder endlich meine Alizarinmethoden anwenden.

\section{§ I09.}

Zellteilung. Bekanntlich unterscheidet man zwei Arten der Zcllteilung, die durch scharfe Differenzen in den Kernen charakterisiert sind. Die eine Art ist die Teilung mittels Karyokinese oder Mitose indirekte Kern- und Zellteilung, die anciere Art ist die direkte Teilung durch Amitose. Die Bedeutung der Worte findet der Anfänger in den gangbaren Lehrbiichern der Histologie auseinandergesctzt.

Zunächst sei die Technik der Untersuchung der mitotischen Teilung beschrieben. Die Methoden der Fixierung und der Färbung sind die gleichen wie bei der Untersuchung der Struktur der ruhenden Zelle; die Resultate sind natülich verschieden, so wie Ruhe und Bewegung von einander verschieden sind. Die Färbbarkeit der chromatischen Substanz ist cine bessere als bei der Ruhe, weil das Nuclein während der Teilung fester gefügt ist. Von Vertebraten eignen sich die Hoden der großzelligen Tiere (urodele Amphibien, Selachier) zurzeit der stärksten Samenbildung für Zellteilungsstudien. Hoden von Salamandra maculosa ist im Juni und Juli, von Triton taeniatus im März, von Triton cristatus im April und Mai vorzüglich geeignct. Für die somatischen Zellen sind die Larven der genannten Tiere hervorragende Objekte. Die Hoden der übrigen Vertebraten eignen sich ebenfalls und natürlich auch die Lmbryonen; nur darf man nicht außer acht lassen, daß man es dann mit kleinen Zellen zu tun hat, bei denen dic Einzelheiten schwer zu überblicken sind und die daher eine schr diskrete Firbung verlangen. Als einen besonders geeigneten ()rt. um somatische Zellteilungen bei Säugern in Massen anzutreffen, hat Rudolf Heidenhain das Coecum des Kaninchens empfohlen. Vun 
Evertebraten sind in erster Linie die Crustaceen und Tracheaten zu nennen, deren Zellen schr groß sind und daher vortreffliche Objekte bilden. Die Hoden von Astacus fluviatilis sind in den Monaten ohne $\mathrm{R}$ zu fixieren. Während in den Salamanderhoden alle Stadien der Kern- und Zellteilung gleichzeitig nebeneinander vorkommen, sind bei Astacus die Stadien getrennt, sodaß immer nur eines angetroffen wird.

Hervorragende Zellteilungsobjekte sind ferner die sich furchenden Eier; die Größe der Elemente und die relative Übersichtlichkeit der Vorgänge erleichtern die Untersuchung sehr. Obenan stehen für Studien am lebenden Objekte die Echinodermeneicr, für solche an konserviertem Material die Eicr der Ascariden. Daß die genaue Untersuchung der Eier der übrigen Gruppen der Metazoën nicht minder wichtig ist, bedarf keiner Erörterung. Die Fürbung der Kernspindeln im Batrachierei erfolgt nach Carnoy und Lebrun nach vorausgegangener Fixierung in Gilsonschem Sublimat in folgender IVeise die Methode ist sicherlich auch für andere Objekte verwendbar): Die Schnitte werden +-5 Minuten in einer stark mit Essigsäure angesäucrten Indigkarminlösung gefärbt, kommen dann für 2 Stunden in eine Safraninlösung ( $19: 100$ Alkohol von $50^{\circ}$ ) , werden in $80^{\circ}{ }_{\text {o }}$ Alkohol langsam entfärbt und dann den übrigen Montierungsprozeduren unterworfen. Resultat: Deutoplasma dunkelblaugrün, Cytoplasma rosa.

\section{$\S$ IIO.}

Amitose. Eine besondere Technik für die Untersuchung der amitotischen Teilung existiert nicht; was für die mitotische Teilung angegeben wurde, gilt auch für die amitotische. Als bestes Objckt, das reichlich amitotische Teilungen liefert, gilt die lymphatische Randschicht der Amphibienleber.

\section{$\$$ I I I.}

Die Granula von Altmann. Der herrschenden Filartheoric der Zellstruktur steht gegeniber die Granulartheorie von Altmann. Um die Kerngranula gut fixieren zu können, bedient man sich der Kali bichromicum-Osmiummischung dieses Autors (vicrtes Kapitel Nr. 36 S. 62); um die Zellgranula darzustellen, wird in Chromsäure-molybdänsaurem Ammoniak fixiert viertes Kapitel Nr. go S. 78). Nach Metzner soll man eine $+\%$ Osmiumsäurelösung sich herstellen $+\mathrm{g}$ Osmiumsäure in $\mathrm{I} / \mathrm{s}^{\circ}$. Kochsalzlösung $100 \mathrm{ccm}$ - und daraus Mischungen mit Chromsäure und deren Salzen anfertigen. Zu starke Osmiumlösungen müssen dic Kerne zertrümmern. Die Färbung cr- 
folgt nach Altmann folgendermaßen: Die Schnitte werden in $20 \%$ Säurcfuchsinlösung (in Anilinwasser) gebracht. Die Farbflotte wird mit den Schnitten über der Spirituslampe erwärmt, bis die Flüssigheit dampft. Dann wird in Thasser abgespuilt und in einer Pikrinsäurclüsung differenziert, die aus I Volumen gesättigter alkoholischer Pihrinsäure und 2 Volumina destillierten Wassers besteht. Darin wird so lange belassen, bis keine Farbwolken mehr ausgehen. Dann absoluter Alkohol, Xylol, Balsam.

Vierzehntes Kapitel.

\section{Die Bindesubstanzen.}

a) Bindegewebe s. str.

S I I 2 .

Indem ich hier, wie selbstverständlich, mich an die in den Lehrbüchern der Histologie übliche Einteilung der Bindesubstanzen oder der Gerrebe mit Interzellularsubstanz halte, hringe ich zunächst die für die Untersuchung des im engeren Simne sogenannten Bindegewebes geeigneten Methoden zur Besprechung. Die Begründung der Einteilung der Bindesubstanzen ist in den Lehrbüchern der Histologie nachzusehen: in einem Lehrbuche der Technik ist für derartige Erörterungen nicht der Platz.

Das lockere Bindegewebe (ungeformtes, areoläres B.) ist zunächst stets in frischem Zustande anzusehen, denn nur so kann man ein Verständnis für dessen natürliches Verhalten erlangen. Namentlich hei den Exertebraten ist dies angebracht, zumal bei diesen das Studium gerade des Bindegewebes sehr vernachlässigt ist.

Die Untersuchung hat in physiologischer Kochsalzlösung $(0,5 \%$ bis 0,75 zu geschehen, in welcher man an geeigneten Objekten Omentum majus. Ligamentum suspensorium hepatis - sehr gut die Fibrillen urkennen kann. Wendet man nun starke Essigsäure oder verdunnte Alkalien Kali-, Natronlauge an, indem man diese Reagentien seitlich an den Deckglasrand bringt und das indifferente Reagens mittels Filtrierpapiers absaugt, dann sicht man, wie die Glutinleim gebende Fibrille allmählich bis zur Unsichtbarkeit aufquillt 
und dadurch die elastische Faser viel intensiver hervortreten läßt, welche durch die genannten Reagentien nicht angegriffen wird. Die Bindegewebskörperchen sind an frischen Präparaten ziemlich gut zu sehen, ebenso, wenn sie vorhanden, die Wanderzellen. Doch ist es empfehlenswert, zum Studium der Zellen das Bindegewebe zu fixieren und zu färben, wobei auch manches Detail hinsichtlich der beiden Fibrillenarten sich enthüllen wird.

\section{S II 3 .}

Das lockere Bindegewebe findet sich als Stiitzsubstanz und als interstitielles Gewebe fast überall. Es wird daher mit den Organen fixiert, so daß namentlich sein Verhalten bei flachenhafter Ausbreitung dabei nicht festzustellen ist. Man mul dafür die größ3eren bindegewebigen Häute und die Bindegewebsausbrcitungen nehmen und diese sind: Omentum majus, Ligamentum hepatis, Mesenterium, Peritoneum, Pcriosteum usw. Fixicrt man diese bindegewebigen Häute und färbt man sie sachgemäß, dann kann man den Bau des lockeren Bindegewebes in seinen Einzelhuiten erkennen. Selbstverständlich ist es, daß die Befunde an den genannten hautartigen Ausbreitungen Rückschlüsse auf die Beschaffenheit des Organstrona und des interstitiellen Gewebes gestatten. und man wird bei entsprechender Prüfung die Richtigheit der Riickschliisse bestätigt finden. Darum haben die für das interstitielle Gewebe angegebenen Methoden auch Guiltigkeit für das flächenhafte lockere IBindegewebe und umgekehrt.

Will man ein Stuick Omentum oder Mesenterium zur Anfertigung von Dauerpräparaten fixieren, so legt man unter die Nembran einen Objektträger und schneidet in gew ünschter Größe die Membran durch. Diese haftet auf dem Glase und wird mit ihm in die Fixierungsflissigkeit gebracht, welche beliebig gewählt werden kann. Nach Lege artis vorgenommener Härtung wird beliebig gefärbt und wie üblich in Balsam eingeschlossen.

Bci Evertebraten verfahrt man nach den Angaben von Brock in derselben Weise. Brock breitet die Bindegewebsplättchen der Mollusken, die sich zwischen den Organen ausspannen, nachdem er die Tiere in Sublimat fixiert hat, vorsichtig auf einem Objektträger aus. Der Alkohol - denn diese Präparation wird nach dem Härten vorgenommen - verdunstet bald, die Plättchen haften dadurch am Objektträger und können nun mit einer starken Alaunhämatoxylinlösung übergossen werden. Nach Einschluß in Balsam treten die Flemmingschen Schleimzellen Langersche Blasen auf das schönste hervor. 


\section{SII 1 .}

Es gibt cine Anzahl besonderer Methoden, welche zur Fixierung: und Färbung des lockeren Bindegewebes angegeben sind. Sie sollen jutzt beschrieben werden. $\mathrm{Zu}$ bemerken ist dabei, daß sie nur fuir Vertebraten, und hicr fast ausschließlich für Säugetiere empfohlen sind. Es dürfte ron großem Wert sein, diese Methoden auch an dem so sehr vernachlässigten Bindegerebe der Evertebraten zu priifen.

Eine höchst originelle Nethode zur Fixierung des Bindegewebes ist die Ranviersche Ödemmethode. Man erzeugt bei lebenden gesunden Tieren durch subkutane Injektion einer rasch fixierenden Flüssigkeit ein Ödem. Z. B. kann man Ranviers Pikrokarmin entweder allein oder nach Zusatz von $0,5^{\circ}$ 。 Osmiumsäurelösung im Verhältnis von $2:$ I injizieren. Das durch die Injektion ödematös gewordene Gewebe ist gefärbt und grenzt sich scharf gegen seine Nachbarschaft ab. Man schneidet es nach beendeter Injektion heraus und bringt es für I $2-2+$ Stunden in reines Pikrokarmin. Dann zerteilt man das Gewebe in kleine Stiickchen und schließt diese in neutralem Glyzerin ein, das leicht mit destilliertem IVasser verduinnt ist. Die Dechgläschen müssen sofort umrandet werden (Methoden vgl. elftes Kapitel). Die Details treten in den Präparaten erst nach $2-3$ Tagen auf. (Die vorstehende Schilderung der Methode ist nach den Angaben von Poljakoff zitiert.)

Zur färberischen Darstellung der Fibrillen des Bindegewebes gemeint sind immer, wenn nichts anderes bemerkt ist, die Leim gebenden Fibrillen - ist die im achten Kapitel (Nr. I I S. I 96) beschriebene Färbung von Mallory empfohlen worden (vgl. daselbst meine Bedenken dagegen). Der Autor, Nallory, gibt sogar an, mit dieser Färbungsmethode eine neue Bindegewebsfibrille dargestellt zu haben.

Besser erdacht, leichter durchführbar und zuverlässiger in ihren Resultaten diirften die folgenden Methoden zur Färbung der Bindegewebsfibrillen sein; sie sind von Dubreuil konstruiert worden.

$0,5^{\circ}$. wässrige Lösung von *Bleu pour micrographie Nr. $2 \ll$ (offenbar ist Methylenblau gemeint) $4 \mathrm{ccm}$, kalt gesättigte wässrige Lösung ron P'ikrinsäure $46 \mathrm{ccm}$. Die von beliebig fixiertem Material stammenden Schnitte kommen auf den Objektträger und werden hier mit der Farbflotte ïbergossen. Die Objektträger müssen hin und her geneigt werden, um dic Schnitte mit der Farblösung grüindich zu durchspülen; Celloidinschnitte, weil sie frei schwimmen, färben sich daher schneller. Nach I5-20 Minuten Färbung wird in Vasser abgespült, in Alkohol extrahiert und in Karbolxylol aufgehellt. Re- 
sultat: Bindegewebsfibrillen dunkelblau, Plasma hellgrin, fast gelb, Kerne dunkelgrün. Noch besser sollen die von demselben Autor herrührenden Doppelfärbungen sein, welche einer Methode von Zacchariadès nachgebildet sind. I) Doppelfärbung mit Acridin rot-Pikrinblau Nr. 2. Nan färbt die Schnitte in $I_{0}^{0}$ wässriger Acridinlösung 5 Minuten, wäscht $a b$ und bringt in die eben beschriebene Pikrinblaulösung für kurze Zeit ein. Nach dem Abwaschen darf nur kurze Zeit in Alkohol behandelt werden, da sonst zu viel vom roten Farbstoff extrahiert wird. Zur Aufhellung darf kein Karbolxylol verwendet werden. 2) Doppelfärbung mit Safranin-Pikrinblau. Färbung der Schnitte $2+$ Stunden lang in Zwaardemakerschem Safranin (rgl. achtes Kapitel Nr. 7 I S. i 83), Ausziehen in $60^{\circ}$. Alkohol, Überführen in Wasser, Färben in Pikrinblau, usw. Auch bei dieser Doppelfärbung darf man kein Karbolxylol anwenden.

Ein besonderer und wichtiger Bestandteil des lockeren Bindegewebes sind die clastischen Fasern. Ihre Darstellung im frischen Gewebe ist bereits erwähnt worden; sie färberisch hervorzuheben gelingt in durchaus sicherer Weise durch die folgenden Methoden:

In erster Linie sind die Weigertsche Fuchsinfärbung und die Röthigsche Kresofuchsinmethode zu nennen. Letztere stellt uibrigens gewissermaßen die Kulmination der ersteren dar, weil das Kresofuchsin der chemisch isolierte Körper ist, der bei der Anfertigung der Weigertschen Fuchsinlösung entsteht. Die Isolierung wurde von Spiegel ausgefiihrt.

Eine ebenfalls gute, wenn auch launenhafte Färbungsmethode ist dic folgende, von Unna empfohlene: Orceïn (Grübler) o, I g, 95\%. Alkohol $20 \mathrm{ccm}$, Aqua destillata $5 \mathrm{ccm}$. Diese Lösung hebt man in einem Tropfglase auf. Ferner stellt man folgende Mischung her: konzentrierte Salzsäure o, I ccm, $95^{\circ}$. Alkohol $20 \mathrm{ccm}$, Aqua destillata $5 \mathrm{ccm}$. Die Farblösung gibt man in verschiedene Uhrschälchen, fügt tropfenweise von dem Salzsäuregemisch zu, und zwar so, daß man den Salzsäurezusatz erhöht. Man setzt dem ersten Schälchen nur halb so viel Salzsäure zu, dem letzten $I^{I}{ }_{2}$ mal so viel. In jedem der Uhrschalchen, die zur Verhütung der Verdunstung des Alkohols gut zugedeckt sein muissen, werden Färbungen vorgenommen. Die elastischen Fasern sollen dunkelbraun hervortreten; diejenige Nischung; welche dies am besten bewirlt, wird zur weiteren Färbung gewählt. Wohlgemerkt: die Methode muß bei jedem Objekte jedesmal von neuem ausprobiert werden.

Eine andere Vorschrift von Unna lautet: Orcein (Grübler) I g, 
absoluter Alkohol $100 \mathrm{ccm}$; nach der erfolgten Lösung Zusatz von I ccm Salzsäure. Mit der Farbflotte werden die Schnitte, die sich in einer Porzellanschale befinden, soweit übergossen, daß sie eben noch bedeckt sind. Dann erwärmt man auf $30^{\circ} \mathrm{C}$. und läßt io bis is Minuten zur Abkiihlung stehen. Dann Alkohol und Montieren. Bei gelungener Färbung sind die elastischen Fasern dunkelbraun, die übrigen Gewebsbestandteile hellbraun. Die Färbung aber gelingi nicht immer, und darum ziehe ich die Weigertsche Fuchsinfärbung und die Röthigsche Kresofuchsinfärbung entschieden vor, weil sic immer gelingen und in scharfer Farbe nur die elastischen Fasern hervortreten lassen.

Eine andere Färbung der elastischen Fasern ist die von Lustgarten empfohlene mit Viktoriablau. Von einer starken alkoholischen Farbstofflösung wird ein aliquoter Teil mit dem doppelten bis vierfachen Volumen destillicrten Wassers versetzt. In dieser Farbflotte bleiben die Schnitte sehr lange; sie müssen nach Lee von chromiertem Naterial stammen. Ich persönlich habe mit Viktoriablau die denkbar schlechtesten Erfahrungen gemacht; entweder wurde aller Farbstoff im IVaschalkohol vollständig ausgezogen oder die Präparate. wenn sie wirklich einmal gefärbt in den Balsam gekommen waren, verloren ihre Farbe nach kïrzester Zeit.

\section{SII 5 .}

Die Zellen des Bindegewebes. Die fixen Zellen des areolären lockeren Bindegewebes, nämlich Bindegewebskörperchen und Plasmazellen, färben sich bei den gewöhnlichen Methoden der Färbung in all den Farbstoffen, welche die Zellsubstanz besonders herrortreten lassen Eosin-Hämatein usw. . Besondere Erwähnung braucht daher keine einzelne Färbevorschrift. Die Wanderzellen sind Leukocyten: ihre Färbung, wenn diese Gebilde im Bindegewebe besonders hervorgehoben werden sollen, wird beim Kapitel :Blut besprochen werden.

Zur Färbung der Mastzellen sind einige Vorschriften angegeben wor:en, deren Aufzählung hier folgt. Ton Ehrlich ist die Verwendung wn Dahlia empfohlen worden achtes Kapitel Nr. 89 S. I 8 ;. Das polychrome Methylenblau von Unna soll Plasma- und Mastzellen gut hervorheben. Diesem Farbstoffe haftet ein großer Nachteil an, nämlich daß man nic ganz sicher weiß, wie stark man verdünnen oder wie lange man unvercünnt färben muß. Allzuleicht überfürbt der Farbstoff und die Differenzierung ist oft ganz unmöglich, selbst wenn man aus der Farbflotte in geeigneter Weise in die von Unna empfohlene 
Glyzerinäthermischung einbringt. Diese käuflich zu habende Mischung versagte mir ebenso häufig vollständig, wie sie oft genug rapide die Präparate entfärbte. Auch die von mir zur Färbung des Nervensystems empfohlene starke Verdünnung des Farbstoffes ívgl. achtes Kapitel versagte entweder oder gab diffuse Bilder vom Bindegewebe. Andererseits: erhält man gelungene Färbungen, so gehören sie zu dem ästhetisch Schönsten, was man unter dem Mikroskop sehen kann. Pappenheim hat zur Mastzellenfärbung folgendes Verfahren angegeben. Schnitte werden 5 Minuten in einer Lüsung von Methylgrin gefärbt. Die letztere gewinnt man in der Weise, daß man $1-2$ Feciermesserspitzen Methylgriin und 3 Messerspitzen Pyronin löst, so daß eine mäßige Konzentration entsteht. D. h. die Lösung soll nicht durchsichtig sein; tropft man sic auf liltricrpapier, so soll der Farbfleck ein rotviolettes Zentrum und einen leuchtend grünen Rand haben. Nach dem Färben in dieser Mischung wird kurz in Wasser abgespült und in Resorcinalkohol differenziert. Letzteren stellt man sich her, indem man 3-4 Spatelspitzen Resorcin in I Reagensglas voll 96 Alkohol löst. IIch habe vorstehende Methode nur angeführt, um einen möglichst hohen Grad von Vollständigkeit zu erreichen. Ich muß jedoch offen bekennen, daß die im höchsten Maße unexakten Angaben diese Anführung nicht verdient hätten. ITohin sollen wir im histologischen Arheiten kommen, wenn Angahen wie: I Messerspitze auf ${ }^{\mathrm{I}}$ = Reagensglas usw. emsthaft veriffentlicht werden und wissenschaftliche Beachtung verlangen. Mit derartigen Methoden ist sicher nur unsauberes Arbeiten möglich, künnen nur unzuver]ässige Resultate erhalten werden. Ich will daher hiermit ausdrüclich vor der Pappenheimschen Methode warnen.

Für Plasma- und Mastzellen-Färbungen dürften dic beiden Schriddeschen Methoden sehr brauchbar sein. Bei der einen Methode wird in einem Altmannschen Gemisch fixiert (viertes Kapitel Nr. 36 u. 9o). Das paraffinierte Naterial wird in $2 \mu($ !) dicke Schnitte zerlegt, die Schnitte werden in Anilinwasser-Säurefuchsin gefärbt und in Pikrinalkohol entfarht. Die Farbflotte wird hergestellt, indem man $20 \mathrm{~g}$ Säurefuchsin in $100 \mathrm{ccm}$ Anilinwasser (vgl. achtes Kapitel) löst. Der Differenzierungsalkohol besteht aus I Teil alkoholischer Pikrinsäurelösung und 7 Teilen 20\% Alkohols. MIan kann auch das Material in einer Mischung von Formol I und Müllerscher Lösung 9 fixieren. Dann wäscht man erst in fließendem, darauf in destilliertem Wasser aus, bringt auf $2+$ Stunden in $\mathrm{I}^{\circ}$. Osmiumsäure, wobei das Präparat ins Dunkel gestellt werden muß, wäscht wiederum in fließendem Wasser aus und härtet in Alkohol von steigender Konzentration. Die Objekte 
werden in Paraffin eingeschmolzen, die Schnitte dürfen nur $I-2 \mu$ dick sein; Färbung wie vorhin.

Um Nerven in Zusammenhang mit Bindegewebskörperchen zu zeigen, färbt E. F. Hoffmann folgendermaßen: Frische Teile des Peritoneum, des Mesenterium, der Membran, welche Bauchhöhle und Cistcrna magna chyli trennt, der sogenannten Magenserosa von S. Mayer, welche Cardia und Oesophagus einscheidet - alle diese Gewebe vom I rosch -, werden in frisch filtrierten Zitronen-

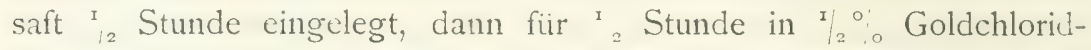
lösung. Zur Redultion wird auf $2+$ bis +8 Stunden zunächst in folgende Mischung gebracht: Aqua destillata $94 \mathrm{ccm}$, Ameisensäure 5 ccm, Amylalkohol I ccm; dann für einige Tage in ein Gemisch von 10 Ameisensäure und 90 Glyzerin. In saurem Glyzerin - mit Ameisensäure angesäuert — wird aufbewahrt.

\section{$\S$ II 6 .}

Das geformte Bindegewebe. Es findet sich in den Aponeurosen, Sehnen, der Cornea, Dura mater, den Fascien und der Sclera. Seine Mazeration hedarf eingreifender Mittel, da die Fibrillen ziemlich fest aneinander haften. Als sehr brauchbar zur Sichtbarmachung der Fibrillen ist das Barytwasser ron Rollet empfohlen worden.

Um eines der Gebilde zu zerzupfen, welches geformtes Bindegewebe ist, mazeriert man am besten in einem der diinnen Alkohole, welche im dritten Kapitel angegeben wurden. Man kann in einem Alaunhämateìn oder Alaunkarmin (Karminsäure) nachfärben. Die gefärbten Objekte lassen sich bei vorsichtiger Behandlung der Zupfpräparate in Balsam einschließen. Auch frische Sehnen von Fröschen oder weißen Mäusen - bei diesen eignen sich besonders die Schwanzsehnen - können in die genannten Farblösungen eingelegt werden. Man färbt bei Hämateinen ${ }^{\mathrm{I}}$ 2 Stunde, bei Karminen 2-3 Stunden und länger, wäscht in Wasser aus und zerzupft in einem Tropfen verdimnten Glyzerins, der zugleich als Einschlußmittel dient. Die Cornea vergoldet man (neuntes Kapitel), pinselt das Hornhautepithel ab und zerschneidet in so kleine Stiiche, daß sie flach dem Objektträger anliegen. In Glyzerin wird aufgehoben. Man kann auch von vergoldeten Hormhäuten Schnittpräparate machen, um den fibrillären Bau der Hornhautlamellen im Balsampräparate zu studieren. In den Flachpräparaten treten die Zellen des Iornhautgewebes trefflich hervor. 


\section{B) Fettgewebe.}

\section{§ II 7 .}

Mit der Untersuchung des lockeren Bindegewebes ist oft die des Fettgewebes verbunden. Die kugelrunde Gestalt der Fettzellen und ihr starkes Lichtbrechungsvermögen machen sie leicht kenntlich. Den Kern der Fettzellen kann man durch irgendein Kernfärbemittel, durch Alaunhämatein oder -karmin oder durch einen basischen Anilinfarbstoff, gut zur Anschauung bringen. Die Verfettung ist ein pathologischer Prozeß, daher hier nicht zu behandeln.

Das Fett selber fixiert sich schwer. Am besten ist dafuir die Osmiumsäure rein oder in Gemischen (vgl. achtes Kapitel), weil dadurch die meisten Fette geschwärzt werden. Behandelt man osmiertes Fett mit Holzessig oder Tannin nach ivgl. achtes Kapitel; , dann erhält man Präparate, die sich in Paraffin ohne wesentliche Einbuße einschmelzen lassen. Nan muß allerdings unter allen Umständen Chloroform als Intermedium verwenden, da nach den Untersuchungen von Flemming, die ich vollauf bestätigen kann, Terpentin, Xylol oder ähnliche Intermedien osmierte Fette zum großen Teil wieder lösen.

Zur Färbung des Fettes sind Scharlach und Sudan III bez. Fettponceau empfohlen worden lachtes Kapitel Nr. 73 u. 74). Leider gehen diese Farbstoffe nicht an osmiertes Material heran; eine andere Fixierung aber ist zum Studium des Fettes ausgeschlossen, da der Härtungsalkohol das Fett stets auflöst. Man muß daher, will man die genannten Farbstoffe verwenden, das Material in Formol bringen, Gefrierschnitte anfertigen und dic mit Sudan usw. gefärbten Schnitte in Glyzerin einschließen. Das hat wiederum seine Schwierigkeiten. da lockeres Bindegewebe, auch wenn es fetthaltig ist, nur schwer zum Gefrieren zu bringen ist.

Olt meint, daß zur Darstellung des Fettes, wenigstens zu diagnostischen Zwecken, der Einschluß frischer Gewebsstiicke in FormolAgarlösung ein gutes Nittel bilden könne. Obgleich es mir sehr fraglich ist, ob die von Bolton und Harris empfohlene Einschließung in Agar histologischen Wert besitzt, will ich sie doch hier erwähnen. Die Agarlösung wird nach Bolton und Harris so angefertigt, daß man in mehrstiindigem Kochen eine $5 \%$ Agarlösung herstellt. Dieser wird auf je 9 Teile immer I Teil reines Formol zugesetzt. Man bringt die frischen Stuiche in das geschmolzene Formol-Agargemisch, das nur $65^{\circ}-70^{\circ}$ warm sein darf, und läßt sie darin 2-12 Stunden bei gleicher Temperatur. Dann hat man es keinesfalls mit frischen. d. h. nichtfixierten Geweben zu tun.) Nach dieser Zeit gießt man die 
Agarblöcke, welche die Objekte enthalten, bringt in absoluten Alkohol und kann nach $3-4$ Stunden schneiden.

r) Schleimgewebe.

S I I 8 .

Die Nabelschnur der Säugetiere, der embryonale Glaskörper des Vertebratenauges und der Gallertschirm der Medusen sind die Objekte, an denen das normale Schleimgewebe zu studieren ist. Zur Fixierung sind Alkohol, Chromsäure, Flemmingsche Lösung, Pikrinsalpetersäure, Chrompikrinsalpetersäure oder Sublimat verwendbar; zur Färbung kann irgendeine Doppelfärbung - Eosin-Hämatein oder OrangeHämatein (achtes Kapitel Mr. IO2 u. IO3 - dienen. Auch die Mallorysche Färbung achtes Kapitel Nr. i I S. Ig6, soll gute Dienste leisten, was mir aber bei cer Buntheit des Bildes zwcifelhaft erscheint.

১) Retikuläres Gewebe.

$\S$ I I 9 .

Diese Form des Bindegewebes kommt niemals als selbständiges Gebilde vor, sondern findet sich ausschließlich als Stroma, als Stiitzgewebe in anderen Organen. Die Neuroglia, die wahrscheinlich mit dem gewöhnlichen retikulären Gewebe nicht zusammenzustellen ist. wird beim Zentralnervensystem besprochen werden.

Das gewöhnliche retikuläre Gewebe, auch lymphadenoides, konglobiertes oder cytogenes Gewebe genannt, findet sich in den lymphoiden Organen. Um es isoliert darzustellen, macht man Pinselpräparate von Schnitten oder schüttelt die feucht hergestellten Schnitte sehr stark und lange in destilliertem Wasser, um die zelligen Elemente zu entfernen. Dann fischt man die zusammenhängenden Gewebsfetzen mit einer Platinnadel heraus und färbt sie in stark verdiunntem Glyzerinalaunhämatein oder Glyzerinkarmalaun achtes Kapitel Nr. 25 u. 3I. Man hebt solche Präparate entweder feucht auf oder man wendet venezianisches Terpentin an (elftes Kapitel).

In den Organen, welche dieses Gewebe als stützende Grundlage enthalten, stellt man es durch die Färbungen des gewöhnlichen Bindegewebes dar vgl. vierzehntes Kapitel $\alpha$. Besonders enpfehlenswert scheint mir die Weigert-van Giesonsche Mcthode achtes Kapitel Nr. I 20 S. 197).

e) Knorpel.

\$ 120.

a) Hyaliner Knorpel. Die naturliche Festigkeit des hyalinen Knorpels gestattet, feine Schnitte mit dem Rasiermesser von frischem 
Material herzustellen. Man kann sie in physiologischer Kochsalzlösung oder in Lugolscher Lösung Jod I g, Jodkalium 2 g, Aqua destillata $300 \mathrm{ccm}$; untersuchen; in letzterer treten Knorpelkapseln und Kerne scharf distinkt hervor. Hämatoxylin in Verbindung mit Alaun färbt die Knorpelgrundsubstanz veilchenblau, die Kerne dunkelblau, die Zellsubstanzen nicht. Leider bleichen die schönen Präparate, wenn man sie von frischem, nichtfixiertem Material angefertigt hat, oft schon nach ${ }^{2} / 2$ Jahre aus.

Zur Fixierung ist am geeignetsten absoluter Alkohol, vorausgesetzt, daß man allein den Knorpel zu fixieren hat. Findet sich dieser in einem Organ, dann hat sich die Fixierung naturlich nach den anderen, weicheren Teilen zu richten. Im allgemeinen verhält sich hyaliner Knorpel gegen die fixierenden Reagentien ziemlich indifferent, insofern keines besondere Vorzüge besitzt, der Knorpul vielmehr nach jeder Fixation gleichmäßig aussieht: nur die Färbbarkeit wird hier und da etwas alteriert. Für fixierte Knorpel sind rorzüglich die Doppelfärbungen Eosin-Hämatein und Orange G-Hämatein (achtes Kapitel Nr. IO2 U. I03', in welchen die Knorpelgrundsubstanz leuchtendblau wird, während die Knorpelkapseln dunkelblau sich färben. In Triacid und Ehrlich-Biondis Dreifarbengemisch (achtes Kapitel Nr. II 3 u. IIf) wirł die Knorpelgrundsuhstanz leuchtend grün gefärbt.

Zur Färbung der Chondrinballen und der Balkennetze dient folgendes von Wolters empfohlene Verfahren: Schnitte ron frischem oder in $90^{\circ}$. Alkohol konserviertem hnorpel werden in einer $1^{\circ}$. Lösung von $\beta$ Naphtolorange Tropaeolin 000 Nr. $21_{\text {is }}^{\mathrm{I}}$ Stunde lang gefärbt, kommen dann für 3 . Winuten in Wasser und auf $\mathrm{I}-2$ Ninuten in cine $\mathrm{O}, \mathrm{I} 5^{\circ}$. Wässrige Methylviolettlösung. Darauf spült man in Wasser ab, entfärbt einige Minuten in $10 \%$ Essigsäure und uiberträgt in absoluten Alkohol. In diesem wird differenziert; die Präparate werden in der gewöhnlichen Weise in Balsam aufgehoben. Besonders für Rippenknorpel geeignet: Chondrinballen prachtrol! blau auf gelbem Grunde.

Um die anastomosierenden Knorpelzellen, die sich in der Patella der höheren Säuger finden, auch bei anderen Knorpeln zur Anschauung zu bringen, muß man die Schnitte mehrere Tage mit Schwefeläther behandeln.

Organe, welche hyalinen Knorpel enthalten, müssen behufs Einschmelzung in Paraffin längere Zeit in Chloroform verweilen, weil der Knorpel sich schwer durchtränkt. 
S I 2 I.

b) Elastischer Knorpel. Der elastische oder Netzknorpel besitzt nicht die Festigkeit des hyalinen und ist daher an frischem Naterial nicht so gut zu studieren wie der hyaline. Man fixiert ihn deshalb, und zwar eignen sich dazu Alkohol absolutus, I\% Chromsäure Pikrinsalpetersäure und Chrompikrinsalpetersäure (viertes Kapitel). Nach Einbettung in Paraffin oder Celloidin werden die Schnitte in beliebiger Weise einfach, doppelt oder dreifach gefärbt. Eine Doppelfärbung mit Hämatoxylin-Säurefuchsin wird sehr gerïhmt. Man färbt in einem Alaunhämatoxylin bzw. -hämatein und bringt dann für höchstens

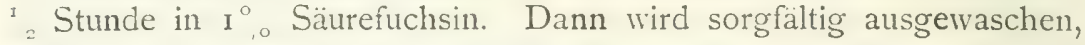
in Alkohol belassen, bis keine Farbwolken mehr ausgehen, und nach Aufhellung in Bergamottöl in Xylolbalsam eingeschlossen.

Zur Färbung der elastischen Fasern des Knorpels sind die Weigertsche Fuchsinfärbung, das Kresofuchsin nach Röthig, sowie die in diesem Kapitel beim fibrillären Bindegewebe angefiihrten Methoden mit Orcein nach Unna und Viktoriablau nach Lustgarten zu verwenden. Nur muß man sehr vorsichtig sein und darf nicht zu lange in der Farbflotte lassen, sonst färbt sich aul3er den elastischen Fasern auch die Knorpelgrundsubstanz, in welcher die Fasern doch nur eingelagert sind.

\section{$\$$ I 22.}

c) Faserknorpel. Auch dieser Knorpel, der nur an beschränkten Stellen vorkommt - Augenlider der Säuger, Menisken und Labra cartilaginea der Gelenke, Zwischenwirbelscheiben - wird am besten an fixiertem Material untersucht. Die beim elastischen Knorpel empfohlenen Methoden sind auch hier brauchbar. Die Färbung wird sich eng an die Methoden anlehnen, welche für das lockere l3indegewebe empfohlen wurden.

乙) Knochen.

$\S 123$.

Die Struktur des Knochens kann man an dem entkalkten oder am kalkhaltigen Objekte studieren. Von entkalktem Knochen, dem sogenannten Knochenknorpel, kann man Schnittpräparate anfertigen, kaikhaltigen Knochen muß man schleifen. Der Schleifprozeß ist der gleiche, ob man frischen oder alten, d. h. mazerierten, Knochen schleifen will, nur dal dor Endefiekt insofern ein verechieciener ist, als man am Schliffe vom frischen Kinochen, richtige Torbehanclung vorausgesetzt, Strukturen crkennen kann, während die Schlifte maze- 
rierten Knochens nur die Textur zeigen. Hierbei ist festzuhalten, daß man unter mazeriertem Knochen etwas anderes versteht, wic z. B. unter einer mazerierten Drïse. Bei letzterer soll der Verband der Elementarbestandteile durch Reagentien so gelockert sein, daß sie mit Leichtigkeit in diese zerlegt werden kann, bei ersterem, dem Knochen, bedeutet es nur, daß durch Auslaugung alles Organisierte entfernt worden ist, so daß die anorganische Grundlage zurüickblieb, welche die Textur des Knochens bewahrt hat, weil das Anorganische dem Organisierten eingelagert ist.

Einen Knochenschliff, gleichgültig ob von frischem oder mazeriertem Material, stellt man auf folgende Art her: Nan sägt mit einer feinen Bogensäge von dem Röhrenknochen cines Säugetieres in der Quer- oder in der Längsachse, je nachdem die Untersuchung auszufuihren ist, ein möglichst feines Blatt ab, das man in nachher zu besprechender WVeise schleift. Man kann aber auch das zu untersuchende Knochenstück in Kolophonium nach v. Koch, Kolophonium und Wachs nach Ehrenbaum oder Schellack nach Giesbrecht (siebentes Kapitel Nr. I, 2, 3) einbetten und dann in der Weise schleifen, wie es im siebenten Kapitel bei Beschreibung jener Methoden auseinandergesetzt wurde. Dabei verzichtet man auf Strukturbilder auch bei frischem Knochen, weil man vorher nicht fixiert hat. Will man aber Schliffe rom Knochen herstellen und zugleich Strukturen, Beziehungen zum Knochenmark usw. daran studieren, dann muß man fixieren. Und zwar legt man ein Stück der Diaphyse eines Röhrenknochens, den man so durchgesägt hat, daß das Knochenmark in seiner Lage geblieben ist, in Alkohol absolutus oder in Flemmingsche Lösung, färbt mit einem Hämatoxylin durch, verfährt nach einer der vorhin genannten Methoden und schleift. Auch die Weilsche Methode (siebentes Kapitel Nr. + S. II I) ist für gut fixiertes, gehärtetes und gefärbtes Material verwendbar.

Anders verfahre ich, wenn ich auf Strukturbilder verzichten und die Umständlichkeit der Kolophoniumeinbettung vermeiden will. Dann schleife ich das, wie vorhin beschrieben, abgesigte Knochenblättchen zunächst auf mittelfeinem Schmirgelpapier. Ist das Knochenblïttchen, das während des Schleifens von Zeit zu Zeit umgedreht wurde, damit die beiden Präparatflächen ganz gleichmäßige Beschaffenheit zeigen, so dünn geworden, daß man die Leisten der Fingerbeere durchschimmern sieht, dann geht man zu allerfeinstem Schmirgelpapier iiber, auf dem so lange, bei wiederholtem Umdrehen des Prïparates, geschliffen werden muß, bis man dic Leisten der Fingerbeere bequem durch den Schliff hindurch sehen kinn. Das beste Kriterium für die 
erreichte Dümheit ist vielleicht darin zu sehen, daß die Ecken des Schliffes übcraus leicht abbrechen. Den fertigen Schliff reinigt man sorgfiltig mittels eines trocknen feinen Haarpinsels und legt ihn in dickfluissigen Xylolbalsam ein.

Das eben geschilderte Verfahren hat den großen Nachteil, daß die Haut der Fingerbeere durch das Schleifen auf dem Schmirgelpapier selber geschliffen, d. h. daß die Epidermis in schmerzhafter Heise verdünnt wird. Und dies geschieht auch, wenn man statt des Schmirgelpapiers einen feinen Schleifstein nimmt. Nan muß, wenn man empfindliche Fingerspitzen vermeiden will, das abgesägte Knochenblatt auf einen Kork mit Gummilösung auflkleben. Nach dem Antrocknen schleift man, bis man den Kork durchschimmern sieht, dann löst man den Schliff in IVasser ab, klebt nochmals auf dem Kork auf, indem man die bisher geschliffene Seite auf die Gummilösung bringt, und schleift ron netum, bis der Schliff dünn genug geworden ist. Dic Umkchrung ist nötig, damit die beiden Schleifebenen einander parallel sind. Wan löst den Schliff in 11 asser ab, trocknet ihn auf Fließpapier, zieht ihn, wenn nötig, einige Nale durch die Spiritusflanme, damit das anhaftende IVasser verdunstet, und legt ihn in letzterem Falle abgekühlt - in dicken Kanadabalsam.

Sind die Schliffe gelungen, dann treten die Knochenkörperchen mit ihren Fortsätzen als dunkle, schwarze, spinnenartige Gebilde auf das schönste aus der farblosen Unterfläche hervor und ebenso sind die Kittlinien, die Grenzen der Lamellen und Lamellensysteme, als dunkle Linien gut zu erblichen. Leider sind diese Präparate nicht von Bestand. Nach kiirzerer oder längerer Zeit tritt der Balsam in dic mit Luft erfülten und darum dunkel aussehenden Knochenkörperchen ein, um so schneller je dünnflüsiger er war. Dadurch wird alles gleichmäßig durchsichtig und jedes Texturbild verschwindet. An gefärhten, von gut fixiertem Material herrihrenden Schliffen ist dieser Ubelstand natülich nicht zu befürchten; derartige Präparate bleiben dauernd gut, vorausgesetzt, daß die Färbung mit einem widerstandskräftigen Farbstoffe ausgefuhrt wurde. Es war daher von je das Bestreben, Knochenschliffe von mazeriertem Material zu färben, und die beiden folgenden Methoden suchen dem zu genügen.

Methode von Zimmermann; sie beruht auf dem Prinzip, den bereits fertigen, d. h. für die mikroskopische Untersuchung genügend dünnen Schliff zu färben. Die von mazeriertem Material angefertigten Schliffe werden in Xylol gekocht und dann gut getrocknet. Darauf bringt man sic in ein Uhrschälchen, das mit gesättigter alkoholischer Fuchsinlösung beschickt ist. Farbflutte und Knochenschliff werden 
in Uhrschälchen mehrere Nale je 2 Minuten lang gekocht: dam läßt man abkiihlen. Darauf nimmt man den Schliff aus der Farbflotte heraus und legt ihn auf die Branchen einer Pinzette, so daß er hohl liegt (dieses Hohlliegen kann man eventuell auch auf anderem Wege erreichen; Bedingung ist, das an dem Schliff noch viel Farbstoff haftet. Wenn er trocken ist, meist nach 3 Tagen, wird aller überschüssige Farbstoff mit einem Skalpell abgekratzt. $L m$ noch anhaftende Farbreste definitiv zu entfernen, bringt man auf einen Schleifstein etwas Xylol, legt darein den gufirhten Schliff und schleift ihn mittels des Fingers einige Zeit, indem man ihn wiederholt unkehrt. Dann pinselt man mit Xylol ab. legt in Xylolhalsam auf einem Objektträger ein, erhitzt ganz kurze Zeit iiher der Spirituslampe und deckt endlich mit einem Duckglas cin. Statt des Fuchsins kann man auch jeden anderen Anilinfarlstoff wählen. Bei gelungener Färbung sind die Knochenhöhen Knochenkirperchen und ihre Verzweigungen dauernd mit Farbstoff erfüllt.

Methode von Ruprecht. Sie weicht von der Zimmermannschen dadurch ah, daß man crst firbt und cann schleift. Ein mit der Laubsäge angefertigter Schnitt von einem mazerierten Knochen wird mit einer mittelgruben Ansatzfeic geebnet. Tit der gechneten Seite wird der Schnitt auf Kork oder eine ahnliche Lnterlase durch Gummi arabicum oder besser mit Siegellack aufgekittet und auf der oberen Seite so lange mit einer Feile gefeilt, his die Unterlage. d. h. die Kittmasse, gleichmäßig durchichinmert. Bei dieser Hantierung wird der Schnitt etwa o,+ mm dick. Nun lüst man ihn los, feilt ihn immer noch mit der mittelgrohen Feile auf beiden seiten so lange, bis man gewöhnliche Druckschrift durch ihn hindurch lesen kann. Dann nimmt man eine feine Ansatzfeile, um die groben Feilstriche zu entfernen; jetzt ist er etwa $0.3 \mathrm{~mm}$ duinn. Die Poren des Schnittes öffinet man, indem man ihn mit einem Skalpell abschabt. Ist das geschehen, dann kommt er trocken, wie er ist, für einige Minuten in Ather, wird darauf auf eine Glasplatte gelegt, üher der Spiritusflamme erhitzt und heiß in $̈$ ther gebracht. Auf diese Weise gelingt es, die Luft aus den Knochenhöhlen und ihren Verzweigungen auszutreiben. Jetzt heschickt man cine offene Porzellanschale mit $20 \mathrm{ccm}$ einer filtrierten, in absolutem Alkohol konzentricrten Lösung von Diamantfuchsin, stcllt die Schale auf ein Drahtnetz und erhitzt mit offencr Flamme bis zum Sieden. In die siedende Lösung loommt der Schnitt, der 5 Minuten oder länger in Äther gelegen hat. und zwar wird er flach eingelest. Man läßt noch 5 Minuten kochen, nimme dann die Flanme wer und läßt das Farbbad auf $34^{\circ} \mathrm{C}$. abkiihlen. Dann wird von neuem er- 
wärmt und bei $70^{\circ} \mathrm{C}$. zur Trockne eingedampft. Die am Schnitt haftende Fuchsinschicht wird mit dem Messer abgekratzt. denn es darf kein IVasser oder Alkohol an den Schnitt heran, damit nicht der in den Knochenhöhlen niedergeschlagene Farbstoff aufgelöst wird. Nun cerst wird geschliffen. Auf eine matte, etwa Quartblatt große Glasplatte hommt Bimssteinpulver, durch gegliihtes Kupfersulfat wasserfrci gemachtes Benzin und dazu etwas Vaselinöl, im Verhältnis I : 10. letzt legt man den Schnitt auf die Schleifmasse, deckt mit einer etwa handtellergroßen matten Glasplatte zu und benutzt diese als Reibplatte. Man schiebt sie nämlich und damit auch den Schnitt hin und her und schleift diesen so auf der Schleifmasse ab; das verdunstende Benzin wird ergänzt. Wenn er biegsam und rot durchscheinend geworden ist, dann spuilt man ihn mit wasserfreicm Benzin ab und prüft seine Durchsichtigkeit unter dem Mikroskop. Zeigt er sich hinreichend diinn, dann glättet man ihn, indem man ihn in einer Mischung von Vaselinöl und wasserfreiem Benzin auf einem Mississippistein Arkansasstein, auf beiden Seiten hin und herreibt. Dann wäscht man in wasserfreiem Benzin, um das Öl zu entfernen, trocknet auf Fließpapier und poliert auf Schreibpapier. Nan legt in helles Kolophonium ein, das pulverisiert in erwärmtem wasserfreicm Benzol gelöst wurde. Und zwar muß sowohl der Objektträger als auch das Deckglas Kolophonium erhalten und beide müssen erwärmt werden. Als Resultat ergibt sich eine vollkommene Ausfüllung der Knochenkörperchen und ihrer Ausläufer.

Will man an Schliffen die sogenannten Sharpeyschen Fasern deutlich erkennen, so legt man nach Kölliker den Schliff in einen rotglühenden Platintiegel oder in einen bis zur Rotglut erhitzten kleinen Porzellantiegel und glüht ${ }_{2}{ }_{2}$ I Minute. Längeres Glühen ist vom Übel, da die Schliffe unbrauchbar werden. Nach dem Gliihen läßt man erkalten und untersucht wie gewöhnliche Schliffe.

Die Knochenkörperchen des frischen Knochens bringt man daclurch zur Ansicht, daß man ein Spongiosabälkchen aus der Epiphrse eines Röhrenknochens herausbricht und nach Cohnheim vergoldet ncuntes Kapitel. Die in Glyzerin aufbewahrten Präparate sind nicht haltbar, weil sie zu schnell nachdunkeln.

\section{\$ 124 .}

Anders verfahrt man naturlich, wenn man entkalkten Knochen, sogenannten Knochenknorpel, untersuchen will. Zunächst muß der Knochen gut fixiert werden; Flemmingsche Lösung und Pikrinsalpetersäure sind hierfür am besten geeignet vicrtes Kapitel Mr. 32 
u. 48. Dann wird sorgfältig entkalkt (fünftes Kapitel) und nun entweder freihändig oder nach Einbetten in Celloidin oder Paraffin geschnitten. Zur Färbung ist am besten Eosin-Hämatein oder Orange GHämateïn (achtes Kapitcl Nr. IO2 u. IO3) geeignet. Nicolle empfiehlt folgende Färbung in Karbol-Thionin: $1 \%$ Karbolwasser $90 \mathrm{ccm}$, konzentrierte alkoholische $(50 \%)$ Thioninlösung $10 \mathrm{ccm}$. Nach 5 bis Io Minuten langer oder noch längerer Färbung wird für einige Minuten in konzentrierte wässrige Pikrinsäure eingebracht und dann wie üblich weiter behandelt.

$U_{m} m$ die Sharpeyschen Fasern an frischem Material zu zeigen, soll man den Knochen kurze Zeit kochen, entkalken und dann schneiden. Ranvier isoliert sie in folgender Weise: Ein dünner polierter Schliff von frischem Knochen wird in ${ }^{1}{ }^{\circ}, 0-I^{0}{ }_{0}$, Salzsäure entkalkt. Dann zerzupft man ihn, wobei sich die Lamellen isolieren lassen und wobei gleichzeitig die Sharpeyschen Fasern vortreten. Man kann auch nach Ranvier Schnitte von entkalktem Knochen in $10^{\circ}{ }_{0}-15^{\circ}$. Kochsalzlösung oder in Alkohol, Essigsäure; Oxalsäure oder konzentrierte Salzsäure legen; in allen Reagentien werden die Sharpeyschen Fasern sichtbar.

Kölliker empfiehlt zur Darstellung der genannten Fasern in Knochenschnitten folgende Methode: Man macht die Schnitte in Essigsäure durchsichtig, bringt sie sofort für ${ }^{\mathrm{I}}{ }_{4}$ - I Minute in unverdünnte Indigkarminlösung, spuilt in Wasser ab und hebt in Glyzerin auf. Safranin und Lithionkarmin sollen ebenfalls brauchbare Bilder liefern.

Die elastischen Fasern im Knochen, die sich genau wie die des lockeren Bindegervebes verhalten, werden durch sehr düne Fuchsinlösungen deutlich. Weigerts Fuchsin und Röthigs Kresofuchsin (achtes Kapitel Nr. 63 u. 6 + S. I 82 ) bringen sie naturlich ebenfalls zur Erscheinung.

Für Kurszwecke behandelt Heidenhain Knochen folgendermaßen. Frische menschliche Knochen kommen mit den noch anhaftenden Weichteilen in $96 \%$ Alkohol. Stücke der Diaphyse bis zu I cm Länge werden ausgesägt und in $5^{\circ}$ 。 Trichloressigsäure zum Entkalken eingelegt. Nach beendeter Entkalkung wird direkt in $96^{\circ}$.。 Alkohol gebracht, dann in üblicher Weise celloidiniert und von dem Knochenknorpel werden 20-25 $\mu$ dicke Schnitte angefertigt. Sollte es nötig sein, so wird das Knochenmark in den Schnitten mit Ïther entfettet. Die Schnitte kommen zunächst in sehr verdünntes Delafieldsches Hämatoxylin und dürfen nicht überfärbt werden, dann bringt man sie nach Auswaschen in Boraxkarmin achtes Kapitel 
Nr. 9) u. 39\%. Der Einschluß in Kanadabalsam ist zu vermeiden, weil die Schnitte schrumpfen; sie müssen in Heidenhains alkoholischem (ilyzerinleim aufgehoben werden (sechstes Kapitel Nr. \& S. gi'

\section{$\$ 125$.}

Das Knochenmark muß in verschiedenen Stadien seiner Ausbildung untersucht werden, nämlich entweder als rotes lymphoides . Wark bei jugendlichen, eventuell in den Epiphysen, den kurzen und platten Knochen bei erwachsenen Tieren oder als Fettmark in den Diaphysen der letzteren. Auf alle Fälle müssen die Knochen gut fixiert werden, und es muß ausreichende Gelegenheit rorhanden sein, daß das Fixierungsreagens an das Knochenmark hetan kann. Epiphysen müssen daher durchgesägt werden, kurze und platte linochen desgleichen, damit das Mark, auf dessen Beschaffenheit es ankommt, in müglichst frischem Zustande fixiert wird. Um das rote Mark in den Diaphysen jugendlicher Säugetiere zugänglich zu machen, wird oft die Abtragung eines Teiles der Substantia compacta mittels eines starken Skalpells zenügen. Bei zu großer Härte auch jugendlicher Knochen wie zum Studium des gelben Markes crwachsener Tiere wird man dagegen eine IVand der Diaphyse mit der Säge abtragen, um so das Knochenmark bequem zugänglich zu machen. Es sind diese letzteren Nethoden jedenfalls besser als jene Vorschrift, wonach die Diaphyse eines erwachsenen Tieres in den Schraubstock gespannt und dieser so lange zugedreht werden muß, bis die Tela ossea springt.

Zur Fixierung sind Sublimat und Pikrinsalpetersäure in erster Linie zu empfehlen. Auch Salpetersäure-Kalibichromicum und Chrompikrinsalpetersäure geben gute Resultate. Nach der Fixierung und Härtung wird entkalkt (fünftes Kapitel. Nach der Entkalkung kann man bei Diaphysen das Knochenmark durch Abtragung des Knochenknorpels frcilegen, bette cin und läßt es so in seiner natürlichen Lage. Bei allen anderen Kinochen - Epiphysen, kurzen und platten Knochen kiamn man es nicht herauspräparieren und bettet es daher eo ipso in seincr natiurlichen Lage ein. Die Schnitte färbt man etweder mit einer der guw ühnlichen Doppelfärbungen oder mit einem Eisenhämatoxylinlack oder aber mit Rücksicht darauf, daß die Medulla ossiun eiri Organ der Blutbereitung ist, mit den ron Ehrlich und seinen schülern zur L'ntersuchung des Blutes angegebenen Farbmitteln (sechzchntes Kapitel. Will man den Fettgehalt des Knochenmarkes untersuchen, dann muß man Osmiumsäure und osmiumsaurehaltige Gemische anwenden und eventucll mit Holzessiz oder Tannin nachbehandeln (viertes Kapitel S. 60). 
Ist die Schwärzung nicht erwïnscht, dann muß das in Formol fixierte Knochenmark der Diaphysen - und nur bei diesen ist die Methode möglich - mit dem Gefriermikrotom geschnitten und in Sudan III oder Fettponceau, Scharlach, (achtes Kapitel Nr. 73 u. it S. 184) gefärbt werden. Die Präparate hebt man in Glyzerin auf.

Daß man rom Knochenmark in seinem Zusammenhange mit der nichtentkalkten Knochensubstanz Schliffe machen kann, ist selbstverständlich. Die vorher gefärbten Stücke - zur Färbung darf natiirlich kein Farbstoff gewählt werden, der Salzsïure oder eine andere anorganische säure enthält bzw: in einer solchen differenziert werden mul3 - werden in Kolophonium oder Kanadabalsam cingebettet, wie dies im siebenten Kapitel genauer beschrieben worden ist.

\section{$\$ 126$.}

Die Knochenentwicklung, 1 . h. den Verlanöcherungsprozeß, studiert man entweder an Embryonen oder an den Röhrenknochen jugendlicher Säugetiere. Bei letzteren nimmt man die Gegend des Epiphrsenknorpels und legt diese mit einem Stiick Epi- und Diaphyse im Zusammenhange in die Fixierungsflissigleit. Bei Embryonen bzw: Föten handelt es sich darum, ob das ()hjekt groß genug ist, um ein Herauspräparieren zu gestatten, oder of man, was namentlich bei jüngeren Stadien der Fall sein wird, die ()ssifikation an dem in toto geschnittenen Embryo studieren muß. Das sind jedoch nur Differenzen der Präparation; Fixierung und Färbung sind für jedes Objelt die gleichen. Retterer, der iibrigens zu Ossifikationsstudien die Rippenknorpel jugendlicher Tiere empfichlt, fixiert besonders in folgenden von ihm konstruierten Gemischen: 1. 3 . Chromsäure $66 \mathrm{ccm}$, Formol $33 \mathrm{ccm}$, Essigsäure $8 \mathrm{ccm}$, oder 2. $5^{\circ}$. Platinchloric $50 \mathrm{ccm}$, Formol $50 \mathrm{ccm}$, Essigsäure $3 \mathrm{ccm}$. Die Objekte werden in der einen oder anderen Mischung 6-12 Stunden lang fixiert und nach Auswaschen in Wasser in Alkohol von steigender Konzentration erhärtet. Außerdem sind zur Fixierung zu empfehlen: Sublimat, Flemmingsche, Zenliersche Lösung, Bendas Fixicrung in Salpetersäurc-Kali bichromicum, meine Chrompikrinsalpetersäure und Chromessigsäure rrgl. viertes Kapitel. Zur Färbung ist besonders Hämatoxylin-Karmin nach Strelzoff (achtes Kapitel, Nr. go S. i 88; zu empfehlen, ferner duirften sich Indigharmin-Boraxharmin und Eosin-Hämatein 'achtes Kapitel Nr. g, u. 102, als gecignet crweisen. Zschokke rühnt fur das Studium der Ossifikation das Benzoazurin in wässriger Lüsung. Nach dessen Anwendung; belicbige Fixierung rorausgesetzt, zeigen die Schnitte rom Ossifikationsrande den Knorpel gar nicht oder nur 
schwach sufurbt, Bindegewebe und Kerne blau oder violett. Osteoblasten, junges Knochengewebe rot.

ๆ) Zähne.

$$
\text { \$ } 127 .
$$

Das Zahngewebe, ein modifiziertes Knnochengewebe, wenigstens seiner histologischen Beschaffenheit nach, wird genau wie das Knochengewebe untersucht. Die für dieses angegebenen Methoden finden laher beim Zahn buchstäbliche Anwendung. Auch was die Methoden des Schleifens anlangt; die Weilsche Methode (siebentes Kapitel Nr. + S. I I I) ist ja besonders zum Studium der Zähne konstruiert worden und gestattet, die Pulpa in ihrer Situation im Innern der Zahnwurzel zu untersuchen.

Besonders günstige ()bjekte zur Untersuchung des feineren Baues der Zähne sind die des definitiven Gebisses vor ihrem Durchbruch durch die Kiefer. Sie sind noch nicht so hart, wie die durchgebrochenen Zähne (namentlich ist dies beim Schmelz der Fall, und lassen sich ferner in Paraffin viel besser durchtränken und viel leichter schneiden, als diese. Ein sehr interessantes Objekt sind auch die Schneidezähne der Nager, weil diese die einzigen Zähne sind, die nach dem Durchbruch sich abnutzen und nachwachsen. Zum Studium der Zahnentwicklung ist jeder embryonale oder fötale Kiefer gecignet, wobei Fixierung und Färbung nach jeder beliebigen Methode vorgenommen werden können. Ein interessantes Material zum Studium des Dentins bieten die Hautzähne der Selachier.

Bödeker hat zur Entkalkung des Zahnschmelzes, dieses härtesten aller Körperbestandteile, folgendes Verfahren angegeben: Die unentkalkten Schliffe werden Lege artis so weit behandelt, daß sie in dünnes Celloidin kommen können. Aus diesem bringt man sie nach kurzem Verweilen in ein dickes Celloidin, dem $6^{\circ},{ }_{0}-\mathrm{IO}^{\circ}{ }_{0}$. Salpetersäure zugesctzt sind. Alle 2-3 Tage müssen einige Tropfen der zur Lösung des Celloidins gebräuchlichen Alkohol-Äther-Mischung zugefügt werden, damit nicht durch Verdunstung die Celloidinlösung zu dick und dadurch die Säurebeimischung zu konzentriert werde. Je nach der Dicke der Schliffe dauert die Entkalkung natülich verschieden lange: bei $30 \mu$ Dicke 2 Wochen, bei I mm 2 Monate. Anfänglich sieht das Präparat lreidig aus, allmählich wird der Schmelz durchsichtiger, bis er verschwunden erscheint. Über die Weiterbehandlung fehlen detaillierte Angaben. ()bgleich ich keine eigenen Erfahrungen mit dieser Methode habe, so scheint es mir doch nötig, das weitere T'erfahren rollständig anzufihren. Fis diirfte nach beendeter Entkalkung ange- 
messen sein, das Zahnstiickchen - um einen eigentlichen Schliff für mikroskopische Zwecke handelt es sich nicht - aus dem sauren in neutrales dickes Celloidin überzuführen, es schnittfähig zu machen und nach Mörlichkeit zu schneiden. Nan wird deswegen $\mathrm{I}-2 \mathrm{~mm}$ dicke Stüchchen vom Zahn absägen müssen. Bevor man die Schnitte färbt, wird das Celloidin zu entfernen sein, damit jede Spur von Salpetersäure aus den Schnitten beseitigt werden kann.

\section{Fünfzehntes Kapite1.}

\section{Das Muskelgewebe.}

$$
\text { \. } 128 .
$$

a) Quergestreifte Muskeln. Wenn man die frischen Muskeln eines cben getöteten Tieres untersuchen will, so nimmt man ein Stiickchen der Skelettmushulatur, das man mit einer auf die Fläche gehogenen und mit etwas physiologischer Kochsalzlösung befeuchteten Schere abgeschnitten hat. (Lebende Muskeln, das sei hier parenthetisch bemerkt, zu untersuchen, d. h. Nuskeln im lebenden Tiere, hat keinen rechten Zweck, da man histologische Einzelheiten kaum zu erkennen vermag.: Das abgeschnittene Stückchen wird in $0,75^{\circ}$. Kochsalzlösung leicht zerzupft, eingedeckt und untersucht. Zum Studium der quergestreiften Nuskulatur wählt man am besten die der Lacertiden unter den Sauriern, ferner Testudo, Emys, von Evertebraten Astacus fluviatilis und alle Coleopterengattungen. Bei den genannten Gruppen sind die Querstreifen sehr breit und daher jedes Detail relativ leicht zu sehen. Dies ist bei den nicht genannten Vertebratengruppen nicht der Fall: bei diesen ist alles viel weniger klar und übersichtlich erkenmbar, wenn auch natürlich das an den paradigmatischen Gruppen Beobachtete bei ihnen gleichfalls zu konstatieren ist. Und es ist wohl selbstverständlich, daß Studien über quergestreifte Muskelsubstanz an allen Gruppen anzustellen sind.

In physiologischer Kochsalzlösung erkennt man nicht viel mehr, als die Tatsache der Querstreifung der Muskelfaser. Nicht einmal die Kerne mit ihren protoplasmatischen Polen sind gut zu sehen. Um sie zur Anschauung zu bringen, setzt man dem Präparate seitlich etwas O.I ${ }^{\circ}$. Essigsäure zu, wobei man gleichzeitig auf der an- 
deren Seite des Deckglases mit Filtrierpapier die Kochsalzlösung absaugt. Diese Aufhellung - denn cine solche ruft die Essigsäure herror - setzt man so lange fort, his die Querstreifung nur noch schwach sichtbar ist; dann sind die Muskelkörperchen von Max Schultze vorzüglich zu erkennen.

\section{\$ิ I 29.}

Die Zusammensetzung der Muskelfaser aus Fibrillen kennen zu lemen, bedarf es ciner eingreifenderen Methodik, als der bisher geschilderten. Eine allerdings oft monatelang wahrende Mazeration in I: oder ${ }^{\text {I }}$ + Alkohol drittes Kapitel, liefert die besten Resultate. Dic Zerzupfung ist leicht, der Fibrillenzerfall ist ausgiebig und die histologischen Details sind wenigstens zum Teil noch erhalten. Will man von derartig vorbehandeltem Material Dauerpräparate anfertigen, so empfiehlt sich die Firbung in meinem Glyzerinkarmalaun, bis das Präparat dunkelrot erscheint, dann Abwaschen in Wasser, Zerzupfon in Glyzerin und Aufheben darin oder trocknes Zerzupfen nach dem Abwaschen und Finschluß in Glyzeringelatine. Die Färbung mazericrter Muskeln mit Indigharmin-Boraxkarmin achtes Kapitel. Nr. ge S. I \&g licfert ausgezeichnete Präparate, dic aber nicht haltbar sind, weil sie im Glyzerin wie in der Glyzeringelatine sehr bald verblassen. Den schnellen Zerfall in Fibrillen herbcizufüren dienen Kühnes Nethode mit chlorsaurem Kali und sapetersäure und Sandmanns Nethode mit schwefliger Siure 'drittes Kapitel Nr. 28 u. 2y, Nur die mit der letzteren erzielten Präparate sind aufbewahrungsfähig, wenn man sie vergoldet. Da hierbei kein Detail des feincren Baues der quergestreiften Faser mehr sichthar ist, sondern nur die Nervenendigungen sich crhalten zeigen, so soll diese Methode erst im dreiundzwanzigsten Kapitel beschrieben werden.

Die von Cohnhein gefundene Gruppierung der Muskelprimitivfibrille zu Muslielsäulchen oder Primitivzylindern ist am Gefrierschnitt fustzustellen. Und zwar muß man den frischen Muskel gefrieren Jasscun. Die aufgetauten Schnitte kann man ohne weiteren Zusatz untersuchen nder man rergoldet sie (vgl. neuntes Kapitel) und hebt auf.

Der Zerfall der quergestreiften Faser in Scheiben, in die sogenannten Discs: wird durch Mazcration in Essigsäure oder Salzsäure erreicht. Nan legt entweder für mehrere Tage in $0,5^{\circ}-I^{\circ}$. Essigsäure ein oder man mazeriert in $0,5 \%$ oder $0,1 \%$ oder $0,05 \%$ Salzsäure. $\mathrm{Zu}$ letzterem Zwecke zerlegt man einen Muskel mit der Schere in kleine Stiickchen und bringt chese in ein Becherglas, das mit einer der gemannten Säurekonzentrationen be:chickt ist. Die Konzentration richtet 
sich nach dem Bindegewebsgehalt des Muskels; je größer letztercr, desto stärker die Säure, von der mindestens das 30 fache des Volumens des Muskelstïckchens genommen werden muß. Das Becherglas hängt man für 24 Stunden in ein konstantes Wasserbad, deșsen Temperatur $30^{\prime \prime}-37^{\circ} \mathrm{C}$. betragen muß. Nach dem Auswaschen wird in Wasser leicht zerzupft und darin untersucht oder nach Absaugen des IVassers in Glyzeringelatine eingeschlossen. Die Präparate vertragen nach meinen Erfahrungen keine Färbung.

Die diffizile Struktur der Querstreifen, über welche die Lehrbücher der Histologie dic nötige Auskunft geben, studiert man nach Rollett am besten an Käferlarven. Man wirft diese in toto für $2+$ Stunden oder länger in $93^{\circ}$. Alkohol. Dann wird ein Stückchen Muskel mit der Schere herausgeschnitten und nach Cohnheim, Löwitt oder Golgi vergoldet Ineuntes Kapitel Nr. I, 2 u. 6). Statt der Metallimprägnation kann man auch färben, und zwar eignen sich hierzu am besten die sehr verdünnten Alaumhämateine bzw. -hämatoxyline (achtes Kapitel).

$$
\$ \text { I } 30 .
$$

Die quergestreifte Muslielfaser zeigt bekanntlich im polarisierten Lichte ganz bestimmte charakteristische Eigentümlichkeiten. Will man diese an Daucrpräparaten untersuchen, so ist es gut, die Muskeln in Alkohol zu fixieren und nach Einschmelzen in Paraffin in Schnitte von Io $\mu$ Dicke zu zerlegen. Die Schnitte dürfen natürlich nicht gefärbt werden und auch für die Fixierung darf kein Reagens genommen werden, das irgendwic färbend einwirkt. Dic Zerlegung in Schnitte ist darum vorteilhaft, weil dadurch die Muskelfasern alle parallel zu einander liegen und daher den polarisierten Lichtstrahl gewissermaßen nicht genieren, was bei wirr durcheinander liegenden Fasern mit ihren verschiedenen Schwingungsebenen der Fall ist. Wie man mit dem Polarisationsmikroskope arbeiten muß, ist kurz in $\leqslant 8$, erstes Kapitel S. 8, auseinandergesetzt worden. Ehendaselbst wurde auch das Buch erwähnt, mit Hilfe dessen man den Gebrauch der Polarisationsinstrumente und deren physikalische Eigenschaften leicht erlernen kann. Ausfiihrlich auf diese rein physikalische Methode einzugehen, wïde uns zu weit führen.

\section{$\$ 13 \mathrm{I}$.}

Organe, in denen quergestreifte Muskin rorkommen, sind im allgemeinen nach denjenigen Grundsätzen zu fixieren, welche in den späteren Kapiteln für die hetreffenden Organe als befolgenswert zu schildern sind. Denn gewöhnlich studiert man Muskelstruktur nicht in 
Organen, wic z. B. in der Zunge. Immerhin mag herorgehoben werden. dals Sublimat, Pikrinsalpetersäure, Chrompikrinsalpetersäure, Chromessigsäure, Fl em mingsche Lösung und Palladiumchlorür solche Reagentien sind, welche die quergestreifte Muskelfaser gut crhalten igl. viertes Kapitel. Sorgfalltig muß entwässert und gruindlich in Chloroform durchtränkt werden, sonst mißlingt das Einschmelzen in Paraffin. Gut färbt sich die quergestreifte Muskulatur der Organe nur in Karmalaun bzw. Glyzerinkarmalaun, Orange G-Hämateïn, EosinHämatein und Indigkarmin-Boraxkarmin (rgl. achtes Kapitel). Besonders der letztere Farbstoff lieferte mir ausgezeichnete Färbungen, die in Xylolbalsam sich sehr gut erhalten. Alle ïbrigen Methoden bzw. Färbemittel geben nach meinen Erfahrungen zu wenig distinkte Bilder, während die genannten die ()uerstreifung sehr schön hervortreten lassen und die Kerne mit ihren Protoplasmapolen scharf kontrastierend färben.

\section{$\$ 132$.}

B) Glatte Muskeln. Während die für die quergestreifte Muskelfaser geeigneten Methoden sowohl für Vertebraten als auch für Arthropoden gelten, jenen Evertebraten, die durchweg quergestreifte Muskeln haben, sind die folgend anzuführenden Methoden nur bei den glatten Muskeln der Vertebraten erprobt. Eine wirklich erschöpfende methodologische Durcharbeitung der glatten Muskeln bei den Evertebraten ist noch Desiderat.

Als geeignetes Objekt, die glatte Nuskulatur zu untersuchen, ist die Harnblase des Frosches oder die eines sehr kleinen Säugetieres zu empfchlen. Nan schneidet die Blase so auf, daß sie auf einem Objektträger glatt aufliegt; man muß dabei darauf achten, daß die Epithelschicht nach oben sieht. Nun nimmt man einen in physiologische Kochsalzlösung getauchten weichen Haarpinsel und pinselt sorgfältig (las Blasencpithel ab. Die Entfernung des Epithels merkt man daran, daß die aus dem Pinsel auf das Präparat kommende Flüssigkeit trübe wird. Man setzt die Pinselung fort, bis die physiologische Kochsalzlüsung sich nicht mehr trübt. Man kann ein solches Präparat in Alkohol fixieren, indem man einfach den Objektträger in eine Glasschalc mit Alkohol taucht. Die Nachfärbung wird beliebig vorgenommen. Oder man kann rergolden. Dann spült man die gepinselte Blase schnell und sorgfältig in destilliertem Wasser ab, indem man sie mit einer Pinzctte faßt und in einem Becherglase mit Wasser schnell hin und herschwenkt. Dann wird nach einer beliehigen Goldmethode vergoldet (neuntes Kapitel. Sorgfältig ist darauf zu achten, 
daß man beim Aufheben der Blasenpräparate die Innenfläche nach oben bringt, damit sie unter dem Deckglase liegt. Die Beschaffenheit, d. h. der Bau der glatten Muskeln wird so leichter verständlich. Statt des mühsamen Abpinselns kann man das Epithel nach der Klebsschen Vorschrift mit Rohrzucker-schwefliger Säure abmazericren (drittes Kapitel Nr. 30 S. 29) und dann nach gründlichem Auswaschen wie vorhin geschildert weiter behandeln.

Zur Isolation der glatten Nuskelzellen ist nach den Angaben von M. Heidenhain die Mazeration in Salizylsäure schr geeignet. Auch dic Methode von Hopkins (Salpetersäure-Alaun ist sehr zu empfehlen vgl. drittes Kapitel Nr. 2 ; S. 28). Man kann die Harnblase kleiner Säuger oder den Darmkanal fettarmer Tiere wählen.

Paul Schultz mazeriert glatte Muskulatur $2+$ Stunden in 10" Salpetersüure und nimmt kleine Stuicke davon, die er nach fluichtigem Abwaschen für 6-S Tage in Osmiumessigsäure nach R. Hertwig (drittes Kapitel Nr. I9 S. 27 einlegt. Zur Mazeration sind ferner nach Reichert $20^{\circ}$, Salpetersäure, nach Moleschott $32^{\circ},-35^{\circ}$. Kalilauge sowie dic im dritten Kapitel aufgefihrten Methoden geeignet.

Will man fixieren, so kann man sich entweder an dic Organe halten, in welchen glatte Muskeln vorkommen (Tractus intestinalis usw.) oder man nimmt die Harnblase. Diese muß natülich mit der Fixierungsflüssigkeit angefüllt werden, damit sie ihre natiirliche Ausdehnung behält. Ohne diese Vorsichtsmaßregel würde sie in der Fixierungsflüssigkeit zu einem unförmlichen Ballen sich kontrahieren und daher ganz unbrauchbare Präparate liefern. Die Methoden der Fixierung und Färbung, die für die quergestreifte Muskulatur empfohlen wurden, eignen sich auch für die glatte. Im übrigen halte ich jede Fixierung und jede Färbung für geeignet, weil dic glatte Muskulatur der Vertebraten etwas ganz Charakteristisches besitzt. Bei den Evertebraten dagegen ist die Färbung durchaus nicht gleichguiltig, hier hat sich mir stets Indigkarmin-Boraxkarmin (achtes Kapitel Nr. 98 S. 189) ausgezeichnet bewährt. 


\section{Sechzehntes Kapite1.}

\section{Blut.}

\section{$\S 133$.}

Lebendes Blut. An denjenigen Gebilden, welche im zweiten Kapitel als die geeigneten Objekte zur Lntersuchung lebendiger GLwehe beschrieben worden sind, läßt sich natiirlich auch lebendes Blut untersuchen. Ferner können noch lehende durchsichtige Fischlarven in der gleichen Weise rerwendet werden, wenn sie klein und diinn genug sind, um unter dem Mikroskop Platz zu finden.

Das sich bei derartigen Beobachtungen darbietende Schauspiel ist ein ungemein reizrolles. Die stoßweise Fortbewegung größerer Blutmengen in den Arterien, die relative Langsamkeit und völlige Gleichmäßigkeit des Blutstromes in den Kapillaren und Tenen: das sind IBilder von höchstem wissenschaftlichen Interesse und von ästhetischer Tollkommenheit. Die Schnelligkeit des arteriellen Blutstromes wie die Massenhaftigkeit des Blutes in den Venen gestatten keinen tieferen Kinblick in die Zusammensetzung dieser eigenartigen Flüssigkeit, haum dal3 man clie träg an den Gefäßwänden entlang schwimmenden Leukocyten zu unterscheiden vermag. Dagegen gewähren die Kapillareu cinen spezialisierteren Limblick. Nan erkennt die Erythrocyten, die sich cinzcln oft mit Niihe durch eine Kapillare hindurchschlängeln. Man sieht ihre Biegsamkeit und Elastizität; wie sie an einer Stelle oft bis zur Unkenntlichkeit ihrer Form gequetscht erscheinen, um bald darauf zu ihrer natuirlichen Größe sich mit einem Schlage auszudehnen. Sie reiten auf den Teilungsstellen der Kapillaren, werden durch den Blutstrom dabei in einer Weise gedehnt, daß man meinen sollte, sie müßten in jeden Augenblicke zerreißen, und schnellen dann plötzlich in ihre normale Gestalt zurück, indem sie sich dem Blutstrome wieder zugesellen.

Auch die Leukocyten sind bequem zu beobachten, was bei der Traghcit ihrer Berregungen nicht Wunder nehmen kann. An geeignuten ()bjekten (Mesenterium z. B. sicht man bei längerer Beobachtungsdauer ihre Diapedese.

Nehr aber lehrt die Lntersuchung lebenden Blutes nicht. Ein drittes körperliches Element, die Thrombocyten (Blutplättchen, entzieht sich der Beobachtung vollkommen, die Differenzen der Leukocyten, welche ron ihrem verschiedenen Entstehungsort herrihren. bleiben unsichtbar. 


\section{$\$ 134$.}

Überlebendes Blut. Bedeutend mehr als beim lehenden sieht man beim überlehenden Blut; ja manche Eigentümlichkeiten sind nur an derartigen Präparaten zu konstatieren. Unter iiberlehendem Blute ist solches 2 u rerstehen, das aus der Ader entnommen sofort untersucht wird. Es dauert nämlich immer einige Minuten, ehe die Blutgerinnung eintritt, durch welche das : Überlehen beendet wird.

Nan sticht, um uiberlebendes Blut zu erhalten, mit einer frisch geglühten und dadurch sterilisierten kleinen staarnadel in die eigene Fingerbeere oder in dic eines anderen Menschen, wischt den ursten heraustretenden Blutstropfen weg. weil er mit den der Haut, wenn auch in noch so geringem Maße, anhaftenden Partikeln verunreinigt ist, nimmt den zweiten nit einem gut gercinigten Deckglase oder ()hjektträger auf und untersucht unter dem Tihroskope, indem man dais mit Blut beschickte Deckglas auf einen Objektträger auflegt bzw. den mit dem Blutstropfen versehenen ()bjektträger mit einem Deckglase zudeckt. Man darf niemals einen zu großen Tropfen nehmen, wei! man sonst infolge der Massenhaftigheit der Blutkürperchen nichts sieht. Und man muß bei jedem frischen Präparate, zu welchem der Blutstropfen aus der bereits benutzten Stichstelle entnommen werden soll. den jedesmaligen neuen ersten Tropfen abwischen und erst den zweiten benutzen.

Statt der menschlichen Fingerbeere kann man die Planta pedis oder die Auricula des Hundes bzw. cines anderen leicht zu erhaltenden Säugetieres nehmen, man kann von Vögeln und von anderen Wirheltieren Präparate machen. Schwieriger sind die Blutuntersuchungen an Evertebraten anzustellen, für die eine derartig durchgebildete Methodik wie für Vertebraten nicht existiert.

Die Untersuchung überlebenden Blutes fürdert wichtige Tatsachen zutage. Daß die Erythrocyten der Mammalia die geldrollenartige Anordnung zeigen, ist nur an solchen Präparaten zu konstatieren: und daß hei Sauropsiden und Ichthyopsiden diese eigenartige Gruppicrung der Erythrocyten nie eintritt, ist mit apodilistischer Sicherheit cbenfalls nur an iherlebendem Nateriale zu beobachten. Die Differenz kernhaltiger und kernloser Erythrocyten, welch letztere nur bei den Säugern sich finden, ist an überlehendem Naterial zu konstatieren, wie an solchem allein ein richtiger Einblick in die Gestalt der roten Blutkörperchen zu gewinnen ist. Daß Blut in dünnen Schichten gelbgriinlich erscheint und daß der Farbstoff in den Kürperchen sitzt, daß die Erythrocyten ungemein vulnerable Gebilde sind. dal 
bei der Gerinnung feinste Fibrinfäden zwischen den Blutkörperchen auftreten, daß die Leukocyten sehr viel geringer an Zahl sind als die Erythrocyten: alle diese uberaus wichtigen Eigentümlichkeiten des Vertebratenblutes sind mit Sicherheit nur an iiberlebendem Naterial zu beobachten. Daß neben Erythro- und Leukocyten noch ein drittes kürperliches Element, die Thrombocyten oder Blutplättchen, vorhanden ist, hat ebenfalls die Untersuchung frisch aus der Ader entnommenen Blutes gelehrt. Freilich muß für diese eben genannten Gebilde zugegeben werden, daß der exalite Nachweis ihrer Präexistenz, der in neuester Zeit geliefert wurde, nur durch spezielle Fixierungs- und Färbungsmethoden möglich ist (vgl. \& I 43), während das iiberlebende Material keine einwandfreien Bilder liefert.

\section{$\$ 135$.}

Zählung der Blutkörperchen. Die Zahl der im Kubikmillimeter Blut vorhandenen Erythrocyten und ihr Verhältnis zu den Leukocyten kennen zu lernen, ist von höchstem wissenschaftlichen und praktischen Intercsse. Bestimmte Erkrankungen gehen einher mit einer dauernden oder vorübergehenden Vermehrung oder Verminderung der Leukocyten. Um aber zu wissen, wie sich das Verhältnis beider Blutkörperchenarten geändert hat, muß man deren normale Zahlen kennen, und sie zu erfahren dient der folgend beschriebene Apparat. Es ist dies der von Thoma erfundene, von Abbe und Zeiß zu tadelloser Exaktheit vervollkommnete Blutkörperchen-Zählapparat. Er besteht aus einer genau kalibrierten Pipette und einer bestimmt gebauten Glaskammer. Dic Pipette hat an einer Stelle, die ihrem weiten Ende genähert ist, eine spindelförmige Erweiterung, in welcher sich eine kleine Glasperle befindet. Man bringt nun in die Pipette Blut, indem man ihre Spitze in letzteres eintaucht und mit dem am entgegengesctzten Ende befindlichen Gummischlauche saugt. Zwischen der spindelförmigen Erweiterung und der Spitze der Pipette finden sich zwei Marken; die untere ist mit ${ }^{\mathrm{I}} / 2$, die obere, dicht unter der Erwciterung befindliche, mit I bezeichnet. Oberhalb der Erweiterung findet sich eine dritte Marke, IOI genannt. Man saugt nun Blut entweder bis zur Marke ${ }^{I} / 2$ oder bis zur Marke I. Dann wischt man dic Pipettenspitze ab, taucht sie in $3^{\circ}$ Kochsalzlösung und saugt bis zur Marke IoI. Jetzt schiittelt man gut durch, damit sich Blut und Kochsalzlüsung genau mischen, was durch die mitgeschiittelte Glasperle ausgiebig bewirlt wird. Bei Aufziehen des Blutes bis zur Marke ${ }^{\mathrm{T}} \mathrm{I}_{2}$ wird $200 \mathrm{mal}$, bis zur Marke I nur Ioomal mit Kochsalzlïsung verdunnt. Yun bringt man in die Zähikammer. Diese bc- 
steht aus einem breiten, planparallel geschliffenen Objektträger, auf den eine o, I $\mathrm{mm}$ tiefe Glaskammer aufgekittet ist. Der Boden von letzterer ist so in Quadrate eingeteilt, daß jedes von diesen die Grundfläche eines Raumes darstellt, der ${ }^{\top}$ tom Kubikmillimeter Inhalt besitzt. In diese Kammer gibt man das zu untersuchende Blut. Nan tut gut, die ersten sich zeigenden Fliissigkeitsmengen von der Pipettenspitze abzuwischen und nur das Blut zu nehmen, welches in der spindelförmigen Erweiterung sich findet, weil nur dieses exalit verdiinnt ist. Nan deckt mit einem planparallel geschliffenen Deckglase ein, das dem Instrumente beigegeben ist. Nun zählt man die Erythrocyten in mehreren Quadraten, multipliziert jeden Befund mit +000 und erhält dadurch die Anzahl der Blutkürperchen in einem Kubikmillimeter verdünnten Blutes. Stimmen die Zählungsergebnisse in den verschiedenen Quadraten ganz und gar nicht uiberein, so nimmt man zunächst das arithmetische Mittel, macht aber ein neues Zählpräparat. Zeigen sich auch bei der zweiten Zählung schr große Differenzen zwischen den einzelnen Quadraten, dimn war das Blut mit dem Kochsalz schlecht gemischt und es muls eine neue Verdimnung vorgenommen werden. Ist dagegen das Ergebnis mehrerer Zählungen in einem Präparate im wesentlichen in L bereinstimmung und bleibt das Ergebnis auch in einem zweiten Zählpräparate zu recht bestehen, dann multipliziert man das arithmetische Mittel, wie gesagt, mit 4000 . Da man aber dadurch nur die Zahl der Körperchen im verdünnten Blute erhält, so muß man noch einmal multiplizieren, und zwar mit Ioo, wenn das Blut Ioomal, mit 200, wenn es 200 mal verdiinnt worden war.

Andere Zählapparate wie der beschriebene sind zu kompliziert in ihrer Anwendung und trotzdem oder vielleicht gerade deswegen zu unsicher in ihren Resultaten.

Wenn man die Kochsalzlösung mit sehr dünner Gentianaviolettlösung anfärbt, dann erscheinen die Leukocyten bläulich tingiert und man kann sie neben den Erythrocyten zählen. Diese Methode erscheint mir brauchbarer als jene andere, bei welcher zum Blut ro Teile $0,5^{\circ}$ 。 Essigsäure gesetzt werden sollen. Die Erythrocyten sind zwar dadurch völlig zerstört, aber die Leukocyten zuglcich so durchsichtig, daß sie nur sehr schwer erkennbar sind.

$$
\$ 136 .
$$

Das Blut besteht bekanntlich aus körperlichen Elementen und aus einer Flüssigkeit, in welcher jene suspendiert sind. Blut ohne Körperchen heißt Blutplasma, Plasma ohne Fibrin heißt Serum. Auf die 
Einzelheiten von Plasma und Fibrin gehen die Lehrbücher der Physiologie ein: sie hier zu erörtern erübrigt also. Nur die Färbung von librin in mikroskopischen Präparaten ist besonders zu erwähnen; dies soll im § I44 erfolgen.

Die Erythrocyten sind immer leicht zu erkennen; dafür bürgt ihre Massenhaftigkeit und ihre spezifische Färbung. Schwer dagegen sind stets die Leukocyten zu sehen, weil sie sehr durchsichtig sind. Von Wert ist daher eine Methode, sie isoliert, gewissermaßen in Reinkultur, zu erhalten. Nan injiziert zu dem Ende etwas Curarelösung in den Rückenlymphsack eines Frosches. Nach $2+$ Stunden hat sich massenhaft Lymphe angesanmelt; man saugt diese mit einer Pravazschen Spritze ab und untersucht tropfenweise. Da die Leukocyten klein und, wic gesagt, vollkommen farblos und durchsichtig sind, so muls man zu ihrer Untersuchung enge Blenden und starke Linsen nchmen. Um nun das System des Mikroskopes auf die richtige Ebene des Präparates einstellen zu können, ist es ratsam, in den Lymphtropfen ein diinnes Haar einzubringen, auf dieses das System einzustellen und dann die Leukocyten zu suchen.

\section{$\S 137$.}

Färbung lebenden Blutes. Im achten Kapitel Nr. $13+$ S. 208 wurde die Nethode von Ehrlich, lebendes Blut mit Neutralrot zu färben, bereits crwähnt. Es handelt sich hier allerdings um einen Farbstoff, der wesentlich die Granulaeinlagerungen der Leukocyten hervorhebt. Anders ist die Methode von Bizzozero, welche die Blutplättchen intra vitam färbt. Auf 5000 Teile $0,75^{\circ}$. Kochsalzlösung kommt I Teil konzentrierter wässriger Methylviolettlösung, oder auf 3000 Teile der physiologischen Kochsalzlösung I Teil gesättigter wässriger Gentianaviolettlösung. Setzt man diese Farbflotte zu lebendem oder zu ïberlebendem Blute, dann fïrben sich die Thrombocyten.

\section{$\$ 138$.}

Fixieren des Blutes. Eine besondere Methodik, Blut zu fixieren, hat II. Heidenhain durch ausgiebige Benutzung der Zentrifuge ausgebildet. Man defibriniert zunächst das 13lut, indem man das frisch aus einer Arterie oder Vene gelassene Blut während seines Ausströmens mit einem Stabe oder einer Rute schlägt. Dadurch setzt sich das Fibrin an das schlagende Instrument und das Blut bleibt flissig. Dieses defibrinierte Blut zentrifugiert man, wobei sich die lörperlichen Elemente am Boden des Zentrifugierungsgeräßes sammeln. 
Das Serum gießt man ab. Man kimn g-leich nach der Defibrinierung physiologische Kochsalzlösung zusetzen und dann zentrifugieren, was den Torteil hat, daß die Blutkörperchen sich leichter absetzen. Nachdem man das Serum ron dem Bodensatze abgegossen hat, gießt man etwa I $2 \mathrm{ccm}$ physiologischer Kochsalzlösung zum geschleuderten Blut und fixiert in folgendem Gemisch: $+\mathrm{ccm}$ in Kochsalz gesättigter Sublimatlösung: I ccm $2^{\circ}$. Osmiumsäure und $16 \mathrm{ccm}$ Aqua destillata. $\mathrm{Zu}$; ccm dieses Gemisches werden 20-2S ccm physiologischer Kochsalzlösung zugesetzt. In dieser Flüssigkeit werden die geschlcuderten, in $0,75^{\circ}$, Kochsalzlüsung aufgeschwemmten Blutkörperchen fixiert. Am anderen Tage gießt man dic Flüssigkeit vom liodensatze ab, bringt destilliertes Whasser zu, zentrifugiert und härtet in Alkohol ron steigender Konzentration. Man muß jedesmal abgießen und nach Zusatz der neuen Fliissigkeit zentrifugieren. Nach dem Härten kann man färben und dann einschließen: alles bei dauerndem Gcbrauch der Zentrifuge, wic diese Methode in dritten Kilpitel S. 23 beschrieben wurde.

\section{$\$ 139$.}

Wihrend die Heidenhainsche Wethode große Mengen defibrinierten Blutes zu fixiercn gestattet, kann man mit den folgend zu beschreihenden ILthoden kleine IIengen nichtlefibrinicrten, also ganz frischen Blutes fixicren. Beicie Verfahrungsweisen ergänzen cinander also auf das schönśte.

Man nimmt - und diese ist die einfachste der folgenden Methoden - eine gut sturilisierte Impflanzette, taucht die Spitze in Flemmingsche Lüsung und sticht vorsichtig in den eigenen Finger, der iibrigens vorher sorgfailtig gereinigt sein muß. Der aus der Stichwunde herausquellende Blutstropfen wird auf diese IVeise fixicrt. Nan heht ihn vorsichtig von dem Finger ab. wäscht, härtet, wie nach ()rganfixierung in Flemmingscher Lösung (vicrtes Kapitel, und färbt beliebig.

In sehr ingeniöser Weise hat Arnold diese Methode für den Frosch modifiziert, die auch auf Säuger und Tögel anwendbar ist. Er läßt Blut in $I^{\circ}$. Osmiumsäure tropfen, nach 24 Stunden wäscht er aus und härtet in Alkohol von steigender Konzentration. Dann bringt en in der üblichen Weise den so gehärteten Blutstropfen in Celloidin /sechstes Kapitel, gießt in sehr dimner Schicht auf eine Glasplatte aus und löst die erstarrte Celloidinhaut wie bei der Weigertschen Kollodiumlappenmethode (siebentes Kapitel S. Ito) in Wasser ab. Der celloidinierte Blutstropfen kann in irgendeiner Farbflotte gefärbt werden. 
Nach Hayem fixiert man Blut folgendermaßen. Man stell zunächst eine Fixicrungsflussigkeit her, die $5 \mathrm{~g}$ Natriumsulfat, I g Kochsalz und $0.5 \mathrm{~g}$ Sublimat in $200 \mathrm{ccm}$ Aqua destillata gelöst enthält. In cinen aliquoten Teil, der stets das roofache der zu fixicrenden Blutmenge sein muß, träufelt man Blut ein. Nach $2-2+$ Stunden ist die Fixicrung beendet, die Körperchen ruhen auf dem Boden dus Gefäßes. Nun wird abgegossen und nach Auswaschen in EosinHämatein |achtes Kapitel Nr. I02) gefärbt. Oder man träufelt Blut in Flemmingsche Lösung, fixiert 2-24 Stunden, wäscht aus, härtet und schmilzt in Paraffin ein. So kann man Blutschnitte herstellen, welche mit Anilinen oder sonstwie gefärbt werden.

Die Foàsche Fixierung (viertes Kapitel Mr. 22 S. 5 t) ist geeignct, Blut in den Organen gut zu erhalten, weil sie das Hämoglobin nicht entfärbt.

Zur Fixicrung des Blutes bestimmt und geeignet ist die Pacinische Fliissigkeit. Ihre Zusammensetzung ist die folgende: Sublimat I g. Kochsalz $+\mathrm{g}$, Aqua destillata $200 \mathrm{ccm}$. Löwitt hat die Pacinische Flüssigkeit folgendermaßen modifiziert. Für Kaninchen: Kochsalz $2 \mathrm{~g}$, schwefelsaures Natron $5 \mathrm{~g}$, kalt gesättigte wässrige Sublimatlösung + ccm, Aqua destillata $300 \mathrm{ccm}$. Für Hunde lautet die Löwittsche Fliissigkeit: Kochsalz 2 g, schwefelsaures Natron 5 S; kalt gesättigte wässrige Sublimatlösung + ccm, Aqua destillata I 20 ccnı. Man darf nicht zu große Mengen Blut in einen aliquoten Teil dieser Flüssigkeiten bringen. Das Blut gerinnt darin nicht, sondern wird nur fixiert; in Wasser darf nicht ausgewaschen werden.

Lavdowsky, welcher die Anschauung vertritt, daß überall im Blute der Säuger gekernte rote Elemente rorhanden sind - er ist der Meinung, daß die Erythrocyten des Menschen in vollkommen reifem Zustande Reste von Kernsubstanz enthalten, die von ihm sogenannte nucleoide Substanz - empfichlt als vortreffliches Blutfxierungsmittel die Jodsäure in $2^{\prime \prime}-t^{\circ}$. Lösung. Man geht nach cer Angabe dieses Gelchrten folgendermaßen vor: Auf den Objehtträger wird ein großer Tropfen $2^{\circ}$ 。Jodsäure gebracht, dahinein ein kleiner Tropfen Neuvictoriagrülösung und in dieses Gemisch cin Tropfen lebenden Blutes aus der Fingerspitze oder sonstwoher, gegeben. Man mischt Blut und Farbflotte gut miteinander, deckt mit einem Decleglase ein und untersucht. Nach einigen Minuten ist das Hämoglobin cntfunt und es treten die Nucleoide in den Erythrocyten auf. Man kimn auch mit Methylviolett $6 \mathrm{~B}$ färben, muß dann aber $4 \%$ Jodsäure nehmen. 


\section{$\S \mathrm{I} 40$.}

Deckglaspräparate. Die von Robert Koch für die Bakteriologie ausgebildete Methode, Lntersuchungen auf Mikroorganismen an solchen Präparaten zu machen, welche durch Ausstrich des zu untersuchenden Naterials auf Deckgläser hergestellt waren, ist von Ehrlich für das Studium des normalen und pathologischen Blutes verwendet worden. Die Methode, welche allgemeine Anerkennung gefunden hat, ist die folgende: Man macht beim Menschen oder beim Säugetier in der vorhin geschilderten Weise einen Einstich in die Haut. Den ersten hervortretenden Tropfen wischt man ab, den zweiten hebt man mit einem Deckglase ab, was dadurch geschieht, daß man mit der Nitte des Dechglases die Kuppe des Tropfens beriihrt. Schnell legt man auf den Blutstropfen ein zweites Deckglas auf und zieht beide Deckgläser auseinander. Die kapillare Blutschicht, welche so auf jedem Deckglase haftet, läßt man an der Luft trocken werden. Die Anfertigung solcher Deckglaspräparate erlernt sich leicht, man muß nur auf folgendes achten: Die Stichwunde darf nicht zu tief sein, weil sonst das Blut zu reichlich kommt und die Präparate zu dick, zu massenhaft werden. Das zweite Deckglas muß sehr schnell aufgelegt werden, damit der Blutstropfen nicht zu lange an der Luft bleibt. Das Auseinanderzichen der Dechgläser hat erst zu beginnen, wenn der Blutstropfen völlig ausgebreitet ist; es muß gleichmäßig, aber nicht zu schnell geschehen. Ein Versehen wird von Anfängern in Blutuntersuchungen leicht dadurch gemacht, daß sie die feuchten Deckgläser mit der feuchten Seite nach unten zum Trocknen hinlegen. Man muß lernen, auch darauf zu achten.

Wie bei Säugern verfährt man auch bei allen andern Vertebraten, mit Ausnahme der Fische. Bei diesen muß jedesmal ein Tier geopfert werden, da ein Zurüickbringen ins Wasser selten einen Wert hat; die Tiere gehen nämlich an den leichtesten Stichwunden sehr schnell ein. Man bedarf zur Anfertigung der Blutpräparate eines Assistenten, der den Fisch an Kopf und Schwanz so packen muß, daß er sich nicht rühren kann. Dann schneidet man bei Teleostiern mit derbem scharfen Skalpell auf der Ventralseite in der Mitte zwischen den Kiemenöffnungen die sogenannte Kehle durch und fertigt ron dem massenhaft heraustretenden Blute die Dechglaspräparate an. Sorgfältiges und zugleich schnelles Arbeiten ist von großer Wichtigkeit bei Fischblutuntersuchungen. Will man Selachier- und Ganoidenblut studieren, so schneidet man ventral nach hinten rom Kiefer durch und verfährt wie beschrieben. 
Daß der Blutstropfen zwischen zwei Dechgläser gebracht und damit gewissermaßen gepreßt wird, ist beim Säugerblut ohne Belang, denn die Elastizität der Kernlosen Erythrocyten verträgt ein noch viel größcres Quetschen, als beim Anfertigen der Deckglaspräparate ausgeubt wird. Anders beim Blute der iibrigen Yertebratenklassen. Bei meinen Studien iiber die Blutkörperchen einiger Fische habe ich die Beobachtung gemacht, daß, falls der Blutstrepfen zwischen den Dechgläsern sehr klein war, so klein wie bei Menschenblutpräparaten. dann beim Auseinanderziehen der Deckgläschen sehr viele Erythrocyten zertrimmert waren. Offenbar hatte der prominierende Kern den Druck nicht vertragen; bei dem starken Quetschen zersprengte er das ganze Blutkörperchen. Ich habe daher stets einen großen Blutstropfen auf das erste Deckglas gebracht, sodaß eine relativ große Flüssigkeitsmenge zwischen beiden Deckgläscrn sich befand, welche jeden Druck unmiglich machte. Ich kann fur das Studium der kernhaltigen Erythrocyten daher nur auf das dringendste empfehlen, nicht zu kleine Blutstropfen für Deckglaspräparate zu wählen.

Die Deckglaspräparate müssen fixiert werden, weil sonst bei cier zum Studium unumgänglich nötigen Färbung das Blut abgewaschen werden würde.

Die gewöhnlichste Methnde besteht darin, die Deckglaspräparate lufttrocken werden zu lassen und sie dann zu dörren. Man erhitzt sie im Trockenschrank 5 Minuten bis 2 Stunden bei einer Temperatur ron $120^{\prime \prime} \mathrm{C}$. - für nachherige Triacidfärbung darf nur 5- ro Minuten lang gedört werden - oder. Was aber grolser Torsicht und Übung bedarf, man zieht die Dechglaser ein paarmal durch die Spiritusflamme, bis dic Ieuchtigheit aus ihnen verschwunden ist. Letzteres crkennt man schr leicht daran, daß die dunkle Farhe des Präparates heller wird. Torsicht ist dabei geboten, damit nicht das Blut verbrannt werde, was man daran sieht, daß die Farbe des Präparates schmutzigrot wird. Statt des Wärmekastens ist ein Frhitzen auf einer Kupferplatte empfohlen worden. Die etwas sonderbar beschriebenc Nuthode wird wie folgt ausgefuhrt: Eine Kupferplatte, welche $5 \mathrm{mal}$ so lang wie breit sein muß, wird durch die Flamme eines Bunsenbrenners an einem Encle I Stunde lang erhitzt. Nun sucht man die Stelle, welche Io0" C. Warm ist, in der Weise, daß man Wasser auf die Platte tropft. Wo es siedet, sind $100^{\prime \prime} \mathrm{C}$. Nähert man sich der Flamme um $2 \mathrm{~cm}$, so hat man die Temperatur $120^{\prime \prime}$ und auf dieser Stelle wird geciort. (Die ganze Beschreibung macht den Eindruch. als ob das Thermometer erst erfunden werden müßte.)

Für die kernhaltigen Erythrocyten der Sauropsiden und Ich- 
thyopsiden ist diese Dörrung nach meinen Erfahrungen ganz zu verwerfen, denn infolge der zu betrïchtlichen Hitzewirkung springt der Kern rom Körper; es entstehen Risse und Springe oder es schrumpft das ganze Blutkörperchen und nur die Randschicht bleibt erhalten. Ich habe bei meinen Studien über das Fischblut die Trocknung und Jamit die Fixierung der Präparate im Paraffinofen vorgenommen, in welchem die Deckgläser mindestens $2+$ Stunden, manchmal auch länger, verweilen müssen. Die Temperatur des Ofens darf nicht unter ó $0^{\prime \prime}$ und nicht über $70^{\circ} \mathrm{C}$. betragen. Die auf solche Weise erhaltenen Präparate sind ganz vortrefflich fixiert. Ich glaube, daß diese won mir empfohlene milde Trocknung, wie ich sie im Gegensatz zur scharfen Trocknung von Ehrlich anwenden mußte. sich für alle kernhaltigen Erythrocyten eignen duirfte.

Fin eigentimliches Verfahren hat Gulland ausgebildet; er umgeht Gic Fixierung in cier Hitze, fixiert vielmehr feucht und farbt dabei zugleich. Man bringt die noch feuchten Deckglaspräparate mit der Blutscite auf folgende Fixienungsflüsigheit: in absolutem Alkohol gesättigte Eosinlïsung $25 \mathrm{ccm}$, Ither $25 \mathrm{ccm}$, 5 Tropfen Sublimat $2 \mathrm{~g}$ in 10 com absoluten tllichols gelijst. Dic . Wischung wird immer unmittelbar zum Gebrauch angefertigt. Die Deckglischen bleiben 3 bis + Minuten auf cur Lösuner, Werten durch Schwenlien in Wasser abgewaschen und kommen auf I Minute in gesittigte wissrige Methylenblaulösung. Abwaschen in Masser, Akohol, Aylol, Aylolbaliam. Erythrocyten rosa, Leukocyten 'ro:a, eosinophile unc basophile Körnungen gefiurbt, Blutplittchen hellur blau als die Kerne. Will man 2+ Stuncen lang fixieren, so scháct das nichts, nur muls man dann auch $2+$ Stunden auswaschen. Die Methylenblaufirbung darf aber nur höchstens 2 Winuten lang vorgenommen werden, sonst dauert Lie Entfirbung in Alkohol zu lange. Die Nethode scheint mir sehr geeignet, um bei kernhaltigen Erythrocyten angewencet zu werden.

Die Schilderung der Gullandschen Methode hat uns schon etwas vom Fürben der Präparate gezeigt; doch will ich, bevor ich die Färbungsmethoden im Einzehnen vornehme, die allgemeinc Weiterbehandlung cer Deckglaspräparate auseinandersetzen.

Die gedörrten Präpanate läßst man abliihlen und färbt sie dann. Als allgemeingültige Kegel für die Lntersuchung des Blutes aller ITirbultierklassen ist fustzuhalten: niemals dürfen wässrige Lösungen, niemals dürfen verdünte Lüsungen angewendetwerden. Was jene anlangt, so laugen sie die Erythrocyten aus; der Farbstoff fürbt schlecht und dic Präparate verblassen mit der Zcit. Verduinnte Lösungen geben, auch wenn man sie noch so lange anwendet; nur 
verschwommene Färbungen, ganz im Gegensatz zu dem Terhalten den ()rganen gegenüber, bei welchen gerade die dünnsten Lösungen die besten Färbungen geben. Man kann die konzentriertesten Hämatoxyline anwenden, ohne Überfärbung zu erhalten.

Die gefärbten Präparate spiilt man in Wasser ab, trocknet die Deckglïser sorgfältig zwischen Filtrierpapier, noch besser zwischen Seidenpapier und hebt in nicht zu dinnem Xylolbalsam auf. Ehrlich hat einen seiner Kunstgriffe, um die Balsampräparate des Blutes schnell hart zu machen, durch einen ron seinen Schülern veröffentlichen lassen. Dieser Kunstgriff besteht darin, daß man einen Tropfen dicken Balsams auf dem Objekttrïger zum Sieden erhitzt, das Deckglas fest aufdrücht und nun das Präparat durch Gegenhalten gegen eine Fensterscheibe schnell abkiihlt. Im Sommer diirfte sich eine Metallplatte zum Ablühlen des Präparates eignen, da die Fenster oft sehr warm sein können.

Ich gebe nun die einzelnen Färbungsmethoden. Die Farbflotten sind entweder gesättigt glyzerinige oder gesättigt alkoholische Lösungen.

Will man nur die Blutelemente sichtbar machen, so färbt man in Eosin-Hämatein: die Erythrocyten sind leuchtend rot, rorausgesetzt daß man Eosin gelblich gewählt hat, ihre eventuellen Kerne tiefblau, das Plasma der Leukocryten ist sanft rosa angefärbt, ihre Kerne zeigen Blaufärbung in rerschiedenen Nïancen. Die Thrombocyten sind blaßrosa, doch ist ihre Erkennung sehr schwierig; man bedient sich für sie am besten der in $\$$ I $43 \mathrm{zu}$ beschreibenden Methoden. Ich kenne keine Färbung, welche gleich Eosin-Hämateïn die Elemente des Blutes scharf distinkt hervorhebt. Allerdings für die spezifischen Granula von Ehrlich reicht sie nicht aus, da müssen besondere Methoden angewendet werden.

Eosin-Hämatoxylin-Färbung kann man nach einer der beiden folgenden Methoden ausführen. Ein zcitiges Färben: In roo ccm Ehrlichschem Hämatoxylin (achtes Kapitel Nr. + I S. I;6) löst man I g Eosin und setzt die Nischung 3 Wochen dem Licht aus. Zum Gebrauch gießt man einen Tropfen auf die Blutseite eines Deckglaspräparates, spiilt nach 2 Stunden in gewöhnlichem Wasser $a b$ und behandelt weiter wie vorhin beschrieben.

Ich ziehe dem einzeitigen das zweizeitige Färben ror, weil ich gefunden habe, daß wenigstens bei Ichthyopsiden die Resultate besser, d. h. die Färbungen schöner, distinkter und haltbarer sind. Ich färbe zuerst $2+$ Stunden in meinem unverdünnten Glyzerinalaunhämateïn (achtes Kapitel Nr. 3 I S. I-6: Nayers Hämalaun ist hierfür ganz 
unbrauchbar), wasche dann in gewöhnlichem Wasser ab und bringe für mindestens 2 Stunden in eine honzentrierte glyzerinige Lösung von Eosin gelblich. Unter Umständen, wenn nämlich nach 2 Stunden die Färbung noch zu schwach ist, färbe ich länger, ja dehne die Eosinfärbung bis zu $2+$ Stunden aus. Das erscheint Manchem vielleicht zu langweilig, die Resultate aber sind tadellos. Ich gieße entweder einen Tropfen der Farblösung auf die Blutseite des Deckglases, das auf flacher Unterlage aufruht oder, und dieses Verfahren ziehe ich vor, ich gieße die Farbflotte in eine flache Glasschale und bringe dahinein die Deckglastrockenpräparate. Dic Farbflotten kann man immer wieder benutzen, braucht sie nicht wegzugießen, wie beim ersten Verfahren. Beim Einbringen der Deckgläser muß man sorgfältig darauf achten, daß die Blutseite nach oben kommt; sie ist daran zu crkennen, daß sie bei schrägem Aufblick auf das Deckglas rauh aussieht, während die entgegengesetzte (blutfreie) Seite glänzt.

Statt des Eosins ist Erythrosin empfohlen worden. Ich sehe keine Notwendigkeit für diese Empfehlung ein.

Ehrlich hat eine Anzahl Färbungsmethoden konstruiert, mit deren Hilfe es ihm gelungen ist, spezifisch verschiedene Körnungen in den Leukocyten nachzuweisen. Er nannte diese Körnungen acidophile oder eosinophile, wenn sie den Eosinfarbstoff festhielten; die neutrophilen Granula sind die, welche sich in Triacid, die basophilen, welche sich in Methylenblau färben. $\mathrm{Ob}$ es richtig ist, Gebilden, welche an der Grenze des Sichtbaren liegen, Namen zu geben, die eine chemische Reaktion prätendieren, bleibe dahin gestellt. Ehrlichs Verdienste, diese Dinge erkannt und zu ihrer Darstellung die guten Methoden gegeben zu haben, wird durch den eben gemachten Einwand nicht alteriert. Die Methoden der Granulafärbung sind die folgenden:

Eosinophile Granula. Aurantia, Indulin, Eosin werden zu gleichen Teilen in starker Konzentration gelöst, etwa $2 \mathrm{~g}$ von jedem Farbstoffe in $30-50 \mathrm{ccm}$ Glyzerin. Ich glaube, die größere oder geringere Löslichkeit hängt mit der dïnneren oder dickeren Beschaffenheit des Glyzerins zusammen; in dünnerem löst sich mehr als in der gleichen Quantität dicheren Glyzerins. Darum muß man von letzterem für die $6 \mathrm{~g}$ Farbstoff $50 \mathrm{ccm}$ nehmen. Man färbt 24 Stunden und länger; wenigstens habe ich am Fischblut gute Resultate nur bei mindestens 24 stündiger Färbungsdauer erhalten. Die Nachbehandlung nach der Färbung braucht nicht mehr besonders geschildert zu werden. 
Diese Ehrlichsche Fürbung ist, wie selbstverständlich, mehrfach abgeändert worden. So hat Pappenheim folgendes Verfahren angegeben: Die Kerne werden in Hämatein gefärbt. Das Plasma fürbt man in einer Mischung aus: 6 Teilen Rose bengale, 2 Teilen Orange $G$, I Teil Aurantia. Dazu werden unter kräftigem Umschiitteln und gelindem Erwärmen, bis die Lösung anfängt durchsichtig zu werden, sugefügt: Aqua destillata ı Teile, Glyzerin und Alkohol absolutus je I Teil.

Chenzincky empfiehlt für die cosinophile Granulation folgende Methode, bei welcher die Kerne blaugefärbt werden: gesättigte wässrige Methylenblaulösung to Teile, $0,5 \%$ Eosin in $70 \%$ Alkohol 20 Teile, Glyzerin to Teile. Dic Lösung hält sich nur \& Tage; die Blutpräparate müssen 2 Stunden fixiert und $2+t$ Stunden gefärbt werden.

Neutrophile Granula. Zur Darstellung dieser Granulaform dient in erster Linie Ehrlichs Triacid (achtes Kapitel Nr. I 4 S. 195). Die Färbungen mit Ehrlich-Biondis 3 Farbengemisch (achtes Kapitel Nr. I 3 S. I 94) sind gut, aber nicht haltbar. Triacid muß unverdiunnt $2+$ Stunden einwirken. Durch seinen Schüler Reinbach hat Ehrlich folgende nur fuir Granulafärbung sich eignende Vorschrift zur Ilerstellung des Triacid veröffentlichen lassen: gesättigte wässrige Lösung von Orange G I $20 \mathrm{ccm}$, gesättigte wässtige Säurefuchsinlösung $80 \mathrm{ccm}$, gesättigte wïssrige Methylgrïnlösung $100 \mathrm{ccm}$, Aqua destillata $300 \mathrm{ccm}$, Alkohol absolutus $x$ 80 ccm, Glyzerin $50 \mathrm{ccm}$. Nan darf die Mischung niemals schütteln, ja man mul3 sogar den jedesmaligen Bedarf abpipettieren.

Basophile Granula werden durch Methylenblau in konzentrierter glyzeriniger Lösung gefärbt.

Unna hat zur spezifischen Färbung der Erythrocyten in Schnittpräparaten folgende beiden Methoden angegeben: Schnitte auf I Minute in I\% Wasserblaulösung, dann Wasser usw. Die Erythrocyten sind hellgelb gefürbt. Die zweite Methode ist dic SäurefuchsinPikrimmethode. Die Schnitte kommen für I Minute in $2 \%$ Säurefuchsinlüsung, werden in Wasser gewaschen, dann I Minute in gesättigter wässriger Pilirinsäurelösung, 5 Minuten in gesïttigtem Pikrinsäurealkohol behandelt, dann in Alkohol, Öl, Balsam. Erythrocyten gelb.

Die Kerne der Leukocyten besonders hervorzuheben färbt Prince Schnitte oder Trockenpräparate in folgender Mischung: gesittigte wässrige Toluidinblaulösung 24 Teile, gesättigte wässrige Säurefuchsinlösung I Teil, 2"。Eosinlösung 2 Teile. Die Farbstoffe sind von Gribler zu bezichen.) Die Mischung wird in der angefuhten 
Reihenfolge vorgenommen, man schüittelt einige Minuten, dann läßt man abstehen und gießt ab. Die frische Farbflotte färbt in ' I Minute, eine ro-I2 Wochen alte braucht $5-7$ Minuten.

L. Michaelis empfiehlt zur Leukocytenfärbung Thionin, bis zur Sättigung in $50 \%$ Alkohol eingetragen.

Um eosinophile Zellen im Sputum nachzuweisen, verfährt Teichmüller folgendermaßen: Das Sputum wird auf dem Objektträger ausgebrcitet - Deckglïser sind unbrauchbar -; man läßt es lufttrocken werden und fixiert es über der Flamme. Noch warm kommt das Präparat in ein Standglas mit 0,5\% alkoholischer Eosinlösung auf mindestens 3 Minuten bis beliebig lange Zeit, wird in Wasser abgewaschen und in honzentrierter wässriger Methylenhlaulösung I Ninute nachgefärbt. Weiterbehandlung wie gewöhnlich. Nur die cosinophilen Zellen haben das Eosin beibehalten.

\section{\$ $14 \mathrm{I}$.}

Die IBestrebungen, Nethylenblau und Eosin zu einer Doppelfärhung zu lombinieren, haben zur Erfindung des Farbstoffes Methylenazur gefuihrt. Seit langem diirfte es wohl allgemein bekannt sein, daß selbst die intensirsten Nicthylenblaufirbungen, die einer noch so langen Alkoholbehandlung Widerstand leisten, in wïssriger, nicht zu duinner Eosinlösung sehr schnell ausblassen. Auf diese WTeise habe ich z. B. beim Zentralnervensystem schr instruktive Färbungen crhalten: urst 24 stiundiges Einhringen in polychromes Nethylenblau, dann Nachbehandeln in konzentrierter wïssriger Lüsung von Eosin gelblich, his fast alles Blau entfirlot ist. Indessen sind die Resultate, die solcherweise zu erhalten sind, wenig sicher, weil das Methylenblau nicht gleichmäßig clurch das Eosin ausgetriehen wird. Besser sind die folgenden Dopplfitrbungen, bei denen es wohl zur Bildung des Azur im Gewebe bez. im Ausstrichpräparate kommt. Nach L. Nichaelis, Willehrand, Becker u. a. mischt man gleiche Teile $0,5^{\circ}$. Eosinlösung (in $7 \mathrm{O}^{\circ}$, Alkohol gelöst und konzentrierte wässrige Nethylenblaulösung, gibt auf je $50 \mathrm{ccm}$ des Gemisches ro- 5 Tropfen Essigsäurelosung unmittelbar vor dem Gebrauch zu und filtricrt. Die Färbungsdaucr ist 5-10 Minuten, das Resultat soll eine gute Fürbung der neutrophilen Granula sein. Chenzincky mischt die obigen beiden Farbflotten in cinem anderen Terhältnisse; er nimmt I ccm Eosin und 2 ccm Methylenblau und fügt $2 \mathrm{ccm}$ Glyzcrin oder Aqua destillata hinzu.

Romanowsky hat bei bakteriellen Färbungen festgestellt (NalariaParasiten), daß in Eosin-polychromem Methylenblau die Parasitenkerne 
rot, Ceren Plasma blau und die Leukocytenkerne violctt sich färben. Nach Nocht gibt man, um diesen Effekt zu erreichen, 2-3 Tropfen I Eosinlösung in $\mathrm{I}-2 \mathrm{ccm}$ Aqua destillata, setzt ron einem Gemisch von I Teil Methylenblau, = Teil Natriumkarbonat und Ioo Teilen Wasser mehrere Tage bei $50^{\circ}-60^{\circ} \mathrm{C}$. aufbewahrt, kalt ansewendet) zur Eosinlösung soviel Tropfen zu, daß das Rot nicht mehr erkennbar ist. Nan kann mit dem genannten Quantum nur I Deckglas färben, da die Färbckraft bez. die Färbeeigentümlichkeit sehr bald nachläßt.

Für die Romanowskysche Färbung hat Giemsa eine Lösung konstruiert, die bei Blutuntersuchungen und namentlich bei Blutmikroorganismen usw, eine ausgedehnte Anwendung gefunden hat. Die Giemsasche Lösung hat folgende Zusammensetzung: Azur II-Eosin 3 g: Azur II 0,8 s, Glyzerin Merck $250 \mathrm{ccm}$, Methylalkohol Kahlbaum $250 \mathrm{ccm}$. Azur I ist reines Azurchlorhydrat, Azur II ist Azur I - Methylenblau Höchst zu gleichen Teilen.) Dic Lösung ist durch das Grüblersche Institut käuflich zu bezichen, da ihre Herstellung ziemlich schwierig ist. Der Vollständigkeit halber und für die, welche durch eventuelle Modifikationen Terbesserungen in der Farbwirkung herbeifuhren wollen, folge hier die Anweisung zur Anfertigung der Giemsaschen Lösung: Azur II-Eosin $3 \mathrm{~g}$ und Azur II o,8 g werden im Exsiccator über Schwefelsäure getrocknet, sehr fein gepulvert, gesiebt und in $250 \mathrm{ccm}$ Glyzerin 'chemisch rein, ron Nerck' bei $60^{\circ}$ C. unter Schuitteln gelöst. Dann werden $250 \mathrm{ccm}$ Methylalkohol, der auf $60^{\circ} \mathrm{C}$. erwärmt ist, hinzugefuigt, das Gemisch wird ordentlich geschüttelt, $2+$ Stunden bei Zimmertemperatur sich selbst überlassen und dann filtriert.

Un erfolgreich mit dieser Giemsaschen Lösung färben zu können, muß man genau nach den Anweisungen verfahren, welche Dr. Hollborn, der Inhaber des Grüblerschen Institutes, erteilt hat. Diese Anweisungen lauten folgendermaßen: Das sehr dünne Ausstrichpräparat kommt lufttrocken für I 5-20 Ninuten und länger in absoluten Alkohol zum Härten. Dann wird es auf Fließpapier abgetrocknet und gefärbt. Die Farblösung (käufliche Giemsasche Lösung) wird unmittelbar vor dem Gebrauche in einem weiten Meßzylinder unter kurzem und leichtem Umschütteln mit destilliertem Wasser verdiunt, und zwar io Tropfen Farbflotte in Io ccm Wasser. Nan kann eventuell weniger Farbstoff nehmen, mehr auf keinen Fall. Vorteilhaft ist es, besonders bei Spirochaetenfärbungen, zu dem Wasser 5-IO Tropfen einer $0, \mathrm{I}^{\circ}$ 。 Lösung von Kaliumkarbonat hinzuzufigen und es erst dann zur Yerdünnung der Farblösung zu ver- 
wenden. Mit der auf die eben geschilderte Weise hergestellten Farbflotte übergießt man die eben aus dem Alkohol genommenen und getrockneten Präparate und färbt ı-30 Minuten; die Färbungsdauer richtet sich nach dem Alter und der Art der Präparate. Frische Präparate müssen länger gehärtet werden, bedürfen dafuir einer kürzeren Färbungsdauer, für alte Präparate ist das Umgekehrte zutreffend. Nach der Färbung wird kurz aber kräftig das Präparat mit IVasser abgespritzt, schnell und kurz mit Filtrierpapier abgetupft, trocknen gelassen und in neutralem Kanadabalsam eingeschlossen.

Dr. Hollborn gibt zur Romanowskyschen Fürbung mit der Giemsaschen Lösung noch folgende Verhaltungsmaßregeln: Überfärhte Präparate werden $I_{-5}$. Minuten in destillicrtem IVasser gewaschen und dadurch gut differenziert. Zur Verdünnung muß die Giemsasche Lösung aus einer Tropfflasche gegeben werden; diese Tropfflasche ist mit Alkohol absolutus zu waschen und stets gut verschlossen zu halten. Verdünnte Lösungen dürfen nie cin zweites Mal henutzt werden. Man kann ungefärbte und ungehärtete Präparate jahrclang aufheben, so daß sie ihre Färbbarkeit behalten, wenn man sie in Exsiccatoren ïber gegliihtem Chlorcalcium hält.

Eine eigentuimliche Kombination von Hämatoxylin- und Methylenazurfarbung hat Siegel crsonnen; sie erinnert ein wenig an die Rablsche Kombination Hämatoxylin-Safranin (achtes Kapitel'. Ich verdanke die Siegelsche Färbung der liebenswürdigen miindlichen Mitteilung des betreffenden Gelehrten. Schnitte - und darin besteht der Unterschied zu der Romanowslisschen Färbung, welche für Ausstrich(Deckglastrocken präparate gilt - werden mit Delaficldschem Hämatoxylin gefürbt, in salzsaurem Alkohol extrahiert, bis sie fast weiß geworden sind. Dann werden sie gewässert, in wässriger Azurlösung (r: I000) ${ }^{\mathrm{I}}$ : Stunde auf dem Paraffinschrank oder $2+$ Stunden bci Zimmertemperatur gefärbt und in Alkohol differenziert. Hierbei muß man aufpassen und vor völliger Entfärbung einschließen. Protoplasma rot, Kerne tiefblau.

Assmann färbt Trockenpräparate mit der bei Grübler käuflichen Lösung ron eosinsaurem Methylenblau (Azur) in Methylalkohol derart, daß er die mit dem nichtfixierten Objekte beschickten Objektträger in eine flache Glasschale legt, to Tropfen der methylalkoholischen Farblösung so aufbringt, daß die Farbflotte nicht überläuft, und 3 Minuten einwirken läßt. Darauf übergießt man mit $20 \mathrm{ccm}$ Aqua destillata, denen 5 Tropfen $\mathrm{O}, \mathrm{I}^{\circ}$. $\mathrm{T}$ Kaliumkarbonatlösung beigefuigt sind. Nan schüttelt die Schalen so lange, bis eine gleichmäßig klare, hellviolette Farblösung vorhanden ist, welche keine 
Niederschläge enthalten soll. Nach 5 Minuten wird das I'räparat herausgenommen, ohne Abwaschen mit Filtrierpapier getrocknet und aufgehoben. Das Übergießen - dies sei zum Verständnisse des Verfahrens bemerkt - mit der alkoholischen Farblösung dient zur Fixierung des Trockenpräparates, die Verdünnung mit Wasser zur Fürbung, weil nach Assmann nur dic dünne Farbflotte wirklich haltbar färbt. Ähnlich verfährt man nach demselben Autor bei Schnitten, welche nicht über $5 \mu$ dick sein sollen. Die Verdünnung wird mit Wasser vorgenommen, welchem 5 Tropfen $0,1 \%$ Essigsäure beigemischt sind, die Färbungsdauer ist 15 Minuten und zum Einschluß in Balsam nuß in Alkohol absolutus entwässert und in Xylol aufgestellt werden.

\section{乌 142.}

Ein eigentümliches Strukturelement an den Erythrocyten der Amphibien ist der von Dehler, Nicolas, Meves, Kopsch usw. beschricbene Randrcifen. Zu seiner Darstellung wird das Blut in I $\%$ - $\%$ Osmiumsäurelösung eingebracht und darin 5- Io Tage gelassen. Meves verwendet besonders die von Lavdowsky zuerst für Blutuntersuchungen empfohlene Jodsüure. Diese ist namentlich gut in der Konzentration von $2 \%-3 \%$ mit einem Kochsalzzusatz von $1 \%$. Des ferneren fixiert Meves Blut in folgendem Gemisch: Salpetersäure (I,+ spec. Gew.) 23-30 Tropfen, I, $8 \%-2 \%$ Kochsalzlösung $50 \mathrm{ccm}$, I $\%$ Sublimatlösung $50 \mathrm{ccm}$.

Wenn man Blut mit $t^{\prime \prime \prime}$ Jodsäure bchandelt, die mit Neuvilitoriagrïn oder mit Methylviolett versetzt ist, so werden die Qucrmembranen des Randreifens der Erythrocyten von Salamandra maculosa gefärbt. Mischt man zu $20 \mathrm{ccm} 5 \%$ Jodsüure $1,5 \mathrm{~g}$ Kochsalz, setzt $5 \mathrm{ccm} 2 \%$ Osmiumsäure $z u$, nimmt man ferner von dieser Nischung einen Tropfen auf einen Objektträger, mischt ihn mit einem kleineren Tropfen Malachitgriin und rührt einen klcinen Tropfen Salamanderblut hinein, so erkennt man nach MIeves nach dem Eindecken und Umranden des l'räparates mit Paraffin, daß in sämtlichen Erythrocyten cin oberflichliches Fadennetz vorhanden ist. Nur beim Froschblut tritt dies Strukturelement nicht auf.

\section{§ 43.}

Die Thrombocyten (Blutplïtchen) werden nach Deetjen am besten in folgender Weise fixiert: Man bringt lebendes Blut auf Agar, die man nach Deetjen sich selber folgendermaßen herstellt: Eine I \% filtrierte Agarlüsung wird nit $0,6 \%$ Kochsalz hergestellt, dann wird $0,6 \%$ Natriummetaphosphat und $0,3 \%$. Dikaliumphosphat zu- 
gesetzt. Die Metaphosphate sind für die Thrombocyten die Hauptsache. Ein Tropfen dieser warmen Agarlösung wird auf einem Objektträger ausgebreitet und nach dem Erkalten mit einem Tropfen lebenden Blutes beschickt. Man legt ein Deckglas auf und bringt auf einen bis $+0^{\circ} \mathrm{C}$. erhitzten Objekttisch, wo die Thrombocyten bis + Stunden lebendig bleiben. Man setzt nummehr seitlich irgendeine Fixierungsflissigkeit hinzu, dann hebt man das Deckglas ab und färbt, usw.

Deetjen fixiert im Dech-glaspriiparate die Blutplättchen durch Einbringen in $90^{\circ}$. Alkohol für 2 Minuten. lïßt lufttrocken werden, bringt für $3-5$ Minuten in $0,5^{\circ}$. Formollösung, wäscht ab und färbt in Hämatoxylin. Dadurch werden die Kerne der Thrombocyten sichtbar gemacht, die Deetjen als amöboide kernhaltige Zellen ansieht.

Deckhuyzen fixiert Blutplättchen in einer Mischung von 3 oder 9) Volumina Osmiumsïure von 2\%, und I Volumen 5\% Essigsïure. Gefärbt wird in ' $\mathrm{I}$ 'Jethylenhlaulösung. Auch hier zeigt sich dic Zellnatur der Blutplättchen.

Kopsch bringt $1^{\circ}-2^{\circ}$, Osmiumsiume oder Jodjodkaliumlösung (Lugolsche Lösung rol. achtes Kapitel) auf die Fingerbeere, sticht durch den Tropfen hindurch und fixiert so das Blut, das er dann zwischen Deckglas und Objeltträger bringt. Auch er weist dadurch die Zellnatur der Thrombocyten nach. Wichtiog ist es, den in die Fixierungstlüsigkeit ausgetretenen Tropfen Blut umzurüren. Nan farbt mit Tetrajodfluorescein, dessen Lösung man sich jedesmal frisch berciten muß: in einem Reagensglase wird zu Eosin- oder Lrythrosinlïsung utwas Silzsiure zugesetzt. Es entsteht der in WVasser unlösliche Niederschlag ron Tetrajodfluorescein. Durch Zusatz von Chloroform oder Tolıol lüst sich durch Schütteln der Niederschlag. Diese Lösung gibt man in ein zugedeclites Schälchen, hringt das nur lufttrockne (nicht fixierte) Deckglastrockenprïparat für einige Minuten ein, spieilt in Toluol oder Chloroform und schließt direlit in Kanadabalsam ein. Erythrocyten und Kerne ungefïrht, Protoplasma, Thrombocyten und Leukocyten rot gefärbt.

Nach Hans Rabl werden dic lufttrocknen Deckglaspräparate ${ }_{1 / 4}$ bis ${ }_{i 2}$ Stunde in wïssriger Sublimatlösung fixiert, in Wasser ausgewaschen und mit Eisenhïmatoxylin gefärbt: nur die Thrombocyten und die Leukocyten haben sich tingiert, die Erythrocyten sind ungefärbt geblieben. 


\section{$\S \mathrm{I} 44$.}

Das Fibrin färbt man nach Weigert mit Anilinwasser-Mlethylviolett, indem man konzentriertes Anilinwasser und konzentrierte wissrige Lösung von Methylviolett $6 \mathrm{~B}$ zu gleichen Teilen mischt. Furrbungsdauer 5 Ninuten, Waschen in Wasser, Einbringen in Lugolsche Lösung achtes Kapitel bis I Ninute, wiederum Waschen in Trasser, nur seliundenlanges Eintauchen in Alkohol, Xylolanilin i2 Xylol $\div$ I Anilinöl, bis keine Farbstoffwolken mehr ausgehen, Xylol, Balsam.

\section{$\$ \mathrm{I} 45$.}

Blutbildung. Zum Studium des embryonalen und fötalen Blutes hat die Methode der Dechglastrockenpräparate mit nachfolgender Dörrung ausgedehnte Anwendung gefunden. Unstreitig sind mit ihr und mit den verschiedenen Färbungsmethoden schöne Resultate erzielt worden, wenn auch die Deutungen oft noch weit auseinandergehen. Tielleicht ist die Differenz der Anschauungen dadurch hervorgerufen, dal3 die starke Erhitzung der fötalen Erythrocyten zu ungleiche Resultate hervorgerufen hat, wie dies bei kernlosen Gebilden nicht der Fall ist. Es dürfte sich empfehlen, in Zukunft die starke Dörrung bei Studien uiber Blutbildung zu vermeiden und sich auf diejenigen Temperaturen zu beschränken, welche ich bei meinen Studien über Fischblut als geeignet erkannt und weiter oben (\$ 1 fo) genauer geschildert habe.

Löwitt fixiert Organe, an welchen er die Blutbildung studieren will, in $0,1^{\circ}{ }_{0}-0,3^{\circ}$. Platinchloridlösung, schmilzt nach üblicher Weiterbehandlung in Paraffin cin und färbt die Schnitte in Safranin. Dann bringt er die gefärbten in eine jedesmal frisch bereitete Mischung aus $I^{\circ}$ 。alkoholischer Pikrinsäurelösung $3-5 \mathrm{ccm}$ mit $\mathrm{I}-2$ Tropfen offizineller Jodtinktur. Die Kerne der Erythroblasten und einiger fixer Zellen werden leuchtend rot, alles übrige ist entfärbt, bzw. durch die Pikrinsäure gelb geworden.

$$
\S \mathrm{I} 46 .
$$

Blutkristalle. Die Darstellung der Kristalle des Blutes ist außler von wissenschaftlichem auch von hervorragend medizinisch-praktischem Interesse. Niumand sollte daher versäumen, sich mit den einschlägigen Methoden völlig rertraut zu machen. 3 Arten von Kristallen haben wir bekanntlich zu unterscheiden, nämlich die Hämoglobin-, Häminund Hämatoidinkristalle. 
I. Die Hämatoiđinkristalle, welche Rudolf Virchow zuerst in alten Bluterguissen gefunden hat, bedürfen im allgemeinen keiner besonderen kïnstlichen Darstellung, da sie die Natur ron selher darstellt. Sie erscheinen als kleine rhombische Prismen von lebhaft orange- oder rubinroter Farbe mit dunklen kaminroten Ecken und

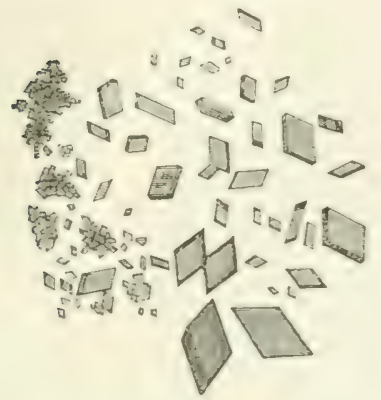

Fig. I4. Hämatoidinkristalle.

Rändern. Um einen Anhalt zu ihrer Unterscheidung von den beiden anderen Kristallarten zu geben, sind Hämatoidinkristalle der gewöhnlichen Form in Fig. I4 abgebildet. Hämatoidinkristalle von ungewöhnlicher Form und Größe, bis zu $0,4 \mathrm{~mm}$, hat Städeler durch Behandlung der Ovarien der Kühe mit Chloroform oder Schwefolkohlenstoff erhalten.

2. Die Hämoglobinkristalle, d. h. die Kristalle des Blutfarbstoffes, haben bei den verschiedenen Gattungen der Süugetiere sehr verschiedene charakteristische Formen, wie dies Fig. I 5 zeigt. Ihre Darstellung ist nicht leicht, die Methoden dazu ziemlich kompliziert; man muß sich daher auf zahlreiche Mißerfolge gefaßt machen, che man die Methode vullig beherrscht. Nach Rollett verfährt man zur Darstellung der Kristalle folgendermaßen: Defibriniertes Blut wird in Platintiegel in eine Kältemischung gebracht, bis es durch und durch gefroren ist. Dann läßt man es allmählich auftauen. Die nunmehr lackfarbene Fliissigkeit wird in 
eine flache Schale in einer Schicht ausgegossen, dic höchstens $I^{I^{\prime}}: \mathrm{mm}$ hoch ist; am kiihlen Orte läßt man langsam abdunsten.

Einfacher ist die folgende Methode: Ein Tröpfchen Blut, an besten aus der Milzvene, wird einige Minuten auf dem Objektträger der Luft ausgesetzt, wird dann mit einem Tropfen Aqua destillata rermischt, mit einem Declogläschen überdeckt und sich selbst überlassen. Nach einiger Zeit schießen am Rande des Deckgläschens dic Kristalle an. Bringt man nach dem Eindecken an den Rand des Deckgläschens einen Tropfen konzentrierter Pyrogallussäure, so crhält man nach 3-5 Stunden sehr große Hämoglobinkristalle.

Die Anwendung der Pyrogallussäure ist forensisch wichtig: weil man selhst aus faulem und eingedicktem Blute Kristalle erhalten kann, wenn man wie eben geschildert verfährt.

3. Häminkristalle (Teichmannsche Kri-

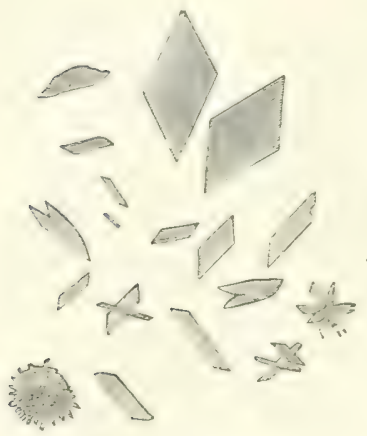

Fig. I6. Häminkristalle. stalle). Die forensisch wichtigste Kristallform, von Teichmann gefunden, ist die jetzt zu beschreibende, weil sie aus allen Blutarten, aus gefaultem Blut, aus Blut im Kot, auf Holz selbst nach Jahren sich noch darstellen läßt. Nur der Übelstand haftet ihr an, daß im Gegensatz zu den Hämoglobinkristallen die Häminkristalle stets dasselbe Aussehen haben, stamme der Blutflecken nun vom Menschen, vom Rinde oder einem anderen Tiere. Ja selbst vom Regenwurmblut sind Häminkristalle herzustellen.

Die Iäminkristalle sind klcine rhombische Tafeln. Bällkchen oder Stäbchen, zuweilen sehen sie wie Hanfkömer oder Weberschiffchen aus, oft sind sie in der Form eines Andreaskreuzes gekreuzt Fig. I6. Sie sind, wie die Hämoglobinkristalle, doppeltbrechend, zeichnen sich abur vor jener Kristallart dadurch aus, daß sie auf dunklem Grunde goldgelb aufleuchten. Es gehört ein bei gekreuzten Nicols untersuchtes Haminpräparat zu dem schönsten, was man unter dem Mikroskop sehen Kann: wie auf tiefdunklem Nachthimmel die Sterne aufleuchten, so glinzın in dunklem Gesichtsfelde die goldgelben Häminkristalle. Sie sind optisch cinachsig, erscheinen bei auffallendem Lichte blauschwarz wie angelaufencr Stahl, sind bei durchfallendem Lichte mahagonibraun.

Zur Darstcllung gibt es nur die Teichmannsche Methode, die aber in gewissen Grade je nach der Substanz modifiziert wird, auf welcher sich die zu untersuchenden Blutflecken finden. 
Blutgetrïnkte Lappen und eingetrocknete Bluthrusten. Nan muß zunächst wasserfreies Kochsalz in Vorrat haben, das man sich so darstellt, daß man gewöhnliches Kochsalz im Porzellanmörser zu einem feinen Pulver zerreibt und dieses in den Trockenschrank stellt, welchen man allmählich auf $100^{\circ} \mathrm{C}$. erhitzt. Nach 24 Stunden ist das Kochsalz anwendbar. Man bringt nun etwas von der Blutkruste oder ein Stiickchen ron dem mit Blut getränkten Lappen auf einen Objektträger, gibt cinen großen Tropfen Eisessig und einige Körnchen Kochsalz zu und verreibt tuichtig, bis dic Fliissigkeit braun geworden ist. Nun erwärmt man über der Spirituslampe, bis die Flüssigkeit eben aufkocht, nimmt den Lappenrest weg, liißt verdunsten und untersucht. Vom Rande her schießen die braunen Kristalle an. Man gibt einen Tropfen Kanadabalsam zu, deckt mit einem Deckglase ein und hat so ein Präparat, das sich unbegrenzt lange hïlt. Man kann auch nach beendetem Aufkochen mit einem Deckglase zudecken und die Kristallbildung unter dem Dechglase vor sich gehen lassen. Dann ahor verzichtet man auf die Herstellung von Dauerpräparaten.

Dasselbe Material (Lappen, Blutkrusten) kann man auch mit Wasser auslaugen, zur wisssigen Lösung des Blutfarbstoffes I Tropfen konzentrierter Pyrogallussäure bringen und mit einem Deckglase eindecken. An der unteren Fliiche des letzteren bilden sich dann sehr schöne Kristalle.

Blutflecken auf porösen Kürpern (Holz usw.). Da sich hier das Blut nicht abwaschen läß3t, so extrahiert man ein auf Blut verdiichtiges Stuick Holz mit verdiinntur Kalilösung und filtricrt. Das Holz behandelt man dann mit Masser, filtriert ebenfalls und setzt zu beiden Filtraten Tanninlösung und Fssigsüure zu, bis eine deutlich saure Reaktion eintritt. Es bildet sich ein dunkler Niedurschlag, welcher heim Filtrieren zuriekbleibt und auf dem Filter gewaschen wird. Von diesem gewaschenen Niederschlag nimmt man eine I'robe auf einen ()bjektträger, setzt ein Körnchen Kochsalz zu und läßt eintrocknen. So ist eine Kruste entstanden, die man zur Darstellung der Häminkristalle wie vorhin angegeben weiter behandelt. Waren die verdächtigen Flecken im Iolz kein Blut, dann kommt es auch nicht zur Bildung der Häminkristalle.

Blutflecken auf Eisen. Alten Eisenrost von Blutflecken zu unterscheiden ist eine der schwierigsten Aufgaben, weil nicht immer die Häminprobe gelingt. Die Beschreibung der von Heinrich Rose angegebenen Methode gehört in die Physiologie. Man kann oder viehmehr man mul3 aber jedenfalls dic folgende Methode versuchen, mit der sich eventuell noch Häminkristalle herstellen lassen. Fin 
negatires Ergcbnis beweist allerdings nichts, während ein solches bei Krusten, Lappen und Holz, die als blutverdächtig betrachtet werden, dagegen entscheidende Bedeutung besitzt.

Blutiger Eisenrost wird in einem Reagensglase mit gepulvertem Kochsalz und einigen Tropfen Ammoniaklösung gemischt. Nach + Stunden filtriert man, dampft einige Tropfen des Filtrates sorgfältig ab und macht mit dem sich ergebenden Rückstande die Probe, die vorhin beschrieben wurde.

\section{Siebzehntes Kapite1.}

\section{Die Organe des Kreislaufs, die Blutgefäßdrüsen und die Drüsen ohne Ausführungsgang.}

a) Die Organe des Kreislaufs.

$$
\S \text { I } 47 .
$$

Das Herz. Die Muskulatur des Vertebratenherzens ist wie die Skelettmuskulatur quergestreift; die charakteristischen Differenzen beider Muskelarten findet man in jeder Histologie auseinandergesetzt. Für die mikroskopische Untersuchung ergibt sich im wesentlichen die gleiche Methodik wic für die Skelettmuskeln; daher sei auf das fünfzehnte Kapitel verwiesen. Die fibrillïre Zusammensetzung, die Existenz der Nebenfasern, dic Kittlinien am Nazerationspräparate kennen zu lernen, bedarf es keiner neuen, besonderen Technik. Anders liegt die Sache, wenn man Schnittpräparate untersuchen will, die anzufertigen sich sehr empfichlt, weil das feinere histologische Detail ïber den Bau der Herzmuskelfaser sich am besten an Schnittpräparaten crkennen läßt, ganz im Gegensatz zur Skelettmuskulatur, deren histoIngische Einzelheiten an Mazerationspräparaten besser in die Erscheinung treten. Es hängt dies wahrscheinlich damit zusammen, daß die Skelcttmuskulatur sich sehr schwer schneiden läßt, weil sie sowohl mit I'araffin wie mit Celloidin sich nach meinen Erfahrungen ungleichmäßig durchtrïnkt. Dic Herzmuskulatur dagegen gibt gute Präparate, denn bei ihr sind die eben genannten Nachteile nicht vorhanden.

Zur Fixicrung sind besonders geeignet: absoluter Alkohol, der allerdings nicht allzulange einwirken darf, Müllersche Flüssigkeit, 
Sublimat und Pikrinsalpetersäure viertes Kapitel). Die Färbung der Schnitte ist ziemlich gleichgiiltig; am besten finde ich Orange GHämatein, Glyzerinkarmalaun, Eosin-Hämatein, Hämatoxylineisenlacke und Indigkarmin-Boraxkarmin achtes Kapitel). Auch Vergoldung (neuntes Kapitel) gibt gute Resultate; nur dunkeln die nach dem Vergolden angefertigten Schnitte leicht nach, auch wenn sie ron Licht abgeschlossen aufbewahrt werden.

Eine besonders empfehlenswerte Methode ist dic folgende: Man fixiert Säugetierherz in Müllerscher Fliussigkcit, durchtränkt mit Celloidin und färbt mit Karmin-Hämatoxylin nach G. Fritsch (achtes Kapitel Nr. 97 S. I88). M. Heidenhain, der das Herz eines Hingerichteten untersuchen konnte, hat es noch lebenswarm für drei Tage in Sublimat eingelegt. Dann wurde direkt, also ohne Auswaschen, in $40^{\circ}$. Alkohol übertragen, dessen Konzentration alle $2+$ Stunden um 10\% gesteigert wurde. Heidenhain hat die Jodierung natuirlich im Stuick vorgenommen, nicht aber im Schnitt, wie neuere schlechte Empfehlungen lauten. Beziiglich der Fürbung der Herzmuskulatur macht er einige näherc Angaben. Zur Färbung kann Eisenhämatoxylin oder Vanadiumhämatoxylin genommen werden. Ferner empfiehlt er eine Kombination von sauren und basischen Anilinfarben. Zuerst wird die saure Anilinfarbe angewandt, was Heidenhain sonderbar genug als Beizung: bezcichnet, sodann wird in eine dünne basische Anilinfarbe ïbergefuihrt. (Dic an diese Regel sich anschließenden Auseinandersetzungen über die Theorie der Färbung brauchen hier nicht beriicksichtigt zu werden. Sie haben implicite im achten Kapitel ihre Widerlegung gefunden.) Als saure Farbstoffe führt Heidenhain an: Thiazinrot B, Thiazinbraun, Coerulein S; als basische: Thionin, Toluidinblau, Methylenblau, Phenosafranin. Diese beiden Gruppen sind in folgender Weise zu kombinieren: Thiazinrot-Toluidinblau; Thiazinrot-Methylenblau; Thiazinbraun-Toluidinblau; Coerulein S-Safranin. Thiazinrot und Thiazinbraun in ${ }^{\mathrm{I}} \%$ bis $1 \%$ wässriger Lösung; Cocrulein $\mathrm{S}$ gesättigt (es löst sich aber nur sehr wenig; Toluidinblau I : I000 VYasser, Methylenblau 0,5: 1000 Viasser. Alle Farbstnffe miissen vor dem Gebrauche angesäuert werden; in den sauren werden die Schnitte stark tingiert, müssen aber durchsichtig bleiben. Für das Färben in den basischen Stoffen genügt eine Stunde, man kann aber auch bis zwölf Stunden in der Farbflotte belassen Die Differenzierung wird in absolutem Alkohol vorgenommen; reicht diese Bchandlung nicht aus, dann wird in Mcthylalkohol weiter differenzicrt. Die Kittstreifen färben sich sehr intensiv, ebenso auch die verschiedenen Streifen des Muskelkästchens mit Aus- 
nahne des Streifens O. Die Schnitte von Herzmuskulatur muissen sehr duinn sein $(3-4 \mu)$.

Auch schwarze Farben empfiehlt Heidenhain, z. B. Brillantschwarz und Blauschwarz (achtes Kapitel). Gute Effekte sind zu erzielen, wenn man erst mit Karmin und dann mit Blauschwarz I". 5--Io Minuten färbt. Die Schaltstücle und die Streifen Z Wcrden darin dunkelblau, die iibrige Muskelsubstanz rotviolett, Bindegewebe und Kapillaren blau. Beim Färben muß man sehr aufpassen, daß die Schnitte nicht zu hell und nicht zu dunkel werden; doch ist das Färbungsresultat nicht konstant. Brillantschwarz liefert keine Metachromasien, überfarbt aber auch nicht so leicht wie das Blau. Man muß nach beendeter Färbung mit Brillantschwarz oder Blauschwarz ohne Karminvorfärbung mit Safranin oder Toluidinblau nachfärben.

Der Klappenapparat wird natülich mit der Nuskulatur zugleich fixiert, und zwar empfiehlt es sich, die Ventrikel und Atrien mit der Fixicrungsflüssigkeit anzufüllen, um so die Muskeln der Klappen nach Möglichkeit anzuspannen. MIan kann die Klappen dann isoliert schneiden, d. h. nach Herausnahme nach beendeter Fixierung, oder man schncidet sie in situ. Zur Darstellung ihrer elastischen Fasern dient Weigerts Fuchsin-Methode und Röthigs Kresofuchsin (achtes Kapitel Nr.63 u. $6+$ S. I 82). Um ihren Bau überhaupt zu zeigen, dürften die Färbungen ausreichen, die bei der Herzmuskulatur als angemessen erkannt worden sind. Zur Mazeration kann man jede beliebige Methode anwenden; freilich dürften gerade bei diesen Gebilden Mazerationspräparate unnïtig sein, da sie kaum eine wichtige Einzelheit mehr zur Anschauung bringen werden als Schnitte.

Die Nerven des Herzens studiert man mit Gold- oder Golgischen Silbermethoden (neuntes Kapitel) oder mit der vitalen Methylenblaufärbung achtes Kapitel). Schr schön sind im Septum atriorum des Froschherzens die Ganglienzellen und Nervenfasern zu sehen. Man präpariert unter IVasser oder Kochsalz $(0,75 \%)$ das Septum aus dem noch schlagenden Herzen heraus, wäscht, wenn man in Kochsalz pripariert hat, schnell aus und vergoldet entweder oder färbt mit Methylenblau.

Das Pericard wird wie gewöhnliches Bindegewebe untersucht.

$$
\text { @ } 48 \text {. }
$$

Die Gefäße. Dcr Bau der Aorta, der größeren Arterien und Venen ist am besten an Schnitten quer oder längs zur Achse des Gefäßes zu studiercn. Fixierung und Färbung sind gleichguiltig; hier führen alle Vege zum Ziele. Die Semilunarklappen der Aorta und 
der Arteria pulmonalis werden in situ fixiert, aber am besten isoliert geschnitten.

Kleinere Arterien und Venen werden am sichersten in irgend einem Organ untersucht. Denn in einem jeden solchen findet man in hinreichender Menge Längs-, Quer- und Tangentialschnitte, die vollständigen Aufschluß über den Gefäßbau geben.

Die Kapillaren kann man mit $I^{\circ}$, Lijsung von Argentum nitricum injizieren. um ihre endotheliale Natur zu erkennen. Man führt zu dem Zwecle in eine Arterie des Nesenteriums eines nicht zu großen Säugers oder des Frosches die Kaniile einer mit der Höllensteinlösung gefuilten Pravazschen Spritze und injiziert. Die Weiterbehandlung wird nach einer der im neunten Kapitel angegebenen Methoden vorgenommen.

Sigmund II yer hat die Kapillaren in der Harnblase des Frosches mittels Methylenblau und nachfolgender Fixierung in pikrinsaurem Ammoniak untersucht (achtes Kapitel). Er hat dabei die interessante Tatsache gefunden, daß die Kapillaren ron Muskelfasern umsponnen sind.

Sehr instrulitive Übersichtsbilder iiber kleine Arterien, Venen und Kapillaren erhält man nach ( $\mathrm{rth}$ an der I'ia mater eines kleinen Säugetieres. Man faßt cin Stiick P'ia des Großhirns mittels ciner Pinzette und spannt es an, sodaß sich die Blutgefäße aus der Hirnrinde herauszichen. Mit cinem in $0,75^{\circ}$ 。 Kochsalzlösung getauchten Pinsel spiilt man die anhaftenden Hirnteile ab. Man breitet das Piastiick auf einem Objektträger glatt so aus, daß die cerebrale Seite nach oben sieht. Nun kann man in beliebiger IVeise fixicren und färben.

\section{$\S 149$.}

Blutgefäßbildung. Zur Orientierung io uber die Art der Gefäßbildung nehme man den Flossensaum einer Kaulquappe oder ciner Salamanderlarve, wobei man gut tut, nicht zu dunkel pigmentierte Tiere zu wählen, damit die Pigmentzellen den Einblick nicht hindern. Man fixiere und fürbe beliebig. Im übrigen sind die Embryonen aller Vertebratenklassen natiirlich sehr geeignete Objekte fiir derlei Studien.

b) Die Blutgefä $\beta$ drüsen.

$$
\text { § } 150 .
$$

Milz. Ein mit einem scharfen Skalpell gemachter Einschnitt in die frische Milz eines Tieres gewährt die Möglichkeit, die zelligen Bestandteile dieses Organes frisch zu untersuchen. Nan braucht nur 
mit der Schneide des Skalpells über die Schnittfläche hiniiberzustreichen, um Zcllen aus dem Parenchym auszudriicken. Diese abgestrichenen Massen untersucht man in $0,75^{\circ}$. Kochsalzlösung; auf das J)eckglas übt man einen leichten Druck, um die Massen in der Zusatzflussigkeit gut zu verteilen. Man kann aber auch die abgestrichenen Jassen nach Art eines Dech-glastrochenpräparates fuir Blutuntersuchungen verteilen (sechzehntes Kapitel). Dann fixiert und färbt man die Aufstrichpräparate gurade so wic Blutprïparate, worüber im vorigen Kapitel das Nähere nachzusehen ist.

Zur Nazeration ist jede der in dritten Kapitcl aufgeführten Methoden geeignet; die Zentrifugierung dürfte hier sehr wertvolle Präparate liefern.

In den feineren Bau der Milz dringt man nur ein mit Hilfe von feinen Schnitten. Fixierung in Carnoyscher Fliissigkeit, Sublimat, I'ikrinsalpetersaure, Müliersche Lösung liefert gute Bilder, vorausgesetzt, daß man jede nur cinigermaßen voluminöse Nilz zerkleinert hat. Denn dies Organ ist sehr schwer permeabel, zumal es direkt falsch ware, ror der Fixierung die Kapsel abzuziehen. Dadurch wiircle man sich nur der Möglichkeit berauben, einen Einblick in dic Art und Weise der Trabelelbildung zu crlangen. Zur Farbung ist jede Doppelfürbung geeignet, die scharfe Kontraste liefert; wie Eosin-Hämateïn usw. Die Dreifachfärbung von Graberg ist direkt für die Milz empfohlen achtes Kapitel Nr. i 6 S. I ,6). Kultschitzly cmpfiehlt bei der Milz zunächst die Tene, dann die Arterie zu unterbinden und dann in Mïllerscher Flüssigkeit zu fixieren. Die Schnitte ron solchem Naterial werden in folgender Farbflotte $2-3$ Minuten und länger gefärbt: Patentsäurefuchsin $0,25 \mathrm{~g}$ bis $0,5 \mathrm{~g}, 3^{\circ}$ 。 Essigsäure $100 \mathrm{ccm}$. Nach beendeter Färbung wird in $2^{\circ}$. Essigsäure ausgewaschen und in Helianthin, Mandarin, Orange, Chinablau oder Wasserblau nachgefärbt. Jede Substanz wird $z u \quad 0,5 \mathrm{~g}$ in $100 \mathrm{ccm}$ Essigsäure von $2^{\circ}$ 。 gelöst. In jeder dieser zur Nachfärbung hestimmten Lösungen bleiben die Schnitte, bis sie gelb oder blau sind, und kommen dann direkt in Alkohol.

Die Milz ist ein Organ der Blutbildung; letztere zu studieren bedarf es daher anderer Fixierungsmittel als die vorhin genannten. Flemmingsche, Hermannsche Lösung, die Niessingschen Mischungen - diesc namentlich für Salamandermilz - stehen hier oben an. Ebenso gibt dic Bendasche Salpetersäure-Kali bichromicum-Fixicrung viertes Kapitel! gute Resultate. Die Foasche Lösung soll hesoncers geeignet sein, die Bildung der Erythrocyten zu verfolgen vicrtes Kapitel Nr. 22!. Zur Färbung sind die Hämatoxylinlacke ron M. 
Heidenhain und Benda, Safranin-Gentiana nach Flemming oder Hermann, Flemmings Orangeverfahren, Triacid usw. achtes Kapitel) geeignet.

Die Pulpa und die Malpighischen Körperchen treten an der Milz der Nagetiere, die Trabelel besonders stark an der Milz der Huftiere hervor, während beim Menschen, beim Hund und bei der Katze beide Bestandteile in einem Gleichgewichtszustande zueinander stehen. Zur Erkennung der Nuskelelemente hat Kultschitzky folgende Methode empfohlen: Schnitte von Müller-Material kommen in eine gesättigte Lüsung ron Lakmoid in Schwefuläther für $2+$ Stunden und länger. Das Plasma der Muskelzellen ist blau gefärbt. chie Kerne sind ungefärbt geblieben, das fasrige Bindegewebe ist rötlich, die roten Blutkörperchen fast schwarz, Leukocyten grau. Besonders gecignet ist hierfür die Nilz der Katze.

Die Injelition der Iblutgefälle, welche schr schwierig ist, erfolgt mit einer der im zehnten Kapitel angegebenen Methoden. Dic Milz dürfte ein für dic Altmannsche Korrosion zehntes Kapitel Nr. 6 S. 22I) sehr geeignetes Objekt sein.

\section{\$ 151 .}

Lymphdrüsen. Was bei dor Milz über Ausstrichpriparate, Mazerationen mit Zcntrifuricrung und Fürbung der I)eckglastrockenpräparate gesagt wurde, finciet bei den Lymphdriisen buchstäbliche Anwendung.

Zur Erlienmung des Stiitzretikulum ist es empfehlenswert, die Zellen curch die Pinsel- oier Schüttelmethode zu entfernen (drittes Kapitel; Zur Fixierung sind die gleichen Reagention wie bei dor Milz zu empfohlen; auch Zenkersche Lösung (viertes Kapitel Nr. 23 S. 54) ist sehr geeignet. Das Gleiche ist hinsichtlich der fü die Milz empfohlenen Färbungen zu sagen; auch sie sind bei Lymphdrisenstudien ohne weiteres anwendbar. Torzüglich geeignet ist außerdem noch die Weigert-van Giesonsche Methode achtes Kapitel Nr. 120 S. I97).

Thom é fixiert Lymphdrisen in Zenkerscher Flüssigkeit, schmilzt in Paraffin cin und behandelt die Schnitte erst mit $10^{\circ}$. Phosphormolybdänsäure. Nach 5-10 Minuten wird in Wasser abgewaschen, dann für 5-20 Minuten in einen aliquoten Teil folgender Hämatoxylinlissung gebracht: Hämatoxylin Kristalle 1.75 g, Aqua destillata $2 \mathrm{cocm}$, I0 "Phosphormolybdiinsäure Io ccm, krystallisierte Karbolsäure $5 \mathrm{~g}$. Dann wird gewaschen und nach der ïblichen IVeiter- 
bchandlung in Kanadabalsam eingeschlossen. Das Stiitzretikulum ist tiefblau.

Bartel und Stein fixieren zur Darstellung des Retikulum ebenfalls in Zenkerscher Flïssigkeit, behandeln dann aber die von paraffiniertem Naterial gemachten Schnitte folgendermaßen: Die Schnitte werden mit Wasser aufgeklebt, lommen für $2-3$ Ninuten in eine O. I', wässrige Lüsung von Säurefuchsin, werden in Wasser ahgewaschen, für 5 -7 Minuten in $\mathrm{I}^{\circ}$, wässerige Phosphormolybdänsäure übergefuihrt und dann nachgefürbt in: Anilinblau $0,5 \mathrm{~g}$, Orange G. $0.2 \mathrm{~g}$, Oxalsäure $2 \mathrm{~g}$, Aqua destillata roo $\mathrm{ccm}$. Hierin bleiben die Schnitte 20 Minuten, dann in Wasser, Alkohol, Nylolanilin (beide zu gleichen Teilen gemischt) Xylol, Balsam.

Die Terzweigungen dur Lymphgcfäße stellt man an den großen Drüsen durch Injektion der Vasa afferentia dar. Die kleinen lymphatischen Gebilde, wic dic Peycrschen Haufen, werden mit Einstichinjektion behandelt.

\section{\$ 152 .}

Tonsillen. Das fuir Milz und Lymphdrüsen Gesagte findet hicr buchstäbliche Anwendung.

\section{$\S 153$.}

Thymus. Auch dieses Organ wird wie cine Lymphdriise behandelt. Da es für fixierende Reagention schr schwer permeabel ist, so dürfen nur kleine Stiicke eingelegt werc̉en.

\section{c) Drüsen ohne Ausführungsgang.}

\section{$\$$ I 54.}

Thyreoidea. Normale Schilddrüsen frisch zu untersuchen hat keincn Sinn, denn das frische Präparat gibt weder über Struktur noch Textur des Organes Aufschluß. Zun Fixieren sind solche Reagentien auszuwählen, welche das in der Drüse enthaltene Colloid nicht zu hart machen. Tritt das nämlich ein, dann durchtränken sich die Objckte nur schwer mit Paraffin, das Colloid bröckelt beim Schneiden und die Schnitte zerreißen infolgedessen. Am geeignetsten dürften sich Carnoysche Fliissigkeit, Pikrinsalpetersäure und Sublimat erweisen (vicrtes Kapitel). Da die Thyreoidea sich schwer mit Reagentien durchtränkt - das gerinnende und geronnene Colloid setzt dem Vorschritt der Fixierungsfliissigkeit ein Hindernis -, so muß man kleine Stiicke einlegen und die Flüssigkeiten mindestens $2+$ Stunden einwirken lassen. Zur Färbung kann man beliebige Farbstoffe wählen; 
die schönsten Bilder liefert nach meiner Erfahrung Eosin-Hämatein. Auch die Weigert-van Giesonsche Färbung dürfte Gutes leisten (achtes Kapitel. Heidenhain empfiehlt die Färbung mitBlauschwarz; die Kerne werden dadurch rötlich violett gefärbt, das Bindegewebe tief dunkel blauschwarz.

Will man die Nerven des Organes untersuchen, so mul3 man kleine Stiicle frischen Materials mit Methylenblau behandeln (achtes Kapitel).

\section{S 155.}

Hypophysis, Glandula coccygea, Ganglion intercaroticum. Das für die Thyreoidea Gesagte findet hier Anwendung.

$$
\text { \$ } 156 .
$$

Nebenniere. Dic Capsulae suprarenales der Anuren fixicrt man nach Ciaccio in: Kali bichromicum $+g$, Formol $10 \mathrm{ccm}$, Aqua destillata $100 \mathrm{ccm}$, reine Amcisensïure $3-7$ Tropfen. Stücke, die so behandelt sind, kommen noch in I" Sublimat und werden in fließendem Wasser ausgewaschen. Die Methode ist unl-lar beschrieben und das Fixierungsmittel ist nicht sehr vertrauenerweckend zusammengestellt.)

Die Nebennieren der höheren Vertebraten fixiert man in Formol, Pikrinsalpetersäure, Müllerscher Flüssigkeit usw. Dic Färbung ist belicbig vorzunchmen; bei guten Doppelfïrbungen treten die verschiedenen Zonen deutlich hervor. Geschnitten wird entweder quer zum Längs- oder quer zum Dickendurchmesser. Die Bchandlung des Organes mit Methylenblau achtes Kapitel kann noch viele Unvollkommenheiten unseres Wissens von ihm beseitigen.

\section{Achtzehntes Kapite1.}

\section{Die Atmungsorgane.}

\section{$\S 157$.}

Die Luftwege. Dic cinzelnen Kehliopflnorpel, ob sie nun hyalin, elastisch oder fasrig sind, werden nach den Methoden untersucht, welche im vierzehnten Kapitel für Knorpelgewebe angegeben wurden. Die Feststcllung der Tatsache, zu welcher Knorpelart einer der Teile 
des Larynx zu rechnen ist. hat damn großen Wert, wann es sich um solche Arten handelt, die histologisch selten oder noch gar nicht untersucht sind.

Die Schleimhäute kann man frisch untersuchen, um die Flimmerung fuststellen zu künnen. Man schneidet daher aus der Trachea cines eben getöteten kleinen Süugetieres mit gebogener Schere cine kileine Schleimhautfalte ab und untersucht sic in physiologischer Kochsalzlüsung. Ist die Flimmerbewegung fast röllig erloschen, so geniigt nach der Angabe von R. Virchow Zusatz von $0,25 \%-0,5 \%$ Kalioder Natronlauge, um die Bewegung wieder anzufrischen.

Um Dauerprïparate zu erhalten, um eventuell auf Schnittserien die topographischen Verhältnisse namentlich der Glottis zu eruieren, fixiert man in: Formol, I'ikrinsalpetersäure, Sublimat, Sublimat-Aceton, Niullersche Lösung, vicrtes Kapitel). Die Fürbung kann ganz heliebig vorgenommen werden; für die elastischen Fasern sind selbstrerständlich Weigertsche Fuchsinfürbung und Rüthigs Kresofuchsin zu verwenden (achtes Kapitel).

Die Innervation der Kehlkopfschlcimhaut wird an Goldprïparaten, an Silberpriparaten nach Golgi neuntes Kapitel und an Methylenblaumaterial (achtes Kapitel) studiert.

\section{S 158 .}

Die Lungen. Frische Schnitte macht man nur, wenn man versuchen will, das Alveolenendothel durch Versilberung zur Anschauung zu bringen. Besser ist es für diesen Zweck, von einem kleinen Bronchus aus cinen Lungenlobulus mit I Argentum-nitricum-Lösung zu injizicren und ihn mit dem umgebenden Gewebe in absolutem Alkohol zu hïrten, in Paraffin einzubetten und zu schneiden.

$\mathrm{Zu}$ instruktiven Zwecken über den Bau der Lungen fixiert man in Alkohol, Miillerscher Lösung; Sublimat oder sonst beliebig. Es ist empfehienswert, die Lungen ron der Trachea aus aufzublasen, die aufgeblasene Lunge nach Ilöglichkeit mit der Fixierungsflissigkeit zu fuillen und dann das Organ in ein Gefäß mit derselben Fluissigkeit zu tum. Man beschwert die Lunge in belichiger Weise, vielleicht durch Anhängen eines Bleigewichtes, damit sie nicht an der ()berfläche der Fliissigkeit schwimmt. Zur Färbung genuigen einfache Kernfärbemittel wie mein Glyzerinkarmalaun oder Mayers Karmalaun achtes Kapitel ; zur Darstellung der elastischen Fasern sind die oft genannten Weigertschen und Röthigschen Methoden anzuwenden.

Die sehr wichtige Gefäßrerteilung ist an Injektionspräparaten zu untersuchen (zehntes Kapitel). 
Die im folgenden Kapitel genauer zu beschreibende Methode der Semperschen Trockenpräparate gestattet auch für die Lunge gute Ubersichtsbilder. Nan muß dazu die Lunge gut aufblasen und die Trachea fest verschließen, damit beim Härten keine Einziehung, d. h. Schrumpfung des Organes eintritt. Die Semperpriiparate untersucht man im auffallenden Lichte auf schwarzer Unterlage.

\section{ร I 59.}

Kiemen. Namentlich bei niederen Tieren ist die Lntersuchung frischer Kiementeile ron Wichtigleit, um die Art und don L'mfang dur Wimpcrung bzw. deren Fchlen festzustellen. Zur Fixicrung reichen Alkohol, Pikrinsalpetersäure und Sublimat aus, zur Färbung ist namentlich Eosin-Hämatein cmpfohlenswert. Als Mazerationsmittel - um die Art der Epithelzellen genauer zu erkennen - sind ${ }^{x}$ : Alkohol, I Alkohol, Drostsches Gemisch (rittes Kapitel) in crster Linie zu nennen. Die Behandinng der Kiemen erfordert im allgemeinen nicht dieselbe Torsicht wie die cier Lunge, weil die Kiemen leine durch Luft geblähten ()rgane sind. Dic Injuktion der Kiemengefißße ist naturlich von sehr grolsur Wichtigkeit, un den Kimenkreislauf kennen zu lernen.

\section{Nerinzehntes Kapite1.}

\section{Die Verdauungsorgane.}

$\$ 160$.

Tractus intestinalis. Dic Epithelzellen des Verdauungskanals zu isolieren ist notwendig, um ihe verschiedene Form genau zu erkennen. Denn in Schnitten ron fixiertem Material treten dic Unterschiede nicht mit der Genaugkeit und Deutlichkeit hervor wie an mazeriertem Material. Daß mittels der Zentrifugierungsmethode rogl. drittes Kapitel) gut gefarbte isolierte Zellen zu Dauerpräparaten verarbeitet werden können, bedarf nur der Erwähnung.

Zur Mazeration sind in erster Linie mein ${ }^{2}$, Alkohol und die Hopkinssche Salpetcrsïure-Alaunmethode geeignet; in zweiter Linie stehen ${ }^{ }$. Alkohol, dünne Chromsäure und $\mathrm{O}, \mathrm{I}^{\circ}$ 。Chromsäure (drittes Kapitel). Wenn die Mazeration beendet ist, dann schuittelt man das 
Darmstiick in der Mazerationsflüsigheit, so daß die Epitelzellen abfallen. Diesc Flussigkeit mit den Zellen zentrifugiert man: dann wire absegossen, in destilliertem Masser geschüttelt, zentrifugiert. das Thasser durch den Farbstoff ersetzt usw. bis zum Aufheliungsmittel. In diesem werden die gefürbten Zellen in eine Uhrschale gegossen, mit der Pipette werden sie auf den Objektträger gebracht und. nachdem die Aufhellungsflüsigkeit verdunstet ist, in Balsam eingeschlosscn. Bergamottül ist zur Aufhellung am geeignetsten, weil es am schnellsten verdunstet.

Die Mazeration bei Kaltbliitern bedarf längerer Zeit als bei Warmblitern; daß der Prozeß beendet ist, erkennt man daran, daß beim Schuitteln des (Objektes in der Fliissigkeit dic Zellen sich mit Leichtigkeit von ihrer Unterlage ablösen.

Auch dic Vergoldung nach Cohnheim (neuntes Kapitel) gibt gute Präparate. Man schneidet mit gebogener Schere eine feine Schleimhautfalte ron dem bereits versoldeten Darmstücke ab, zerzupft in rerdünntem Glyzerin und schließt darin ein. Oder man zerzupft in Wasser, saugt dies mit Filtrierpapier $a b$ und schließt in Giyzeringelatine ein. Derartige Präparate halten sich sehr lange.

Zur Fixierung sind ron den im vierten Kapitel beschriebenen Reagentien die folgenden geeignet: Sublimat, Pilrrinsalpetersäure. Zenkersche Fliissigkeit, Müllersche Fliissigkeit. Neniger gut sind die Chromsäure und ihre verschiedenen Gemische. Die Flemmingsche Lösung hat sich mir nur bei Amphibiendarm bewährt, bei Sauropsiden und Sïugern habe ich keine allzu guten Resultate mit ihr erzielt.

Kultschitzky fixiert in folgendem Gemisch: Kaliumbichromat $2 \mathrm{~g}$, Sublimat $0: 25 \mathrm{~g}, 2^{\circ}$ 。 Essigsäure $50 \mathrm{ccm}$, 90\% Alkohol $50 \mathrm{ccm}$. Kleine Stuicke werden in +-6 Tagen fixiert. Aus dieser Angabe geht hervor, dal das Reagens nur geringe Penetrationskraft besitzt und dal3 es nicht rationell zusammengesetzt ist. Denn der Zusatz les Alkohol zu cincr Kaliumbichromat-Lösung bedingt Niederschläge, die selbst durch wiederholtes Filtrieren nicht beseitigt werden können.

Nicolas fixiert in $3^{\circ}$. Salpetersäure mit Zusatz ron ${ }^{\mathrm{I}}={ }^{\circ}$. Osmiumsäure. I)ie Färbbarkeit der Gewebe soll nachher eine vortreffliche sein.

Ich möchte, beror ich die geeigneten Färbungen anfiihre, hinsichtlich Aer beim Fixieren zu beobachtenden Kautelen nach meinen Erfahrungen folgendes bemerken: Der Darmkanal fixiert sich ungemein schwer, tadellose Priparate sind nicht leicht zu erhalten. Übersichtsbilder uiber die grobe Textur erhält man wohl, aber eigentliche Struk- 
turpräparate - feinerer Bau der Drüsen, feinere Innervierung usw. bekommt man nur sehr selten in wirklich tadelloser Beschaffenheit. Ich kenne nur ein Reagens, dem ich bisher die besten Präparate verdanlie: die Pikrinsalpetersaure. Alle anderen Fixierungsmittel haben zwar nicht röllig rersagt, aber ihre Irirkung war keine gleichmäßige, keine unbedingt zurerlässige. Ich vermute, daß dies mit dem jeweiligen Tätigkeitszustande zusammenhängt, in welchem sich der zu fixierende Darmabschnitt befindet, kann aber fuir diese Termutung keine stringenten Beweise anführen. Folgende Erfordernisse muß ein Fixierungsmittel erfüllen, soll es beim Tractus intestinalis etwas leisten: Es muß schnell durch das Epithel in die Drüsenschicht dringen, darf aber andererseits nicht zu sturmisch cinwirken. Letzteres ist bei der Flenmingschen Lösung der Fall; ich fincle, daß ihre Wirkung am Terdauungskanal der Warmbliiter und Reptilien in einer Zertrimmerung des Strukturbildes der Driisen besteht, wiahrend sie bei Ichthyopsiden, ich möchte fast sagen, besonnener wirlt. Sublimat und Zenkersche Lösung dringen nicht schnell genug in die Drüsenregion, wenigstens nicht an allen Darmteilen gleichmïlig schnell ein. Magen, Duodenum und der Anfangsteil des Jejunum zeigen fast stets ungenïgende Konservicrung, der Endteil des Jejunum an seinem L̈bergange zum Ileum, dieses selber und das Coccum werden durch Sublimat und Sublimatgemische meist zufriedenstellend fixiert. Die Abschnitte des Dickdarmes habe ich nach Sublimat usw. niemals gut fixiert erhalten. Wic gesagt: ich kann nur vermuten, daß die verschiedenen Darmzustinde es sind, welche diese unkontrollierbare Differenz der Fixierungswirkung hervorrufen. Pikrinsalpetersiure dringt schnell in die Tiefe und ist doch nicht so sturmisch wie Flemmingsche Lösung.

Bei Crustaceen habe ich die relativ besten Erfolge mit der Frenzelschen Sublimat-Salpetersäure-1lischung (vicrtes Kapitel Nr. 65 S. 73: erzielt, die bei Vertebraten völlig versagt hat. Auch bei Tracheaten wirlt die Frenzelsche Flüsiglicit gut, und zwar kann sie kalt angewendet werden, während sonst die Reagentien in heilsem, fast kochendem Zustande auf Tracheatenorgane cinwirlen müssen.

Darmkanal, wenn er in das fixierende Reagens konmt, kontrahiert sich sehr stark. WTar er rorher aufgeschnitten - es hat dies stets an der Ansatzstelle des Mesenterium zu geschehen -, dann rollt er sich so zusammen, daß er wie um seine Längsachse gewickelt erscheint. War das Aufschneiden unterlassen worden, dann zieht er sich in sich zusammen. Beides ist bedeutungslos für den Erhaltungszustand bzw. fuir die Einwirkung des Reagens, nicht aber wenn es 
sich um Studien handelt, bei welchen die Schnittrichtung genau bestimmt scin muß. Für solche Zwecke muß ror dem Einlegen die betruffende Partie des Darmtraktus gespannt werden und mul.3 in gespanntem Zustande in die Fixierungsflüsigkeit kommen.

Zu Unterrichtszwecken wird Müller-Material benutzt, das mit Lithionkarmin. Pikrolithionkarmin oder mit Karmin-Hämatoxylin nach Fritsch achtes Kapitel gefürbt werden kann. Die letztere Kombination empfiehlt sich auch für die anderen Fixierungen. Bismarckbraun ist für den Darmkanal ron der Gegend der Magenschleindrusen $a b$ ein rorzügliches Fürbemittel, denn es hebt die Becherzellen und Schleimdrïsenzellen durch intensive Bräunung auf das schärfste hervor und macht ferner die durch das Epithel des Dünndarms wandernden Leukocyten sehr deutlich. Fuchsin und Safranin sind nach Flemming-Fixierung verwendbar. Tor allem aber verdienen Anwendung die Dreifarbenkombinationen: Erlich-Biondisches Gemisch, Triacid-Gemisch ron Ehrlich und Dreifarbengemisch ron Oppel achtes Kapitel Nr. II3-i15!) Bei dem erst genannten Gemisch ist dic Krausesche Modifikation zu wählen.

Eine eigenartige Methode, welche mikroskopische Übersichtsbilder im auffallenden Lichte gestattct, Bilder, welche höchst instrulitiv sind, ist dic schon bei den Atmungsorganen erwähnte Sempersche Wethode der Trockenpräparate. Man härtet Darmpartion in starker Chromsäure oder starker Kaliumbichromat-Lösung. Nach \&, It Tagen, 3 Wochen und länger - die Härtungsdauer richtet sich nach der Größe des Objektes - nimmt man aus der Chromsäure usw. heraus, trocknet flüchtig auf Filtricrpapier ab und legt in reines Terpentinül ein. Sind die Objekte ganz durchsichtig geworden, dann nimmt man heraus und hängt zum Trocknen auf, d. h. die Darmstiicke, wenn sie nicht, um Schrumpfungen zu verhüten, in einem Holzrahmen aufgespannt waren, müssen so untergebracht werden, daß die Luft von allen Seiten an sie heran kann. Hierin werden sie nicht nur trocken, sondern sie nehmen auch die Konsistenz des Handschuhleders an und werden vollkommen weiß, mag Gas Chrom auch noch so lange eingewirkt haben. Von diesem Lecier kann man mit der Schere kleine Teile abschneiden, in beliebiger Weise unter das Nikroskop bringen und mit schwachen Vergrößcrungen bei auffallendem Lichte untersuchen. Das Verhalten ron Zotten und Krypten ist gut nur auf diese Neise zu erkennen. 


\section{\$ I6I.}

Der Nervenapparat des Darmes kann auf dreierlei Art untersucht werden: entweder mit der Methylenblau- oder mit der Golgischen Chromsilbermethode oder nach Mazeration durch Vergoldung. Lnd zwar sind sownhl der submuküse Plexus von Meissner wie der Plexus myentericus ron Auerbach auf diese Weise zu untersuchen.

Der Meißnersche Plexus submucosus wird mit Mcthylenblau so dargestellt, daß man Stiicke der frischen Schleimhaut und Submucosa, die man mit gebogener Schere ron der Muscularis abgetragen hat, in Methylenblau nach Sigmund Nayer achtes Kapitel bringt und nach desselben Forschers Vorschriften weiter behandelt. Das Auerbachsche Geflecht stellt man ähnlich dar, nur muß man Teile der gesamten MIuscularis einlegen. Ist die Färbung gelungen, dann sucht man bei dem ersten Objekte das Epithel durch Pinseln zu entfernen, bei dem zweiten heide Muskellagen vorsichtig roneinander zu trennen. Golgipräparate stellt man in der üblichen Weise her (neuntes Kapitel). Die Schnitte müssen Flachschnitte sein, wenn sie die Plexus, Querschnitte, wenn sie die Nervenendigungen zeigen sollen.

Anders ist das Verfahren bei der Vergoldung. Nan legt ganz frische Stücke Darm eines kleinen Säugers in eine dïnne Lösung von gereinigtem Holzessig oder in $0,1^{\circ}$ 。 Essigsäure. Man kann auch, um Verkrimmungen zu verhiiten, das Darmstiick an einem Ende zubinden, es mit der Mazerationsfliissigkcit anfüllen, auch das zweite Ende zubinden und nun das ganze Stuick in die Säure legen. Nach $2+$ Stunden, oft auch erst nach 2-3 Tagen kann man die Präparation vornehmen. Man schneidet den Darm auf und spannt ihn fest aus, indem man mit Stecknadeln auf einer Wachsplatte die + Ecken des Darmstiickes in stark gespanntem Zustande befestigt. Nun schneidet man die Mucosa ein und sucht diese und dann die Submucosa abzuziehen. Besser aber, man zieht die Submucosa zugleich mit der Mucosa ab, legt sie so auf einen Objektträger, daß die Epithelseite auf dem Glase aufliegt, und rergoldet. Ebenso verfährt man mit der zurïckbleibenden Nuscularis: man legt sie mit der Submucosa-Seite nach unten auf einen Objektträger und rergoldet. Dic Präparate werden in Glyzerin aufgehoben und halten sich viele Jahre unverändert. Ich besitze ein derartiges Präparat noch aus meiner Studentenzeit.) Bei pulmonaten Gastropoden, wo die Darminnervation sehr leicht zu sehen ist - bei anderen Evertebraten gelang es mir bisher nicht, sie zur Anschauung zu bringen -, legt man in rerdunnte Essigsäure für I 2 Stunden und vergoldet. 
Leo Gerlach empfichlt Einlegen in verdinnte Lösungen ron doppultchromsaurem Kali oder in $10^{\circ}$. Kochsalzlösung für 12 bis 24 Stunden.

I)ie Lymphfollikel des Darmes werden wie die großen Lymphdrüsen untersucht.

Die Blutgefäße werden von einem Mesenterialgefäße aus injiziert, die Lymphgefäße stellt man durch Einstichinjektion dar.

$$
\$ 162 .
$$

Speicheldrüsen. Zur Isolierung der Drüsenschläuche benutzt man konzentricrte wässrige Oxalsäure oder reine Salzsäure; man kann nach beendeter Nazeration auswaschen, färben und durch Zentrifugierung nach Prokowski Dauerpräparate anfertigen. Speziell die Speicheldriisen wirbelloser Tiere (Cephalopoden, liefern sehr instruktive Bilder ïber die Gestalt des Drüsenschlauches.

Zum Studium der feineren Bauverhältnisse der + großen Speicheldrüsen der Säuger - Parotis, Submaxillaris, Sublingualis und Pankreas - bedient man sich der Schnitte von fixiertem Material. Man kann auch nach R. Heidenhain die ersteren 3 Drüsen elektrisch reizen; eine gereizte Drïse ist eine sekretleere, also erschöpfte, eine ungereizte ist eine selaretgefuillte, also tätige Drüse. Da die Speichelabsonderung ununterbrochen vor sich geht, so findet man auch in jeder ungereizten Drüse erschöpfte, also sich regenerierende und sekretgefüllte, also tätige Partien nebeneinander; man muß sie nur suchen.

Zur Fixierung eignen sich besonders Pikrinsalpetersäure und Flemmingsche Lösung. Garnier empfiehlt als ganz ausgezeichnetes Fixierungsmittel: gesättigte wässrige Pikrinsäurelösung $30 \mathrm{ccm}$. Formol io $\mathrm{ccm}$ und Eisessig $2 \mathrm{ccm}$. Nicht gut sind absoluter Alkohol und Sublinat, ganz schlecht Müllersche Lüsung, Zenkersche Lüsung und reine I'ikrinsäure. Als Färbemittel stehen obenan: Eosin-Hämatein, Orange G-Hämatein, in welchen die mucinhaltigen Zellen veilchenblau, die Zellen der serösen Drüsen leuchtend rot bzw. gelb werden. Auch Bismarckbraun hat eine entschiedene Verwandtschaft zum MIucin, seröse Zellen werden darin gelb. NB. Ich verwende stets Bismarckbraun der Berliner Anilinfabrik; das ganz andere färberische Eigenschaften hat wie z. B. das ron Nerck in den Handel gebrachte.)

Ferner sincł für seröse und mucinöse Drüsen Ehrlich-Biondis ron Krause modifiziertes Farbengemisch, Ehrlichs Triacid und Oppels Dreifurbengemisch sehr geeignet. Diese geben namentlich an den gemischten Drisen, solchen mit seröser und mucinöser Se- 
kretion, sehr instrultive Bilder. Als besonders geeignete Objelite zum Studium solcher gemischten Drüsen empfehle ich die hinteren Speicheldrüsen der Cephalopoden und die intralingualen Drüsen von Talpa europaea.

Für mucinöse Drüsen ist Thionin empfohlen. Nur ist nicht alles, was sich mit Thionin intensiv färbt, Mucin, wie überhaupt mit dem Namen Mucin eine Anzahl chemisch sehr verschiedener Körper bezeichnet wird. Mit Recht hat Paul Mayer diese Tatsache den Histologen eingeschärft, und wie nötig dies war, lehren die Angaben von Unna. Dieser Pathologe hält alles für Mucin, was sich mit Thionin und polychromem Methylenblau metachromatisch färbt. In Osmium- und Chrompräparaten wird nach demselben Forscher das Mucin durch Tannin fixiert.

Besondere. Mucinfärbemittel sind dic folgenden: Mucikarmin Mayer|, Mucikarminsäure Rawitz, Glychämalaun Mayer) und Muchämatein (Mayer) (achtes Kapitel).

Die Nerven der Drüsen werden am besten in Nethylenblau untersucht, indem man dïnne Scheibchen der frischen Organe in die Farbflotte bringt. Ferner eignen sich die Marinescusche Goldmethode und die Golgische Chromsilbermethode dazu (neuntes Kapitel).

Daß zur Erkenntnis der Vascularisation Injektionen unerläßlich sind, versteht sich von selber.

$$
\text { \$ } 163 \text {. }
$$

Leber. Zur Fixicrung verwendet man Alkohol absolutus, Carnoysche Flüssigheit, l'ikrinsalpetersäure und Müllersche Lösung viertes Kapitel'. Einfache Färbungen mit Kernfärbemitteln, welche zugleich das Plasma leicht mittingieren - mein Glyzerinkarmalaum, Glyzerinalatunhämatcin — reichen völlig aus. Für Zeillstudien muß in einem Osmium haltigen Gemische fixiert und mit Lisenhämatoxylin, Flemmings ()rangeverfahren, meinen Anilinlacken oder meiner Alizarinmethode (achtes Kapitel) gefärbt werden.

Die sogenannten Gallenkapillaren stellt man nach dem Böhm() ppelschen Silberverfahren folgendermaßen dar: Frische Leber vom Kaninchen wird in 2 Kali bichromicum Lösung gehracht, die rasch auf $5^{\circ}$, ansteigt. Nach 3 Wochen wird in *". Höllensteinlösung eingelegt, in welcher schon nach wenigen Tagen, sehr ausgebreitet nach 8 Tagen lie Gallenkapillaren sich imprägnieren.

Böhm legte zur Darstellung der Gitterfasern frische Leberstiiclic von I cm Größe auf 48 Stunden in $\% / 2 \%$ Chromsäure, dann für 
3 Tage in $3 \%$ Höllensteinlösung. Daraus einige Stunden in Aqua destillata, dann Alkohol und Schneiden.

Oppel modifiziert diese Methode in sehr beträchtlichem Maße, so caß in Alkohol gehärtete Leber verwendbar wird. Aus dem Alkohol hommen L eberstücke für I Tag in ${ }_{1 / 2} \%$ wässrige Lösung von chromsaurem Kali (Kalium chromicum flavum). Sie werden in sehr dünner Höllensteinlösung gewaschen - einige Tropfen der ${ }^{3} \%$ Lösung auf jo ccm Wasser - und in die ${ }^{3}:$ Lösung dann übergeführt. Schon nach I Stunde, besser noch nach 6 Stunden treten die Gitterfasern, welche die Gefäße umspinnen, schön hervor. 24 Stunden Aufenthalt in der Höllensteinlösung bedingt keinen Vorteil, da keine Vermehrung der Imprägnation statt hat. Große Stücke kommen in $t^{\circ}$ Kali chromicum Lösung. Nan kann aber auch nach Oppel $30^{\circ}$ Kaliumbichromat oder $0,5 \%$ Chromsïure statt des Kaliumchromat nehmen. Nach beendeter Versilberung wird einige Stunden in destilliertem Wasser gewaschen und nach üblicher Weiterbehandlung in Paraffin eingeschmolzen. Man kann Leber benutzen, die bereits I Jahr in Alkohol gelegen hat.

Die Blutgefäße, deren Verteilung zu kennen sehr wichtig ist, werden von der Arteria oder Vena hepatica oder von der Vena portarum aus injiziert. Nan kann auch alle 3 Gefäße gleichzeitig injizieren und rom Ductus hepaticus aus noch die Gallengange anfillen.

Die Nerven der Leber sind mit den neueren Methoden meines Wissens noch nicht untersucht worden.

\section{Zwanzigstes Kapitel.}

\section{Die Harnorgane.}

\section{$\S \mathrm{I} 64$.}

Niere. Das Kanalsystem der Vertebratenniere so zur Anschauung zu bringen, daß man, ohne Rücksicht auf die Beschaffenheit der Epithełzellen. nur die Form der Kanäle - ihre Schlängelung oder ihr gerader Verlauf oder die Henleschen Schleifen - erkennt, ist sehr wertvoll. Denn manches, was man aus Schnittbildern sich mühsam konstruieren muß, zeigt ein gelungenes Mazerationspräparat. Reine Salzsäure und kalt gesättigte wässrige Oxalsäurelösung sind 
hierfü die sichersten und besten Mittel. Die Mazeration ist beendet, wenn die Objekte - ganze Nieren kleiner, Nierenstücke großer Tiere - nach Herausnahme aus dem mazerierenden Reagens beim Schütteln in Wasser in ihre Kanäle leicht zerfallen. Daß solche Präparate dank der Zentrifugierungsmethode (drittes Kapitel) dauernd aufgehoben werden können, ist eine Errungenschaft der neueren Technik. Man muß nur, da die isolierten Elemente durch die Reagention sehr sauer geworden sind, die Vorsicht gebrauchen, sie sorgfältig in WTasser zu waschen - geschieht durch Schiitteln in einem Reagensglase -, damit nachher haltbare Fürbungen vorgenommen werden können. Glyzerinkarmalaun oder Karmalaun reichen völlig aus, um die Schläuche als gefärbte Stiicke sichtbar zu machen. Auch die Niere der Crustaceen grine Drüse des Flußkrebses) ist auf diese Weise gut zu mazerieren. während ich bei der Molluskenniere bisher keine Erfolge hatte.

Die vorstehend erwïhnten Methoden involvicren einen Verzicht auf histologische Feinheiten. Will man die Beschaffenheit der Drüsenepithelien an Mazerationspräparaten untersuchen, so muß man andere Verfahren wählen. Nach den Angaben von Sauer ist physiologische Kochsalzlösung $\left(0,75^{\circ}\right)$ direkt $\mathrm{zu}$ vermeiden, weil in ihr die Nierenepithelien quellen. Gut soll dagegen Humor aqueus die Gestalt der Zellen erhalten. Zur Isolation emptichit derselbe Forscher $5^{\circ}$ molybdänsaures Ammoniak oder 5", neutrales chromsaures Ammoniak; doch geben diese Reagentien nicht immer getreue Bilder.

Die Injektion der Nierenkaniale vom Ureter aus ist iiberaus schwierig; einen Wert kann ich dieser Methode, welche in den Anfangszeiten der Histologie guibt wurde, nicht beimessen.

Hinsichtlich der Fixierung gibt Sauer folgendes an: Gut ist das Carnoysche Gemisch (viertes Kapitel Nr. 3 S. .t) in seiner chloroformhaltigen Zusammensetzung; es muß 3-5 Stunden einwirken. Pikrinsalpetersäure liefert nur bei Amphibien gute Resultate, doch hahe ich auch bei der Süugetierniere gute Bilder mit ihr erhalten. Alle uibrigen Reagentien, auch die Osmiumsäure mit ihren Gemischen und das Sublimat, verwirft Sauer fur die Vertebratenniere. Ich möchte noch den absoluten Alkohol als fixierendes Reagens empfehlen, namentlich wenn man vorher, nach Reinigung der Gefäße mit $0,75^{\circ}$ \% Kochsalzlösung, diese mit Alkohol absolutus ausgespritzt hat. Man bindet zu dem Zwecke eine Kanüle in die Nierenarterie ein, spritzt mit $0,75 \%$ Kochsalzlösung so lange durch, bis diese klar aus der Nierenvene abläuft, und nimmt dann zur Injektion den Alkohol. Im übrigen stimme ich Sauer in der Verwerfung der meisten Reagentien völlig zu. Eine gut fixierte Niere zu erhalten, ist nicht leicht; denn 
die von Sauer aufgestellten Erfordernisse für einen guten Fixierungszustand: tadelloses Epithel, Bürstenbesatz deutlich und nicht abgerissen, Lumina frei, zeigt selten ein Präparat vereinigt. Auch der Angabe von Sauer, daß man die Entwässerung nur sehr allmählich vornehmen soll, kann ich vollinhaltlich zustimmen.

Man paraffiniert oder celloidiniert das fixierte Material und färbt die Schnitte mit einem Kernfärbemittel. Auch die Weigertsche Modifikation der van Giesonschen Färbung muß wertvolle Resultate liefern.

Bei der Crustaceenniere grine Drüse von Astacus) liefert Flemmingsche Lösung eine vorzügliche Fixierung; die Färbung geschieht in basischen Anilinen.

Sehr wichtig ist beim Studium der Niere die Erkennung der Blutgefäßverteilung. Über die Injektionsmethoden vgl. zehntes Kapitel; iiber die Injektion mit indigschwefelsaurem Natron sind die Lehrbiicher der Physiologie zu konsultieren.

\section{$\$ 165$.}

Ausführende Wege. Eine besondere Methodik für Nierenkelche, Nierenbecken, Ureter und Harnblase gibt es nicht. Will man die Epithelien abmazerieren, so nimmt man irgend eines der im ciritten Kapitel empfohlenen Reagentien; will man fixieren, so fixiert man in Zusammenhang mit der Niere. Nur bei der Harnblase geht dies nicht; dies Organ wird daher isoliert fixiert. Man injiziert die Fixierungsflissigkeit von der Urethra aus, um die Blase prall gespannt zu erhalten, und legt in dieselbe Fliissigkeit das gefuillte Organ. Auch hierfuir gibt es lieine besonderen Methoden; man halte sich an das, was bei der Niere gesagt wurde.

Glans penis und Lrethra fixiert man in Alkohol oder in Carnoyscher Fliissigkeit. Die Färbung der Schnitte von den ausfuihrenden Wegen ist ziemlich gleichgiiltig; cin gutes Kernfärbemittel zeigt alles histologische Wissenswerte.

Die Innervation der Blase wird hauptsächlich an Methylenblaupriparaten untersucht achtes Kapitel. Bedient man sich der Fixierung solcher Präparate nach Bethe oder S. Mayer, (ibidem), so kann man gute Dauerpräparate erhalten.

Goidiäparate und Golgische Versilherung sind ehenfalls anwendbar neunter Kapitel, fuir crstere ist zu empfehlen, cas Epithel etwa durch Kohrzucker - schweflige Säure /drittes Kapitel Nr. 30 S. 29. vor der Vergoldung zu entfernen. Es ist dies darum ratsam. Camit nach eingetretculr Reduktion die Präparate nicht zu dunkel werden. 


\section{Einundzwanzigstes Kapitel.}

\section{Die Geschlechtsorgane.}

a) Männliche Geschlechtsorgane.

$\S 166$.

Sperma. Das männliche Geschlechtsprodukt, den Samen, isoliert, d. h. außerhalb des keimbereitenden Organes zu untursuchen, ist von grüßter Wichtigkeit, und zwar aus zwei Gründen. Einmal ist es ron Wichtigkeit festzustellen, ob dic Samenelemente - Spermatozoen, Spermatosomen, Zoospermien, Spermien - eigene Beweglichkeit hahen oder nicht und welcher Art die Beweglichkeit erentuell ist. Und zweitens ist es ron Wichtigkeit zu erfahren, wie das Spermatosoma, dessen Genese durch Untersuchung von Hodenschnitten studiert werden kann, sich nach seiner Entleerung aus dem Körper verhält, wie seine Zellnatur in seinem Aufbau gewahrt ist usw.

Wie gervinnt man frischen Samen, um ihn mikroskopisch untersuchen zu können? Betrachten wir zunächst die Vertehraten. Bei Säugern und Sauropsiden gewinnt man kräftigen, gut heweglichen Samen aus der Epididymis des frisch getöteten Tieres. Man schneidet den heraus präparierten Nehenhoden in einer flachen, mit $0.75^{\circ}$ 。 Kochsalzlüsung gefiillten Schale durch und schiittelt ihn in der genannten Fliissigkeit. Für gewöhnlich, wenn nämlich keine Impotenz vorliegt, trübt sich die Kochsalzlösung zum Beweise, daß die Samenfïden entleert sind. Ein unter dem Mikroskop fliichtig untersuchter Tropfen zeigt dic Anwesenheit von Spermatosomen. Bei sehr kleinen Tieren, namentlich den Lacertiliern, dürte es nicht immer leicht sein, den Vehenhoden isoliert, also ohne den Hoden zu verletzen, zu entleeren. In solchen Fällen diirfte es sich empfehlen, den ganzen Geschlechtsapparat herauszupräparieren und in physiologischer Kochsalzlösung mit einer Schere in kleinste Stiicke zu zerschneiden. Bei Amphihien und Petromyzonten muß der Hoden in $0.75^{\circ}$. Kochsalzlösung zerschnitten werden. Bei Fischen, besonders Selachiern, gewinnt man Samen aus dem zerschnittenen Vas deferens. Da die Vertebraten nicht zu allen Zeiten des Jahres reifen d. h. bewegungsfähigen Samen haben, so muß man sich natülich die Zeiten der Brunst aussuchen, weil nur dann reifes Sperma vorhanden ist. 


\section{$\$ 167$.}

Bei Evertebraten, bei welchen große Gruppen von Tieren vorkommen, die bewegungslose Samenfäden haben z. B. Nematoden, Crustaceen), verfährt man im großen und ganzen wie bei Vertehraten. Im einzelnen ist folgendes zu beachten: Die Gonaden der Coelenteraten zerschneidet man in einer Schale mit Seewasser, ruihrt dieses mit einem Glasstabe gut um und untersucht einen Tropfen Fliissigkeit. Bei Echinodermen, speziell bei Seeigeln, welche die klassischen Objekte der experimentell-entwicklungsgeschichtlichen Studien sind, schiittelt man die Hoden in Seewasser. Eine milchweiße Fliissigkeit strömt dabei aus dem Hoden — vorausgesetzt natiirlich, daß man zur Zeit der Samenreife untersucht - und mischt sich, wenn man mit einem Glasstabe leicht umrihrt, mit dem Seewasser. Bei dieser Gelegenheit möchte ich Anfänger auf ein Merkmal aufmerksam machen, an dem sie männliche und weibliche Seeigel von einander unterscheiden können. Dies ist nicht leicht, weil diesen Tieren alle sekundären Geschlechtscharaktere fehlen. Bezeichnend für männliche, frisch aus dem Meere geholte Seeigel ist, daß sie alle mehr oder minder große Steine in hald größerer bald geringerer Zahl auf dem Rücken tragen. Weibliche Tiere haben sich nie derart belastet. Worauf diese Differenz heruht, vermag ich natuirlich nicht zu sagen; genug, sie ist vorhanden. Allerdings zeigen männliche Seeigel, welche längere Zeit in Aquarien gehalten wurden, dieses Merkmal nicht; in der Gefangenschaft tragen diese Tiere keine Lasten. Übrigens ist es nicht empfehlenswert, an solchen Seetieren Untersuchungen anzustellen, welche schon lange in der Gefangenschaft gehalten wurden. Künstliche Befruchtungsversuche gelingen an frisch eingefangenen Tieren immer, während sie an Aquariumsexemplaren oft genug versagen. Bei den hermaphroditischen Ascidien. die man aus ihrem Mantel herauspräparieren muß - am geeignetsten ist Phallusia mammillata; nur wird das Messer beim Durchschneiden des fast knorpelharten Mantels dieses Tieres schwarz - , ist der Samenabschnitt durch seine grünliche Farbe kenntlich. Man entleert ihn in eine Glasschale mit Seewasser. Bei hermaphroditischen Mollusken muß man auf gut Glück die Zwitterdrüse zerschneiden, bei gonochoristischen die Hoden. Überhaupt sind bei allen Evertebraten mit beweglichen Spermatosomen die Hoden zur Entlecrung der reifen Samenfäden in physiologischer Kochsalzlösung bez. in Seewasser zu zerschneiden. Bei Tieren mit unbeweglichen Samenfäden kann man diese nur an Zupfpräparaten und Schnitten durch die Vasa deferentia studieren; beim Flußkrebs aber 
ist es mir bisher noch immer nicht gelungen, vom Vas deferens wirklich brauchbare Schnitt- oder Zupfpräparate zu erlangen. Ballowitz empfiehlt Mazeration in $0,6 \%-3 \%$ Kochsalzlösung.

\section{$\S \mathrm{I} 68$.}

Einige allgemeine Regeln für die Anfertigung von Spermapräparaten seien hier angefügt.

Man darf die Hoden nicht in zu viel Fliissigkeit zerschneiden, weil sonst die Spermalösung zu dünn wird, was selbstverständlich die Beobachtung sehr erschwert. Das Gleiche ist zu beachten, wenn man Nebenhoden von Säugern usw. in eine Glasschale entleert. Die zur Anfertigung der Spermapräparate gewählte Glasschale darf nicht zu hoch sein, weil ein hoher Schalenrand das Arbeiten mit der Schere beträchtlich hindert. Hat man die Organe zerschnitten oder, wie z. B. Seeigel-Hoden, ausgeschiittelt und dadurch die Spermatosomen frei gemacht, dann rühre man mit einem Glasstabe die Fliissigkeit einige Male um, damit das Sperma sich gleichmäßig verteilt. Dann warte man ab, bis die Organreste auf dem Boden der Schale zur Ruhe gekommen sind, und gieße die Flüssigkeit in eine reine Glasschale, wobei sorgfaltig darauf zu achten ist, daß alle Organfetzen in der alten Schale bleiben. Hodensubstanz nämlich fault sehr leicht, tötet dadurch die ohnehin nur kurzlebigen Spermatosomen noch schneller, als sie für gewöhnlich abstcrben würden, und verunreinigt außerdem die anzufertigenden Präparate.

Zur mikroskopischen Untersuchung nehme man einen Tropfen der Flüssigkeit, bringe ihn auf einen Objektträger und decke ihn mit einem Dechglase zu. Ist der Tropfen zu grol3, dann schwimmt das Deckglas, ist er zu klein, dann werden die Spermatosomen*) gepreßt und verlieren dadurch ihre Beweglichkeit. Ein wenig Übung lehrt bald. das richtige Maß des Tropfens zu treffen. Man kann selbstverständlich auch im hängenden Tropfen untersuchen (vgl. zweites Kapitel), muß es sogar, wenn man eine der später zu schildernden Fixierungsmethoden anwenden will.

*) Anmerkung. Ich gebrauche die Bezeichnung \$Spermatosomen\&, obgleich die Autoren neuerdings spermien zu sagen pflegen. Der Ausdruck "Spermatosoma stammt, wenn ich nicht irre, von Waldeyer und ist sprachlich korrekt gebildet. Der A usdruck Spermie» dagegen ist ein sprachliches Unding, wenigstens für das, was er bezeichnen soll: Entweder nämlich wird er von $\sigma \pi \epsilon \rho \mu \epsilon i ̂ v$ abgeleitet, dann bedeutet er Same und nicht Samenfaden, denn $\sigma \pi \epsilon \rho u \in i o v$ und $\sigma \pi \epsilon \rho u \alpha$ sind iden-

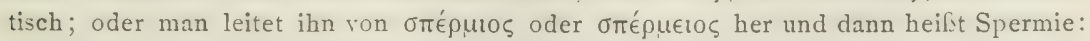
vom Samen, aber nicht Samenfaden. Jedenfalls also ist der Ausdruck $\gg$ Spermie für denjenigen, der etwas Sprachgefühl hat, von entsetzlichem Barbarismus. 
Die geringe Lebensdauer der beweglichen Samenfiden, auf die vorhin hingewiesen wurde, bedingt auch die Reihenfolge der Operationen bei der künstlichen Befruchtung. Ob man ein Froschei oder ein Echinidenei befruchten will: immer müssen zuerst die sehr widerstandsfähigen Eier in die zum Experiment bestimmte Glasschale kommen und dann erst darf der Samen zugesetzt werden.

$$
\$ 169 \text {. }
$$

Samenpräparate, angefertigt wie vorstehend angegeben, lassen sich natürlich auch zu Dauerpräparaten verarbeiten, und zwar kann man die Spermatosomen entweder fixieren oder man verfährt nach der Art der Deckglastrockenpräparate beim Blut. Ballowitz macht von einer in physiologischer Kochsalzlösung hergestellten Samenlösung einen hängenden Tropfen und fixiert mit Osmiumsäuredämpfen (viertes Kapitel Nr. 27 S. 60\%. Ebenso gut ist das andere Verfahren, die Herstellung der Deckglastrockenpräparate. Man taucht einen Glasstab in die Samenfliissigkeit und führt ihn über ein Deckglas. Oder man bringt einen Tropfen der Samenflissigkeit auf ein Deckglas, deckt nach Art der Blutpräparate ein zweites darauf und zieht, wenn sich der Tropfen ausgebreitet, beide Deckgläser schnell auseinander. (Um derartige Präparate anfertigen zu können, darf die Samenlösung nicht zu dünn sein, aus demselben Grunde, der schon im $\S$ i 68 genannt wurdc.) Diese Deckglaspräparate läßst man lufttrocken werden, indem man sie an einen vor Staub geschützten Ort stellt. Dann fixiert man; und zwar indem man auf $2-4$ Stunden in den Paraffinofen bei $60^{\circ}$ bis $65^{\circ} \mathrm{C}$. einstellt oder indem man in eine Fixierungsfliissigkeit einlegt. Zur Fixierung sind geeignet: Sublimateisessig, Sublimat, absoluter Alkohol, Flemming sche Lösung, Osmiumsäure $(\mathrm{r} \%)$ und ihre Dämpfe. Zur Färbung würde ich dieselben Methoden wie bei der Blutfärbung empfehlen und auch dieselben Anwendungsweisen, also konzentrierte glyzerinige oder alkoholische Farbflotten.

\section{$\S 170$.}

I3ei der Fixierung des Hodens muß man beachten, daß bei allen Tieren dieses Organ ein verschiedenes Verhalten zeigt, das von dem jeweiligen Funktionszustande abhängt. Zeiten vollkommener Funktions]ausen und Zeiten encrgischester Funktion wechseln mit einander $\mathrm{ab}$. Zwischen beiden liegen Übergänge, in denen, die Geschlechtsorgane wiederum ein anderes Verhalten darbieten. Will man bloß die Textur des Hodens, die Art seiner konstituierenden Zellen untersuchen, so muß man natürlich andere Methoden wählen, wie 
wenn man die Spermatogenese studieren will. Füir letztere gelten die Methoden, welche im dreizehnten Kaptel bei der Zellteilung empfohlen wurden, und ebenso die dort angefuhrten Färbungen. In erster Linie stehen die Doppelfärbungen Safranin-Gentianaviolett, Safranin-Lichtgrü (achtes Kapitel), Flemmings Orangeverfahren, meine Alizarinfärbungen. In zweiter Linie sind die verschiedenen Hämatoxylinlacke zu nennen. Bei bloßen Texturstudien genügen Fixierungen in Sublimat, Pikrinsalpetersäure und Färbungen wie Eosin-Hämatein usw.

Amphibienhoden mul3 unzerkleinert in die Fixierungsfliissigkeit kommen, weil beim Zerteilen die Hodenfollikel zerrissen und die Zellen gequetscht werden. Der Hoden der ïbrigen Gruppen - auch der Evertebraten - muß immer in kleine Abschnitte zerteilt werden, damit die Fixierungsflïsigkeit gut eindringen kann. Die meisten Schwierigkeiten hat mir immer Crustaceenhoden beim Fixieren bereitet. Bei Seewassercrustaccen Brachyuren) tritt oft Zersetzung im Innern ein trotz besten Erhaltungszustandes der Organperipherie; bei Süßwassercrustaceen (Astacus) sind einigermaßen brauchbare Bilder nur mach Fixierung in Flemmingscher Lösung zu erzielen.

Anhangsweise will ich noch ein für Hodenuntersuchungen empfohlenes Färbererfahren der Vollständigkeit halber anführen, obgleich die Methode im höchsten Grade irrationell ist. Reinke hat folgende Dreifachfärbung mit Safranin-Gentiana-Orange G angegeben. Die Schnitte werden für $2+$ Stunden in konzentrierte Lösung von Kali sulfurısum gegehen, nach kurzem Abspiilen in Wasser I-2 Stunden in Safranin gefärbt und dann in ein Gemisch von Gentiana-Orange G. für 2 t Stunden gebracht. Dieses Gemisch virel so hergestellt, daß man zu einem aliquoten Teil konzentrierter wässriger GentianaviolettLösung einige Tropfen konzentrierter wässriger Orange G-Lösung zusetzt. Diese nichtexakte Angabe wird nicht exakter durch das ron Reinke empfohlene Prüungsverfahren, nämlich einen Tropfen des Gemisches auf Filtrierpapier zu bringen, wo bei richtiger Mischung cin blauer oder blaubrauner Fleck einen schwach orangefarbenen Rand hat. Es tritt Truibung ein, die durch Wasserzusatz sich hebt; filtriert darf nicht werden. Möglich daß Reinke recht hat mit der Annahme, es bilde sich bei der Vermischung von Orange und Gentiana ein neuer Farbstoff (etwa wie bei Losin-Methylenblau), rationell aber ist die Mischung wegen der auftretenden Trübungen nicht.

Um die Membran der Samenkanälchen darzustellen, empfiehlt Regaud die Anwendung der Renautschen Flüssigkeit: gesättigte wässrige Pikrinsäurelösung $\varepsilon \mathrm{ccm}, \mathrm{I}^{\circ}$ 。 Osmiumsäure $20 \mathrm{ccm}$. $\mathrm{Zu}$ je 
$3 \mathrm{ccm}$ dieses Gemisches fügt man I ccm einer $\mathrm{I}^{\mathrm{c}}$ 。Höllensteinlösung und injiziert interstitiell in den Hoden; d. h. man macht eine Einstichinjektion, indem man z. B. die Kanüle einer Pravazschen Spritze in die Hodensubstanz tief einsticht. Dann, d. h. nach der ersten Injektion injiziert man interstitiell $93 \%$ Alkohol, zerlegt das Organ in Scheiben, die man in Nelkenöl dem diffusen Licht zur Redultion des Silbers aussetzt. Nach eingetretener Reduktion kann man beliebig weiterbehandeln.

\section{§ I 7 .}

Ausführende Wege. Die Epididymis der Säugetiere und Sauropsiden fixiert man in Pikrinsalpetersäure oder Sublimat, färbt mit irgend einem Kernfarbstoffe und erzielt dadurch gute Bilder. Namentlich die Wimpern sind rorzuiglich erhalten. Benda hat durch seinen Schüler Jkeda fur die Epididymis des Menschen folgendes Verfahren empfehlen lassen. Die frischen Organe kommen für mindestens 2 Tage in $93^{\circ}$. Alkohol, können aber auch beliebig länger darin verweilen. Dann in Salpetersäure I ccm der offizinellen Säure in $10 \mathrm{ccm}$ Aqua destillata gelöst) für $2+$ Stunden, in $2^{\circ}$ 。 Kaliumbichromat-Lösung für ebenfalls $2+$ Stunden und darauf schlicßlich für 4 S Stunden in I 0 Chromsäure. Nun wird $2+$ Stunden lang in destilliertem Wasser gewaschen, das mehrere Male erneuert werden muß, und in steigendem Alkohol gehärtet. Färbung in Kristallviolett achtes Kapitel .

Dic iibrigen Teile der ausfihrenden Wrege und dic Anhangsgehilde: Vas deferens, Ductus ejaculatorii, Giraldessches Organ. Paradidymis, Tas aberrans Halleri und Morgagnische Hydatide, werden ganz wie Epididymis behandelt.

Der Penis wird in Mïllerscher Flüssigkeit, in Alkohol absolutus oder in Carnoyscher Fliissigkeit fixiert. Die beliebig hergestellten Schnitte werden beliebig gefärbt. Bezüglich der Darstellung der präputialen Nerrenendigungen wird auf das dreiundzwanzigste Kapitel verwiesen, wo die einschlägigen Methoden zu finden sind. Prostata und Cowpersche Driisen werden wie Speicheldriisen behandelt (neunzehntes Kapitel).

b) Weibliche Geschlechtsorgane.

$$
\$ I 72 .
$$

Eierstöcke. Die Art, wie man reife Ovarialeier untersucht, soll später im Anhang zu diesem Kapitel, der die bei Eiern und Embryonen anzuwendende Mikrotechnik enthalten wird, genauer beschrieben wer- 
den. Unreife Eier werden an Schnittpräparaten von den Ovarien untersucht.

Zur Fixierung bei Vertebraten wie Evertebraten sind in erster Linie zu nennen: Carnoysche Flüssigkeit, van Benedensche Fluissigkeit und ihre Modifikation von Zacharias - diese beiden besonders für Nematoden-Ovarien —, Flemmingsche Lösung, Hermannsches Gemisch, Bouinsche Lösung (viertes Kapitel. Dann kommen die Pil-rinsäure-Gemische, während alle Sublimat-Gemische schlechte Resultate liefern.

Die Ovarien aller Tiere durchtränken sich ziemlich schwer, am schwersten die der Säuger. Hier ist die Parenchymzone oft schon iiberfixiert, während die Gefäßzone vom Reagens kaum berïhrt worden ist. Sïugetierovarium muß daher zerkleinert werden; nur bei sehr kleinen Tieren - Mäuse usw. - ist dies nicht nötig. Entsprechend dem Grade der Permeabilität richtet sich die Einwirkungsdauer des fixierenden Reagens. Hierfür können Regeln nicht aufgestellt werden, hier mul3 der Einzelne seine Erfahrungen selber sammeln.

Ebenso wie die Fixierung nicht unerhebliche Schwierigkeiten bereitet, ebenso ist dies der Fall bei der Paraffinierung. Gute Entwässerung und gute Durchtränkung mit Chloroform ist die Conditio sine qua non für brauchbare Paraffinschnitte. Für Übersichtsbilder genügt ein Kernfarbstoff oder eine einfache Doppelfürbung wie EosinHämatein. Für oogenetische Studien sind die Fürbungsmethoden anzuwenden, welche auch bei der Spermatogenese und bei der Zellteilung als besonders gecignct empfohlen wurden. Die Bindesubstanz der Gefäßzone wird nach den bein Bindegewebe (vierzehntes Kapitel) angegebenen Methoden oder nach den im vierundzwanzigsten Kapitel bei der Haut anzugebenden untersucht.

\section{$\S 173$.}

Ausführende Wege. Tuba Fallopiae, Uterus und Vagina werden nach den Regeln untersucht, welche für den Darmkanal (neunzehntes Kapitel, angegeben wurden. Die eventuell vorzunehmende Isolation der glatten Muskulatur erfolgt nach den Methoden des fünzehnten Kapitels.

Die äußere Scham wird wie die Haut (vierundzwanzigstes Kapitel, die Clitoris wie der Penis (S I I I), die Bartholinischen Drüsen werden wie die Verdauungsdrüsen (neunzehntes Kapitel fixiert, geschnitten und gefärbt. Hinsichtlich der Wollustkörperchen wird auf das dreiundzwanzigste Kapitel, Nervenendigungen, verwiesen. 


\section{$\S I 74$.}

Milchdrüsen. Die mikroskopischen Bilder, welche man von einer unreifen Mamma, einer Mamma in der Funktionspause, während der Gravidität und während der Lactation erhält, weichen natürlich sehr bedeutend von einander ab. Für die Fixierung und Färbung ist das aber gleichguiltig. Alkohol absolutus, Nüllersche Flüssigkeit, Flemmingsche Lösung und Pikrinsalpetersäure sind die besten für die Milchdrüsen verwendbaren Reagentien. Alle übrigen möchte ich nach meinen Erfahrungen widerraten, auch die Altmannsche Mischung (viertes Kapitel Nr. 36 S. 62); für ganz schlecht halte ich die sublimathaltigen Gemische. Zur Färbung wird man im allgemeinen die Methoden anwenden, welche bei den großen Verdauungsdriisen (neunzehntes Kapitel als Erfolg versprechend empfohlen wurden. Nach Fixierung in Flemmingscher Lösung sind die Anilinfarben bez. die Hämatoxylinlacke, nach den anderen Fixierungen Karmine, Hämatoxyline usw. zu benutzen.

\section{$\$ 175$.}

Placenta und Eihüllen. Um die Zotten der Placenta foetalis darzustellen, schüttle man diese in Wasser; bei Nachfärbung in einem Karmin kann in Glyzerin oder Glyzeringelatine dauernd aufbewahrt werden. Zur Fixierung, die beim Studium über die Bildung der Placenta unerläßlich ist und wobei es sich empfiehlt, die Lteruswand mit einzulegen, sind in erster Linie Foàsche Lösung (viertes Kapitel Nr. 22 S. 54) und Sublimat zu empfehlen, in zweiter Linie Müllersche Lösung, die wochenlang einwirken muß, und endlich die salpetersäurehaltigen Gemische. Zur Färbung der von paraffiniertem oder celloidiniertem Material angefertigten Schnitte sind Eosin-Hämatein, Orange G-Hämatein und die Weigert-van Giesonsche Färbung zu empfehlen. Eosin-Methylblau achtes Kapitel' soll die Blutgefäße spezifisch gefärbt hervortreten lassen.

Die Eihüllen werden nach den für das Bindegewebe geeigneten Methoden untersucht oder nach belicbiger Fixierung im Schnitt heliebig gefärbt. 


\section{Anhang zum einundzwanzigsten Kapitel.}

\section{Eier und Embryonen.}

$$
\S \text { I } 76 .
$$

Die Untersuchung frischer Eier, die Fixierung dieser Gebilde und die Untersuchung an Embryonen haben im Laufe der Zeit eine Technik gezeitigt, die sich rielfach nicht unbedeutend von jener Technik unterscheidet, welche wir bisher kennen gelernt haben und die für die Untersuchung der Gewebe und Organe erwachsener Tiere crsonnen ist. Mit Recht hat daher dieser Teil der mikroskopischen Technili cine Zusammenfassung in besonderen Lehrbiichern gefunden, von denen das "Handbuch der embryologischen Technik von Röthig an erster Stelle zu nennen ist. Spezialinteressenten seien daher auf das genannte Buch verwiesen. Hier sollen nur die hauptsächlichsten Methoden, gewissermaßen nur die Leitmotive der embryologischen Technik angefuihrt werden.

Die frischen Eier der Evertehraten werden bei Wassertieren entsprechend in Salz- oder Süßwasser, bei Landtieren in physiologischer Kochsalzlösung untersucht. Eine durartige Lntersuchung hat natiolich nur Zweck, wenn die Eicr völlig durchsichtig sind, wie z. B. hei Echinodermen und Tunicaten, oder wenn man im auffallenden Lichte an befruchteten undurchsichtigen Eiern die Furchung betrachten will. Besondere Schwierigkeiten hat dic Untersuchung der frischen Eier der Meeres-Gastropoden, namentlich der P'rosohranchier, ferner der Cephalopoden und der Hirndincen, weil e's kaum möglich sein diirfte, die Fier unverletzt aus ihren verschiedenartigen Hiillen herauszupräparieren.

Frische Vertebrateneier zu untersuchen ist ebenfalls mit großen Schwierigkeiten verknipft. Nur die Eier der Säugetiere und einiger Teleostier z. 13. Uranoscopus sind durchsichtig genug, um in unzerkleinertem Zustande, d. h. ohne in Schnitte zerlegt zu sein, mikroskopiert werden zu können. Ton Teleostiern, namentlich des Mecres, findet man zu den Zeiten der Eiablage im Auftrieb häufig genug befruchtete Eier, die man bequem betrachten kann. Bei Säugern muß man vorsichtig einen Graafschen Follikel durch Einstich öfnen, den Inhalt auf einem Objektträger auffangen und einen Tropfen physiologischer Kochsalzlösung zusetzen. Während man an gecigneten 
Telcostiereiern erentuell Furchungsstadien wird sehen können, ist dies bei Säugern natïlich ausgeschlossen.

Die Eier der Amphibien, soweit diese nicht vivipar sind, besitzen wenig Durchsichtigkeit, ebenso die Eier der meisten Teleostier. Die Betrachtung der frischen befruchteten Eier gibt daher nur Oberflichenbilder der Furchung, aber keine tieferen Einblicke.

Bei Selachiern und Sauropsiden ist eine mikroskopische Betrachtung, die ehenfalls nur Oberflächenbilder auch am durchsichtig gemachten Objekte liefert, nur ausfïhrbar, wenn man die Keimscheibe von dem Dotter abpräpariert hat.

\section{$\S 177$.}

Fixierung. Bei Evertebrateneiern und -Embryonen richtet sich natirlich die Fixierung nach der Beschaffenheit des Eies. Ein Hirudineenei mit seinen zahlreichen Schalen bedarf einer ganz anderen Behandlung; als das zarte durchsichtige Echinidenei vol. hierzu das Buch von Röthig!. Bei letzteren sind Pikrinessigsäure, Chromessigsäure, Bouinsche Fliissigkeit angebracht (rgl. viertes Kapitel): Reagentien, die für alle diejenigen Eier geeignet sind, welche durchsichtig sind. und die keine schwer abpräparierbaren Hüllen besitzen. Zur Fixierung der Nematodeneier sind die Fliissigkeiten von van Beneden, Carnoyund Zacharias ganz besonders geeignet viertes Kapitel. Selbstverständlich gelten alle diese Vorschriften nicht bloß für die Eier sondern auch fiir die Embryonen, so lange deren Entwicklungsgrad noch keine Präparation der einzelnen Organe ermöglicht. Ist letzteres der Fall - bei Evertebraten sehr selten -, dann werden die Fixierungsmethoden angewendet, welche sich an den Organen erwachsener Tiere bewährt haben.

\section{$\S \mathrm{I} 78$.}

Bei Vertebraten ist die Fixierung verschieden je nach dem Dotterreichtum des Eies.

Selachier und Sauropsiden haben Eier mit mächtigem Nahrungsdotter; die Fixierung des Eies (und des Embryo) erfordert daher hicr große Vorsicht. Am besten soll sein - ausgedehnte eigene Erfahrungen besitze ich hier nicht -, die in der geöffneten Eischale liegenden Eier, aus denen bei Vögeln das Eiweiß entfernt ist, mit der Fixierungsflüssigkeit zu übergießen. Ist der Nahrungsdotter hart geworden, dann hebt man den Keim oder Embryo mit einem gebogenen Hornspatel von der Lnterlage ab, fixiert zu Ende und härtet in der für das Reagens angemessenen ITeise. Zur Fixierung sind geeignet: 
die Rablschen Flüssigkeiten, Sublimat, Sublimateisessig (viertes Kapitel . Für Sauropsideneier hat Nowak folgende besondere Fixierung empfohlen: $\mathrm{I}^{\circ}$ 。 Chromsäure $\mathrm{I}_{5} \mathrm{ccm}$, gesättigte Sublimatlösung I $50 \mathrm{ccm}$, Aqua destillata $135 \mathrm{ccm}$, Eisessig $15 \mathrm{ccm}$, Formol $50 \mathrm{ccm}$. Nan fixiert 24 Stunden lang, wäscht $2+$ Stunden in fließendem Wasser aus und härtet in steigendem jodiertem Alkohol. Zur Dotterfärbung hat Peter folgende Cochenillefärbung angegeben: Io g gepulverte Cochenille werden in $250 \mathrm{ccm}$ Aqua destillata gekocht und unter stetem Umrühren auf $50 \mathrm{ccm}$ eingekocht. Dann fillt man destilliertes Wasser bis zu $150 \mathrm{ccm}$ nach und filtriert. Auf je $40 \mathrm{ccm}$ des Filtrates werden 7 Tropfen Salzsäure zugesetzt. Der hierbei entstehende Niederschlag hat sich nach 2 Tagen gesenkt. Die Farblösung wird unverdünnt angewendet und eignet sich zur Schnitt- und Stückfärbung.

Für Teleostiereier, die sehr leicht brüchig werden, ist die Mingazzinische Mischung empfohlen viertes Kapitel Nr. 58 S. 72). Folgendes von H. Virchow ersonnene Verfahren wird sehr geruhmt: Die Eier werden in eine Chromeisessig-Mischung gebracht (Chromsäure I $\mathrm{g}$, Eisessig $50 \mathrm{ccm}$, Aqua destillata $450 \mathrm{ccm}$ ), bleiben darin etwa 2 Minuten, bis sich der Keim trübt. Darauf kommen die Eier auf $\mathrm{I}_{2}{ }_{2}$ Stunden in $0,2 \%$ Chromsäure und werden in physiologischer Kochsalzlösung geöffnet. Der Dotter wird dann mittels einer Pipette abgeblasen. Dann wird der Keim in Sublimat oder Flemmingscher Lösung fixiert und wie üblich nachbehandelt.

Die Eihaut der Amphibieneier ist schwer durchdringlich und außerdem setzen auch die Schleimmassen des Laichs dem Wirken der Reagentien erheblichen Widerstand entgegen. Daher ist oft eine verlängerte Einwirkung der Fixierungsflüsigkeiten angemessen; so z. B. fixiert van der Stricht Tritoneier in Flemmingscher Lösung 5 Tage lang. Pikrineisessig, Sublimateisessig in verschiedener Kombination, Chromessigsäure, Flemmingssche Lösung sind geeignete Fixierungsmittel (vgl. viertes Kapitel). Michaelis empfiehlt zur Fixierung der Eier von Tritonen folgendes Gemisch: konzentrierte wässrige Sublimatlösung $1000 \mathrm{ccm}$, Eisessig $50 \mathrm{ccm}$, Aqua destillata $2000 \mathrm{ccm}$ konzentrierte wässrige Pikrinsäurelösung $1000 \mathrm{ccm}$. Nach beendeter Fixierung werden die Gallerthüllen abgetragen und dann erst wird in Alkohol gehärtet.

Um die Eihaut der Amphibieneier schonend zu entfernen, hat Blochmann folgende Methode ersonnen: Die in Flemmingscher Lösung fixierten und dann wie üblich ausgewaschenen Froscheier werden in ein Becherglas getan, welches eine Mischung von einem Teil 
Eau de Javelle und $3-4$ Teilen Wasser enthält. Der Laich schwimmt auf der Flüssigkeit. Von Zeit zu Zeit muß er geschüttelt werden, damit immer neue Teile von ihm mit dem mazerierenden Reagens in Berührung kommen. Nach I5-30 Ninuten sind Gallertschicht und Eihäute zerstört, die Eier liegen am Boden. Nun gießt man sehr vorsichtig, um die Eier nicht zu verletzen, die Lauge ab, wäscht sorgfältig in destilliertem Vasser aus und härtet im Dunkeln in steigendem Alkohol. Eben befruchtete Eier und junge Embryonen geben rorzügliche Resultate; bei älteren Stadien muß vor der Mazerierung die Eihaut gesprengt werden.

Säugetiereier sind im Ovarium oder nach geschehener Befruchtung in den ausfuhrenden Wegen (Tubae, Uterus) zu fixieren. Die bisher genannten Fixierungsmittel sind auch hier anzwenden (vgl. das Buch von Röthig).

\section{§ I 79.}

Hinsichtlich der künstlichen Befruchtung wird auf das weiter oben (beim Sperma) Gesagte verwiesen. Mit Sorgfalt ist darauf zu achten, daß nach eingetretener Befruchtung - man erkennt sie leicht an der abgehobenen Eihaut - das Wasser des Gefäßes, in welchem sich die Eier entwickeln sollen, völlig klar ist. Man muß also die leicht faulende Samenflussigkeit abgießen und sic durch frisches reines Vasser (salziges oder siißes) ersetzen. Dieses MTasser ist so oft zu erneuern, bis keine Trübung mehr vorhanden ist.

\section{$\S \mathrm{I} 80$.}

Die Fixierung der Embryonen verlangt die Beachtung aller der Regeln, welche allgemein für Fixierung angegeben wurden. Carnoysche, van Benedensche, Rablsche Flüssigkeit und Sublimat (viertes Kapitel) werden als fixierende Reagentien von den Embryologen bevorzugt. Solange nicht Zellteilungsformen studiert werden sollen es treten dann die im dreizehnten Kapitel beschricbenen Methoden in ihre Rechte - , sobald es sich vielmehr un Untersuchungen iiber den Aufhau des Embryo handelt, färbt man am besten die fixicrten Enbryonen im Stiick. Alauncochenille, alkoholisches Boraxkarmin, Parakarmin und Hämacalcium sind dic geeignetsten Färbemittel.

\section{$\S \mathrm{I} 8 \mathrm{I}$.}

Die im zwölften Kapitel geschilderte plastische Rekonstruktion findet in der Embryologic die ausgedehnteste Anwendung. Diese 
Abbildungsmethode hat in dem bereits erwähnten Buche von Röthig eine eingehende Beschreibung gefunden; ferner ist einzusehen das Buch von Peter: Die Methoden der Rekonstruktion.

\title{
Zweiundzwanzigstes Kapitel.
}

\section{Zentrales Nervensystem.}

\author{
$\S 182$.
}

Orientierende Vorbemerkung. Die beiden letzten Jahrzehnte neurohistologischer Forschung standen unter dem Einflusse dreier Methoden: der Weigertschen Hämatoxylinfärbung, der Golgischen Chromsilberimprägnation und der Ehrlichschen Methylenblaumethode. Angeregt durch die interessanten Resultate, welche jede dieser Methoden bei nur einigermaßen geschickter Anwendung liefert, haben sich immer wicder neue Scharen von Histologen der Erforschung des Zentralnervensystems gewidmet; sodaß selbst die Zahl der cytologischen Arbeiten geringer ist als die Zahl jener Publikationen, welche über das Nervensystem handeln. Verwunderlich ist diese Erscheinung nicht. Die Weigertsche Methode liefert uns die beste Handhabe, den zentralen Verlauf der Nervenfasern zu verfolgen; das Golgische Verfahren zeigt uns die Verästigungen der Ganglienzellen in einem Lmfange, wie er vorher nicht einmal geahnt wurde, und das Methylenblau fuihrt uns feinstes Strukturdetail vor Augen.

Freilich ist mit dieser Wertschätzung auch mancher Übelstand verbunden, zum Beweise der Richtigkeit des Satzes: wo viel Licht, da viel Schatten. Teils nämlich hat sich die Begeisterung fuir die Methoden in einer Polypragmasie geäußert, welche dem niichternen Zuschauer bedenklich erscheinen muß. Jeder noch so kleine Kunstgriff, den Jemand anwendet, wird als große, wertrolle Modifikation der Hauptmethode ausposaunt, wahrend er bei näherem Zusehen wertlos erscheint. Teils ist dic Mertschätzung in cine Überschätzung der Leistungen der Methoden entartet. Ein wertloser Kunstgriff z. B. ist die subkutane Anwendung des Methylenblau, denn auch nicht einen Vorteil bietet diese Art der Anwendung gegeniiber den iblichen Verwendungsweisen des Methylenblau. Eine Überschätzung tritt ganz besonders bei der Golgischen Methode in die Erscheinung; aber 
diese von den verschiedensten Forschern gerügte Kritiklosigkeit hat bis jetzt noch kein Eindämmen der "Silberflut " bewirkt. Den glän-

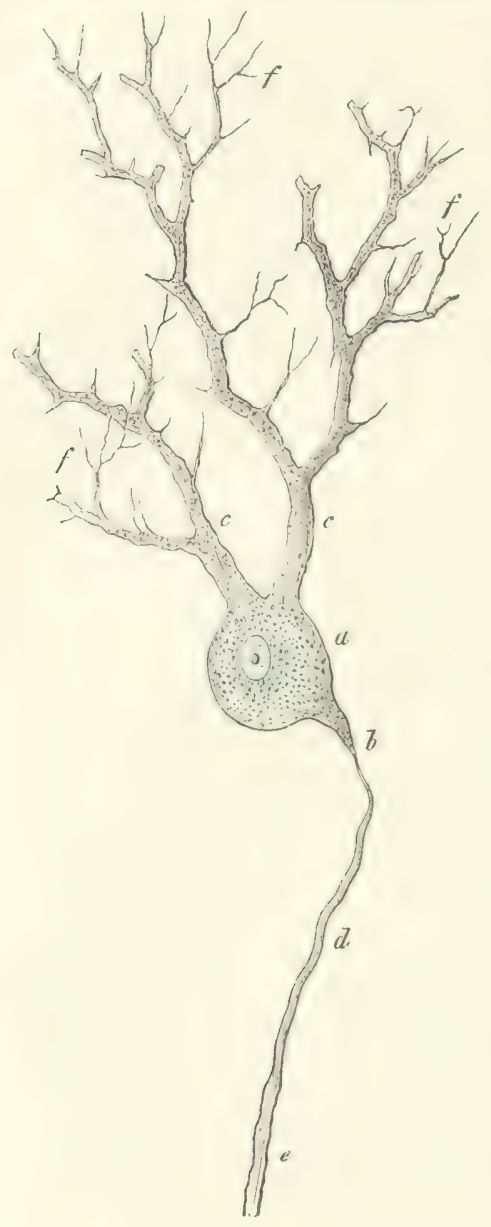

Fig. 17. Eine Purkinjesche Ganglienzelle aus dem Cerebellum des Menschen. $a$ Zelle; $b$ Spitzenfortsatz; $c$ Hirschgeweihartige Ausläufer mit feinsten Ästen $f$; $d$ Achsenzylinder; $\ell$ Nervenfaser ( $d$ und $e$ vom Hunde ergänzt). zenden Resultaten gegenuiber, welche mit der Golgischen Methode erzielt werden können, wird ganz übersehen, daß die Chromsilberbilder uns niemals gelehrt hätten, was eine Ganglienzelle eigentlich ist und wie sie in Wirklichkeit aussieht. Man vergleiche nur die beiden beigegebenen Figuren 17 und 18. Daß jene eine Zelle darstellt und eine Purkinjesche Zelle, erkennt zwar selbst der Anfänger. Daß diese ebenfalls eine Purkinjesche Zelle ist, muß selbst dem Geuibteren erst gesagt werden; denn nichts in diesem schwarzen Stromgebiete erinnert an eine Zelle. Ohne auch nur andeutungsweise das große Verdienst von Golgi anzweifeln zu wollen: darauf hinzuweisen, worauf ich schon frïher bei einer anderen Gelegenheit hingerviesen und worin ich einig bin mit Forschern wie Bethe, Benedikt Friedländer, Nissl, Krause u. a., nämlich daß die Resultate der Golgischen Methode durchaus nicht die absolute Sicherheit besitzen, welche ihr ihre Verehrer zuschreiben, halte ich für meine Pflicht. Vorsicht in der Beurteilung der Präparate, Vorsicht in der theoretischen Verwertung der Silberbefunde ist dringend geboten. Außerdem haben alle Versilberungen den Fehler, daß die versilberten Elemente viel größer, viel voluminöser erscheinen, als sie in Wirklichkeit sind. Das Silber färbt nicht, sondern schlägt sich auf Ganglienzellen, Gefiißen, Fibrillen usw. nieder, bildet um die Gewebsbestandteile gewisscrmaßen einen metallischen Mantel. Diese Tatsache ist von den Silberleuten: wenig oder gar nicht beachtet wor- 
den, sie ist aber von großer Bedeutung, will man nicht kritiklos der eigenen Methodik gegenüberstehen.

Natürlich sind seit dem Aufkommen jener drei Methoden die alten Mazerationsmethoden völlig vernachlässigt worden, denn das Arbeiten mit ihnen ist miihsamer und zeitraubender als das Anfertigen von Schnitten. Und doch sollte man sie nicht völlig bei Seite lassen, namentlich wenn es sich um zentrales Nervensystem von Evertebraten handelt. Bei diesen leisten gelungene Isolationspräparate oft mehr als

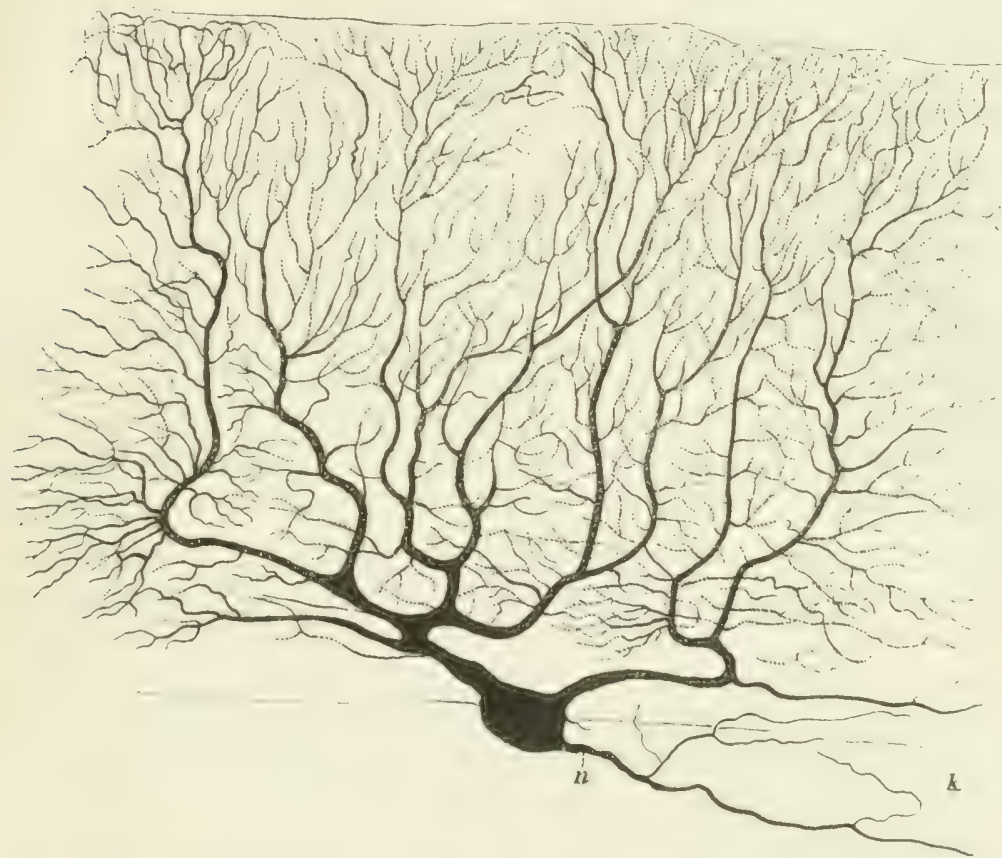

Fig. I8. Purkinjesche Zellen aus der Rinde des Kleinhirns, mit stark verästelten Dendriten nach Kölliker. $n$ Nervenfortsatz. $k$ Collateralen desselben.

die feinsten Schnitte von best fixiertem Material. Und man sollte nicht vergessen, daß wir nur den Mazerationen die schönen Resultate von Deiters verdanken, ohne welche wir kein Verständnis für den Aufbau des Zentralnervensystems erlangt hätten. Ja manche von den Befunden, welche Deiters gemacht, sind dank der neueren Technik verschollen, weil sie mit den modernen Methoden des Schneidens usw. nicht wieder zu erhalten sind. So z. B. hat Deiters an den Protoplasmafortsätzen, den heutigen Dendriten, der motorischen Riickenmarkszellen sckundäre Achsenzylinder (feine Achsenzylinder) gezeigt, von denen dic heutige Neurohistologie nichts mehr weiß. Weder 
Chromsilber noch Methylenblau zeigen sie und doch müssen sie vorhanden sein, sonst hätte sie Deiters nicht abgebildet. Darum rate ich jedem Anfänger, sich einzuiiben, gute Isolationspräparate rom Zentralnervensystem anfertigen zu können, und ich rate jedem Forscher, wenn er an das Studium von Gehirn und Rückenmark histologisch bisher vernachlässigter Gruppen geht, nach Möglichkeit mit Nazerationen anzufangen.

In der Darstellung der zur Untersuchung von Gehirn und Ruickenmark empfohlenen Methoden werde ich folgende Einteilung machen. Zunächst sollen die Mazerationsmethoden beschrieben werden. Dann folgen die Methoden der Fixierung und Färbung, soweit diese geeignet sind, die Textur der Zentralorgane klar zu machen, während die Methoden, welche den feineren Bau der Ganglienzellen, die Verästigung dieser, den zentralen Verlauf der Nervenbahnen und die Neuroglia zur Anschauung bringen, in einem späteren Abschnitte Unterkunft finden sollen. Dieser spätere Abschnitt ist der dann folgende. Er enthält die Spezialmethoden, und zwar die verschiedenen Metaliimprägnierungen, die Osmium-, die Methylenblau-Methoden, die Verwendung anderer Aniline und die Hämatoxylinfärbungen. Daran schließen sich die Neurogliamethoden und endlich folgen die Methoden zur Untersuchung der Hüllen des Zentralnervensystems.

a) Mazerationsmethoden.

$$
\S 183 .
$$

Für das Nervensystem der Vertebraten und in erster Linie für das der Säuger sind ron klassischer Bedeutung die von Deiters benutzten und empfohlenen Kali bichromicum-Terdunnungen (drittes Kapitel Xr. 15 S. 26:. NIan muß zur Erreichung guter Isolationspräparate sorgfailtig darauf achten, daß nicht zu viel Flüssigkeit genommen wird, damit das Reagens nicht crhärtet. Und ferner darf man nicht zu roluminüse Stücke von Gehirn und Rückenmark mazerieren. Diese Organe lassen die Nazerationslösungen sehr schwer eintreten, sodaß bei zu großer Masse nur die peripheren Teile der mazerierenden Mirkung ausgesetzt sind, während das Zentrum des Stiickes fault. Fäulnis aber ist keine Mazeration. Die Vollendung der Mazeration mul durch wiederholtes Probieren festgestellt werden. Ein Zerfall der Hirn-oder Riickenmarkstiiclie in ihre Elementarteile, wie er z. B. bei dur Drüisenmazeration sich crziclen läßt, ist nicht zu erreichen, dazu ist die Neuroglia zu widerstandskraffig. Aber nur geringe Nuihe braucht bei gelungener Mazeration angewendet werden, um ein Stückchen grauer Substanz so zu zerzupfon, chals die einzelnen Ganglienzellen völlig isoliert sind. 
Man tut gut, das mazerierte Objekt vor dem Zerzupfen durchzufärben und benutzt dazu entweder ein Pikrokarmin und ein verduinntes Hämatein (achtes Kapitel). Nan zerzupft in verdünntem Glyzerin, in welchem zugleich aufgehoben wird.

Lavdowsky mazeriert Amphibien-Rückenmark entweder in ${ }_{1 / 3}$ Alkohol oder in Landois-Gierkescher Fluissigkeit (drittes Kapitel). $\mathrm{Zu}$ je $10 \mathrm{ccm}$ des ersteren Reagens fügt er 5- Io Tropfen wässriger Lösung von Magdalarot $\left(\mathrm{I}^{\circ}, \mathrm{o}\right)$ oder $0,5^{\circ}$, bis $1^{\circ},{ }^{\circ}$ wässriger Lösung von Methylenblau II. Wird ${ }_{13}$ Alkohol verwendet, so wird ihm, wie gesagt, der Farbstoff zugesetzt; mazeriert man in LandoisGierkescher Flüssigkeit, so wartet man die Vollendung der Nazeration $a b$, wäscht zweimal aus und färbt dann im Stiick. Bei Mazeration in ${ }^{\mathrm{I}}$. Alkohol + Magdalarot wird in dieser Lösung zerzupft, zu der auf dem Objektträger I Tropfen $0,5 \%$ \% OsmiumsäureLösung zugesetzt werden muß. Bei schonendem Absaugen der Zupfflüssigkeit kann in Kanadabalsam eingeschlossen werden. Ist zur Färbung Methylenblau II verwendet worden, so kann mit wässriger Fuchsin- oder Safraninlösung nachgefärbt werden.

Langerhans hat bei Amphioxus eine Isolicrung des Nervensystems auf folgende Weise erhalten: Er legt die Tiere fuir 3 Tage in $20^{\circ}$. Salpetersäure, bringt dann für I Tag in IVasser und schüttelt nach dieser Zeit tüchtig. Das bewirkt eine Isolierung des ganzen Nervensystems, aber nicht eine derartige Mazeration, wie sie zum Studium der einzelnen Elemente erforderlich ist.

Bei Evertebraten - ich besitze eigene Erfahrungen nur über das Zentralnervensystem der Mollusken, Crustaceen und einiger Anneliden - sind ${ }^{\mathrm{I}}{ }_{+}$Alkohol, ${ }_{6}{ }_{6}$ Alkohol, die Nethode von Buchholz, $O, I^{\circ}$. Kali bichromicum-Lösung und sehr verdünnte Pikrinsäure zu empfehlen (drittes Kapitel). Man kann wie nach Mazeration von Vertebraten-Rückenmark nachfärben und in verdünntem Glyzerin aufheben. Möglicherweise geben die oben erwähnten Methoden von Lavdowsky - Färbung mit Magdalarot oder Methylenblau - gute Bilder.

b) Fixieren und Färben.

$$
\text { \$ } 184 \text {. }
$$

Vorbereitung. Das Zentralnervensystem der Vertebraten erfordert eine unter Umständen recht sorgfältige Vorbereitung zur Fixierung, damit die angewendeten Reagentien gut und gleichmäßig eindringen, damit der Untersuchende iiber die zu untersuchenden Teile orientiert ist, usw. 
Beim Amphioxus dürfte es sich empfehlen, das Medullarrohr in situ zu studieren. Nan fixiert daher das ganze Tier und macht Schnitte durch den ganzen Körper. Zur Fixierung dirften Sublimat, Pikrinessigsäure, Pikrinsalpetersäure oder ähnliche Reagentien sich empfehlen.

Bei den Cyclostomen ist es ratsam, in situ zu fixicren. dann aber, vor beendeter Härtung, das fixierte Zentralnervensystem aus seiner Kapsel heraus zu präparieren. Man öffnet vorsichtig die Schädelkapsel und die Wirbelsäule, die man beide von den unter ihnen liegenden Organen befreit hat. U'm V'erkrümmungen zu vermeiden, diirfte es sich empfehlen, das in der genannten Weise präparierte Nervensystem in einem hohen Standgefäße aufzuhängen und seine untere Partic durch ein angehängtes Bleigewicht zu beschweren. Dieses Standgefä $\Omega$ ist mit der Fixierungsflüssigkeit zu füllen.

Bei den übrigen Vertebraten ist folgendermaßen zu verfahren:

Das Rückenmark wird sorgfältig aus dem Wirbelkanal herauspräpariert. Nertvoll ist es, die Dura mater dabei nicht anzuschneiden. Hat man die Wirbelbögen weit genug weggebrochen, dann kann man auch die Wurzeln mit den Spinalganglien mit der Nedulla zugleich herausschneiden: eine allerdings mühsame und zeitraubende Arbeit. An dem herauspräparierten Rückenmarke schneidet man dorsal mit einer Schere die Dura der Länge nach auf. Mit einem scharfen Rasiermesser teilt man nun das Rückenmark in zwei bis drei Abteilungen, wobei schr sorgfältig darauf zu achten ist, daß die Dura ventral nicht durchschnitten wird. Ist das Rückenmark zu lang; um in einem einzigen Gefäße fixiert werden zu können, z. B. bei Schlangen und großen Säugern, dann muß man es natürlich in mehrere Abschnitte zerlegen. Die Teilungsschnitte wercen quer zur Längsachse des Rückenmarki's ausgefuihrt. Solcher Art vorpräparierte Rückenmarke hängt man, wie es vorhin für Cyclostomen angegeben wurde, in angemessener Weise in einem Standgefäße auf, beschwert die nach unten hängenden Enden und füllt das Gefäß mit der Fixierungsflüssigkeit.

Oder - und so verfahre ich - man zerlegt der Quere nach das Rückenmark in höchstens $2 \mathrm{~cm}$ lange Stiicke, welche untereinander durch die rentral unverletzte. dorsal aufgeschnittene Dura mater zusammenhängen. Solche Rückenmarke kann man in tiefen Schalen oder in hohen Standgefäßen fixieren und braucht sie in letzteren nicht zu beschweren. Denn die hie und da sich einstellende Krümmung ist geringfigig und kommt auch aus folgendem Grunde nicht in Betracht. $2 \mathrm{~cm}$ hohe Stiicke kann man in Celloidin nicht schnei- 
den, weil bei dem relativ geringen Dickendurchmesser des Rückenmarkes derartig hohe Objekte beim Schneiden federn und daher zur Sicherung einer ruhigen und gleichmäßigen Schnittführung in circa 3 Teile zerlegt werden müssen. Damit aber wird die Krimmung ausgeglichen. In Paraffin soll man ebenfalls so hohe Rückenmarksstücke nicht einschmelzen. An den meisten für Paraffinmaterial geeigneten Mikrotomen erlaubt die Mikrometerschraube, mit der das Präparat in die Höhe gehoben wird, keine derartig hohen Objekte. Und will man feucht ohne Linbettung oder mit dem Gefriermikrotom schneiden, so federt in ersterem Falle ein $\mathrm{I}-2 \mathrm{~cm}$ hohes Präparat zu stark, ist daher unschneidbar oder, im letzteren Falle, gefriert nicht.

Sorgfältig ist heim vorbereitenden Zerteilen des Rückenmarkes in viele Stücke auf den Ort zu achten, wo man die Querschnitte anlegt. Da, wo die Vervenwurzeln eng stehen, muß man den Querschnitt immer dicht vor dem Wurzelaustritte anlegen. Da, wo sie weit stehen, wie am Dorsalmark; legt man die Schnitte am besten in der Mitte zwischen den Wurzelaustritten an. Auf alle Fälle muß man wissen. wo man cingeschnitten hat, weil man sonst bei dem aus seiner Lage entfernten Riickenmarke keine Möglichkeit zur Oriuntierung hat.

Es ist selhstverständlich, daß die Schnitte genau quur zur Längsachse des Rückenmarkes gemacht werden, was hei einiger Aufmerksamkeit leicht gelingt. Im besten sind für derartige Zerteilungen solche Messer, die keinen zu dicken Rücken haben, also etwa Messer, wie sie die Schlächter zum Zerschneiden der Fleischwaren (Wurst usw: anzuwenden pflegen.

Die Gehirne kleiner Vertebraten (Teleostier, Amphibien, Mïuse usw:) können unzerkleinert in die Fixierungsflussigkeit kommen. Selbstierständlich muß die Dura rorher entfernt sein. Bei größeren Gehirnen, wenn diese noch frisch sind, ist ebenfalls ein Einbringen der unzerteilten Organe in dic Fixierungsflüssigkeit angüngig. Freilich muß man dann darauf verzichten, Strukturdetails zu erhalten, nur eine topographische Untersuchung, d. h. die Erkennung der Art und Verteilung, der Ganglienzellen und des Verlaufes der Nervenbahnen, wird auf diese Weise zu erzielun scin. Zur Fixierung ganzer Guhirne sind nur solche Reagentien zu gubruuchen, welche wie Müllersche Fliissigkeit, nicht Formol, nebun der fixierenden zugleich eine erhärtende Wirkung ausuiben. Bloß fixierende Reagentien - Sublimat, Filemmingsche Lösung usw. - sind zu vermeiden.

Oft aber ist es notwendig, namentlich für Strulkturstudien und Degenerationsuntersuchungen, das Gehirn in cinzelne Abschnitte quer 
zu seiner Längsachse zu zerlegen. Das ist nicht leicht, wenn man es aus freier Hand tun will. Daher empfiehlt es sich, einen von Starlinger konstruierten Apparat zu benutzen, welcher die Zerlegung sclbst größerer Gehirne in planparallele Scheiben gestattet. (Die Beschreibung dieses Apparates gehört nicht hierher.)

Für alle Fixixierungsweisen hat man sich zu merken, daß die Pia mater nicht entfernt werden darf. Bei der relativen Zartheit von Gehirn und Rückenmark würde die Abtragung der Pia tiefgreifende Verletzungen machen. Nach der Fixierung ist es bei Celloidin- und Paraffineinschmelzung nicht nötig, die Pia abzuziehen; bei feuchtem Schneiden ohne Einbettung ist es zu widerraten, weil die Pia die nicht zusammenhängenden Teile, z. B. an der Medulla oblongata, zusammenhält. Nur bei Anwendung des Gefriermikrotoms muß die Pia sorgfältig abgezogen werden, da ihre Anwesenheit das Gefrieren direkt hindert.

Für das Zentralnervensystem der Evertebraten lassen sich Regeln nicht aufstellen. Im allgemeinen sind die Organe klein und selbst relativ voluminöse Gebilde, wie das Gehirn der Cephalopoden, durchtränken sich leicht. Ich glaube, es ist dies eine Folge des Mangels an Nervenmark, denn dieses setzt bei Vertebraten dem Eindringen der Reagentien einen erheblichen Widerstand entgegen. Eine Zerlegung der Nervenmassen in einzelne Teile ist daher nicht nötig. Andererseits dürfte es sich vielleicht empfehlen, das Zentralnervensystem erst dann heraus zu präparieren, wenn es durch das fixierende Reagens eine etwas derbere Konsistenz crlangt hat, als es sie in frischem Zustande besitzt.

\section{S 185 .}

Fixieren. Die in diesem $\S$ empfohlenen Fixierungsmittel sollen nur dazu dienen, das Zentralnervensystem für Texturstudien vorzubereiten. D. h. wer die Absicht hat, die Verteilung von grauer und weißer Substanz zu untersuchen, die Ganglienzellanhäufungen, ihre Formen, ihre Beziehungen zu aus- und durchtretenden Nerven zu studieren, der bediene sich einer der folgenden Methoden. Alle anderen Methoden, auch diejenigen, welche den Verlauf der Nervenbahnen verfolgen lassen, werden in Abschnitt c dieses Kapitels I\$ Igo bis $\S 203$ inkl.) ausführlich geschildert werden.

Absoluter Alkohol, Formol mit und ohne Kali bichromicum-Nachbehandlung, Mïllersche Flüssigkeit, Jod-Alkohol nach Betz sind die einzigen fuir den genannten Zweck brauchbaren Methoden. Alle übrigen Fixicrungsmittel sind nach meinen sehr ausgedehnten Erfah- 
rungen völlig wertlos. Entweder dringen sie nicht ein, wie die Flemmingsche Lösung, oder sie machen Schrumpfungen, wie Sublimat. Auch die von Mann geiibte Methode, von den Carotiden aus die Gefaße des Gehirns mit Sublimat zu injizieren und so die Fixierung einzuleiten, sieht mehr nach Exaktheit aus, als daß sie exakt ist. Denn die Fixierungsresultate sind darnach genau so schlecht, wie wenn man einzelne Stücke Gehirn in Sublimat fixiert hätte. Die meisten Zellen der Hirnrinde sind geschrumpft oder von den ausgeschiedenen Sublimatkristallen durchlöchert und die Nervenfasern sind stets ungleichmäßig geschrumpft.

I. Jod-Alkohol, nach Betz. Diese zurzeit nur noch wenig geübte Methode sei wieder der allgemeinen Aufmerksamkeit empfohlen. Offenbar erleichtert der Jod-Alkohol, d. h. die Jodierung, das nachherige Eindringen des Kaliumbichromat und ermöglicht eine so ausgiebige Fixierung und Härtung; daß die auf solche Weise behandelten Objekte sich ohne Einbettung sehr bequem schneiden lassen. Man nimmt $80 \%$. Alkohol, dem man so viel offizinelle Jodtinktur zusetzt, daß er hellbraun erscheint. Dahinein hängt man in hohem Standgefäß乃 Rückenmark, während man Kleinhirn und Großhirn auf Watte legt. Nach drei Tagen soll man die Arachnoidea und Pia entfernen, was durchaus nicht absolut notwendig ist. Dem sich entfärbenden Alkohol — das Jod geht in die Organe - setzt man von Zeit zu Zeit Jod zu, damit die ursprügliche Farbe wieder hergestellt wird. Die Vorschrift lantet nun, da $B$ die Jodierung 6 Tage dauern soll. Selbstverständlich hat diese Zeitbestimmung keinen absoluten Wert, ja ist nicht einmal approximativ richtig. Die Dauer der Jodbehandlung wird sich darnach richten, wie lange Zeit erforderlich ist, um das zu fixierende Objekt völlig bis ins Zentrum zu jodieren. Und dieser Zeitpunkt wird natürlich variieren, je nach der Permeabilitiit des Objektes, nach dem Volumen des zu fixicrenden Stückes und nach der Quantität der angewendeten Flüssigkeit. Nach beendeter Jodierung wird in Kali bichromicum-Lösung übertragen und zwar bringt man Rückenmark in $3^{\circ}$, Großhirn in $4^{\circ}$ und Kleinhirn in $5^{\circ}$. Lösung des Chromsalzes. Bei Reptilien, Amphibien und Fischen reicht die $3 \%$ Lösung aus. Ist die Chromicrung beendet, was man durch Einschnitte feststellen kann, dann wird in Wasser gewaschen und schließlich in ${ }_{12}^{2} \%$ Kali bichromicum-Lösung aufgehoben. Nachhärten in Alkohol ist unnötig und bei beabsichtigter Karminfärbung zu widerraten, da ammoniakalisches Karmin nicht gern an Alkoholmaterial herangeht.

2. Müllersche Flüssigkeit. Dieses alte Mittel ist noch immer 
eines der besten Fixierungs- und Härtungsmittel, welches wir für das zentrale Nervensystem aller Tiergruppen, Vertebraten und Evertebraten, besitzen. Freilich erfordert selbst bei kleinen Objekten, wie z. B. oberes Schlundganglion von Astacus, die Fixierung mehrere WVuchen. Bei großen Säugetiergehirnen sind Monate erforderlich, ehe die richtige Schnittkonsistenz erreicht wird; für ein unzerteilt eingelegtes Menschenhirn bedarf es zur Vollendung der Fixierung und Hairtung mindestens I Jahr. Ist die Fixierung beendet, so kann man in gewöhnlichem Wasser grïndlich auswaschen und in Alkohol von steigender Konzentration nachhärten. Oder man bringt sofort in $\mathrm{g}^{\circ}$ 。 Alkohol ein und stellt ins Dunkle (vgl. viertes Kapitel).

3. Formol. Die $10^{\circ}$ 。 Formollösung ist das zurzeit beste Fixierungsmittel für alle Ticrgruppen, härtet aber nicht zugleich, so daß zur Anfertigung von Schnitten das Naterial nachgehärtet werden muß. Man kann in 10 . Formol eingebrachte Objekte - ich spreche hier selbstrerstïndich nur ron normalem Zentralnervensystem - unbegrenzt linge aufheben. Man muß nur folgende 3 Einzelheiten bzw. Vorsichtsmaßregeln bei der Fixierung beobachten, wenn man tadellosen Erhaltungszustand des Materials beansprucht. Dic Oberfläche ron Gehirn und Rückenmark muß ron etwaigen Blutkoagulis gut gereinigt sein, denn Blutungen unter cier Pia halten nach meinen Erfahrungen das Eindringen des Formols etwas auf. Nan muß riel Flissigkeit nchmen und diese in den ersten 24 Stunden cinmal wechseln. Für Gehirn ist es ratsam, auf den Boden des zur Aufnahme der Flüssigkeit bestimmten Gefäß3es etwas Watte zu legen, damit das Organ sich nicht platt druicht. Beachtet man diese 3 Vorsichtsmaßregeln, dann crhält man in der Tat tadelloses Material. Je nach der Größe des zu fixierenden Objektes richtet sich die Zeit, die mindestens rergehen muß, che man Schnittpräparate anfertigen kann; nach meinen Erfahrungen sind selbst bei einem so kleinen Objekte wite oberes Schlundganglion rom Flulkrebs 2 Tage als Ninimum der Fixierungsdauer anzusehen.

Wenn hie und da sich Angaben finden, daß die einzulegenden Stiicke nicht mehr als $5 \mathrm{~mm}$ dick sein und nur + Tage in Formol bleihen düfen, so handelt es sich dabei offenbar um pathologisches Material. Denn cine derartige Angabe für normales Naterial wäre geradezu sinnlos.

Will man Formolmaterial ohne weitere Nachhärtung in Chromsalzen schneiden, so muls man in Alkohol ron $05^{\circ}$ o einbringen. Beror das geschieht, ist es wichtig, die Y'ia mater zu entfernen, sonst dringt cler Alkohol nicht gleichmaing genug ein. Man nehme viel Fïissigkeit 
und wechsle den Alkohol in den ersten Stunden wiederholt; auch sollte man erst nach + sstündiger Alkoholeinwirkung schneiden, denn früher ist die Härtung kaum beendet. Wenn es sich nicht um die Anfertigung von Gefrierschnitten handelt, die einer Vorhärtung in Alkohol bedürfen, sollte man die reinen Formolpräparate nicht rerwenden. Denn die Färbung wird nachher, auch wenn man die Schnitte noch so lange gewässert hat, eine sehr ungleiche; die einen Schnitte färben sich gut, die anderen fast gar nicht, oft genug sind bei Rückenmarksmaterial die peripherste Zone des Narkes und die graue Substanz intensiv gefärbt, während die Hauptmasse der weißen Substanz keine Spur von Farbe angenommen hat.

Marcus fixiert in $\stackrel{\circ}{=}$ o Formol $5 \mathrm{~mm}$ dicke Rückenmarkstücke $2-4$ Wochen lang, bringt dann für eine Woche in Miillersche Fliissigkeit bei $37^{\circ} \mathrm{C}$. und härtet in $45^{\circ}$. Alkohol. Die Vorbehandlung in ${ }^{\prime}: \circ$ Formol kann ich nicht für sehr sinnreich halten, sie grenzt beinahe an eine mazerierende Verdiinnung. Andererseits bietet die ron Lachi angewandte Konzentration ron $20^{\circ}$ o keinen Vorteil vor der gewöhnlich angewandten $10^{\circ}$ 。 Lösung, nur daß sie nach meiner Erfahrung noch mehr die Farbungsmöglichkeit der Schnitte alteriert. Auch die ron van Gieson verwendeten $t^{\circ}$, und $6{ }^{\circ}$, Formollösungen haben keinen Vorteil vor der $10 \%$ voraus.

Die Tatsache, daß Formol allein dem Zentrainerensystem keinen geniigenden Härtungsgrad verleiht, hat viele Forscher dazu veranlaßt, dieses treffliche Fixierungsmittel mit Chromsïure und ihren Salzen zu verbinden. Schon im vierten Kapitel wurde hervorgehoben S. 47), laß diese Mischungen wenig rationell sind. Sie müssen immer frisch bereitet werden, was an und für sich kein Ungliick ist; aber sie zersutzen sich während ihrer Fixicrungswirkung, und das ist ein großer Nachteil. Immerhin mögen hier einige der für das Zentralnervensystem gegebenen Vorschriften folgen. Marina fixiert in: $5 \mathrm{ccm}$ Formol, roo ccm 90 Alkohol, welcher Lösung o, I g Chromsäure zugesetzt wird. Täglich wird die Flüssigkeit erneuert, nach beendeter Fixicrung wäscht man in $45^{\circ}$. Alkohol aus und schneidet, ohne einzubetten. Orth härtet in einem Gemisch ron I Teil Formol und Io Teilen Miillerscher Fliissigkeit. Diese Orthsche Fliissigkeit rerdirbt schr leicht; dic Härtung ist zudem leine vollkommene, da in Miillerscher Fliissigkeit nachgchärtet werden muß. Die Schnitte werden in $0,5 \%$ Chromsäurelösung gebeizt.

Kopsch gibt folgende Vorschrift, die allerdings für die Golgische Chromsilbermethode empfohlen ist, aber auch für allgemeine Härtungszwecke dienen kann: to ccm einer $3,5^{\circ}:$ Kali bichromicum- 
Lösung werden mit ro $\mathrm{ccm}$ Formol vermischt. In die jedesmal frisch bereitete Nischung kommen die Objekte und zwar muß man für je $2 \mathrm{ccm}$ Substanz $50 \mathrm{ccm}$ Fliissigkeit nehmen. Nach $2+$ Stunden wird in reine, d. h. nicht Formol-haltige, Kali bichromicum-Lösung ron $3,5^{\circ}$ 。 übergeführt. Die weitere Dauer der Chromierung hängt von den gew ünschten Resultaten ab; bei allgemeinen Texturstucien wird man. wie ich nach meinen bei anderer Verwendungsart des Kali bichromicum gewonnenen Erfahrungen weiß, $3-4$ Wochen chromieren miissen.

Ich verwerfe alle Gemische von Formol und Chromsäure bzw. Chromsalzen und empfehle dringend die zweizeitige Fixierung: erst Formol und dann heiß konzentrierte Lösung ron Kaliumbichromat. Ich verweise hinsichtlich dieser Methode auf meine ausfiihrliche Beschreibung im vierten Kapitel unter Nr. 6 'S. 47 . Bei meinen Untersuchungen über das Rückenmark der Cetaceen habe ich mit Hilfe dieser Methode ein ganzes Phocaena-Ruickenmark in eine lïckenlose Serie zerlegen können und ebenso habe ich bei einer noch nicht abgeschlossenen Arbeit über die Oblongata der Säuger damit tadellose Präparate erhalten.

Sargent fixiert Gehirne von Fischen in $10 \%$ Formol, hebt in $5^{\circ}$. Formol auf, wäscht dann, wann er das Naterial verarbeiten will, in $/$ asser aus und bringt für $2+$ Stunden in eine $5^{\circ}$. Lösung ron Kupferacetat ein. Die Einbettung geschieht in Paraffin.

Burckhardt legt bei Protopterus den Kopf in ein Gemisch von Chromosmiumsalpetersäure/viertes Kapitel. Man kann nachher, d. h. nach beendeter Fixierung, das Hirn aus der Schädelkapsel bequem herauspräparieren, wäscht I 2 Stunden in $1 \%$ Kochsalzlösung aus und härtet in Alkohol.

Für Desmognathus hat Fish folgendes Verfahren empfohlen: Fixierung in $5 \mathrm{~g}$ Sublimat, I $\mathrm{g}$ Pikrinsäure, $5 \mathrm{ccm}$ Eisessig und $100 \mathrm{ccm}$ $50^{\circ}$. Alkohol. Dauer der Einwirkung 22-2+ Stunden, Übertragen in Alkohol ron steigender Konzentration. Ein Jodieren des Objektes ist nötig.

\section{\$ 186.}

Schneiden. Material ron Zentralnervensystem kann man nach jeder beliebigen Fixierung mit dem Gefriermikrotom schneiden. Man verzichtet dabei naturlich auf eine Serienanordnung der Schnitte, erlangt aber in kurzer Zeit zahlreiche und sehr gleichmäßige Präparate. Dies ist für Färbungsstudien, für Lntersuchungen über den Aufbau der grauen Substanz und für Kurszwecke sehr angenehm. Und da in 
der genannten Richtung Zellstudien nicht liegen, so ist die Herstellung von Gefrierschritten vielfach ausreichend. Über die Art, wie man das Jungsche Gefriermikrotom gebraucht, uber die Vorteile und Nachteile, die mit seiner Anwendung verbunden sind, ist die ausfihrliche Schilderung einzusehen, welche ich im siebenten Kapitel $\S 52$ gegeben habe.

Die hauptsächlichste Einbettungsmasse, Wenn man nicht freihändig oder feucht schneidet (vgl. die Methoden im siebenten Kapitel, ist das Celloidin. Diese Substanz ist die recht eigentliche Einschlußsubstanz für das Zentralnervensystem, während sie für andere Objekte weniger gut erscheint. Paraffineinschmelzung ist nicht gebräuchlich, wird nur fuir ganz bestimmte Spezialzwecke empfohlen.

Hinsichtlich der Schnittdicke sind bestimmte Vorschriften nur für besondere Zwecke zu geben, also wenn es sich z. H. um die Untersuchung der Strukturen der Ganglienzellen, der Neurofibrillen usw. handelt. Für gewöhnliche Untersuchungen über die Textur des Gehirns oder Rückenmarks soll man nur darauf achten, die Schnitte nicht zu dünn anzufertigen. Denn man zerschneidet dabei nur die Verästelungen der Ganglienzellen, ihren Zusammenhang mit den Nervenfasern und eventuell auch die Nervenbahnen. Freilich wird man auch nicht zu dicke Schnitte anfertigen dürfen, weil bei den gewöhnlichen Färbungen die Präparate dann nicht mehr durchsichtig genug sind, um die nötigen Einzelheiten zu zeigen. Unter $20 \mu$ sollte man bei Texturstudien nicht herunter gehen und auch nicht dickere Schnitte als to $\mathrm{u}$ anfertigen, während bei den Chromsilbermethoden viel dickere, bei Zellstrukturstudien viel dünnere nötig sind. Paraffinmaterial gestattet nur relativ dünne Schnitte, Celloidinmaterial Schnitte bis zu to $u$, während bei dickeren der Celloidinblock leicht von seiner Unterlage abspringt. Feucht hergestellte Schnitte ron nicht eingebettetem IIaterial sowie Gefrierschnitte können sehr viel dicker sein.

\section{$\S 187$.}

Färben. Das beste Färbcmittel für Schnitte des Zentralnervensystems, das in Nüllerscher Fluissigkeit oder in Formol-Kali bichromicum nach meiner Vorschrift viertes Kapitel fixiert war, wäre das ammoniakalische Karmin, wenn nicht die Karmine des Handels so überaus ungleiche tinktoriale Eigenschaften besäßen. Jedenfalls sollte man einen Versuch mit Karmin bei jeder Untersuchung anstellen. Das chromierte. Material darf freilich nicht mit Alkohol nachbehandelt sein, weil dadurch dic Färbungsmöglichkeit ganz vernichtet wird. In gelungenen Karminfärbungen treten Ganglienzellen und 
Achsenzylinder scharf hervor, während die Neuroglia durch blassere Farbung sich abhebt. Freilich ist dies sicher nur beim Ruickenmark der Fall, während beim Großhirn und auch beim Kleinhirn häufig genug eine diffuse Rotfärbung eintritt. IVorauf letzteres beruht, vermag ich nicht zu sagen; ob dem Karmin oder der Fixierung oder dem Material die Schuld beizumessen ist, dürfte nicht zu entscheiden sein. Und nicht bloß beim Karmin geht es so, sondern - es sei dies rorweg bemerkt - bei allen anderen möglichen und anwendbaren Färbemitteln, die Methylenblaufärbung ausgenommen.

Die Karminfärbung wird in folgender Weise vorgenommen: Ton der vorrätigen dunkelkirschroten ammoniakalischen Lösung des Karmins gibt man so viel Tropfen in eine Schale mit destilliertem IVasser, daß die Verdunnung einen hellen Farbenton hat. Genauer läßt sich nach meinen Erfahrungen wirklich die Verdünnung nicht beschreiben; denn selbst die peinlichste Dosierung gewährt keine Garantie für gute Resultate. In dieser Farbflotte bleiben die Schnitte ron chromiertem IIaterial, bis sie gleichmäßig rot gefärbt sind, wozu Tage, oft auch Wochen erforderlich sind. Man wäscht in destilliertem Wasser ab, dem etwas Essigsäure Io Tropfen auf Ioo ccm zugesetzt ist, und schließt wie üblich in Kanadabalsam ein.

Die ron Fritsch empfohlene Doppelfärbung Karmin-Hämatoxylin (achtes Kapitel Nr.97 S. I I \&) liefert schnell brauchbare Färbungen. Nur muß man sich hiiten, im neutralen Karmin zu stark zu färben und darf nur diunne Schnitte, nicht iiber $25 \mu$, dazu nehmen. Beide Fehler nämlich hindern jede färberische Differenzierung. Urankarmin (achtes Kapitel Nr. I S. I67) wird für Achsenzylinderfärbung gerühmt.

Hat man chromiertes Material mit Alkohol nachbehandelt oder hat man Schnitte von reinem Formol-NIaterial gemacht, dann versagt die Karminfärbung. Hier tritt für Rückenmarksschnitte mit stets sicherem Erfolge meine Färbung mit Coerulein S (achtes Kapitel Nr. 77 S. I 8 t ein. Im übrigen sind die Hämatoxylinlacke, und zwar die Eisen- wie die Kupferlacke, ferner die Rosinsche Färbung achtes Kapiteli zu verwenden. Methylenblau in wässriger Lösung gibt gute Bilcler, die aber nicht lange sich halten. Färbt man in konzentrierter Lösung, so bleiben die Schnitte höchstens 5 Minuten in der Farbflotte; nimmt man dagegen sehr dünne Lösungen, so kann man $2+$ Stunden und länger färben. Auch polychromes Methylenblau ist derartig verwendbar (achtes Kapitel).

Zur Darstellung ron Fett im Zentralnervensystem - Verfettung der Zellen, degenerativer Zerfall der Bahnen — ist Sudan III geeignet. Über die Verwendung dieses Farbstoffes vgl. vierzehntes Kapitel bei Fettgewebe. 
Lm Fettkörnchenzellen darstellen zu können, empfiehlt Busch folgendes Verfahren: Man fixiert I-2 Tage in $5 \%$ Formol, härtet in Alkohol von steigender Konzentration, bettet in Celloidin ein und kann nun entweder eine Osmium- oder eine Hämatoxylinfärbung vornehmen. I. Osmiumfärbung. Die Schnitte des wie vorstehend fixierten Materials kommen auf $2-3$ Stunden in $0,5 \%$ Chromsäure, werden in Wasser abgespiilt und für $2+$ Stunden in eine Osmiumsäurelösung I : 500 eingebracht. In den hraunen Schnitten sind die Fettkörnchen schwarz. Oder man bringt aus der $0,5^{\circ}$. Chromsäure in Nasser und dann in folgendes Gemisch: $2^{\circ}$. Osmiumsäure 2 Teile, $2^{\circ}$. Formol 2 Teile, Aqua destillata ro Teile, Alkohol $05^{\circ}$. i o Teile. Darin bleiben die Schnitte $2+$ Stunden; die Fetthörnchenzellen sind intensiy schwarz gefärht. 2. Hämatoxylinfärbung. Die Schnitte kommen direkt in Böhmersches Hämatoxylin, worin sich die Körnchenzellen intensiv farben; man hebt in Balsam auf. Oder man bringt dic in Hämatoxylin gefärbten Schnitte in $I^{\circ}$, Pikrinsäurelösung, worin die Schnitte eine grünliche Färbung annehmen, während die Fettkörnchen tiefblau bleiben.

Es sei noch ausdriicklich hervorgehoben, daß die in diesem $\$$ geschilderten Färbungen, vielleicht mit Ausnahme der Buschschen Methode, sowohl für Vertebraten als auch für Evertebraten Guiltigkeit haben.

\section{$\$$ I 88 .}

In diesen $\leqslant$ sollen einige Methoden L'nturkunft finden, welche zwar keine allgemeine Anwendung gestatten. die aber dennoch gute Texturbilder liefern.

Osmium-Tanninmethode, mach Rawitz. Schnitte ron chromicrtem Naterial, gleichgiiltig ob es cellodiniert war oder nach Lmrandung geschnitten wurde, Werden für $24-48$ Stunden in eine Mischung ron 5 Teilen Mïllerscher Flussigkeit und I Teil I ${ }^{\circ}$ Osmiumsäurelösung eingelegt. Nach sorgfältigem Auswaschen in Wasser wird für $2+$ Stunden in $20^{\circ}$. Tanninlösung eingebracht und nach gutem Auswaschen usw, in Kinadabalsam eingeschlossen. Die markhaltigen Jervenfasern sind tief schwarz gefarbt, während alles Übrige unģefärbt geblieben ist. Die Methode dürfte sich dazu eignen, an mikroskopischen Schnitten namentlich umfänglicherer Hirnteile in einer schon mit bloßem Auge crkennbaren Weise die Nerrenbahnen aufzuzeigen.

Montische Methode. Monti fixiert in Kaliumbichromat-Lösung oder in Mïllerscher Flüssigkeit längere Zeit, ohne dic Fixierung und 
die mit ihr verbundene Härtung durch Einwirkung der Wärme zu beschleunigen. Er bringt (nach etwa 8 Tagen vermutlich, denn die Angaben sind herzlich ungenau dann in ein aus gleichen Teilen Miillerscher Flüssigkeit und $20^{\circ}$ 。 Kupfersulfatlösung bestehendes Gemisch ein. Nach 24 Stunden bräunt sich das Gewebe, doch werden nur einzelne Teile des Nervensystems gefärbt und noch dazu nicht in jedem Stiick die gleichen. Die Methode soll sich zur Demonstration von Nervenfasern und Gliazellen besonders eignen.

Nichollssche Nethode. Nicholls empfiehlt Nervensystem nach Cox zu fixieren (viertes Kapitel Nr. 2 I S. 54 ; und bringt Schnitte von solchem Material in eine $50^{\circ}$ 。 Lösung von Kali causticum. Gefärbte Teile werden darin dunkler, nicht gefärbt erscheinende werden deutlicher.

Sargentsche Methode. Fischgehirne, die mit der in $5 \delta_{5}$ beschriebenen Methode fixiert waren, bettet Sargent in Paraffin ein, klebt die Schnitte auf dem Objektträger auf und färbt 15-20 Minuten in folgender Mischung: $30 \%$ \% Phosphormolybdänsäure $1 \mathrm{ccm}$, Hämatoxylin Kristalle, I g, Chloralhydrat io $\mathrm{g}$. Aqua destillata $400 \mathrm{ccm}$. Dann in Wasser auswaschen usw. Nervenfasern, Neuroglia und Dendriten sind verschieden gefärbt.

\section{\$ 189.}

Wie schon bemerkt, finden alle Methoden, die fur clas Zentralncrvensystem der Vertebraten gelten, sinngemäße Anwendung auf die gleichen Organe der Evertebraten. Selbstverständlich fallen die Methoden weg; welche die Darstellung des Nervenmarkes bezwecken, da dieser Bestandteil im Zentralnervensystem der Evertebraten fehlt.

c) Spezialmethoden.

a) Metallimprägnationen.

I. Die Silbermethoden.

$\S 190$.

Die Golgische Methode und ihre Anwendung. Im neunten Kapitel (S. 2 I 3 ff. sind die Angaben ron Golgi über seine Mcthode, sowie die wichtigen Modifikationen ron Fusari, Ramon y Cajal und Külliker genauer beschrieben worden. Die an der genannten Stelle dargestelite Methode ist die sogenannte langsame Methode, weil die Fixierung in Miillerscher Flüssigkeit oft viele Wochen in Anspruch nimmt. I)ie erwähnten Modifikationen gestatten ein schnelleres Terfahren dank der Osmiumwirkung. Auch Golgi hat eine Muthode 
mit Osmiumvorbehandlung angegeben, und diese schnelle Golgische Methode soll hier erledigt werden. Die frischen, nicht zu großen Stücke von Zentralnervensystem werden in eine Mischung gebracht, welche I Teil $I^{\circ}$ 。Osmiumsäure und + Teile $2^{\circ} \mathrm{r}$ bis $2^{\mathrm{I}}{ }^{\circ}, 0^{\circ}$ Kali bichromicum-Lösung enthält. Darin wird 2-3 Tage fixiert und dann werden die Stücke in die ${ }^{3}{ }^{\circ}$. Lösung von Silbersalpeter gehracht, ganz wie dies im neunten Kapitel l. c. genauer beschrieben wurde.

Außer den genannten Modifikationen ist noch eine Unzahl anderer angegeben worden, von denen nur diejenigen hier einen Platz finden sollen, welche entweder eine erhebliche Erleichterung des ursprünglichen Verfahrens darstellen oder die auf das gewünschte Resultat von Einfluß sind.

van Gehuchten empfiehit, dem Silberbade der Cajalschen Modifikation neuntes Kapitel S. 215 auf je $100 \mathrm{ccm}$ I Tropfen Amcisensäure zuzufiggen. Sollen die Stiicke länger als 2 t Stunden versilbert werden, so müssen sic ins Dunkle gestellt werden. Die Zeichnung der Zellen s,ll sich darnach durch besondere Schwärze auszeichnen.

Ramin y Cajal hat darauf aufmerksam gemacht, daß das Alter der Embrymen und der jugendlichen Säugger von erheblichem Einflusse auf das Gelingen der Silberimprägnation ist. Er empfiehlt daher, um dic Molekularschicht im Cerebcllum gut darzustellen das Silberbad mit den ()bjekten fuir 5 Tage in den auf $25^{\circ}-26^{\circ} \mathrm{C}$. erwärmten Thermostaten zu stellen. Lm Collateralen gut zu erhalten, muß cie Erwirmung sogar auf $6 \ldots$ - Tage ausgedehnt werden Die zu vursilhernden Objekte dürfen nur $5 \mathrm{~mm}$ dick sein und für ein jedes solches Stick sind 25-30 ccm Silberhad erforderlich. Ramin y Cajal empriehlt auch, embryonale Wirbclsäulen von Vögeln Gallus 3 Tage lang in scinem Genisch neuntes Kapitel zu fixieren, dann für 36 Stunden in eine $x_{2} \%-3 / 4 \%$ Lösung von Argentum nitricum einzubringen. wiederum die Stiicke für $30-48$ Stunden in das erste Gemisch zurückzutun, sie kurz zu waschen und dann ron neuem in das Silberbad einzulegen.

Die Netze in den Ganglienzellen stellt Golgi folgendurmaßen dar: Er fixiert in cinem Genisch von 2 Teilen $5^{\circ}$. KaliumbichromatLösung, 2 Teilen $0_{1}$ ' Platinchloridlösung und $1-2$ Teilen I ${ }^{\circ}$ Osmiumsäure Verattisches Gemisch. Die Versilberung findet wie gewöhnlich statt.

Kopsch empfichit seine Mischung von Formol und Kali hichromicum $\leqslant 185$ mit nachheriger Versiberung. Die Fixierungsdauer schwankt zwischen 3 und 6 Tagen.

Ich sclber kiann dringend zu der Behandlung des Zentrahnerven- 
systems raten, die ich im $\$$ i 85 empfohlen und im vierten Kapitel S. 47 ausführlich beschrieben habe. Die Chromierung dauert 8-it Tage, dann werden die Objekte aus der Lösung des doppeltchromsauren Kali herausgenommen, mit Filtrierpapier äußerlich abgetrocknet und in Stücken von höchstens o, $6 \mathrm{~cm}$ Dicke in $\mathrm{I}^{\circ}$, Silberlösung gebracht.

Bolton und Bari empfehlen, Formolpräparate für $2-3$ Tage in eine $2^{\circ}$. Lösung von Kali bichromicum zu bringen und dann in $0.75^{\circ}$ Höllensteinlösung überzuführen. Die Schnitte müssen $2+$ Stunden in Terpentin bleiben, kommen dann in Kreosot und schließlich in Kanada (vgl. später).

Alle Methoden, welche zur Versilberung ein Material benutzen. das in Formol vorfixiert war, haben den Nachteil, daß sich die Blutgefäße in weitester Ausdehnung mit Silber imprägnieren. Das ist allerdings ein Übelstand, der aber meines Erachtens nicht groß genug ist, um die Vurwendung von Formol-Material zu verbieten. Der Vorteil der Formolmethoden beruht darin, daß man das Material jahrelang aufheben kann, ehe man es verwendet, und daß die Silberimprägnierung nicht ganz so launenhaft ist, wie bei dem Material, das frisch in die Chromsalzlösungen gebracht wurde.

Kallius verwendet Ammoniumbichromat und Natriumbichromat. die vor dem Kalisalze manche Vorteile voraus haben sollen.

Eine eigenartige Methode hat Lavdowsky ausgebildet, dic aber bei den Neurohistologen, soweit sie Anhänger des Golgischen Verfahrens sind, wenig Anklang gefunden zu haben scheint. Er fixiert sein Material in Müllerscher Flüssigkeit, die er jedoch stärker anwendet, als sie urspringlich vorgeschrieben ist. Er nimmt $3-3^{\mathrm{I}}=\mathrm{g}$ Kaliumbichromat, i g Natron sulfuricum und $\mathbf{s} 00 \mathrm{ccm}$ Wasser. Zu je $20 \mathrm{ccm}$ der Lösung nimmt er $2-+\mathrm{ccm}$ ciner $\mathrm{I}_{\text {\% }}^{\circ}$ Osmiumsäurelösung und bringt nach beendeter Fixierung in eine $\mathrm{I}_{10}^{\circ}$ Lösung ron Höllenstein, in welcher er das Material $2+-48$ Stunden bei $20^{\circ}-30^{\circ} \mathrm{C}$. beläßt. Nach der Imprägnierung wird direkt in $95 \%$ Alkohol iibertragen. Die Schnitte färbt er in einer alkoholisch-wässrigen Lösung von Magdalarot nach; die Färbung erfolgt fast augenblicklich. Dann bringt er sie fuir einige Sekunden bis I Minute in eine Chlorgoldbeize. und zwar in $5 \mathrm{ccm}$ Wasser, dem 3-6 Tropfen $1 \%$ Goldchloridlösung zugesetzt sind. Seine Angabe, daß gute Doppelfärbungen selten seien, erscheint sehr glaubhaft.

\section{$\$$ IgI.}

Allgemeine Regeln für die Ausfuhrung der Golgischen Methode. Wird das chromierte Material aus der Chromsalzlösung direkt in die 
Höllensteinlösung gebracht, so entsteht ein so mächtiger Niederschlag von Chromsilber - manche Autoren zweifeln daran, daß es sich wirklich um Chromsilber handelt —, daß dadurch eine Imprägnierung verhindert wird. (Denn um eine Imprägnierung handelt es sich und nicht um eine Färbung. Nicht die Ganglienzelle, Nervenfaser usw. wird mit Chromsiber gefärbt, sondern in den Lymphräumen der genannten Gebilde wird Silber körnig niedergeschlagen!. Zu gleicher Zeit wird auch das Silberbad triibe und damit unbrauchbar. Es ist daher anzuraten, folgendermaßen zu verfahren: Die Prïparate, welche nicht abgewaschen werden düren, damit das Chromsalz nicht ausgelaugt wird, werden äußerlich mit Filtrierpapier abgetrocknet. Dann legt man sie in eine Glasschale mit Wasser ein, dem so viel $1^{2}$ o oder $0,75^{\circ}$. Höllensteinlüsung zugesetzt ist, daß es eine ${ }^{\mathrm{z}}$ " " bis höchstens t: Lüsung des Silbersalzes darstellt. Hierin werden die Stuicke nur wenige Sekunden gewälzt; die Lösung kann gelb, darf aber nicht trübe werden. Sie werden dann für 1 Minute in ein etwas stärkeres Silberbad, dann wiederum für I Minute in eine ${ }^{2} \circ$ Silberlüsung unc schließlich in das definitive Silberbad $I^{\circ}$ o oder $3^{3}{ }^{\circ}{ }^{\prime}$ übergefuhrt. Hierin bleiben sie im diffusen Tageslichte stehen und können nach 3-4 Tagen verwendet werden. Längere Vursilberung scheint cher schädlich als nutzlich zu sein, jedenfalls findet nach + Tagen keine Imprägnierung mehr statt.

Ist die Versilburung beendet, so darf nicht in Wasser ausgewaschen werien, da sonst das (hromsilher sich lösen wüde. Man bringt daher nach der Forschrift der Autoren auf ${ }_{2}$ - I Stunde in $50^{\circ}$. Alkohol, auf $\mathrm{I}-2$ Stunden in absoluten . Alkohol, dann dirckt für $\mathrm{I}$ bis 2 Stunden in Celloidin, klebt auf und schneidet. Ich halte dic Uherfihrung in $50^{\prime \prime}$. . Ikohol fur unnötig, habe vielmehr ohne weiteres aus dem Silherhade fur mehrere Stunden his I Tag in absoluten Alkohol gebracht und dabei licine Spur ron Schrumpfung gesehen. Auch das Eintauchen in Celloidin halte ich nicht für nötig: ich umrande die Objekte: die ich aus dem absoluten Alkohol entnehme und mit Filtrierpapier abtrockne, mit etwas geschmolzenem Paraffin, klebe mit Parafin auf geeigneter Lnterlage Holzblock, Metallzylinder usw.) auf und schneide unter y $6^{\circ}$. Alkohol. Das Messer hat dabei zur Mikrotomachse einen Winkel ron $20^{\circ}-30^{\circ}$. Die Schnitte von Golgi-Material müssen sehr dick sein: unter to $\mu$ darf man, wenigstens bei erwachsenen Säugern, nicht heruntergehen. Das Optimum der Schnittdicke ist $60 \mu$.

Vom Messer werden die Schnitte direkt in weißes Kreosot ge- $^{\circ}$ bracht, worin sic fast augenblichlich aufhellen. Aus diesem kommen 
sie in Terpentinöl und daraus in Ayloldammar. Sie diirfen nicht mit einem Deckglase eingedeckt werden, denn aus nicht ersichtlichen Grinclen schwindet im eingedeckten Präparate die Versilberung.

Obregia hat eine Methode honstruiert, welche gestattet, die Golgipräparate mit einem Deckglase einzudecken. Sie ist dem hei der Photographie üblichen Tonfixierbade nachgcbildet, gelingt aber nur selten - ich habe noch nie einen positiren Erfolg mit ihr gehabt und ist daher nur mit Vorsicht zu verwenden. Die Schnitte kommen rom Messer in absoluten Alkohol und ron da in ein Goldbad, das $=$ Stunde vor dem Gebrauch bereitet wird. Es besteht aus $10 \mathrm{ccm}$ Alkohol absolutus und 8-io Tropfen einer I ${ }_{0}^{\circ}$ Goldchloridlösung; das Goldbad muß im diffusen Tageslichte gestanden haben. Unmittelbar nach dem Einlegen der Schnitte in das Bad soll man alles ins Dunkle stellen, schon aber kann auch alle Silberimprägnation zerstört sein. Im Dunkeln bleiben die Schnitte I5-30 Minuten; hierbei wird das Silber durch das Gold ersetzt. Dann werden die Schnitte in $50^{\circ}$. Alkohol gebracht, nach wenigen Minuten in Aqua destillata übergeführt und abermals nach wenigen Iinuten in folgendes Bad cingelegt: kristallisiertes unterschwefligsaures Natron ro g, Aqua destillata $100 \mathrm{ccm}$. Hierin verweilen die Schnitte 5- io Minuten, keinesfalls länger. Die Dauer des Aufenthaltes in dem zweiten Bade hängt ron der Schnittdicke ab. Dann wird gewaschen, in Alkohol absolutus entwässert, in Kreosot, Terpentin, Dammar übergeführt und mit cinem Dech-glase eingedeckt. Man kann nach dem Entwässern in Karmin, Hamatoxylinalaun, Wuigertschem- oder Palschem Hämatoxylin nachfärben.

Sehrwald hat einc Methode empfohlen, Golgi-Präparate in Paraffin einzuschmelzen. Er rät, alle Intermedien (Alkohol, Xylol oder Chloroform; und auch das Paraffin mit Chromsilber zu übersattigen und die Sättigung unter Erwärmung der betreffenden Reagentien auszuführen.

Lavdowsk $y^{-}$hellt nicht in Kreosot-Terpentinöl auf, sondern bringt in einen Resina-Sandarak-Lack ein. Er empfiehlt, 2 Konzentrationszracic von ihm herzustellen. Man löst 25-30 g reinsten Sandarakharzes in $40-50 \mathrm{ccm}$ absoluten Nlkohols Lack II'. Ein Teil der Lösung wird mit dem gleichen Quantum von absolutem Alkohol verdünnt Lack I. Der Schnitt wird aus dem Entwässrungsalkohol direkt auf den ()bjektträger gebracht. Ist der Alkohol nahezu völlig verdunstet. so wirci der Schnitt mit Lack I übergossen; der Objcktträger bleibt bei Zimmertemperatur horizontal liegen. Wenn der Lack ausgebreitet und etwas eingedicht ist, wird mit Lack II übergossen, 
der mit einem Glasstabe unter Schonung der Schnitte gleichmäßig ausgebreitet wird. Wiederum bleiben die Objektträger flach liegen. Nach ${ }_{4}^{3}{ }_{4}$ Stunde sind die Schnitte fertig. Um Sprünge im Lack zu verhïten, übergießt man mit Dammarlack oder Kanadabalsam, die in Benzin sehr dünn gelöst sind. Zum Trocknen wird der Objektträger auf einen Tag in den Wärmeschrank gelegt.

\section{$\$ 192$.}

Silberfärbung der Neurofibrillen. Zur Färbung bzw: Imprägnierung des Fibrillen, welche Ganglienzelle und Achsenzylinder zusammensetzen, sind eine Reihe verschiedener Methoden empfohlen worden, welche hier folgen sollen. Diese Methoden wurden auch von den Bakteriologen verwandt, um die sogenannte Spirochaete pallida der Syphilis oder den Diphtheriebacillus darzustellen. Es dïrfte daher gerechtfertigt sein, auch eine nur fir die genannten bakteriologischen Zwecke konstruierte Methode, die von Levaditi, hier anzufïgen, weil sie möglicherweise auch für neurohistologische Studien brauchbar ist. Andere bakteriologische Silbermethoden, die im wesentlichen dem auch von den Neurohistologen innegehaltenen Prinzipe folgen, das bei der Entwicklung der Negative in der Photographie maßgebend ist, habe ich bei Seite gelassen. Sie haben für rein histologische Zwecke keinen besonderen Wert; und es gibt auch für ein Lehrbuch eine Grenze im zitieren.

I. Methoden von Ramòn y Cajal zur Imprägnierung von Neurofibrillen, Achsenzylindern und Endverzweigungen.

I. Nethode. Neurofibrillen; kleinere und mittlere Nervenzellen. Versilberung. Stiicke ron Nerrengewebe, die nur $3 \mathrm{~mm}$ dick sein diirfen, kommen frisch fuir 3 Tage in den Thermostaten bei $30^{\circ}-35^{\circ} \mathrm{C}$. in eine $0,75^{\circ}-3^{\circ}$ 。 Lösung von Argentum nitricum. Im Sommer bei mehr als $+22^{\circ} \mathrm{C}$. Außentemperatur kann man die Stuicke auch im Zimmer lassen, nur müssen sic dann 2-3 Tage länger im Silberbade bleiben. Sonst, d. h. bei niedrigerer Temperatur, ist die Anwendung des Thermostaten unerläßlich. W'enn die Stiicke "reif: sind, dann muß ihre Schnittfläche gelb sein. Größere Stiicke (z. B. Cerebellum rom Kaninchen! müssen + Tage, Großhirn sogar 5 Tage in der Höllenstcinlösung bleiben. Die »Reifungszeit variiert nach Zahl und Größe der Stücke, nach der Spezies und nach der Temperatur; man muß sie daher jedes Mal durch Probieren feststellen. Unreife Stücke geben bei der Reduktion einen körnigen Niederschlag; ïberreife zeigen Gelb- oder Braunfärbung und Niederschläge ohne Kontraste. 
Als Regel bezüglich des Silberbades hat zu gelten: je schwächer die Konzentration der Lösung, um so größer der Kontrast in der Färbung der Neurofibrillen und des Untergrundes, je stärker die Konzentration des Silberbades, desto schwächer heben sich die Neurofibrillen ab. Kräftige Silberlösungen aber fixieren die Zellen besser (Auerbachsche Endknospen treten besser gefärbt hervor), schwache Lösungen färben die Nucleolen und die intranucleären Bazillarkörper. Daher ist folgendes festzustellen:

$\mathrm{I}, 5^{\mathrm{O}}$ 。 Lösung von Höllenstein ist in den meisten Fällen anwendhar. Die Neurofibrillen sind gut imprägniert und ebenso die Nucleolen und die Endverzweigungen.

$0,75^{\circ}$ 。- $0,5^{\circ}$. Höllensteinlösung eignet sich vortrefflich bei Embryonen und neugeborenen Tieren. Bei erwachsenen Individuen wirkt sie zusammenziehend auf die Zellen ein.

$5 \%-6 \%$ Lösung ist für Evertebraten geeignet.

Reduktion des Silbers. Die Objekte, wenn sie »reif geworden sind, werden I-2 Minuten in destilliertem Wasser gewaschen und dann für $2+$ Stunden in folgendes Gemisch von PyrogallussäureFormol oder Hydrochinon-Formol gebracht: Pyrogallussäure (bzw. Hydrochinonj $\mathrm{I}-2 \mathrm{~g}$, Formol $5 \mathrm{ccm}$, Aqua destillata $100 \mathrm{ccm}$. Das Formol fixiert und härtet.

Ein betten. Aus der Reduktionsflüssigkeit werden die Stücke fiir einige Ninuten in destilliertes Wasser, dann in Alkohol gebracht und auf die übliche Weise in Celloidin eingebettet. Paraffin ist zu vermeiden, weil darin das Material zu hart und brïchig wird. Die Schnitte sind $10 \mu$ bis $30 \mu$ dick zu machen; sie werden ohne Gegenfärbung in Dammarlack eingeschlossen. Die oberflächlichsten Schnitte sind zu dunkel, die innersten sind nicht genügend imprägniert. Die Schnitte der Mittelzone sind hell kaffeebraun oder rotbraun; diese sind gut. Die Neuroglia ist ungefärbt geblieben.

2. Methode. Neurofibrillen der großen Zellen; markhaltige Achsenzylinder. Tersilberung. Die frischen Gewebsstiicke kommen auf $2+$ Stunden in $97^{\circ}$ 。. Alkohol, dann auf einige Sekunden in destilliertes Wasser und darauf in $\mathrm{I}^{\circ}$ 。 Höllensteinlösung in den Thermostaten bei $30^{\circ}-35^{\circ} \mathrm{C}$. Die Dauer der Versilberung wie bei Methode I. Darauf werden sie einige Sekunden gewaschen und kommen zur Reduktion in folgende Hydrochinonlösung: Hydrochinon $2 \mathrm{~g}$. Formol $5 \mathrm{ccm}$, Aqua destillata $100 \mathrm{ccm}$. Bei sehr großen Stüclien wird dieser Reduktionsflissigkeit ${ }_{2}^{{ }^{\prime}}$ g Natriumsulfitanhydrit zugesctzt. Jan wäscht nach beendeter Reduktion und führt allmählich in Celloidin über. Ist die Reduktion in den Schnitten zu 
schwach, dann wird in folgendes Goldbad eingebracht: sulfocyansaures Ammonium $3 \mathrm{~g}$, unterschwefligsaures Natron $3 \mathrm{~g}, \mathrm{I}_{10}^{\circ}$ Goldchloridlösung einige Tropfen, Aqua destillata? im Originalartikel ist keine Quantität des II assers angegeben; vielleicht Ioo $\mathrm{ccm}_{\text {;. Dann }}$ werden die Schnitte gewaschen und wie vorhin eingeschlossen.

3. Methode. Marklose Fasern; Endverzweigungen. Läßt man in Methode 2 den Alkohol 3 Tage lang einwirken, dann findet sich bei weiterer identischer Behandlung die Redultion nur in den marklosen Fasern, den perizellulären Verzweigungen und den Endknospen. Diese Methode empfiehlt Ramon y Cajal als wertvoll für die pathologische Anatomie.

4. Methode. Neurofibrillen; große Zellen; feine Nervenfasern. Man legt die Gewebsstiicke in ammoniakalischen Alkohol 0,5-I ccm Ammoniak, $97^{\circ}$ i Alkohol $100 \mathrm{ccm}$ und läßt sie darin $2+$ Stunden. Hat man große oder hat man zahlreiche Stuicke zu verarbeiten, dann läßt man $1,5^{\circ}$ o oder gewöhnlichen? Ammoniakalkohol t8 Stunden einwirken. Man wäscht in destilliertem Wasser aus, bringt in $1,5^{\circ}$ 。 Argentum nitricum-Lösung ein und verfährt weiter wie bei Iethode 2. Am besten ist es, wenn der ammoniakalische Alkohol 24-36 Stunden einwirkt. Eventuell, hei ungeniigender Reduktion nämlich, behandelt man im Goldbade nach (Methode 2).

Statt ammoniakalischen Alkohols kann man auch ammoniakalisches Formol verwenden: Formol $20 \mathrm{ccm}$, Ammoniak $0.5 \mathrm{ccm}$, Aqua destillata $100 \mathrm{ccm}$. Nan läßt 24 Stunden einwirken.

Alle ammoniakhaltigen Objekte muissen $2+$ Stunden in fließendem Wasser ausgewaschen werden.

Ramon y Cajal hat seine eben beschriebenen Methoden zur Darstellung der Neurofibrillen modifiziert.

Neuere Cajalsche Methode. Das Material, das aus höchstens $5 \mathrm{~mm}$ dicken Stïcken bestehen muß, kommt auf ${ }_{2}$ Stunden in $96^{\circ}$. Alkohol, kann darin aber auch ohne Schaden fur die weitere Behandlung 2-3 Tage bleiben. Dann halbiert man die Organstiicke in der Dicke, legt sie auf einige Minuten in destilliertes Wasser (wahrscheinlich bis sie untergesunken sind und fuihrt sie in $\mathrm{I}^{\circ}{ }_{0}-\mathrm{I}, 5^{\circ}$ 。 Argentum nitricumLösung über. Bei einer Temperatur von $30^{\circ}-35^{\circ} \mathrm{C}$. bleiben sie darin durchschnittlich + Tage. Nach flüchtigem Abspuilen in destilliertem Wasser wird die Redultion in folgendem Gemisch vorgenommen: Pyrogallussäure (oder Hydrochinon) $\mathrm{I}-2 \mathrm{~g}$, Formol (käuflich) $5 \mathrm{ccm}$, schwefligsaures Natron 0,25-0,5 g, Aqua destillata $100 \mathrm{ccm}$. Für Groß- und Kleinhirn muß man I g schwefligsaures Natron nehmen. IIann kann Natriumsulfit und Formol auch weglassen, nur wird dann 
die Imprignation weniger fein. Nach beendeter Reduktion wird flichtig in destilliertem Wasser ausgewaschen und in üblicher Weise in Celloidin eingebettet. Die Schnitte werden in Xylol aufgehellt.

Zeigt es sich, daß die Schnitte aus der Mitte blaß sind, so kann man verstarken. Man bringt sie nämlich in folgendes Gemisch: Schwefelcyanammonium $3 \mathrm{~g}$, unterschwefligsaures Natron 38 , Aqua destillata $100 \mathrm{ccm}$. Im Augenblicke des Gebrauches setzt man einige Tropfen einer $\mathrm{I}^{\circ}$ 。 Goldchloridlösung zu. Dann wird gewaschen, entwässert, in Xrolol aufgehellt und in Dammarlack eingeschlossen.

Zur Färbung der marklosen Fasern und der Neurofibrillen gibt Ramòn y Cajal folgendes Verfahren an: Organstücke von $3,5 \mathrm{~mm}$ Dicke werden für $2+$ Stunden in ammoniakalischen Alkohol gebracht $\left(96^{\circ}\right.$, Alkohol $100 \mathrm{ccm}$, einige Tropfen bis I ccm Liquor ammonii caustici'. Dann werden sie in mehrere Nale zu wechselndem Viasser einige Ninuten lang ausgewaschen und kommen für 3 bis 5 Tage in $1,5^{\prime \prime}$. Höllensteinlösung bei $30^{\prime \prime}-35^{\circ} \mathrm{C}$. Nach Abwaschen wird die Reduktion in folgendem Gemisch vorgenommen: $2 \mathrm{~g}$ Pyrogallussiture, $5 \mathrm{ccm}$ Formol, $100 \mathrm{ccm}$ Aqua destillata. Nach beendeter Reduktion wird auf behannte IVeise in Celloidin eingebettet.

Diese Versilberungsmethoden sind auch auf Evertebraten anwendbar. Ramon y Cajal empfichlt bei Lumbricus folgendes Trerfahren. Stuiche des Regenwumes werden bei Zimmertemperatur fïr It Stunden in folgende Fixierungsflussiglicit gelegt: Formol io ccm. Aqua destillata to ccm, Ammoniak $4^{-6}$ Tropfen. Nach Auswaschen wird mit einer der vorhin beschricbenen silbermethoden versilbert.

2. Methoden von Bielschowsky zur Imprägnierung der Neurofibrillen. Bielschowsky fixiert Zentralnervensystem in $10^{\circ}$. Formol, fertigt Gefrierschnitte an ohne Alkoholbehandlung und bringt diese in Formol zurïck. Die Schnitte kommen dann in eine a mmoniakalische Silberlösung, welche folgendermaßen hergestellt wird: $\mathrm{Zu}$ offizincllem Ammoniak wird tropfenweise so viel von einer $\mathrm{o}^{\circ}$ Arģentum nitricum-Lösung zugesetzt, bis ein weißlicher, sich rasch braun fürbender Niederschlag entsteht, welcher durch Zusatz ron Ammoniak zum Schwinden gebracht wird. Die Schnitte also kommen direkt in diese Lösung, daraus wieder in $10 \%$ Formol - die Verdünnung des käuflichen Formol wird mit Leitungswasser hergestellt -; hierin werden sie gelblich. Diese Prozedur des Einbringens in das Silberbad und Zurückbringens in das Formol wird wiederholt vorgenommen; man kann zwischendurch auch einen Moment in destilliertes Wasser einbringen, doch ist dies nicht nötig. Hat die graue Substanz einen gelblichbraunen Farbenton an- 
genommen, dann wird in destilliertem Wasser ausgewaschen und darnach zur Tergoldung geschritten. Mlan gibt auf Io ccm gewöhnliches WVasser 2 Tropfen $\mathrm{I}^{\circ}$ 。 wässriger Goldchloridlösung, fügt dem Gesamtbade einige Tropfen Boraxlösung (Konzentration?, und einige Tropfen 10\% Kaliumkarbonat-Lösung zu. Die hineingebrachten Schnitte werden grau oder graubraun, während die gelbliche Färbung schwindet. Nun kommen die Schnitte in die Fixage, nämlich fuir einige Minuten in eine $10 \%$ wässrige Thiosulfatlösung. Dann wird gewaschen, entwässert, in Cajeputöl aufgehellt und in Xylolbalsam eingeschlossen.

Ganze Stuicke sind auch zu imprägnieren. Man fixiert sie in $20^{\circ}$ 。 Formol, bringt in das Höllensteinbad auf + Tage, für einige Minuten in eine Lösung ron I Teil Ammoniak + Io Teilen Wasser, in IO? Formol wie oben, dann auf 3 Tage in den Brütofen bei $30^{\circ} \mathrm{C}$. und schließt in Paraffin ein.

Neuere Methode von Bielschowsky. Die eben beschriebene Methode hat Bielschowsky selber modifiziert. (Es scheint das Schichsal der neueren Silbermethoden zu sein, fortwährend von ihren eigenen Erfindern verbessert zu werden.' Sie ist dadurch für solches menschliches Material verwertbar geworden, das erst $2+$ Stunden nach dem Tode zur Seltion gelangt. Nan bringt die Stiicke in $12^{\circ}$ 。Formol, worin sie nur wenige Tage zu licgen brauchen, aber auch mehrere Jahre liegen können. Die mit dem Gefriermikrotom herzustellenden Schnitte diirfen nicht dicker als $20 \mu$ sein. Sie kommen auf $12-2+$ Stunden in eine $2 \%$ Lösung von Argentum nitricum, wo hinein sie mit einer Glasnadel übertragen werden. Dann werden sie je nach ihrer Dicke Io-20 Selunden in $3^{\circ}$ 。 Ammoniaklösung /d. h. Konzentrierter Salmialigeist in Iofacher Verdunnung) gebracht und für Io Minuten in cine Lösung übertragen, welche auf roo ccm gewöhnliches Wasser $20 \mathrm{ccm}$ Formol cnthält. Eventuell fügt man zur größeren Alkalescenz auf je $100 \mathrm{ccm}$ dieser Lösung I Tropfen konzentrierte wässrige Lithion carbonicum-Lösung. Hierauf werden die Schnitte durch die $3^{\circ}$. Ammoniaklösung durchgezogen und direkt in $0,5^{\circ}$. Argentum nitricum-Lösung eingelegt. Da in der Filiissigkeit Niederschläge entstehen, so muß das Silberbad gewechselt werden. Nach Minute sind die Schnitte gebräunt; sie kommen jetzt in $20^{\circ}$. Formollösung, bis sie dunkelbraun geworden sind, werden wieder durch die $3^{\circ}$. Ammoniaklösung gezogen, worin der Farbenton braunschwarz wird, kommen für einige Minuten noch einmal in $20^{\circ}$. Formol oder, wenn der Farbenton sehr dunkel geworden ist, in destilliertes Wasser. Nunmehr wird vergoldet. Auf je ro ccm destilliertes 
Wasser kommen 2-3 Tropfen einer $1^{\circ}, 0$ Goldchloridlösung: dem Gesamtbade werden 2-3 Tropfen Eisessig zugefügt. In dem Goldbade bleiben die Schnitte, bis sie grau oder grauviolett geworden sind. Überhaupt sind alle im Kopierverfahren der Chlorsilberpapiere gebräuchlichen Bäder entsprechend verdünnt benutzbar. Um ungenügend reduziertes Silber zu entfernen, kommen die Schnitte in $5^{\circ}$. Natriumthiosulfat-Lösung, wozu auf je Io ccm Flüssigkeit I Tropfen Natriumsulfit $(? \%)$ zugesetzt wird.

Neueste Methode von Bielschowsky. Da bei der nneueren* Methode sich auch Bindegewebsfibrillen und elastische Fasern mitfärben, so hat Bielschowsky seine Methode wiederum modifiziert. Stiicke von I cm Dicke werden in $10^{\circ}{ }_{0}-15^{\circ}$ 。 Formollösung fixiert, einige Stunden in fließendem Wasser gewaschen und mit dem Gefriermikrotom geschnitten. In destilliertem Wasser aufgefangen, kommen sie für $2+$ Stunden in $2^{\circ}$ 。 Höllensteinlösung. Dann fuihrt man sie rasch durch destilliertes Wasser hindurch in eine stets frisch zu bereitende alkalische Silberlösung von folgender Zusammensetzung: I0 Argentum nitricum-Lösung $5 \mathrm{ccm}+5$ Tropfen $40^{\circ}$ 。 Natronlauge. Den bei der Bereitung entstehenden Niederschlag löst man unter stetem Schütteln durch tropfenweisen Zusatz von Ammoniak.) Diese Mischung wird mit $20 \mathrm{ccm}$ Aqua destillata verdünnt. Hierin bleiben die Schnitte i 5 Minuten, bis sie dunkelbraun geworden sind. Dann kommen sie in Essigsäure $/ 5$ Tropfen Eisessig auf $20 \mathrm{ccm}$ Aqua destillatal, worin sie geblich werden. Ist dieser Farbenton erreicht, dann bringt man sie in $20^{\circ}$. Formol, worin sie solange, wie noch weißliche Wolken aufsteigen, bleiben müssen.

Nunmehr kommt das Goldbad. In ein Bad, das auf ro $\mathrm{ccm}$ Aqua destillata 5 Tropfen einer $I^{\circ}$ 。Goldchloridlösung enthält, werden aus dem reduzierenden Formol die Schnitte eingelegt, bis sie rötlichviolett geworden sind (nach circa I Stunde). Dann kommen sie, um schlecht reduziertes Silber zu entfernen, auf ${ }^{ }$. Minute in $5^{\circ}$. Lösung von Natriumthiosulfat. Sie werden sorgfältig in Aqua destillata gewaschen, in Alkohol von steigender Konzentration erhärtet, entwässert. in Karbolxylol aufgehellt und in Kanadabalsam eingeschlosssen. Resultat: Achsenzylinder schwarz, Bindesubstanzfasern violett oder blauviolett, Markscheiden manchmal rötlich.

Nan kann ganze Stuicke, nicht bloß Schnitte, so behandeln, indem man natürlich für die einzelnen Prozeduren längere Zeit anwendet. Die fertigen Präparate bettet man in Paraffin oder Celloidin ein.

Auch für pathologisches Material ist nach Schaffer die Bielschowskysche Methode zu gebrauchen. Doch empfiehlt es sich 
statt der $2^{\circ}$ 。 eine $t^{\circ}$, Höllensteinlösung zu nehmen und darin 48 Stunden, nicht bloß 24, zu belassen.

3. Mossesche Argentamin-Methode. Nach Fixierung in Carnoyscher Flüssigkeit (viertes Kapitel Nr. 3 S. 4t) wird in Paraffin eingeschmolzen. Die Schnitte kommen für $2-3$ Minuten in $2^{\circ}$; Argentamin und daraus für kurze Zeit in $10 \%$ Pyrogallol. Darnach haben sich die Zellen des Nervensystems, ja sogar die Nissl-Körper gefärbt. Zur Warkscheidenfärbung bringt man Celloidinschnitte von dem wie angegeben fixierten Material auf Io Minuten in $2^{\circ}$. Argentamin, spült $a b$, legt auf wenige Minuten in Pyrogallol ein und wendet die Palsche Differenzierung an (achtes Kapitel Nr. 127 S. 202).

+. Levaditische Methode zur Färbung der Spirochaete pallidata vielleicht verwendbar'für Neurofibrillen). I mm dicke Organstucke werden $2+$ Stunden lang in $10^{\circ}$, Formol fixiert, dann gewaschen und für $2 .+$ Stunden in $96^{\circ}$. Alkohol getan. Dann bringt man sie von neuem in destilliertes Wasser, wartet, bis sie darin zu Boden gefallen sind, und legt sie in $1,5^{\circ},-3^{\circ}$ Argentum nitricumLösung ein. Hierin verbleiben sie bei $38^{\prime \prime} \mathrm{C}$. Temperatur $3-5$ Tage, werden kurzc Zeit in destilliertem Tasser ausgewaschen und dann in dic Redulitionsfluissigheit iihergefuhrt. Diese besteht aus 2- 8 g Progallussäure, $5 \mathrm{ccm}$ Formol und $100 \mathrm{ccm}$ Aqua destillata. Bei Zimmertemperatur lïßt man die Objekte $24-4 \delta$ Stunden darin, wäscht in destilliertem Wasser, härtet und schließst durch Nylol in Paraffin ein. Die Schnitte müssen $5 \mu$ dick sein.

Die aufgeklebten Schnitte fürbt man einige Minuten nach Giemsa ssçchszehntes Kapitel S. 298), wäscht, differenziert in absolutem Alkohol, dem etwas Velkenöl zugesetzt ist, hellt erst in Bergamottöl, dann in Xijol auf und schließ3t in Kanadabalsam cin. Oder man färbt in konzentrierter Toluidinblaulösung nach, differenziert in absolutem Alkohol. dem man einige Tropfen der Glyzerinäthermischung von Unna achtes Kapitel S. IS6, beigemischt hat, hellt auf und schließt ein wie vorher.

\section{Die Goldmethoden.}

\section{$\$ 193$.}

Durch die allgemeine Aufnahme, welche die Neigertsche Hämatoxylinmethode gefunden hat, durch die Sicherheit, welche bei ihrer Anwendung hinsichtlich der Resultate vorhanden ist. sind die friiher viel geübten Vergoldungen des Zentralnervensystems ganz in Mißkredit gekommen. Und das mit Recht. Fast alle Methoden, wie z. B. die von Flechsig, von Freud u. a., waren unsicher in ihren Re- 
sultaten. Die Absicht, Ganglienzellen und Nervenfasern zu fïrben. wurde selten in rollem Umfange erreicht. Am relativ sichersten, wenn auch sehr langwierig, ist die

Ziehensche Vergoldungsmethode. Man legt Stiicke von frischem 7entralnervensystem in eine Mischung von $I^{\circ}$ 。Goldchloridlösung und $I^{n}$ 。Sublimatlösung zu gleichen Teilen. Die Dauer der Einwirkung ist mindestens 3 Wochen, muß aber oft auf 5 IIonate ausgedehnt werden. Die einzelnen Stiicke miissen ein metallisch rotbraunes Aussehen erlangen. Man klebt auf und schneidet ohne Einbettung. Dic Schnitte werden in verdïnnte Lugolsche Lösung achtes Kapitel gebracht i : Wasser, Worin sie je nach ihrer Dicke verschieden lange bleiben. Dann wäscht man gut aus und schließt auf bekannte Weise in Kanadabalsam ein. Außer dem Nikrotommesser dürfen keine Metallinstrumente mit dem vergoldeten Material in Berïhrung kommen. Bei gelungener Imprägnation sind Nervenfasern, Ganglienzcllen und Gliazellen blaugrau. Auch nach Chromhärtung kann, wie oben angegeben, verfahren werden. Die Ganglienzellen sind dann hell und sind scharf begrenzt, die Protoplasmafortsätze (Dendriten treten deutlich hervor und haben einen schwarzen Färbungsbelag.

\section{S I94.}

Die Vergoldung der Neurofibrillen. Wesentlich verschieden von der gewöhnlich geübten V'ergoldung der Organe und Gewebe rgl. neuntes Kapitel ist die Methode, durch welche die Neurofibrillen in Ganglienzelle und Nerr zur Anschauung gebracht werden sollen. Apathy ist es gewesen, der hier bahnhrechend gewirkt und fur die Vergoldung neue Grundsätze aufgestellt hat.

I. Apathysche Goldmethode. Es darf nicht zur Imprägnation kommen, sondern es geht vielmehr die Absicht dahin, reine Tinktionen zu crhalten und Farbentöne von hellrosa bis dunkelviolett zu erzielen. $\mathrm{Zu}$ dem Zwecke muß das Licht gleichmäßig eindringen können, daher darf man nur dünne Membranen oder feinfasrige Objekte wählen oder man muß das Material, wenn es lompakter ist, in diinne Streifen zerlegen.

Von dem Metallsaize, dem gelben Goldchlorid, wird so viel Lösung verwendet, wic notwendig ist, um das Material damit zu sättigen. IIan muß also an Fliissigkeit ı omal das Volumen des Stuiches nehmen. Die Lösung kann so oft wieder verwendet werden. wic sie noch gelb ist. Gold wirkt kontrahierend auf die Gewebe ein. daher muissen Schnitte aufgeklebt werden. Nach der Vergoldung wird in $I^{\circ}$. Ameisensäure eingebracht. Man lüst kristallisierte Ameisensäure 
ron spez. Gew. 1,223 in Aqua destillata.) Da das Licht zur Reduktion ron allen Seiten in das Objekt eindringen soll, so stellt man die Glasschale mit der Reduktionsflïssigkeit auf einen Spiegel. Es muß stets riel Reduktionsflïsigkeit genommen werden, aber man darf auf die Glasschale keinen Deckel legen. Die Reduktion soll im Tageslichte erfolgen, die Einwirkung direkter Sonnenstrahlen ist wegen der damit verbundenen Erwärmung der Objekte zu vermeiden.

Fixiert wird in Sublimat in Kochsalz gesättigt; oder in Sublimatalkohol (die vorige Lösung mit absolutem Alkohol zu gleichen Teilen vermischt) oder unter Lichtausschluß in Sublimatosmiumsäure Sublimatkochsalzlösung und $1^{\circ}$. Osmiumsäure zu gleichen Teilen). Dic letztere Mischung ist für Vertebraten besonders bestimmt, die beiden ersteren für Evertebraten. Die Stücke dürfen nicht zu dick sein und kommen auf $16-2+$ Stunden in die Fixierungsflüssigkeit. Dann werden sie $0-s$ Stunden ausgewaschen, und zwar sind dem Wasser auf je $100 \mathrm{ccm}$ I $\mathrm{g}$ Jodkalium und $0.5 \mathrm{~g}$ Jod zuzusetzen. Damn werden die Stiicke in $95^{\circ}$. Alkohol übertragen, worin sie über Nacht bleiben, in Jod-Jodkalium-Alkohol gehracht, welcher dieselbe Zusammensetzung hat wie das vorhin erwähnte Waschwasser, zurück in $95^{\circ}$ 。 Alkohol, bis sie gelb geworden sind. Nunmehr wird das Jod-Jodkalium durch absoluten Alkohol entfernt und das Naterial entweder Gurch Chloroform in Paraffin oder auf übliche IVeise in Celloidin eingebettet. Paraffinmaterial hält sich unbegrenzt, Celloidinmaterial muB sofort geschnitten werden oder man mul3 es in Glyzerinleim aufheben. Das geschicht in der Art, daß man den Celloidinblock abwäscht und ihn in eine antiseptisch gemachte Glyzerinleimlösung bringt, welche bei Zimmertemperatur erstarren muß. Zum Schneiden wird der Leim leicht crwärmt, der Block herausgenommen und in lauwarmem IIasser ahgespiilt. Die Paraffinschnitte müssen auf dem ()bjektträger aufgeklebt werden, das Paraffin wird durch Chloroform entfernt und man fuihrt allmählich die Objekte in destilliertes Wasser iiber. In diesem bleiben die Schnitte 2, höchstens 6 Stunden, sie kommen dann in das Goldbad I" gelbes Goldchlorid: Oder man taucht auf I Minute in I". Ameisensäure ein, wäscht ab und bringt in das Goldbad ein. In diesem bleiben die Schnitte $2+$ Stunden, mindestens aber über Nacht, werden in destillicrtes Wasser eingetaucht und in I" Ameisensäure vgl, vorher zur Reduktion eingebracht. Jeder Objektträger wird für sich in einem besonderen Gefäß so aufgestellt, daß die Schnitte nach unten sehen, damit sich kein Gold auf ihnen niederschlägt. Sie miissen gut durchlichtet werden. Nach beendeter Redultion wird in 
Wasser abgewaschen und auf die übliche Weise in Balsam, konzentriertem Glyzerin oder Gummisirup eingeschlossen.

Die Celloidinschnitte werden unter $95^{\circ}$. Alkohol hergestellt und nach IVässerung ebenso behandelt wie Paraffinschnitte.

Die Schnittdicke soll 7 -IO $\mu$ betragen. $5 \mu$ Schnitte sind $z u$ hell in der Färbung, I $5 \mu$ dicke zu dunkel.

2. Jorissche Colloidalgold-Methode. Man fixiert in einer von den beiden folgenden Lösungen: Sublimat $7-8 \mathrm{~g}$, Essigsäure $5 \mathrm{ccm}$, Aqua destillata $100 \mathrm{ccm}$. Darin bleiben die Objekte $4-6$ Stunden und werden in Jodwasser gewaschen. Oder: $2^{\circ}$. Formol $10 \mathrm{ccm}$. Salpetersäure $6 \mathrm{ccm}$, Aqua destillata $100 \mathrm{ccm}$. Fixierungsdauer $2+$ Stunden, sehr kurzes Auswaschen.

Die weitere Behandlung ist nach beiden Methoden identisch. Man bringt zunächst das Naterial für $8--12$ Stunden in molybdänsaures Ammoniak $5 \mathrm{~g}$ + Aqua destillata $100 \mathrm{ccm}$, wäscht aus, härtet in Alkohol von steigender Konzentration und schmilzt in Paraffin ein. Die Schnittdicke kann zwischen $2 \mu$ und $20 \mu$ schwanken, das Optimum liegt bei 7- I $2 \mu$. Um die nachfolgende Färbung erfolgreich zu machen, muß jeder Allohol und jede Spur von molybdänsaurem Ammoniak entfernt werden; man muß also die Schnitte sehr gut, bis mehrere Tage, auswaschen. Gefärht wird in Colloidal-Gold aus der chemischen Fabrik von Heyden in Radebeul bei Dresden), das in $1,5^{\circ}$. wässriger Lösung angewandt wird. Die Substanz lüst sich schwer, man mul die Lösung mindestens 24 Stunden ror dem Gebrauche angesetzt haben. Die Färbung ist nach Io Minuten beendet; längeres Verweilen der aufgeklebten Schnitte im Colloidalgold-Bade ist unangebracht, weil sie dadurch zu dunkel werden. Die Zellen der Oliven und manche Zellen der Großhirn- und Kleinhirnrinde reagieren auf Gold nicht.

3. de Nabiassche Goldmethode. Das Prinzip dieser Methode besteht darin, daß die Gewebe durch Jodlösung für die Vergoldung so empfindlich gemacht werden, daß die schwächsten Mittel zur Reduktion ausreichen. Starke Verdünnung der Lugolschen Lösung. denn mit dieser wird die Jodierung vorgenommen, verzögert die Reduktion, macht aber die Imprägnation zarter (rosa- oder malvenfarben . Die Stiicke des Nervensystems muissen so fixiert werden, daß Jod eintreten kann. Diese mehr als ungenaue Angabe von de Nabias ist dahin zu crliutern, daß zur Fixierung Chromsäure und deren Salze nicht rerwencet werden duirfen. Die Schnitte werden mit sehr verdünter Lugolscher Lösung (achtes Kapitel. - die Verduinnung beträgt 1:1000 Wasser - solange behandelt, bis sie gelb geworden 
sind, werden dann mit Wasser übergossen und in $\mathrm{I}_{10}^{\circ}$ Goldchloridlösung übergefuihrt. Die Reduktion wird in Anilinwasser vorgenommen (achtes Kapitel S. I 79); ist dieses konzentriert, dann tritt die Reduktion in den vergoldeten Schnitten sofort ein, ist es schwach, so dauert dies einige Augenblicke. Dann wird abgewaschen, in Alkohol entwässert und in Balsam eingeschlossen. Statt des Anilinwassers kann man auch die reduzierende Wirkung des Lichtes benutzen. Man setzt die Schnitte im Wasser dem Lichte aus, die Reduktion tritt um so schneller ein, je stärker das Licht ist. Aber auch Ameisensäure nach Apáthy (vgl, vorherj oder Resorcin liefern gute Reduzierungen.

\section{Die Bleimethode.}

\section{§ 195.}

Kronthalsche Bleimethode. In sehr ingeniöser Weise hat Kronthal das a meisensaure Blei zur Färbung der Nervenelemente benutzt. Er stellt es sich selber dar, indem er in wässriges Bleiacetat Ameisensäure solange eintropft, bis alles Blei ausgefällt ist. Jetzt wird filtriert und der Filterruichstand in Wasser gesättigt gelöst.

Frische Gehirn- und Rückenmarkstuicke kommen für 5 Tage in eine Nischung, welche aus gleichen Teilen obiger Lösung von ameisensaurem Blei und $10 \%$ Formol besteht. Dann wird direkt, ohne Auswaschen, in ein Gemisch aus 10\% Formol und Schwefelwasserstoffwasser zu gleichen Teilen ibertragen, nachdem man vorher, um dieses Reagens nicht zu verderben, die Stuckic mit einem aliquoten Teil davon begossen hat. In diesem Schwefelgemisch bleiben die Objekte ebenfalls 5 Tage, werden dann in Alkohol ron steigender Konzentration übertragen und in Celloidin eingebettet. Dic Schnitte werden in Karbolxylol aufgehellt und in Xylolbalsam eingeschlossen.

Bei der Verwendung des ameisensauren Blei hommt es nicht, wie bei der Golgischen Chromsilber-Methode, zu einer - Ausfüllung der Lymphräume der Zellen und Fasern, sondern es findet angeblich eine wirkliche Färbung statt. Diese ist viel vollständiger als bei jeder anderen Methode.

Corning hat die Kronthalsche Methode ctwas verbessert. Er fixiert die Teile des Zentralnervensystems erst in $10^{\circ}$. Formol, ehe er sie in das Gemisch von ameisensaurem Blei und Formol einlegt. Und zweitens bezieht er das Bleisalz von Merck, statt es selber darzustellen. 
4. Die Quecksilbermethode.

$\$ 196$.

Golgische Chromquecksilbermethode. Diese schr vernachlässigte Methode sollte, wenn man überhaupt die Metallimprägnationen vornimmt, mehr als bisher beachtet werden. Freilich erfordert ihre Anwendung sehr viel Zeit.

Man härtet Gehirn und Rückenmark in bekannter Weise in Mïllerscher Flïssigkeit oder in Kali bichromicum. Ist dies geschehen, dann iiberträgt man direkt in Sublimatlösung von $0,25^{\circ}, 0,5^{\circ}$ oder $I^{\circ}$. Die Objekte entfärben sich in der häufig zu erneuernden Flüssigkeit fast völlig, doch dauert es oft Monate, ehe dies Resultat erreicht ist. Die Stiicke künnen unbegrenzt lange in Sublimat bleiben. Man wäscht nach eingetretener Entfärbung gut aus, härtet in Alkohol und schneidet. Es hat sich im Gewebe ein Quecksilberchromat gebildet, das die Zellen färbt.

5. Die Eisen-Tanninmethode.

\$ 197.

Allerhandsche Eisen-Tanninmethode. Das Prinzip dieser, wic es scheint, ganz unbeachtet gebliebenen Methode beruht in ciner Doppelfärbung mit Tinte (Eisen-Tannin) und einer Nachdifferenzicrting mit dem Palschen Verfahren. Allerhand rïhmt der Mcthode Küurze des Verfahrens, Billigkeit und ungewöhnliche Schönheit der Bilder nach. Die Einzelheiten des Verfahrens sind die folgenden:

Das beliebig vorbehandelte Material — Chromhärtung oder Alkoholhärtung bedingen keinen nennenswerten Unterschied - wird in möglichst dünne Schnitte zerlegt. Diese werden für $15-20$ Minuten in eine $50^{\circ}$. Lösung des offizinellen Liquor ferri sesquichlorati getan, wobei es zweckmäßig ist, die Eisenbeize mit den Schnitten mäßig zu erwärmen. Dann wird abgespült und in eine $20^{\circ}$. Tanninlösung übertragen. Letztere hat man sich in folgender 1 Teise bereitet. $20^{\circ}$ Tanninlösung wird durch einmaliges Aufliochen der Substanz in destilliertem IVasser angefertigt. Diese Lösung muß man faulen lassen, indem man den offenen Glaskolben im Sommer in die Sonne. im Winter in den Brïtofen stellt. Das Faulen bewirkt eine teilweise Zersctzung des Tannin zu Gallussäure, Melansäure usw. Nach circa 2 oder 3 Wochen ist die Fäulnis genügend ausgiebig, man filtriert und verwendet das liiltrat, das nicht wieder faulen darf. Denn zu übermäßiges liaulen des Tannin rernichtet die Reduktionshraft des Reagens. 
Die in Eisenchlorid gebeizten Schnitte werden also, wie schon bemerkt, in IVasser kurz abgespült und dann in die vorstehend beschriebene $20 \%$ Tanninlösung gebracht. Man erwärmt die Schale, welche Flüssigkeit und Schnitte enthält, vorsichtig und stellt sie dann für I- 2 Stunden in den Brütofen. Die Schnitte müssen tief dunkelschwarzblau sein, wenn die Reduktion als gelungen betrachtet werden soll; ist das nicht der Fall, was an Alkoholmaterial gelegentlich eintritt, so müssen Beizung und Tannisierung wiederholt werden, wenn auch freilich die Einwirkungsdauer der Reagentien jetzt wesentlich abgegekürzt werden kann.

Nun wird nach dem Palschen Verfahren entfärbt achtes Kapitel Nr. 127 S. 202), nur hat Allerhand die Differenzierungslösung doppelt so stark gemacht. Also: ${ }^{\mathrm{I}}=0$, Kaliumpermanganat, $\mathrm{I}^{\circ}$ 。Oxalsäureund $I^{\circ}$ 。 Natrium sulfurosum-Lösung (vgl. l. c.). Das Resultat der Differenzierung ist: Markscheiden schwarzblau, Zellen mit allen Auslïufern gelb gefärbt, Nucleolus der Ganglienzellen schwarz, Zwischensubstanz entfärbt. Nach beendeter Differenzierung wird sorgfältig gewaschen, für einige Minuten in $\mathrm{I}:$ Essigsäurclösung eingelegt, dann direkt in Alkohol cntwässert, in Xylol aufgehellt und in Balsam eingeschlossen. Die Ansïuerung der Schnitte nach vollendeter Differenzierung macht die Färbung schärfer und erhöht die Haltbarkeit des Materials.

6. Die Chlorpalladiummethode.

§ 198.

Henle-Merkelsche Nervenfärbung. Man bringt Schnitte beliebig fixierten Materials auf etwa ro Minuten in eine $0,05^{\circ}$. wässrige Lösung von Palladiumchlorid, bis sie strohgelb geworden sind. Darauf kommen sic in ammoniakalische Karminlösung; worin sie intensiv rot werden. IVill man die starke Mitfärbung der Neuroglia beseitigen, so soll man nach dem Torschlage von Ranvier auf 5-10 Stunden in eine alkoholische Ameisensäurelösung (Alkohol 2, Ameisensïure I einlegen. Man montiert in gewöhnlicher Weise.

B) Die Osminmmethoden.

$$
\text { \$ I99. }
$$

I. Marchische Methode. Die Neuropathologen bedienen sich dieser Methode, um durch sie den zentralen Verlauf der einzelnen Faserbahnen festzustellen. Man durchschneidet bei Tieren in der Narkose bestimmte Nerven oder hestimmte Hirnteile und tötet nach $2-3$ Wochen. Man untersucht also frische Degenerationen und kann, 
wie Lewandowsky hervorhebt, dadurch den Terlauf geschlossener langur Nerwenbahnen verfolgen. Denn das Prinzip der Methode beruht Carauf, durch Osmium die in der Degeneration begriffenen und daher mit vereinzelten Fettschollen erfiillten Bahnen zu schwärzen. Man verfährt folgendermaßen:

Die vom frisch getöteten Tiere entnommenen Hirn- und Rückenmarkstuicke werden auf $2+$ Stunden in $10^{\circ}$, Formol eingelegt. Nach dieser Zeit hesitzen sie hinreichende Konsistenz, um mit dem Rasiermesser in diinne Scheiben zerlegt werden zu können. Das geschicht nämlich, damit die Chromierung eine gleichmäßige wird und das $\mathrm{Os-}$ mium eindringt. Nan zerlegt die Objekte in $2-3 \mathrm{~mm}$ dicke Stiicke und bringt diese in Mïllersche Lösung ein. Unter häufigem Erneuern der Lösung hleiben die Stiicke \& Tage bis + Wochen darin. Dann kommen sie für 8-I2 Tage in ein Gemisch von 2 Teilen Miillerscher Lösung und I Teil Osmiumsäure von I . Man tut nach Lewandowsky gut, die zu osmierenden Stücke an Fäden in dem Osmiumgemisch aufzuhängen und sie darin $a b$ und $z u$ etwas zu bewegen. Es muß sehr viel Flüssigkeit genommen werden, damit deren Osmiumgehalt ron den Objekte gut ausgenutzt werden hann. $\mathrm{Zu}$ diesem Zwecke empfiehlt es sich oft, die Osmierung hei $37^{\circ}$ C. im Brütofen vorzunehmen. Nan wäscht dann $\mathrm{I}-3$ Tage in IVasser aus, härtet $1-2$ Tage in absolutem Alkohol und bettet num cntweder in Celloidin ein oder klebt die Stiicke mit Kollodium auf Kork auf. Wahrend in ersterem Falle wie nach jeder anderen Celloidineinbettung verfahrun wird, darf man in letzterem höchstens ts Stunden in $80^{\circ}$. Alkohol lassen und mul dann uneingebettetes Naterial schneiden Das hat seinen Ĺbelstand an briichigen oder unzusammenhängenden ()bjekten: bei diesen muß daher jeder Schnitt mit Kollodium uberzogen werden (vgl. siebentes Kipitel S. I 20). Die unter 95 Alkohol angufertigten Schnitte werden nun aufgehellt. Während einige Autoren zur Aufhellung nur Bergamottöl für zulässig erachten, weil anclere Intermedien die Fettschollen angeblich zerstören. sind andere. wic Lewandowsky, weniger ängstlich und hellen in Karbolxylol auf. Letztere Autoren rermeiden aber das Eindecken der Präparate mit unem Dechglase aus Besorgnis, daß das Xylol des Balsams die Fettschollen auflöse, während crstere diese Eventualität nicht befürchten. Aus demselben Grunde betten die einen, die nicht ängstlichen Autren, in Celloidin ein, während die ängstlichen dies vermeiden: dur Xther könnte den Fettschollen geführlich werden. Das Resultat der Marchischen Osmiummethode besteht in einer Schwärzung der Fettscholien in den degenerierenden Nervenbahnen. 
Freilich ist nicht zu rerkennen, daß das Osmium nicht in die Tiefe dringt, daß daher bei etwas beträchtlicher Dicke der Stücke die zentralen Partien ungefärbt bleiben. Solches tritt auch ein, wenn zu wenig Flüssigheit genommen wurde. Außerdem kommt es nach Stransky oft genug zu artifiziellen Schwärzungen; d. h. es treten an Stellen Schollen auf, wo gar keine Degenerationen rorkommen können. Diese ron vielen Seiten gemachte Beobachtung hat zu folgenden Modifikationen geführt:

2. Teljatniksche Modifikation der Marchischen Methode. Um, wie rorhin gesagt, falsche Schwärzungen, also falsche Resultate zu vermeiden, bringt Teljatnik $1,5 \mathrm{~cm}$ dicke Stücke von Zentralnervensystem in eine verdiinnte Mischung von Osmiumsäure + MIillerscher Lösung (den Grad der Verduinnung hat der Autor nicht angegeben!). Dann steigert er den Konzentrationsgrad allmählich bis zur Norm und fuihrt endlich ioffenbar die Stiicke, wenn auch daron nichts gesagt wird) in die Palsche Differenzicrung (Kaliumpermanganat und Oxalsäure: achtes Kapitel Nr. I 2; S. 202i über. Hierin sollen die falschen Schwärzungen schwinden.

3. Buschsche Modifikation der Marchischen Methode. Um den vorhin gerügten Nangel dur Marchischen Methode, nämlich daß sie nicht in die Tiefe dringt, zu beseitigen, hat Busch folgendes Verfahren ersonnen: Stiicke ron I, I $2 \mathrm{~cm}$ Dicke werden nach Formolhärtung in folgendes Gemisch gebracht: Osmiunsäure I g, Natriumjodat $3 \mathrm{~g}$, Aqua destillata $300 \mathrm{ccm}$. Darin bleiben die Objekte 5 bis ; Tage, werden in Alkohol von steigender Konzentration gehärtet und in Celloidin eingebettet. Dic Färbung soll die gleiche sein wie nach der gewöhnlichen Marchischen Methode; nur die normalen Teile treten heller vor.

4. Kaisersche Methode: Osmiumsäure - Eisenhämatoxylin. Kaiser legt größere Stücke von Zentralnervensystem in Müllersche Lösung ein, zerschneidet sie nach 2-3 Tagen, wenn sie genügende Konsistenz erhalten haben, in Scheiben von $\mathrm{I}-2 \mathrm{~mm}$ Dicke, legt auf fernere 5-6 Tage in Mïllersche Lösung ein, bringt dann nach Marchi auf 8 Tage in 2 Teile Muiller +1 Teil $I^{\circ}$. Osmiumsäure. Dann wird ausgewaschen und auf übliche Weise in Celloidin eingebettet. Die Schnitte kommen für 5 Minuten in folgende Eisenbeize: Liquor ferri sesquichlorati ro $\mathrm{ccm}$, Aqua destillata 1 o $\mathrm{ccm}$. Spiritus rectif. $30 \mathrm{ccm}$. Dann spült man flüchtig in Weigertschem Lithionhämatoxylin ab achtes Kapitel Nr. I 26 S. 20 I , bringt in ein zweites Quantum dieser Hämatoxylinlösung für einige Minuten, erwärmt sehr vorsichtig, wäscht ab und differenziert nach Pal (achtes Kapitel Nr. 27 S. 202). 
5. Ramòn y Cajalsche Modifikation der Marchischen Methode. Cajal will bei den nach Marchi osmierten Objekten das Myrelin färben und verfährt dazu folgendermaßen:

Feine Marchischnitte kommen zunächst in destilliertes Vasser und dann in folgendes Hydrochinongemisch: Hydrochinon +3 ; kristallisierter Eisessig $5 \mathrm{~g}$, Aqua destillata $100 \mathrm{ccm}$. Darin bleiben die Schnitte 24 Sekunden, werden einige Sekunden in destilliertem Wasser abgespiilt und kommen nun in ein Silberbad: Argentum nitricum $1 \mathrm{~g}$; Aqua destillata $100 \mathrm{ccm}$, Ammoniak I Tropfen. Dieses Silberbad darf sich durch die Schnitte nicht trüben, man muß sie daher öfters in ein neues Bad übertragen. L̇brigens kann man auch eine $0,75^{\circ}$ 。 Silberlösung nehmen. Die Versilberung dauert zunächst ro Minuten, dann werden die Schnitte in die schon gebrauchte Hydrochinonlösung; in welcher sie bereits $2+$ Stunden verweilten, zuriickgebracht. Nach 2-5 Minuten kurzes Abspülen in MTasser, wiederum ins Silberbad für 5-10 Minuten, Abwaschen in Wasser, dann in folgendes Entfärbungsbad: Kaliumeisencyanür I g, Kaliumkarbonat $0,5 \mathrm{~g}$, Aqua destillata $100 \mathrm{ccm}$. Bei sehr feinen Schnitten kann man auch weniger Kaliumkarbonat nehmen oder kann dieses sogar ganz fortlassen. Im Entfärbungsbad bleiben die Schnitte, bis die weiße Substanz hellbraun ist und die Faserzüge anfangen, schwarz hervorzutreten, d. h. etwa $2-5$ Minuten. Nunmehr bringt man sie zur Fixierung in eine $12^{\circ}$ 。 Lösung ron unterschwefligsaurem Natron und läßt sie darin 2 bis 5 Minuten. Man kann auch, jedoch ohne besonderen Vorteil, Entfarbung und Fixierung in einem Bade vornehmen, welches folgende Zusammensetzung hat: Kaliumeisencyanuir I g, Kaliumkarbonat $0.5 \mathrm{~g}$; unterschwefligsaures Natron io g, Aqua destillata $200 \mathrm{ccm}$. Dieses Bad wird jedes Mal kurz vor dem Gebrauche bereitet, da es nicht aufhebbar ist. Endlich nach dem Fixieren wird in mindestens 2 bis 3 mal gewechscltem destilliertem Wasser 2-3. Minuten ausgewaschen, in Alkohol von $10^{\circ}$ 。 ïbertragen, daraus auf sehr kurze Zeit in Alkohol absolutus eingelegt, in Bergamottöl aufgehellt und in Dammarlack eingeschlossen. Man darf bei der ganzen Operation keinerlei metallische Instrumente verwenden, muß sich vielmehr entweder kleiner Holzstäbchen oder kleiner Röhrchen aus gerolltem Papier bedienen. Resultat: Nervenfasern schwarz oder dunkelkastanienbraun auf hellgelbem Grunde.

r) Methylenblaumethoden.

$\S 200$.

Über die Terwundung des Methylenblau und polychromen Methylenblau zur Färbung ron Schnitten ist das achte Kapitel einzusehen. 
In demselben Kapitel S. 206 findet sich ausführlich die Methode der vitalen Methylenblaufärbung beschrieben. Zugleich ist an der zu zweit genannten Stelle die ältere Bethesche Methode der Fixierung vitaler Färbungen genau auseinandergesetzt. In diesem $\leqslant$ sollen einige speziellere Verwendungsweisen des Methylenblau, die $n$ ur für das zentrale Nervensystem sich eignen, geschildert werden. Und der folgende $\S 20$ I enthält die neuere Methode von Bethe zur Methylenblaufixierung.

I. Nisslsche Färbung. Durch eine eigenartige T"erwendung unseres Farbstoffes hat Nissl die nach ihm benannten Körperchen, die $\mathrm{N}$ isslkörperchen oder die tigroide Substanz, zur Anschauung gebracht.

Das Material - Großhirn, Kleinhirn, Rückenmark, periphere Ganglien - wird in $96^{\circ}$. Alkohol fixiert und ohne Einbettung unter $90^{\circ}$ Alkohol geschnitten. Eine Kontrastfärbung mit sauren Farbstoffen verwirft Nissl ganz.

Die Schnitte werden in folgender Farbflotte gefärbt: Methylenblau B Patent 3,75 5, venetianische Seife $1,75 \mathrm{~g}$, Aqua destillata $1000 \mathrm{ccm}$. In ein Uhrschälchen wird ein aliquoter Teil der Farbflotte gegeben. die Schnitte werden hineingetan und nun wird über der Spiritusflamme erhitzt, bis mehrere Luftblasen hörbar zerplatzen. Dann wird in Anilinöl-Alkohol ausgewaschen: wasserhelles Anilinöl, das sorgfältig vor Licht behütet werden muß, io $\mathrm{ccm}$ und $46^{\prime \prime}$. Alkohol go ccm. Hierin bleiben die Schnitte, bis keine Farbstoffwolken mehr ausgehen. Dann bringt man sie auf einen Objektträger, trocknct sie mit Filtrierpapier ab. hellt mit Cajeputöl auf, saugt dieses mit Filtrierpapier $a b$, bringt Benzin auf, um das Öl auszutreiben, tut Benzinkolophonium auf die Schnitte, erhitzt, bis alle Benzingase verschwunden sind, und deckt mit einem Deckglase ein. Das Benzinkolophonium stellt man dar, indem man auf Kolophonium Benzin gießt und $24-30$ Stunden stehen läßt. Die sich oben abscheidende durchsichtige Masse ist gebrauchsfertig.

2. Cajalsche Methylenblau-Färbung. Ramon y Cajal bestreut frische Gehirnschnitte mit Methylenblaupulver, fixiert nach Bethe (achtes Kapitel S. 207 und härtet in $1^{\circ}$ 。 Platinchloridlösung $5 \mathrm{ccm}$. Formol $40 \mathrm{ccm}$, Aqua destillata $60 \mathrm{ccm}$.

3. Modifikation von de Gothard. Schnitte. die nach Nissls Vorschrift gefarbt sind, differenziert de Gothard in folgendem Gemisch: Cajeputöl to ccm, Iylol $50 \mathrm{ccm}$, Kreosot $50 \mathrm{ccm}$, absoluter Alkohol $160 \mathrm{ccm}$. Er bettet aber auch in Celloidin ein, färbt mit polychromem Methylenblau die Schnitte und differenziert in dem eben genannten Gemisch. Dieses soll leicht in die Schnitte ein- 
dringen, das Celloidin lösen und dann seine differenzierende Virkung entfalten.

4. Teljatniksche Modifikation. Die Nisslsche Ganglienzellfärbung: modifiziert Teljatnik folgendermaßen: Die Schnitte, welche von dem in $96 \%$ Alkohol gehärteten Naterial stammen, werden 15 Minuten bei Zimmertemperatur in nachstehender Farbflotte gefärbt: Nethylenblau I3 Patent $3,75 \mathrm{~g}$, Sapo venetus marmoratus $1,75 \mathrm{~g}$; Aqua destillata $1000 \mathrm{ccm}$ (also genau die Nisslsche Fürbung). Sie werden in Wasser abgewaschen und in Anilinöl I ccm $+96 \%$ Alkohol Io $\mathrm{cm}$ differenziert. Aufhellen in Origanumöl, Einschließen in Kanadabalsam.

5. Ilbergsche Methylenblaumethode. Das Prinzip dieser Methode besteht im Gegensatz zu den bisher beschriebenen in einer Durchfärbung der Stücke. Diese, also Hirntcile, Rückenmarksteile usw. kommen, je nach ihrem Volumen, für 5-1o Tage nach der Härtung: in die Nisslsche Methylenblaulösung (vgl. oben). Dann wird in g6 $0^{\circ}$, Alkohol 2-3 Tage lang ausgewaschen und auf üblichem Wege in Paraffin cingeschmolzen. Die Schnitte werden nicht aufgeklebt, sondern vom Messer direkt in Xylol gebracht. Dann legt man sie zur Differenzierung in $96^{\circ}$. Alkohol ein und, falls dicser nicht genügend wirkt, in das von Nissl angegebone Anilinöl-Alkohol-Gemisch ivgl. oben). Daraus in absoluten Alkohol, Xylol, Xylolbalsam.

6. Heldsche Methylenblaumethode. Gleich Ruzicka ist Held der Ansicht, daß dic Nisslschen Körper, die Tigroidsubstanz, keine Bestandteile der frischen normalen Ganglienzellen seien, sondern daß sie erst aufträten, wenn die Ganglienzellen mit Säuren behandelt wiirden. Härtet er nämlich in $80^{\circ}$. Alkohol Stiicle von Zentralnervensystem, dem er ${ }^{\mathrm{S}}{ }_{40} \mathrm{C}^{\mathrm{I}}+{ }_{4}^{\circ}$ Natronlauge zugesetzt hat, so fehlen die Nisslkürper völlig, statt ihrer sind Lücken vorhanden. Seine Methode der Methylenblaufärbung ist die folgende:

Er färbt aufgeklebte Paraffinschnitte zunächst in einer sauren Erythrosinlösung; (Erythrosin Grübler I \&, Aqua destillata I $50 \mathrm{ccm}, 2$ Tropfen Eisessig), welche er I-2 Minuten lang erwärmt. Dann wird in Wasser gewaschen, in eine Methylenblaulösung eingebracht, welche aus Nissls Gemisch und $5 \%$ Acetonlösung zu gleichen Teilen besteht. Die Farbflotte wird so lange erwärmt, bis der Acetongeruch verschwunden ist. Die Objektträger - denn auf diesen wird die Färbung vorgenommen - läßt man abkiihlen und bringt zur Diff́crenzierung in $O, I^{\circ}$. Alaunlösung ein. Sowie die Schnitte wieder rötlich sind, wird in Wasser abgespiilt, schnell in absolutem Alkohol entwässert und durch Xylol in Benzinkolophonium vgl. oben) ein- 
geschlossen. Die Bilder sind sehr verschieden, denn die Nisslschen Körper sind nur körnige Fällungen.

7. Methylenblau-Fuchsinfärbung, nach Ramòn y Cajal. Um die Struktur des Nervenplasma zu studieren, empfiehlt Ramòn y Cajal zunächst Fixierung in Sublimat und nach üblicher Weiterbehandlung dic Färbung der Schnitte in folgender Farbflotte: $1 \%$ wässrige Lösung von Methylenblau $\beta$ und $1 \%$ wässrige Fuchsinlösung werden zu gleichen Teilen gemischt. Nach beendeter Färbung wird in Alkohol entfärbt. Resultat: Farbspindeln blau, Nucleolen der großen Ganglienzellen, chromatisches Netz der Neurogliazellen und kleine Ganglienzellen rot oder rotviolett.

8. Sahlische Färbung mit Methylenblau-Säurefuchsin. Man hïrtet am besten Stücke von Zentralnervensystem in $3 \%-4 \%$ Kali bichromicum-Lösung. Die Schnitte, von nicht celloidiniertem Material angefertigt, werden 5- io Minuten in Wasser gewaschen und kommen dann in konzentrierte wässrige Methylenblaulösung, worin sie tief dunkelblau werden müssen. Damn werden sie in Wasser gespiilt und auf 5 Minuten in gesättigte wässrige Säurefuchsinlösung übergeführt. Nach kurzem ibwaschen werden sie für wenige Sekunden in $0,1 \%$ Itzkalialkohol nach Weigert iibertragen (vgl. $\$$ 202) und sofort in viel Wasser gewaschen. Hier differenziert sich das Farbenbild. Die weiße Substanz erscheint für die Betrachtung mit bloßem Auge blau bis violett, die graue Substanz ist rot. Man entwässert in Alkohol, hellt in Cedernöl auf und schließ3t in dickem Cedernölbalsam ein. Das Bild, welches man erhält, ist ein ganz merkwürdiges (vgl. achtes Kapitel S. 160). Einige Nervenfasern besitzen cine rote, andere eine blaue Narkscheide inach der rom Autor veröffentlichten Figur zu schließen). Die Präparate sind nicht haltbar. Unterläßt man die Anwendung des Ätzkalialkohols, dann sind die Achsenzylinder rot, die Markscheiden blau.

9. Bethesche Methylenblaumethode für Evertebraten. Bei Astacus wendet Bethe folgendes Verfahren an: 5 Tropfen einer I". Methylenblaulösung 'Ehrlich-Grübler) kommen auf die venösen Herzostien, nach Io Minuten werden die zu untersuchenden Stücke herausgeschnitten und in die feuchte Kammer gebracht. Nach 3 bis 4 Stunden ist das Optimum der Färbung erreicht.

$\$ 20 I$.

Neuere Bethesche Methode der Fixierung von Methylenblaufärbungen. Im achten Kapitel bei Beschreibung der vitalen Färbung mit Methylenblau wurde die Nethode geschildert (1. c. S. 20\%), 
welche Bethe vor längerer Zeit zur Fixierung dicser sonst so vergänglichen Färbung angegeben hat. Hier an dieser Stelle möge die neuere Fixierungsmethode ihren Platz finden, welche gegen die frühere insoweit verbessert ist, als die Eiskühlung fortfällt.

Die Stücke duirfen nicht zu groß sein, wenn die Fixierung statthaben soll. Sind sie mit Methylenblau gefärbt - offenbar wird beliebige Durchfärbung vorgenommen - , dann werden sie mit pikrinsaurem Ammoniak in wässriger Lösung (nicht in glyzeriniger vgl. achtes Kapitel S. 20 ) IO- I 5 Minuten lang vorfixiert. Darauf kommen sie, ohne daß sie abgewaschen werden, in eine der folgenden 6 Lösungen:

I. Ammoniummolybdat I $\mathrm{g}$; Aqua destillata $20 \mathrm{ccm}$, offizinelle Salzsäure I Tropfen. 2. Ammoniummolybdat I g, Aqua destillata Io ccm, $2 \%$ Chromsäure ro ccm, offizinelle Salzsäure I Tropfen. 3. Ammoniummolybdat I $\mathrm{g}$, Aqua destillata $\mathrm{ro} \mathrm{ccm}, 0,5^{\circ}$. Osmiumsäure Io ccm, offizinelle Salzsäure I Tropfen. 4. Phosphormolybdänsaures Natron I $\mathrm{g}$, Aqua destillata $20 \mathrm{ccm}$, offizinelle Salzsäure I Tropfen. 5. Phosphormolybdänsaures Natron I $g$, Aqua destillata Io $\mathrm{ccm}, 2 \%$ Chromsäure ro ccm, offizinclle Salzsäure I Tropfen. 6. Phosphormolybdänsaures Natron I $\mathrm{g}$, Aqua destillata I o $\mathrm{ccm}, 0.5^{\circ}$. Osmiumsäure Io ccm, offizinelle Salzsäure I Tropfen.

$\mathrm{Zu}$ diesen Lösungen kann man I $\mathrm{ccm}$ Wasserstoffsuperoxyd setzen.

Zur Herstellung der aufgezählten 6 Lösungen sei das Folgende bemerkt: Dic Miolybdate werden unter Erhitzen in Wasser gelöst, bis, und dies ist sehr wichtig, keine Trübung mehr vorhanden ist. Der Salzsäurezusatz gibt weiße IVolken freier Molybdänsäure bei den ersten Flüssigkeiten. Durch Schütteln lösen sich diese Wolken zu sauren Salzen. Bei den Flüssigkeiten $4-6$ entstehen gelbe Wolken von freier Phosphormolybdänsäure, welche man in gleicher IVeise zum Schwinden bringt.

Im allgemeinen sind die ersten 3 Lösungen vorzuziehen. Lösung I und + ist bei dicken Objekten ohne Nachfärbung angebracht, ähnlich Lösung 2 und 5. Die Lösungen 3 und 6 sind entweder nur für Schnitte oder sehr dünne Totalpräparate verwendbar und geben hier die besten Fixierungen. Sie sind auch für Nervenendigungen brauchbar.

Die Nachfixicrung nimmt im allgemeinen 45-60 Minuten in Anspruch; bei den Lüsungen 3 und 6 aber sind 4-12 Stunden erforderlich. Dann wird in W'asser gewaschen und entweder in der üblichen Weise in Paraffin eingeschlossen oder man kann, bei sehr 
dünnen Objekten, aus Alkohol direkt in Xylol bringen und dann in Balsam aufheben. Will man nachfärben, so sind dazu Alaunkarmin, Alauncochenille oder neutrale Aniline geeignet.

§) Andere Anilinfarben.

$\S 202$.

I. Weigertsche Säurefuchsinmethode. Es war dies die erste Nethode, welche IVeigert zur Untersuchung der Nervenbahnen im Zentralnervensystem empfohlen hatte. Heute wird sie kaum noch angewendet, da ihr die Weigertsche Hämatoxylinmethode achtes Kapitel Nr. 126 S. 200) den Rang abgelaufen. Und zwar mit Recht, denn die Säurefuchsinmethode ist umständlich und, nach meinen früheren Erfahrungen, keineswegs absolut zuverlässig. Im Interesse der historischen Gerechtigkeit soll sie jedoch hier ihren Platz finden.

Gehirn bez. Rückenmark werden in Müllerscher Lösung fixiert und in Alkohol erhärtet. Dic von nicht cingebettetem Material hergestellten Schnitte werden in eine gesättigte wässrige Lösung von Säurefuchsin eingelegt. worin sie Stunden, oft auch Tage verweilen miissen. Dann werden sie in Wasser abgewaschen (nicht ausgewaschen) und in Itzkalialkohol übergefuhrt. Letzterer wird auf folgende Art angefertigt: In $100 \mathrm{ccm}$ Alkohol absolutus bringt man I $\mathrm{g}$ Kali causticum fusum und läßt 24 Stunden stehen. Dann hat sich gelüst, was sich lösen kann. Ton dieser Stammlösung werden Io ccm mit in $\mathrm{ccm}$ Alkohol absolutus rermischt, sodal3 man eine circa $0, I^{\prime}$ ' L'sung von Ätzkali in Alkohol erhält. Der gefärbte Schnitt wird in diesen verdünnten Ätzkalialkohol gebracht und gibt darin sofort Farbe ab. Man bewegt ihn dauernd in der Flissigkeit, bis die graue Substanz deutlich hervortritt. Nun wird in destilliertem Nasser abgewaschen, das mehrere Male zu erneuern ist, bis keine Farbstoffwolken mehr entweichen. Dann Alkohol, Xylol, Kanadabalsam. Resultat: nur die weiße Substanz bez. die Nervenfasern sind rot gefärbt, dic graue Substanz ist hell.

2. Toluidinblaufärbung nach Bethe zur Darstellung der Neurofibrillen und der Golginetze. Bethe hat diese etwas komplizierte Methode als Molybdänverfahren bezeichnet; die einzelnen Phasen der Methode sind die folgenden:

a) Fixieren. +-io $\mathrm{mm}$ dicke Stiiche von Zentralnervensystem werden auf Filtrierpapier gelegt und dann in $3 \%-7,5 \%$ Salpetersäure getan. Unter wiederholtem Umwenden bleiben die Stücke darin 24 Stunden. (Das Filtrierpapier soll verhüten, daß die frischen Rückenmark- usw. Stiicke auf dem Boden der Glasschale gewisser- 
maßen ankleben, wodurch die fixierende Fliissigkeit nicht von allen Seiten an das Matcrial treten kann.) Die Salpetersäure, von welcher die channten V'erdinnungen herzustellen sind, soll ein spezifisches Gewicht von 1,40 haben. Die starken Konzentrationen sind bei niclerer Temperatur, cie schwachen bei hoher Temperatur der L'mgebung anzuwenden; die Fixierung ist dann für beide Konzentrationsgrade identisch. Bei starker Nitrierung des Materials tretcn die Golginetze, bei schwacher die Neurofibrillen besonders gut hervor.

b) Härten. Aus der Salpetersäure kommen die Objekte direkt in $g t^{\circ}$ 。. Alkohol fuir mindetens $12-2+$ Stunden. Ein mehrtägiger Aufenthalt im Alkohol schadet nichts.

c) Ammoniak-Alkohol. Aus dem 96\% Alkohol werden die ()bjekte fur $12-2+$ Stunden in folgenden Ammoniak-Alkohol eingebracht: Ammoniak spezifisches Gew. 0,95-0,96) I Teil, Aqua destillata 3 Teile, $c 6^{\circ}$, Alkohol \& Teile. Dieses Gemisch soll nicht iiber $20^{\prime \prime}$ C. warm sein. Aus diesem alkalischen kommen nach der angegebenen Zeit die Objekte in neutralen Alkohol.

d) Weiterbehandeln. Aus dem neutralen A.lkohol wird das Taterial in einen Salzsäurealkohol von folgender Konzentration gebracht: konzentrierte Salzsäure (spezifisches Gew. I, I $8=37^{\prime \prime}$ ") I Teil, Aqua destillata 3 Teile, $96 \%$ Alkohol 8-12 Teile. Nach 12-24 Stunden direktes Einbringen in neutraien Alkohol für $10-2+$ Stunden, dann für 2-6 Stunden in Aqua destillata. Ein längeres Wässcrn ist unter allen Umständen zu vermeiden. Nun folgt das

e Molybdänicren. Das zu verwendende molybdänsaure Ammon soll ein weißes Präparat sein, da dieses besser wirkt als das gelbe. Nan bringt die Objekte aus cen VTasser in cine $4^{\circ}$. Lösung ron molybdänsaurem Ammoniak und läßt sie darin $2+$ Stunden. Bei niedriger Temperatur werden mehr die Fibrillen, bei höherer mehr die Golginetze zur Darstellung gebracht.

f) Einbetten. Nach Beendigung des Molybdänierens wird kurz in Aqua destillata abgespuilt, in $90 \%$ Alkohol auf höchstens $2+$ Stunden eingehracht, dann in absoluten Alkohol bis $2+$ Stunden, Xylol oder Chloroform, Paraffin. Celloidin ist streng zu vermeiden.

Bei der später zu schildernden Differenzicrung treten zuerst clie Fibrillen und dann die Golginetze hervor. Dann werden die Fïbrillen undeutlicher, schwinden schlicßlich ganz und es sind nur noch die Golginetze vorhanden. Für die Zellen des Rückenmarkes und der Spinalganglien gibt daher Bethe folgende Modifikation an: Aus dem Ammoniakalkohol c/ kommen die Objekte für 6- r 2 Stunden in neutralen Alliohol, 2-6 Stunden in Wasser und 2t Stunden in $4^{\circ}$ 。 
Molybdänammonium. Es fällt also die Behandlung mit salzsaurem Alkohol weg.

g) Schneiden. Die Paraffinschnitte werden nur mit Eiweiß aufgeklebt: die Verwendung ron Eiweiß und Wasser ist unzulässig, weil das Wasser das Molybdän auszieht. Die Schnittdicke soll io $\mu$ betragen. Die aufgeklebten Schnitte kommen in Xylol, dann in Alkohol, dann auf kurze Zeit in Wasser.

h) Differenzierung und Färbung. Für jeden Paraffinblock und für jede Zellart muissen diese Prozeduren besonders ausprobiert werden. Auch ist zu beachten, daß im Innern des Paraffinblockes sich die Differenzierungsfähigkeit ändert.

Die auf dem Objektträger aufgeklebten Schnitte werden, um aus ihnen die letzte Spur von Alkohol zu entfernen, mit der Spritzflasche (Wasser; abgespritzt. Die Objektträger werden an den Rändern mit einem reinen Tuche abgetrocknet. Auf die Schnittseite der Objektträger liommt eine dünne Schicht von Acjua destillata, die man mit der Spritzflasche auf den horizontal gelegten Träger aufspritzt; diese Wasserschicht ist etwa $1,5-2 \mathrm{~mm}$ dick und repräsentiert somit ein Quantum von I-I,5 ccm Wasser. Mit dieser Wasserschicht wird der Objekttrïger auf 2-10 Minuten (hüchstens I2 Minuten) in einen auf $55^{\prime \prime}-60^{\circ} \mathrm{C}$. erhitzten Wärmeschrank gelegt. Dann nimmt man ihn heraus, gießt das noch ctwa draufstehende Wasser ab, spiilt 3-4mal mit frischen destilliertem Wasser kurz ab, trocknet die Ränder des Objektträgers und bringt nun die Farblösung auf dic Schnitte. Wie vorhin die $1,5 \mathrm{~mm}$ hohe Wasserschicht, so bringt man jetzt eine ehenso hohe Schicht von Toluidinblaulösung ( $\&$ Farbstoff auf $3000 \mathrm{ccm}$ Aqua destillataj auf dic Schnitte und legt den so beschickten Objektträger in denselben Wärmeschrank bei gleicher Temperatur. Nach Io Minuten wird herausgenommen, der Farbstoff mit Vrasser aus einer Spritzflasche abgespuilt und der Objektträger in $96^{\circ}$. Alkohol gebracht. Hierin lüst sich der nicht an das Molybdän gebundene Farbstoff mit blaugriiner Farbe. IVenn kein Farbstoff mehr ausgeht, nach $34-2$ Ninuten, wird in absoluten Alkohol eingebracht, dann in Xylol und Balsam. Absolut notwendig ist die volle Wasser- und Alkoholfreiheit der Schnitte. Zum Einschluß wird der neutrale Kanadabalsam aus dem Grüblerschen Institut empfohlen.

Gut differenzierte Präparate sind violett bis rötlichviolett; blaue sind schlecht differenziert. Kleinhirn und Großhirn differenzieren in 2-6 Minuten (bei $58^{\circ} \mathrm{C}$ ), Rückenmark in 5-ro Minuten.

Bei Evertebraten erleidet die beschriebene, nur für Vertebraten giiltige Methode mancherlei Abänderungen. 
Bei Hirudo wird in konzentrierter Sublimatlösung i 2 Stunden fixiert, dann in Jodalkohol (vgl viertes Kapitel) fuir 24 Stunden iiberfuihrt und wic üblich in Paraffin eingeschmolzen. Die Schnitte kommen auf ro Minuten in eine $\mathrm{I}^{\circ}$. Lösung von Ammoniummolybdat, dann auf ro Minuten in Aqua destillata und werden 5 Minuten lang bei $58^{\circ} \mathrm{C}$. in Toluidinblaulösung ( $: 3000$, gefärbt. Will man die Fibrillen darstellen, dann muß das in Sublimat fixierte Stück mit Ammoniak und mit Salzsäure ausgezogen und dann molybdäniert werden (vgl. vorher. Die Schnitte von solchem ausgezogenen Material sind immer zu differenzieren und zwar verwendet man dazu wässrige Lösungen von Ammoniak oder alkoholische Lösungen von Natriumkarbonat. Die Ammoniaklösungen enthalten I Teil gewöhnliches Ammoniak auf 500-2000 Teile Aqua destillata. Die Natriumkarbonatlösungen stellt man sich folgendermaßen her: I Teil einer $1 \%$ Sodalösung (in Wasser) wird mit Io-30 Teilen Alkohol von $50^{\circ}$. rersetzt. In diesen Lösungen bleiben die Objektträger 2 bis so Sekunden, werden schnell mit Wasser resp. Alkohol abgespritzt und kommen auf 5 Minuten bei $58^{\circ} \mathrm{C}$. in eine Toluidinblaulösung von $1: 3000$.

Bei Carcinus und Astacus wird in folgender Mischung fixiert: 3 Teile konzentrierte Pikrinsäurelösung + I Teil konzentrierte Lösung ron pikrinsaurem Ammoniak. Die Ammoniakschnitte zeigen of ohne weiteres die Fibrillen.

3. Thioninfärbung, nach Lenhossék. Man bringt Teile des Zentralnervensystems für 2 Tage in $5^{\circ}$. Formol, dann für 2 Tage in absoluten Alkohol und bettet in Paraffin oder Celloidin ein. Die Schnitte werden 5 Minuten in konzentrierter wässriger Losung von Thionin gefärbt, dann zur Differenzierung nach kurzem Abwaschen in ein Gemisch ron I Teil Anilinöl + ı Teile Alkohol absolutus eingebracht, in Cajeputöl aufgehellt, dann Xylol, Dammarlack oder Kanadabalsam. Die Präparate halten sich nicht.

4. Congorotfärbung, nach Rehm. Schnitte ron alkoholischem Naterial kommen für einige Minuten in eine konzentrierte wässrige Congorotlösung. Dann werden sie in salzsaurem (oder salpetersaurem Alkohol ro Minuten lang extrahiert - sie werden darin blau - dann neutraler Alkohol, Origanumöl, Balsam. Die Notwendigkeit dieser Methode vermag ich nicht einzusehen, denn das Congorot ist, nach meinen Erfahrungen mit dicsem Farbstoffe, beim Zentralnervensystem gänzlich wertlos.)

5. Fuchsinfärbung, nach Sadowsky. Das Material wird in $10^{\circ}$ Formol fixiert und auf hekannte Weise - ohne Nachfixierung - 
in Celloidin eingebettet. Die Schnitte werden ${ }_{/ 2}^{\mathrm{T}}-3$ Minuten in Karbolfuchsin gefärbt 'achtes Kapitel Nr.6 6 S. I 8 I), dann in I ${ }_{0}$ Essigsäure so lange differenziert, bis die beiden Substanzen sich scharf abheben. Dann absoluter Alkohol, Xylol, Balsam. Das Fuchsin soll die Nisslkörper stärker färben als das Methylenblau.

6. Kresylviolettfärbung, nach Bielschowsky. Alkohol- oder Formolmaterial wird in Celloidin eingebettet. Die Schnitte lommen fuir 24 Stunden in folgende Farbflotte: 6- Io Tropfen konzentrierter wässriger Lösung von Kresylviolett auf $50 \mathrm{ccm}$ Aqua destillata. Die gefäbten Schnitte werden rasch durch Wasser gezogen, dann in Alkohol von steigender Konzentration gebracht, durch Cajeputöl und Xylol in Kanadabalsam eingeschlossen.

€) Die Hämatoxylinmethoden.

$$
\$ 203 .
$$

Die Hämatoxylinfärbungen des Zentralnervensystems dienen in erster Reihe der Erforschung des zentralen Verlaufes der Nervenbahnen. Es beruht dies auf der Eigenschaft des Hämatoxylins, das Nervenmark bei bestimnter Behandlung intensiv zu färben, so daß dieses die Farbe festhält, während die gliösen und zelligen Teile die Farbe leicht abgeben. Neuerdings hat Apathy eine Methode angegeben, welche das Färben der Neurofibrillen mit Hämatoxylin gestattet; über sie wird der nächste § berichten.

Unter allen zur Färbung der Nerrenbahnen in Gehirn und Rüclienmark angegebenen Methoden nimmt die Weigertsche Hämatoxylinfärbung unstreitig den ersten Rang ein achtes Kapitel Nr. I 26 S. 200,. Man kann sie an Müller-Material oder an Formolmaturial, das nachher mit Kali bichromicum behandelt wurde, anwenden und wird selten einen Fehlschlag habcn. Dem in achten Kapitel 1. c. gesagten habe ich nichts hinzuzufiigen; nur erneut will ich hervorheben, daß man Hämatoxylin, nicht Hämatein verwenden muß. Nach meinen Erfahrungen tritt bei Huftieren die Entfäbung, d. h. die Differenzierung; am schwersten unter allen Säugern ein; hier habe ich 'rgl. achtes Kapitel, die Entfärbungsflissigkeit in doppelter Konzentration anwenden müssen.

Die viclgeübte Palsche Modifikation ist cbenfalls in achten Kapitel (Nr. I27 S. 202, beschrieben worden. Hier mögen einige Modifikationen folgen, die cmpfohlen sind und gebraucht werden; notwendig sind diese Modifikationen aber nicht.

I. Kultschitzkysche Hämatoxylinfärbung. I g Hämatoxylin wird in einer ganz geringen Quantitat absoluten. Mlkohols gelöst. Dieses 
Hämatorylin gießt man in ein Gemisch aus $20 \mathrm{ccm}$ gesättigter wässriger Borsiturelösung und so ccm. Aqua destillata. Nach 2-3 Wochen ist die Lösung brauchbar, weil sie dann reif ist. Nimmt man nur $0.25 \mathrm{~g}$ Hämatoxylin in alkoholischer Lösung, dann ist das Borsäuregemisch sofort verwendbar. Man gießt einen aliquoten Teil der Hämatoxylinlösung in cin Lhrschälchen und giebt dazu 2-3 Tropfin Essigsäure. Die ron celloidiniertem Müller-Material angefertigten Schnitte werden I\&-2+ Stunden gefärbt und dann in Alkohol ahgewaschen. Nur die marhhaltigen Nerren sind gefärbt und zwar intensiv blau, die übrigen Substanzen sind gelblich oder fast farblos. Säuert man die Farblösung nicht an, dann gelingt die Färbung nicht.

Kultschitzky hat die eben geschilderte Methode folgendermaßen modifiziert. I $g$ Hämatoxylin in einer geringen Menge von absolutem Alkohol gelüst wird in $100 \mathrm{ccm} 2^{\circ}$ 。 Essigsäure gegeben; es ist sehr lange Zeit zum Ausrcifen nötig. Man fürbt $2+$ Stunden und wäscht in Alkohol aus.

2. Berkleysche Osmium-Kupfer-Hämatoxylinfärbung. Man fixiert Stucke ron nur 2,5 $\mathrm{mm}$ Dicke 24-30 Stunden in Flemmingscher Lüsung (viertes Kapitul bei $25^{\circ} \mathrm{C}$. Dann wird direkt in absoluten Alkohol iiberfihrt, den man innerhalb $2+$ Stunden zweimal erneuern muß. Aus dem Alkohol bringt man für 12 bis $2+$ Stunden in Celloidin ein und schneidet nachher unter $95^{\circ}$. Niliohol. Die sehr diinnen Schnitte fängt man in TVasser auf und bringt sie in eine gesättigte wässrige Lösung ron Kupferacetat. Erwärnt man ${ }^{\mathrm{I}}$ : Stunde lang auf $35^{11}-70^{\circ} \mathrm{C}$, , so sind die Schnitte unmittelbar darnach rerwendbar, läßt man dagegen bei Zimmertemperatur stehen. so muß die Kupferung bis zum nächsten Tage fortgesetzt werden. Dann wird in IVasser abgewaschen und in eine auf folgende Art hergestellte I Iämatoxylinlösung eingebracht: $50 \mathrm{ccm}$ Aqua destillata werden gründlich gekocht und dazu $2 \mathrm{ccm}$ gesättigter Lösung ron Lithion carbonicum gefuigt. Jetzt kocht man wiederum I Minute lang und fügt $\mathrm{I}, 5-2 \mathrm{ccm}$ einer alkoholischen Hämatoxylinlösung hinzu io $\mathrm{g}$ Hämatoxylin in $100 \mathrm{ccm}$. Alkohol absolutus gelöst). Man schiittelt gut durch, rerkorlit und läßt $2+$ Stunden stehen; dann ist die Lijsung brauchbar. Die Schnitte kommen in eine Glasschale mit diesen Hamatoxylin, die Schale wird auf ein geheiztes IVasserbad gestellt und so die Färbung bei $40^{\circ} \mathrm{C}$. in etrva $15-25$ Minuten ausgefuhrt. Dann lälst man abhïhlen, wäscht in Wasser aus und bringt in Weigerts Borax-Blutlaugensalzlösung achtes Kapitel S. 20r, welche bis ${ }^{\mathrm{I}}$ mit destilliertem Wasser verdiunt ist. In I--3 Minuten ist die Differenzierung beendet; dann wird ausgewaschen und auf 
iibliche Weise in Kanadabalsam eingeschlossen. Die feinsten markhaltigen Fasern sollen sich hierbei erhalten.

3. Woltersche Hämatoxylinfärbungen. Material, das in Mïller scher Flüssigleit fixiert war, wird in üblicher Weise in Celloidin eingebettet. Die Schnitte kommen auf $2+$ Stunden bei $45^{\circ} \mathrm{C}$. in dic oben erwähnte modifizierte Hämatoxylinlösung von Kultschitzky (Hämatoxylin und Essigsäure), werden herausgenommen und nun in Miillersche Fliissigkeit zurückgebracht. Der so entstandene Chromlack des Hämatoxylins wird nach der Methode der Palschen Hämatoxylinfärbung differenziert achtes Kapitel $\mathrm{Nr}$. I2; S. 202).

Tanadium-Hämatoxylin. Diese Methode soll sich in erster Linic für das in Müllerscher Flüssigkeit fixierte Kleinhirn eignen. Die Schnitte kommen in folgende Beize: Io "Lüsung ron Tanadium chloratum 2 Teile, Liquor Aluminis acetici \& Teile. In der Beize bleiben die Schnitte wahrscheinlich Io Minuten.) Dann für 24 Stunden? in Kultschitzlysche Hämatorylinlüsung (Essigsäure). Resultat: Markfirbung und Färbung der Dendriten der l'urkinjeschen Zellen.

besser noch soll es sein. das . Iaterial in der für Neurogliastudien angegehenen Kultschitzhyschen Fliissiglieit vigl. ș 205) zu härten und Lann die ron celloidiniertem Material heresestellten Sichnitte nach der eben beschrichenen Vanadiumbeize in Kultschitzkyschem Essigsäure-Hämatoxyliin z + Stunden a uf dem Brïtofen $z u$ färben. Dic Schnitte werden in $80^{\circ}$, Alkohol, welcher mit Salzsiuture angesïuert ist. so lange differenziert, bis sie cinen heliblauroten Ton haben.

i. Stoeltznersche Eisenhämatoxylinfärbung. Das Material wird in Formol fixiert und in Celloidin eingebettet. Die Schnitte kommen auf 5 Minuten in den offizinellen Liquor ferri sesquichlorati. Dann werden sie in destilliertem Wasser gewaschen und für mindestens 10 Minuten in eine $0,5^{\circ}$. wässrize Hämatoxylinlüsung übertragen. Ein längeres Verweilen in der Farbfotte ist von Vorteil. Darauf wïscht man in destilliertem Wasser aus und differenziert entweder in der Weigertschen Borax-Blutlaugensalzlösung (achtes Kapitel S. zor oder in der $\mathrm{I}$ ofach verdïnnten Eisenbeize. Letztere Vorschrift verwertet die bekannte firberische Erfahrung, daß die Lache in einem Üherschuß der Beize sich lösen (vgl. Heidenhainschen Hämatoxylineisenlack S. I 99).

\section{$\$ 204$.}

Apathysche Neurofibrillenfärbung mit Hämateïn. Das Material wird in wässriger Sublimatlösung; Sublimat-Alkohol, Sublimatessigsäure, Pikrinsublimatessigsäure, Pikrinsäure, Pikrinschwefelsäure, Zen- 
kerscher Lösung oder Sublimat-Osmiumsäure fixiert (achtes Kapitel). Welche Lösung man auch wähle, jede muß kalt angewendet werden. Die Stüclie von höchstens $5 \mathrm{~mm}$ Dicke kommen in die Apáthysche Hïmateinlösung I A (achtes Kapitel Nr. 32 S. I74), bleiben darin mindestens 48 Stunden bis zu 3 Tagen. Längerer Aufenthalt in der Farbflotte könnte leicht schädlich werden. Dann wird 24 Stunden in häufig erneuertem Aqua destillata ausgewaschen. Die Schwierigkeit der Methode besteht darin, die richtige Auswaschung zu treffen. Nan bringt daher vorteilhafterweise auf $3-5$ Stunden in etwas kalkhaltiges gewöhnliches Wasser und dann noch einmal auf 2 Stunden in destilliertes Wasser. Es wird rasch entwässert, indem man das Objekt in einem zylindrischen Gefäße mit viel Alkohol hoch aufhängt. Die Celloidin- oder Paraffineinbettung soll möglichst unter Lichtausschluß vorgenommen werden.

\section{d) Neuroglia.}

$$
\$ 205 \text {. }
$$

Zur Darstellung der Neuroglia sind eine Anzahl besonderer Mcthoden empfohlen worden, deren Beschreibung hier folgen soll.

I. Schaffersche Neurogliafärbung. Fixierung in Müllerscher Flüssigkeit, Einbettung in Celloidin; Färbung der Schnitte mit Kultschitzkyschem Hämatoxylin $(\$ 203)$. Nach beendeter Färbung wird $2+$ Stunden in Aqua destillata ausgewaschen und bis 3 Wochen in sehr verdünnter wässriger Eosinlösung nachgefärbt. Man nimmt von einer 1 : Eosinlösung 2 Tropfen auf ro $\mathrm{ccm}$ Aqua destillata und färbt darin $1-2$ Schnitte. Will man eine größcre Anzahl von Schnitten färben, so nimmt man entsprechend mehr Farbstoff und mehr Lösung. Resultat: Neuroglia rot, Gefäße, Pia und ihre Fortsätze braun, markhaltige Nerven schwarz.

2. Weigertsche Neurogliamethode. Man fixiert kleine Stücke von ${ }^{1 /} \mathrm{cm}$ Dicke in großen flachen Schalen, deren Boden mit Filtrierpapier hedeckt ist, in $10 \%$ Formollösung. Diese wird nach 24 Stunden gewechselt. Nach + Tagen kommt das Material in das Härtungsgemisch, welches zugleich als Beize wirkt: $5 \mathrm{~g}$ Kupferacetat, $\stackrel{2}{ }^{\mathrm{y}}=3$ Chromalaun und $5 \mathrm{ccm}$ Essigsäure in $100 \mathrm{ccm}$ Wasser gelöst. Zuurst wird das Chromalaun durch Kochen gelöst, dann wird die Essigsäure und schließlich das fein pulverisierte Kupferacetat zugesetzt. Hierhinein kommen die Sitiicke $4-5$ Tage bei Britofentemperatur; für 8 Tage bei Zimmertemperatur. Man kann aber auch, besonders wenn man nur dic Neuroglia darstellen will, die frischen $0,5 \mathrm{~cm}$ dicken Objekte 
in die Kupferchromalaun-Mischung bringen, wenn man ihr die gleiche Quantität $10 \%$ Formollösung zugesetzt hat. Die Objekte bleiben 8 Tage darin.

Statt der Kupferchromalaun-Nischung kann man auch folgende Fliissigkeit nehmen: $5 \mathrm{~g}$ Natrium- (oder Kalium- oder Ammonium-) Bichromat und $2 \mathrm{~g}$ Chromalaun werden in $100 \mathrm{ccm}$ Aqua destillata durch Kochen gelöst. Nach dem Erkalten wird filtriert und Io\% Formol hinzugefügt. Die Objekte bleiben $4-5$, höchstens 8 Tage darin; längeres Verweilen macht sie brüchig. Sie werden in Wasser ordentlich gewaschen und in Alkohol gehärtet.

Wie auch das Naterial vorbereitet ist, d. h. welches der 3 hier erwähnten Verfahren gewählt wurde, es wird in Celloidin eingebettet. Die Schnitte kommen zur Reduktion auf Io Ninuten in $1 / 3 \%$ wässrige Lösung von Kalium hypermanganicum, werden in Vasser gewaschen und dann in folgende Lösung gebracht: $5 \mathrm{~g}$ Chromogen und $5 \mathrm{ccm}$ Ameisensäure spez. Gew, I,20 werden in Ioo ccm Aqua destillata gelöst. Auf je $90 \mathrm{ccm}$ der Chromogenlösung gibt man $10 \mathrm{ccm}$ einer I0 ${ }^{\circ}$ Lösung ron kristallisiertem Natriumsulfat. In dieser Lösung bleiben die Schnitte 2-+ Stunden und werden darin, da sie durch das Kali hypermanganicum gebräunt waren, wieder entfïrbt. Dann kommen sie, damit sich das Bindegewebe mitfärbt, in eine $5 \%$ säurefreie, gut filtrierte Lüsung von Chromogen. Dann werden sie zweimal in Wasser gewaschen und in folgender Methylviolettlösung gefürbt: Man stellt mit $70^{\circ},-80^{\circ}$. Alkohol eine heiß gesättigte Lösung ron Methylviolett her, die man nach dem Erkalten rom Bodensatze abgießt. Zu $100 \mathrm{ccm}$ der Farbflotte fügt man $5 \mathrm{ccm}$ einer $5^{\circ} .0$ wässrigen Oxalsäurelösung und färbt damit auf dem Objektträger. Die Farbflotte wird auf den mit Filtrierpapier abgetrockneten Schnitt aufgeträufelt; die Färbung erfolgt momentan. Dann gicßst man den Farbstoff $\mathrm{ab}$ und bringt eine Jodjodkaliumlösung auf, die eine gesättigte Lösung von Jod in $5 \%$ Jodkalium darstellt. Man bringt auf, d. h. man träufelt von dem Jodgemisch auf den Schnitt auf und gießt sofort ab. Dann differenziert man in Anilinöl-Xylol (zu gleichen Teilen gemischt) grïndlich; erst nach ${ }_{14}^{\mathrm{I}}-{ }_{2}^{\mathrm{I}}{ }_{2}$ stïndiger Einwirkung blassen die feinen Fasern aus. Aus dem Anilinöl-Xylol überführen in reines Xylol, dann wird der Schnitt abgetrocknet, wobei man gekörntes Filtrierpapier vermeiden muß, man schließt in Balsam ein, setzt $2-5$ Tage dem diffusen Licht aus und bringt dann ins Dunkle.

Die Methode eignet sich nur für Mensch und Affe, soll aber bei anderen Säugern versagen.

Rawitz, Mikroskopische Technik. 
Ramòn y Cajal gibt an, daß diese Weigertsche Neurogliamethode auch viele marklose Nervenfasern mitfärbe.

3. Kultschitzkysche Neurogliamethode. Man fixiert in folgender Kultschitzkyschen Fliissigkeit: In 50 ${ }^{\circ}$. Alkohol wird so viel Kaliumbichromat und Kupfersulfat eingetragen, als sich bei Zusatz von $0,5 \mathrm{ccm}$ bis I ccm Essigsäure anf Ioo ccm Alkohol lösen will. Die Lösung und die Fixierung muß im Dunkeln vorgenommen werden. Nach einiger Zeit, d. h. nach 2-3 Monaten, wird direkt in starken Alkohol iibertragen, der ebenfalls ins Dunkle gestellt werden muß. In Paraffin wird eingeschmolzen, die Schnitte müssen 5- 10 $\mu$ dick sein. Gefärbt wird in: patentsaures Rubin (Rubin S rein pat., bad. Anilinfabr.) $0,25 \mathrm{~g}, 2^{\circ}$ 。 Essigsäure $100 \mathrm{ccm}$, konzentrierte wässrige Pikrinsäurelösung $100 \mathrm{ccm}$. Wenige Sekunden reichen zur Färbung aus; will man langsam färben, so verduinnt man $3-5 \mathrm{ccm}$ obiger Rubinlösung mit roo Teilen $46^{\circ}$. Alkohol. Aus der Farbflotte kommen die Schnitte in $96^{\circ}$. Alkohol, worin der Farbstoff nahezu unlöslich ist. Resultat: Neuroglia rotviolett, Ganglienzellen und Achsenzylinder gelbrot. (Diese Färbung ist der van Giesonschen SäurefuchsinPikrinfärbung nachgebildet.)

4. Mallorysche Neurogliamethode. Kleine Stiicke von Zentralnervensystem werden mindestens + Tage in $10^{\circ}$. Formollösung fixiert, kommen dann für mindestens 4 Tage in konzentrierte wässrige Pikrinsäurelösung und + Tage in $5 \%$ wässrige Lösung von Ammonium bichromicum. Nit letzterer Flüssigkeit werden sie in den Briitofen gestellt. Die von celloidiniertem Naterial angefertigten Schnitte werden nach desselben Autors Säurefuchsin-Orange-Anilinblau-Färbung behandelt achtes Kapitel Nr. is S S. I96/. Nan kann aber auch in phosphorwolframsaurem Hämatoxylin, das ebenfalls Mallory angegeben hat, färben und verfährt dazu folgendermaßen: Die Schnitte kommen auf $15-30$ Minuten in $0,5^{\circ}$ 。 wässrige Lösung ron Kaliumhypermanganat, werden in Wasser abgespuilt, in $I \%$ wïssrige Oxalsäurelösung auf I 5-30 Minuten eingelegt, gut ausgewaschen und in folgender Hämatoxylinlösung gefärbt: Hämatoxylin O. I g, Aqua destillata $80 \mathrm{ccm}, 10^{\circ}$. Phosphorwolframsäure-Lösung IIerch- $20 \mathrm{ccm}$, Wasserstoffsuperoyd amerikanische Pharmaliopöe. $0,2 \mathrm{~g}$. Darin hleiben die Schnitte I 2-2+ Stunden, werden gewaschen und wie iblich montiert. Resultat: Kerne, Neuroglia und Fibrillen blau, Bindegewebe rosa, Ganglienzellen und Achsenzylinder blaßrosarot.

5. Yamagiwasche Neurogliamethode. Man fixiert dinne Stiicke I Monat lang in Mïllerscher Flïsigkeit, welche anfänglich täglich zu 
erneuern ist. Dann werden sie direkt in absoluten Alkohol bis zu einer Woche eingebracht; der Alkohol muß täglich erneuert werden. In Celloidin wird eingebettet. Die Schnitte kommen auf I 2 Stunden und länger in konzentrierte alkoholische Eosinlösung, dann auf 4 bis 6 Stunden in eine konzentrierte wässrige Anilinblaulösung und werden in Alkohol differenziert, der durch Einträufeln ciner $\mathrm{I}^{\circ}$ 。Kalilösung schwach alkalisch gemacht worden war. Hierin werden die Schnitte rötlichbraun. Man wäscht sie nun in destilliertem Wasser, bringt sie in verdünnten Alkohol, wo sie rötlich werden, führt sie in absoluten Alkohol, dann in Origanumöl über, worin sie blau werden, und schließt in Balsam ein. Resultat: Achsenzylinder tiefblau, Gliafasern und Erythrocyten dunkelrot, Mark hellrot, Protoplasma der Gliazellen blaßviolett oder bläulichrötlich, der Ganglienzellleib blaßbläulichgrau mit grïnlichen Kernen, Adventitia und Intima himmelblau bis schwach grünlich, Media bläulichrötlich, Kernmembran bläulich, Nucleolen der Ganglienzellen tiefviolett bis tiefblau, Nucleolen der Gliazellen bläulich-rötlich. Ein Bild von geradezu unheimlicher Buntscheckigkeit!)

6. Bendasche Neurogliamethode. Man härtet schr dünne Scheiben nach der Weigertschen Vorschrift ivgl. diesen $§$. Nach der Anwendung der Gliabeize wird 1 Tag in IVasser ausgewaschen, dann 2 Tage in $0,5^{\circ}$. Chromsäurelüsung nachgehärtet, wiederum in Wasser I--2 Tage ausgewaschen und in Alkohol von steigender Konzentration gehärtet. Dann wird in Paraffin eingeschmolzen, da Celloidin für diese IIethode entschieden zu widerraten ist, und zwar empfiehlt Benda folgende Art der Paraffinierung. Aus dem absoluten Alkohol kommen die Stuicke auf 24 Stunden in reines Benzin, dann in ein Benzin, welches mit Paraffin von $42^{\circ}$ Schmelzpunkt gesättigt ist. Darin bleiben die Stücke bei gut verschlossenem Gefäß $2+$ Stunden, um darnach bei offenem Gefäß in den Brütofen auf solange gestellt zu werden, bis das Benzin fast verdunstet ist und das

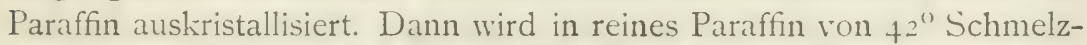
punkt übergeführt, auf 6 Stunden in den Brïtofen gestellt und endlich zum Mikrotomieren in Paraffin von $58^{\circ}$ Schmelzpunkt eingeschlossen. Einzelschnitte von solchem Paraffinmaterial klebt man auf das Deckglas, Serien auf den Objektträger.

Zur Färbung empfiehlt Benda folgende 3 Methoden:

A Alizarin-Toluidinblaufärbung. Die Schnitte werden 24 Stunden in $4^{\circ}$. Eisenalaunlösung oder ebenso lange in Liquor ferri sulfurici oxydati $\mathrm{I}: 2$ Wasser gebeizt. Dann spiilt man in fließendem II asser I 5-30 Sekunden $a b$ und bringt in düne (bernsteingelbe) 
wässrige Lösung von sulfalizarinsaurem Natron ein. Man taucht in destilliertes Wasser ein, tupft mit Fließpapier ab und bringt in eine $\mathrm{O}, \mathrm{I}$ 。 wässrige Toluidinblaulösung ein, die man im Uhrschälchen erwärmt. In der erhaltenden Farbflotte bleiben die Schnitte i 5 Minuten, werden mit $1 \%$ Essigsäure abgespuilt, mit Fließpapier abgetrocknet. in absoluten Alkohol eingetaucht und auf Io Minuten in Kreosot gebracht. Hier muß von Zeit von Zeit der Differenzierungsgrad mit dem Mikroskope festgestellt werden. Dann wird abgetrocknet, mehrere Hale mit Xylol zur Entfernung des Kreosot abgespült und in Balsam eingeschlossen.

B Eisenhämatoxylinfärbung mit einer Anilinfarbe kombiniert. Nach rorausgegangener Eisenbeizung und Abspiilung in fließendem Wrasser wird auf $2+$ Stunden in weingelber wässriger Hämatoxylinlösung gefärbt. Dann kommen die Schnitte in $30^{\circ}$. Essigsäure, bis sie blaugrau sind, werden in destilliertem VTasser ausgewaschen, dann abgetrocknet und mit einer Anilinfarbe nachgefärbt. Entweder gießt man auf die Schnitte Anilinwasser-Gentianaviolett nach Ehrlich achtes Kapitel Nr. 90 S. I87) oder MethylviolettOxalsäure nach Weigert (vgl. diesen \$) oder Kristallviolett nach Benda. Letztere besteht aus gesättiģter alkoholischer $70^{\circ}$ ) Lösung

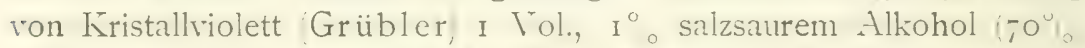
I Vol. und Anilinwasser 2 Vol, Man erwärmt die Farbflotte mit den Schnitten, bis Dämpfe aufsteigen, spült in WTasser ab. tupft mit Filtrierpapier ab, bringt in Anilinöl-Xylol zu gleichen Teilen, tupft wiederum ab, dann reines Xylol und Balsam.

C Hämatoxylin-ran Giesonsche Färbung. Die Beizung und Spülung genau wie bei Methode A. Dann wird 24 Stunden lang in weingelber wässriger Hämatoxylinlösung gefärbt. Nach Auswaschen wird in der Säırefuchsin-Pikrinsäure-Mischung nach van Gieson lachtes Kapitel Nr. II9 S. I97 nachgefärbt. Dann Alkohol und Balsam.

e) Die Häute des Zentralnervensystems.

$\S 206$.

Die cinzelnen Hirnhäute werden wie Bindegewebe behandelt; die im vierzehnten Kapitel angegebenen Methoden finden daher hier entsprechunde Anwendung. Die Nerven der Dura mater färbt man nach Jacques in folgender WVeise: Man färbt die frische Haut junger Tiere in Mcthylenblau, das in physiologischer Kochsalzlösung gelöst ist achtes Kapitel. und zwar legt man sie so auf einen Objektträger, daß die Innenfläche nach oben sicht und gießt die Farblösung auf. 
Nach ${ }^{1}{ }_{2}-$ I Stunde wird die Dura in Salzwasser (gemeint ist wohl physiologische Kochsalzlösung: abgewaschen, in kalt gesättigte wässrige Lösung ron pikrinsaurem Ammon übertragen, darin 12 Stunden belassen und nach Abspülen in Glyzerin und wässriger Ammoniumpikratlösung zu gleichen Teilen eingeschlossen. (Zum Gelingen der Färbung dürfte es sich empfehlen, die genauen Vorschriften im achten Kapitel zu befolgen.)

\section{Dreimndzwanzigstes Kapite1.}

\section{Peripheres Nervensystem.}

$$
\$ 207 \text {. }
$$

Am peripherun Nerwensystem, das infolge der Zerstreung seiner Bestandteile durch den ganzen Körper sich scharf ron dem straff zusammengefaßten Zentralnervensystem unterscheidet, haben wir die Ganglien, die Nervenfascrn und die Nervenendigungen zu unterscheiden.

Die Ganglien können als sclbständige Gebilde vorkommen, wie die Spinalganglien, die sympathischen Ganglien und dic Ganglien des Trigeminus und Vagus. Oder aber sie finden sich eingebettet in das Innere der Organe, z. B. das Ganglion spirale in der Säugetierschnecke, die gangliösen Anhäufungen in der Zunge derselben Tiergruppe, der Nervus pallialis im Mantelrande der Acephalen usw: Diese eingebetteten Organganglien werden mit dem ganzen Organ untersucht, sie isoliert zur Anschauung zu bringen, ist selten möglich. Doch können die für das Nervensytem in diesem und dem vorigen Kapitel angegebenen Methoden auch fur die Organganglien hier und da Anwendung finden. Dic von diesen Ganglien ausgehenden Nerven werden nach Art der Nervenendigungen behandelt.

Die Nerven, in markhaltige und marklose cingeteilt, sind auf das leichteste der mikroskopischen Untersuchung zugänglich. Ihre Endigungen, die motorischen wie die sensiblen, bieten chenfalls keine allzugroßen Schwierigkeiten für ihre Sichtbarmachung. Ein Teil der sensiblen Nerven geht in besondere Organe, die Sinnesorgane, uiber. deren Bau eine besondere Besprechung finden wird. 
Eigentümliche Nervenendorgane sind die eleketrischen Organe, die als Gebilde des peripheren Nervensystems hier ebenfalls erwähnt werden sollen.

\section{$\S 208$.}

Die selbständigen peripheren Ganglien. Die ältere Histologie hat die Spinal- und die sympathischen Ganglien in toto untersucht. Handelt es sich um kleine Gebilde, wie z. B. von urodelen Amphibien oder kleinen Lacertiliern, dann ist eine solche Untersuchung durchaus angebracht. Auch bei Evertebraten, dies sei hier parenthetisch bemerkt, kann man kleine Ganglien, z. B. des Bauchstranges bei Hirudo, Astacus usw., in toto sich ansehen. Man wird beide Male sicher einen Einblick in die Topographie des Organes erlangen, der für die Verwertung der auf anderem Wege gewonnenen Erkenntnisse nicht ohne Nutzen sein dürfte. $U m$ in toto zu untersuchen, bringt man das ganz frische Organ in $30 \%$ Kalilauge, legt ein Deckglas auf und iibt auf dieses einen leichten Druck aus. (Bei dieser Gelegenheit sei darauf hingewiesen, daß gerade dieser Konzentrationsgrad der Kalilauge etwas wie fixierende Eigenschaft besitzt. Dünnere Lauge wirkt eminent zerstörend ein. Natronlauge zerstört wohl bei jeder Konzentration.)

$\mathrm{Zu}$ einem eindringenderen Verständnisse ist diese Methode der Untersuchung nicht ausreichend. Die besten Resultate liefert beim Studium der selbständigen peripheren Ganglien die Mazeration. Die auch an diesen Objekten neuerdings ausschließlich verwendete Schnittmethode kann meines Erachtens die Mazeration nicht ersetzen.

Als die beste, zuverlässigste Methode, welche zudem Nachfärbung mit Karmin und Hämatoxylin sowie Nachvergoldung in beliebiger Weise gestattet, ist die Arnoldsche Methode (drittes Kapitel Nr. 12 S. 25) zu bezeichnen. $I_{3}$ Alkohol und $1 / 4$ Alkohol (drittes Kapitel Nr. 6 u. 7 S. 24 ) sind ebenfalls noch verwendbar. Von allen anderen Reagentien würde ich abraten.

Die Haupttechnik der Gegenwart ist die Schneidenethode und daher ist es notwendig, die peripheren selbständigen Ganglien zu fixicren und die angefertigten Schnitte zu färben. Es verstcht sich von selher, daß die für das Zentralnervensystem angegebenen Methoden auch auf die peripheren Ganglien anwendbar sind. Die Methoden zur Färbung der Nissischen Körper, die Silber-, die Goldmethoden usw. können, ohne daß man den Modus procedendi zu ändern braucht, bei den peripheren Ganglien gebraucht werden. Es gibt aber noch eine 
Reihe Spezialmethoden, welche im folgenden $\S$ aufgezählt werden sollen. Die Autoren haben sie zwar nur für die Spinalganglien empfohlen; ich bin aber der Meinung, daß sie ohne weiteres auch für die sympathischen Ganglien, für Ganglion Gasseri und Ganglion jugulare verwendet werden können.

\section{$\S 209$.}

I. Methode von van Gehuchten und Nélis. Die Ganglien werden in Gilsonscher Lösung fixiert: 46 grädige Salpetersäure (nach Behrens' Tabellen $=$ spez. Gew. $1,456=79 \%$ ) $15 \mathrm{ccm}$, Eisessig $4 \mathrm{ccm}$, Sublimat $20 \mathrm{~g}, 60 \%$ Alkohol $100 \mathrm{ccm}$, Aqua destillata $880 \mathrm{ccm}$. Nach beendeter Fixierung wird $I$ Stunde in fließendem Wasser ausgewaschen, in Alkohol von $90 \%$, dem Tinctura Jodi zugesetzt ist, eingebracht und nach üblicher Weiterbehandlung in Paraffin eingeschmolzen. Dic Schnitte werden in Toluidinblau gefärbt.

2. Methode von Cox zur Methylenblaufärbung. Paraffiniertes Material wird geschnitten (Fixierung nicht angegeben) und die Schnitte werden mit Karbolmethylenblau gefärbt. (Bezuiglich der Zusammensetzung dieses Methylenblau vgl. die nächste Nr.) Die gefärbten Schnitte werden entfärbt und differenziert und Cox hat dazu 2 Alkoholgemische und 3 Anilinölgemische konstruiert. Alkohol I. Alkohol absolutus $30 \mathrm{ccm}$, Xylol $\mathrm{I} 20 \mathrm{ccm}$. Alkohol II. Alkohol absolutus $60 \mathrm{ccm}$, Xylol $90 \mathrm{ccm}$. Anilin I. Anilin $10 \mathrm{ccm}$, Alkohol absolutus ı $\mathrm{ccm}$, Xylol $30 \mathrm{ccm}$. Anilin II. Anilin $25 \mathrm{ccm}$, Alkohol absolutus $10 \mathrm{ccm}$, Xylol $15 \mathrm{ccm}$. Anilin III. Anilin $20 \mathrm{ccm}$, Alkohol absolutus $20 \mathrm{ccm}$, Xylol $10 \mathrm{ccm}$. Die gefärbten Schnitte werden abgespült, mit Filtrierpapier getrocknet und in Alkohol I übergeführt. Dieser reicht für dünne Schnitte aus, die in Xylol zu übertragen sind. Dicke Schnitte, die bis zu 2 Tagen in der Farbflotte bleiben müssen, kommen aus Alkohol I in Alkohol II. Falls sie noch nicht genuigend entfärbt sind, werden sie gradatim in die Aniline übergeführt. (Es will mir nicht recht einleuchten, daß eine derartige Komplikation der Methode unbedingt nötig ist.)

3. Coxsche Methode der Fibrillendarstellung. Die Spinalganglien werden in einer der beiden folgenden Lösungen fixiert: Gesättigte wässrige Sublimatlösung $30 \mathrm{ccm}, 1 \%$ Osmiumsäure $10 \mathrm{ccm}$, Eisessig $5 \mathrm{ccm}$. Oder: Gesättigte wässrige Sublimatlösung I $_{5} \mathrm{ccm}$, $5 \%$ Platinchloridlösung $15 \mathrm{ccm}, 1 \%$ Osmiumsäure $10 \mathrm{ccm}$, Eisessig $5 \mathrm{ccm}$. Man fixiert $2-3$ Tage, schmilzt in Paraffin ein und schneidet. Die Schnitte kommen für \& Stunden in $20 \%-25 \%$ Tanninlösung, werden ausgewaschen und dann mit Indoinblau oder Methylenblau ge- 
färbt. Indoïnblaufärbung. Aus dem Tannin bringt man die Schnitte auf 5-10 Minuten in $5^{\circ}$. Brechweinsteinlösung, wäscht Io Minuten aus und legt für I 2 - 8 Stunden in ein Farbgemisch aus $5 \%$ Indoinblau BB Merck $20 \mathrm{ccm}$ und $5^{\circ}$ 。Alaunlösung $10 \mathrm{ccm}$. Die Mischung der Farbflotte darf erst unmittelbar vor dem Gebrauche erfolgen. Methylenblaufärbung. Die tannisierten Schnitte kommen nach Auswaschen auf 5- 10 Minuten in 2,5\% Eisenalaunlösung, sie werden dann I 2-i 8 Stunden ausgewaschen und in Karbolmethylenblau gefärbt. Letztere Farbflotte erhält man folgendermaßen: Zunächst macht man sich eine alkalische Methylenblaulösung: Methylenblau I g; Kalium carbonicum I g, IVasser $100 \mathrm{ccm}$. Man kocht 15 Minuten auf dem Wasserbade, um alles zu lösen. Zur Färbung mischt man unmittelbar vor dem Gebrauche $\mathrm{I}-2$ Teile der alkalischen Methylenblaulösung mit 15 Teilen $2 \%$ Karbolsäure.

4. Kopschsche Methode zur Darstellung der Golginetze. Man legt in $2 \mathrm{ccm}$ einer $2 \%$ Osmiumsäure bis zu 6 Spinalganglien von Lepus cuniculus, stellt ins Dunkle und läßt 8 Tage darin. Gelegentlich schüttelt man das Gefäß mit der Osmiumsäure und den Ganglien um und erneuert die Säure, falls Nieclerschläge entstehen. Die Paraffinierung muß in einem Tage vorgenommen werden; die Schnitte brauchen keine Färbung.

\section{$\$ 210$.}

Nervenfasern. a) Markhaltige Nerven. Die markhaltigen Nervenfasern lassen sich vortrefflich am lebenden Objekte studieren. Und zwar sind dazu besonders geeignet die Lunge, das Mesenterium und die Zunge vom Frosch (vgl. hierzu zweites Kapitel S. I3 u. I4).

Den sichersten Aufschluß über den Bau der Nervenfasern geben Zupfpräparate der frischen oder leicht mazcricrten Gebilde. Da die Nerven der Homoiothermen, der sogenannten Warmbluiter, sehr schnell absterben und die dabei entstehenden kadaverösen Veränderungen Strukturbilder vortäuschen können, so hält man sich am besten an die Poikilothermen, die sogenannten Kaltbliiter. Am bequemsten zu buarbeiten sind dic Nerven des Frosches. Man schneidet also ein hüchstens $2 \mathrm{~mm}$ langes Nervenstiick heraus, legt es in physiologische Kochsalzlösung, zerreißt schnell mit Nadeln das derbe bindegewebige Perineurium, zerzupft den frei werdenden Nerveninhalt vorsichtig und deckt ein. Hat man gerade genug Zusatzflissigkeit gewählt - hei zuviel schwimmen die Fasern fort, bei zu wenig werden sie durch das Deckglas gequetscht -, dann kann man stundenlang die Nerven beobachten. 
Statt der Kochsalzlösung kann man $0, \mathrm{I}^{\circ}$. Osmiumsäure benutzen. Man verfährt wie vorhin, zerzupft in einem Tropfen der Lösung und deckt ein. Man kain derartige Präparate auch dauernd aufbewahren, wenn man nach beendeter Zerzupfung folgendermaßen verfährt: Mittels Filtrierpapiers saugt man an einem Rande des Deckglases die Osmiumsäure ab, während man gleichzeitig an den entgegengesetzten Rand einen kleinen Tropfen verdünnten Glyzerins gebracht hat. So ersetzt man vorsichtig die eine Flüssigkeit durch die andere. Dann trocknet man vorsichtig den Objektträger $a b$ und umrandet in beliebiger Weise vgl. elftes Kapitel. Diese Präparate lassen sich lange aufbewahren, wann man sie vor Licht schützt. Statt in einem Tropfen Osmiumsäurelösung zu zerzupfen, was der beizenden Dämpfe wegen sehr unangenehm ist, kann man ein Nervenstückchen - nicht üher $2 \mathrm{~mm}$ groß - in $0,05^{\circ}$ - O. I ${ }^{\circ}$, Osmiumsäure iiber Nacht einlegen; man muß nur vorher das Perineurium gespalten haben. Am nächsten Tage wäscht man etwa ${ }^{\mathrm{r}}$ + Stunde in destillicrtem Wasser aus und zerzupft in rerdunntem Glyzerin. Bei ciniger Übung gelingt es sehr leicht, gute Zupfpräparate herzustellen.

IIan kann auch die Nerven in ihrer Gewehsflüssigkeit, also gewissermaßen trocken zerzupfen, dann mit einem Deckglase eindecken und seitlich an dessen Rand das Reagens bringen. Das Mikroskop lchrt dann, in welcher 1 ceise die einzelnen Reagentien verändernd auf die markhaltige Nervenfaser einwirken. Es ist selbstverständlich, daß das Zerzupfen sehr schnell geschehen muß, weil sonst die Nervenfasern eintrocknen.

Die Myelinformen erkennt man, wenn man in Kochsalzpriparaten ron Nerven die physiologische Kochsalzlösung durch destilliertes NTasser auf dieselbe IVeise ersetzt, wie es vorher für das Glyzerin geschildert wurde. Das destillierte Wasser verflissigt den Nervenfaserinhalt.

Der Achsenzylinder läßt sich an frischen l'räparaten auf folgunde Weise zur Anschauung bringen. Ein Stuickchen Nerv wird trucken, d. h. ohne Zusatzflüsigkeit, zerzupft, dann tropft man etwas Kollodium auf, deckt sehr schnell zu und untersucht. Dic Achsenzylinder treten bei dieser von Pflüger ersonmenen Methode auf das schönste hervor; das Präparat ist allerdings nach wenigen Minuten infolge der Verdunstung des im Kollodium enthaltenen Äthers unbrauchbar. Statt Kollodium kann man auch reinen Schwefeläther nehmen, doch sind die Bilder viel weniger schön als nach Kollodium, verderben aber cbenso schnell. Legt man über Nacht Stuicke frischer Nerven - mit gespaltenem Perineurium - in Chloroform und zer- 
zupft man am nächsten Tage in etwas IVasser, so erhält man ebenfalls Präparate vom Achsenzylinder. Aber auch diese sind nicht haltbar und können sich mit den Kollodiumpräparaten nicht vergleichen.

Zur Färbung des lebenden Achsenzylinders hat Harris das Toluidinblau empfohlen, welches man dem lebenden Tiere injizieren muß. MIan injiziert, ob subcutan oder intravenös wird nicht gesagt. eine mit physiologischer Kochsalzlösung zu gleichen Teilen verdünnte $0, I^{\circ}$. Lösung von Toluidinblau. Nach I Stunde wird das Tier getotet, kleine Nervenstückchen werden herausgeschnitten und, mit physiologischer Kochsalzlösung befeuchtet (damit sie nicht vertrocknen), Io-I5 Minuten der Luft ausgesetzt. Dann sind die Nerven gewöhnlich gefärbt. Um Präparate zu erhalten, härtet und fixiert man in der bei der Färbung der Stiicke nachher zu erwähnenden Weise. Sensible Nerren färben sich schneller als motorische; die Gewebe sind blau, die Achsenzylinder purpurn.

Für Stiicke, also iiberlebendes Material, lautet die Vorschrift von Harris folgendermaßen: Die Stuicke kommen in eine $0,1 \%$ Lösung von Toluidinblau, welche in physiologischer Kochsalzlösung hergestellt ist. Und zwar nimmt man von der Farbflotte 2 Teile und fügt hinzu I Teil $0,25^{\circ}$ 。 wässriger Ammoniumchloridlösung und I Teil Eiweiß (Hühnereiweißj. Diese Lösung wird jedesmal frisch hergestellt. Die Stücke kommen hinein, dürfen aber niemals von der Farblösung völlig bedeckt scin, sondern man darf von dieser nur soriel nehmen, daß die Objekte feucht blieben. Man färbt ${ }^{\mathrm{I}}{ }_{2}-\mathrm{I}$ Stunde und bringt während dieser Zeit alles in die feuchte Kammer bei $37^{\circ} \mathrm{C}$. Temperatur. Nachher wird fixiurt. Man spïlt zunächst das Präparat in Wasser und bringt es darauf in eine gesättigte wässrige Lösung von gelbem oder rotem Blutlaugensalz, welcher zur Verhiitung mazericrender Wirkungen etwas Osmiumsäure zugesetzt ist. Diese Lösung darf nur wenig uiber $0^{\circ}$ warm sein. Darin bleiben die Objekte $3-27$ Stunden, während welcher Zeit auch dic umgebende Temperatur niedrig sein muß. Darauf wird I Stunde in Aqua destillata abgewaschen, in abgekiihlten absoluten Alkohol übertragen und durch Xylol in Paraffin überführt.

Der Anwendung der Höllensteinlösungen auf die frischen Nerven verdanken wir die Entdeckung der Ranvierschen Einschn ürungen. Ein Stïckchen Nerr wird in $0,2^{\circ}{ }_{10}-\mathrm{I}^{\circ}$ 。 Lösung von Höllenstein eingebracht und nach Spaltung des Perineurium bis 2 Stunden darin belassen. Man wäscht in Aqua destillata aus und läßt hierin zugleich die Reduktion im Lichte cintreten. Zerzupfung in verdünntem Glyzerin. Auch das Fuchsin kann man zur Darstellung der Schniurringe 
verwenden. In ein Uhrschälchen mit etwa $5-10 \mathrm{ccm}$ destillierten Wassers bringt man $6-7$ Tropfen einer $4^{\circ}$, alkoholischen Fuchsinlösung und legt mehrere Nervenstückchen ein. Die Spaltung des Perineurium ist notwendig. Nach $4-24$ Stunden wird ausgewaschen und in Glyzerin zerzupft. Die Ranvierschen Einschnïrungen sind braunrot gefärbt und treten plastisch hervor. Diese von mir vor Jahren angegebene Methode liefert stets gute, aber nicht haltbare Präparate.

Die Lantermannschen Einkerbungen, unstreitig Artefakte, erkennt man an jedem Zupfpräparate frischer Nerven, vorausgesetzt daß die eventuellen Reagentien nicht zu lange eingewirlt haben und nicht zu konzentriert waren. Johansson und Segall haben an den Einkerbungen sogenannte Ringbänder beobachtet, zu deren Darstellung sie auch hesondere Methoden angegeben haben. Die Johanssonsche Methode lautet folgendermaßen: Dic Nerven werden in einer Mischung von $3^{\circ}$. Kali bichromicum und ${ }^{2}{ }^{\circ}$ 。 Kupfersulfat eingebracht (das Mischungsverhältnis hat der Autor nicht angegeben) und darin It Tage lang im Briitofen bei $t 0^{\circ} \mathrm{C}$. gehärtet. Dann zerzupft man in Wasser und bringt für ${ }_{12}^{\mathrm{I}}-4$ Stunden in folgende Hämatoxylinlösung ein: $100 \mathrm{ccm}$ einer $0,5 \%$ Alaunlösung und 20 Tropfen einer $5^{\circ}$. alkoholischen Hämatoxylinlösung. Die Segallsche Methode ist die folgende: Ein frischer Froschnerv wird in einigen Tropfen 1 ! O Osmiumsäure rasch zerzupft. Fängt er an braun zu werden, dann wäscht man in destilliertem IVasser aus, bringt in $2^{\circ}$ 。 Höllensteinlösung ein und zerzupft von neuem. Dann setzt man in der Höllensteinlösung 20 Minuten bis ${ }^{3}$ Stunden dem Lichte aus, wobei man den Nerven von Zeit zu Zeit bewegt. Dies geschieht, damit möglichst alle Fasern mit dem Argentum nitricum in Beriihrung kommen. Darauf wäscht man in destilliertem Wasser aus, zerzupft in Glyzerin oder färbt erst noch in $\mathrm{I}^{\circ}$ 。 wässriger Eosinlösung, neutralem Karmin oder Hämatoxylin und zerzupft dann. Die Silberreduktion macht sich nur an den Einschnürungen (keine Achsenkreuze!) und an den Einkerbungen bemerkbar.

Die im dritten Kapitel Nr. 17 S. 26 beschriebene Neumannsche Methode liefert ausgezeichnete Isolierungen der Nervenfasern.

Wie Zupfpräparate, so kann man auch Schnittpräparate von Nerven anfertigen. Die für das Zentralnervensystem angegebenen Fixierungsmethoden geiten auch für die peripheren Nervenstämme, nur wird man gut tun, wenn man Seetiere untersucht, namentlich die osmiumhaltigen Gemische mit Seewasser anzusetzen. Die Nerven verhrümmen sich dank der Elastizität des Perineurium in allen Fixie- 
rungsfüssigkeiten, wenn sie aus ihrer natülichen Verbindung gelöst sind. Nan muß sie daher auf irgend einer unnachgiebigen Unterlage so spannen, daß diese Verkrimmungen nicht möglich sind und daß die Fixierungsfliissigkeit gut von allen Seiten an den Nerven heran kann.

Bei der Wahl der Fixierungsmittel ist zu beachten, daß die Form des Achsenzylinders durch sie außerordentlich beeinflußt wird. Nach Fixierung in Chromsalzen erhält man auf Querschnitten die bekannten Sonnenbildchen, d. h. einen kleinen Achsenzylinder. Reine Alkoholhärtungen lassen den Achsenzylinder viel breiter erscheinen und Osmiumfixierung zeigt, daß nur der sogenannte doppelte Kontur geschwärzt ist, die Binnensubstanz nicht. Letztere ist der Achsenzylinder, der also nach Osmium am breitesten erscheint. Es diirfte nicht ohne historisches Interesse sein, daß auf Grund der eben genannten Tatsachen manche der fruheren Histologen bis in die Mitte der yoer Jahre des vorigen Jahrhunderts merkwuirdigerweise die flüssige Natur des Achsenzylinders behaupteten.

Zur Achsenzylinderfärbung hat Ströbe folgende Methode empfohlen: Die Nerven werden $4-5$ Monate in Müllerscher Lösung gehärtet und dann in Alkohol von steigender Konzentration übergeführt. Die von celloidinicrtem Material hergestellten Schnitte müssen Io $\mu$ dick scin. Gefärbt wird in gesättigter wässriger Anilinblaulösung ${ }^{1}=$ - I Stunde lang. Dann wird abgewaschen und in absolutem Alkohol differenziert, welchem 20-30 Tropfen Ätzkalialkohol beigefügt sind. (Über die Herstellung dieses $̈$ tzkalialkohol vgl. die Weigertsche Säurefuchsinmethode; zweiundzwanzigstes Kapitel.) In dem Kalialkohol werden die bisher blauschwarzen Schnitte rostrot. Wenn keine Farbstoffwolken mehr ausgehen, die Schnitte also durchscheinend und hellbraunrot geworden sind, dann ist die Differenzierung beendet. Nun wird 5 Minuten lang in einer großen Menge Aqua destillata ausgewaschen, wobei die Schnitte hellblau werden. Jetzt färbt man in Safranin (konzentrierte wässrige Lösung mit Aqua destillata zu gleichen Teilen verduinnt) ${ }^{1} / 4{ }^{x}{ }_{2}$. Stunde nach, zieht in Alkohol aus, dann Xylol und Balsam.

Eine besondere Karminfärbung des Achsenzylinders hat Chilesotti angegeben: I $\mathrm{g}$ Natriumkarmin (Grübler) wird mit o,5 g Urannitrat verricben und in roo $\mathrm{ccm}$ Aqua destillata $\mathrm{T} / 2$ Stunde lang gekocht. Vor dem Gebrauch kommen zu I ccm der Farbflotte 2 Tropfen I $\%$ salzsauren Alkohols. Schnitte von Müller-Material werden 5 bis Io Minuten gefärbt, Formolmaterial, gleichgiiltig ob man daron Gefrierschnitte gemacht oder in Paraffin bzw. in Celloidin eingebettet 
hat, wird $\mathrm{r}_{5}-20$ Minuten, mit Weigerts Neurogliabeize (zweiundzwanzigstes Kapitel S. $38+$ behandeltes Naterial wird 30-60 Minuten, Marchimaterial $2-+$ Stunden gefärbt. Bei Überfärbung wird in $0,5 \%$ - I salzsaurem Alkohol ausgezogen.

Die Fibrillen des Achsenzylinders der peripheren Nervenfasern können mit den Methoden zur Anschauung gebracht werden, welche fuir die Neurofibrillen des Zentralnervensystems empfohlen wurden. Auf diese im zweiundzwanzigsten Kapitel ausfihrlich geschilderten . Methoden wird hiermit verwiesen. Nit folgender Spezialmethode werden vorziigliche Resultate erzielt. Froschnerven werden zur Fixierung auf + Stunden in $0,5^{\circ}$. Osmiumsäure gelegt, dann werden sie + Stunden in destilliertem Wasser ausgewaschen und in Alkohol von $90^{\circ}$ 。 eingebracht. Nach $2+$ Stunden befreit man im Alkohol den bis dahin aufgespannt gebliebenen Nerven ron seiner Unterlage und färbt ihn I 2 Stunden mit gesättigter wässriger Säurefuchsinlösung. In absolutem Alkohol wird ausgezogen und dann wie iiblich in Paraffin eingeschmolzen. Als Intermedium ist Chloroform zu wählen, in welchem die Jerven nur einen Tag weilen dürfen; Xylol ist zu rerwerfen, da es osmierte Fette nach Flemmings Untersuchungen löst. Die Schnitte sind schr dün anzufertigen.

\section{S 2 II.}

Die Neurokeratinscheiden sind mittels der Kühne-Ewaldschen Trypsinmethode gefunden worden. Zu ihrer Darstellung wird man sich daher zunächst dieser Methode bedienen (drittes Kapitel Nr. 35 S. 30. Doch sind noch zwei Methoden empfohlen, die sicherer und weniger umständlich dic fraglichen Gebilde zur Anschauung bringen sollen.

Dinitroresorcinmethode, von Platner. Frische Nervenstämmchen vom Kaninchen werden von Fett und anhaftendem Bindegewebe befreit und in folgende Eisenbeize gebracht: Liquor ferri sesquichlorati Pharmacopoea germanical I Teil, Aqua destillata oder Spiritus rectificatus $3-+$ Teile. Je nach ihrer Dicke bleiben die Nerven bis zu mehreren Tagen in der Eisenlösung. Dann werden sie sehr gut in Wasser bzw. in Alkohol ausgewaschen, bis keine Eisenreaktion mehr vorhanden ist, und in Echtgrü (Dinitroresorcin) eingelegt. Diese Substanz ist eine graue Paste, ron der man, so viel sich lösen will, in $75^{\circ}$. Alkohol löst. Wenn die Nerven grün sind, werden sie in reinen Alkohol gebracht und auf die gewöhnliche Weise in Paraffin eingeschmolzen.

Corningsche Färbung der Neurokeratinscheiden. Die 
Nerven werden I Stunde lang in konzentrierter wässriger Sublimatlösung fixiert und dann auf bekannte Weise in Paraffin eingeschmolzen. Die $3-4 \mu$ dicken Schnitte werden 24 Stunden mit Eisenalaun gebeizt und dann 48 Stunden lang in Weigerts Hämatoxylin achtes Kapitel Nr. I26 S. 20r), das halb mit Wasser verdünnt ist, gefärbt.

\section{$\S 212$.}

Die Schwannsche Scheide stellt man an osmierten Nerven nach den Angaben von Key und Retzius durch Färben mit ammoniakalischem Karmin dar.

Das Perineurium wird wie gewöhnliches Bindegewebe untersucht, seine elastischen Fasern bringt man durch Weigertsches Fuchsin oder Röthigs Kresofuchsin zur Anschauung.

Eine neue Nervenscheide hat Ruffini auf folgende IVeise dargestellt: Kleine Stiicke Haut oder Muskeln kommen für mindestens I) Stunde in ein frisch bereitetes Gemisch aus 66 Teilen 10\% Ameisensäure und $3+$ Teilen gesättigter Sublimatlösung. Dann wird flüchtig in fließendem Wasser gewaschen und auf 20-40 Minuten in $\mathrm{I}^{\circ}$. Goldchloridlösung eingelegt. Man trocknet das Material mit Fließpapier oder einem reinen Tuche $a b$ und bringt es für $12-15$ Stunden in ein Glasgefä $\beta$ mit I ${ }^{\circ}$ Ameisensäure. Dieses Gefä $\beta$ stellt man dann auf 6-8 Stunden, ohne die Flüssigkeit zu wechseln, ins direkte Sonnenlicht und sorgt dafür, daß von allen Seiten das Licht bequem hinzutreten kann. Dann wird das Material herausgenommen, abgetrocknet und auf 8 - Io Tage in Glyzerin eingelegt. Darauf wird zerzupft und in Glyzcrin eingeschlossen. Die Markscheide der Nerven erscheint an gelungenen Präparaten dunkelviolett, schwarz oder rötlichriolett, die Hilfsscheide IRuffinische Scheidej ist hellviolett. Nur am Endabschnitte der Nerven, also innerhalb der Organe, ist die Hilfsscheide vorhanden.

\section{$\$ 213$.}

Nervenfasern. b) Marklose Nerven und Nerven der Evertuhraten. Marklose Nerven finden sich bei den Gnathostomen unter cen Vertebraten im Sympathicus, bei den Cyclostomen iiberall, da diese Ticre keine markhaltigen Nerven besitzen, und ferner bei allen Evertebraten. Man zerzupft, färbt, fixiert usw. ganz wie bei den markhaltigen Nerven. Tielleicht sind die marklosen oder grauen Fasern ganz besonders geeignete Objekte fuir die Nethylenblau-Färbung.

Schreiber modifiziert für Crustaceennerven das Golgische Verfahren zur Untersuchung des peripheren Nervensystems. Er legt 
Crustaceenteile auf I Tag in folgendes Gemisch: 2,5 micum-Lösung 25 Teile, $4^{\circ}$. Formol 5 Teile, oder auf 2 Tage in: $2,5^{\circ}$. Kali bichromicum-Lösung 6 Teile, $5^{\circ}$. Formol 12 Teile. Dann auf I Tag in $\mathrm{I}^{\circ}$ 。 Argentum nitricum-Lösung und bewahrt in $70^{\circ}$ 。 Alkohol + Glyzerin zu gleichen Teilen auf. Die Schreiberschen Lösungen müssen unmittelbar vor dem Gebrauche angefertigt werden, weil sie sonst verderben.

\section{S 214.}

Elektrische Organe. Man kann sie mit denselhen Methoden wie das Zentralnervensystem studieren, auch ist zur Erkenntnis der Nervenverzweigungen die Golgische Methode verwendet worden. Dagegen soll die Metallimprägnation frischer Organe keine guten Resultate liefern. Andererseits sind auch die für Zellstudien empfohlenen Methoden 'Flemmingsche Lösung, Sublimat usw' geriihmt worden.

Eine originelle Methode hat Iwanzoff crsonnen: Er spritzt $z^{\circ}-2^{\circ}$. Osmiumsäure interstitiell ein und legt nach einigen Minuten die herausgeschnittenen injizierten Teile in $2^{\circ}$. Kali bichromicumLüsung oder in Nï̈llersche Iilüsigkeit. Dann, d. h. nach beendeter Härtung, färbt er die Stïclie in wässriger oder alkoholischer Hämatoxylinlösung und schmilzt in Paraffin ein.

\section{S 2 I 5 .}

Motorische Nervenendigungen. Die Endigung der Nerven in den quergestreiften .Iuskeln bringen am klarsten Goldpräparate zur Anschaung und die geeignetsten Objekte sind dic Muskeln der Reptilien und Säuger. Man kann entweder eine der im neunten Kippitel Nr. I-7 S. 2 I I beschriehenen Vergoldungsmethoden anwenden oder man folgt dem Rate von Muschenkoff und hringt dic zu vergoldenden Muskeln vor dem Ansäuern und Vergolden in eine Lösung von Ammoniumbichromat.

Verzichtet man auf die Erkcnntnis des feineren Details der motorischen Endplatten, will man nur die Zahl der Nervenendigungen an einer Muskelfaser feststellen, so kann man sich der Sandmannschen Vergoldung bedienen. Muskelfasern, die nach Sandmann mittels schwefliger Säure isoliert sind drittes Kapitel Nr. 29 S. 28 , hommen in eine Goldlüsung, die auf Io $\mathrm{ccm}$ Aqua destillata I bis 3 Tropfen einer I ". Goldchloridlösung enthält. Die Muskelfasern bleiben darin, bis sie gelb geworden sind, dann bringt man sie in cin Reagensglas mit Wasser, das mit einigen Tropfen Essigsäure an- 
gesäuert ist, und kocht. Nach eingetretener Reduktion kann man beliebig aufheben.

Ramon y Cajal bringt zum Studium der Nervenendigungen $3-4 \mathrm{~mm}$ dicke Stücke auf 24 Stunden in eine $25^{\circ}$ owässrige Formollüsung, der auf Ioo $\mathrm{ccm}$ einige Tropfen bis I ccm Ammoniak zugesetzt ist. Dann wäscht er 6- I 2 Stunden in fließendem Wrasser aus und führt in $3 \%^{\circ}$ Argentum nitricum-Lösung über, die er bei $30^{\circ}$ bis $35^{\circ} \mathrm{C}$. einwirken läßt. Die Reduktion wird mit $2^{\circ}$ 。 Pyrogallussäure ausgefüht, der $5^{\circ}$. Formol zugesetzt sind igl. zweiundzwanzigstes Kapitel).

Negro, der als Objekt zu Studien über die Endigungen der Nerven im quergestreiften Muskel Lacerta viridis, Tropidonotus natrix und Brusthautmuskel des Frosches empfiehlt, verfährt auf folgende Art: Er stellt eine Hämatoxylinlösung her, indem er zu $\mathrm{I} 80 \mathrm{ccm}$ konzentrierter wässriger Ammonalaunlösung $2 \mathrm{~cm}$ einer gesättigten alkoholischen Hämatoxylinlösung zufügt. Dies Gemisch bleibt 8 Tage an der Luft stehen, dann werden je $25 \mathrm{ccm}$ Methylalkohol und Glyzerin hinzugefügt. Dic frischen Präparate nun werden mit einem Tropfen der Lösung begossen und nach beendeter Färbung in hekannter Weise in Kanadabalsam eingeschlossen.

II. Krause hat folgendes Verfahren angegeben: Muskelstiiche kommen auf 24 Stunden bei $35^{\circ} \mathrm{C}$. in $\mathrm{o}, \mathrm{OI}^{\circ}$ 。 Schwefelsäure; dadurch wird das intermuskuläre Bindegewebe in Leim rerwandelt. Nun wird vergoldet und zwar mit einer $0,0006^{\circ}$-0,001 $8^{\circ}$. Goldchloridlösung. Die Vergoldung ist gelungen, wenn die Juskeln purpurfarben geworden sind; haben sic sich zu dunkel imprägniert, so kann man sie entfärben (fünftes Kapitel).

Eine Methode, welche auch die Nervenendigungen an den glatten Muskeln und an den Gefäßen zur Erscheinung bringt, ist die folgende ron Sichler herstammende: Quergestreifte Muskeln, die dick wie cin Gänsekiel sein sollen - am besten vom Frosch -. werden in folgendem Gemisch mazeriert: Essigsäure I Volumen, Glyzerin I Volumen und ebensoviel I \% wässrige Chloralhydratlösung. Nach I 8 Stunden wird in Glyzerin zu Stecknadeldicke zerzupft und für 3-Io Tage in folgendes Hämatoxylin gelegt: Ehrlichsches Hämatoxylin achtes Kapitel Nr. + I S. I;6) I Volumen, Glyzerin I Volumen, I\% wässrige Chloralhydratlösung 6 Volumina. Man stellt durch probeweises Zerzupfen den Grad der Färbung fest und zerzupft definitiv in Glyzerin mit etwas Essigsäurezusatz. Herz und Blase brauchen weniger lange zu mazerieren, Rattenmuskeln brauchen mehr als ${ }_{2}+$ Stunden. ITenn beim Probezerzupfen die Nerven. welche die 
Kapillaren begleiten, deutlich blau sind, dann sind auch die Nervenendigungen gefärbt.

$\mathrm{Da} B$ auch die Methylenblaufärbung anwendbar ist, versteht sich von selber (vgl. achtes Kapitel und zweiundzwanzigstes Kapitel;.

$$
\S 216 .
$$

Sensible Nervendigungen. Im Vordergrunde der Methoden steht die Methylenblaufärbung, die namentlich Dogiel in ausgedehntestem Maße angewandt hat (vgl. achtes Kapitel und zweiundzwanzigstes Kapitel). Ebenfalls anwendbar sind die Goldmethoden und die Golgische Chromsilbermethode (neuntes Kapitel). Mit letzterer ist die Lehre von den freien Nervenendigungen aufgekommen.

Für die Vaterschen und Herbstschen Tastkörperchen geniigt Osmierung oder leichte Vergoldung; letztere werden in der Wachshaut des Entenschnabels gefunden.

Die Tastkolben können entweder frisch ohne jeden Zusatz untersucht werden oder man bringt in $8 \%-10 \%$ Natronlauge oder $5^{\circ}$. Salzsäure oder in $2^{\circ}$ 。- $3^{\circ}$. Essigsäure oder endlich — und dies ist die beste Wethode; sie rührt von $\mathrm{WValdeyer}$ her - in $\mathrm{O}, \mathrm{I}^{\circ}$ 。 Osmiumsäure. Die Reagentien müssen mindestens 2.t Stunden cinwirken; doch hat man fur jedes Reagens und für jedes Objekt die Einwirkungsdauer durch Probieren festzustellen.

\section{Vierundzranzigstes Kapite1.}

\section{Die Haut.}

\section{$\S 2 \mathrm{I} 7$.}

Zur Erkennung des feineren Baues der Haut, und zwar sowohl um Uhersichtsbilder als auch um das intimere Verhalten der einzelnen Schichten darzustellen, sind Schnitte von fixiertem Material am geeignetsten. Nur fü gewisse topographische Studien (\$222) sind Mazerationen verwendbar, die dann grobe Übersichten, aber keine feineren Einzelheiten zur Anschauung bringen. Bei der ungemeinen Elastizität, welche der Haut eigen, diurfte es nicht gleichgiiltig sein, ob die Fixierung bei Spannung des Hautstückes vorgenommen wurde oder ob das Stück in die Fixierungsflüssigkeit kam, ohne daß Vor- 
kehrungen gegen scine starke Kontraktion getroffen worden waren. Es ist nicht falsch, wenn man auf die letztere I'eise fixiert, denn gute Übersichtsbilder lassen sich auch so erhalten. Aber wenn man z. B. cine genaue Kenntnis von der Verteilung der elastischen Fasern erstrebt, wenn man auf eine physiologische Anatomie der Haut ausgeht, dann muissen gespannte und ungespannte Hautstücke untersucht werden.

Zur Fixierung eignen sich absoluter Alkohol, Carnoysche Fliissigkeit, Müllersche Lösung, Formol mit nachfolgender Chromkalibehandlung, Flemmingsche Lösung und Pikrinsalpetersäure (viertes Kapitel). $\mathrm{Zu}$ vermeiden sind alle Gemische, welche stark salpetersäurehaltig sind, da in ihnen die Epidermis sich blasenartig abhebt. Nur die Pikrinsalpetersäure macht eine Ausnahme, denn bei ihrer Anwendung habe ich niemals eine blasige Abhebung beobachtet.

Die Haut des Menschen, der Säuger und der Amphibien ist ein schwer permeables Organ. Мan muß daher kleine Stucke und viel Fixierungs- und Härtungsflüssigkeit nehmen und muß sorgfältig entwässern, damit das Paraffin bzw. Celloidin gleichmäßig alle Schichten durchdringen kann.

Die behaarte Haut sinkt infolge des Haartalges in wässrigen Fixierungsmitteln nicht unter. Es duirfte sich empfehlen, falls es nicht auf eine Untersuchung des Haares in seiner ganzen Lange außerhalb der Haartasche ankommt, die Haare vor dem Fixieren kurz abzuschneiden und die Haut erst mit Alkohol und dann mit Äther von dem ihr anhaftenden Fett zu reinigen.

Die Haut der Reptilien und Fische, soweit sie nicht wie die der Aale und Cyclostomen nackt ist, kann wegen der in ihr steckenden Horn- bzw. Zahngebilde (Selachier) nicht so ohne weiteres geschnitten werden. Man wird die Hautzähne der Selachier erweichen müssen oder man mazeriert. Paul Mayer empfiehlt zur Mazeration der Haut, besonders von Raja, einige Stunden in: $50^{\circ}$ 。 Essigsäure 80 Teile, $I^{\circ}$ 。Chromsäure I $_{50}$ Teile und Wasser 750 Teile einzulegen. Bei Teleostiern und Reptilien Saurier, wird man die Horngebilde entfernen müssen, che man fixiert. Die Hautpanzer anderer Tiere (Chelonier usw.) sind wie Knochen zu behandeln.

Zur Färbung kann man die beliebigsten Farbstoffe wählen: Safranin, Fuchsin, diese nach Fixierung in Flemmingscher Lösung. Ferner: Pikrokarmin, eventuell in Kombination mit Hämatoxylin, EosinHämateïn, Orange G-Hämateïn, Triacid, Hämatoxylineisenlack usw. (vgl. achtes Kapitel. Alle diese Färbungen werden gute Übersichtsbilder geben und werden auch die Hautdrüsen in charakteristischer Weise hervorheben. 
Zur Färbung nach Fixierung in Flemmingscher Lösung hat Lustgarten das Viktoriablau empfohlen. Die Schnitte kommen in eine Farbflotte, welche aus $\mathrm{I}-2$ Teilen konzentrierter alkoholischer Viktoriablaulösung und + Teilen Wasser besteht, und bleiben darin $2+$ Stunden. Dann spült man sie 5- Io Sekunden in absolutem Alkohol, hellt mit Bergamottöl auf, bringt in Xylol ein, welches das Öl verdrängen soll, und schließt in Balsam ein. Die Färbungen halten sich, bei Lichtabschluß aufbewahrt, höchstens ${ }^{\mathrm{I}}$ = Jahr. Bindegewebe und Zelleiber sind schwach grünlich, Kerne dunkelgrin, elastische Fasern blaugrün.

Muschenkoff und Frey geben folgendes Verfahren an: Kleine, O.I $\mathrm{ccm}$ dicke Hautstiicke kommen in $2^{\circ}$. AmmoniumbichromatLösung für längere Zeit zum Härten. Dann werden sie Io Minuten in fließendem Wasser ausgewaschen und in ein Goldbad ibertragen, welches in $100 \mathrm{ccm}$ Wasser I g Goldchlorid und I ccm Salzsäure enthält. In diesen Goldbade bleiben die Stiicke I Stunde, werden in Wasser abgespiilt und kommen zur Reduktion in $0,02^{\circ}$. Chromsäure. Die Reduktion muß unter Ausschlul3 des Lichtes erfolgen. Nach $2+$ Stunden wird das nicht reduzierte Gold entfernt, indem man mit starker, photographischer Lösung von Natriumhyposulfit behandelt. Diese Prozedur muß an den Schnitten vorgenommen werden. Gefärbt sind: Stratum granulosum, markhaltige Nerven mit Endapparaten und Fettgewebe dunkelblaugrün bis bläulichschwarz.

Bonnet rät, die Haut in ${ }^{3}{ }^{\circ}$. Chromsäure zu fixieren, die Schnitte mit Hämatoxylin zu überfärben und in alkoholischen Lösung von rotem Blutlaugensalz zu differenzieren.

\section{§ 2 I 8.}

Epidermis. Zur Untersuchung der feineren Einzelheiten, welche die einzelnen Hautschichten darbieten, sind zahlreiche Spezialmethoden ersonnen worden, die in diesem und in den nächsten §̧ geschildert werden sollen. Sic sind fast ausschließlich für die Haut der Säugetiere angegeben; will man sie auf andere Vertebraten - die Evertebraten kommen hier nicht in Betracht - anwenden, so wird man sie modifizieren müssen, wenn man nach Befolgung der gegebenen Vorschriften zu keinem brauchbaren Resultate gelangt.

Die Epithelzellen der Haut zeigen eine eigentïmliche Faserung und diese Epithelfaserung bringt man auf folgende Wieise zur Anschauung: Schnitte von Alkoholmaterial, welche sehr dünn sein müssen, werden auf dem Objektträger in Anilinwasser-Methylviolett gefärbt. Dic Farbflotte stelit man dar, indem man jedesmal zum Gebrauche 
gleiche Mengen konzentricrter wässriger Lösung von MLethylviolett $6 \mathrm{~B}$ und Anilinwasser mischt. Die Einwirkung der Farbflotte dauert 5 Minuten. Dam wird in Wasser abgespuilt und in Lugolscher Lösung bis zu I Minute behandelt. Dann Wasser, Alkohol (wenige Sekunden, Xylolanilin (Xylol 2, Anilin I), bis keine Farbwolken mehr cntweichen, Xylol, Kanadabalsam. Diese Methode ist der Weigertschen Fibrinfärbung von Kromayer nachgebildet (vol. sechzehntes Kapitel).

Unna hat fuir die gleichen Zwecke (Fibrinfärbung) folgende vier Methoden angewendet: I. Methylenblau-Jod-Methode. Schnitte von Alkoholmaterial werden ${ }_{5}$ Minuten in polychromem Methylenblau gefärbt, dann in Wasser gespuilt und auf I Minute in eine $5^{\circ}$ Jodkaliumlösung getan, der I Jodkristall beigesetzt ist. Nan trocknet auf dem Objektträger ab, bringt in Xylolanilinöl zu gleichen Teilen, Xylol, Balsam.

2. Fuchsin-Tannin-Methode. Schnitte auf 2 Minuten in Karbolfuchsin (achtes Kapitel Nr.6I S. ISI); dann Wasser, I Minute konzentrierte wässrige Tanninlösung; Wasser, Alkohol, Bergamottöl, Balsam.

3. Eosin-Gentiana-Jod-Methode (modifizierte Weigertsche Tỉbrinfärbung). Schnitte auf I Minute in I wässrige Eosinlösung: dann in Wasser abspülen und Io Minuten in Gentiana-Alaunlösung (i Gentiana, ı Alaun, I oo IVasser). Abspülen in V'asser, I Minute in eine Lösung von Jodkalium und Wasserstoffsuperoxyd, Abtrocknen der Schnitte, auf $\mathrm{I}-2$ Minuten in Anilinorange $25+$ Xylol 25, dann Xylol, Balsam.

4. Wasserblau-Orcein-Methode. Zunächst macht man folgende Farbflotte: Wasserblau I g, Orcein I $\mathrm{g}$; Eisessig $5 \mathrm{ccm}$, Glyzerin $20 \mathrm{ccm}$, Spiritus $50 \mathrm{ccm}$, Wasser ad 100 . Die Haut wird in Alkohol oder Formol fixiert und in Celloidin eingebettet. Die Schnitte kommen in ein Gemisch, das aus I ccm der genannten Farbflotte, $0,3 \mathrm{ccm}$ einer $\mathrm{I}^{\circ}$. Lösung von spirituslöslichen Eosin in $80^{\circ}$. Alkohol und $0,3 \mathrm{ccm}$ einer $I^{\circ}$ o wässrigen Hydrochinonlösung besteht. Man färht im Reagensglase ro Minuten in der Kälte, wäscht in destilliertem Wassser ab, färbt Io Minuten in $I^{\circ}$. wässriger Lösung von Safranin $O$ (Griibler), wäscht wiederum in Wasser, bringt auf so-30 Minuten in eine ${ }^{1} \circ$ Lösung von Kali bichromicum, wäscht, entwässert und schließt auf übliche Weise in Balsam ein.

J. Frick bringt Schnitte von Alkohol-Alaterial in Kresylviolett; das Stratum granulosum färbt sich darin metachromatisch.

Zur Färbung des Keratohyalins rät Unna unter anderem an, 
Schnitte der unbehaarten Haut in Alaunhämatoxylin zu überfärben und dann auf Io Sekunden in übermangansaure Kalilösung ( 1 : 2000) einzubringen.

\section{\$ 219.}

Cutis. Die elastischen Fasern der Cutis werden mit IVeigerts Resorcinfuchsin und Röthigs Kresofuchsin achtes Kapitel Nr. 63 u. $6+$ S. I 82) ausgezeichnet zur Anschauung gebracht. Älter als diese beiden Methoden ist die Unna-Tänzersche Orceïnärbung. Schnitte aus Alkohol-1Iaterial werden folgendermaßen behandelt: Man stellt zunächst 2 Lösungen her. I. Lösung: Orcein (Grübler) o, I g, $95^{\circ}$, Alkohol $20 \mathrm{ccm}$, Aqua destillata $5 \mathrm{ccm}$. II. Lösung: konzentrierte Salzsäure $0,1 \mathrm{ccm}, 95^{\circ}$. Alkohol $20 \mathrm{ccm}$, Aqua destillata $5 \mathrm{ccm}$. Man beschicht mehrere Uhrschälchen mit Lösung I und fügt von Lösung- II tropfenweise so viel $\mathrm{zu}$, daß das erste Uhrschälchen halb so viel, das letzte $I^{1}{ }_{2}$ mal so viel erhält wie Orceinlösung. In jedes Uhrschälchen nun kommen Schnitte, man deckt gut zu und probiert aus, welche Kombination die elastischen Fasern dunkelbraun fürbt. Bei dieser Kombination bleibt man für das eben untersuchte Hautstiick. Der fast mathematischen Sicherheit gegenüber, mit welcher die Färbung der elastischen Fasern in Weigerts Fuchsin und Röthigs Kresofuchsin erfolgt, ist die Urceinfärbung mit ihrer Unsicherheit im Nachteil.

Kultschitzky fixiert Haut in Alkohol, der $\mathrm{r}^{\circ}$ 。 Essigsäure enthält. Die Schnitte kommen zur Färbung der clastischen Fasern in folgende Mischung von Magdalarot und Methylenblau: Magdalarot $0,5 \mathrm{~g}$, Methylenblau $0,25 \mathrm{~g}$, I" Lösung von kohlensaurem Kali $10 \mathrm{ccm}, 96^{\circ}$. Alkohol $200 \mathrm{ccm}$. Eine gute Färbung ist nach 18 bis 24 Stunden erzielt.

Ich möchte bei diesur Gelegenheit darauf hinweisen, daß an Formol-1laterial von Cetaccenhaut, das ich untersucht habe, das Ehrlichsche Triacidgemisch die gröberen elastischen Fasern leuchtend rot färbte.

Zum Studium der Cutis, die ja nicht bloß aus elastischen Fasern besteht, sind die Methoden zu verwenden, welche für das Bindegewebe empfohlen wurden (vierzehntes Kapitel).

\section{$\$ 220$.}

Kollagen. Un das Kollagen vom Protoplasma und ron den feinen Bindegewebsfibrillen tinktoriell zu unterscheiden, fixiert $L^{\top}$ nna Haut in Flemmingscher Lösung oder in einem Chromsalz und 
bringt die Schnitte von solchem Material für 20-30 Sekunden in: $I^{\circ}$. Säurefuchsinlösung $2 \mathrm{ccm}, \mathrm{I}^{\circ}$ 。Orangelösung I $\mathrm{ccm}$, Glyzerin $7 \mathrm{ccm}$, Aqua destillata ad roo ccm. In Alkohol wird ausgezogen, dann Bergamottöl, Kanadabalsam.

Zur Unterscheidung des Kollagen von glatten Muskeln gibt Unna cine Nasserblau-Orcein-Methode an, welche aber mit der in $\$ 2 \mathrm{I} S$ angefihrten nicht identisch ist. Die Schnitte, deren Fixierung gleichguiltig ist, kommen in: Orceïn (Grübler) I $\mathrm{g}$, Wasserblau 0,25 g: Alkohol absolutus $60 \mathrm{ccm}$, Glyzerin $10 \mathrm{ccm}$, Aqua destillata $100 \mathrm{ccm}$. Man färbt mindestens 6 Stunden; am besten ist es, wenn die Schnitte iiber Nacht in der Farbflotte bleiben. In saurem Alkohol wird eine Minute ausgezogen, dann wie gewöhnlich verfahren.

Um Kollagen von Elastin unterscheiden zu können, färbt Unna Schnitte ron beliebig fixiertem Material in: Orcein (Griibler) i g; Säurefuchsin $0,1 \mathrm{~g}$, Salzsäure $2 \mathrm{ccm}$, absoluter Alkohol $60 \mathrm{ccm}$, Glyzerin $10 \mathrm{ccm}$, Aqua destillata $\mathrm{I} 00 \mathrm{ccm}$. Die Färbung dauert 2 bis 4 Stunden, dann Alkohol, Öl, Balsam. Resultat: elastische Fasern braun, Kollagen dunkelrot.

Endlich hat Unna zur Kollagenfärbung noch eine neutrale Orceinlösung empfohlen. Die Schnitte werden $=-5$ Minuten in $1^{\circ}$ 。alkoholischer (neutraler) Orceinlösung gefärbt und dann wie üblich in Balsam ubertragen. Das kollagene Gerrebe ist tief orceinrot gefärbt.

Eine Karminfärbung ron Best, die zur Hervorhebung des Glycogen angegeben wurde, möge hier Platz finden (vgl. auch dreizehntes Kapitel $\leqslant$ 10 ); freilich scheint mir bei der außerordentlichen Alkalescenz der Farbflotte ihre Verwendbarkeit nur in sehr engen Grenzen möglich. Die Vorschrift lautet: Karmin $2 \mathrm{~g}$, Ammoniumchlorat $4 \mathrm{~g}$, Lithion carbonicum $\mathrm{I} g$ werden zusammen in $100 \mathrm{ccm}$ Aqua destillata gekocht. Nach dem Erkalten werden $20 \mathrm{ccm}$ Liquor ammonii caustici zugesetzt. Die gefärbten Schnitte werden direkt in $1^{\circ}{ }_{0}-10^{\circ}$ 。 salzsauren Alkohol gebracht und dann wie üblich montiert.

\section{$\$ 22$ I.}

Plasmazellen. Zur Darstellung der Plasmazellen in der Cutis ist eine Reihe besonderer Methoden angegeben worden, welche sich gewissermaßen denen ergänzend anreihen, die im vierzehnten Kapitel beim Bindegerebe beschrieben wurden. Unna fürbt Schnitte in polychromem Methylenblau, spült in WTasser ab und entfäbt in der käuflichen Glyzerinithermischung ${ }^{\mathrm{I}}+$ Ninute. Dann wird sorgfältig gewaschen, entwässert und wie üblich montiert. 
Nach Unna kann man auch +-6 Stunden in alkalischer Methylenblaulösung färben, dann über Nacht in $\mathrm{O}, \mathrm{I}^{\circ}$ 。 alkoholische (neutrale) Orceinlösung einbringen, in Alkohol schnell abwaschen und durch Bergamottöl in Kanadabalsam einlegen. Resultat: Plasmazellen blau, Kollagen orceinrot.

Ferner hat Unna eine Pappenheimsche Nethode, welche die Färbung der Plasmazellen in pathologischen Präparaten gestattet, modifiziert. Die Methode lautet: Nethylgrün 0,15 g; Pyronin 0,25 g. Alkohol 2,5 ccm, Glyzerin $20 \mathrm{ccm}, 0,5^{\circ}$, Karbolwasser $100 \mathrm{ccm}$. Färbung ı Minuten, Alkohol, Öl, Balsam.

Eine besondere Methode hat Ehrlich konstruiert, indem er die Haut vom lebenden . Ienschen excidicrt. Man reinigt die Hautstelle, die man untersuchen will, vereist sie durch Chloräthyl, macht sie also anästhetisch, und trägt sie flach mit dem Rasicrmesser ab. Das excidierte Hautstiickchen wird je nach seiner Dicke $24-48$ Stunden in absolutem Alkohol fixiert: jecles andere Reagens ist zu verwerfen. Dann kommt das Stiickchen auf $12-48$ Stunden in diinnes, I 2 - $\&$ Stunden in dickes Celloidin und wird aufgeklebt. Die Holzklütze und Korke, die zum Aufkleben benutzt werden, müssen nach Ehrlich so lange vorher in Alkohol gehalten werden, bis in diesem durch die Eiscnreaktion kein Tannin mehr nachweisbar ist. Stabilit macht eine solche Torbehandlung nicht nütig.) Die celloidinierten Stiicke werden in So Alkohol aufbewahrt. Dic ro $u$ dicken Schnitte kommen zur Auflösung des Celloidin in Alkohol absolutus + Ather zu gleichen Teilen, dann in $80^{\circ}$. Alkohol und werden sehr grüdlich gewaschen. Ehrlich empfichlt drei verschiedene Färbungsmethoden:

1. Polychromes Methylenblau. Man fürbt in diesem Farbstoffe 2-5 Minuten, wïscht in Vasser 15-30 Minuten aus, bis keine Farbwolken mehr ausgehen, bringt auf 5-1o Minuten in ein Schälchen mit IVasser, in das 15-20 Tropfen der Glyzerinäthermischung gegeben wurden, wäscht darauf sehr gut in Wasser aus, dann I Minute absoluter Alkohol, Bergamottül, Balsam. Das Granoplasma muß tiefdunkelblau sein: die Entfärbung muß beaufsichtigt werden, sie dauert etwa 3 mal so lange wie die Färbung.

2. Polychromes Methylenblau-Anilin-Alaun. Nachdem die Schnitte 2-5 Minuten lang in polychromem Methylenblau gefärbt wurden. kommen sie nacheinander in 3 Schälchen mit folgenden Mischungen: a) + Teile Alkohol + 3 Teile Xylol: b) 3 Teile Alkohol + 3 Teile Xylol: cl 2 Teile Alkohol +3 Teile Xylol. In jeder Mischung bleiben die Schnitte ${ }^{2}$. Minute, dann I Minute in Xylol, 5- =0 Minuten 
in Anilin-Alaun-Nischung bei mikroskopischer Kontrolle, Xylol, Kanada. Um Faltenbildung an den Schnitten zu vermeiden, werden sie aus den Flüssigkeiten mit einem dicken Glasstab herausgeholt, um den sie sich rollen.

3. Karbol-Methylgrün-Pyronin. Die Schnitte werden mit einer Platinnadel in ein mit der Farblösung beschicktes Reagensglas gebracht, im Wasserbade auf $40^{\circ} 5-7$ Minuten erwärmt und unter der Wasserleitung schnell abgekühlt. Diese Abkiihlung ist die Hauptsache. Dann werden die Schnitte gewaschen, in absolutem Alkohol extrahiert, bis keine Farbe mehr ausgeht, und montiert.

\section{$\$ 222$.}

Cutisleisten. Den Papillarkörper der Cutis topographisch zu studieren, hat Blaschko folgende Methode ersonnen: An totfaulen menschlichen Früchten trennen sich schon intrauterin Epidermis und Cutis. Man reinigt nun die Haut solcher Früchte, zieht die Epidermis in Lappen ab und legt diese so auf einen Objektträger, daß das Rete nach oben sieht. Dann übergießt man die Haut mit einer konzentrierten Alaunhämatoxylinlösung, schïttet diese nach 3-5 Minuten fort, spuilt in WVasser $a b$ und untersucht entweder in Glyzerin oder man entwässert, hellt auf, ïbergießt mit Kanadabalsam und deckt ein. Man kann auch, statt zu entwässern, die Haut lufttrocken werden lassen, was nach $\mathbf{I}-2$ Tagen eingetreten ist, und clann in Kanadabalsam aufheben.

Bei Säugern verfährt man nach Blaschko, ebenfalls um die Cutisleisten zu studieren, so, daß man Hautstiicke in $6{ }^{\circ}$, wenn sie sehr zart sind in $\mathrm{I}^{\circ}$ 。 Holzessig legt. Nach einiger Zeit, die natürlich auszuprobieren ist, kann man die Epidermis von der Cutis abziehen und verfährt wic vorhin. Philippson hat zur Mazeration ${ }^{x} / 3 \%$ Essigsäure empfohlen.

\section{$\S 223$.}

Nerven der Haut. Goldmethoden, Chromsilberimprägnierungen und Tethylenblaufärbungen mit nachträglicher Fixierung: das sind die Methoden, um die Nerven der Haut sichtbar zu machen. Vor der Vergoldung düfte es ratsam sein, durch eine duinne organische Säure (Essigsäure oder Ameisensäure) das Stratum corneum zu entfernen: das Gold dringt dann besser ein. Zur Methylenblaufärbung muß man schr diinne Scheibchen nehmen. Die in \$ 2 I 7 erwähnte Methode von Muschenkoff und Frey ist auch hier anwendbar. 
Smirnow fixiert die Haut in Altmannscher Lösung (viertes Kapitel Nr. 36 S. 62) 3-Io Tage, bringt dann zum Abspülen in $\mathrm{O}, \mathrm{I}^{\circ}$. Höllensteinlösung auf kurze Zeit und legt in $\mathrm{I}^{\circ}$ 。Höllensteinlösung auf I 8- 40 Stunden. Auswaschen in $90^{\circ}$. Alkohol, 2 bis 3 Stunden absoluter Alkohol; dann Schneiden, Entwässern, Xylol oder Terpentin, Abtrocknen mit Fließpapier, Dammarlack. Eberth und Bunge stellen die Nerven der Chromatophoren folgendermaßen dar: Haut um die Mundspalte kleiner Fische wird nach Golgi versilbert und geschnitten. Die Schnitte kommen in Chlorwasser, worin die Chromatophoren gebleicht werden; gleichzeitig entsteht aus dem Chromsilber dabei Chlorsilber, erforderlich sind dazu 15-20 Minuten. Dann wäscht man ${ }^{x}$ + Stunde in destilliertem Wasser $a b$, bringt in absoluten Alkohol und dann in Nelkenöl. Nunmehr bringt man die Schnitte auf einen Objektträger, gibt I Tropfen Nelkenöl zu und deckt mit einem Deckglase ein. IVerden die Schnitte jetzt dem Lichte ausgesetzt, dann wird aus dem Silberchlorid Silberchlorür und es kann nunmehr in Dammarlack mit Deckglas eingeschlossen werden.

Um die Nervenendigungen in der Haut ron Lumbricus zur Anschauung zu bringen, werden Teile dieses Tieres in einer Mischung von $5^{\circ}$, Kali bichromicum-Lösung und I ${ }^{\circ}$. Osmiumsäure zu gleichen Teilen $5-28$ Tage lang fixiert.

\section{$\$ 22$.}

Fettgewebe. Den Panniculus adiposus untersucht man wie dies bei den Isindesubstanzen vierzehntes Kapitel S. 26-j angegeben wurde. Ich will hier wiederholt darauf hinweisen, daß, wenn man osmiertes Fett in Paraffin einschmelzen will, als Intermedium Chloroform genommen werden muß. Denn Flemming hat nachgewiesen, daß alle anderen Intermedien osmiertes Fett auflösen, selbst dann, wie ich nach meinen Erfahrungen hinzufügen möchte, wenn man die Osmiumsäure durch Holzessig reduziert hat.

\section{$\$ 225$.}

Daß Injektionen der Haut sehr lehrreiche Bilder geben, ist selbstverständlich. Die Methoden vgl. zehntes Kapitel; die Blutgefäße muß man für jede Hautpartie besonders aufsuchen. Auch die Injektionen der Lymphbahnen durch das Einstichrerfahren geben schöne Resultate. 


\section{$\$ 226$.}

Haare. Nägel. Horn. Nan mazeriert entweder in starken Säuren oder in starken Alkalien, die man entweder kalt oder warm anwenden kann. Der mikroskopischen Schneidetechnik sind nur die Haare zugänglich. Sie werden mit der Haut zugleich geschnitten und wie diese gefärbt. Nach M. Günther wird mit Hämatoxylin (nach Böhmer usw.) gefärbt, in salzsaurem Alkohol ausgezogen, in etwas ammoniakhaltigen Wasser abgestumpft, wobei dic Schnitte blau werden, und mit Methyleosin-Pikrinsäure nachgefärbt.

Von Sinushaaren empfiehlt es sich, Querschnitte namentlich aus der Gegend des Bulbus anzufertigen. Sonst kann man, will man Haarquerschnitte von dem über der Haut stehenden Teile haben, eine größere Anzahl Haare in Gummiglyzerin einbetten (sechstes Kapitel) und unter Alkohol schneiden. Dic Henlesche Methode, Haarquerschnitte zu erlangen, nämlich sich scharf auszurasieren, sofort nachzurasicren und in dem zweiten Seifenschaum die Haarquerschnitte mit der Lupe herauszufischen, ist mehr originell als zuverlässig.

\section{Fünfundzwanzigstes Kapite1.}

\section{Das Geschmacksorgan.}

$$
\$ 227 .
$$

Mazerationspräparate ron den verschiedenen Papillen der Zunge anzufertigen, ist schr ratsam. Namentlich die beiden zelligen Elemente der Schmeckbecher werden in ihrer natürlichen Form nur so zu erkennen sein. Hallersches Gemisch, Oxalsäure /drittes Kapitel, oder andere etwas eingreifende Mittel werden gute Resultate liefern.

Zur Fixierung sind alle Mittel geeignet, welche keine starken Salpetersäuregemische sind, da diese wie bei der Haut das Epithel ahhcben. Bei Osmiumfixierungen ist die Nachbehandlung mit Holzessig dringend anzuraten, da sie namentlich von den Schmeckbechern vortreffliche Bilder liefert. Zur Färbung kann man nach Belieben und Geschmack wählen, was man will.

Bei der Fixicrung hat man darauf $z u$ achten, daß man nur kleine Stiicke einer großen Säugetierzunge nimmt, etwa ${ }^{I} \mathrm{~cm}$ um die 
Schmeckbecher herum, und daß nicht zuviel Muskulatur am Stück haftet. Klein soll das Objekt sein, weil die Zunge sich schwer durchtränkt, und zuriel Muskulatur ist vom Übel, weil sie sich schwer schneidet.

\title{
$\S 228$.
}

Zum Studium der Nervenendigungen sind die drei üblichen Methoden zu wählen: Gold, Golgis Chromsilber und Ehrlichs Methylenblau. Für letztere Färbung wird folgende Spezialvorschrift gegeben: Das eben getötete Tier wird mit $4 \%$ Methylenblaulösung injiziert. Aus der intensiv blau gewordenen Zunge, welche in ${ }_{5}$ bis 20 Minuten abblaßt, wird eine Papilla circumvallata oder, bei Lepus. eine Papilla foliata herausgeschnitten, nach Einklemmen in Hollundermark geschnitten und mit pikrinsaurem Ammoniak oder einer anderen Methode fixiert.

\section{Sechsundzwanzigstes Kapitel.}

\section{Das Geruchsorgan.}

\author{
$\S 229$.
}

Zur Mazeration der Regio respiratoria ist ${ }^{\mathrm{T}}$. Alliohol empfehlensWert, zur Mazeration der Regio olfactaria sind Jodserum, künstliches Jodserum, diinne ()smiumsüure und Chromsäure geeignet vgl. drittes Kapitel. Die Pacinische Fluissigkeit soll besonders geeignet sein; ihre Zusammensetzung -.. es existiercn 2 Formeln - ist nach Bchrens die folgcnde: I. Sublimat I $\mathrm{g}$, Chlornatrium $2 \mathrm{~g}, 80^{\circ}$. Glyzerin $13 \mathrm{ccm}$, IVasser I I $3 \mathrm{ccm}$; oder 2. Sublimat I $\mathrm{g}$, Chlornatrium $2 \mathrm{~g}, 80^{\circ}$, Glyzerin $+j \mathrm{ccm}$, Eisessig $2 \mathrm{ccm}$, Wasser I $15 \mathrm{ccm}$. Ich besitze über die Leistungen dieser Flüssigkeit keine Erfahrung.

Zum Studium ron Schnitten durfte die Fixierung in Flemmingscher Lüsung die allein geeignete sein. Nachbehandlung mit Holzessig erspart das Färben der Schnitte; sonst kann man dieses in Safranin, Fuchsin, Triacid oder in einem Eisenhämatoxylinlack vornehmen. Läßt man die Schleimhaut auf ihrem Knochen, was unter allen Umständen anzuraten ist, dann muß man entkalken (vogl. fünftes Kapitel). 
\$230.

Die Nervenverteilung wird an Gold-, Chromsilber-oder Methylenblaupräparaten studiert (vgl. achtes und neuntes Kapitel).

\title{
Siebenundzwanzigstes Kapite1.
}

\section{Das Gesichtsorgan.}

\author{
$\$ 231$.
}

Den inneren Aufbau des Auges der Vertebraten 'Evertebraten vgl. \$232) kann man gut nur an Schnitpräparaten studieren, denn nur an diesen stellen sich die Bezichungen der einzelnen Häute des Bulbus so dar, wie sie in Wirklichkeit sind. Die anatomische Zerlegung kann niemals eindeutige Bilder liefern, weil sie die genannten Bezichungen zerstören muß, will sie in das Innere des Organs eindringen. Die Schnitte sind entweder in der transversalen oder in der dorsoventralen Ebene zu legen. In der transversalen ermöglichen sie den Überblick über dic rechte und linke Seite des Bulbus, in der dorsoventralen zeigen sie zu gleicher Zeit oben und unten.

Um Schnitte anfertigen zu können, ist es nötig, Fixierungsmittel anzuwenden, und diese, hat man nur dic richtige Auswahl getroffen, dringen nicht allzuschwer in das Bulbusinnere ein. Nur die Augen der Mystacoceten sind anders zu behandeln. Die cnorme Dicke der Sclera, die an der Eintrittsstelle des Opticus wohl Zweidrittel des Augendurchmessers beträgt, verhindert jede Fixierung. Kann man die Augen dieser Tiere nicht gleich frisch verwenden, so muß man am oberen Scheitel ein Loch in die Sclera bohren, das Auge in $4^{\circ}$ 。 Formol legen und es später zu geeigneter Zeit gefrieren lassen. Durch das gefrorene Organ macht man mit einer sehr großen und sehr scharfen Knochensäge oder mit einer Tischlersäge - ich habe letztcre benutzt - einen Schnitt in der gewiunschten Richtung. Erkennung mikroskopischer Details bleibt dabei natiirlich ausgeschlossen.

Bei den Augen aller übrigen Vertebratengruppen liegen die Verhältnisse viel günstiger. Man beachte folgende Regeln bei der Fixierung und wird dann wohl selten Fehlschläge zu verzeichnen haben. 
Zunächst sind die Bulbi vom Orbitalfett frei zu präparieren, denn dieses hindert nicht unbeträchtlich das Eindringen der Fixierungsflüssigkeiten. Dann entferne man die Augenmuskeln bis zu ihrer Insertion, lasse aber entweder oben oder unten, rechts oder links irgend ein Restchen von irgend einem Muskel stehen, damit man eine gute Orientierungsmarke behalte. Noch besser ist es, wenn auch nicht in allen Fällen anwendbar, die Lider in Verbindung mit dem Bulbus zu lassen. Einmal wird dadurch möglich, den Übergang der Conjunctiva bulbi auf die Palpebra zu erkennen, und zwcitens geben die Augenlider eine untrügliche Orientierung.

Um das Eindringen der Flüssigkeiten in clen Bulbus zu erleichtern, ist empfohlen worden, an irgend einer Stelle ein Fenster einzuschneiden und so dem Reagens den Weg ins Innere zu eröffnen. Wenn dies geschieht, dann soll man es in der Fixierungsflüssigkeit vornehmen, damit nicht infolge der Aufhebung des intraocularen Druckes die Häute des Bulbus zum Teil herausquellen oder damit nicht, was noch häufiger sich ereignet, der Bulbus zusammenfällt. Dann faltet sich namentlich die Retina sehr stark und mit der topographischen Korrektheit der Präparate ist es vorbei. Indessen ist dies durchaus nicht nötig; denn die in Betracht kommenden fixierenden Reagentien dringen so ein, daß nach mehr oder minder langer Zeit der ganze Bulbus durchtränkt ist. Nach dem Fixieren wird gehärtet. Der Glaskörper bietet hier eine Gefahr für die tadellose Erhaltung der Form des Auges. Härtet man nämlich zu schnell, so schrumpft, wie ich wiederholt zu meinem Schaden erfahren habe, der Glaskörper so stark ein, daß das Auge infolge davon ganz deformiert wird. Also: langsam härten; mit 50 wiederholt wechseln, nach mehreren Tagen $60 \%$ usw.

Die Einbettung muß in Celloidin vorgenommen werden; in Paraffin wird der ganze Bulbus zu brüchig - die cinzelnen Teile lassen sich natürlich in Paraffin einschmelzen - ; uncingebettet zu schneiden ist nicht ratsam, weil dadurch namentlich die Lage der Linse verändert werden kann. Die Linse bietet dem Schneiden uibrigens unüberwindliche Schwierigkeiten, denn ihr Kern wird so hart, daß er sich nicht schneidet. Er muß daher, nachdem man den ersten Schnitt nicht genau im Scheitel der Cornea angelegt hat, in geeigneter Weise ausgestoßen werden.

Die Resultate von Schnitten durch den ganzen Bulbus sind Übersichtsbilder; der feinere Bau der einzelnen Häute muß an Einzelpräparaten erforscht werden.

Zur Fixierung ganzer Bulbi kommen nur in Betracht: $10 \%$ For- 
mol, Niillersche Flüssigkeit nnd Bendas Salpetersäure-Kali bichromicum-Methode (viertes Kapitel). Ich würde raten, der $10^{\circ}$ Formollösung, die Leber sehr empfiehlt, eine Nachfixierung in Kali bichromicum folgen zu lassen (vgl. viertes Kapitel S. 47). Dic bloße Formolisierung gerade solcher Gebilde, wie sie den Bulbus oculi bilden, schädigt nach meinen Erfahrungen die Färbbarkeit der einzelnen Gewebe. Die Farben, welche man auch wählen möge, erscheinen schmutzig, gehen ungleichmäßig an die Objekte heran und im selben Schnitte wechseln tadellos gefärbte Stellen mit schlecht gefärbten und gar nicht gefärbten ab.

Das Auge der Sauropsiden muß wegen des knöchernen Scleralringes nach der Fixierung einem Entkalkungsprozeß unterworfen werden (fünftes Kapitel). Die Augen der Ichthyopsiden werden wie die der Mammalia nach den eben geschilderten Regeln behandelt. Für ganz kleine Organe, z. B. Augen der Tritonen, kann man sich eine Vorschrift ron Ranvier zu Nutze machen. Man fixiert die Augen solcher Tiere 10 Minuten lang in Dämpfen der Osmiumsäure, viertes Kapitel Nr. 27 S. 60) und kann nun langsam härten. (Ranvier will nur die Retina fixieren und eröffnet daher nach ro Minuten den Bulbus.)

Zur Färbung genügen die Methoden, welche gute Übersichtsbilder liefern: Karmin und Hämatoxylin mit Alaun, Eosin-Hämatein, die Hämatoxylinlacke. Empfehlenswert ist das Durchfärben für die Übersichtsbilder und als besonders geeignet sind dafuir Parakarmin und Hämacalcium zu empfehlen (vgl. die Färbungsmethoden im achten Kapitel).

\section{$\$ 232$.}

Die Augen der Evertebraten verlangen eine verschiedene Behandlung, die sich nach der Komplikation ihres Baues richtet. Primitive Augen wie die der Anneliden, der Acephalen, Gastropoden, Asteroideen können in Sublimat, Osmiumessigsäure, Pikrinsalpetersäure fixiert werden. Bei diesen Gebilden wie auch bei den übrigen Evertebratengruppen sind übrigens Mazerationen höchst angebracht.

Das Cephalopoden-Auge muß wic das Vertebratenauge behandelt werden; die Fixierung zur Erlangung von Übersichtsbildern ist eine andere wie die zum Studium intimerer Strukturen. Miillersche Fluissigkeit möchte ich allerdings widerraten, sie wirkt auf Molluskenorgane nicht gut ein. Dafuir diurfte Formolfixierung mit nachfolgender Behandlung in Kali bichromicum (viertes Kapitel S. 47) durchaus geeignet sein. 
Beim Auge der Arthropoden, fuir das sich Sublimat und Flemmingsche Lösung eignen, ist auf den chitinigen Nantel, den manche Augen haben, und auf die Körperstelle, wo sie sich finden, Rücksicht zu nehmen. Gestielte Augen nämlich werden leichter zu fixieren sein, als ungestielte.

Die Augen sind oft sehr reich an Pigment, zu seiner Entfernung eignen sich die Methoden, die im fünften Kapitel beschricben sind.

\section{$\S 233$.}

Ich gebe nummehr die Methoden, nach welchen die einzelnen Teile der Augen zum Studium ihres feineren Baues untersucht werden können. Daß diese Einteilung sich an das Vertebratenauge hält, erscheint wohl selbstverständlich, und ebenso selbstverständlich ist, daß die hier zu beschreibenden Methoden sinngemäß den Verhältnissen des Evertebratenauges anzupassen sind.

a) Conjunctiva: Ihre Beschaffenheit ergibt sich an Schnitten durch die Cornea und Sclera Conjunctiva bulbi und durch die Palpebrae Conjunctiva palpebrae). Zum Studium der Nervenendigungen ist nach W. Krause am geeignetsten die Untersuchung des lebenswarmen Objektes ohne irgend welchen Zusatz. Freilich ist heutzutage eine derartige Methode nicht nach Jedermanns Geschmack und ist es auch niemals gewesen. Nach W. Krause ist 24 stiindige Mazeration in $3^{\circ}$. Essigsäure oder käuflichem Essig, nach Waldeyer ist 24 stündige Behandlung mit $0,1 \%$ Osmiumsäure am besten.

b; Sclera. Zur Mazeration sind die verschiedensten Methoden verwendbar; solche, welche für die Bindegewebsfibrillen besonders empfohlen wurden (vierzehntes Kapitel), eignen sich natiirlich auch für die Sclera. Fixierung in Sublimat, Pikrinsalpetersäure usw. und beliebige Färbung.

c) Cornea. Zur Mazeration bringt man die Hornhaut zunächst in diinne Essigsäure, um das Epithel zu lockern, und pinselt dieses dann ab. Dann werden die für das Bindegewebe gebräuchlichen Methoden auch hier in Anwendung kommen. Barytwasser soll sehr geeignet sein, die Fibrillen der Hornhautlamellen zu isolieren.

Abgesehen von den gewöhnlichen Fixierungsmethoden: Alkohol, Sublimat, Pikrinsalpetersäure, Flemmingsche Lösung, welche sehr schöne Bilder liefern, gibt es noch einige Spezialmethoden. Zunächst die Berlinerblaumethode von Leber. Hornhaut des Frosches kommt frisch auf kurze Zeit in eine $0,5^{\circ}{ }_{0}-1^{\circ}$ 。 Lösung eines Eisenoxydulsalzes. Dann pinselt man das Epithel ab und legt von neuem in die Eisenlösung. Im ganzen soll das Organ 5 Minuten in der 
Eisenlösung verweilen. Dann wird in Wasser abgewaschen und in $I^{c}$ Lösung ron Ferridcyankalium geschwenkt, bis die Cornea gleichmäßig intensiv blau ist. Die Grundsubstanz ist, wie sich nach Abspiilen in Wasser zeigt, blau, die Hornhautkörperchen und deren Ausläufer sind ungefärbt geblieben.

Zur Versilberung verfährt man folgendermaßen. Man bringt die Cornea frisch in $I^{\circ} \%$ Silberlösung nach einer der Methoden im neunten Kapitel. Nach eingetretener Reduktion Alkoholhärtung und Schneiden. Resultat: Hornhauthörperchen mit Fortsätzen hell auf dunklem Grunde, sogenanntes negatives Bild. Nach Stöhr kann man positive Bilder erlangen, d. h. dunkle Hornhautkörperchen auf hellem Grunde, wenn man die frisch versilberten Objekte auf 5 Minuten in $3^{\circ}$. Kochsalzlösung einlegt und in destilliertem Wasser zur Reduktion ins Sonnenlicht setzt.

Bezüglich der Vergoldung, der Versilberung nach Golgi und der Behandlung mit Methylenblau, für welche die Cornea ein iiberaus geeignetes Objekt ist, vgl. die betreffenden Methoden im achten und neunten Kapitel.

d) Die Chorioidea wird an Zupfpräparaten untersucht, die man von dem frischen Objekt anfertigt, oder an Schnittpräparaten in Zusammenhang mit Sclera und Retina (vgl. \$ 23t!, wobei es zuweilen nötig werden kann, das intensive Pigment zu entfernen ifünftes Kapitel. Die Gefäßverteilung studiert man an Inj̣ektionspräparaten.

e) Iris. Mazeriert wird die Iris wie glatte Muskulatur fünfzehntes Kapitel). Um Schnitte von diesem Gebilde zu erhalten, fixiert man in situ mit der vorderen Bulbushälfte.. Das Auge wird im Äquator halbiert und die vordere Hälfte in Pikrinsalpetersäure, Sublimat usw. fixiert. Zum Schneiden kann man entweder die Iris in situ belassen und schneidet sie dann mit Cornea, Sclera und Linse, was für die Untersuchung des Iriswinkels sehr wichtig ist. Oder man trennt sie nach dem Härten an ihrer Insertion $a b$, bettet sie in Segmenten cin und schneidet diese cinzeln. Zur Färbung sind am besten EosinHämatein, Bismarckbraun und Indigkarmin-Boraxkarmin achtes Kapitel); letztere Färbung ist mir merkwürdiger Weise nach kurzer Zcit völlig ausgeblaßt.

f) Linse. Zur Mazeration ist ${ }^{2} / 3$ Alkohol, $0,1 \%$ Osmiumsäure und dumne Essigsäure $\left(\mathrm{I}^{\circ}, \mathrm{O}, \mathrm{I}^{\circ}{ }^{\circ}\right) \mathrm{zu}$ empfehlen. Nan sticht am vorderen oder hinteren Pol die Linsenkaspel an, damit die Reagentien gut eindringen kömnen, und prifft von Zeit zu Zeit, ob sich die Linsenkaspel bequem abziehen läßt, die man ebenfalls untersucht, 
und versucht dann die Isolation der Linsenfasern. Letzteres muß leicht vonstatten gehen, wenn die Mazeration gelungen ist.

Gebhardt schlägt folgendes Terfahren zur Isolation der Linsenfasern ror: Ganze Bulbi kommen auf $1-2$ Tage in $t^{\circ}-10^{\circ}$ Formol. Dann werden sie auf einige Stunden in $50^{\circ}, 60^{\circ}$. Alkohol gelegt, um das Formol zu beseitigen, und nun nimmt man die Linse heraus. Man faßt sie am Äquator zwischen zwei Fingern und sprengt sie durch festes $\mathrm{Zu}$ sammendrücken. Nun sind die Fasern sehr leicht in Wasser oder Glyzerin zu isolieren und die isolierten in Glyzeringclatine einzuschließen.

Welche Schwierigkeiten die Linse beim Schneilen bereitet und wie diese $z u$ beheben sind, ist in $\$ 23$ I auseinandergesetzt worden. Embryonale Linsen und Linsen jugendlicher Föten schneiden sich sehr gut.

g) Glaskörper. Eine besondere Methodik ist für das Corpus vitreum nicht vorhanden. Man behandelt es, untersucht man erwachsene Tiere, wie die Bindesubstanzen bez. Schleimgewebe, vierzehntes Kapitel. Oder man untersucht den Glaskörper an Schnitten durch das embryonale Auge und dafuir ist ebenfalls keine spezielle Vorschrift erforderlich.

\section{$\$ 234$.}

h) Retina. Zur Isolation der Elemente der Netzhaut ist Mazeration in Jodserum, kïnstlichem Serum, ${ }_{3}$ Alkohol, dünner Osmiumsüure (drittes Kapitell erforderlich und zum Studium der Retina unerlä13lich. Denn niemals erhailt man eine Ahnung rom Bau der Licht empfindenden Haut des Auges, wenn man sich auf Schnittpriparate beschränkt. Namentlich auch die sehr schwierigen Verhältnisse der bindegewebigen Stiitzsubstanz sind in erster Linie durch Nazerationen zu erkennen, welche die Stibchen und Zapfen beseitigen.

Um die Retina gut zu fixieren, muß man den Bulbus oculi im Äquator halbieren. Dann legt man die hintere Hälfte in recht viel Fixierungsflussigkeit und entfernt nach einiger Zeit vorsichtig, ohne die Bulbuswand zu dricken, das Corpus vitreum. Dadurch daß man Retina, Chorioidea, Sclera und Opticus zusammen fixiert, vermeidet man jede Verkrümmung der Haut und kann nachher sich jeden beliebigen Teil zur Untersuchung wählen.

Sublimat, Flemmingsche Lösung sind brauchbare Fixierungsmittel. Ferner werden $3^{\mathrm{I}} \approx$. Salpetersäure nach Engelmann und Salpetersäure-Müllersche Flüssigkeit nach Angelucci (viertes Kapitel sehr empfohlen. Zur Färbung kann man nach Belieben aus- 
wählen, da kein Farbstoff nach meinen Erfahrungen vor dem anderen besondere Vorzüge besitzt.

IT. Krause hat ein eigenartiges Verfahren ersonnen, um nur die Kerne der Ganglienzellen und die Körnerschichten zu färben. Er bringt frische Retina in eine $1 \%$ Eisenlösung oder in eine $2 \%$ Vanadiumchloridlösung und trägt dann in eine $2 \%$ Lösung von Pyrogallussäure oder Gerbsäure ein. Nachfärbung mit einer Anilinfarbe ist möglich; dadurch werden die anderen Retinaschichten deutlich.

Bei der Evertebratenretina (Mollusken, Arthropoden) muß man oft: wie schon einmal erwähnt wurde $(\$ 232$, das Pigment entfernen.

Zum Studium der Nervenendigungen in der Retina dienen die bekannten 3 Methoden der Gegenwart: Gold, Chromsilber, Methylenblau. Mit letzterem hat namentlich Dogiel wertvolle Resultate erzielt.

Bezüglich der Chromsilbermethode gibt für die Retina der Vögel Ramòn y Cajal folgendes Verfahren an: Man legt die frische Retina in ein Gemisch ron 4 Teilen $3 \%$ Kali bichromicum-Lösung und I Teil I : Osmiumsäure und beläßt darin 2-3 Tage. Für jede Retina sind I $5-20 \mathrm{ccm}$ Flüssigkeit erforderlich. Dann direktes Übertragen in $3: \%$ Höllensteinlösung. Die dicken Schnitte müssen in $40 \%$ Alkohol wiederholt gewaschen werden; Aufhellen in Nelkenöl.

Hosch gibt folgende Methode fuir die Behandlung der Retina nach Golgi an: Er trennt nach dem Vorschlage von Ramòn y Cajal die Retina an der Papille ab, rollt sie vorsichtig mittels eines Pinsels auf und taucht sie auf Sekunden in dünnes Celloidin. Nun bringt er sie, abgelöst vom Pinsel, als Röllchen in $3 \%$ Natrium bichromicum-Lösung 20 Teile $+\mathrm{I} \%$ Osmiumsäure 6 Teile. Darin bleiben die Röllchen im Dunkeln 6 Tage, werden darauf in 3-4 Stücke zerschnitten und direkt in $0,75^{\circ} \%$ Argentum nitricum-Lösung auf 3 Tage eingelcgt. Darauf bringt man sie in die gebrauchte Natrium bichromicum-Lösung für 3 Tage zurück und darnach in frische Silberlösung für 2 Tage. Dann kurze Zeit $96^{\circ}{ }_{10}$ Alkohol, ${ }_{14}$ Stunde dicke Celloidinlösung. Aus dieser nimmt man die zerkleinerten Röllchen heraus, steckt sie in ein ausgehöhltes Stuick Hollundermark, gibt Celloidin zu und legt, wenn dieses angetrocknet ist, für ${ }^{\mathrm{I}} / 2$ Stunde in $80^{\circ}$. Alkohol ein. Dann wird geschnitten. In Alkohol rollen sich die Schnitte auf und der Hollundermarkmantel wird mit der Pinzette durch rasches Heben leicht entfernt. Dann kommen die Schnitte in 90\% Alkohol, darauf Bergamottöl I Teil + Kreosot 3 Teile; hierin breiten sie sich flach aus. Xylol, Dammarlack.

Ramon y Cajal hat zur Darstellung der Neurofibrillen in der Retina (vgl. zweiundzwanzigstes Kapitel) eine Versilberungsmethode 
angegeben: Frische Retinastücke werden mit der Sclera auf 3 Tage bei $30^{\circ}-35^{\circ} \mathrm{C}$. in $1,5^{\circ}$. Argentum nitricum-Lösung eingelegt. Die Konzentration der Höllensteinlösung kann zwischen $0,75 \%-3 \%$ schwanken. Nach der angegebenen Zeit wird einige Sekunden in destilliertem Wasser abgewaschen und dann auf 24 Stunden in eine Lösung von I g Hydrochinon (oder Pyrogallussäure, auf $100 \mathrm{ccm}$ Aqua destillata und 5- $10 \mathrm{ccm}$ Formol zur Reduktion eingelegt. Man wäscht in destilliertem Wasser aus, härtet schnell in Alkohol von steigender Konzentration, bringt in Celloidin, hellt dic Schnitte in Origanumöl auf, dann Xylol, Dammarlack.

Um den Sehpurpur so zu fixieren, daß man ihn in mikroskopischen Schnitten findet, hat Stern folgende Methode angegeben: Man bringt einen Frosch auf 2 Stunden ins Dunkle, tötet ihn bei rotem Licht durch Dekapitation, nimmt die Augen heraus, eröfnet die Bulbi und bringt die eröffneten in $2,5 \%$ Lösung von Platinchlorid (auch $0,5 \%$ und $10 \%$ sind verwendbar fuir I $2-14$ Stunden; dann absoluter Alkohol, Xylol, Paraffin. Die Stäbchenaußenglieder sind intensiv orange gefärbt.

i) Die Blut- und Lymphgefäße des Bulbus werden in der bekannten Weise durch Injektion deutlich gemacht. Besonderer Methoden, sogenannter Spezialmethoden, bedarf es hier nicht.

$$
\$ 235 \text {. }
$$

Die Schutzorgane des Auges. Die Augenlider werden wie die Haut (vierundzwanzigstes Kapitel), die Tränendrüsen wie alle anderen Drüsen (neunzehntes Kapitel) untersucht.

\section{Achtundzwanzigstes Kapite1.}

\section{Das Gehörorgan.}

$$
\S 236 \text {. }
$$

Der mikroskopischen Untersuchung des Gehörorgans stellen sich durch seine eigentümlichen Lagerungsverhältnisse nicht unerhebliche Schwierigkeiten in den Weg. Der Hauptteil des Organs, da wo die Gehörsempfindung zustande kommt, liegt tief in einem Knochen der Schädelkapsel eingebettet, der zu den härtesten Knnochen des 
Skeletts gehört. Es ist daher nicht leicht, die Reagentien, mögen sie zum Fixieren oder zum Mazerieren verwendet werden, bis ins innere Ohr zu bringen. Lnd auch derjenige Teil des Gehörorgans, welcher die Schallwellen leitet, das Nittelohr, verlangt eine so sorgialtige Behandlung, wie man sie nicht bei allen Organen anzuwenden braucht. Geduld, lange Übung und etwas Geschick sind erforderlich, um rom Gehörorgan gute Präparate zu erhalten; den meisten Mikroskopikern wird hier wenigstens zu Anfang schr vicles mißgliicken. Ich folge in meinen Auseinandersetzungen den Angaben, die L. Katz, einer der erfahrensten Mikroskopiker des Ohres, gemacht hat.

a Mittelohr. Die Schleimhaut der Paukenhöhle und die Tuba Eustachii bilden das Hauptobjekt für eine Fixierung des ganzen Mittelohres, denn die Gehörknöchelchen sind Knochen und wie diese zu behandeln. Nach L. Katz legt man das Mittelohr in Müllersche Flüssigkeit oder in eine Mischung aus dieser und Formol Miillersche Flüssigkeit 95 Teile, Formol 5 Teile). Katz hält das Formolgemisch sogar für besser als die einfache Miillersche Flüssigkeit; daß diese Ansicht nicht ganz zutreffend ist, wurde im vierten Kapitel des breiteren auseinandergesetzt. Die Objekte bleiben in den genannten Flüssigkeiten mindesten 3 Wochen und während dieser Zeit muß mindestens 3 mal eine Erneuerung der Reagentien vorgenommen werden. Dann wird entkalkt; und zwar bringt man die Objekte entweder in $5 \%$ - $10 \%$ Salpetersäure oder in $5 \%-10^{\circ} \%$ Salzsäure. Bis der Knochen vollständig entkalkt ist, müssen die Säuren alle 48 Stunden erneuert werden. Um ein besseres Eindringen der Chromsalze in das Mittelohr zu ermöglichen, empfiehlt es sich, beim Menschen (und natülich bei allen großen Säugern, das Tegmen antri vorsichtig mit dem Meißel zu eröffnen.

Alle anderen Fixierungsmittel hält $\mathrm{Katz}$ nach seinen Erfahrungen fuir völlig überfluissig; bei der großen Resistenz der Epithelien des Mittelohres erhält man auf die geschilderte einfache Weise sehr gute Präparate.

Um das Trommelfell isoliert untersuchen zu können, eventuell auf Schnitten, schneidet man es nach der Härtung des ganzen Mittelohres mit dem Annulus tympanicus und dem Hammer heraus, entlallit in $2^{\circ}$. Salpetersäure und bettet in Paraffin ein. Es ist dies nebenbei bumerkt das einzige Gebilde des Gehörorgans - mittleres und inneres Ohr —, das in Paraffin eingebettet werden kann. Alle übrigen Ohrabschnitte müssen celloidiniert werden.

Will man die Schichten der Membrana tympani untersuchen, dann legt man die Haut in gewöhnliches Wasser zum Nazerieren. Nach 
einiger Zeit, die jedesmal auszuprobieren ist, löst sich die Cutis ab und man kann nun mit Hilfe der Lupe die Radiär- und die Circulärfaserschicht präparieren.

Zum Studium der Trommelfelinerven dient die Methylenblaufärbung.

\section{$\$ 237$.}

b Inneres Ohr. Will man die Elemente des häutigen Labyrinths isolieren, so nimmt man verdünnte $\|$ ülle rsche Flüssigkeit oder rerdünnte Osmiumsäure. Die Konzentration ist fuir jedes einzelne Objekt besonders festzustellen; im allgemeinen wird man dünne Lösungen und geringe Quantitäten nehmen müssen. Auch dic Retziussche Goldmethode 'neuntes Kapitel Nr. 7 S. 212; ist für diese Zwecke sehr empfehlenswert, nur darf man den Knochen nicht entkallien. Mlan schabt ihn vielmehr mit einem Skalpell ab und schneidet von der Membrana basilaris oder den Ampullen mit einer feinen Schere Stiicke ab, welche dann zerzupft werden müssen.

Zur Fixierung von Schnecke und Bogengängen hat L. Katz früher folgende Vorschriften gegeben: Kleine junge Säugetiere Meerschweinchen, Fledermaus, Kaninchen, Katze usw: gehen die geeigneten Objekte. IIan präpariert das Felsenbein heraus, eröfnet die basale Schneckenwindung und allenfalls auch noch den oberen (analis semicircularis. Nun wird für etwa ro Stunden in eine ${ }^{2} / 2 \%$ Osmiumsäure eingelegt. Zu dieser Lösung fügt man nach clieser Zeit $100 \mathrm{ccm}$ folgender (hromessigsäure: (hromsäure $0,3 \mathrm{~g}$, Eisessig $0,5 \mathrm{ccm}$, Aqua destillata roo ccm. In dem nunmehr osmiumhaltigen Gemisch bleiben die Objekte + Tage, kommen darnach für fernere + Tage in frische Chromessigsäure (ohne Osmium). Auswaschen' ${ }_{2}$ Stunde und Entkalken in den von Kat\% angegebenen Gemischen 'fünftes Kapitel Nr. 7 u. 8 S. 8I).

Neuerdings hat Katz sein Verfahren stark modifiziert. Zunächst gibt er die sehr wichtige Regel, die kleinen Tiere durch Dekapitation zu töten. Vergiftungen mit Chloroform, Blausäure usw. rufen während der Agonie sehr leicht Blutungen im Gehörorgan und V'eränderungen in den Ganglienzellen hervor. Vorbehandelt wird wie vorhin, d. h. Eröffnung der basalen Windung usw. Das Gehörorgan kommt zunächst in eine Osmiumessigsäure $\left({ }^{1} z^{*}\right.$ 。 Osmiumsäure $25 \mathrm{ccm}$, Eisessig 5 Tropfen' auf $4-6$ Stunden, dann werden zu diesem Reagens, ohne daß das zu fixierende Objekt herausgenommen werden darf, die 5 fache Menge an ${ }^{x}=$ 。 Platinchlorid und ${ }_{5} 5$ Tropfen Eisessig hinzugefügt. Man erneuert die Platinchloridessigsäure, wahrscheinlich wie 
bei der vorigen Methode, und bringt zur Reduktion der Osmiumsiture nach 4 Tagen für " ${ }^{\prime}$ Tag in dünnen Holzessig (I Holzessig + I Wasser).

Die frühere (vgl, oben) Chromessigsäurebehandlung hat Katz folgendermaßen abgeändert. Auf $4-6$ Stunden Einlegen in $0,5 \%$ Osmiumsäure $30 \mathrm{ccm}$, konzentrierte Essigsäure 5 Tropfen; dann Zusatz von $=\%$ Chromsäure $60 \mathrm{ccm}$, konzentrierte Essigsäure 10 Tropfen. In dem Doppelgemisch bleiben die Präparate 4 Tage und werden nunmehr weiter behandelt, wie die auf die anderen Weisen fixierten Objekte, worüber bald das Nähere zu sagen sein wird.

Katz empfiehlt noch die Bendasche Salpetersäure-Kali bichromicum-Methode (viertes Kapitel), wenn sie auch das Sinnesepithel nicht so gut erhält, wie die eben geschilderten Methoden.

Held hat sehr gute Resultate mit der Zenkerschen Lösung erzielt (viertes Kapitel).

Die Weiterbehandlung der fixierten Gehörorgane besteht nun in der Entkalkung. Außer den oben erwähnten, von Katz angegebenen Entkalkungsflüssigkeiten empfiehlt dieser Forscher noch $5 \%-10 \%$ Salpetersäure oder Salzsäure. Folgende für die Entkalkung sehr wichtigen Regeln stellt er auf. Die Entkalkungsflüssigkeiten müssen alle 48 Stunden erneuert werden und stets muß man von ihnen eine große Quantität anwenden. Die Dauer der Entkalkung richtet sich nach der Größe des Felsenbeins, nach der Konzentration der Säure und nach deren häufigem Wechsel. $5 \%$ Salpetersäure z. B. entkalkt menschliches Felsenbein in 3 Wochen, bei $10 \%$ Salpetersäure und häufigem Erneuern ist oft die Entkalkung schon nach io Tagen beendet; doch bietet eine solche Beschleunigung keinen Vorteil. Man priff mit einer Präpariernadel den Fortschritt der Entkalkung. Bei kleinen Tieren ist eine Entkalkung meist nicht nötig. In Celloidin wird auf die übliche Weise eingebettet; gefärbt wird mit EosinHämatein, van Giesonscher Methode oder einem Eisenhämatoxylinlack (vgl. achtes Kapitel).

$$
\S 238 .
$$

Zur Erkenntnis der Innervation ist die Osmiumgoldmethode von Retzius (neuntes Kapitel Nr. 7 S. 212) und die Ehrlichsche Methylenblaumethode empfohlen worden. Der Golgischen Chromsilberbehandlung duirften sich sehr beträchtliche Schwierigkeiten in den $\mathrm{H}^{\top}$ eg stellen. 


\section{\$239.}

Ferreri legt Gehörorgan in Mingazzinische Flüssigkeit: 2 Teile Sublimat, I Teil Alkohol absolutus und I Teil Essigsäure (vgl auch S. $72 \mathrm{Nr} .58)$. Er läßt in dem Gemisch 15 Minuten. Daß innerhalb dieser Zeit selbst bei eröffnetem Schneckenkanal keine Fixicrung stattgefunden haben kann, leuchtet ohne weiteres ein. Zur Entkalkung schlägt Ferreri Phlorogluzinsalzsäure vor (fünftes Kapitel).

\section{$\S 240$.}

c) Äußeres Ohr. Auricula und äußerer Gehörgang werden wie Netzknorpel bzw. wie Haut behandelt (vierzehntes und vierundzwanzigstes Kapitel). 


\section{Register.}

(Die Zahlen verweisen auf die Seiten.)

A.

Abbe 286.

Abbescher Beleuchtungsapparat 6 .

Abbesches Wiirfelchen $23^{8}$.

Abbilden 235.

Abkühlung (des Parafins) 120.

Abziehvorrichtung II3.

Achromatische Substanz 258.

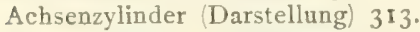

Achsenzylinder (Färbung) 396.

Achsenzylinder (Fibrillen) 397.

Aceton 42. 96.

Acidophile Granula 295.

Acridinrot-Pikrinblan 263 .

Adjektive Färbung 152. $197 \mathrm{ff}$.

Adsorption 158 .

Äther (zum Gefrieren) 130 .

Ätherspray I3I.

Äthyläther I 30 .

Äthylchlorid 130.

Agarlösung 267. 300.

Alauncochenille 163 .

Alaunhämatoxylin I76. I77.

Alaunkarmin 167.

Alaun-Salpetersäure (zur Mazeration) 28.

Alaunwasser I' $\mathbf{2}$.

Albrecht I39.

Albumin (zum Aufkleben) 139.

Albumose 37 .

Alcool au tiers 24.

Alexander 124.

Alizarin 204.

Alizarincyanin 205.

Alizarinmonosulfosaures Natron 205.

Alizarinorange 204.

Alizarin-Toluidinblau 387.

Alkohol 42. 43.

Alkohol absolutus 43 .

Alkohol I/3, I/4, I/6 24 .

Alkohol (ammoniakalisch) 359. 360:

Alkohol $(50 \%)$ zum Aufkleben 137 .
Alkohol-Eisessig 44.

Alkohol-Eisessig-Chloroform 44.

Alkohol-Eisessig-Chloroform-Sublimat 45 .

Alkohol (salpeters.) 83.

Alkohol (salzs.) 83.

Allerhand 368 .

Alt I 80 .

Altmann 88, I 83, 221. 259. 260.

Altmannsche Lösung 62 .

Aluminiumchlorid-Hämatoxylin $\mathbf{1 7 7}$.

Ambronn 8 .

Amitose 259.

Ammoniakalisches Karmin 165 .

Ammonium bichromicum $0,025 \%-0,1 \%$ 25.

Amöboide Bewegung 245 .

Analysator 8 .

Andeer 82.

Angelucci 54.

Anilinblau 185 .

Anilinblau-Orange-Oxalsäure $3 \mathbf{I} 2$.

Anilinfarben $\mathbf{1} 78 \mathrm{ff}$.

Anilinfarben (für Zentralnervens.) 377.

Anilinfarben: basische I 80 , blaue 185 , braune 187 , gelbe 184 , grüne 184 , rote I8o, saure I 80 , schwarze I 88 , violette I 87 .

Anilinlacke 203.

Anilinwasser I 79 .

Anilinwasser-Gentianaviolett 187 .

Anilinwasser-Methylviolett 302 .

Anilinwasser-Methylviolett (für Haut) 403.

Anilinwasser-Säurefuchsin 260 .

Anilinwasser-Säurefuchsin 265.

Anthracene 204.

Aorta 308.

Apáthy 27. 73. 96. II9. I74, $210,213$.

Apáthysches Gemisch 27.

Apáthysche Goldmethode 364 .

Apáthysche Hämatoxylinfärbung 383 .

Aplanatische Lupe 2.

Archiplasma 255. 
Argentamin-Methode 363 .

Argentum nitricum (zur Imprägnation) $2 \times 3$.

Argutinski I39. 140.

Arkansasstein 274.

Arnold 289.

Arnoldsche Methode 25.

Arterien 308.

Arthropoden (Augen) 415.

Ascariden (Eier, zu Zellstudien) 252.

Asphaltlack 234.

Assmann 299. 300.

Attraktionssphäre 251. 255.

Aqua destillata (zum Aufkleben) I37.

Anerbach 319.

Auerbachsche Endknospen $35^{8}$.

Aufheben (der Präparate) 223.

Aufheben: feucht 233, trocken 224, trocken mit Intermedien 228, trocken ohne Intermedien 264 .

Aufkleben 86. 135 .

Aufklebemethoden 135 .

Aufkleben von Gefrierschnitten 143 .

Auge (Evertebraten) 414.

Auge (Vertebraten) 412.

Augenlider 419.

Aurantia-Indulin-Eosin 295.

Auricula 423.

Auswaschen 42 .

Automatische Mikrotome I29.

Azoulay 60.

Azur 185.

Azur I 268.

Azur II-Eosin 298.

\section{B.}

Babes 169.

Babessches Safranin $1 \$_{3}$.

Balkennetze (im Knorpel) 269.

Ballowitz 327. 328 .

Bancroft 152 .

Bandwurmmethode II 7.

Bartel 312.

Bartholinische Drisen $36 \mathrm{r}$.

Barytwasser 266.

Basophile Granula 295. 296.

Becker 297.

Behrens 235. 411 .

Beize 152.

Beizfärbung I 54 .

Belebung (alten Materials) I62.

Belegkörper 19.

Beleuchtungsapparate 5 .

Beleuchtungsapparat nach Abbe 6.

Benda 49. 157. 185. 187. 192. 198. 199. 200. 205. 252. 253.330.

Bendasche Fixierung 54.

Bendasche Neurogliamethode 387 .

van Beneden 44.

Benzoazurin 277.

Benzol (als Intermedium) 96.
Benzopurpurin 180.

Berg, W. 36. 40. 70.

Bergamottöl: zum Aufhellen 230, als Intermedium 96.

Bergonzini 195.

Berkley 382 .

Berliner Blau (zur Injektion), 220, 221.222.

Berliner Blau nach Leber $4 \mathbf{1 5}$.

Bernsteinlack 235.

Best 256. 406.

Bethe 150. 338. 375.377 .

Betz 345 .

Bewegung (amöboide) 245 .

Bielschowsky 360. 36r. 362. 38r.

Bimsteinpulver (für Knochenschliffe) 274.

Bindegewebe 260; areoläres 260, Fibrillen 262, geformtes 266, lockeres 260, ungeformtes 260, Zellen 264.

Bindegewebskörperchen 26r. 264, Zusammenhang mit Nerven 266.

Bindesubstanzen 260.

Biondi (s. Ehrlich-Biondi).

Bismarckbraun $\mathbf{1} 87$, zur vitalen Färbung 246.

Bizzozero 288 .

Blaschko 408.

Blauholz 172.

Blauschwarz 138 .

Blei (ameisensaures, für Zentralnervens.) 367.

Bleichvorschriften (für Osmiummaterial) 58.

Bleu de Lyon 185 .

Bleu pour micrographie 262.

Blochmann 189.335.

Blum 45.

Blut 284; lebend 284, überlebend 285, Färbung lebenden B1. 288, Fixieren 288.

Blutbildung 302 .

Blutelemente (Färbung) 294.

Blutflecken (Untersuchung) 305.

Blutgefäßbildung 309 .

Blutgefäßdrüsen 309 .

Blutgerinnung 285 .

Blutkörperchen (Zählung) 286.

Blutkörperchen-Zählapparat 286.

Blutkristalle 302.

Blutkrusten 305.

Blutplasma 287.

Blutplättchen 300 .

Bödeker 278.

Bogengänge $42 \mathrm{r}$.

Böhm-Oppelsches Silberverfahren $32 \mathrm{I}$.

Böhmersches Hämatoxylin $\mathbf{I} 75$.

Boll 27.

Bolton 267.

Bolton und Bari 354.

Bonnet 403 .

Boraxkarmin 166.

Boraxkarmin-Bleu de Lyon 189 .

Boraxkarmin-Indigkarmin 189 .

Boraxkarmin-Methylblau $\mathrm{I} 89$. 
Borderauxrot iso.

Bordeauxrot-Thionin-Methylgrün 196 .

Born 240.

Borsäure-Sublimat 249.

Bouin 66. 72. 77 .

Boveri 65. 155 .

Brandt, K. 206. 246.

Brasilin 177.

Brab 96.

Brillantschwarz 188.

Brock 26r.

Briicke 210.

Buchbolzsche Methode 25.

Buchsbaumklotz 122.

Bunge 9I.

Burckhardt 62. 348 .

Busch 59.

Buschsche Methode für Fettkörnchenzellen $35 \mathrm{I}$.

Buschsche Modifikation für Marchi 37r.

Bütschli 249.

\section{C.}

Cajalsche Methylenblaufärbung 373 .

Cajeputöl 23 I.

Calberla 91.

Calleja I94.

Camera lucida von Abbe 237.

Camera lucida von Oberhäuser 236.

Carnoy 259.

Carnoysche Flüssigkeit 259.

Celloidin (zur Einbettung) 105.

Celloidin nach Unna 105.

Celloidinlappenmethode I4I.

Celloidin-Paraffin 106.

Centrosoma 25I. 252. 253.

Cephalopoden (Auge) 4I 4 .

Certes 246.

Chemische Theorie (des Färbens) 157 .

Chenzincky 296. 297.

Chilesotti 396.

Chinablau 310.

Chinablau (zur vitalen Färbung) 246.

Chitinpanzer (Entkalkung) 82.

Chloralhämatoxylin $\mathbf{1 7 6 .}$

Chlordämpfe (zum Entfärben) 84.

Chloroform zur Celloidinhärtung 108.

Chloroform zur Fixierung 44. 45.

Chloroform als Intermedium 97.

Chloroform-Kanadabalsam I12.

Chloroformparaffin 99.

Chloroform-Zedernöl 96.

Chlorpalladiummethode (f.Zentralnervens.) 369.

Chlorpalladiumsalzsäure 8I.

Chondrinballen 269.

Chorioidea 416.

Chromalauncochenille $x 65$.

Chromalaunhämateïn $I 75$.

Chromameisensäure $5 \mathrm{I}$.
Chromatin 25I. 258.

Chromatische Substanz 258.

Chrombeizen 204.

Chromessigsäure 51 . 52 .

Chromogen 385 .

Chromosmiumessigsäure 62 .

Chromosmiumsäure $6 \mathbf{r}$.

Chromosmiumsäureisessig $6 \mathbf{I}$.

Chromosmiumsalpetersäure 62 .

Chromotrop 180.

Chrompikrinsalpetersäure 67 .

Chrompikrinsäure 66 .

Chromquecksilber (fïr Zentralnervens.) 368 .

Chromsalpetersäure $\mathbf{5} \mathbf{I}$.

Chromsalpetersäure (zum Entfärben) 84.

Chromsalpetersäure (zum Entkalken) 8I.

Chromsalpetersäure-Palladiumchlorür $8 \mathbf{I}$.

Chromsaures Ammonium 25.

Chromsäure $0,1 \%-0,005 \% 25$.

Chromsäure zur Fixierung 49.

Chromsäure-Formol-Essigsåure 277.

Chromsaures-Chromoxyd 204.

Chromsilber 2 I4.

Chromsilbermethode nach Golgi 213, nach

Fusari 215, nach Kölliker 215, nach Ramòn y Cajal 215.

Chromsilbermethode (für Retina) 4I8.

Ciaccio $3 \mathbf{I} 3$.

Clitoris $33 \mathrm{I}$.

Cochenille 163 .

Cochenille mit Chromalaun 165.

Cochenille mit Eisen 164. 165.

Cochenilletinktur 164.

Coeruleïn $\mathrm{S}$ I84.

Coeruleïn S-Safranin 307.

Cohnheim 2II. 280 .

Collateralen 353 .

Colloidalgold 366 .

Conjunctiva $4 \mathrm{I} 5$.

Congo-Corinth I8o.

Congorot I8o. 380 .

Cori 59.

Cornea 4I5.

Corning $367,397$.

Corti 165 .

Cowpersche Drüsen $33^{\circ}$.

Coxsche Fibrillendarstellung 39I.

Coxsche Lösung 54 .

Coxsche Methylenblaumethode 39r.

Cutis 405.

Cutisleisten 408.

Cytogenes Gewebe 268.

Czokor 163.

D.

Daddi $\mathrm{I}_{4} 4$.

Dahlia 187; zur vitalen Färbung 246.

Dammarlack 232.

v. Davidoff 65. I 20.

Deckglaspräparate vom Blut 29I. 
Deckhuyzen 40, 63, 213. 247. 30r.

Deetjen 300. 30I.

Defibrinieren 288.

Definierebene 240.

Dehler 300.

Deiters 19. 50. 339. 340.

Deiterssche Vorschriften zur Isolation 26.

Delafieldsches Hämatoxylin 175.

Deutoplasma (Färbung) 259.

Dextrin $\mathbf{1} \mathbf{I}$.

Dialysator 94 .

Diaphragma (am Mikroskop) 6.

Differenzieren I 54 .

Dikaliumsulfat 300 .

Dinitroresorcin 397.

Direkte Färbung I $5 \mathbf{I}$.

Dises 280 .

Dogiel A. S. 207. 418 .

Doppelfärbungen $\mathrm{r} 88 \mathrm{ff}$.

Doppelmesser 16 .

Dörren der Blutpräparate 292.

Dreifachfärbungen $\mathbf{1 9 3 .}$

Dreifarbengemisch 196.

Drostsches Gemisch 27.

Drüner 75 .

Dubreuil 262.

Ductus ejaculatorii 330 .

Durchfärbung 147.

Durchströmungskammer II.

Durchtränken 85.89 .

Duval 105.

E.

Eau de Javelle 29. 83.

Eberth und Bunge 409 .

v. Ebners Flüssigkeit 8I.

Edinger 50.

Ehlers $5 \mathbf{I}$.

Ehrenbaum III. 27I.

Ehrlich 150. 151. 157. 179. 180. 187. 195. 204. 206. 208. 209. 256. 264. 276. 288. 291. 293. 294. 295. 296. 407.

Ehrlich-Biondisches Gemisch 194.

Ehrlichsches Hämatoxylin 176.

Eier (von Ascariden, für Zellstudien) 252.

Eier (Fixierung) 334.

Eier (Vertebraten und Evertebraten) 333.

Eierstöcke 330.

Eihüllen 332 .

Eimer 6I.

Einbetten 84.

Einbetten mit Intermedien 92, ohne Intermedien 90.

Einklemmen 86.

Einschlußflüssigkeiten 233.

Einschlußmittel (trocken) 232.

Einschmelzung im luftverdünnten RaumIO4.

Einstichverfahren 219.

Eisen (Name) 193.

Eisen 78 .
Eisen (zur Färbung) 210. 216.

Eisenalaun 164. 198.

Eisencochenille 164 .

Eisenhämatoxylin (Stöltzner) 383 .

Eisenhämatoxylin-Pikrin-Säurefuchsin 197.

Eisenkarmin 171 .

Eisenperchlorid 78 .

Eisen-Tannin-Methode 368 .

Eiweiß (fiir Celloidinschnitte) $\mathbf{I} 39$.

Eiweiß-destilliertes Wasser 139.

Eiweißeinbettung $9 \mathrm{I}$.

Eiweißglyzerin 139 .

Eiweißmethode (zum Aufkleben) 138 .

Eiweiß und Talg $9 \mathrm{r}$.

Elastische Faser 26r.

Elastische Faser (Färbung) $26_{3}$.

Elastischer Knorpel 270.

Elektrische Organe 399.

Elemente (mehrwertige) I59.

Elsässischer Stein II3.

Embryograph 237.

Embryonen (Fixierung) 336.

Endothelzellen 247.

Engelmann 49.

Entchromung 51 .

Entfärben 83 .

Entfärben von Chrommaterial 5o.

Entfärbung (maximale) I5I.

Entkalken 78 .

Entkalkungsmittel 8o.

Entkieseln 82.

Eosin 18r.

Eosin-Äther-Sublimat 293.

Eosin-Gentiana-Jod-Methode (für Haut) 404.

Eosin-Hämateïn 190.

Eosin-Hämatoxylin 190.

Eosin-Methylblau 191.

Eosin-Methylenblau 192.

Eosin-Methylgruin I9I.

Eosin-Methylgrün für Protozoën 249.

Eosinophile Granula 295.

Eosinophile Zellen im Sputum 297.

Eosinsaures Kalium 192.

Epidermis 403.

Epididymis 330.

Epithelfaserung (in d. Haut) 403.

Erlickische Flüssigkeit 53.

Erythrocyten 288.

Erythrosin I8I.

Essigsäure 48.

Essigsäure (gefärbt, für Protozoën) 249.

Essigsäurekarmin 167 .

Essigsaures Kupfer und Kupferchlorid (zum Fixieren) 77.

Ewald 30.

$$
\text { F. }
$$

Fädige Struktur 34.

Fällungsprodukte 37 . 
Farben $\mathrm{I} 63 \mathrm{ff}$.

Farbflotte 147.

Farblack 153.

Farbstoffe 163 .

Färben I44; Arten des F. 147, Chemische Theorie I57, feste Lösung (Theorie) 157 , physikalische Theorie 158 , Theorien des F. 156, Vorbereitung zum F. 161, Zweck des F. I 44 .

Färbung, adjektiv 152.197, direkt 15I, echt 153, elektiv. 150, indirekt 15 I, panoptisch I 5 I, progressiv I5 I, regressiv I 5 I, singulär 15I, substantiv 152, I63, subtraktiv 156 , vital 206.

Färbung, vitale der Protozoën 246.

Färbungsmethoden für Blut 294.

Faserknorpel 270.

Fasern, elastische (Darstellung) 263.

Fernambukbolz 177 .

Ferreri 82, 423.

Ferricochenille 165 .

Feste Lösung I57.

Fett 34 .

Fettgewebe 267 .

Fettgewebe der Haut 409.

Fettkörnchenzellen $35 \mathrm{I}$.

Fettponceau 184.

Fettzellen 267.

Feuchte Kammer Io. II

Fibrillen des Bindegewebes 262.

Fibrin 288

Fibrinfärbung 302.

Filarsubstanz 251 .

Fischer, A. 30. 34. 36. 39. 46. 48. 49. 55. 57. 64. 70. 72. 76. I55. I 57. 158 . I6I. 184, 204, 249. 348 .

Fixieren 33; Prinzip des F. 34.

Fixieren (Zentralnervens.) 341. 344.

Fixierung durch Injektion 4I.

Flagellatenkolonien 248 .

Flechsig 363.

Flemming 26. 51.92. 191. 193. 194. 196. $198,212,232,247,257,267$.

Flemmingsche Lösung $6 r$.

Flesch $6 \mathbf{r}$.

Fluorwasserstoffsäure 82 .

Flußsäure 63 .

Foàsche Lösung 54.

Fol 52, 61. 62, 66, 68, 79, 81, 83, 104. 226. 227.249.

Folsche Einschlußmassen 226.

Forel 88. 89. I 26.

Formaldehyd 45 .

Formalin 45.

Formalose 45 .

Formol 45.

Formol-Agarlösung 267.

Formol-Ammoniak 359.

Formolgelatine 87.143 .

Formol-Kalibichromicum 47.

Formol-Kombinationen 47 .
Formollösungen 45.46 .

Formol (Mazeration) 25.

Franceïn I 8 I.

Freibandschneiden 134 .

Frenkel 75 .

Frenzel 73 .

Freud 363 .

Frey 28, 92. i69.178. 220

Frick, J. 404.

Friedländer, B. 338 .

Fritsch, G. I 88, 228. 350.

Fritschsches Mikrotom I27.

Froriep 29.

Fuchsin $18 \mathrm{I}$.

Fuchsinalkali 182.

Fuchsinfärbung für Zentralnervens. 380 .

Fuchsin (Nissl) I 8I.

Fuchsin-Resorcin $\mathbf{1} 8 \mathbf{2}$.

Fuchsin $\mathrm{S}$ I83.

Fuchsin Tannin (für Haut) 404.

Fusari 215.352 .

\section{G。}

Gage 20. 25. 8I. I 76 .

Gallenkapillaren 32 I.

Ganglien (peripher) 389 .

Ganglienzellen (Netze i. d. G.) $353^{\circ}$.

Ganglion intercaroticum 313 .

Garnier 320.

Gaule 137 .

Gebhardt 4I7.

Gefäßse (Blut-) 308 .

Gefrieren 130.

Gefriermassen 134 .

Gefriermikrotom 127. I30.

Gehörgang (äußerer) 423.

van Gehuchten 353.

van Gehuchten und Nélis 391.

Geißelbewegung 245.

Geldrollenartige Anordnung 285 .

Gentianaviolett 187 .

Gerinnsel 36.

Gerinnselbildner 37 .

Gerlach, J. I65. 2 I1, 220.

Gerlach, L. 320.

Gesamttod I4.

Geschlechtsorgane, männliche 325 , weibliche 330.

Gewebe (interstitiell) $36 \mathbf{I}$.

Gewebsflüssigkeit 2 I.

Giemsasche Lösung 298.

Gierke 157. 158. 159.

Giesbrecht 97. I1 1. 135. 136, 271 .

van Gieson 250. 347 .

van Giesonsche Färbung 197.

Gilson 74.

Giraldèssches Organ 330.

Glandula coccygea 3 I 3 .

Glaskörper 4I 7 .

Glaswinkel (für Paraffin) 102. 
Globuline 37 .

Glutinleim 260.

Glychämalaun 173 .

Glycogen $25^{6}$.

Glyzerin (zum Einschluß) 233.

Glyzerinäthergemisch I\$6. 265.

Glyzerinalaunbämateîn 173 .

Glyzerinalaunhämatoxylin 175 .

Glyzerineiweiß 138. I40.

Glyzeringelatine (zum Aufkleben) 87.

Glyzeringelatine (zum Einschließen) 226 .

Glyzerinkarmalaun $\mathbf{1} 70$.

Glyzerinleim (zum Einbetten) 90. 9I.

Glyzerinseife 92 .

Goldbad (für Neurofibrillen, von Cajal) 359.

Goldchlorid 209.

Goldchlorid (gelb) 364 .

Goldchlorid-Borax 36x.

Goldchloridkalium 209.

Goldchloridnatrium 209.

Goldmethoden (für Zentralnervens.) 363 .

Golgi 212. 213. 21 4. 352. 368 .

Golgische Chromsilbermethode $21_{3}$.

Golgische schnelle Methode 353.

Golgische Methoden, Anwendung 352, Regeln 215.

Golginetze (Darstellung) 392.

de Gothard I86.

de Gothardsche Differenzierung 373.

Grảberg 196 .

Graafscher Follikel 333.

Gramsches Verfahren I 79.

Granula 34. 36.

Granula (im Blut) 295.

Granula (Zelle) 259.

Granulabildner 37 .

Granulafärbung 295.

Granulierte Struktur 34.

Grenacher I66. I67.

de Groot I7I.

Guddensche Masse 88.

Guddensches Mikrotom I26.

Gulland 293.

Gummilösung (zum Aufkleben) 87

Gummilösung (zum Einbetten) 90.

Günther, K. I 79.

Gïnther, MI. 410.

\section{H.}

Haare 410.

Hämacalcium 174 .

Hämalaun 173 .

Hämateïn $\mathbf{1 7 2 .}$

Hämateïn I A 174.

Hämateïn-Ammonalaun 173.

Hämateïn-Chloraluminium 174 .

Hämateïn-Chlorcalcium I 74 .

Hämateïn-Eisen 174 .

Hämatoidinkristalle 303 .

Hämatoxylin 172.
Hämatoxylin (Apáthy, für Nervensyst.) 383 .

Hämatoxylin (Böhmer) I75.

Hämatoxylin (Delafield) $\mathbf{I} 75$.

Hämatoxylin (Ehrlich) I76.

Hämatoxylin (Kleinenberg) I 76.

Hämatoxylin (Kultschitzky) 38 I.

Hämatoxylin (Mallory) 386 .

Hämatoxylin (Pal) $20 \mathrm{I}$.

Hämatoxylin (Weigert) 200.

Hämatoxylin (Wolters) $38_{3}$.

Hämatoxylin-Ammonalaun 175. I76.

Hämatoxylin-Chloral 176.

Hämatoxylin-Chromalaun I 75 .

Hämatoxylinchromlack 197.

Hämatuxylineisenalaunlack 198 .

Hämatoxylineisenlack 200.

Hämatoxylineisenoxydullack 198 .

Hämatoxylin, Färben mit dünnen Lösungen 173 .

Hämatoxylin-Karmin 188 .

Hämatoxylin-Kupferlack 200.

Hämatoxylinlacke 197.

Hämatoxylin-Mangan 175 .

Hämatoxylinmethoden (für Zentralnerv.) $38 \mathrm{r}$.

Hämatoxylin-Molybdän. 176 .

Hämatoxylin-Phosphormolybdänsäure $3 \mathbf{I}$ I.

Hämatoxylin- Phosphormolybdänsäure-

Chloral 352.

Hämatoxylin-Pikrin-Säurefuchsin 197.

Hämatoxylin-Safranin 189 .

Hämatoxylin-Säurefuchsin 270.

Hämatoxylin-Schwefel 176 .

Häminkristalle 304.

Hämoglobinkristalle 303 .

Hängender Tropfen Io.

Härtemittel 20.

Härten 33.

Härtung 42.

Häute (granulierte) 37 .

Hallersches Gemisch 27.

Handzentrifuge 23 .

Hannover 49.

Hansen 165. 174. 175 .

Harnblase 324 .

Harris $176.177,267,394$.

Harting 220.

Harz 234.

Haug 82.

Hautnerven 408 .

Hayem 290.

Hayemsche Flüssigkeit 72.

Heidenhain, MI. 23. 29, 48, 49, 9I, 97. I17. I39. 152. I55. 157, 180.184. I87. I88. I98. I99. $275 \cdot 283 \cdot 307 \cdot 308.313$.

Heidenhain, R. 68. 70. 197. 198. 223. 258.320.

Heider 120.

Held 73.422 .

Heldsche Methylenblaumethoden 374.

Helianthin $3 \mathbf{1 0}$. 


\section{Henle 4 ro.}

Henlesche Schleife 322.

Henle-Merkelsche Nervenfärbung 369 .

Henneguy 138 . 139.

Hennings 82.83 .

Hensen 125.

Herbstsche Tastkörperchen 40I.

Herla 252.

Hermann 60. 192. 202.

Hermannsche Flüssigkeit 76 .

Hertwig, O, 6r. 65. 75 .

Hertwig, R. 27.

Herxheimer I 84, I87.

Herz (Methoden der Untersuchung) 306.

Hesse II 9.

His 124.237 .240$.

Hissche Pinselmethode 22 .

Hoden (Fixierung) 328.

Hoffmann, E. F. 266.

Hoffmann, F, W. I04.

Hohlkörper 37.

Hollborn 298.

Höllenstein (zur Imprägnierung) 209.

Höllenstein (zur Injektion) 222.

Hollundermark 86.

Holmgren, E. 207.

Holmgrenscher Apparat I4.

Holzblock 87.

Holzessig nach Osmium 60.

Holzklötze 122.

Homoiothermen 15 .

Hopkins 27. 28.

Horizontalmikroskop II.

Horn 410.

Hosch 418.

Hoyer 168. 187. 221 .

Hoyers Pikrokarmin (für Methylenblau) 207.

Humor aqueus 16.

Hyaliner Knorpel 268.

Hydrochinon-Formol 358 .

Hypertonische Lösungen 40.

Hypophysis 3 3 .

Hypotonische Lösungen 40.

\section{I.}

Jander 84 .

Javellesche Lauge 83 .

Idiozoma 255.

Jellinek 65 .

Ikeda 330.

Ilbergsche Methylenblaumethode 374.

Indirekte Färbung 151 .

Injektion (der Blutbahnen) 217.

Injektion (konstanter Druck) $2 \mathbf{I} 8$.

Injektion (Methylenblau zur vitalen Färbung) 206.

Injektionsflüssigkeiten 220 .

Injektionsmassen (erstarrende) 220.

Injektionsmassen (nicht erstarrende) 222.

Injizieren 216 .
Intermedien 90.

Intermedien (zum Aufhellen) 228.

Interstitielles Gewebe 26r.

Interzellularsubstanzen 260 .

Inversion der Färbung 203.

Jod-Alkohol 345 .

Jodsäure 290. 300 .

Jodserum 24; kuinstliches 24.

Johnson 63 .

Jodtinktur (bei Sublimat) 69.

Johanson 395 .

Jorissche Colloidalgoldmethode 366 .

Iridiumchlorid-Platinchlorid 78 .

Iris $4 \mathbf{I} 6$.

Irisblende 6.

Isolation 19.

Isolationsmethoden $22 \mathrm{ff}$.

Isotonische Lösungen 40.

Isotonische Lösungen (Deckhuyzen) 63.

Isotonische Lösungen (Stöltzner) 72.

Israel, O. 177. 234.

Iwanzoff 399 .

\section{K.}

Kaiser 73.

Kaiser (Marchimethode) 37 I.

Kali aceticum (zum Einschluß) 234.

Kali bichromicum (Fixieren) 52.

Kali bichromicum (Mazerieren) 26.

Kali bichromicum-Essigsäure 53 .

Kali bichromicum-Natrium sulfuricum 53 .

Kali bichromicum-Sublimat 54 .

Kali chloricum-Salpetersäure 28 .

Kalilauge $32 \%-35 \% 283$.

Kalilauge (für Wimperbewegung) 314 .

Kallius 354 .

Kaliumbichromat und Kupfersulfat 53.

Kaliumbichromat-Sublimat-Eisessig 54 .

Kaliumkarmin 256.

Kaliumphosphat 25.

Kampescheholz 172.

Kampferlösung 226.

Kanadabalsam (Einschluß) 232.

Kanadabalsam (in Chloroform) I1 12.

Kanadabalsam (zum Schleifen) I I I.

Kandiszucker I4I.

Kanüle (zur Injektion) 2 I 8.

Kapillaren 309.

Karbolfuchsin $\mathbf{1} 8 \mathbf{r}$.

Karbol-Methylgrün-Pyronin 408.

Karbol-Thionin 275.

Karbol-Xylol 231.

Karmalaun I 70.

Karmin 165.

Karmin (Alaun) 167.

Karmin (Ammoniak) 165.

Karmin (Borax) 166.

Karmin (Chloralaluminium) I68.

Karmin (Essigsäure) I67.

Karmin (Lithion) 166. 
Karmin (Magnesia) 167.

Karmin (Salzsäure) 166.

Karminfärbang nach Best 406.

Karmin-Hämatoxylin $\mathbf{1} 88$.

Karmin-Hikroindigkarmin 194.

Karminsäure 163.165

Karminsäure (Ammonalaun) I70.

Karminsäure (Chloraluminium) I 7 I.

Karminsäure (Chloraluminium-Chlorkalium) I 70.

Karminsäure (Eisen) I 7 I.

Karminsäure (Kalialaun) 170.

Karyokinese 258.

Kastschenko 240.

Katz, L. 8I, 420. 42 I. 422.

Krysinski 105.

Kern 251 ; ruhend 256.

Kernbilder 35 .

Kernfärbemittel 146. 257.

Kernspindeln (gefärbt nach Carnoy) 259.

Kernschwarz 177 .

Key 398.

Kiemen 315.

Kittlinien (Endothelzellen) 247.

Klappenapparat des Herzens 308.

Klebs 29. 90.

Kleinenbergsche Flüssigkeit 66.

Kleinenbergsches Hämatoxylin 176 .

Klemmleber 86.

Knorpel 268.

Knorpelzellen (anastomosierende) 269.

Knochen 270, entkalkter 274 .

Knochenentwicklung 277.

Knochenknor el 270. 274 .

Knochenkörperchen 272.

Knochenmark 276.

Knochenschliff, Herstellung 27I, Färbung 272.

Knochenschnitt 275 .

v. Koch IIO. 27 I.

Koch, R. 291.

Kochsalzlösung (physiologische) I 7 .

Kollagen 405.

v. Kölliker 215. 274. 275. 352 .

Kollodium (gegen brïchige Schnitte) 120.

Kollodiumlappen I40.

Kollodiumnelkenöl I 37 .

Kollossow 60.

Kolophonium (zum Einschluß) 227.

Kolophonium (zum Schleifen) I ro.

Kolophonium-Wachs II I.

Kolster 95.

Konglobiertes Gewebe 268.

Konkarspiegel 6.

Konservieren 33 .

Konservierungsmittel 20.

Kontraktilität (der Zelle) 245.

Kopsch 47. 300. 301. 347. 353.

Kopsch und Szymonowicz 75.

Kopschsche Methode 392.

Kork (zum Aufkleben) 87.
Körnchenströmung 245.

Korrosionsverfahren 221 .

Krause, R. 195. 199. 338 .

Krause, W. 400. 415. 418 .

Kreosot 23I.

Kreosot-Terpentinöl 23 I.

Kreosofuchsin 182. I83.

Kresylechtviolett 187 .

Kresylviolett (für Nervens.) 38 r.

Kristallviolett $\mathbf{I} \$ 7$.

Kristallviolett für Centrosomen 253, für Mitochondria 255.

Kromayer 404.

Kronecker 17 .

Krönigsche Masse 235 .

Kronthalsche Bleimethode 367 .

Krümel 34.

Kühne 28. 30.

Kultschitzky 3 IO. 3 I I. 405.

Kultschitzkysche Flüssigkeit 386.

Kultschitzkysches Gemisch für Darm 316.

Kultschitzkysches Hämatoxylin 381 .

Kultschitzkysche Neurogliamethode 386 .

Kupfersulfat 44 .

L.

Lachi 347.

Lakmoid (für Milz) 3 I I

Lamellen (der Knochen) 272.

Landois-Gierkesche Flüssigkeit 25.

Langerbans $34 \mathbf{I}$.

Langersche Blasen $26 \mathrm{r}$.

Langsche Flüssigkeit 73 .

Lantermannsche Einkerbung 395.

Lappen (blutgetränkte, für Kristalle) 305.

Lauffs Violett 187.

Laurent I92.

Lavdowsky 25. 162. 290. 300. 341.

Lavdowskysches Verfahren bei Golgipräparaten $354 \cdot 356$.

Lazarus $15 \mathbf{I}$.

Lebendes Material 9.

Leber (Name) 414. 415.

Leber (Organ) 321 .

Lebrun 259.

Lee 59. 96. 108. 227. 234. 264.

v. Lendenfeld 120.

Léon 18 I.

Leukocyten (isoliert) 288.

Levaditische Silbermethode 363 .

Lewandowsky 370.

Lichtgrün 184 .

Linin 251. 258.

Linse 416.

Linsensystem 4.

Liquor kali acetici 234 .

Liquor natri hypochlorosi 29.

List, Th. 2 I0. 216.

Lithion carbonicum bei Pikrin 65 .

Lithionkarmin 166. 
Lo Bianco 51, 61, 63, 66, 73, 74, 75 .

Löffler I 82.186.

Löwenthal 169 .

Löwitt 76. 2II. 290. 302 .

Luftwege 313 .

Lugolsche Lösung 170. 269; bei Sublimat 69 .

Lunge des Frosches 14.

Lungen 3 I4.

Lupe 2.

Lustgarten 26.4. 270. 403 .

Lymphadenoides Gewebe 268.

Lymphdriisen $3 \mathbf{I}$.

Lymphgefäße 2 rg.

Lysol 30.

\section{II.}

Magdalarot 183 .

Magenta 181 .

Magnesia (pikrinsaure) 169.

Magnesiakarmin 167 .

Magnesiawasser 167 .

v. Mährenthal 60. 167 .

Malachitgrün - Säurefuchsin - Martiusgelb 253.

Malaria-Parasiten 297.

Malassez 169.

Mallory 176, 196, 262.

Mallorysches Hämatoxylin 386 .

Mallorysche Neurogliamethode 386.

Mandarin 310.

Manganhämateïn 175 .

Mann 72. 75. I20. I39, I9I.

Marchische Methode 369.

Marcus 347.

Marinasche Fixierung 347.

Marinescu $2 \mathrm{I} 2$.

Maskenlack 234.

Mastixkollodium 82 ; für brüchige Schnitte 120.

Mastzellen (Färbung) I 87. 264.

Maximale Entfärbung 151.

Maximale Überfärbung 15 I.

Mayer, P. 43. 47. 50. 5I. 59. 66. 67. 69. 70. 71. 79. S2. 83. 84, 96. 119. I35. 136. 138 . 140.150, I5 I. 152, 154. 157. 164. 165. 166. 167. 168. 169. 170. 171. 172. 173. 174. 177, 219.249.294. 321. 402.

Mayer, P. u. Schöbel II9.

Nayer, S. 31. 207. 266. 309. 319.

Mazeration 19.

Mazerationsmethoden (für Nervens.) 340.

Mazerationsmittel 23.

Meissner 319.

Membrana tympani 420 .

Merkel 189 .

Merkelsche Flüssigkeit 76.

Mesenterium (Frosch) I4.

Messerneigung II9.
Messerstellung I I 7 .

Metachromasie 161.

Metallimprägnation 209.

Metallplatten 122.

Metallwinkel ro2.

Metazoën 9. I 9.

Metazoënzelle (lebend und überlebend) 246.

Methylalkohol 107.

Methylblau 185.

Methylenazur I85. 192; für Blut 297.

Methylenblau I86; alkalisch 186; polychrom I 86.

Methylenblau: vitale Färbung 206; Fixierung 207; Fixierung nach Bethe 207. 375 .

Metbylenblau (für Zentralnervens.) 372.

Methylenblau-Jod-Methode (für Haut) 404.

Methylenblau-Fuchsin 375 .

Methylenblau-Säurefuchsin 375 .

Methylgrün 185; sauer 249.

Methylgriin-Eosin (für Protozoën) 249.

Methylgrün-Karbol-Pyronin 408 .

Methylgrin-Pyronin 265.

Methylviolett 187 .

Metzner 259.

Meves 300.

Meyer, Sem. 206.

Michaelis, L. 157. 192. 297. 335.

Mikroaquarium 12; für Paraffin 104.

Mikromillimeter 105.

Mikron 105.

Mikrophotographie 239.

Mikrosomen 254.

Mikrotechnik 9.

Mikrotom 85. 87. I24.

Mikrotommesser 113 .

Mikroskop 2; nach Siedentopf 160.

Milchdrüsen 332 .

Milz 309.

Mingazzinische Flüssigkeit 72, 423 .

Mississippistein I I3.

Mitochondria (Darstellung) 254.

Mitose 258 .

Nittelohr 420 .

Modellierung (der Embryonen) 240.

Mohrsches Salz I 71 .

Moleschott $28_{3}$.

Möller 47.

Molybdänhämatoxylin 176 .

Molybdänsaures Ammon-Chromsäure 78 .

Molybdänverfahren 377 .

Montieren (der Präparate) 223.

Montische Methode $35^{1}$.

Morgagnische Hydatide 330.

Mosse 363 .

Muchämateïn 174 .

Mucikarmin 168.

Mucikarminsäure $\mathbf{1 7} \mathbf{1}$.

Mucin 34.

Mucinfärbemittel 321 .

Muscheln (Mantelrand) 247. 
Muschenkoff 399.

Muschenkoff und Frey 403. 408.

Muskelfibrillen 280.

Muskelgewebe 279.

Muskelkörperchen 280 .

Muskeln, glatte 282 ; quergestreifte 279.

Muskelprimitivfibrille 280 .

Muskelsäulchen 280 .

Müllersche Flüssigkeit 53 .

Müllersche Flüssigkeit-Salpetersäure 54 .

Muillersche Lösung-Sublimat 54 .

\section{N.}

de Nabiassche Goldmethode 366 .

Nachvergoldung 210.

Nägel 410.

Naphtolorange 269 .

Natriumbisulfit-Rohrzucker 29.

Natriumkarmin I67.

Natriumkarmin-Urannitrat 396 .

Natriummetaphosphat (bei 'Thrombocyten) 300.

Natriumphosphat 25 .

Natronlauge (zum Entfärben) S4.

Natronlauge (bei Wimperbewegung) 314.

Natronpikrokarmin 169 .

Nebenniere 313.

Negro 400.

Nelkenöl (zun Aufhellen) 231.

Nervenapparat des Darmes 319.

Nervenendigungen (motorische) 399.

Nervenendigungen (sensible) 401 .

Nervenfasern (markhaltige) 392.

Nervenfasern (marklose) 398.

Netzknorpel 270.

Neumann 26.

Neurofibrillen (Darstellung nach Bielschowsky) 360. 36I. 362.

Neurofibrillen (Darstellung nach Cajal) 357. 359. 360.

Neurofibrillen (Silberfürbung) 357.

Neurofibrillen (Vergoldung) 364 .

Neuroglia 268. 384 .

Neurokeratinscheiden 397 .

Neutralrot $I 6_{3}$, zur vitalen Färbung 208.

Nentrophile Granula 295. 296.

Netuvictoriagriin 290.

Nichollssche Methode $35^{2}$.

Nicolas 91. 300.

Nicolassche Fixierung des Darmes 316 .

Nicolle 275 .

Niere 322.

Nierenbecken 324.

Nierenkelche 324 .

Niessing 76 .

Nissl 227. $33^{8}$.

Rawitz, Mikroskopische Teclnnik.
Nisslsche Färbung 373 .

Nocht 298.

Norris und Shakespeare IS9.

Nöscke IS6.

Nowaksche Mischung 335.

Nucleïn $2 j S$.

Nucleoide 290.

Nucleolen 251 .

Nussbaum 137.

O.

Oberfächenattralition $\mathbf{I}_{5} \mathrm{~S}$.

Objektiv 4.

Objekttischaquarium 12.

Objekttisch (beizbarer) I 7 .

Obregia I4I. I4j. 200.

Obregiasche Modifikation für Golgimethoden 356 .

Oedemmethode 262.

Ohlmacher 45. 72 .

Ohlmachersche Lösung 45.

Ohr, äußeres 423, inneres 421 .

Okular 4 .

Oleum origani cretici $23 \mathrm{I}$.

Olimmersion 4.

ÖImasse (zur Injektion) 221.

Olstein $1 \mathrm{I}_{3}$

Olt 143. I44. 267 .

Oppel 196. 322.

Orange G $1 \mathrm{~S}_{4}$.

Orange G-Alaunkarmin $\mathbf{I} \delta_{9}$.

Orange G-Hämateïn (bzw. Hämatoxylin) I 90.

Orange G-Säurefuchsin-Methylgrün 194 .

Orangeveriahren 196.

Orceïn 177.

Orcein-Eisessig 177.

Orceïn (für elastische Fasern) 263 .

Orceïnfärbung (Unna-Tänzer) 405 .

Orcin 177.

Origannmöl $23 \mathrm{I}$.

Organstroma 261 .

Orseilleflechte 177 .

Orth 47. I66. 347 .

Osmiumdämpfe 60.

Osmiumeisenhämatoxylin 6r

Osmium-Essigsäure (zur Mazeration) 27.

Osmium-Kupfer-Hämatoxylin $3 \mathrm{~S} 2$.

Osminmlösungen (Klarhaiten) 59.

Osmiummethoden (für Zentralnervens.) 359.

Osmiumsäure zum Fixieren 55, zur Mazeration $26,4 \% 259$.

Osmiumsäure-Kali bichromicum 62. 63 .

Osmiumsäure-Kali bichromicum-Platinchlorid 63.

Osmitum-Tanninmelhode $35 \mathrm{I}$.

Osmiumtetroxyd 55 . 
Ovarialeier 330.

Overton 58.

Oxalsäurelösung 27.

\section{P.}

Pacinische Flüssigkeit 290. 4 II.

Palladiumchlorïr, zum Fixieren 75 , zum Entkalken Sr.

Palsche Hämatoxylinfärbung 202.

Palsches Hämatoxylin mit Safranin 202.

Paneth 64.

Pankreas 320 ,

Pankreatin $3 \mathbf{r}$

Panniculus adiposus 409.

Panoptische Färbung I5I.

Papierkästchen 92. 102.

Papillarkörper 408.

Pappenheim 265. 296.

Paradidymis 330.

Paraffin (fadenziehendes) II 7 .

['araffinblock II6.

Paraffindurchtränkung nach Rabl IoO, nach Retterer Ioo.

Paraffinmethode 93.

Paraffinöl 114, zum Einschluß 234.

Paraffinschmelzpunkt Ioo.

Paraffinumrandung 88.

Paraffinum liquidum I 4 , zum EinschluB 234.

Parakarmin i 70.

Parenchymflitssigkeit I6. 2 I.

Parotis 320.

Partsch 163 .

Patentsäurefuchsin 310.

Pavlow ro7.

Penis 330.

P'epsin $3 \mathrm{I}$.

Perényische Fliissigkeit $5 \mathbf{I}$.

Perineurium 398.

I'eter 337.

Pfliger 393.

Pharynxschleimhaut (Frosch) 247.

Phenolgelatine (zum Aufkleben) 143.

Phenylenbraun 187 .

Philippson 408.

Phlorogluzinsalpetersäure $\$ 2$.

Phlorogluzinsalzsäure 82 .

Phosphormolybdänsäture 3II.

Photoxylin 105.

Physikalische Theorie des Färbens I $5^{\text {S. }}$

Pianese 253.

Pikrinblau 262. 263.

Pikrineisessig 65 .

Pikrinessigosmiumsäure 68 .

Pikrinessigsäure 65 .

Pikrinessigsäure-Formol 66 .

Pikrin-Jod (für Blut) 302.
Pikrinosmiumsäure 68 .

P'ikrinosmiumsäure-Höllenstein (zur Injektion) 222.

Pikrinosmiumsalpetersäure 68 .

l'ikrinsalpetersäure 67 .

Pikrinsaure Magnesia 169.

Pikrinsäure 63 , als Farbe 184, zur Mazeration 27 .

P'ikrinsäure-Alkohol zur Mazeration 27.

Pikrinsäure-Formol-Eisessig 320.

Pikrinsäure-Sublimat-Eisessig 75 :

Pikrinschwefelsäure 66.

l'ikroindigkarmin 194.

Pikrokarmin 168. 169.

Pikrokarmin-Hämatoxylin $\mathbf{I} 94$.

Pikrolithionkarmin $\mathbf{x} 69$.

Pikromagnesiakarmin $\mathbf{1} 69$.

P'insel (zum Zerzupfen) 22.

Pinselmethode von $\mathrm{His} 22$.

Placenta 332.

Planspiegel 6 .

Plasma 287.

Plasmazellen 264; der Haut 406.

Plasomen 253. 254 .

Plastische Rekonstruktion 240. 336.

Platinchlorid (zum Fixieren) 76 .

Platinchlorid-Chromsäure 76 .

P'latinchlorid-Formol-Essigsäure 277.

Platinchlorid-Osmiumsäure-Eisessig 76; mit Sublimatzusatz 76 .

Platinchlorid-Pikrinsäure 77; mit Eisessigzusatz 77.

Platinchlorid-Pikrin-Formol-Ameisensäure 77.

Platinchlorid - Pikrin - Osmium - Eisessig 77.

Platinchlorid-Sublimat 77 .

Platner I 77. 397.

Plattenmodellier-Methode 240.

Plexus myentericus 3 I9.

Plexus submucosus 319.

Podwyssozki 74 .

Poikilothermen 15.

Pokrowski 22, 23. 223.

l'olarisationsapparat 8.

Polarisator 8 .

Poljakoff 262.

Polychromes Methylenblau 186. 407; mit Anilin-Alaun 407; mit Eosin I93.

Poncearl 183 .

Praeoccupation (tinktorielle) 156.

Pranter $\mathrm{I}_{3}$.

Präparatenliammer 87. I 16.

Präpariermikroskop 2.

Pravazsche Spritze 219. 222.

Prichardsche Mischung 2 II.

Primitivzylinder $2 S 0$.

Prince 296.

Progressive Färbung $\mathbf{1} 5 \mathbf{I}$.

Prostata 330. 
Protozoën 9. I9; lebend zu untersuchen 245 ; fixieren 248 .

Pyrogallussäure fiir Blut 304. 30 j.

Pyrogallussäure-Formol 358 .

Pyrogallusäure nach Osmium 60.

Pyronin 265.

\section{Q.}

Quecksilberchlorid 69.

Quecksilbermethode (bei zentralem Nervens.) 368 .

Querschnitter 125.

\section{R.}

Rabl 51, 74, 76, 77. 137. 163. IS9.

Rabl, H. 30r.

Rablsche Paraffindurchtränkung 100.

Ramòn y Cajal 215. 352, 353. 357. 359. 360. 371. 373. 375. 386. 400. 418.

Ranvier 60, 168, 212, 213, 247, 262. 275. 414.

Ranviers $\mathrm{T} / 3$ Alkohol 24.

Ranviersche Einschnürung 395.

Ranviersches Mikrotom I26.

Rasiermesser 85. I I 2 .

vom Rath 68. 74. 77. 199. 200.

Rawitz 60. 67. 68, 84. 157. I70. I71. I 73. 175. 184. 189.190. 203.

Rawitz I/4 Alkohol 24.

Reagentien (klärende) 144 .

Regaud 222. 329.

Regio olfactoria und respiratoria 4II.

Regressive Färbung I5I.

Rehm 227. 3 So.

Reichert $28,2 S_{3}$.

Reifungsprozeß des Hämatoxylins 172 .

Reinbach 296.

Reinke 30. 329.

Rekonstruktion (plastische) 240. 336 .

Renaut 190.

Renautsche Flüssigkeit 329.

Resina-Sandara-Lack 356 .

Resorcinalkohol 265.

Retikuläres Gewebe 268 .

Retina 417.

Retterer 100. 277.

Retzius 212. 398.

Rhumbler 160. I6I. 249.

Rindsleber (zum Einklemmen) 86.

Ripart und Petit 77.

Ritzer 240, 24 I.

Rivet-Leisersches Mikrotom 127.

Rizinusöl-Injektion 221.

Rohrzucker und Natriumbisulfit 29.

Rohrzucker und schweflige Säure 29.

Rollett 266. 281. 303.
Romanowskysche Färbung 297. 299.

Rose, H. 305.

Rose bengale-Orange G-Aurantia 296.

Rosin I94.

Röthig 74. 77. 159. 182. 183.270. 333. 336. 337 .

Rotholz 177.

Ruffinische Scheide 398 .

Ruprecht (gefärbte Knochenschliffe) 273.

Russ (zur Definierebene) $24 \mathrm{I}$.

Rutheniumrot-Thionin 193.

Ruzicka 374 .

\section{S.}

Sadowsky 3 So.

Safranin I83, nach Ehrlich 192.

Safraninanilinwasser $\mathrm{I}_{3}$. 192 .

Safranin-Gentiana I9I. I92.

Safranin-Lichtgriin 192.

Sahli 160

Sahlische Färbung 375 .

Salizylsäure zur Mazeration 29.

Salpetersäure, zum Entkalken So, zur Fixierung 49, zur Mazeration 28.

Salpetersäure-Alaun 28, 8I.

Salpetersäure-Chrom-Pikrin-Sublimat-Gemisch 82 .

Salpetersäure-Kali chloricum 28 .

Salpetersäure-Kaliumbichromat 54 .

Salpetersäure-Müllersche Lösung 54 .

Salzsäure (zur Mazeration) 29.

Salzsäure Karmin 166.

Salzsäure-Kochsalz 8r.

Sandmann 28.

Sandmannsche Goldmethode 399.

Sargent 348 .

Sargentsche Methode 352 .

Sauer 323. 324.

Säurefuchsin 183 .

Säurefuchsin-Anilinwasser 260. 265 .

Säurefuchsin - Malachitgrün - Martiusgelb 253.

Säurefuchsin-Methode nach Weigert 377.

Säurefuchsin-Orange G-Anilinblau 196.

Säurefuchsin-Pikrin (für Blut) 296.

Schaffer S2. 362 .

Schaffersche Neurogliamethode 384 .

Schällibaum 137 .

Scham (äußere) $33 \mathbf{I}$.

Schaper 72.

Scharlach I 84 .

Schaudinn 104. 245. 246. 248. 249.

Schaukelmikrotom 129.

Schaumige Struktur 34 .

Schellack, zum Aufkleben 136, zum Schleifen II I.

Schiefferdecker 31. 105. I 80.

Schiefferdeckersches Mikrotom I 26.

Schienenmikrotom 127 . 
Schleifen (der Hartteile) I09.

Schleifen (der Messer) I13.

Schleifstein 1 I 3 .

Schleimgewebe 268.

Schleimzellen (Flemmingsche) $26 \mathrm{r}$.

Schmeckbecher 4 IO .

Schnecke 42 I.

Schneiden II2; von Celloidinmaterial 122, von gefrorenem Material I3O, von $\mathrm{Pa}$ raffinmaterial 115; Tempo des Sch. II 9.

Schneider 167.

Schnelleinschmelzung 93.

Schnellfärberei I 50 .

Schnittdicke I 2 I.

Schnittfärbung I49.

Schnittstrecker II 9 .

Schraubenschienen-Mikrotom I28,

Schraubenzylinder-Mikrotom 126.

Schreiber 398.

Schridde (Bindegewebsfärbung) 265 .

Schultz, P. 283.

Schultze, M. 24. 27. 49. 234. 2So.

Schultze. M. (heizbarer Objelttisch) I 7.

Schulze, F. E. 75. 94. 98. 102. 245.

Schwannsche Scheide 398.

Schweflige Säure zur Entkalkung 8I, zur Mazeration 28.

Schwefelkohlenstoff (als Intermedium) 97.

Schwimmbaut des Frosches I3.

Sclera 4I5.

Segall 395.

Sehpurpur 4r9.

Sehrwald 356.

Semilunarklappen 308 .

Sempersche Trockenpräparate 3I5. 3IS.

Senkverfahren 97.98 .

Serum 287.

Serum, künstliches 17.

Serumalbuminmethode I39.

Sharpeysche Fasern 274. 275.

Sirupus simplex I4I.

Siding 120.

Siedentopfsches Mikroskop I60.

Siegelsche Färbung 299.

Silberlösung (ammoniakalisch) 360 .

Silberverfahreu von Böhm-Oppel 32 I.

Singuläre Färbung 151 .

Skelettmuskulatur 279 .

Smirnow 409.

Solbrig ${ }^{\mathrm{I}} / 6$ Alkohol 24.

Speckleber (zum Einklemmen) 86.

v. Sipee I 7 .

Speicheldrüsen 320.

Sperma 325.

Spermatosomen 325 .

Spermatozoën 325 .

Spermien 325.

Spiegel I 82.263.

Spiegelfärbung 155 .

Spirochaetenfärbung 298.

Spraygebläse 132.
Spritze (zur Injelition) $2 \mathbf{I} 8$.

Spuler $\mathbf{r} 64$.

Squire I 99.

Stabilit 87. 122.

Städeler 303.

Stein 3 I 2.

Stöhr 416.

Stoeltzner 40. 84.72

Stoeltznersche Hämatoxylinfärbung $3 S_{3}$.

Stoerk I39.

Stransky 234. 37 I.

Strasser 240. 24I.

Strehl I6r.

Streichriemen I14.

Strelzoff I 88 .

van der Stricht 335.

Ströbe 396.

Stiickfärbung 147.

Stiitzsubstanz 26r.

Sublimat 45; zum Fixieren 68.

Sublimat-Aceton 73 .

Sublimat-Borsäure 249 .

Sublimat-Chromsäure 74 .

Sublimat - Chromsäure - Eisessig - Osmiumsäure 74 .

Sublimat-Eisessig 72. 73 .

Sublimat-Eisessig-Osmiumsäure 75 .

Sublimat-Formol 72.

Sublimat-Kupfersulfat 75 .

Sublimat-Natriumsulfat 72 .

Sublimat-Pikrinsäure 74 .

Sublimat-Pikrinsäure-Formol 72 .

Sublimat-Pikrinsäure-Osmiumsäure 74 .

Sublimat-Pikrinsäure-Tannin 75 .

Sublimat-Rohrzucker 72 .

Sublimat-Salpetersäure 73 .

Sublimat-Salpetersäure-Eisessig 74.

Sublingualis 320 .

Submaxillaris 320 .

Substantive Färbung 152, I63.

Subtraktive Färbung 156 .

Sudan III I 84 .

Symmetrische Lupe 2.

System 4 .

I.

Tandler 220.

Tannin-Brechweinstein-Methode 203.

Tannin nach Osmium 60.

Tastkolben 4 or.

Tegmen antri 420.

Teichmannsche Kristalle 304.

Teichmiiller 297.

Teljatnik (Marchimethode) 37I, (Methylenblau) 374 .

Tellyesniczky 36. 43. 49. 67. 70. I I 7.

Tellyesniczkysche Fliissigkeit 53.

Terpentinöl 25. 230.

Terpentin, venezianisches 27 .

Tetrajodfltoresceïn 301 . 
Thermostat 97 .

Thiazinbraun-Toluidinblau 307.

Thiazinrot Methylenblau 307.

Thiazinrot-Toluidinblau 307.

'Thiersch 220.

Thionin 187 , für Zentralnervens. 380.

Thionin mit Karbol 275.

Thionin-Rutheniumrot 193.

Thoma 91. 127. 256.

Thomé 3 II.

Thrombocyten 300 , lebend gefärbt 288.

Thymus 312.

Thyreoidea 3 I2.

Tinktorielle Praeoccupation 156 .

Tintinnen 249.

Toluidinblan 1S6; nach Bethe 377 .

Toluidinblau-Säurefuchsin-Eosin 296.

Tonsillen 3 I 2 .

Tractus intestinalis 315 .

Trambusti 195.

'Tränendriisen 4 I 9.

Transparentseife 92.

Triacidgemisch 195; für Granula 296.

Trichloressigsäure 48 .

Trockenpräparate nach Semper 318 .

Trocknung der Blutpräparate 293.

Trommelfell 420.

Tropaeolin 269.

Trypsinverdaung 30 .

Tuba Fallopiae 33I.

\section{U.}

Überlebendes Material I4.

Überfärbung (maximale) $15 \mathrm{I}$.

Überosmiumsïure 55 .

Uhrmacherlupe 2 .

Umranden 88.

Umrandungsmittel 234.

Unna 105. 155. 156. 157. 158. 176. I86. 199. $263.264 .270 .296 .321 \cdot 404.405$. 406. 407.

Urankarmin 167.

Ureter 324.

Uroglenalingeln $24 \mathrm{~S}$.

Uterus 33 I.

\section{V.}

Vagina 331.

Valentinsches Doppelmesser I6.

Valenzen I59.

Vas aberrans Halleri 330.

Vas deferens 330.

Vatersche Tastkörperchen $40 \mathrm{I}$.

Venen 308.

Venetianisches Terpentin 227.

Verattisches Gemisch 353.

Verfettung 267 .

Vergoldung (Methoden) 210.

Verknöcherungsprozeb 277.
Versilberung (Methoden) 2 I3.

Vesuvin 187 .

Victoriablau 264. 403.

Virchow, H. 50. 335 .

Virchow, R. 303. 314.

Vitale Färbung 206.

Vorvergoldung 210.

Vusseler 227.

Vulpian 78 .

\section{W.}

Wachs (Ümrandung) 234.

Wachsplatten 240.

Waldeyer SI. I7S. 40I. 415.

Walrat (Umrandung) 88.

Wanderzellen 26r, 264 .

Wärmeschrank 97.

v. Wasielewski 36. 43. 52. 64. 70. 73. 75. 76 .

Wasserblau 296. 310.

Wasserblau-Orceïn; für Epithelfasern 404, für Kollagen 406.

Wasserimmersion 4 .

Wasserstoffsuperoxyd (zum Bleichen) $5^{8}$.

Wassersaugpumpe roo. 104.

Weigert 140. 157. 168. 182. 197. 200 201. 231. 250. 270.301 .377$.

Weigertsche Fibrinfärbung (modifiziert) 404 .

Weigertsche Hämatoxylinfärbung 200.

Weigertsche Neuroglia-Methode $3^{84}$.

Weil III, 27x.

Westinghausen 62 .

Villebrand 297.

Wimperbewegung 245.

IVitt 157.

Wollustkörperchen 33r.

Wolters 269.

Wolterssche Hämatoxylinfärbung $3{ }^{8} 3$.

\section{$\mathbf{x}$.}

Xylol, zum Aufhellen 230, als Intermedium 95 .

Xylolanilin 302 .

\section{Y.}

Yamagiwasche Neurogliamethode 387 .

\section{Z.}

Zacchariadès 263 .

Zacharias $44 \cdot 248$.

Zähne 278 .

Zahngewebe 278 .

Zahnschmelz 278 .

Zedernöl, zum Einschluß 234, als Intermedium 96. 
Zedernöl-Chloroform 96.

Zeichenapparate 236.237.

Zeichenprisma 237.

Zeiss 286.

Zeitlin 204.

Zelle, fixiert 248 , lebend 245 , mazeriert 248 , ruhend 248,250 , iberlebend 246.

Zelleinschlüsse 34 .

Zellstrukturen 35 .

Zellteilung 258.

Zelltod I4. 20.

Zenkersche Lösung 54.

Zentralnervensystem, Färben 349, Häute 388, Schneiden 348 .
Zentrifugieren 23. 223. 224 .

Zerzupfen 22.

Ziegler I I. 81.

Ziehensche Vergoldung 364.

Ziehl I8I.

Zimmermann (Färbung von Knochenschliffen) 272.

Zoja 252.

Zoospermien 325 .

Zschokke 277 .

Zunge des Frosches 13 .

Zugparaffin 120.

Zwaardemakersches Safranin 183 .

Zylinderblenden 6 .

Zylindermikrotom 87 .

Berichtigung.

․ $157 \%$ I2 \&. O.: Michaelis statt Miachelis. 


\section{Anthropogenie}

oder

\section{Entwicklungsgeschichte des Menschen.}

Keimes- und Stammesgeschichte.

Gemeinverständliche wissenschaftliche Vorträge

vou

\section{Ernst Haeckel}

Professor an der Universităt Jena.

\section{Fuinfte, umgearbeitete und vermehrte Auflage. $=$}

Mit 30 Tafeln, 512 Textfiguren und 60 genetischen Tabellen.

= 2 Biinde. gr. 8. Geh. /l 25.-; in Leinen geb. $/ 428 .-=$

Herr Prof. Dr. I. Plate schreibt im Archiv für Rasscn- und Gesellschafts-Biologie I. 1904. Heft 1:

s Hacekels Anthroporgenie bedarf keiner weiteren Empfehlung. Seit seinem ersten Erscheinen in Jahre 1877 hat sich das W erk alle Kreise der naturwissensehaftlich Interessirten erobert und hat 'Tausende davon überzeugt, das cine sallgemeine Bildung hentzutage nicht mehr möglich ist whe ein gewisses Maß ron biologischen und anthropologischen Kenntnissen. Wie entsteht ein menschliches Wesen. welche Vorginge spielen sich bei der Befruchtung ab, wie entwiekeln sich die Organe des Kindes, während es im Schoße der Mutter ruht, wie rerhält sich diese Eutwicklung zu der der übrigen Lebewesen und speziell zu der der Sïugetiere? Solche Fragen hat jeder denkende Mensch eimmal an sich gerichtet, denn näher als alle Geschichte über den Werdegangr der Völker liegt uns sehließlich die Geschichte unseres eigenen Ichs. Das Hacekelsche Werk gibt auf solche Fragen eine ausführliche Antwort, die ebenso sehr durch die Klarheit der Schilderung, wie durch die Fülle der philosophischen Perspelitiven fesselt. Kein Prozeß in der Fmbryonalentricklung der Menschen wird bloß als solcher betrachtet, sondern überall wird zum Vergleich auf verwandte Erscheinungen, innerhalb der Tierwelt hingewiesen und gezeigt, daß gleiche oder sehr ähnliche Zustïnde, wie sie bei niederen Wirbeltieren dauernd angetroffen werden, in der Ontogenic der Süuger und des Mensehen vorübergehend durchlaufen werden. Wie ein roter Faden zicht durch die ganze Darstellung dieser Gesichtspunkt des vbiogenetisehen Gesetzes , daß die Stammesereschichte sich in dem Verlauf der Keimgeschichte deutlich widerspiegelt und daß, wo seenogenetische Abweichungen dieses Bild trüben, sie als Anpassungen an sekundïre Terhältnisse aufzufassen sind. Es gewährt auch dem Fachmanne ein großes Vergnügen, zu sehen, wie Haeckel jede Tatsache der Ontogenie uns durch eine phylogenetische oder physiologische Betrachtungstreise verständlich zu machen weiß im wohltuenden Gegensatz zu so manchen Iehrbüchern der Entwicklungsgeschichte, welche die einzelnen Stadien trocken aneinanderreihen und glauben, schon etwas geleistet zu haben, wenn sie eiumal einen mechanischen Gesichtspunkt, eine Faltung, eine Oberflächenspanuung oder dergleichen als kausales Moment betonen. $\approx$ 


\section{Im australischen Busch}

\section{und an den Küsten des Korallenmeeres.}

Reiseerlebnisse und Beobachtungen eines Naturforschers in Australien, Neu-Guinea und den Miolukken Von

\section{Prof. Richard Semon.}

Nit 86 Abbildungen und 4 Karten.

\section{Zweite, verbesserte Auflage.}

gr. 8. Geh. Mk. 15.-; in Leinen geb. MIk. 16.50.

Üher die zweite Autlage dieses hervorragenden Reisewerkes urteilt die Naturwissenschaftliche Rundschau:

,,Daß ein Reisewerk cine zweite Auflage erfährt, liommt ziemlich selten vor und ist fast immer cin Beweis dafür, daß es sich um eine das Tagesinteresse überdauernde Arbeit handelt. Zu diesen Erzeugnissen gehört das Semonsche Rcisewerk ohne Frage; ja, man kann es nach Form und Inhalt getrost unter die heute sehr spärlich gewordenen klassischen Erzeugnisse dieser Literaturgattung rechnen; denn sein Tatsachenreichtum und seine Gedankenfülle erheben die Reiseschilderung selbst weit über das Niveau der immer mehr anwachsenden Flut der Reisebeschreibungen. Über die erste Auflage ist im 70. Bando des Globus ausführlich referiert worden, es sei also hier nur daran erinnert, daß Professor Semons achtzehnmonatige Reise nach Australien, Neu-Guinea und dem malaiischen Archipel in die Jahre 1891 bis 1893 fiel und vor allem der Erforschung der eigenartigen australischen Fauna galt. Dementsprechend ist der Hauptinhalt zoologisch, wotei die Tierbeobachtungen zu den schönsten und anziehendsten ihrer Art gehören und an die formvollendetsten Schilderungen der älteren südamerikanischen Reiseliteratux erinnern. Nicht minder aber kommt der Ethnograph und der Botaniker in dem Semonschen Buche zu seinem Recht, und der Aufmerlisamkeit des Verfassers entgingen auch koloniale und rerwandte Dinge nicht. So bildet Semons Buch eine harmonisch in sich geschlossene und ausgestaltete literarische und wissenschaftliche Arbeit, die heute inresgleichen sucht.“ 


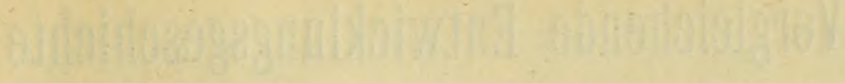

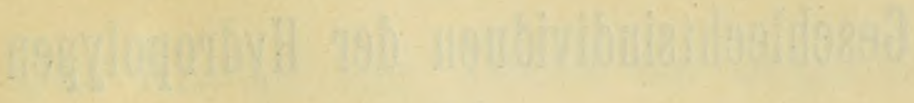

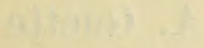

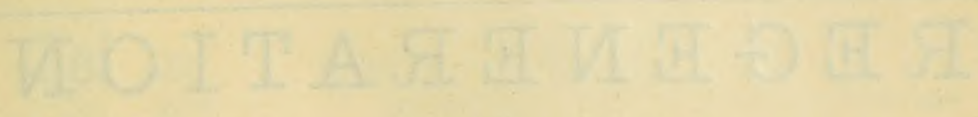

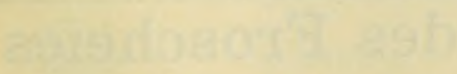

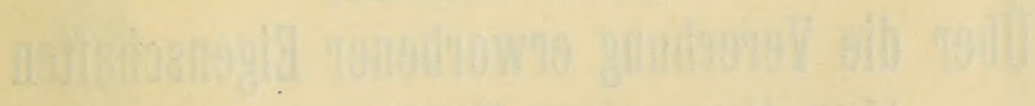


:: VERLAG VON WILHELM ENGELMANN IN LEIPZIG ::

Vergleichende Entwicklungsgeschichte

der

Geschlechtsindividuen der Hydropolypen

\author{
Von \\ A. Goette
}

(Sonderabdruck aus der Zeitschrift für wissenschaftliche Zoologie, Band 87)

Mit 18 Tafeln. Gr. 8. Geheftet $\mathscr{M}$ 30.-

\title{
REGE NERATION von
}

Thomas Hunt Morgan

Mit Genehmigung des Verfassers aus dem Englischen übersetzt und in Gemeinschaft mit ihm vollständig neu bearbeitet von

\section{Max Moszkowski}

Deutsche Ausgabe, zugleich zweite Auflage des Originals

= Nit 77 Figuren im Text

gr. 8. Geheftet $\mathscr{M} 12$.-; in Leinen gebunden $\mathscr{M} 13.20$

Die Autoren haben in ihrem verdienstvollen Buche, dem wir weite Verbreitung wünschen, eine große Fülle von Stoff dargeboten, gesichtet und bewältigt, wenn auch natürlich nicht alle von ihnen mit weitsichtigem Blick herangezogenen Materialien erschöpfend behandelt sind. Wir müssen ihnen für ihr Werk dankbar sein; das von ihnen gelieferte wird vielfachen Nutzen bringen.

(Prof. W. Roux im Archiv f. Entwicklungsmechanik, Bd. XXIII.)

\section{Die Entwicklung des Froscheies}

Eine Einleitung in die experimentelle Embryologie von

\section{Thomas Hunt Morgan}

Nach der zweiten englischen Auflage übersetzt von

Dr. Bernh. Solger

Mit 62 Figuren im Text. gr. 8. Geheftet M 6.-

\section{Eusenio Rignano}

Über die Vererbung erworbener Eigenschaften Hypothese einer Zentroepigenese

Teilweise Neubearbeitung und Erweiterung der französischen Ausgabe Mit 2 Figuren im Text. gr. 8. Geheftet $\mathscr{M} 5$.- 


\section{Schriften von Wilhelm Roux.}

\section{Der Kampf der Theile im Organismus.}

Ein Beitrag zur

Vervollständigung der mechanischen Zweckmäßigkeitslehre. gr. 8. It 4. -

Zei

\section{BioMed}

PLEASE DO NOT REMOVE CARDS OR SLIPS FROM THIS POCKET 
